\title{
BIOTOPPFLEGE MIT PFERDEN
}

\author{
Auswirkungen einer ganzjährigen Beweidung \\ mit Exmoor-Ponys (Equus ferus f. caballus) \\ auf halboffene Weidelandschaften \\ am Beispiel Süd-Langeland
}

\author{
Dissertation \\ zur Erlangung des mathematisch-naturwissenschaftlichen Doktorgrades \\ „Doctor rerum naturalium" \\ der Georg-August-Universität Göttingen \\ im Promotionsprogramm Biologie \\ der Georg-August University School of Science (GAUSS)
}

vorgelegt von

Tonja Mannstedt

aus Hannover

Göttingen, 2015 



\section{Betreuungsausschuss}

Prof. Dr. Rainer Willmann, Abteilung Morphologie, Systematik und Evolutionsbiologie mit Zoologischem Museum, Johann-Friedrich-Blumenbach Institut für Zoologie und Anthropologie

Prof. Dr. Erwin Bergmeier, Abteilung Vegetationsanalyse \& Phytodiversität, Albrecht-von-Haller-Institut für Pflanzenwissenschaften

\section{Mitglieder der Prüfungskommission}

\section{Referent:}

Prof. Dr. Rainer Willmann, Abteilung Morphologie, Systematik und Evolutionsbiologie mit Zoologischem Museum, Johann-Friedrich-Blumenbach Institut für Zoologie und Anthropologie

Korreferent:

Prof. Dr. Erwin Bergmeier, Abteilung Vegetationsanalyse \& Phytodiversität, Albrecht-von-Haller-Institut für Pflanzenwissenschaften

Weitere Mitglieder der Prüfungskommission:

Prof. Dr. Markus Hauck, Abteilung Pflanzenökologie und Ökosystemforschung, Albrecht-von-HallerInstitut für Pflanzenwissenschaften

Prof. Dr. Eckhard W. Heymann, Abteilung Verhaltensökologie \& Soziobiologie / DPZ, Johann-FriedrichBlumenbach Institut für Zoologie und Anthropologie

PD Dr. Thomas Hörnschemeyer, Abteilung Morphologie, Systematik, Evolutionsbiologie mit Zoologischem Museum, Johann-Friedrich-Blumenbach Institut für Zoologie und Anthropologie

PD Dr. Mark Maraun, Abteilung Tierökologie, Johann-Friedrich-Blumenbach Institut für Zoologie und Anthropologie 

Für meinen Großvater 



\section{INHALT}

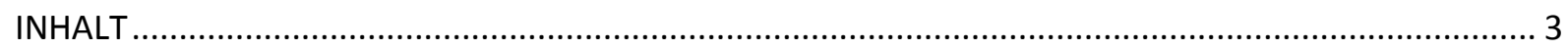

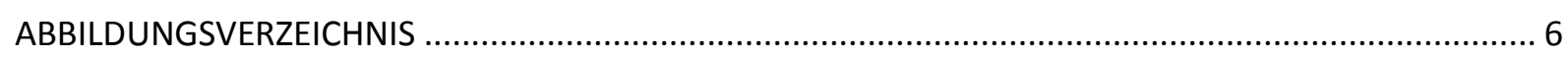

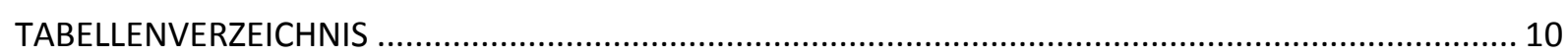

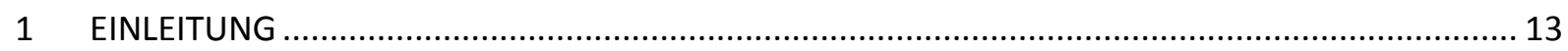

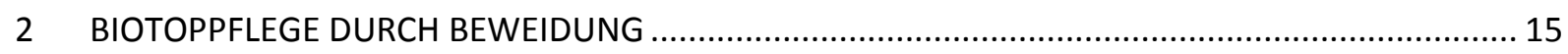

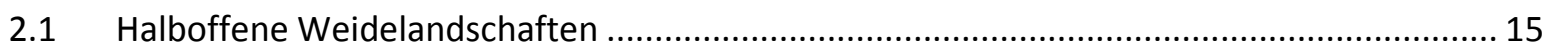

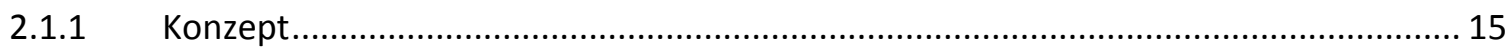

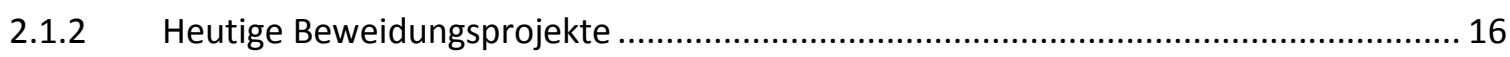

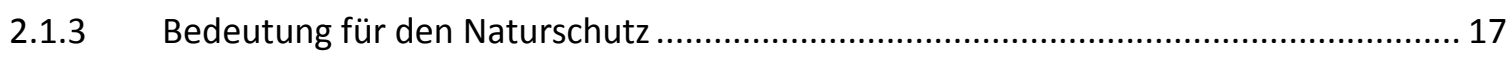

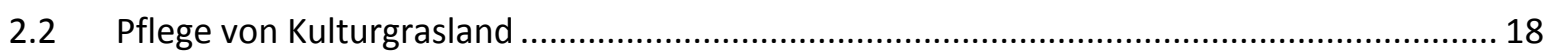

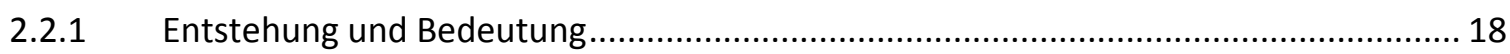

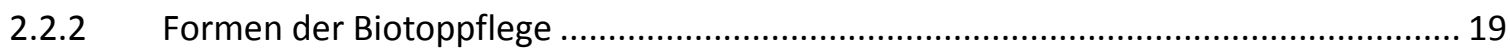

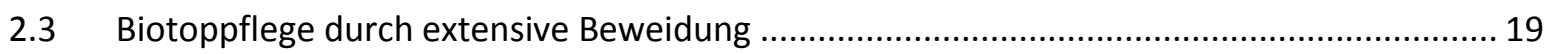

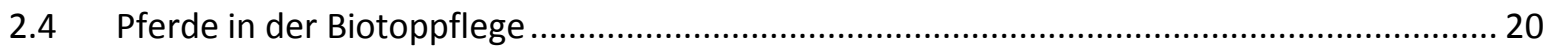

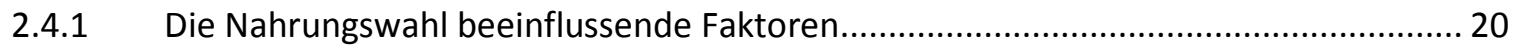

2.4.2 Der Einfluss der Weidetiere auf die Vegetation ............................................................ 22

2.4.3 Vergleich von Pferden zu anderen Weidetierarten ...................................................... 23

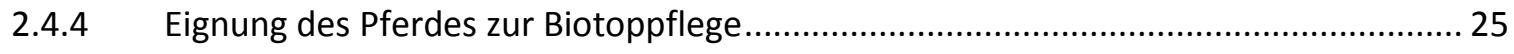

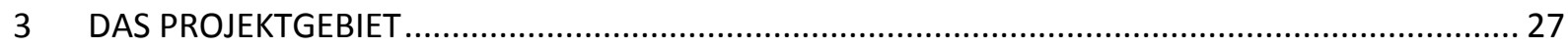

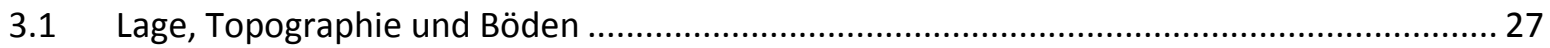

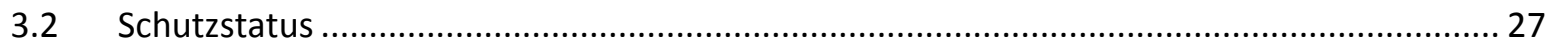

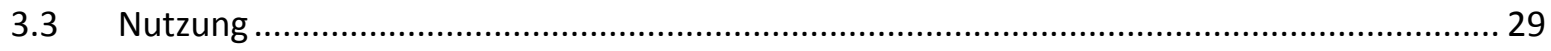

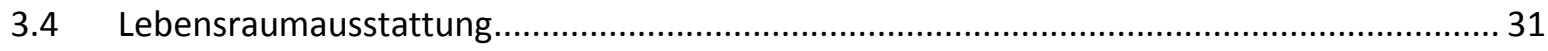

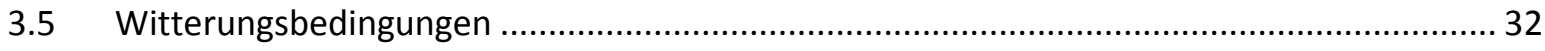

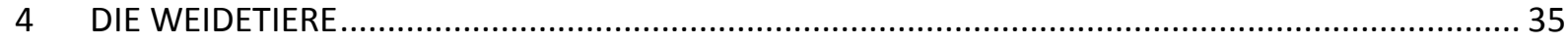

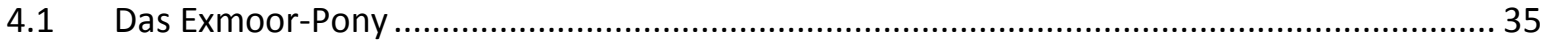

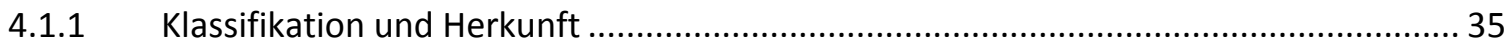

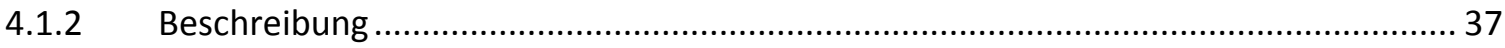

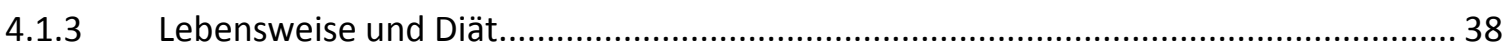

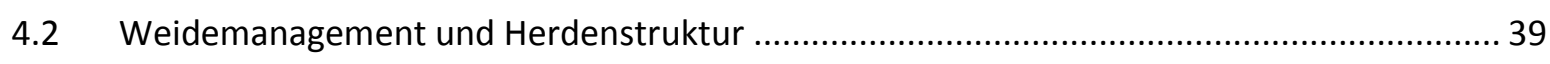

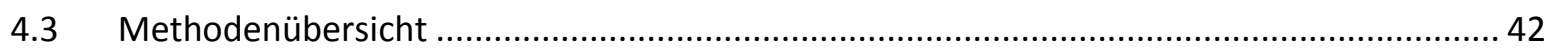




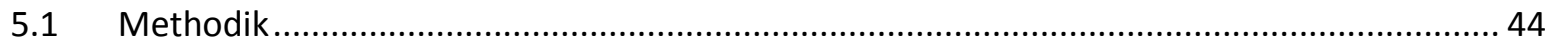

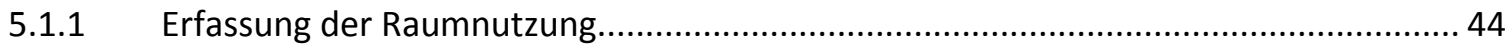

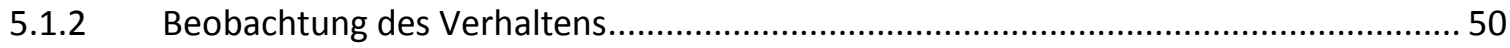

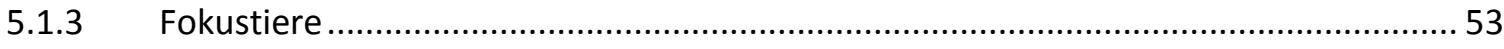

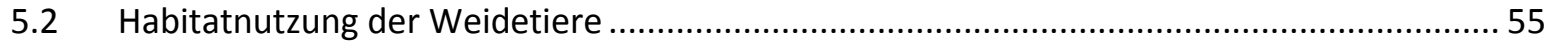

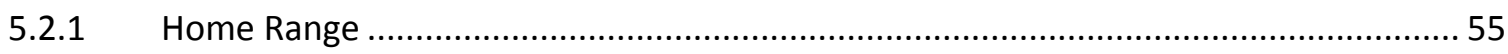

5.2.2 Räumliche und zeitliche Habitatnutzung ................................................... 58

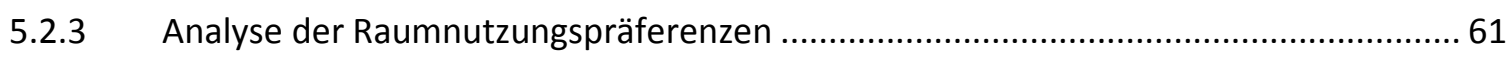

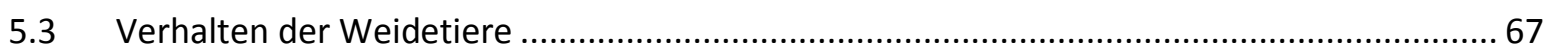

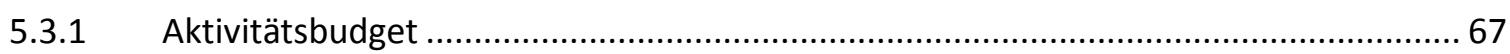

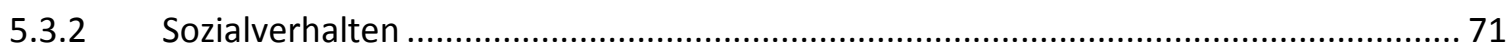

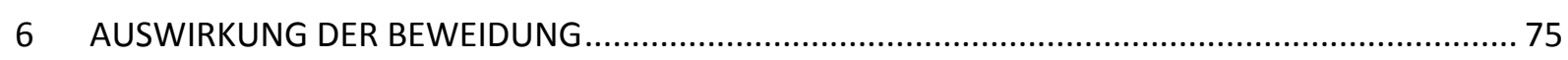

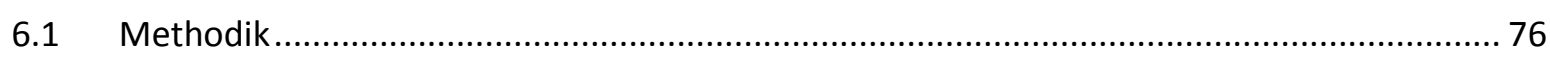

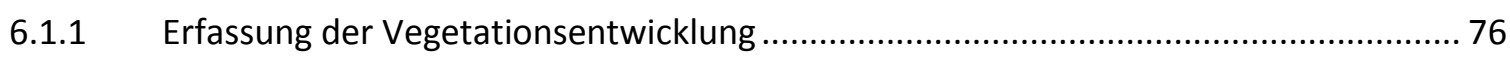

6.1.2 Erfassung der Strukturentwicklung .............................................................. 91

6.2 Vegetationsausstattung zu Beginn der Beweidung .........................................................99

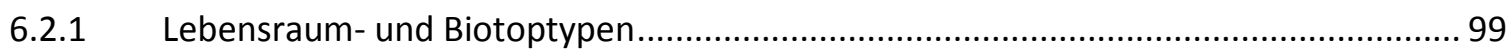

6.2.2 Pflanzengesellschaften im Grünland ........................................................... 105

6.3 Entwicklung des Gebietes unter Beweidung ......................................................... 107

6.3.1 Entwicklung der Vegetation ....................................................................... 107

6.3.2 Entwicklung der Strukturen................................................................... 119

6.4 Entwicklung einzelner Lebensräume unter Beweidung.............................................. 134

6.4.1 Entwicklung der Pflanzengesellschaften einzelner Lebensräume ........................... 134

6.4.2 Entwicklung der Strukturen einzelner Lebensräume ........................................... 157

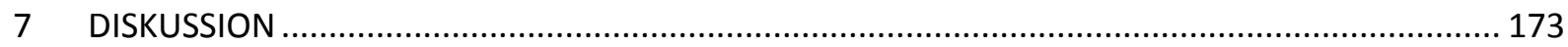

7.1 Eignung des Gebietes zur Pferdebeweidung .................................................... 174

7.1.1 Raumnutzung und Anforderungen der Weidetiere an ihren Lebensraum ................ 174

7.1.2 Bewertung von Nahrungspräferenzen durch Kotuntersuchungen .......................... 181

7.2 Auswirkungen der Beweidung auf die Vegetation............................................... 183

7.2.1 Einfluss der Weidetiere auf unterschiedliche Vegetationstypen ............................ 183

7.2.2 Förderung einer halboffenen Weidelandschaft .............................................. 184

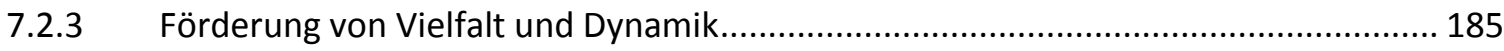

7.2.4 Ausmagerung von Grünlandflächen ....................................................... 188

7.3 Auswirkungen der Beweidung auf die Fauna .................................................. 189

7.3.1 Anforderungen von Tierarten an ihren Lebensraum ....................................... 189 
7.3.2 Vorkommen besonderer Tierarten im Projektgebiet................................................ 190

7.3.3 Auswirkungen der Pferdebeweidung aus tierökologischer Sicht................................ 190

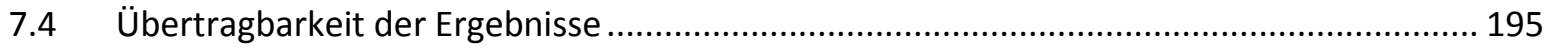

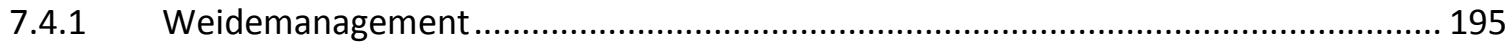

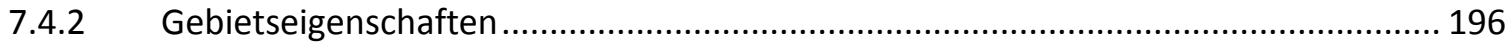

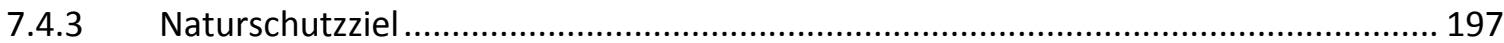

7.5 Empfehlungen für eine extensive Pferdebeweidung ...................................................... 198

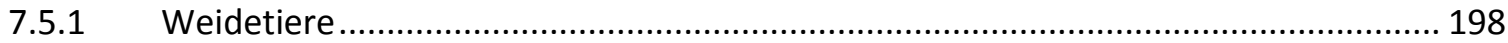

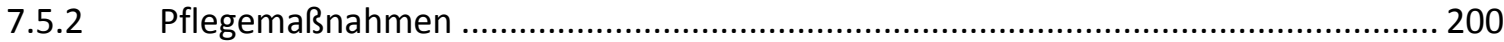

7.5.3 Erholungsnutzung und begleitende Öffentlichkeitsarbeit ......................................... 201

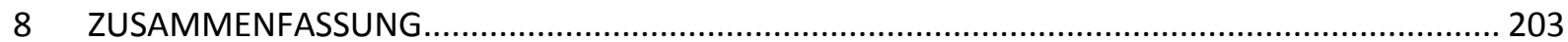

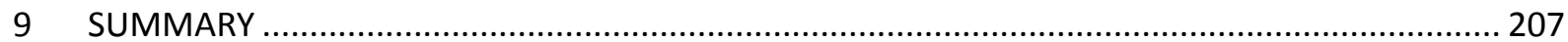

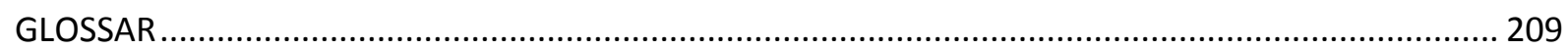

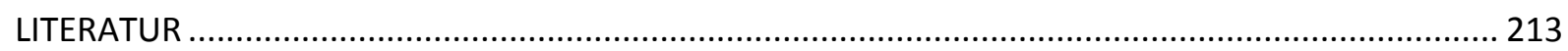

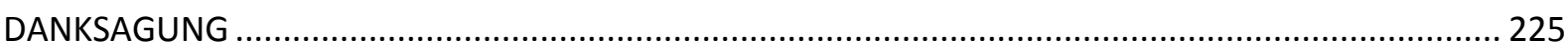

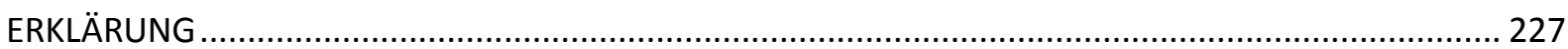

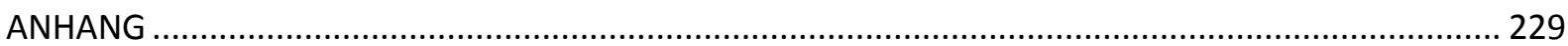




\section{ABBILDUNGSVERZEICHNIS}

Abb. 1: Vegetationseinheiten in Hudegebieten (aus Pott 1993)

Abb. 2: Einteilung typischer warmzeitlicher Herbivorenarten Mitteleuropas in Ernährungstypen (links) im Vergleich zu der heutigen potenziellen Großherbivorenfauna (aus Bunzel-Drüke 1997)

Abb. 3: Topographische Karte des Projektgebietes im Maßstab 1:10.000 28

Abb. 4: Satelliten-Aufnahme des Projektgebietes aus dem Jahr 2006. 28

Abb. 5: Frühere Nutzung der Teilflächen im Projektgebiet 31

Abb. 6: Monatsdurchschnittstemperaturen in den Jahren 2008-2011 im Vergleich zum langjährigen Mittel... 32

Abb. 7: Monatliche Sonnenscheinstunden in den Jahren 2008-2011 im Vergleich zum langjährigen Mittel 33

Abb. 8: Monatliche Niederschlagsmenge in den Jahren 2008-2011 im Vergleich zum langjährigen Mittel... 33

Abb. 9: Exmoor-Pony im Winterfell mit Aalstrich 37

Abb. 10: Habitus des Exmoor-Ponys mit Mehlmaul und heller Augenumrandung als charakteristische Merkmale ........... 37

Abb. 11: Merkmale des Exmoor-Ponys (aus Riediger 1995) .............................................................................38

Abb. 12: Entwicklung der Herdengröße und Anzahl der Fohlen, die den ersten Winter überlebt haben.......................... 40

Abb. 13: Manly-Chesson-Selektivitätsindex $\alpha$ zur Berechnung von Habitatpräferenzen .................................................47

Abb. 14: Pearsons Produkt-Moment-Korrelationskoeffizient r zur Berechnung des Zusammenhanges zwischen Strukturparametern und Raumnutzung 47

Abb. 15: Berechnung des Futterwertes im Projektgebiet. 49

Abb. 16: Leithengst Felix (Tier 1) 53

Abb. 17: Zora (Tier 2) 54

Abb. 18: Narbe (Tier 3)

Abb. 19: Aufenthaltswahrscheinlichkeiten der Fokustiere im Projektgebiet (Gauß-Kernel, April 08 - März 11)................56

Abb. 20: Aufenthaltswahrscheinlichkeiten (Gauß-Kernel) der Fokustiere mit zunehmender Beweidungsdauer ................57

Abb. 21: Aufenthaltswahrscheinlichkeiten (Gauß-Kernel) der Fokustiere zu unterschiedlichen Jahreszeiten................... 57

Abb. 22: Habitatnutzung der Weidetiere im Untersuchungszeitraum im Vergleich zur Gebietsausstattung ....

Abb. 23: Bevorzugung oder Meidung von Pflanzengesellschaften im Projektgebiet durch die Weidetiere unter Verwendung des Selektivitätsindexes $\alpha$. 59

Abb. 24: Jahreszeitliche Unterschiede in der Habitatnutzung der Weidetiere (2008-2011). 60

Abb. 25: Tageszeitliche Unterschiede in der Habitatnutzung der Weidetiere (2008-2011)... 61

Abb. 26: Einfluss des Verhaltens auf die Habitatwahl in ausgewählten Habitattypen 62

Abb. 27: Prozentuale Anteile der Verhaltenskategorien an der Gesamtaktivität in den Jahren 2008-2010 67

Abb. 28: Anteile der Verhaltensweisen im Jahresvergleich 2008-2010 68 
Abb. 29: Tagesrhythmus der Weidetiere im Frühjahr (oben), Spätsommer (Mitte) und Winter (unten) im

Beobachtungszeitraum von 2008-2010

Abb. 30: Häufigkeiten sozialer Verhaltensweisen zwischen den Jahren 2008-2010.

Abb. 31: Häufigkeiten von Sozial-, Territorial- sowie Sexualverhaltens im Jahres- (oben) und jahreszeitlichen (unten) Vergleich. . .72

Abb. 32 Häufigkeiten sozialer Verhaltensweisen im Tagesverlauf zu unterschiedlichen Jahreszeiten ...............................73

Abb. 33: Form der Dauerflächen als Rechteck mit 4 Quadranten (a) oder als Transekt (b) ..........................................79

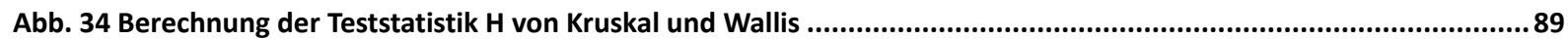

Abb. 35: Berechnung des Shannon-Diversitäts-Indices und der Evenness …..........................................................90

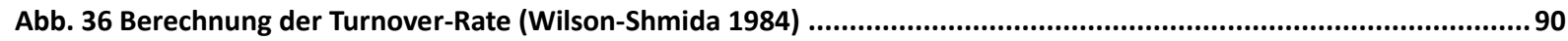

Abb. 37: Screeplot der Hauptkomponentenanalyse (PCA) von sieben Strukturparametern im offenen Weideland ............98

Abb. 38: Biotoptypen im Projektgebiet zu Beginn der Untersuchung ......................................................................... 101

Abb. 39: Lebensraumtypen im Projektgebiet zu Beginn der Untersuchung ............................................................. 102

Abb. 40: Dendrogramm der TWINSPAN-Analyse mit der Zuordnung der Gruppen zu Vegetationseinheiten ................... 109

Abb. 41: Vegetationskarte des Schutzgebietes Süd-Langeland mit Vegetationseinheiten (2008) ...................................110

Abb. 42: Dendrogramm der TWINSPAN-Analyse mit Zuordnung der Cluster zu Vegetationseinheiten (2011)................. 113

Abb. 43: Kartierte Pflanzengesellschaften im Uferbereich des Weihers von Gebiet 1 in den Jahren 2008 (links) und 2011

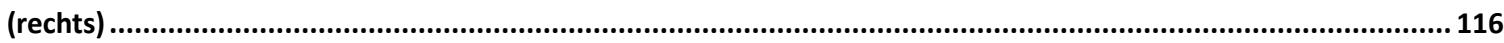

Abb. 44: Südlicher Uferbereich am Weiher im Gebietszentrum im Juli 2008 (oben) und 2010 (unten) ...........................117

Abb. 45: Grünland-Pflanzengesellschaften im Gebietszentrum in den Jahren 2008 (oben) und 2011 (unten) .................. 118

Abb. 46: Verteilung der Gehölze vor Beginn der Pferdebeweidung (links) nach 5 Beweidungsjahren (rechts) mit Angabe

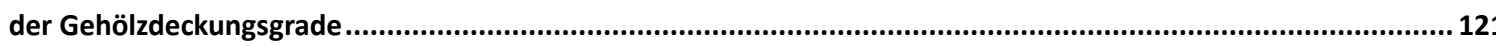

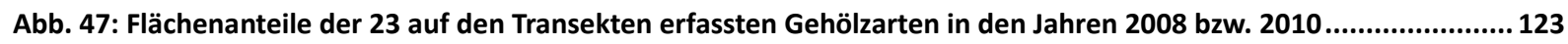

Abb. 48: Attraktivität der untersuchten Pflanzenarten auf den Transekten im Hinblick auf den Verbiss im Winter 2010/11

Abb. 49: Verbissschäden nach Schadensarten (oben) und Höhenstufen (unten) auf den Transektflächen. 124

Abb. 50: Gehölzschäden verursacht durch Scheuern und Knabbern in Widerristhöhe (links) oder durch Fraß von Trieben an Stockausschlägen (rechts)

Abb. 51: Beweidungsintensitäten in 5-stufiger Skala im Juli 2008 (links) und 2010 (rechts) im Vergleich 127

Abb. 52: Anteile der Weiderückstände in 6-stufiger Skala im Winter 2009/10 (links) und 2010/11 (rechts) im Vergleich 128

Abb. 53: Anteile offenen Bodens in 6-stufiger Skala im Sommer 2008 (links) und 2010 (rechts) im Vergleich 130

Abb. 54: Offene Bodenstellen an feuchten Standorten hervorgerufen durch Tritt (links) oder durch Scharren (rechts) ... 131

Abb. 55: Weidetierpfade im Projektgebiet - Hauptpfad im Laubwald (links) und grüne Pfade mit vereinzelten offenen Bodenstellen im Grünland (rechts). 131

Abb. 56: Geilstelle mit einer Anhäufung von Pferdedung im Juli 2010 132

Abb. 57: Nährstoffeintrag durch Pferdedung in 4-stufiger Skala im Sommer 2008 (links) und 2010 (rechts) im Vergleich 133 Abb. 58: Deckungsgrad der Krautschicht auf den Untersuchungsflächen zwischen den Jahren 2008-2011 135 
Abb. 59: Deckungsgrad der Krautschicht auf den Kontrollflächen zwischen den Jahren 2008-2011

Abb. 60: Anteil an offenem Boden auf den Untersuchungsflächen zwischen den Jahren 2008-2011

Abb. 61: Anteil an offenem Boden auf den Untersuchungsflächen im Grünland zwischen den Jahren 2008-2011.

Abb. 62: Mittlere Vegetationshöhe der Krautschicht auf den Untersuchungsflächen zwischen den Jahren 2008-2011.... 137

Abb. 63: Mittlere Vegetationshöhe der Krautschicht auf den Kontrollflächen zwischen den Jahren 2008-2011.

Abb. 64: Turnover-Raten $b_{t}$ zwischen den Vegetationsaufnahmen des Höhentransektes im Gradienten der differenzierbaren Vegetationstypen in den Jahren 2008-2011.

Abb. 65: Turnover-Raten $b_{t}$ der 13 Dauerflächen und 7 Plots des Höhentransektes, angeordnet nach steigender

Artendynamik der Pflanzengesellschaften zwischen 2008-2011

Abb. 66: Deckungsgrade wichtiger Gräser der Typischen Fettweiden (CYN_LOL, $n=4$ ) zwischen den Jahren 2008-2011.156

Abb. 67: Deckungsgrade wichtiger Arten der artenarmen Typischen Fettweiden (CYN_LOL arm, $n=3$ ) zwischen den Jahren 2008-2011. 156

Abb. 68: Relative Anteile an kurz-, mittel- und langrasiger Vegetation im Grünland $(n=5)$. 158

Abb. 69: Entwicklung auf der Strukturdauerfläche SDF 2 im Frischgrünland bei den Frühjahrserhebungen Ende April in den Jahren 2008 (oben), 2009 (Mitte) und 2010 (unten)

Abb. 70: Anteile von Gräsern, Kräutern, Moosen, Streu und offenen Boden an der Deckung der Krautschicht im Grünland in den Jahren 2008-2010 ( $n=5)$ 160

Abb. 71: Entwicklung der Verbuschung im Grünland auf Strukturdauer- (SDF) und Ausschlussflächen (A, schraffiert) im Vergleich $(n=10)$ 160

Abb. 72: Entwicklung auf der Strukturdauerfläche SDF 7 auf Magerrasen bei den Frühjahrserhebungen Ende April in den Jahren 2008 (oben), 2009 (Mitte) und 2010 (unten) 163

Abb. 73: Entwicklung der mittleren Höhe der Kraut- und Streuschicht bei zunehmender Besatzstärke auf Magerrasen ( $n=$ 1)..

Abb. 74: Anteile von Gräsern, Kräutern, Moosen, Streu und offenen Boden an der Deckung der Krautschicht auf Magerrasen auf Strukturdauer- (SDF) und Ausschlussflächen (A, schraffiert) $(n=2)$.

Abb. 75: Anteile von Gräsern, Kräutern, Moosen, Streu und offenen Boden an der Deckung der Krautschicht im Uferbereich $(n=2)$.

Abb. 76: Anteile von Gräsern, Kräutern, Moosen, Streu und offenen Boden an der Deckung der Krautschicht im Uferbereich auf der Strukturdauerfläche (SDF) und ihrer Vergleichsfläche (A, schraffiert) $(n=2)$

Abb. 77: Entwicklung auf der Strukturdauerfläche SDF 6 im Uferbereich bei den Frühjahrserhebungen Ende April in den Jahren 2008 (oben), 2009 (Mitte) und 2010 (unten)

Abb. 78: Entwicklung der mittleren Kraut- und Streuschichthöhe bei zunehmender Besatzstärke im Uferbereich $(n=2) 167$

Abb. 79: Relative Anteile von Gräsern, Kräutern, Moosen, Streu und offenen Boden an der Deckung der Krautschicht im Wald, dargestellt im zeitlichen Verlauf $(n=2)$

Abb. 80: Anteile von Gräsern, Kräutern, Moosen, Streu und offenen Boden an der Deckung der Krautschicht im Wald auf Strukturdauer- (SDF) und Ausschlussflächen (A, schraffiert) $(n=3)$.

Abb. 81: Anteile von Gräsern, Kräutern, Moosen, Streu und offenen Boden an der Deckung der Krautschicht auf dem Waldweg $(n=1)$.

Abb. 82: Hauptkomponentenanalyse des Frühjahraspektes von 7 Strukturparametern in 7 Lebensraumtypen 170

Abb. 83: Hauptkomponentenanalyse des Sommeraspektes von 7 Strukturparametern in 7 Lebensraumtypen. 
Abb. 84: Hauptkomponentenanalyse des Spätsommeraspektes von 7 Strukturparametern in 7 Lebensraumtypen ........ 171

Abb. 85 Einflussfaktoren der Habitatnutzung bei Pferden unter Ganzjahresbeweidung auf Süd-Langeland

Abb. 86: Wirkungsgefüge einiger für das Exmoor-Pony wesentlicher ökologischer Faktoren bei der Habitatnutzung im offenen Weideland am Beispiel Süd-Langeland..

Abb. 87: Mögliche positive Auswirkungen einer extensiven Pferdebeweidung auf die Fauna der mitteleuropäischen Kulturlandschaft

Abb. 88: Mögliche negative Auswirkungen einer extensiven Pferdebeweidung auf die Fauna der mitteleuropäischen Kulturlandschaft 194

Abb. 89: Faktoren von Pflanzengesellschaften nach Dierschke (1994).. .209

Abb. 90: Räumliche Betrachtungsebenen von Vegetation (nach Tremp 2005, Kent \& Coker 1996, Ellenberg 1996) ..... .211 


\section{TABELLENVERZEICHNIS}

Tab. 1: Frühere Nutzung der Teilflächen im Projektgebiet (Quelle: L. Vester, Dänisches Generaldirektorat für Natur) ........ 30

Tab. 2: Entwicklung der Herden- und Altersstruktur seit Beweidungsbeginn ..............................................................39

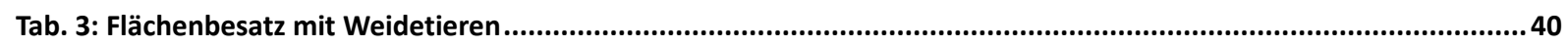

Tab. 4: Fohlenmortalität im Projektgebiet Süd-Langeland in den Jahren 2007-2011.................................................41

Tab. 5: Übersicht zum Arbeitsprogramm der wissenschaftlichen Begleituntersuchung .................................................. 42

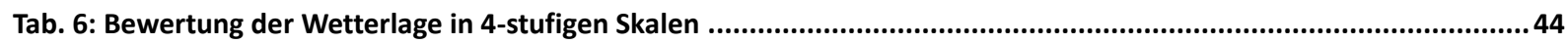

Tab. 7: Die im linearen Regressionsmodell getesteten, erklärenden Variablen mit Code und Wertebereich ......................48

Tab. 8: Beobachtungszeiten in Minuten der Langeländer Exmoor-Pony-Herde über einen dreijährigen

Untersuchungszeitraum (April 2008 - März 2011) ......................................................................................................5 50

Tab. 9: Ethogramm mit Abkürzungen und Definitionen der verwendeten Verhaltensweisen ...........................................51

Tab. 10: Aufnahmepunkte pro Jahreszeit, Tier und Untersuchungsjahr...................................................................55

Tab. 11: Bewegungsmuster der Weidetiere im Projektgebiet zu unterschiedlichen Jahreszeiten .....................................63

Tab. 12: Futterwahl der Weidetiere im Januar 2011 in Abhängigkeit von der Umgebungstemperatur nach Pötzinger (2011)

Tab. 13: Futterwahl der Weidetiere im Januar 2011 in Abhängigkeit vom Schneeaufkommen nach Pötzinger (2011) .......64

Tab. 14: Individuelle Unterschiede in der Raumnutzung zwischen den Fokustieren ......................................................65

Tab. 15: Ergebnis der schrittweisen multiplen Regressionsanalyse (Poisson-Regression) zu den Faktoren, die das Raumnutzungsverhalten der Pferde im Untersuchungszeitraum steuerten .........................................................66

Tab. 16: Erweiterte Braun-Blanquet-Skala (nach Dierschke 1994) ..........................................................................77

Tab. 17: Skala zur Bewertung der Tritt- und Verbissbelastung ......................................................................................78

Tab. 18: Beschreibung der vegetationskundlichen Dauerflächen und ihrer Kontrollflächen im Gebiet Süd-Langeland........80

Tab. 19: Skalenwerte und entsprechende Deckungsgrade der Londo-Skala (nach Dierschke 1994) ................................81

Tab. 20 Übersicht über die mit TWINSPAN ausgewerteten Daten ...........................................................................8 82

Tab. 21: Prozent-Übersetzung der Werte der Braun-Blanquet-Skala und Beziehung zwischen den Skalenwerten und den

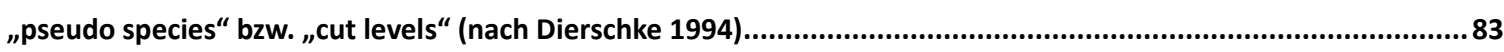

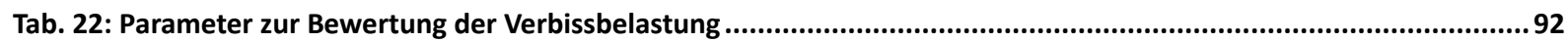

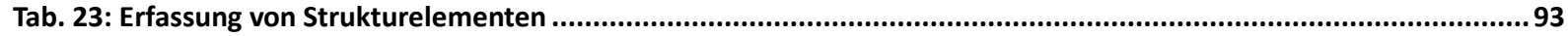

Tab. 24: Relative Anteile an kurz-, mittel- und langrasiger Vegetation.........................................................................93

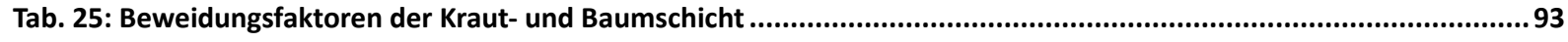

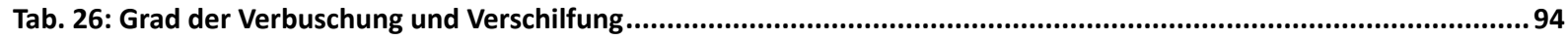

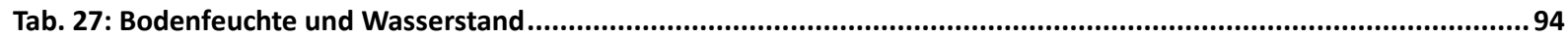


Tab. 28: Anteile der Lebensraumtypen im Projektgebiet, auf den Strukturdauer- sowie den Ausschlussflächen

(Kontrollflächen).

Tab. 29: Beschreibung der Strukturdauerflächen und ihrer Kontrollflächen im Gebiet Süd-Langeland .96

Tab. 30: Pflanzensoziologische Einordnung der Gruppen 1-12 der Voruntersuchung im offenen Weideland (2007) mit

Angabe des Teilgebietes, aus dem die Vegetationsaufnahmen stammten .....................................................106

Tab. 31: Größe und Flächenanteile der Vegetationseinheiten oder Bestände, gegliedert nach Formationen (2008) ........ 111

Tab. 32: Systematik der im Projektgebiet aufgetretenen Gefäßpflanzen, Moose und Algen

Tab. 33: Artenzahlen der den Glatthaferwiesen und Fettweiden zugeordneten Gruppen der Vegetationskartierungen .. 117

Tab. 34: Relative Flächenanteile der Gehölzdeckungsgradklassen im Projektgebiet vor und nach 5 Jahren

Pferdebeweidung

Tab. 35: Anteile der Beweidungsintensitäten im Projektgebiet in den Jahren 2008 und 2010 . 126

Tab. 36: Weiderückstände in 5-stufiger Skala auf den Teilgebieten im Projektgebiet in den Jahren 2008-2010. 129

Tab. 37: Anteile offenen Bodens in 6-stufiger Skala auf den Teilgebieten im Projektgebiet in den Jahren 2008-2010 ...... 129

Tab. 38: Entwicklung von Vegetationsparametern auf den Vegetationsdauerflächen zwischen den Jahren 2008-2011... 138

Tab. 39: Entwicklung von Vegetationsparametern auf beweideten und nicht-beweideten Dauerflächen zwischen den Jahren 2008-2011

Tab. 40: Zusammenhänge zwischen den Aufnahmescores der beiden ersten Achsen der DCA und den Umweltvariablen (Pearson-Korrelationen)

Tab. 41: Zusammenhänge zwischen den Aufnahmescores der beiden ersten Achsen der DCA und den Umweltvariablen im Grünland (Pearson-Korrelationen) 140

Tab. 42: Die auf den Untersuchungsflächen vorkommenden Arten mit Kürzeln 144

Tab. 43: Eigenwerte unterschiedlicher Korrespondenzanalysen (CA, DCA, CCA) für die Daueruntersuchungsflächen im Jahr 2008 145

Tab. 44: Eigenwerte der Korrespondenzanalyse (CA) der Untersuchungsflächen in den Jahren 2008-2011. 147

Tab. 45: Artendiversität $H^{\prime}$ und Evenness E der untersuchten Grünländer zwischen den Jahren 2008-2011 150

Tab. 46: Turnover-Raten $b_{t}$ auf den VDF im offenen Weideland zwischen den Jahren 2008-2011 



\section{EINLEITUNG}

Ziele des Forschungsvorhabens

Für viele Tier- und Pflanzenarten offener Lebensräume stellten die in Europa einst weit verbreiteten extensiv bewirtschafteten Weidelandschaften wichtige Ersatzlebensräume dar (Finck et al. 2002). Die Intensivierung der Landnutzung, aber auch ein deutlicher Strukturwandel in der Landwirtschaft haben zu einem kontinuierlichen Verlust dieser Lebensräume und damit verbunden an biologischer Vielfalt in Mitteleuropa geführt (von Oheimb et al. 2006). Im Naturschutz entwickelte Konzepte für naturschutzfachlich bedeutsames Grünland sollen diesem Abwärtstrend Einhalt gebieten. Naturschützer stoßen jedoch bei der konkreten Umsetzung sowohl finanziell als auch personell an ihre Grenzen, so dass Pflegeziele vielerorts nicht erreicht werden.

Erst seit wenigen Jahren haben sich neue Formen extensiver Beweidungssysteme als wichtige Strategie des Biotopschutzes etabliert (Finck et al. 2002). Ein Konzept zur Erhaltung gefährdeter Biotoptypen, das - ausgehend von historischen Vorbildern - von Seiten des Naturschutzes vorgeschlagen und mittlerweile in einer Reihe von Projekten umgesetzt wird, ist das der halboffenen Weidelandschaft. Dieses Konzept verknüpft naturschutzfachliche Zielsetzungen mit denen einer extensiven Grünlandwirtschaft und eignet sich für großräumige, vormals extensiv genutzte Landschaften wie beispielsweise Grenzertragsstandorte oder brachliegende Flächen (Schröder 2010). Zahlreiche Autoren erörtern Vor- und Nachteile dieses Pflegekonzeptes aus unterschiedlichen Blickwinkeln (u.a. Dierking 1992, 1993, Assmann \& Falke 1997, Finck et al. 1997, 1998, 2004, Klein et al. 1997, Riecken et al. 1997, 2001, Voss 1999, Kleyer et al. 2004, Wagner \& Luick 2005, von Oheimb et al. 2006, Mann \& Tischew 2010, Schröder 2010).

Um die Auswirkungen einer ganzjährigen Beweidung auf Ökosysteme zu bewerten, sind Langzeitstudien unerläßlich. Ein reines Naturschutz-Monitoring ohne wissenschaftliche Begleituntersuchung dient lediglich der Überprüfung eines definierten Schutzzieles, beispielsweise der naturnahen Landschaftsentwicklung. Zu Langzeitstudien bezüglich einer Beweidung mit Equus finden sich in der Fachliteratur kaum Angaben (vgl. Scheibe et al. 1998, Roth 2003, Sonnenburg et al. 2003).

Das Dänische Umweltministerium hat sich die Erhaltung der dänischen Kulturlandschaft und die Offenhaltung von Wiesen, Strandwiesen, Weiden und Mooren zum Ziel gesetzt. Seit den siebziger Jahren hat es Flächen auf Süd-Langeland aufgekauft, um dort durch eine extensive Beweidung mit Rindern, Schafen und eben Exmoor-Ponys die Artenvielfalt zu erhöhen und bedrohten Vogel- und Insektenarten einen Lebensraum zu bieten. Bislang fehlte jedoch eine wissenschaftliche Langzeituntersuchung zu den Auswirkungen einer großflächigen, ganzjährigen Beweidung mit Pferden, obwohl Exmoor-Ponys seit Jahrzehnten in ganzjähriger Freilandhaltung auf der Insel Taero und später auf Langeland lebten. Aus diesem Grund wurde das Forschungsvorhaben „Halboffene Weidelandschaft Süd-Langeland“ initiiert.

Das Projekt versteht sich als Pilotstudie zur Untersuchung der Auswirkungen einer ganzjährigen Beweidung mit wild lebenden Pferden unter ökologischen Gesichtspunkten. Die Weidetiere wurden zur Biotoppflege eingesetzt. Ihre Habitatansprüche und die Auswirkungen ihrer Lebensweise auf die Vegetation standen im Mittelpunkt der vorliegenden Untersuchung.

Die Ergebnisse des Projektes sollen der Beantwortung folgender Fragen dienen: 
- Welche Auswirkungen hat eine extensive Ganzjahresbeweidung mit großen Pflanzenfressern wie dem Exmoor-Pony auf die Vegetation? Als Bewertungskriterien dienen dabei die Entwicklung der Vegetation und der Landschaftsstruktur.

- Welche Naturschutzziele können erreicht werden? Welche Bedeutung kommt dem ExmoorPony bei der Landschaftspflege zu?

- Wie nutzen die Weidetiere das innen zur Verfügung stehende Gebiet? Wie ist ihr Raumnutzungs- und Fraßverhalten zu bewerten?

- Welche Rahmenbedingungen sind bei der Einrichtung halboffener Weidelandschaften zu berücksichtigen? Welche natürlichen Bedingungen müssen vorliegen, um große Pflanzenfresser dauerhaft im Gebiet zu halten?

- Sind die Ergebnisse auf vergleichbare Vorhaben in ähnlichen Naturräumen übertragbar? 


\section{BIOTOPPFLEGE DURCH BEWEIDUNG}

Theoretisches und Grundlagen dieser Arbeit

\subsection{Halboffene Weidelandschaften}

\subsubsection{Konzept}

Die Begriffe "halboffene Weidelandschaften“ oder "wilde Weiden“ stehen für ein neues Konzept im Naturschutz (u.a. Finck et al. 2004, von Oheimb et al. 2006, Bunzel-Drüke et al. 2008, Plachter \& Hampicke 2010). Es wird aus traditionellen Wirtschaftsformen wie der Waldweide oder Hudeviehhaltung und aus neuen Thesen zur Struktur des Primärwaldes unter dem Einfluss von natürlichen Großherbivoren-Gemeinschaften abgeleitet, wobei Weidenutzungen historischer Zeiten wie ehemalige Hutewälder oder Allmendweiden (Abb. 1) Vorbilder für moderne großflächige Weidevorhaben geworden sind (LÜBW 2006), gleichwohl sich die heutige extensiv genutzte Standweide in zahlreichen Bedingungen von der historischen Hutung unterscheidet (Mühlenberg \& Slowik 1997). Bauschmann (2005) differenziert hier begrifflich zwischen der Weidenutzung und der Wildnisentwicklung. Erstere dient der Erhaltung der Kulturlandschaft und historischer Nutzungsformen. Ihr Leitbild ist die Kulturlandschaft zwischen 1800 und 1950. Beweidet wird selten ganzjährig mit angepassten Nutztierarten, die meist medizinisch versorgt werden, da eine Nutzung der tierischen Produkte anschließen soll. Bei der Wildnisentwicklung ist das naturschutzfachliche Ziel hingegen die Entwicklung von neuer Wildnis oder Urwald. Sie setzt Wildtiere wie Elch und Wisent und dedomestizierte Nutztiere (z. B. Heckrind) in großflächiger Ganzjahreshaltung ein. Die Tiere werden weder medizinisch betreut noch ökonomisch genutzt. Im Gegensatz zur früher üblichen Hutehaltung werden sie großräumig gekoppelt und idealerweise ganzjährig in halbwilder Form gehalten. Die Infrastruktur der Viehhaltung ist auf ein Minimum begrenzt, so dass bewusst in Kauf genommen wird, dass weder die Entwicklung exakt steuerbar noch das Ergebnis genau vorhersagbar ist. Für dieses Weidemanagement eignen sich vor allem robuste Nutztiere wie Galloway-, Hochland- oder Heckrinder, Konikpferde und Exmoor-Ponys (BfN 2013).

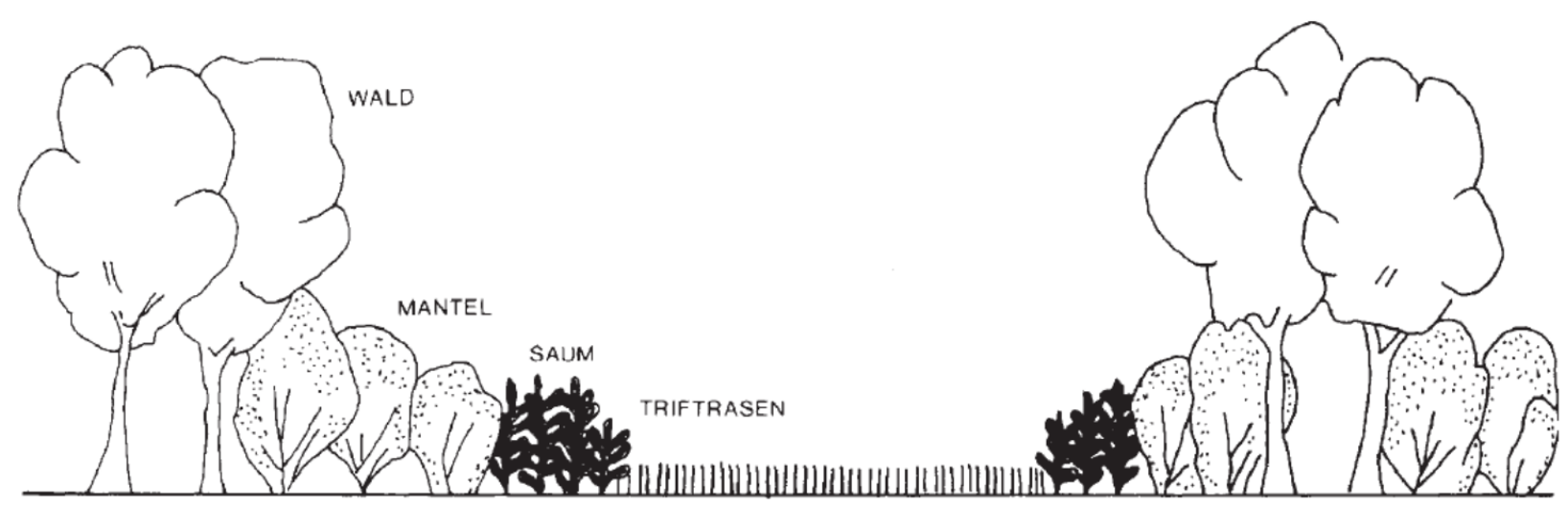

Abb. 1: Vegetationseinheiten in Hudegebieten (aus Pott 1993)

Durch extensive Beweidung können reich strukturierte Saumbiotope und Waldmäntel entstehen. 
Angewendet wird das Konzept insbesondere für grünlandgeprägte, extensiv genutzte Kulturlandschaften, die Hotspots der Biodiversität darstellen, die aber durch moderne Entwicklungen in der Landwirtschaft europaweit hochgradig gefährdet sind (von Oheimb et al. 2006). Ihm liegt die Ansicht zugrunde, dass ein langfristiger Schutz der heute noch vorhandenen Vielfalt eine gewisse Offenhaltung der Landschaft voraussetzt (von Oheimb et al. 2006) und dass große Pflanzenfresser eine zentrale Rolle bei der Gestaltung von natürlichen Lebensräumen und der Pflanzen- und Tierevolution hatten (u. a. Pott \& Hüppe 1991, Remmert 1991, Bunzel-Drüke 1997, 1999, 2001, Hüppe 1997, Riecken 1998, Gerken \& Görner 1999, König et al. 2003).

\subsubsection{Heutige Beweidungsprojekte}

Viele der traditionellen Bewirtschaftungsweisen und Pflegemaßnahmen zur Offenhaltung von Landschaften sind heute zu kosten- und personalintensiv. Daher werden seit den 1990ern domestizierte Huftiere in ganzjähriger Freilandhaltung gezielt eingesetzt, um Offenlandbiotope der Kulturlandschaft zu pflegen, bestimmte Lebensräume zu erhalten und FFH-Richtlinien umzusetzen (Bunzel-Drüke et al. 1999, Kampf 2000, Holsten 2003, Sonnenburg et al. 2003, LÜBW 2006, Vermeulen 2014). Ein mäßiger Verbiss von Gehölzen und konkurrenzstarken Arten ist dabei durchaus gewünscht, um Verbuschung und Verschilfung der offenen Grünland- und Gewässerflächen zu verhindern. Eine großflächige, extensive und ganzjährige Beweidung von Landschaften kann eine sinnvolle Alternative zur punktuellen Beweidung mit Haustierrassen sein, die man in der Landwirtschaft findet (Bunzel-Drüke et al. 1997, 1999, 2008, Klein et al. 1997, Reisinger 2004, von Oheimb et al. 2006).

Großflächige Beweidungsprojekte finden sich meist in West- und Mitteleuropa mit überwiegend milden Wintern. Vorreiter sind die Niederlande, die seit 25 Jahren - zunächst in Oosvaardersplassen, heute in zahlreichen Gegenden - große Pflanzenfresser ganzjährig halten, um sie in naturnahe Ökosysteme zu integrieren (Vulink \& van Eerden 1998, Kampf 2000, Vermeulen 2014). Damit entstand neben dem multifunktionalen und dem halb-natürlichen Weidemanagement das naturnahe Management (Kampf 2000). Weitere Projekte mit Pferden in Mischbeweidungen entstanden im "New Forest“ in England (Taylor 2001) oder in der Camargue (Menard et al. 2002). Das erste Projekt dieser Art in Deutschland wurde 1991 von der Arbeitsgemeinschaft Biologischer Umweltschutz im Kreis Soest initiiert. Es setzt Heckrinder zur naturnahen Entwicklung der Lippeaue ein (Bunzel-Drüke et al. 1999). Zahlreiche Projekte folgten, in denen Pferde in Misch- oder Alleinhaltung weideten. Verwendet wurden oftmals ursprüngliche Pferderassen wie Przewalski, Koniks und Exmoor-Ponys.

Meist wurde dabei kein konkretes Pflegeziel verfolgt. Die Weidetiere wurden in die Entwicklung naturnaher Wildnisgebiete integriert. Ziel vieler Beweidungsprojekte ist weniger der Erhalt spezieller Arten oder Biotope durch gezielte Pflegemaßnahmen. Vielmehr sollen sich durch die natürliche Sukzession und Dynamik und möglichst ohne menschliche Eingriffe naturnahe Landschaften entwickeln (LÜBW 2006). Andere Vorhaben verfolgen hingegen vermehrt eine Offenhaltung und Pflege der Landschaft auf kostengünstigem Wege (Reisinger \& Schmidtmann 2001, Beije et al. 2002, Bunzel-Drüke et al. 2002, Riecken et al. 2004). In heutigen Beweidungsprojekten gilt es also, zwischen dem oben beschriebenen Wildnisansatz und dem Erreichen von Biodiversitätszielen zu unterscheiden (Schulte 2014). In Wildnisprojekten wird die Entwicklung nicht gesteuert, so dass sie mittel- bis langfristig Arterhaltungszielen im Gebiet zuwider laufen kann. 


\subsubsection{Bedeutung für den Naturschutz}

Der Naturschutz hat über zwei Jahrzehnte Erfahrungen mit „wilden Weiden“ gesammelt. Die Vision von Wildnisgebieten mitten in Europa durch neue Formen der Beweidung konnte nicht überall erfolgreich umgesetzt werden, da tierschutzrechtliche Vorgaben und ökonomische Rahmenbedingungen manches Projekt haben scheitern lassen (Schulte 2014). Dennoch stellt die Beweidung mit Großherbivoren auch aus heutiger Sicht eine der wichtigsten Möglichkeiten dar, die biologische Vielfalt gefährdeter Lebensräume der Auen, Moore, Heiden und des Grünlandes zu erhalten.

Die Managementform halboffener Weidelandschaften stellt eine innovative und kostengünstige Pflege von geschützten Biotopen dar. Durch extensive Beweidung mit Groß-Herbivoren soll sich eine Landschaft einstellen, die überwiegend aus offenen und zumindest kleinflächig auch durchaus relativ intensiv beweideten Bereichen sowie aus unterschiedlichen Sukzessionsstadien einschließlich der natürlichen Schlusswaldgesellschaften besteht (von Oheimb et al. 2006, Bunzel-Drüke et al. 2008). Vorteil ist die Auflösung von vorgegebenen Nutzungsgrenzen durch Verbiss und Komfortverhalten (Wiegleb \& Brunk 2004). Die entstehenden abwechslungsreichen Mosaike aus Weiderasen, Hochstaudenfluren, offenen Böden, Gebüschen und Wäldern bieten dabei seltenen Tieren und Pflanzen einen Lebensraum (Bunzel-Drüke et al. 2008). Zudem leisten Großherbivoren in der Ganzjahresbeweidung einen wichtigen Beitrag bei der Verzögerung oder dem Zurückdrängen von Verbuschungen im Offenland (Schrautzer et al. 2004, Schwabe et al. 2004, Sonnenburg \& Gerken 2004, van Klink \& Kampf 2004).

Die Möglichkeiten und Probleme dieser Beweidungsform wurden in den vergangenen Jahren bereits vielerorts studiert und beschrieben (u.a. Dierking 1992, 1993, Assmann \& Falke 1997, Finck et al. 1997, 1998, 2004, Klein et al. 1997, Riecken et al. 1997, 2001, Voss 1999, Kleyer et al. 2004, Wagner \& Luick 2005, von Oheimb et al. 2006, Mann \& Tischew 2010, Schröder 2010). Zusammenfassend sind laut von Oheimb et al. (2006) folgende Naturschutzziele und Erwartungen mit dem Konzept verknüpft:

- Erhalt offener Landschaftsbereiche wie artenreicher Grünlandflächen, Halbtrockenrasen und Heiden als Lebensräume für Arten der mitteleuropäischen Natur- und Kulturlandschaft

- Auflösung der parzellenscharfen Trennung zwischen unterschiedlichen Biotoptypen und Entwicklung ausgedehnter Übergangsstadien zwischen Gehölzstrukturen und Offenlandschaft

- Schaffung von Pionierstandorten in Bereichen unterschiedlicher Hydrologie

- Gewährleistung einer dynamischen Flächenentwicklung in zeitlicher und räumlicher Hinsicht im Sinne des Prozessschutzes.

Neben ihrer Bedeutung für die Arten- und Strukturvielfalt haben halboffene Weidelandschaften einen hohen Stellenwert für die Umweltbildung, bieten sie doch die Möglichkeit, in der Öffentlichkeit ein Bewusstsein für ökologische Fragestellungen und naturnahe Landschaften zu schaffen (Schröder 2010). Große Pflanzenfresser wie Wildpferd und Auerochse sind zwar ausgestorben, jedoch erscheint es sinnvoll, die Rahmenbedingungen für eine Wiederherstellung von nahezu unberührten Naturlandschaften mit entsprechender Artenvielfalt im Sinne des Nationalparkgedankens anhand von extensiver Nutztierbeweidung zu erproben und erforschen (Meßner 2005).

Ziel des Naturschutzes sollte es sein, das Modell halboffener Weidelandschaft über die derzeitigen Pilotprojekte hinaus in der Fläche zu etablieren. Das wird ohne Partner aus der Landwirtschaft nicht möglich sein. Da diese neuen Weidesysteme wesentlich günstiger und effektiver zur Erhaltung vieler Arten sind als die meisten herkömmlichen Maßnahmen, besteht hier die einmalige Chance, ein positives Miteinander von Naturschutz und Landwirtschaft auf eine neue Ebene zu heben und kostengünstig umzusetzen (Kämmer 2010). 


\subsection{Pflege von Kulturgrasland}

Halboffene Weidelandschaften spielen heutzutage flächenmäßig in Mitteleuropa keine nennenswerte Rolle. Die Bemühungen im Naturschutz konzentrieren sich vorrangig auf den Erhalt der strukturreichen Kulturlandschaft, die zahlreichen Tieren und Pflanzen einen Lebensraum bietet.

\subsubsection{Entstehung und Bedeutung}

Die Kulturlandschaft ist eine vom Menschen intensiv genutzte, durch kleinräumige Wirtschaftsweisen geprägte Agrarlandschaft, deren Haushalt durch eine Vielzahl von Landschaftselementen ökologisch relativ stabil ist und in ihrer Physiognomie naturräumliche Verschiedenheiten wahrt (Briemle 1978). Einen wesentlichen Teil stellt dabei das Kulturgrasland dar, welches die durch Gräser dominierten Wiesen- und Weidelandschaften des gemäßigten Europas bezeichnet (Dierschke \& Briemle 2002).

Die heutige Kulturlandschaft in Mitteleuropa ist in vielen Zwischenschritten aus einer vom Menschen unbeeinflussten Naturlandschaft entstanden. Historische Kulturlandschaften sind häufig Resultat jahrhundertelanger Landbewirtschaftung, bei Magerrasen und Feuchtgrünland insbesondere durch extensive Weidewirtschaft (Beutler 1997). Auf den entwaldeten Flächen konnten sich Pflanzen etablieren, die viel Licht brauchten und die Nutzung durch den Menschen tolerierten (Gerken \& Meyer 1998). Aus relativ monotonen Wäldern wurde so ein vielfältiges Mosaik unterschiedlich stark beeinflusster Ökosysteme mit Wäldern, Gebüschen, Heiden, Äckern, Ruderalfluren und Grasland (Dierschke \& Briemle 2002). Die jahrhundertelang relativ gleichförmige Bewirtschaftung führte zu standorttypischen floristischen und faunistischen Artengemeinschaften, die von der menschlichen Nutzung der Fläche abhängig waren und sind (Schumacher 1988, Beck 1994, Kapfer 1995a, 1995b). So bildeten sich beispielsweise durch Beweidung und Mahd allmählich zahlreiche Graslandtypen heraus, die es heute in unterschiedlichsten Ausprägungen gibt (Dierschke \& Briemle 2002).

Mit der extensiven Landnutzung seit dem Mittelalter ist in Mitteleuropa die biologische Vielfalt an Arten und Lebensgemeinschaften gewachsen. Durch die Intensivierung der Landnutzung in den vergangenen 200 Jahren kam es jedoch zu einer deutlichen Produktivitätssteigerung der Weiden und Wiesen und damit verbunden zu einem kontinuierlichen Verlust an biologischer Vielfalt (Ewald 1994, Schuster 1995). Über Jahrhunderte gewachsene Kulturlandschaften wurden seit dem Zweiten Weltkrieg entweder melioriert oder aus der Produktion herausgenommen: Während die landwirtschaftliche Nutzung von kleinen, inhomogenen Grünflächen und von Grenzertragsstandorten aus ökonomischen Gründen aufgegeben wurde (LÜBW 2006), wurde sie auf produktiveren Standorten intensiviert. Beide Entwicklungen sind aus Sicht des Arten- und Biotopschutzes problematisch und haben sich negativ auf die biologische Vielfalt von wertvollen extensiv bis mittelintensiv genutzten Agrarlandschaften ausgewirkt (Dierschke \& Briemle 2002, von Oheimb et al. 2006).

Während junge Brachen teilweise biologisch besonders wertvolle Bestände darstellen können, geht die Artenvielfalt mit fortschreitender Sukzession zurück. Typische Begleiterscheinungen sind Entmischung, Herden- und Dominanzbildung, Verkrautung oder Vergrasung sowie das Ausbilden einer Strauch- oder Baumschicht (Dierschke \& Briemle 2002). Eine regelmäßige Pflege von Kulturgrasland ist erforderlich, um die typischen Arten und das charakteristische Landschaftsbild zu erhalten. Durch das Bundesnaturschutzgesetz sind historische Kulturlandschaften deswegen grundsätzlich unter Schutz gestellt (BNatSchG $\S 2$, Absatz 1 sowie $\S 20 \mathrm{c}$ ), auch wenn sie streng genommen nicht die ursprüngliche Naturlandschaft in Mitteleuropa darstellen, sondern ein Produkt des menschlichen Wirkens sind (Wohlleben 2009). 


\subsubsection{Formen der Biotoppflege}

Die Biotoppflege dient der Erhaltung geschützter Biotope, die durch menschliches Einwirken geformt wurden. Sie wird nach pflegender Nutzung und Pflege ohne Nutzung unterschieden: Nutzende Pflege ist meist mit Landbewirtschaftung verbunden, durch Beweidung wird u.a. Fleisch, durch Mahd Futter produziert. Bei der Pflege ohne Nutzung, zum Beispiel der Entbuschung, entstehen hingegen keine vermarktungsfähigen Produkte (Rahmann 2000).

Als Formen der Biotoppflege gelten Mahd, Entbuschung und Beweidung. Die Mahd bewirkt einen kontinuierlichen Entzug von Nährstoffen aus dem Ökosystem Wiese. Ausschlaggebend für den Wiesengesellschaftstyp sind Standortbedingungen, Zeitpunkt und Intervalle der Mahd sowie Entwässerung und Düngung (Dierschke \& Briemle 2002). Die extensive Wiesenwirtschaft hat einen ein- bis zweimaligen Mahdrhythmus, der artenreiche Lebensräume für Pflanzen und Tiere schafft (Nitsche \& Nitsche 1994). Die Mahd kann manuell oder mechanisch erfolgen.

In der Biotoppflege dient die Entbuschung der Offenhaltung von Flächen, wo krautschicht-dominiertes Grünland mit geschützten Pflanzen- und Tiergesellschaften erhalten bzw. geschaffen werden soll. Als Entbuschung bezeichnet man die Entfernung von Gehölzen auf oder an Freiflächen (Rahmann 2000). Sie bezieht sich auf holzige Chamaephyten (Zwergsträucher), Nanophanerophyten (Sträucher) und junge Phanerophyten (Bäume). Entbuschungen gehören zu den arbeitsintensivsten und teuersten Pflegemaßnahmen. Sie erfolgen meistens nicht im Rahmen der Landwirtschaft, sondern eher kommunal oder durch im Naturschutz engagierte Privatpersonen (Rahmann 2000).

Beweidung mit Haustieren ist die älteste Form landwirtschaftlicher Nutzung. Eine intensivere Weideform setzte sich erst allmählich durch (Dierschke \& Briemle 2002). Die unterschiedlichen Weidetypen werden durch naturgebende Faktoren, die Weidetierart und die Art der Weideführung geprägt (Nitsche \& Nitsche 1994). Im Gegensatz zur Mahd geschieht die Beweidung selektiv, was zu Unter- oder Überbeweidung führen kann (Dierschke \& Briemle 2002).

\subsection{Biotoppflege durch extensive Beweidung}

Die extensive Weidewirtschaft ist eine Betriebsform, die mittels anspruchsloser Weidetiere die natürliche Vegetation nutzt, ohne dass der Landwirt aktiv-fördernd in das Pflanzenwachstum eingreift, Tiere durch Ställe vor der Witterung schützt oder in größerem Ausmaß durch Futterzukäufe Notzeiten zu lindern versucht (Andreae 1972). Diese etwas ältere Formulierung trifft auch heute noch den Kern des extensiven Beweidungskonzeptes. Die extensivste Form der Beweidung ist die Hutung, eine sehr alte Form der Viehhaltung mit Besatzstärken von 0,2 bis 0,8 Großvieheinheiten pro Hektar, die auf Koppelung und Düngung verzichtet.

Die Intensität der Bewirtschaftung wurde früher durch den Tierbesatz, die Anzahl der Koppeln auf einer Fläche sowie die Art der Düngung festgelegt (Nitsche \& Nitsche 1994). In jüngerer Zeit wird der Begriff der extensiven Beweidung jedoch kontrovers diskutiert. Bauschmann (2005) vertritt beispielsweise die Ansicht, dass Düngemittel verringert werden müssen, während die Beweidung oder die Zahl der Beweidungsdurchgänge je nach Anforderung nicht reduziert, sondern intensiviert werden muss, um ein bestimmtes Pflegeziel zu erreichen. Eine Nutzungsextensivierung hilft bedrohten Pflanzenarten erst, wenn die Produktivität auf der Fläche drastisch reduziert wird (Mühlenberg \& Slowik 1997). 


\subsection{Pferde in der Biotoppflege}

Dem Erhalt naturschutzfachlich wertvoller Offenland-Biotope durch gezielte Pferdebeweidung ist bislang wenig Beachtung geschenkt worden, da bei Fachbehörden häufig erhebliche Bedenken bestehen, Pferde in der Biotoppflege einzusetzen (LÜBW 2006). Erst seit wenigen Jahren fokussieren sich Beweidungsprojekte auf Pferde (ANL 2005). Um diese Vorbehalte zu verstehen, sind zunächst einige grundlegende Betrachtungen zum Nahrungsverhalten unterschiedlicher Weidetiere hilfreich.

\subsubsection{Die Nahrungswahl beeinflussende Faktoren}

Die Nahrungswahl eines Tieres hängt von verschiedenen Faktoren ab, die durch das Tier selbst oder seine Umwelt bedingt sind (Forbes 1986). Sie schließen beispielsweise die physiologische Konstitution des Tieres und seine früheren Weideerfahrungen, die umgebende Natur und die Erreichbarkeit von Nahrungspflanzen mit ein, aber auch seine Anatomie, sein Alter oder Hungerlevel (Owen-Smith 1999, van Hoven 2000, Oliver 2007).

\subsubsection{Weidetierbedingte Faktoren}

Die Gestalt der Zähne und der Gebissaufbau weisen auf die Ernährungsweise eines Tieres hin. Bei Paarund Unpaarhufern ist es auf die beiden Funktionen des Greifens und Mahlens von pflanzlicher Nahrung ausgelegt. Aufgrund der Gebissstruktur und der Art der Weidenutzung werden Pflanzenfresser in Ernährungstypen unterteilt (Abb. 2). Die Grasfresser oder grazer ernähren sich - wie der Name bereits sagt - überwiegend von Gräsern. Durch die in den Zellen der Gräser eingelagerten Kieselsäure-Kristallite werden die Zähne der Grasfresser stark abgenutzt. Pferde und viele Paarhufer verfügen daher über hochkronige Zähne. Zwischen Schneide- und Backenzähnen herrscht eine Arbeitsteilung: Die Prämolaren und Molaren bilden eine Reibefläche zum Zermahlen der Nahrung, während die Schneidezähne beim Pferd beispielsweise als Beißzange zum Abrupfen der Gräser dienen (Pflumm 1996).
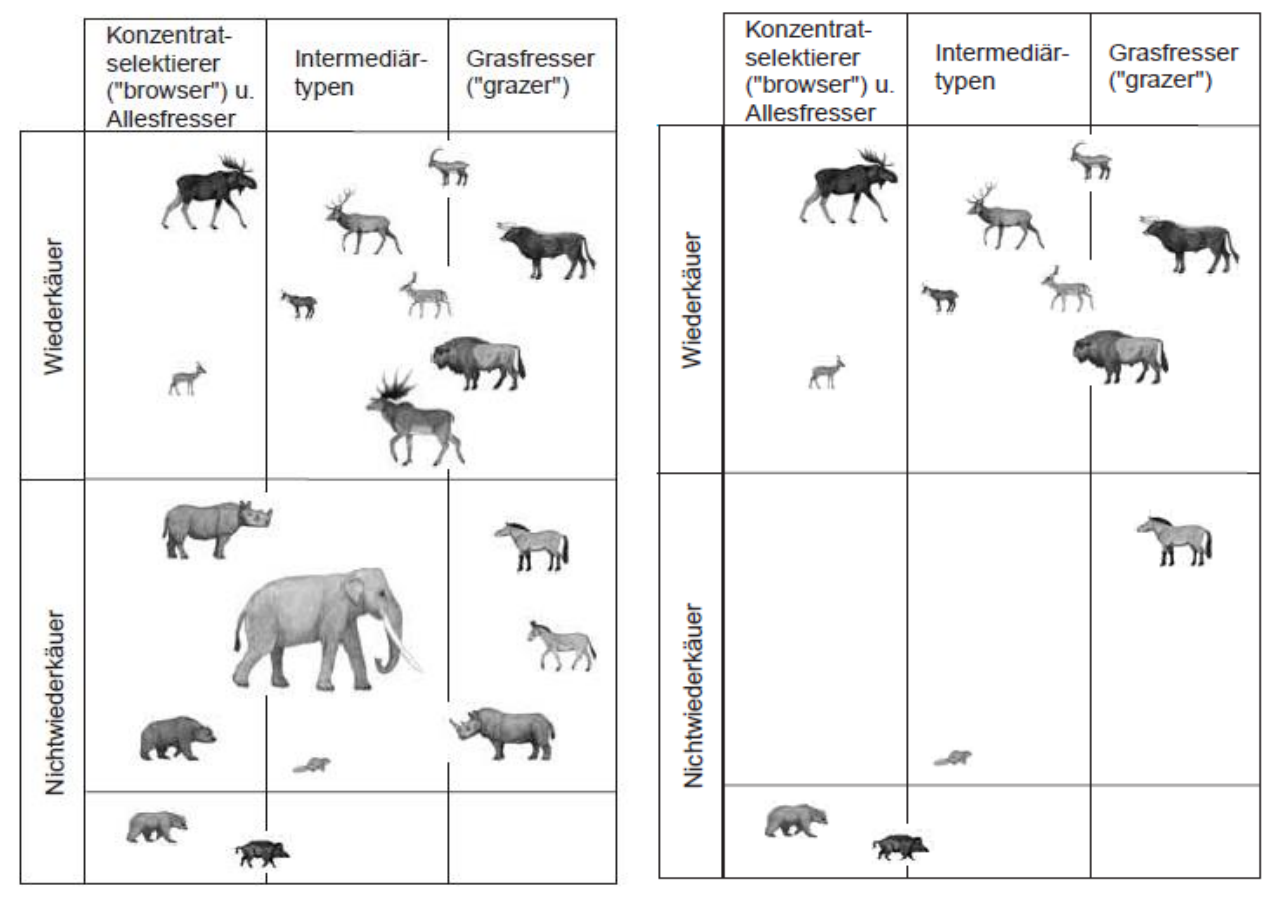

Abb. 2: Einteilung typischer warmzeitlicher Herbivorenarten Mitteleuropas in Ernährungstypen (links) im Vergleich zu der heutigen potenziellen Großherbivorenfauna (aus Bunzel-Drüke 1997) 
Auch der Verdauungsapparat erfuhr im Laufe der Evolution eine beeindruckende Spezialisierung bei pflanzenfressenden Arten. Pflanzennahrung besteht überwiegend aus Stärke und Zellulose, deren Aufspaltung in speziellen Gärkammern erfolgt. Bei Wiederkäuern wird die Zellulose in einer Magenkammer, dem Pansen, mit Hilfe von symbiontisch lebenden Bakterien aufgespalten. Beim Pferd, das kein Vormagensystem besitzt, ist der Blinddarm als Gärkammer ausgebildet. Durch die dem Dünndarm nachgeordnete Lage der Kammer können die aufgespalteten Moleküle kaum mehr absorbiert werden und gelangen mit dem Kot fast ungenutzt nach außen. Der stammesgeschichtliche Erfolg der Paarhufer im Vergleich zu Einhufern wird auf diesen Unterschied in der Verdauung zurückgeführt (Pflumm 1996).

Als weitere Einflussfaktoren auf die Nahrungswahl seien die Körpergröße und der Energieumsatz des Tieres erwähnt. Dabei ist der Energieumsatz umso höher, je größer die Körpermasse ist (Pflumm 1996). Pferde benötigen eine verhältnismäßig große und voluminöse Futtermenge, um ihr Körpergewicht bei normaler Aktivität zu erhalten (Schäfer 1989).

\subsubsection{Vegetationbedingte Faktoren}

Welche Pflanzen gefressen werden, hängt vor allem von Habitatpräferenzen, Futtervorlieben und Nahrungsverhalten ab (Grunow 1980). Gerade bei sehr sozialen Arten wie dem Pferd spielt auch das Herden- und Sozialverhalten eine wichtige Rolle, da Futterzeiten und Fressstandorte durch die Synchronisierung der Verhaltensweisen in der Herde und gemeinsame Ortswechsel beeinflusst werden (Schäfer 1989). Verfügbarkeit und Qualität von Futter und Wasser haben wiederum einen entscheidenden Einfluss auf die soziale Organisation und die Verteilung bei Equiden (Rubinstein 1986), wobei haremsbildende Formen wie das Exmoor-Pony eher nahrungsreichere Gegenden mit atlantischem Klima besiedeln, die ein Leben in der Gruppe über das ganze Jahr hinweg erlauben (Tyler 1972, Berger 1986). Umwelt und Verhalten stehen somit in direkter Wechselwirkung.

Nahrungpräferenzen ergeben sich aus einer Vielzahl von Faktoren: die Fraßhöhe oder Vegetationsschicht, die Artenzusammensetzung, die Grasnarbenstruktur, die Trockenmasseproduktion, die chemische Zusammensetzung der Pflanzen sowie ihre Verdaulichkeit und Schmackhaftigkeit, um nur einige zu nennen (Oliver 2007). Auch individuelle Vorlieben der Tiere spielen eine Rolle. Als Präferenz wird dabei die Auswahl einer bestimmten Pflanzenart aus zwei oder mehreren zur Verfügung stehenden Arten definiert. Bevorzugte Arten werden dabei zu einem deutlich höheren Anteil aufgenommen, als es ihrer Verbreitung in einem bestimmten Areal entspricht, unabhängig davon, welchen Anteil die betrachtete Art an der Gesamtnahrung eines Tieres einnimmt (Petrides 1975). Bevorzugte Pflanzen unterscheiden sich von Hauptnahrungspflanzen, die die Aufrechterhaltung der normalen Körperaktivität gewährleisten, aber in der Regel nicht sonderlich nahrhaft oder schmackhaft sind (Stuth 1991).

Ob eine Pflanzenart gern gefressen wird, hängt von ihrer natürlichen Häufigkeit und ihren morphologischen Eigenschaften ab, aber auch vom restlichen Nahrungsangebot (Stuth 1991). Durch die variierende - zum Beispiel saisonale - Zusammensetzung von Pflanzengesellschaften verändern sich auch die Nahrungspräferenzen der Tiere. Ist auf einer Weide nur nährwertarmes oder überständiges Futter vorhanden, werden auch Pflanzen gefressen, die bei entsprechender Auswahlmöglichkeit verschmäht würden (LÜBW 2006).

\subsubsection{Tagesrhythmik und Saisonalität}

Die Nahrungswahl eines Tieres wird neben weidetier- und vegetationsbedingten Faktoren auch von tages- und jahreszeitlichen Schwankungen beeinflusst. Freilebende Pferde, die über ein großes Areal mit unterschiedlichen Böden und entsprechend verschiedenen Pflanzen verfügen, nehmen im Tagesverlauf unterschiedliche Gräser und Kräuter zu sich (Ebhardt 1954, Schäfer 1989) und weisen kürzere 
und längere Fressperioden auf, wobei die durchschnittliche Fressdauer eines erwachsenen Hauspferdes rund zwölf Stunden beträgt. Jahreszeitliche Einflüsse können den Tagesrhythmus zwar verschieben, aber nicht wesentlich verlängern oder verkürzen. Bei reichlichem Nahrungsangebot wird der lebensnotwendige Futtervorrat für die vegetationsarmen Monate angelegt (Schäfer 1989).

\subsubsection{Der Einfluss der Weidetiere auf die Vegetation}

Großherbivore fressen große Mengen nährstoffarmen Futters und verursachen regelmäßige kleine Störungen in der Landschaft. Sie verbreiten effizient Samen über größere Entfernungen. Die durch Kotund Urinstellen verursachte ungleichmäßige Nährstoffverteilung führt zu einer Bodenheterogenität (Olff et al. 1998), die zur Entstehung von kleinflächigen Mosaikstrukturen führen kann (von Oheimb et al. 2006). Insgesamt wird dadurch die Artenvielfalt erhöht, es sei denn, Weidetiere werden in zu hohen Besatzdichten eingesetzt (Olff et al. 1998).

Die Pflanzenzusammensetzung von Grünland hängt von den Standortgegebenheiten sowie der Art der Bewirtschaftung ab. Während die naturgegebenen Faktoren wie Standort, Höhenlage, Exposition und Klima den Rahmen für die Zuordnung der Pflanzengesellschaften geben, wird die Artenzusammensetzung auf Weiden vor allem durch Verbiss, Tritt, Exkremente und Weidetierverhalten bedingt. Die Art des Weidegangs und die Düngung entscheiden über den Wert der Grünlandgesellschaften als Ökosystem (Nitsche \& Nitsche 1994).

\subsubsection{Fraß}

Die Weidewirkung von Fraß ist abhängig von Maul und Zähnen der Tiere sowie von der Bevorzugung bestimmter Pflanzen (Dierschke \& Briemle 2002). Da Beweidung im Gegensatz zur Mahd selektiv erfolgt, finden sich auf einer Weidefläche gleichzeitig verschiedene Entwicklungsstadien einer jeden Pflanzenart. Während bei Wiesen Obergräser vorherrschen, sind auf Weiden Untergräser wie Deutsches Weidelgras (Lolium perenne), Wiesen-Rispengras (Poa pratensis) oder Rot-Schwingel (Festuca rubra) die Hauptbestandsbildner. Sie zeichnen sich durch niedrigere Wuchsformen, größeren Blatt- als Halmanteil und Rhizombildung aus, denn das häufige Verbeißen fördert einen an den Boden angepressten Wuchs (Nitsche \& Nitsche 1994).

Ist zu viel Futter vorhanden, kann es zu einer Unterbeweidung kommen, da sich die Tiere dann nur die bestschmeckenden Pflanzen heraussuchen. Die übrig gebliebenen werden überständig und rohfaserreich, die Futterqualität verschlechtert sich und es kommt häufig zur Ausbreitung von so genannten Weideunkräutern. Weideunkräuter sind beispielsweise Pflanzen mit Dornen, Stacheln oder Blätter mit starker Behaarung wie Crataegus, Rosa oder Rubus, schlecht schmeckende und unangenehm riechende Arten wie Rumex, Mentha oder Artemisia sowie Pflanzen mit Giftstoffen. Auch Kriech- und Rosettenpflanzen können sich übermäßig verbreiten, da sie aufgrund ihrer Wuchsform dem Fraß teilweise entgehen. Eine sommerliche Unterbeweidung führt zur Bildung von Altgrasbeständen und erhöht die Struktur- und Lebensraumvielfalt (von Oheimb et al. 2006), während eine zu hohe Besatzdichte eine Überbeweidung mit Kahlstellen und einem Leistungsabfall der Weidetiere verursachen kann (Dierschke \& Briemle 2002, Nitsche \& Nitsche 1994).

\subsubsection{Tritt}

Die Weidewirkung von Tritt ist abhängig von der Art der Hufe und Klauen, dem Gewicht der Tiere und den Bewegungs- und Aufenthaltsgewohnheiten des Viehs. Durch mechanische Schädigung wirkt sie direkt auf die Pflanzen ein. Indirekt werden zudem der Oberboden verdichtet und das Porengefüge 
verändert (Dierschke \& Briemle 2002). Je nach Feuchtegrad des Bodens können Wasserstau und Luftarmut auftreten (Nitsche \& Nitsche 1994). Die Beschädigung der Grasnarbe fördert die Ausbreitung trittunempfindlicher Arten (Dierschke \& Briemle 2002, Briemle et al. 2002). Tritt verändert somit die Zusammensetzung der Pflanzenarten auf der Weide und es kommt nach langjähriger Beweidung zu typischen Pflanzengesellschaften (Nitsche \& Nitsche 1994). An stark frequentierten Stellen wie Tränken, Trampelpfaden und Ruheplätzen entwickeln sich häufig Trittgesellschaften oder üppige Lägerfluren (Dierschke \& Briemle 2002). Neue, konkurrenzschwache Arten siedeln sich in artenarmen Beständen in den Lücken an. Streu zersetzt sich schneller, wenn es durch Weidetiere an den Boden gedrückt wird (Nitsche \& Nitsche 1994).

\subsubsection{Dung}

Die Nährstoffe, die durch die Beweidung dem Boden entzogen wurden, gelangen über Kot und Urin zurück auf die Fläche. Die Verteilung der Exkremente ist jedoch ungleichmäßig: An Ruheplätzen oder Geilstellen ist die Konzentration der Nährstoffe deutlich höher als auf der restlichen Weidefläche. Die Nährstoffe an Urinstellen werden relativ schnell von den Pflanzen wieder aufgenommen. Der Aufwuchs an diesen Stellen hat höhere K- und N-Werte und wird nach einer gewissen Zeit vom Vieh bevorzugt gefressen. An Kotstellen tritt hingegen punktuell eine starke Nährstoffkonzentration auf, die verstärkt durch die Tatsache, dass Geilstellen von den Tieren meist nicht beweidet werden - zu einer ungleichmäßigen Nährstoffverteilung führt (Nitsche \& Nitsche 1994). 10-20 \% der Weidefläche können als Nahrungsfläche ausfallen (Klapp 1971), bei Unterbeweidung sogar bis zu 80 \% (LÜBW 2006).

\subsubsection{Einfluss auf Gehölzbestände}

Weidetiere beeinflussen Gehölze durch Verbiss und Körperpflege. Verbiss tolerieren Gehölze bis zu einer bestimmten Intensität. Die Stärke des Verbisses ist von der Tiergattung und -rasse, Alter und Gewohnheiten der Tiere, der Art und Anzahl der Gehölze auf der Fläche, dem restlichen Futterangebot und der Jahreszeit abhängig (Nitsche \& Nitsche 1994). Je nach Weidetierart und Gehölzart fallen die Schädigungshöhe, der Schädigungsgrad und die Absterberate unterschiedlich aus (von Oheimb et al. 2006). Bevorzugt werden vor allem frisches Laub und junge Triebe. Durch häufiges jährliches Verbeißen entstehen Gebüsche und Bäume mit einer typischen Form. Die größten Schäden am Gehölz richten Ziegen an, da sie wie das Rotwild auch Rinde schälen (Nitsche \& Nitsche 1994).

\subsubsection{Vergleich von Pferden zu anderen Weidetierarten}

Die Auswirkungen der Beweidung sind je nach Nutztierart verschieden: Verbisshöhe, Selektionsverhalten, Trittwirkung, Futteraufnahmespektrum und damit die Auswirkungen auf Flora und Fauna unterscheiden sich zwischen den Nutztierarten zum Teil erheblich (Dierschke \& Briemle 2002). Art und Rasse müssen daher dem Standort, den Aufwuchsverhältnissen und dem Pflegeziel angepasst sein (Nitsche \& Nitsche 1994), denn es hat sich längst gezeigt, dass sich nicht jede Beweidung mit Herbivoren positiv auf die Artenvielfalt im Grünland auswirkt (Olff et al. 1998).

\subsubsection{Nahrungsaufnahme}

Rinder haben keine Schneidezähne im Oberkiefer. Sie umfassen die Pflanzen büschelweise mit der Zunge, ziehen sie ins Maul, drücken sie gegen den Oberkiefer und reißen sie ab. Die Pflanzen werden narbenschonend in unterschiedlicher Länge wenige Zentimeter über dem Boden abgerissen (Dierschke \& Briemle 2002). Pferde hingegen fressen nicht nur viel langsamer und sorgfältiger als Wiederkäuer, 
sie nehmen die einzelnen Gräser und Kräuter wesentlich gezielter und differenzierter auf. Sie greifen Futtergräser mit den Lippen und beißen sie mit ihren breiten Schneidezähnen unter kurzem Kopfzuck nach hinten oben ab. Je dichter und artenreicher der Pflanzenbewuchs der Weide, desto sorgfältiger werden die einzelnen Gräser ausgewählt. Irrtümlich aufgenommene Kräuter lassen Pferde seitlich wieder herausfallen. Auf stark abgegrasten Weiden rupften sie die Gräser mitsamt den Wurzeln aus und zerstören dabei die Grasnarbe (Schäfer 1989). Ähnlich selektiv verbeißen Schafe und Ziegen Pflanzen tief am Boden (Dierschke \& Briemle 2002).

\subsubsection{Trittwirkung}

Der Druck des Tritts von Weidetieren ist je nach Art, Rasse und Alter unterschiedlich (Nitsche \& Nitsche 1994). Die bodenverdichtende Wirkung reicht unter Schafweiden etwa 1 bis $4 \mathrm{~cm}$ tief, unter Kuhweiden 10 bis $15 \mathrm{~cm}$ (Woike \& Zimmermann 1992). Rinder treten mehr mit der gesamten Klauenfläche auf, Schafe und Ziegen hingegen mit ihren spitz geformten Klauen. Die häufige Benutzung derselben Wege zwischen Fress- und Ruheplätzen, wie sie vor allem beim Rind auftritt, verursacht ausgetretene Tierpfade mit einer speziellen Bodenstruktur und Artenzusammensetzung, zum Beispiel WeidelgrasBreitwegerich-Trittrasen (Nitsche \& Nitsche 1994). Die Trittwirkung der Pferde wird aufgrund ihres hohen Bewegungsdranges häufig als besonders schädigend beschrieben (Korn 1992, 2009). Bei gleicher Besatzdichte und angepasstem Weidemanagement verursachen Pferde jedoch nicht höhere Trittschäden als andere Weidetiere, insbesondere Rinder (LÜBW 2006).

\subsubsection{Futteraufnahmespektrum}

Aufgrund ihrer gut ausgebildeten Backenzähne und des speziellen Verdauungssystems können Pferde nährstoffarmes, hartes, faserreiches und überständiges Futter besser zerkleinern und verwerten als Wiederkäuer. Bei der Auswahl der Futterpflanzen bevorzugen Pferde jedoch ebenso wie Wiederkäuer in erster Linie nährstoffreiche, junge Futterpflanzen. Wenn diese nicht mehr vorhanden sind, nehmen sie auch faserreiches, älteres Futter gut an. Dies hat für die Biotoppflege die wichtige Konsequenz, dass Pflanzenbestände auch zum schnittreifen oder bei genügsamen Rassen wie dem Exmoor-Pony sogar zum überständigen Zeitpunkt beweidet werden können. Auf Flächen mit älterem Aufwuchs weiden Pferde gerne Fruchtstände der Süßgräser ab und können so langfristig zum Rückgang dieser Gräser beitragen (LÜBW 2006).

Ein weiterer Unterschied im Fraßverhalten gegenüber Wiederkäuern besteht darin, dass Pferde in hohem Maße Binsengewächse, Sauergräser und hartblättrige Süßgräser wie Rasenschmiele (Deschampsia cespitosa) oder Blaues Pfeifengras (Molinia caerulea) fressen. Dies ist bei der Pflege von Feuchtgrünland von Vorteil, da sich sonst dort bei Rinderbeweidung meist Binsen-Arten und Rasen-Schmiele in unerwünschtem Maße ausbreiten (LÜBW 2006).

Pferde haben eine Vorliebe für grasartige Pflanzen, so dass in einem Bestand die Gräser im Verhältnis zu den Kräutern meist überproportional stark genutzt werden. Dies hat auf den Weideflächen oftmals eine Zunahme der Deckungsanteile krautiger Pflanzen zur Folge, zum Beispiel von Schafgarbe (Achillea) oder Flockenblumen (Centaurea). Hierbei unterscheiden sie sich von Schafen, die einen höheren Anteil krautiger Pflanzen auswählen (LÜBW 2006).

Ein positiver Einfluss der Pferdebeweidung zeigt sich allerdings nicht nur im Grünland. Exmoor-Ponys verbeißen beispielsweise bevorzugt Buchensprösslinge in Waldhabitaten und schaffen damit bessere Wachstumsvoraussetzungen für seltenere Baumarten wie Eichen. Im Allgemeinen ist jedoch der Gehölzverbiss von Pferden bei üblicher Weidenutzung auf Grünlandflächen bei ausreichendem Futterangebot gering. Anders als Ziegen, für die Gehölze ein wesentlicher Nahrungsbestandteil sind, fressen 
Pferde nur in Notsituationen und bei Futtermangel Blätter und Gehölztriebe in größerem Umfang (LÜBW 2006). Ein nennenswerter Verbiss findet nur im Winterhalbjahr statt, sofern nicht zugefüttert wird (Krannich 2005). Gehölzverbiss als Pflegeleistung kann somit von Pferden ebenso wenig erwartet werden wie von Schafen oder Rindern. Bei einer Beweidung mit Pferden bleibt eine Nachpflege in Form von Mahd oder Entbuschung in Abständen von mehreren Jahren notwendig (LÜBW 2006).

\subsubsection{Eignung des Pferdes zur Biotoppflege}

Eine Pferdehaltung trägt zur Grünlanderhaltung bei, da Pferde aufgrund ihrer Herkunft an die Bedingungen extensiver Standorte angepasst sind. Ein wesentlicher Vorteil der Beweidung mit Pferden gegenüber Rindern und Schafen ist, dass sie älteres und rohfaserreiches Futter besser annehmen und verwerten und auch hartblättrige Süßgräser und Sauergräser verzehren. Daher können sie auch noch zu den in der Biotoppflege oft gewünschten späten Pflegezeitpunkten eingesetzt werden (LÜBW 2006).

Durch das tiefe Abbeißen der Pflanzen und den selektiven Fraß entstehen auf den Pferdeweiden stark überweidete und teils unberührte Bereiche, auf denen Kot und Urin abgegeben werden. Hier können sich große Bestände von Stickstoff liebenden Arten ausbreiten, während die überweideten Bereiche ihre Regenerationsfähigkeit verlieren. Diese differenzierte Nutzung der Weidefläche führt bei längerer Beweidung zu einer Verschärfung der Gegensätze zwischen Fraß- und Nichtfraßbereichen und bewirkt eine starke Differenzierung der Weidefläche, die zum Verlust von Fressfläche führt, zumal sich die Lage und Ausdehnung der Nichtfraßbereiche im Laufe der Jahre nur wenig ändert (Edwards \& Hollis 1982, Nitsche \& Nitsche 1994, Dierschke \& Briemle 2002, LÜBW 2006).

Aus Sicht des Naturschutzes ist diese Entwicklung nur dann problematisch, wenn man bei einer Biotoppflege eine ganz bestimmte Zusammensetzung der Vegetation bzw. bestimmte Arten erhalten will oder wenn es sich um schutzwürdige Biotope auf nährstoffarmen Standorten handelt. Hier führt ein Nährstoffeintrag zu einer Artenverschiebung hin zu nährstoffliebenden, höherwüchsigen Arten auf Kosten der konkurrenzschwachen Magerrasenarten. Auf anderen Flächen kommt es aufgrund der ausgeprägten differenzierten Nutzung im Wesentlichen nur zu einer Aushagerung der Fraßbereiche, während die Nichtfraßbereiche mit Nährstoffen angereichert werden (LÜBW 2006). Ist eine Neuansiedlung von nährstoffliebenden Arten nicht gewollt, wird eine Mischnutzung mit Rindern oder Schafen, eine Koppelung oder ein Nutzungswechsel mit einer eingeschobenen Rinderweide empfohlen (Nitsche \& Nitsche 1994).

Eine Beweidung mit Pferden hielt man früher in Fachkreisen wenn überhaupt nur auf sehr großen Flächen von über 50 ha und in Mischherden mit Rindern für sinnvoll (ANL 1995). Sie wurde daher lange Zeit kaum als Möglichkeit für den Biotoperhalt in Betracht gezogen und wird in der Landschaftspflege auch heute noch häufig als kritisch bis negativ bewertet (Rahmann 1999, Pain 2005, LÜBW 2006). Dies rührt überwiegend daher, dass Pferde die Grasnarbe von Weiden schädigen können, Geilstellen anlegen und auch Gehölze fressen. Diese aus landwirtschaftlicher Sicht bedenklichen Entwicklungen können aber, wohl dosiert, aus naturschutzfachlicher Sicht durchaus erwünscht sein (Bolz 2005). Die Einsicht, dass mechanische Pflegeverfahren als Ersatz der landwirtschaftlichen Nutzung großflächig nicht auf Dauer finanzierbar sein werden, und die stärkere Berücksichtigung von Artengruppen wie Heuschrecken und Tagfaltern im Naturschutz lassen die Beweidung mit Pferden als Pflegeinstrument mittlerweile in einem positiveren Licht erscheinen (Pain 2005). In den vergangenen Jahren sind daher in Deutschland einige Projekte mit Pferden in der Landschaftspflege und im Naturschutz entstanden, und erste positive Ergebnisse liegen vor (Becker \& Schmidt 1999, Sonnenburg \& Gerken 2004, Demartin 2005, Preuschhof 2005, Rüther \& Venne 2005). 
Die aktuellen Naturschutzprojekte beweiden selten großflächig und ganzjährig oder setzen auf eine Mischhaltung mit Rindern. Die Auswirkungen einer reinen, großflächigen Pferdebeweidung auf den Artbestand von Pflanzen und Tieren sind kaum bekannt, da es nur wenige Veröffentlichungen hierzu gibt (vgl. Nitsche \& Nitsche 1994, ANL 2005, LÜBW 2006). Hier setzt die vorliegende Untersuchung an. Auf der Grundlage der oben ausgeführten Betrachtungen muss die Bewertung der Eignung einer bestimmten Tierart für eine extensive Grünlandnutzung unter zwei Gesichtspunkten erfolgen:

a.) Im Sinne der Tierhaltung: Sind Aufwuchs und Biotopstrukturen im Projektgebiet als Nahrungsgrundlage und Lebensraum für die ausgewählte Weidetierart geeignet?

b.) Im Sinne des Naturschutzes: Sind die vorhandenen Biotoptypen für eine Beweidung mit der Weidetierart geeignet und ist dies mit den Zielen des Biotop- und Artenschutzes vereinbar? 


\section{DAS PROJEKTGEBIET}

Beschreibung des Schutzgebietes Süd-Langeland

\subsection{Lage, Topographie und Böden}

Das Projektgebiet liegt an der Südspitze der dänischen Insel Langeland und umfasst 107,8 Hektar. Die langgestreckte Ostseeinsel ist über ein Brückensystem an das nordwestlich gelegene Fünen angebunden. Östlich erstreckt sich der Langelandsbelt als Zugang zur Ostsee. Die Insel hat rund 13.000 Einwohner, der südliche Inselteil liegt abseits großer Verkehrswege.

Langeland liegt im Randbereich der weichselzeitlichen Vereisung Nordeuropas. Eine Besonderheit der Ostseeinsel stellen die rund 700 hutförmigen Hügel in der umgebenden flachen Landschaft dar. Im Projektgebiet erreichen sie Höhen von bis zu 20 Metern (Abb. 3). Die Hügel bestehen überwiegend aus vom Schmelzwasser eiszeitlicher Gletscher abgelagertem Kies und Sand. Ihre Entstehung ist bis heute nicht geklärt.

Das Schutzgebiet stellt ein Mosaik aus Wiesen, Weiden, Teichen, Mooren, Jungwald und Hecken dar (Abb. 4). Es grenzt direkt an die Ostsee, die Pferde haben jedoch keinen direkten Zugang zum Meer. Im Gelände verteilt finden sich eine Vielzahl kleinerer und größerer stehender Gewässer, die teils grundwasserabhängig sind, teils jedoch ausschließlich von Niederschlagswasser gespeist werden und im Sommer trocken fallen. Die Mehrzahl der Gewässer wurde innerhalb der vergangenen 20 Jahre angelegt. Durch Einstellung der künstlichen Entwässerung im Zuge der Schutzgebietsausweisung hat sich die Fläche der natürlichen Gewässer stark ausgedehnt (Grundkort Fyn 2011). Der Boden besteht vorwiegend aus fruchtbarem lehmigen Moränenboden, der im Bereich des Niedermoors feuchter, auf den rundkuppigen Hügeln hingegen trockener und sandiger ist.

Im Gebiet herrschen überwiegend sandig-lehmige Substrate vor. Der größte Teil der Fläche wird von tonig-sandigem Geschiebelehm eingenommen (Anlage 3.1). Im Bereich des Moores finden sich darüber hinaus zu gewissen Anteilen Torf, Klei und Mudde wieder. Nördlich davon ist der Boden mit glaziofluvialem Sand und Kies angereichert. Die Grünländer an der Nordspitze weisen hingegen neben Lehm und Sand eine Konzentration von Bänderton auf (Geologische Forschungsanstalt für Dänemark und Grönland GEUS 2011).

\subsection{Schutzstatus}

Süd-Langeland ist Teil eines Natura 2000-Gebietes. Natura 2000 ist ein europäisches Netz von Schutzgebieten mit dem Zweck eines länderübergreifenden Schutzes gefährdeter wildlebender heimischer Pflanzen- und Tierarten und ihrer natürlichen Lebensräume. Die Südspitze Langelands ist aufgrund seiner Bedeutung für den Vogelzug Special protection area (Besonderes Schutzgebiet, kurz SPA) und stellt gleichzeitig ein Gebiet von gemeinschaftlicher Bedeutung (Site of Community Importance, SCI) dar. Ferner finden sich im Projektgebiet zahlreiche geschützte Lebensräume (Anlage 3.1). 


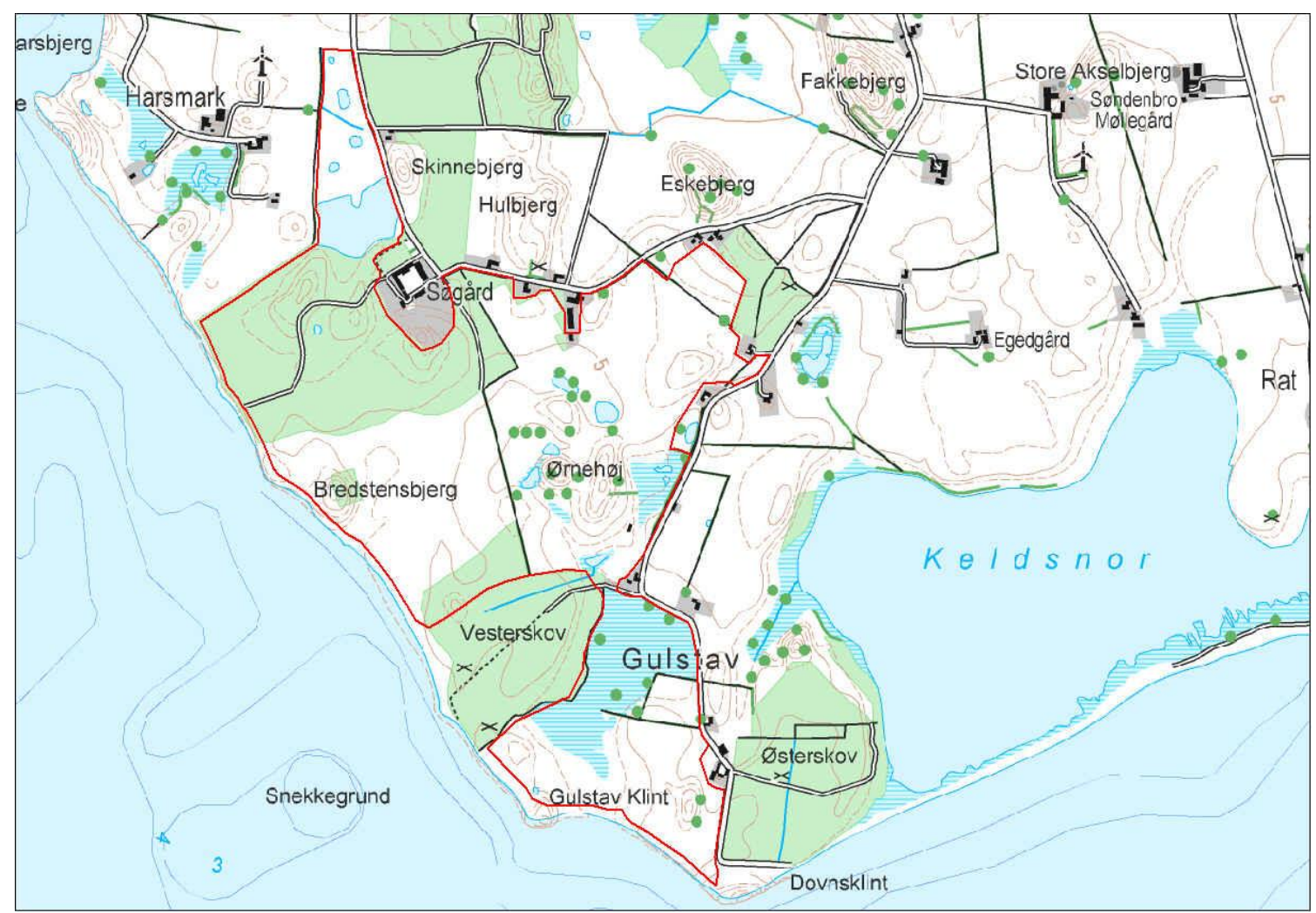

Abb. 3: Topographische Karte des Projektgebietes im Maßstab 1:10.000

rote Linie: Gebietsgrenze

Quelle: Dänisches Generaldirektorat für Natur

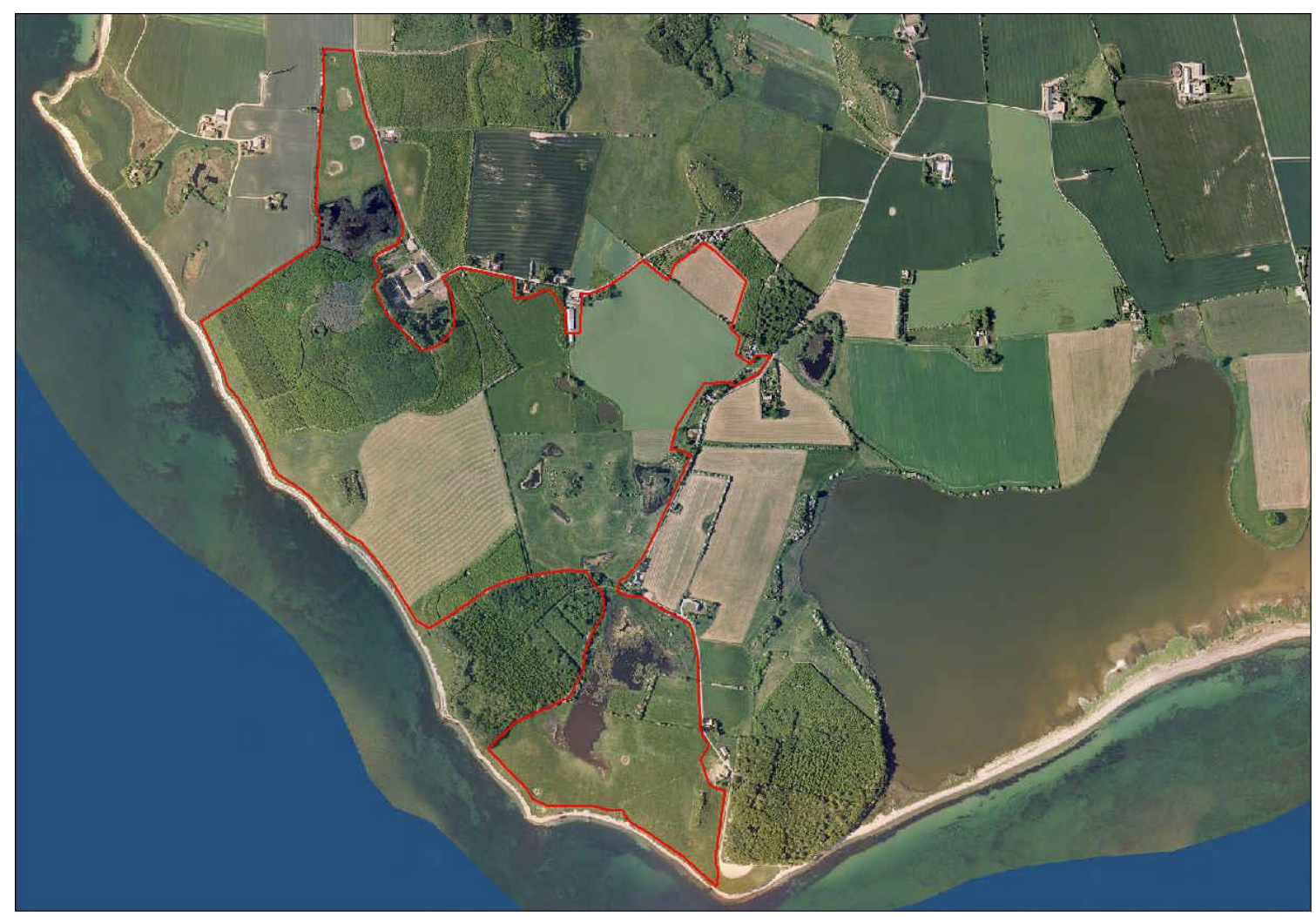

Abb. 4: Satelliten-Aufnahme des Projektgebietes aus dem Jahr 2006

rote Linie: Gebietsgrenze

Quelle: Dänisches Generaldirektorat für Natur 


\subsection{Nutzung}

Die Kulturlandschaft in Dänemark hat sich - wie in vielen anderen westeuropäischen Ländern - in den vergangenen Jahrzehnten stark verändert. Die Landwirtschaft hat sich zu immer größeren und industrialisierten Betrieben entwickelt. Diese Industrialisierung hat extensive Grünländer nach und nach verschwinden lassen, denn die moderne dänische Kuh weidet längst nicht mehr auf natürlichen Weiden. Im Zuge der Umweltbewegung und der Konvention von Rio hat auch in Dänemark ein Umdenken stattgefunden. Zum Schutz der Biodiversität wird zunehmend auf Düngung und den Einsatz von Pestiziden verzichtet (Voigt 2002).

Seit der Novellierung des dänischen Naturschutzgesetzes Nature Conservation Act im Jahr 1992 sind alle Seen und Teiche mit einer Größe von über $100 \mathrm{~m}^{2}$, alle Moore, Salzwiesen, Heiden sowie alle Weiden und Altgrünländer mit über $2.500 \mathrm{~m}^{2}$ geschützt (Dänisches Ministerium für Umweltschutz 2003). Aber der rein hoheitliche Schutz allein gewährleistet nicht den Erhalt des gegenwärtigen Zustandes. Als Folge dieser Extensivierung wird vielerorts die Nutzung von abgelegenen Weiden, abschüssigen Wiesen oder Salzwiesen aufgegeben, obwohl sie ein Beispiel für halbnatürliche Offenlandgesellschaften mit einer artenreichen Flora und Fauna sind, so dass das Küstengrünland in ganz Europa durch Nutzungsintensivierung oder Nutzungsaufgabe gefährdet ist (Bakker \& Berendse 1999, Smith et al. 2000). Um der Verbuschung dieser Flächen und dem damit verbundenen Artenverlust - vor allem von Arten der Roten Liste - entgegenzuwirken, bemüht sich das Dänische Umweltministerium um neue Bewirtschaftungskonzepte. Die Landkreise führen daher - häufig in enger Zusammenarbeit mit den Forst- und Naturschutzbehörden - Beweidungsprojekte durch (Voigt 2002).

Auf dieser Grundlage wurde im Jahr 2006 das Schutzgebiet Süd-Langeland ausgewiesen und seit Oktober desselben Jahres mit Exmoor-Ponys beweidet. Die Ansiedlung der Ponys ist Teil des South Langeland Nature Conservation Project des Umweltministeriums. Ziel ist der Erhalt der offenen küstennahen Landschaft als Brut- und Nistplatz für geschützte Vogelarten und als Lebensraum für bedrohte Insekten- und Amphibienarten (Dänisches Ministerium für Umweltschutz 2006).

In den siebziger Jahren begann die Naturschutzbehörde, bislang landwirtschaftlich genutzte Flächen aufzukaufen, um ein vielfältiges Mosaik an Lebensräumen für viele Tier- und Pflanzenarten zu schaffen und einen Teil des Gebietes wieder aufzuforsten. Vor dem Jahr 1990 wurden die Flächen größtenteils als Agrarland genutzt (Tab. 1). Durch die Anpflanzung von Laub-, Nadel- und Mischwäldern sowie Gebüschstreifen auf rund $20 \%$ der heutigen Fläche und das Anlegen von kleineren Stillgewässern änderte sich das Erscheinungsbild jedoch langsam. Seit den Neunziger wurden die Flächen zunehmend mit Rindern und Schafen beweidet oder zur Mahd genutzt. Die Nutzung blieb jedoch sehr heterogen, so dass Grünlandflächen an Weiden, Brachen an Äcker grenzten. Mit den Vorbereitungen zur Schutzgebietsausweisung wurden die intensiv genutzten Flächen über Jahre hinweg in extensives Grünland umgewandelt. Auf den Altgrünlandflächen wurde die Düngung eingestellt, die Ackerflächen brachgelegt und durch Ansaaten mit standardisierten Saatgutmischungen in Grünland überführt.

Abb. 5 zeigt die frühere Nutzung der Teilgebiete im Projektgebiet. Im Jahr 2006 hat die Behörde die letzten privaten Flächen aufgekauft und ist seither für dessen Pflege verantwortlich. Darunter fallen beispielsweise die Kontrolle und Freihaltung des Elektrozaunes, die extensive Bewirtschaftung der Wälder nach FSC-Kriterien (Forest Stewardship Council) sowie bei Bedarf der Rückschnitt von Gehölzen und das Abmähen von Flächen zur Unkrautbekämpfung.

Hünengräber auf Süd-Langeland weisen auf eine lange Siedlungsgeschichte hin. Eines von ihnen befindet sich am Rande des Projektgebietes auf dem Hulbjerg (s. Abb. 3). Auch Wälder wurden seit mehreren hundert Jahren als Niederwälder bewirtschaftet. Aus kultur- und naturgeschichtlichen Gründen 
stehen sie heute unter Schutz. Beispiele dafür sind Vesterskov und $\emptyset$ sterskov an der Südspitze Langelands. Im Schutzgebiet wurden sie von der Pferdebeweidung ausgeschlossen. Dies begründet die ungewöhnliche Form des Gebietes mit dem schmalen Durchlass zwischen dem zentralen und dem südlichen Gebietsteil.

Mit der Ansiedlung der Wildpferde wurde das Gebiet für den Tourismus interessant. Die Vilde Heste, wie sie in Dänemark genannt werden, sind durch Medienberichte vielen bekannt. Viele steuern die abgelegene Insel an, um die frei lebenden Tiere in der Natur zu erleben. Besucher können dabei das Gebiet uneingeschränkt betreten, dies regelt in Dänemark der Nature Conservation Act (Voigt 2002). Ausgenommen davon ist nur das Vogelschutzgebiet (Teilgebiet 2). Durch empfohlene Wanderwege wird der Besucherandrang auf bestimmte Bereiche konzentriert. Zu den Besuchern zählen Fußgänger, Jogger und Angler, seltener Radfahrer. Das Besucheraufkommen ist unregelmäßig: Es konzentriert sich stark auf die Sommermonate und Wochenenden. Die Wanderwege werden teilweise gemäht.

Tab. 1: Frühere Nutzung der Teilflächen im Projektgebiet (Quelle: L. Vester, Dänisches Generaldirektorat für Natur)

Teilfläche 16 wurde nicht beweidet

\begin{tabular}{|c|c|c|}
\hline Teilfläche & Nutzung von 1990 bis 2006 & Nutzung vor 1990 \\
\hline 1 & Beweidung mit Rindern & Agrarland (Getreide) \\
\hline 2 & Beweidung mit Rindern & - nicht bekannt - \\
\hline 3 & Forstanpflanzung als Schutz für Niederwald & Agrarland \\
\hline 4 & Grünland ohne Düngung seit 2000 & Grünland mit Düngung, Mahd \\
\hline 5 & Grünland mit Düngung bis 2000, dann Brache & Grünland mit Forstanpflanzung \\
\hline 6 & Forstanpflanzung, forstliche Nutzung & Agrarland \\
\hline 7 & Forstanpflanzung, forstliche Nutzung & Agrarland \\
\hline 8 & Beweidung mit Rindern, Entwässerung bis 1991 & Agrarland dank künstlicher Entwässerung \\
\hline 9 & Beweidung mit Rindern & - nicht bekannt - \\
\hline 10 & Seit 1990 Forstanpflanzung (Abies alba), dann Mahd & Agrarland \\
\hline 11 & Agrarland (Getreide) bis 2000 & Agrarland \\
\hline 12 & Beweidung mit Rindern & Agrarland \\
\hline 13 & Agrarland (Getreide) & Agrarland \\
\hline 14 & Beweidung mit Schafen, natürlicher Teich & natürlicher Teich \\
\hline 15 & Steinmauer (denkmalgeschützt) & Steinmauer (denkmalgeschützt) \\
\hline 16 & Garten & Garten \\
\hline 17 & Beweidung mit Schafen, teilweise Forstbestand & - nicht bekannt - \\
\hline 18 & natürlicher Teich & natürlicher Teich \\
\hline 19 & Agrarland bis 2000, dann Grünland ohne Düngung & Agrarland \\
\hline 20 & Grünland, Mahd & - nicht bekannt - \\
\hline 21 & Niederwald & Niederwald \\
\hline
\end{tabular}




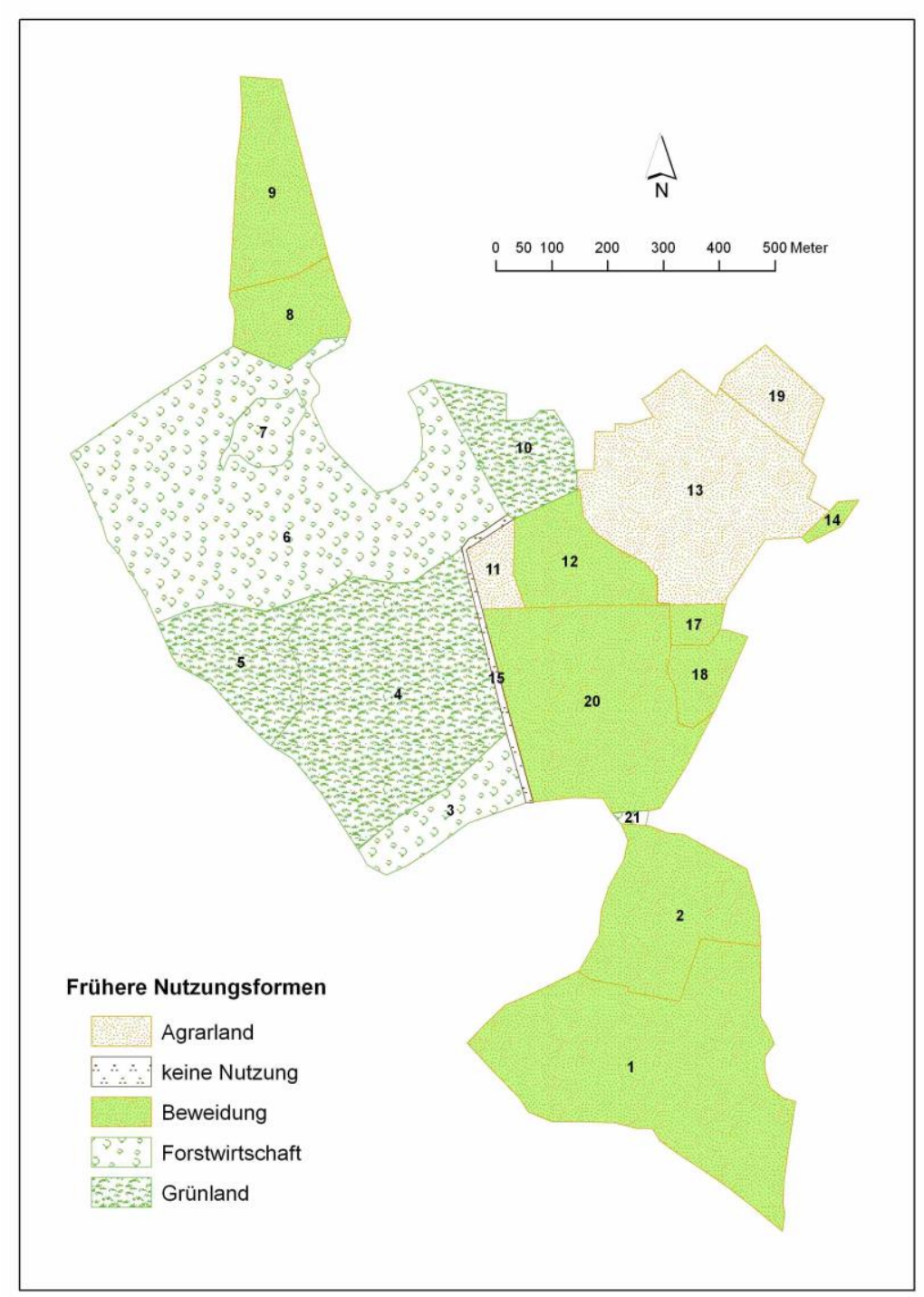

Abb. 5: Frühere Nutzung der Teilflächen im Projektgebiet

Bezeichnung der Teilflächen s. Tab. 1

\subsection{Lebensraumausstattung}

Das Projektgebiet wies zu Beginn des Beweidungsprojektes nach Abkehr von einer überwiegenden Agrarnutzung ein strukturreiches Landschaftsbild mit einer Vielzahl unterschiedlicher Lebensräume auf. Das Gelände war größtenteils mit ausgedehnten Grasfluren bedeckt, die durch Knicks, Gemäuer, Feldgehölze und Stillgewässer in einzelne Teilbereiche gegliedert waren. In Randbereichen der Teilgebiete, am Waldsaum sowie im Bereich der hutförmigen Erhebungen trat eine zunehmende Verbuschung auf.

Auf Sonderstandorten befinden sich im Bereich der Hügel Magerrasen sowie zahlreiche temporäre oder dauerhafte Kleingewässer in den Senken. Eine denkmalgeschützte Steinmauer durchzieht das Gebietszentrum von Norden nach Süden. Ältere Gehölze sind nur vereinzelt und kleinflächig im Uferbereich einzelner Teiche vorhanden. Die aufgeforsteten Waldflächen bestehen aus Jungwald und Gebüsch. Eine ausführliche Beschreibung der Lebensraumtypen findet sich in Kapitel 6.2 Vegetationsausstattung zu Beginn der Beweidung. 


\subsection{Witterungsbedingungen}

Die Witterung hat Einfluss auf die Vegetation und das Verhalten der Weidetiere. Daher werden die Wetterdaten der Region Fünen-Langeland im Untersuchungszeitraum dargestellt. Langeland weist ein ausgeprägtes Meeresklima mit mäßig warmen Sommern und milden Wintern auf. Durch die starke Windexposition kann die Wetterlage innerhalb kurzer Zeit wechseln. Die Maximaltemperaturen betragen in der Regel $20-25^{\circ} \mathrm{C}$, die Mindesttemperatur $0^{\circ} \mathrm{C}$ (Dänisches Meteorologisches Institut 2013). In der Regel konzentrieren sich Niederschläge in der Region auf die zweite Jahreshälfte mit einem Maximum zwischen Oktober und Februar.

Die Jahre 2008 und 2009 waren vergleichsweise warm mit milden Wintern (Abb. 6) und einem höheren Anteil an Sonnenstunden (Abb. 7). Die Jahresdurchschnittstemperatur lag 1-2 Grad Celsius über dem langjährigen Mittel in der Region. Die folgenden Winter waren kälter. Vor allem die Jahre 2010 und 2011 waren regenreich (Abb. 8): Die gesamte Niederschlagsmenge pro Jahr war mit 703 mm bzw. 765 $\mathrm{mm}$ höher als üblich $(629 \mathrm{~mm})$.

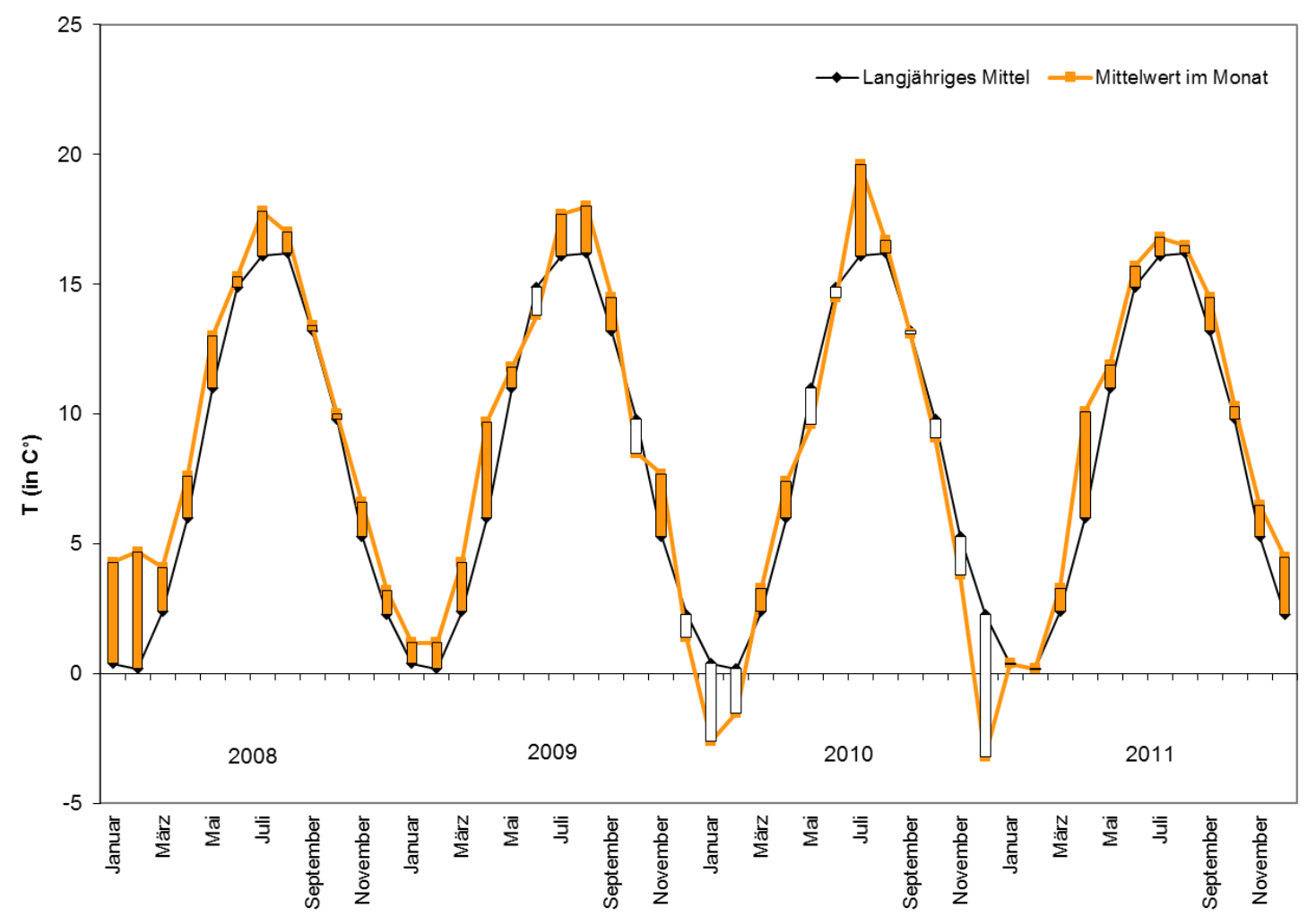

Abb. 6: Monatsdurchschnittstemperaturen in den Jahren 2008-2011 im Vergleich zum langjährigen Mittel

Schwarze Kurve: langjähriges Mittel 1961-1990; orange Kurve: 2008-2011; Balken: positive (orange) und negative (weiß) Abweichung vom langjährigen Mittel

Quelle: Dänisches Meteorologisches Institut DMI 


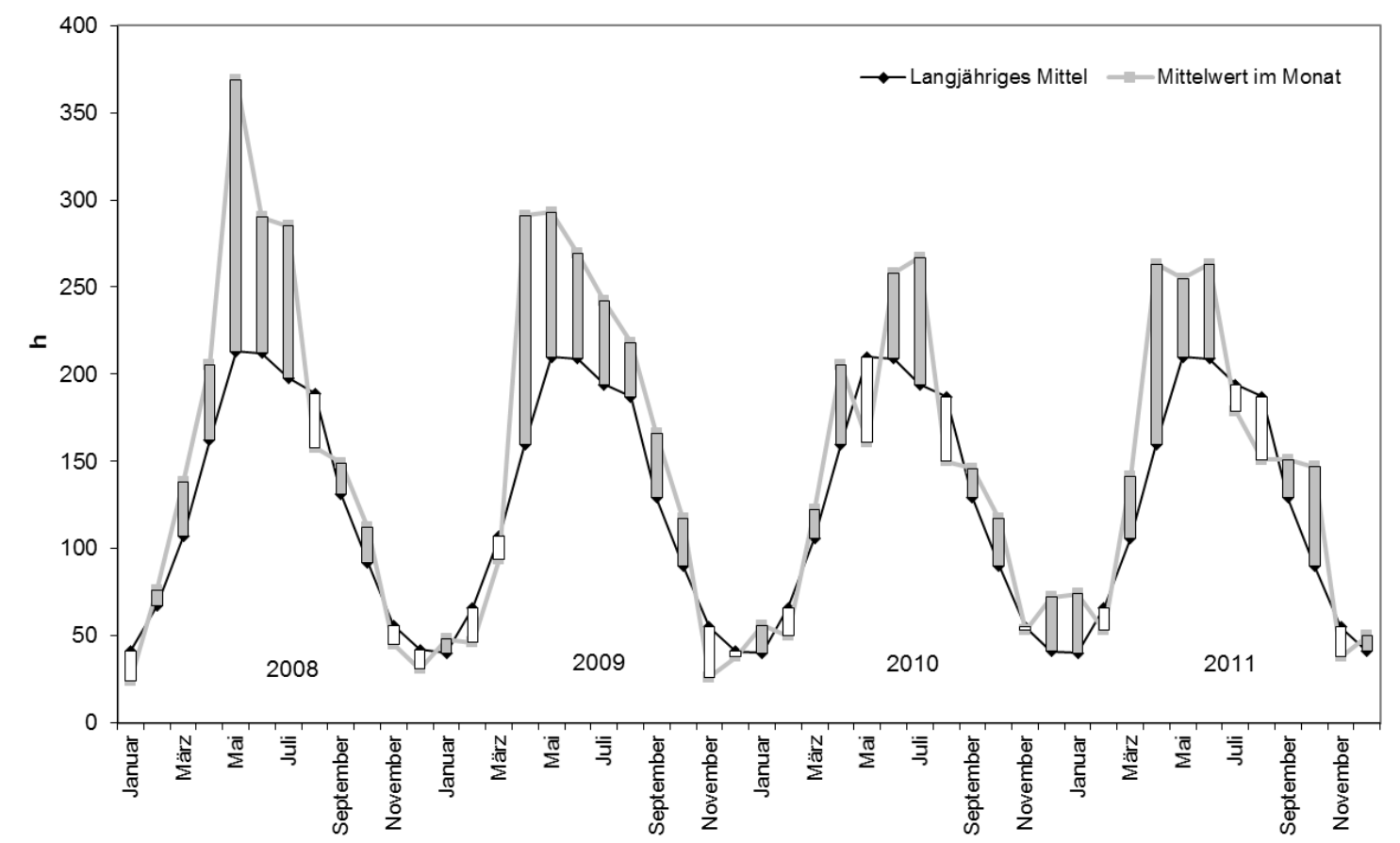

Abb. 7: Monatliche Sonnenscheinstunden in den Jahren 2008-2011 im Vergleich zum langjährigen Mittel

Schwarze Kurve: langjähriges Mittel 1961-1990; graue Kurve: 2008-2011; Balken: positive (grau) und negative (weiß) Abweichung vom langjährigen Mittel

Quelle: Dänisches Meteorologisches Institut DMI

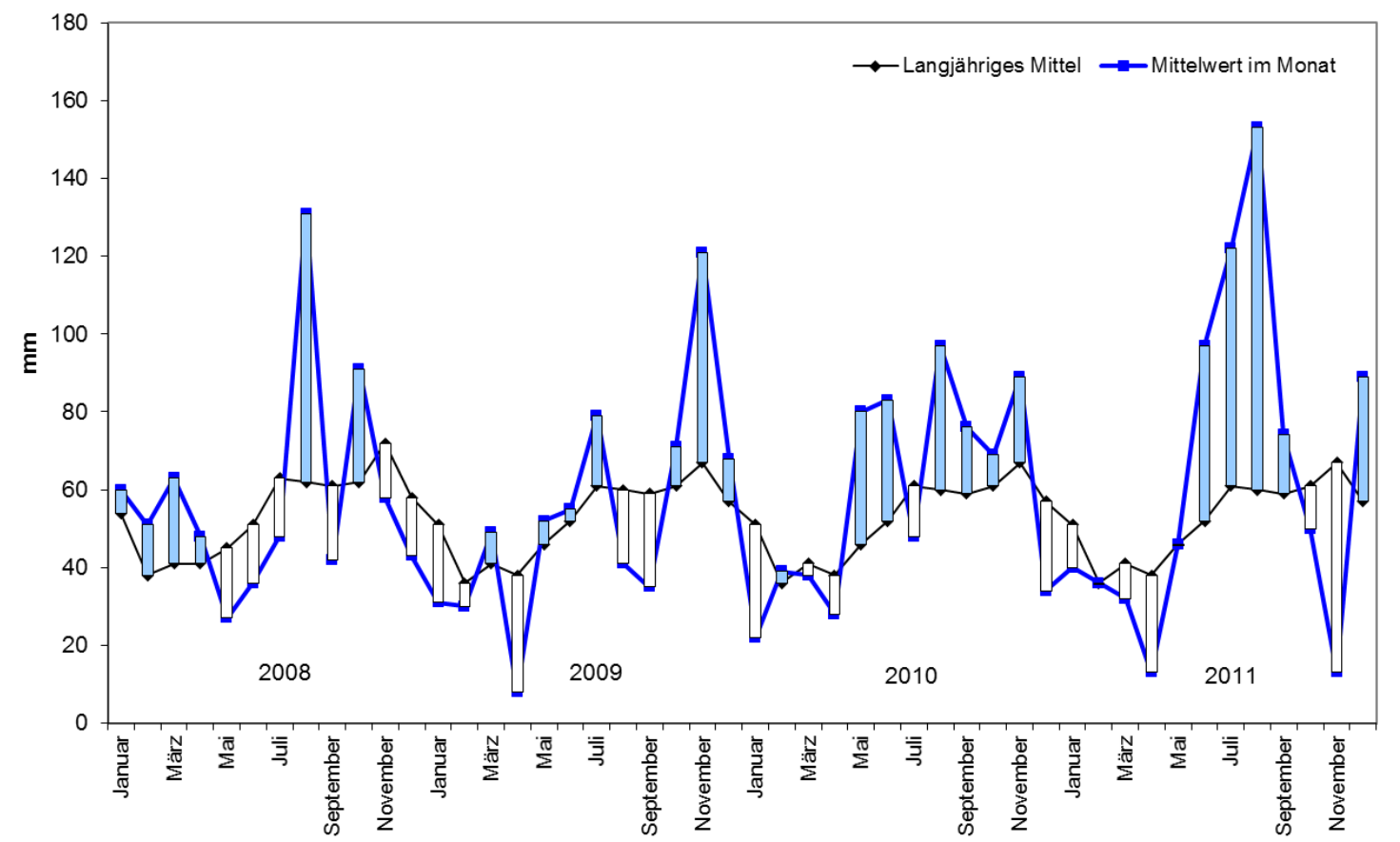

Abb. 8: Monatliche Niederschlagsmenge in den Jahren 2008-2011 im Vergleich zum langjährigen Mittel

Schwarze Kurve: langjähriges Mittel 1961-1990; blaue Kurve: 2008-2011; Balken: positive (blau) und negative (weiß) Abweichung vom langjährigen Mittel

Quelle: Dänisches Meteorologisches Institut DMI 



\section{DIE WEIDETIERE}

Ganzjährige Beweidung mit Exmoor-Ponys

\subsection{Das Exmoor-Pony}

Im Projektgebiet Süd-Langeland wurden Exmoor-Ponys (Equus ferus forma caballus) zur Beweidung eingesetzt. Das Projekt leistet damit einen Beitrag zum Erhalt einer sehr ursprünglichen, seltenen Pferderasse außerhalb seines natürlichen Verbreitungsgebietes.

\subsubsection{Klassifikation und Herkunft}

\subsubsection{Einordnung des Hauspferdes}

Pferde gehören zur Familie der Equidae, die ein Teiltaxon der Unpaarhufer (Perissodactyla) bilden und nur eine Gattung, Equus, umfassen. Zu Equus gehören die Pferde im engeren Sinne (E. ferus), die Esel und Halbesel (E. hemionus, E. asinus, E. kiang) sowie die Zebras (E. quagga, E. zebra, E. grevyi). Diese Einteilung in insgesamt sieben Arten ist jedoch umstritten.

Das Hauspferd (Equus ferus f. caballus) ist die domestizierte Form des Wildpferds, eine Entwicklung, die vor ca. 5.500 Jahren begann (Bökönyi 1984). Die ältesten Funde stammen vom Schwarzen Meer. Ob Hauspferde Europa vom Schwarzen Meer aus einmalig besiedelten (Bibikova 1967, 1986, CluttonBrock 1999) oder ob die Domestikation in Europa unabhängig voneinander in unterschiedlichen Gegenden erfolgte (Uerpmann 1990), ist umstritten. Bunzel-Drüke (2001b) geht davon aus, dass sich die eingeführten domestizierten Pferde mit den überlebenden Wildpferden in Europa gekreuzt haben. Aufgrund des gemeinsamen Lebensraumes kann somit von einer Einkreuzung beider Linien ausgegangen werden. Gene der europäischen Wildpferde wären somit in heutigen ursprünglichen Rassen noch vorhanden. Auch rezente phylogenetische Untersuchungen beim Hauspferd widerlegen die Annahme einer einmaligen Domestikation des Hauspferdes in der eurasischen Steppe. Es wurden Hinweise auf weitere Domestikationszentren gefunden (Jansen 2002).

Die Verwandtschaftsbeziehungen zwischen Wild- und Hauspferden sind bis heute ungeklärt. Das Przewalski-Pferd (E. ferus przewalskii) unterscheidet sich vom Hauspferd durch seine höhere Chromosomenanzahl (66 zu 64) und die Anzahl der Brustwirbel (19 zu 18). Trotz der Chromosomendifferenz sind sie uneingeschränkt untereinander fortpflanzungsfähig. Sie werden in der Literatur teils als verschiedene Species, teils als eine Art beschrieben.

Hauspferde sind heute weit verbreitet, da sie als Nutz- und Lasttiere eingesetzt werden. Wildpferde sind hingegen in ihrem Bestand gefährdet. Sie finden sich heute nur noch in den zentralen Regionen Asiens. Bevor sie in Europa ausgerottet wurden - das letzte Tier verstarb in Gefangenschaft im Jahr 1919 (Slob 1966), waren Wildpferde auch hier weit verbreitet. 


\subsubsection{Herkunft des Exmoor-Ponys}

Das Exmoor-Pony stammt aus einer rauen, hügeligen Region in Südwestengland, dem Exmoor. In ihrem natürlichen Verbreitungsgebiet konnten sich die Ponys seit vielen Jahrhunderten relativ unbeeinflusst entwickeln. Der genaue Status des Exmoor-Ponys ist noch ungeklärt. Unklarheiten in der Domestikationsgeschichte des Pferdes erschweren zudem die Bewertung ursprünglicher Rassen. Es ist dokumentiert, dass bereits vor ca. 1.000 Jahren wilde Pferde im Exmoor lebten. Wilhelm der Eroberer (1027-87) erklärte das Exmoor zum „Royal Forest“ (königlichen Jagdgebiet), wo bereits damals eine Kleinpferdpopulation lebte, die als Jagdbeute für den König reserviert war. Dieser Status blieb bis 1818 erhalten, als das britische Königshaus das Gebiet mit den Tieren verkaufte. Somit ist die Wahrscheinlichkeit groß, dass das Exmoor-Pony bis zu diesem Zeitpunkt von anderen Rassen wenig beeinflusst blieb (Baker et al. 1998). Damit gehört es zu den historisch am weitesten zurück verfolgbaren Populationen oder Rassen überhaupt (Jansen 2002).

Anschließend wurden die Ponys zur Erhaltung der Rasse in Reinzucht gehalten. Zu ihrem Schutz wurde im Jahr 1921 die britische „Exmoor Pony Society“ gegründet. Sie konnte nicht verhindern, dass die Gesamtpopulation nach dem Zweiten Weltkrieg auf einen geringen Bestand schrumpfte. Ein Teil der Tiere wurde aufgrund der schlechten Nahrungsversorgung der Bevölkerung gestohlen und geschlachtet, ein anderer Teil wurde von den alliierten Truppen als lebendige Zielscheibe verwendet und zu Übungszwecken vor der Invasion in die Normandie abgeschossen. Nach dem Ende des Krieges wurden nur noch 50 Tiere gezählt.

Diese Tiere stellen die wesentliche Basis der modernen Exmoor-Ponys dar, denn alle heute lebenden Ponys gehen auf diese Gründerpopulation zurück (Baker et al. 1998). Mittlerweile hat sich der Bestand erholt. Weltweit existieren heute rund 3.000 Tiere (Baker 2008). Da nur ein Zehntel davon in ihrem ursprünglichen Verbreitungsgebiet, dem Exmoor, leben kann, ohne den Lebensraum nachhaltig zu schädigen, werden Exmoor-Ponys auch in anderen Gegenden Mitteleuropas in Tierparks, Naturreservaten oder bei privaten Pferdezüchtern gehalten. Das Exmoor-Pony gilt als gefährdete Rasse.

\subsubsection{Wild- oder Hauspferd?}

Nach dem Zweiten Weltkrieg wurde häufig noch bezweifelt, dass es sich bei dem Exmoor-Pony um reine Nachkommen des steinzeitlichen Wildpferdes (Mohr 1959) oder von E. przewalskii handelte (Herre 1961). Es wurde als ungebunden lebendes Hauspferd eingestuft. Anatomische Vergleiche eiszeitlicher Knochenfunde mit heutigen Exmoor-Ponys folgten (Speed \& Etherington 1952, Dent 1970, Baker 1993), führten aber nicht zu einem eindeutigen Nachweis ihres Wildpferdstatus.

Die Ursprünglichkeit des Exmoor-Ponys wird mit morphologischen Merkmalen begründet: Das Mehlmaul und die helle Augenumrandung wurden bereits bei Urpferden vorgefunden und finden sich auch beim Przewalski-Pferd. Bei einigen Ponys tritt auch ein schwach ausgeprägter Rückenstreifen auf, der an einen Aalstrich erinnert (Abb. 9). Daher wird in Betracht gezogen, dass das Exmoor-Pony die europäische Form des Wildpferdes sei, vom Menschen nur geringfügig beeinflusst (Baker 1991, 1993, 1998, Morris 1993, Willmann 1999). Auch jüngere phylogenetische Untersuchungen von Jansen (2002) unterstützen die These, dass das Exmoor-Pony eine sehr ursprüngliche Pferderasse ist, die möglicherweise auf bodenständige Wildpopulationen zurückgeht.

Wie stark die Population bis heute von anderen Rassen beeinflusst wurde, ist unbekannt (Baker et al. 1998). Eine Verkreuzung mit Pferden anderer Rassen in historischer Zeit lässt sich nicht nachweisen (Willmann 1999). Vermutlich erwiesen sich Kreuzungen mit Hauspferden als nicht widerstandsfähig genug, um in dieser unwirtlichen Gegend zu überleben, daher hat sich das Erscheinungsbild des Exmoor-Ponys kaum verändert (Dent 1974). 


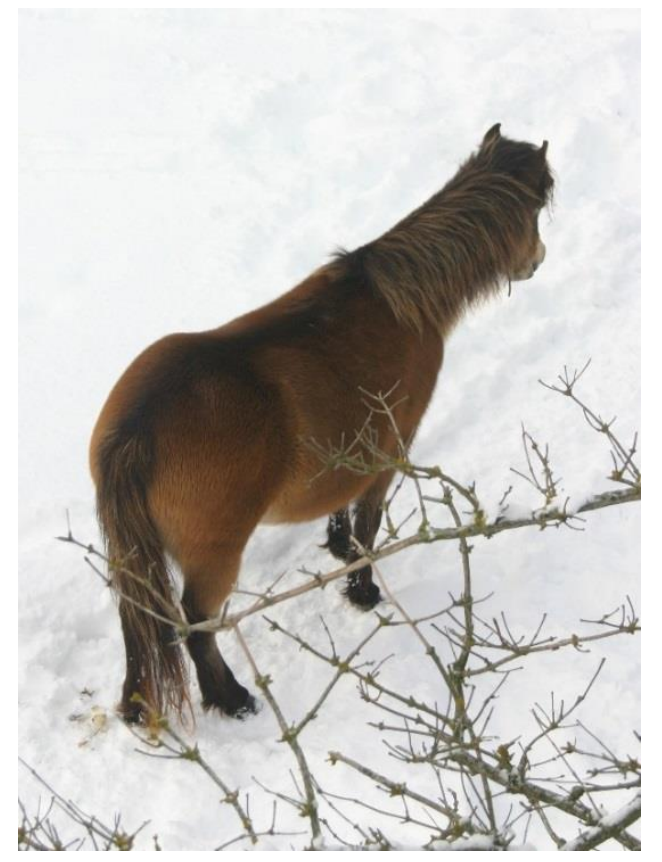

Abb. 9: Exmoor-Pony im Winterfell mit Aalstrich

\subsubsection{Beschreibung}

Das Aussehen des Exmoor-Ponys ist durch seine Ursprünglichkeit geprägt: Es hat hell- bis dunkelbraunes dichtes Fell, ein Mehlmaul mit aufgehellter Mundpartie und eine helle Augenumrandung (Abb. 10). Die meisten Tiere haben fast schwarze Beine und zeigen eine ausgeprägte Aufhellung an der Bauchseite. Sie sehen einander zum Verwechseln ähnlich. Unterschiede bestehen im Detail. Es gibt hellere und dunklere Tiere, der Braunton ihres Fells kann ins Graue, Rötliche oder Schwarzbraune gehen. Gleiches trifft für die lange Hängemähne zu. Sie leitet das Regenwasser von der Hals- und Rückenpartie ab und stellt eine von vielen Anpassungen der Ponys an das kalte, nasse Wetter in ihrer Heimat dar (Willmann 1999). Während das Sommerfell kurz und glänzend ist, weisen die Tiere im Winter ein dickes, aus zwei Schichten bestehendes Fell auf. Die proximale Schicht besteht aus dichtem, isolierendem Fell, die distale wirkt vor allem wasserabweisend (Lohrengel 2011).
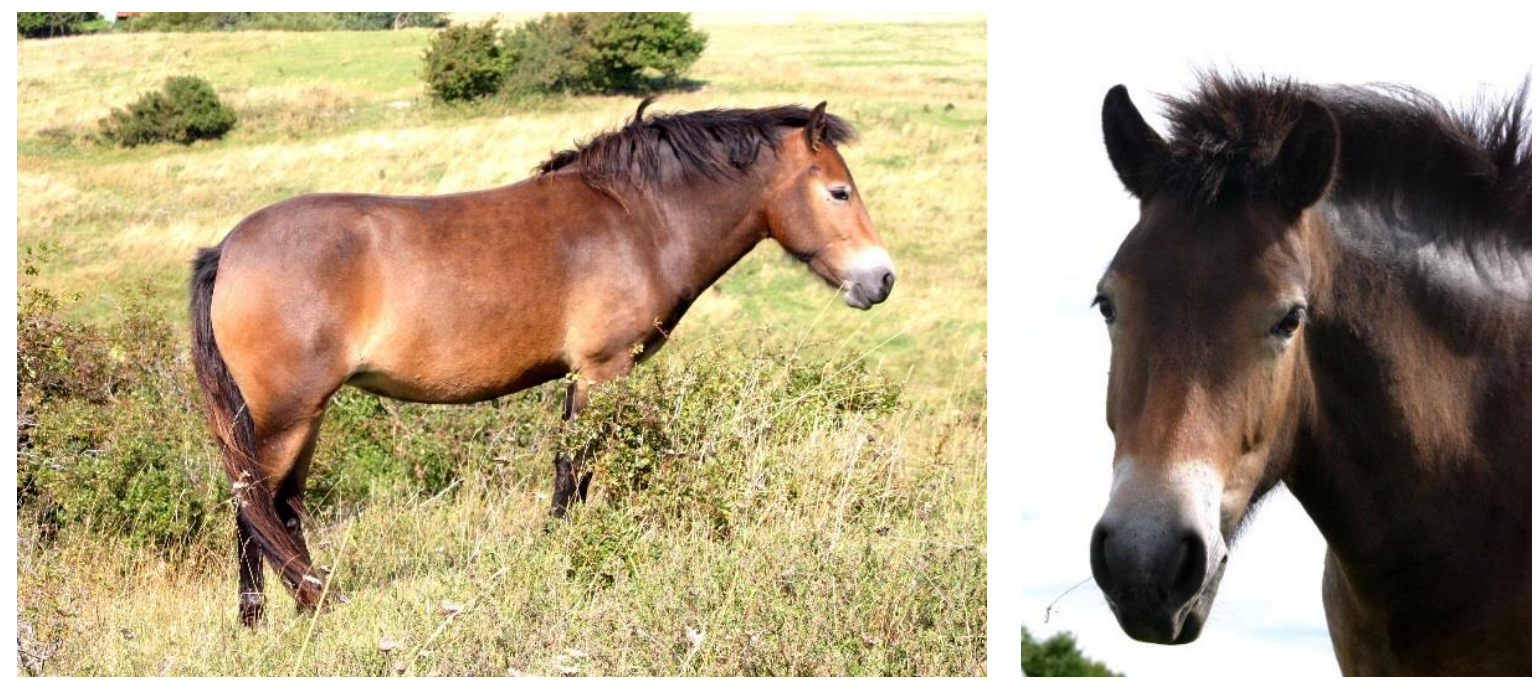

Abb. 10: Habitus des Exmoor-Ponys mit Mehlmaul und heller Augenumrandung als charakteristische Merkmale 


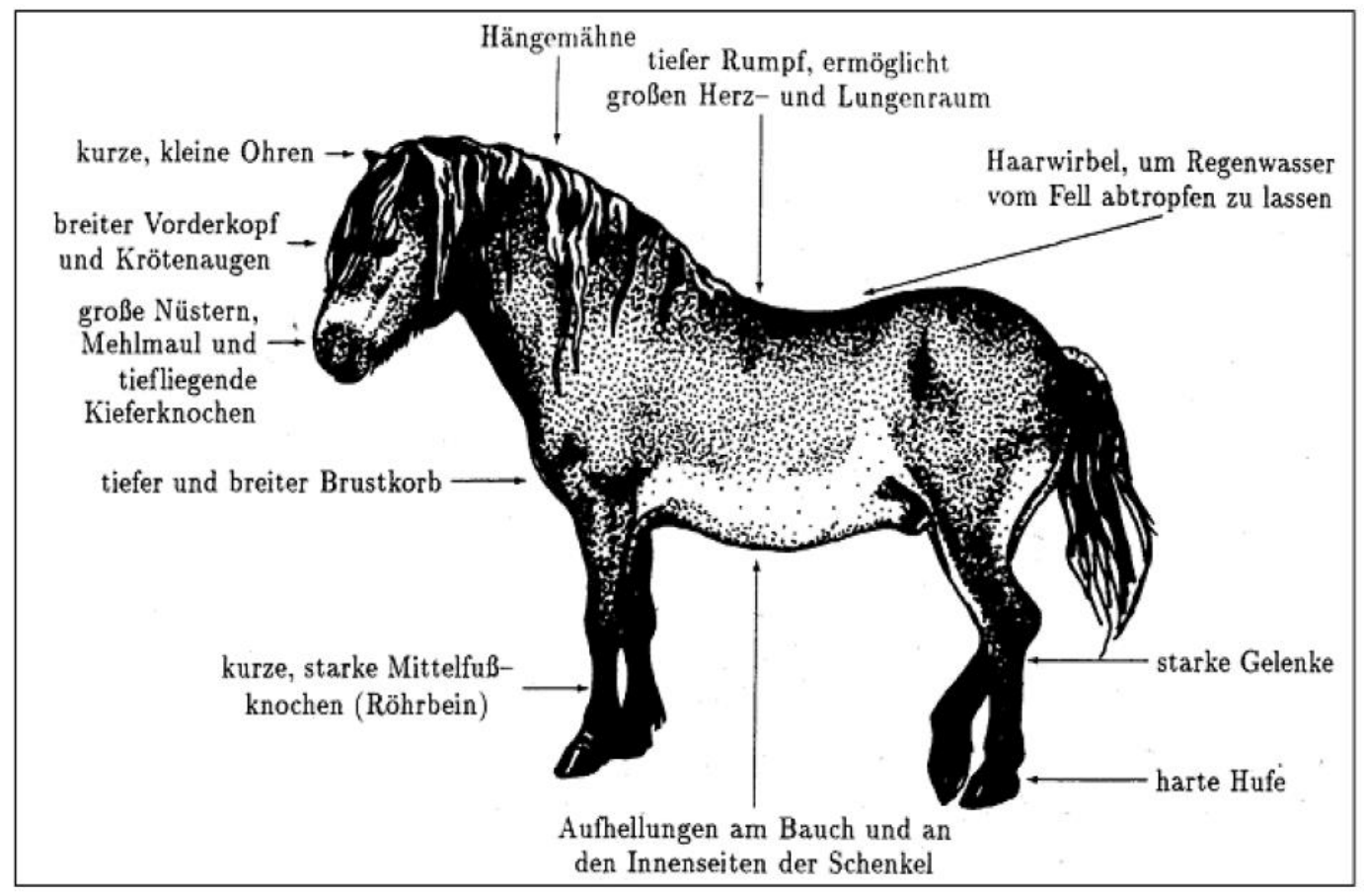

Abb. 11: Merkmale des Exmoor-Ponys (aus Riediger 1995)

Der Körperbau eines Exmoor-Ponys ist robust mit einem Stockmaß von etwa 114 bis $130 \mathrm{~cm}$. An ihrer unterschiedlichen Größe und Körperform, die von schlank bis gedrungen variiert, können sie im Gelände unterschieden werden. Sie besitzen eine hohe Ausdauer und Trittsicherheit, kräftige Beine und Kiefer, einen muskulösen Brustkorb und kleine, harte Hufe (Riediger 1995, Abb. 11).

Die im Projektgebiet eingesetzten Pferde wiesen eine große optische Ähnlichkeit auf, da sie einen sehr engen Verwandtschaftsgrad hatten. Sie wurden anhand von individuellen Merkmalen wie Fellmusterung, Mähnenform, Körperhaltung und Narben identifiziert.

\subsubsection{Lebensweise und Diät}

Exmoor-Ponys leben in ihrem Ursprungsgebiet in freier Wildbahn. Hier dominieren weiträumige Grasund Heideflächen, von großen Farnbeständen durchzogen. Den Pferden stehen oft nur das Bodenrelief, Wallhecken oder vereinzelte Weißdorn- und Ginsterbüsche als Habitatelemente zur Verfügung (Baker 2008). Sie ernähren sich überwiegend von Gräsern. Auch wenn natürliche Feinde fehlen, wirken Hitze und Trockenheit im Sommer und lange, kalte Winter als natürliche Auslese (Willmann 2005). Zudem greift der Mensch durch eine Selektion der Leithengste und des Nachwuchses in die Struktur der frei lebenden Herden ein. Ihre Lebensweise wird daher nur als "halbwild" bezeichnet (Gates 1980). Zweifellos beeinflusst die züchterische Entnahme die Evolution des Exmoor-Ponys (Willmann 1999).

Die Rasse wurde ursprünglich als Arbeitskraft in der Landwirtschaft eingesetzt. Sie diente als Zugpferd oder Lasttier. In England findet sie heute noch gelegentlich als Zugtier Verwendung, überwiegend jedoch als Reitpony. Seit einigen Jahren werden Exmoor-Ponys in der Landschaftspflege meist unter naturnahen Bedingungen in halbwilder Herdenhaltung eingesetzt, da sie widerstandsfähig und genügsam sind. Zufütterungen in Beweidungsprojekten sind nicht notwendig, wenn der natürliche Lebensraum genügend Nahrung bietet. 


\subsection{Weidemanagement und Herdenstruktur}

Die Zuständigkeit für das Schutzgebiet Süd-Langeland liegt beim Dänischen Umweltministerium und der Umwelt- und Forstbehörde. Mit der Ausweisung der Flächen als Schutzgebiet stellte sich die Frage nach einer langfristigen Pflegemethode, mit der der Landschaftscharakter erhalten werden konnte. Man entschloss sich nach zahlreichen Beratungen, Exmoor-Ponys auf einer extensiven Ganzjahresweide einzusetzen, da diese Rasse bereits in der Region lebte und sich dank ihrer Ursprünglichkeit und Robustheit für eine Ganzjahresweide eignet.

Die Ansiedlung der Pferde war Teil des South Langeland Nature Conservation Project mit dem Ziel, die offene küstennahe Weidelandschaft als Brut- und Nistplatz für geschützte Vogelarten und als Lebensraum für bedrohte Insekten- und Amphibienarten zu erhalten. So wurde im Oktober 2006 eine Herde aus 26 Exmoor-Ponys in das Schutzgebiet umgesiedelt. Sie stammten aus dem nahe gelegenen Gebiet Klise Nor, wo sie seit dem Jahr 2003 im Rahmen eines Naturschutzprojektes zum Abweiden der Strandweiden eingesetzt wurden. Ursprünglich kamen sie von der Insel Tærø bei Südseeland, auf der sie seit den sechziger Jahren frei lebten.

Auf Süd-Langeland weideten die Exmoor-Ponys ganzjährig auf der gesamten Fläche ohne Koppelung. Die Pferde hatten Zugang zu allen Habitaten und Biotopen und lebten im Familienverband. Dies entspricht ihrer natürlichen Sozialstruktur. Die Herde bestand aus einem Leithengst, Stuten und deren Nachwuchs. Die Entwicklung der Herdenstruktur ist in Tab. 2 dargestellt.

Ab dem Jahr 2010 zeichnete sich die Entstehung von Junggesellengruppen ab. In der Herde lebten nun 15 ein- und zweijährige Junghengste. Eine dauerhafte Aufspaltung der Herde in zwei oder mehrere Gruppen wurde bis zum Ende der Beobachtung (im Juni 2011) nicht festgestellt. Aufgrund der Größe der Herde kam es jedoch häufiger zu einer vorübergehenden Trennung der Herdenmitglieder, die ein bis mehrere Tage anhielt.

Tab. 2: Entwicklung der Herden- und Altersstruktur seit Beweidungsbeginn

* alle Hengstfohlen aus der Herde entnommen

** im September 2010 wurden 22 Tiere an ein Beweidungsprojekt verkauft

*** im Dezember 2011 wurden 11 Hengste entnommen

\begin{tabular}{lllllllll}
\hline Datum & $\begin{array}{l}\text { Gesamt- } \\
\text { anzahl }\end{array}$ & Hengst & $\begin{array}{l}\text { Adulte } \\
\text { Stuten }\end{array}$ & 2-Jährige & $\begin{array}{c}\text { Jährlinge } \\
\text { Jährlinge } \\
\mathbf{m}: \mathbf{f}\end{array}$ & $\begin{array}{l}\text { Fohlen } \\
\begin{array}{l}\text { Fohlen } \\
\mathbf{m}: \mathbf{f}\end{array}\end{array}$ \\
\hline 31.12 .2006 & 26 & 1 & 10 & 4 & 4 & 0 zu 4 & 7 & $2 *$ zu 5 \\
31.12 .2007 & 33 & 1 & 14 & 4 & 5 & 0 zu 5 & 9 & $2 *$ zu 7 \\
31.12 .2008 & 46 & 1 & 18 & 5 & 7 & 0 zu 7 & 15 & 8 zu 7 \\
31.12 .2009 & 65 & 1 & 24 & 7 & 14 & 7 zu 7 & 19 & 11 zu 8 \\
31.12 .2010 & $56 * *$ & 1 & 23 & 9 & 10 & 8 zu 2 & 13 & 5 zu 8 \\
31.12 .2011 & $60^{* * *}$ & 8 & 21 & 2 & 8 & 3 zu 6 & 21 & 11 zu 10 \\
\hline
\end{tabular}




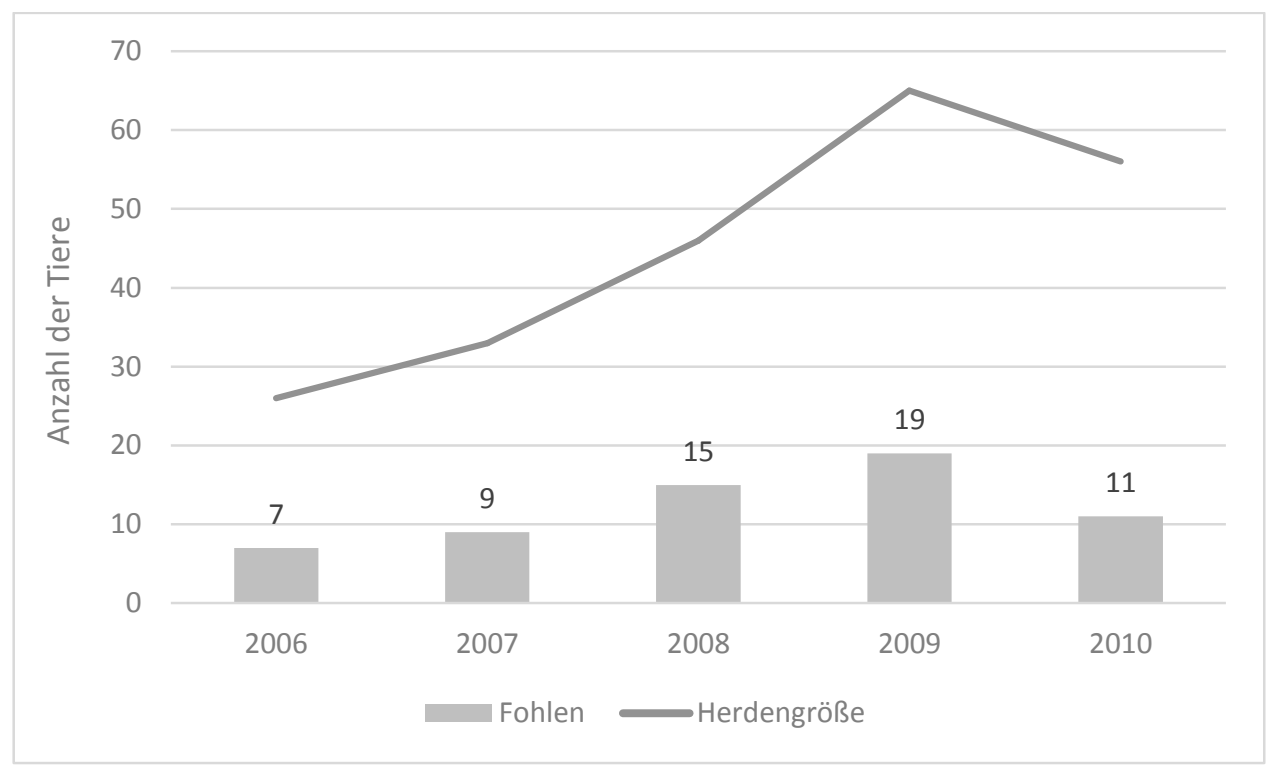

Abb. 12: Entwicklung der Herdengröße und Anzahl der Fohlen, die den ersten Winter überlebt haben

Der Tierbestand und die Besatzdichte erhöhten sich jedes Jahr durch natürliche Herdenvergrößerung durch die Geburt von Fohlen (Abb. 12). Bei der Betrachtung der Besatzstärke wurden nur Weideflächen berücksichtigt (Grünland, Ackerbrache, Waldlichtungen, Feuchtgrünland, Ufervegetation, Röhrichte), die von den Pferden problemlos erreicht werden konnten. Die Prämisse war, dass die Besatzstärke im Gebiet den für eine extensive Beweidung empfohlenen Wert von 0,5 Großvieheinheiten pro Hektar (GV/ha) nicht überschreitet, da der limitierende Faktor bei einer ganzjährigen Beweidungsform der Winterfutterbedarf der Tiere ist. Im Jahr 2010 wurden daher erstmalig 22 Tiere unterschiedlichen Alters eingefangen und an ein Beweidungsprojekt in Jylland vermittelt. Eine weitere Gruppe von 11 Junghengsten verließ die Herde im Dezember 2011, nach Abschluss der Datenaufnahme.

Tab. 3: Flächenbesatz mit Weidetieren

Gesamtfläche: 107,8 ha, Nutzfläche: ca. 70 ha, GV bei Ponys: 0,7

* Im Jahr 2006 weideten die Tiere nur 3 Monate.

\begin{tabular}{lll}
\hline Jahr & $\begin{array}{l}\text { Besatzstärke } \\
\text { (GV/ha) }\end{array}$ & GV \\
\hline $2006^{*}$ & 0,19 & 13,3 \\
2007 & 0,24 & 16,8 \\
2008 & 0,31 & 21,7 \\
2009 & 0,46 & 32,2 \\
$2010 /$ bis 08 & 0,62 & 43,4 \\
$2010 /$ ab 09 & 0,43 & 30,1 \\
$2011 /$ bis 11 & 0,5 & 35 \\
2011/ab 12 & 0,39 & 27,3 \\
\hline
\end{tabular}


Tab. 4: Fohlenmortalität im Projektgebiet Süd-Langeland in den Jahren 2007-2011

$+(x)$ bedeutet $x$ Fohlen mit unbekanntem Geschlecht

*davon 3 verkauft; Geburtsrate in 2010 möglicherweise höher, da 4 tragende Stuten abgegeben wurden

*** Mortalitätsrate ohne Berücksichtigung des ersten Winters

\begin{tabular}{|c|c|c|c|c|c|c|}
\hline Jahr & $\begin{array}{l}\text { Fohlen } \\
\text { bei Geburt } \\
\mathrm{m}: \mathrm{f}\end{array}$ & $\begin{array}{l}\text { Fohlen } \\
\text { nach } 1 \text { Jahr } \\
m: f\end{array}$ & $\begin{array}{l}\text { Anzahl } \\
\text { Stuten }\end{array}$ & $\begin{array}{l}\text { Geborene } \\
\text { Fohlen }\end{array}$ & $\begin{array}{l}\text { davon } \\
\text { verstorben }\end{array}$ & Sterberate \\
\hline 2007 & $4: 8$ & $0: 7$ & 14 & 12 & 3 & 0,25 \\
\hline 2008 & $11: 9$ & $7: 7$ & 18 & 20 & 6 & 0,30 \\
\hline 2009 & $11: 10+2$ & $10: 7$ & 24 & 23 & 6 & 0,26 \\
\hline 2010 & $6: 12+1$ & $4: 10$ & 27 & $19 *$ & 5 & 0,26 \\
\hline 2011 & $12: 9+3$ & n. b. & 24 & 24 & 3 & $0,13 * *$ \\
\hline Gesamt & $44: 48+6$ & $21: 31$ & & 98 & 23 & im Mittel 0,24 \\
\hline
\end{tabular}

Die Fortpflanzungsrate in der Herde war hoch: Fast alle adulten Stuten bekamen Nachwuchs zwischen März und September. Zwillingsgeburten traten nicht auf. Die Fohlenmortalität lag über fünf Untersuchungsjahre gemittelt bei FM =0,24 (Tab. 4). Dies entspricht 5-6 Fohlen, die pro Jahr aufgrund unterschiedlicher Ursachen und in verschiedenen Entwicklungsstadien starben. Rund ein Drittel der Fohlen verstarb während oder unmittelbar nach der Geburt. Ein bis zwei Tiere pro Jahr verendeten in ihrem ersten Winter. Das Geschlechterverhältnis der Fohlen war nahezu ausgeglichen, nach dem ersten Lebensjahr wiesen die weiblichen Jungtiere jedoch eine höhere Überlebensrate auf als die männlichen.

Der Verlust von insgesamt sechs adulten Stuten zwischen den Jahren 2006 und 2011 ist auf Komplikationen im Geburtsverlauf (4 Tiere) sowie auf Verletzungen nach Auseinandersetzungen mit dem Leithengst (1 Tier) zurückzuführen. In 4 Fällen erfolgte ein direkter Abschuss vor Ort durch einen Veterinärmediziner. Eine Altstute verstarb eines natürlichen Todes.

Die Pferde wurden täglich kontrolliert. Sie zeigten im Untersuchungszeitraum keine Anzeichen von Unterernährung. Auf eine Zufütterung wurde verzichtet. Die Verletzungsrate war allgemein gering. Weder eine Hufpflege noch eine Verabreichung von Entwurmungsmittel wurden routinemäßig durchgeführt. Im September 2010 wurde ein hoher Wurmbefall in einigen Kotproben festgestellt. Als Therapie einigte man sich auf eine Einzelbehandlung betroffener Tiere bei starkem Gewichtsverlust. Gleiches galt bei vereinzelt beobachteten Hufproblemen.

Die Pferde im Projektgebiet wurden nicht individuell durch Brand oder Ohrmarken markiert. Dies ist bei einer Haltung von Pferden aus reinen Naturschutzgründen, bei der eine Einbringung in die Lebensmittelkette nicht vorgesehen ist, auch nicht üblich (Schröder 2010). In Dänemark ist jedoch eine Kennzeichnung der Tiere durch Mikrochips bei ihrer Überführung in andere Beweidungsprojekte erforderlich. Diese erfolgte ausschließlich beim Zusammentrieb vor der Entnahme. Eine Identifikation der im Projektgebiet lebenden Tiere über eine Kennzeichnung war somit nicht möglich. 


\subsection{Methodenübersicht}

Die Entwicklung des Projektgebietes unter ganzjähriger Beweidung mit Exmoor-Ponys wurde wissenschaftlich untersucht. Schwerpunkte der Studie waren das Weidetierverhalten und die Habitatnutzung durch die Tiere sowie die Struktur- und Vegetationsentwicklung der Grünland-, Gehölz- und Uferflächen.

Die Ergebnisse der wissenschaftlichen Begleituntersuchung werden in der vorliegenden Dissertationsschrift vorgestellt. Die Untersuchungen zur Habitatnutzung, Ethologie und Ökologie des Exmoor-Pferdes betreute Professor Dr. Rainer Willmann vom Zoologischen Institut, Abteilung für Morphologie, Systematik und Evolutionsbiologie. Die vegetationskundlichen Arbeiten begleitete Professor Dr. Erwin Bergmeier aus der Abteilung für Vegetationsanalyse und Phytodiversität des Instituts für Pflanzenwissenschaften. Das Arbeitsprogramm umfasst die in Tab. 5 aufgelisteten Aspekte und Methoden.

Tab. 5: Übersicht zum Arbeitsprogramm der wissenschaftlichen Begleituntersuchung

\begin{tabular}{|c|c|c|c|}
\hline Parameter & Untersuchungsraum & Methode & $\begin{array}{l}\text { Erhebungs- } \\
\text { zeitraum }\end{array}$ \\
\hline \multicolumn{4}{|l|}{ Weidetiere } \\
\hline Verhalten der Tiere & flächendeckend & $\begin{array}{l}\text { Datenerhebung mittels Beobachtung } \\
\text { ( } 3 \times \text { jährlich) }\end{array}$ & $2008-2010$ \\
\hline Habitatnutzungsanalyse & flächendeckend & $\begin{array}{l}\text { Datenerhebung mittels Beobachtung } \\
\text { ( } 3 \text { x jährlich), zusätzliche Erhebungen } \\
\text { im Jahresverlauf }\end{array}$ & $2008-2010$ \\
\hline Entwicklung der Herdenstruktur & flächendeckend & $\begin{array}{l}\text { Datenerhebung mittels Beobachtung } \\
\text { ( } 3 \text { x jährlich) }\end{array}$ & $2008-2010$ \\
\hline \multicolumn{4}{|l|}{ Strukturen } \\
\hline Gehölzkartierung & flächendeckend & Luftbilder, Begehung & 2007,2010 \\
\hline Gehölzentwicklung / Verbiss & 6 Probeflächen & $\begin{array}{l}\text { Messungen und Schätzungen auf } \\
\text { Dauerflächen ( } 1 \text { x jährlich) }\end{array}$ & $2008-2010$ \\
\hline Vegetationsstruktur & 14 Probeflächen & $\begin{array}{l}\text { Messungen und Schätzungen auf } \\
\text { Dauerflächen ( } 3 \text { x jährlich) }\end{array}$ & $2008-2010$ \\
\hline Strukturelemente & 14 Probeflächen & $\begin{array}{l}\text { Messungen und Schätzungen auf } \\
\text { Dauerflächen ( } 3 \text { x jährlich) }\end{array}$ & $2008-2010$ \\
\hline \multicolumn{4}{|l|}{ Vegetation } \\
\hline Vegetationskartierung & flächendeckend & $\begin{array}{l}\text { Pflanzensoziologische Aufnahmen, } \\
\text { luftbildunterstützte Geländebegehungen }\end{array}$ & $\begin{array}{l}2007-2008, \\
2011\end{array}$ \\
\hline Vegetationsentwicklung & 26 Probeflächen & $\begin{array}{l}\text { Vegetationsaufnahmen auf } \\
\text { Dauerflächen ( } 1 \text { x jährlich) }\end{array}$ & $2008-2011$ \\
\hline Floristische Bestandserfassung & flächendeckend & Beobachtung, Sammlung & 2007-2011 \\
\hline \multicolumn{4}{|l|}{ Nahrungspräferenzen } \\
\hline Kotanalyse & flächendeckend & Datensammlung ( 5 x jährlich) & $2008-2010$ \\
\hline Cuticular-Referenzatlas & flächendeckend & Datensammlung (1 x jährlich) & $2008-2010$ \\
\hline
\end{tabular}




\section{RAUMNUTZUNG UND VERHALTEN DER WEIDETIERE}

Das Schutzgebiet als Lebensraum

Das Projektgebiet Süd-Langeland stellt eine ehemals intensiv genutzte Kulturlandschaft dar, die seit zwei Jahrzehnten zunehmend extensiv bewirtschaftet wird. Die Heterogenität des Gebietes wurde im Wesentlichen durch unterschiedliche Nutzungsarten der Teilflächen hervorgerufen, bei der Weide-, Agrar- und Forstwirtschaft sich abwechselten. Durch eine uniforme, ganzjährige und extensive Beweidung sollte der Charakter der offenen, typischen Kulturlandschaft erhalten und gefördert werden. Gleichwohl wurde eine Zunahme an Biodiversität im Gebiet angestrebt. Es leuchtet ein, dass die Wahl der Weidetierart hierbei einen entscheidenden Einfluss auf die Entwicklungsrichtung und -geschwindigkeit der Landschaft hat. Noch auffälliger sind jedoch die Unterschiede, die durch unterschiedliche Weidesysteme hervorgerufen werden. Während extensive Beweidungsformen im Allgemeinen die Heterogenität der Vegetationsstruktur verstärken, sind bei einem ganzjährigen Weidemanagement ohne Koppelung die Veränderungen im Gebiet nur schwer voraus zu sehen.

Im Mittelpunkt der Untersuchung stand daher die Frage, welche Vor- und Nachteile eine Pferdebeweidung auf offene Weidelandschaften hat. Es wurden Verhaltensweisen und Nutzungsintensitäten der Weidetiere beobachtet, um abschätzen zu können, ob sich die gewünschten Naturschutzziele mittelbis langfristig umsetzen lassen und sich diese Pferderasse zur Offenhaltung und Pflege der Weidelandschaft sowie - darüber hinaus - zur Förderung eines Hudewaldes eignet. Ferner galt es zu überprüfen, ob das Gebiet in seiner aktuellen Form ausreichend Lebensraum für die seltenen Exmoor-Ponys bietet. Dies schließt Fragen zur notwendigen oder maximalen Besatzdichte und zur Habitatvielfalt und -qualität mit ein. Im Mittelpunkt der Auswertung standen somit folgende Fragestellungen:

- Welche Lebensräume werden von den Weidetieren bevorzugt aufgesucht?

- Sind diese Lebensräume in ausreichendem Maße im Projektgebiet vorhanden?

- Sind jahres- und tageszeitliche Tendenzen zu erkennen?

- Werden alle Bereiche beweidet? Nutzen die Tiere auch Bestände mit hoher Verbuschung oder Verschilfung? Und mit welcher Intensität werden Waldareale beweidet?

- Welche Umweltfaktoren beeinflussen die Raumnutzung der Ponys am stärksten? Welche Schlüsse können daraus gezogen werden? 


\subsection{Methodik}

\subsubsection{Erfassung der Raumnutzung}

\subsubsection{Datenerhebung}

Die Beobachtungszeiten der Habitatnutzungsanalyse lagen über den Tag verteilt zwischen Sonnenaufgang und -untergang ( 5 bis $22 \mathrm{Uhr}$ ). Aufgrund der unterschiedlichen Sonnenaufgangs- und Sonnenuntergangszeiten im Jahresverlauf ergaben sich unterschiedliche Beobachtungshäufigkeiten zu den verschiedenen Tageszeiten. Zwischen zwei Aufnahmepunkten lagen mindestens 60 Minuten.

Zwischen April 2008 und März 2011 wurden rund 5.000 Datenpunkte von drei ausgewählten Fokustieren erhoben. Die Fokustiere werden im nachfolgenden Abschnitt beschrieben. Die Positionen der Tiere wurden zunächst auf einer Geländekarte markiert. Anschließend wurden ihre genauen Standorte mit einem handelsüblichen GPS-Gerät (eTrex ${ }^{\circledR} H$ High-sensitivity GPS navigator, GARMIN) bestimmt. Protokolliert wurden Teilgebiet, Tierverhalten und Habitattyp. Der Erfassungsbogen ist dem Anhang beigefügt (Anlage 5.1). Die Verhaltenskategorien werden im Abschnitt Verhalten der Weidetiere erläutert. Die Habitattypen wurden in 11 Kategorien unterteilt (GL = Grünland, $A=$ Ackerbrache, HTR = Halbtrockenrasen $/$ Magerrasen, LW = Laubwald, FG = Feldgehölz, WS = Waldsaum, GE = Gewässer, UF = Ufer, $\mathrm{SCH}=$ Schuttfläche, $\mathrm{S}=$ Lesesteinriegel, $\mathrm{UN}=$ Unterstand). Ihre Erfassung diente lediglich der Überprüfung der im Geografischen Informationssystem (GIS) generierten Daten.

Zur Erfassung der Futterwahl im Winter wurden im Januar 2011 zusätzlich zu den Aufenthaltsstandorten Angaben zu aufgenommenen Nahrungspflanzen von drei Fokustieren getätigt, gegliedert in $17 \mathrm{Ka}-$ tegorien: Blätter, Brennnessel, Brombeerranken, Erde, Gebüsch, Gehölz - Laubbaum, Gras, Hochstauden, hohes Gras, junge Triebe, krautige Pflanzen, Laub, Rinde - Laubbaum, Schilf, Schnee, Streu und Waldrebe. "Gras" entsprach kurzem, grünem Gras, das höchstens bis zum Huf reichte. Unter "hohes Gras" wurde abgestorbenes, trockenes Gras zusammengefasst, welches die Hufhöhe überschritt (s. Pötzinger 2011).

Zur Bewertung des Wettereinflusses auf die Raumnutzung wurden im Erfassungsbogen Bewölkung, Niederschlag, Windverhältnisse und Temperaturen (unterteilt in Kategorien, Tab. 6) dokumentiert sowie ein eventuelles Schneeaufkommen (kein Schnee, leichte oder starke Schneebedeckung) notiert. Ergänzend wurden die Monatsdaten des Dänischen Wetterdienstes hinzugenommen (www.dmi.dk).

Zur Berechnung der durchschnittlichen Wegstrecken von frei lebenden Pferden wurden im Winter 2009 und 2011 sowie im Frühjahr und Sommer 2008 über mehrere Tage die Standorte der Fokustiere in einem 5-Minuten-Abstand dokumentiert. Anhand der aufgezeichneten GPS-Koordinaten wurde im GIS die zurückgelegte Wegstrecke berechnet. Betrachtet wurde der Zeitraum zwischen 8 und 17 Uhr, entsprechend des maximalen Beobachtungszeitraumes im Winter.

Tab. 6: Bewertung der Wetterlage in 4-stufigen Skalen

\begin{tabular}{lllll}
\hline Kategorie-Wert & Bewölkung & Niederschlag & Windverhältnisse & Temperatur \\
\hline 0 & keine & keiner & windstill, leichte Brise & heiß \\
1 & leicht bewölkt & leichter Regen & windig & warm \\
2 & bewölkt & Regen & sehr windig & mild \\
3 & bedeckt & starker Regen, Hagel & stürmisch & kalt \\
\hline
\end{tabular}


Da länger andauernde Tiefschlafphasen bei adulten Pferden überwiegend in die Zeit zwischen 24 Uhr und Sonnenaufgang fallen (Schäfer 1993), besteht die Möglichkeit, dass die Ponys in der Nacht geringere Strecken zurücklegten als tagsüber. Daher wurde der für tagsüber erhobene Wert nicht auf 24 Stunden hochgerechnet.

\subsubsection{Datenauswertung}

\section{Auswertung mit GIS}

Die GPS-Daten wurden in ein Tabellenprogramm (Microsoft EXCEL) eingegeben und in ein GIS übertragen. Die Geo-Koordinaten wurden zuvor von Grad in Dezimalgrad umgerechnet. Die Analyse der Daten erfolgte mit der Software ArcGIS 10 (ESRI 2012). Durch die Überlagerung mit referenzierten Luftbildern wurden die Positionskoordinaten für einzelne Bereiche visualisiert. Durch das Filtern der Daten nach bestimmten Verhaltensweisen oder Habitattypen konnten auf einer Karte bevorzugte Weideflächen oder Ruheplätze sowie Beweidungsintensitäten für einzelne Wochen oder Jahreszeiten dargestellt werden.

\section{Ermittlung des Home Range}

Der Home Range eines Tieres wird im Allgemeinen definiert als "[...] area traversed by the individual in its normal activities of food gathering, mating, and caring for young. Occasional sallies outside the area, perhaps exploratory in nature, should not be considered as in part of the home range" (Burt 1943). Der Aktionsradius der Ponys im Schutzgebiet Süd-Langeland war durch die Einzäunung begrenzt. Dennoch ist eine Auswertung des Home Range für das Verständnis der Raumnutzung und Habitatansprüche der Pferde von Bedeutung: Überlagert man den Home Range im GIS mit Informationen zur Habitatstruktur, kann die Ressourcenverfügbarkeit im Gebiet abgeschätzt werden (Rodgers \& Kie 2011). Hierfür stehen verschiedene Analysemethoden zur Verfügung, die entweder die Form (Minimum-Konvex-Polygon-Methode) oder die Struktur (Kerndichteschätzung) des Aktionsraumes darstellen.

Die Raumnutzung der Tiere wurde mit dem Spatial Analyst Tool in einer ArcView GIS 10-Umgebung (ESRI 2012) ausgewertet. Die Beschreibung des Aktionsraumes der Fokustiere erfolgte mit der Kerndichteschätzung. Die Kernel-Funktion basiert auf der von Silverman (1986) beschriebenen quadratischen Kernel-Funktion (Kernel Density Estimation, KDE): Das Verfahren berechnet anhand der im Gelände erfassten Aufenthaltsstandorte der Fokustiere im Beobachtungszeitraum die Wahrscheinlichkeit, ein Tier an einem beliebigen Punkt im Gebiet anzutreffen. Dafür wird um jede Ausgabe-RasterZelle die Dichte von Punkten berechnet. Dabei wird eine sanft geschwungene Oberfläche über alle Punkte gelegt. So können Gebiete mit unterschiedlichen Aufenthaltswahrscheinlichkeiten dargestellt werden. Die sich ergebenden Oberflächen basieren auf einer quadratischen Formel, wobei der höchste Wert im Mittelpunkt der Oberfläche, also der Punktposition liegt und am Ende des Suchradiusabstands gegen Null geht. Für jede Ausgabezelle wird die Gesamtzahl der akkumulierten Schnittpunkte der einzelnen, verteilten Oberflächen berechnet.

Die Qualität der Kerndichteschätzung hängt stark von der gewählten Bandbreite, dem Glättungsparameter oder smoothing factor h, ab (Rodgers \& Kie 2011, Beyer 2012). Er bestimmt, wie "eng" die Berechnung um die Punkte herum liegt. Am einfachsten wird die optimale Bandbreite mit der so genannten „Glättung nach Augenmaß" ausgewählt. Bei diesem Verfahren betrachtet man eine Reihe von Grafen mit verschiedenen Bandbreiten und wählt jene Bandbreite aus, bei der die Dichtefunktion am sinnreichsten aussieht. Glättung nach Augenmaß kann gute Ergebnisse liefern, wobei eine gewisse Willkür nicht vermieden werden kann (Hafner 2001). 
Das beste Ergebnis ergab $h=50$ bei einer Zellgröße von 5. Als Algorithmus diente die bivariate Normalverteilung (Gauß). Alle Datenpunkte wurden gleich gewichtet. Da die Werte sehr klein ausfielen, wurden sie skaliert (Scaling Factor $=1.000 .000)$.

Zur Darstellung der Aufenthaltswahrscheinlichkeiten der Weidetiere im Projektgebiet zu unterschiedlichen Jahreszeiten oder für verschiedene Untersuchungsjahre wurde als Klassifizierung die Standardabweichung gewählt. Diese Klassifizierungsmethode zeigt den Umfang der Abweichung der Feature-Attributwerte vom Mittelwert, wobei Klassenpausen mit gleichen Wertebereichen erstellt werden. Die Intervallgröße betrug ein Drittel der Standardabweichung.

Die Form und Größe des Home Range wurde mittels der Minimum-Konvex-Polygon-Methode (MCP) berechnet. Hierbei wird ein Polygon um die äußeren Punkte des Standortclusters gelegt, deren Verbindungslinien konvex verlaufen. Punkte mit konkav verlaufenden Linien zum Nachbarpunkt werden nicht berücksichtigt. Obwohl stark kritisiert, wird diese Methode aufgrund der guten Vergleichbarkeit mit anderen Studien noch häufig verwendet (Rodgers \& Kie 2011). Sie liefert zwar keine differenzierten Informationen zur Intensität der Gebietsnutzung wie die Kerndichteabschätzung, ergänzt diese aber um einen weiteren Aspekt. Da Pferde Herdentiere sind, wurden ähnliche Aktionsräume der einzelnen Herdenmitglieder erwartet. Überprüft wurde dies mittels Überlagerung der Home Range der drei Fokustiere. Ferner wurde untersucht, ob sich der Aktionsraum in Abhängigkeit von den Jahreszeiten und vom Entwicklungszustand der Vegetation verschob.

\section{Zusammenhang zwischen Raumnutzung und Umweltparametern}

Für den Aufbau des GIS wurden vom Projektgebiet verschiedene thematische Karten zu Habitat- und Vegetationsstrukturen sowie Geländeeigenschaften erstellt und mit den Positionskoordinaten der Tiere überlagert. Jedem Datensatz wurden mit Hilfe einer Punkt-in-Polygon-Analyse (Auswählen eines Punktes anhand eines Polygons) bestimmte Attribute der Vegetationskarten zugeordnet. Je nach Fragestellung wurden die räumlichen Abfragemethoden „Überschneiden“ oder „In einer Entfernung liegen von" gewählt.

\section{Habitatpräferenzen}

Zur Analyse der Habitatwahl auf Individuenebene wurden die prozentualen Anteile der Habitattypen eines Tieres mit ihrer Abundanz im Untersuchungsgebiet verglichen. Zur Analyse individuenübergreifender Tendenzen der Habitatwahl wurde die durchschnittliche Habitatnutzung der Herde ermittelt (als Mittelwert der 3 Fokustiere) und die daraus resultierenden Habitatanteile mit ihrer Abundanz im Untersuchungsgebiet verglichen. In gleicher Weise wurde mit den Anteilen der 37 Vegetationseinheiten verfahren. Für die Analyse saisonaler sowie tageszeitlicher Unterschiede in der Habitatnutzung wurden die Aufnahmedaten in Zeitintervalle unterteilt: Die Jahreszeiten gliederten sich in Frühjahr (20.3.-21.6.), Sommer (22.6.-21.9.), Herbst (22.9.-21.12.) und Winter (22.12.-19.3.), die Tageszeiten in morgens (5-9 Uhr), mittags (10-13 Uhr), nachmittags (14-17 Uhr) und abends (18-22 Uhr).

Unterschiede in der räumlichen und zeitlichen Habitatnutzung wurden mit Hilfe eines Chi-QuadratTests auf Signifikanz überprüft. Dieser Unabhängigkeitstest zeigt Differenzen zwischen den beobachteten Häufigkeiten und den unter $\mathrm{H}_{0}$ erwarteten Häufigkeiten auf, wobei die Null-Hypothese lautete: „Alle Habitattypen haben dieselbe Häufigkeitsverteilung“. Verglichen wurden also die absoluten Häufigkeiten $h \_i$ der einzelnen Habitate mit jenen Werten, die sich unter der Annahme identischer relativer Häufigkeiten ergeben würden, also: $g_{-} i=$ Flächenanteil * Gesamtzahl aller Beobachtungen. Die Werte $\left(h \_i-g_{-} i\right)^{2} / g_{-} i$ wurden aufsummiert und mit dem $95 \%$-Chi-Quadrat-Quantil verglichen. Mit dem Test ließ sich auch nachweisen, welche Habitate zu welcher Jahres- und Tageszeit häufiger aufgesucht wurden. Eine Chi-Quadrat-Verteilung ist nur dann gegeben, wenn die einzelnen Gruppen so groß 
sind, dass die erwarteten Häufigkeiten mindestens 5 sind. Gruppen mit $\mathrm{n}<5$ Datenpunkten wurden daher nicht berücksichtigt.

Die Bevorzugung oder Meidung bestimmter Habitate oder Pflanzengesellschaften wurde unter Verwendung des Manly-Chesson-Selektivitätsindex $\alpha$ (Manly 1974, 2009, Chesson 1978) berechnet. Die Werte liegen zwischen 0 und 1, wobei $\alpha=1 / \mathrm{m}$ ein neutrales Verhalten, $\alpha<1 / \mathrm{m}$ Meidung und $\alpha>1 / \mathrm{m}$ Präferenz bedeuten, wobei $m$ der Anzahl potenzieller Habitatkategorien entspricht (Abb. 13).

Ob es einen Zusammenhang zwischen Strukturparametern und Aufenthaltshäufigkeiten der Weidetiere gab, wurde mit Pearsons Produkt-Moment-Korrelationskoeffizienten $r$ berechnet (Abb. 14). Er ist ein Maß für den Grad des linearen Zusammenhangs zwischen zwei intervallskalierten Merkmalen. Bei einem Wert von +1 (bzw. -1 ) besteht ein vollständig positiver (bzw. negativer) linearer Zusammenhang zwischen den betrachteten Merkmalen. Bei Werten von $0,5<r \leq 0,8$ liegt ein mittlerer, bei $0,8<r \leq 1,0$ ein hoher linearer Zusammenhang vor. Wenn der Korrelationskoeffizient den Wert 0 aufweist, hängen die beiden Merkmale nicht linear voneinander ab.

Strukturparameter waren die maximale und durchschnittliche Vegetationshöhe der Kraut- und Streuschicht sowie die Deckungsgrade von Gräsern, Kräutern, Streuauflagen und Erde. Verwendet wurden die gemittelten Daten der Jahre 2008-2010 der Strukturdauerflächen in den Habitattypen Grünland, Ackerbrache, Uferfluren / Röhrichte, Laubwald, Gebüsch, Waldsaum sowie Magerrasen (siehe 6.1.2.3 Kartierung von Strukturelementen auf Dauerflächen )

$$
\alpha_{i}=\frac{r_{i}}{n_{i}} \frac{1}{\sum_{j=1}^{m}\left(r_{j} / n_{j}\right)}
$$

Abb. 13: Manly-Chesson-Selektivitätsindex $\alpha$ zur Berechnung von Habitatpräferenzen

$r_{i}, r_{j}=$ Häufigkeit, mit der das Tier im Habitat $i-j$ angetroffen wurde $\mathrm{n}_{\mathrm{i}}, \mathrm{n}_{\mathrm{j}}=$ Anteil des Habitats am Gesamtgebiet

$\mathrm{m}=$ Anzahl potentieller Habitatkategorien

$$
r=\frac{S_{x y}}{S_{x} S_{y}}=\frac{\sum_{i=1}^{n}\left(x_{i}-\bar{x}\right)\left(y_{i}-\bar{y}\right)}{\sqrt{\sum_{i=1}^{n}\left(x_{i}-\bar{x}\right)^{2} \sum_{i=1}^{n}\left(y_{i}-\bar{y}\right)^{2}}}
$$

Abb. 14: Pearsons Produkt-Moment-Korrelationskoeffizient $r$ zur Berechnung des Zusammenhanges zwischen Strukturparametern und Raumnutzung

$\mathrm{S}_{\mathrm{xy}}=$ empirische Kovarianz

$\mathrm{s}_{\mathrm{x}}, \mathrm{s}_{\mathrm{y}}=$ empirische Standardabweichungen

$x, y=$ Mittelwerte von $x, y$

$\mathrm{n}=$ Anzahl der Wertepaare 


\section{Modellansatz und Umweltparameter}

Der Zusammenhang zwischen dem Raumnutzungsverhalten der Langeländer Herde und den Umweltbedingungen im Projektgebiet wurde mittels eines verallgemeinerten linearen Modells analysiert. Hierbei wurde das Vorkommen der Tiere mit 12 Umweltparametern, den erklärenden Variablen, in Beziehung gesetzt (Tab. 7). Diese Faktoren wurden zwei Betrachtungsebenen zugeordnet: der Vegetations- und der Landschaftsebene. Ausgewertet wurden die Entfernung der Pferde zu bestimmten Strukturen im Gelände wie Elektrozaun, Wasserstellen oder Gehölze, Strukturparameter wie Deckungsgrad und Höhe der Krautschicht, Futterwert, Nährstoffgehalt, Feuchte und Reaktionszahl der Pflanzengesellschaften sowie deren Evenness und Shannon-Diversität-Index. Die Messwerte wurden für eine bessere Vergleichbarkeit in 10-stufige Skalen umgewandelt (Anlage 5.2).

Die Evenness fließt in den Shannon-Index mit ein, auch Feuchtezahl und Höhe stehen im Verhältnis zueinander. Zur Vermeidung von Scheinkorrelationen (Multikollinearität) wurden die Variablen daher paarweise über die Pearson-Korrelation getestet. Bei Paaren mit $|r|>0,7$ wurde die Variable mit dem größeren $p$-Wert in der Modellberechnung von der weiteren Analyse ausgeschlossen (vgl. Leyer \& Wesche 2007, Santos et al. 2011, Newmark \& Rickart 2012).

Für die Auswertung wurden im GIS (ArcGIS 10, ESRI 2013) thematische Karten für jeden Umweltfaktor erstellt. Die Grundlage für die Variablen der Vegetationsstruktur bildeten die Daten der Biotop- und Vegetationskartierung aus dem Jahr $2008(n=199)$ sowie Satellitenfotos aus den Jahren 2006 und 2010. In die Berechnung des Futterwertes gingen alle Arten mit einem Deckungsgrad $d \geq 1$ der erweiterten Braun-Branquet-Skala ein. Der Futterwert pro Teilfläche wurde gemittelt. Hierfür wurden die Deckungsgrade mit ihrem Futterwert FW nach Briemle et al. (2002) multipliziert und die Summe aller Produkte durch die Anzahl der Arten mit $d \geq 1$ dividiert. Die Formel ist in Abb. 15 dargestellt.

Tab. 7: Die im linearen Regressionsmodell getesteten, erklärenden Variablen mit Code und Wertebereich

\begin{tabular}{llll}
\hline Ebene & Code & Beschreibung & Wertebereich \\
\hline Landschaftsstruktur & & & $-1-30$ \\
& HOEHE & Höhenmeter (in m) & $0-400$ \\
& ZAUN & Entfernung zum Elektrozaun (in m) & $0-400$ \\
& WASSER & Entfernung zu Gewässern (in m) & $0-400$ \\
Vegetationsstruktur & GEHOELZ & Entfernung zu Gehölzen (in m) & $0-210$ \\
& H_KRAUT & Durchschnittliche Höhe der Krautschicht (in cm) & $0-100$ \\
& D_KRAUT & Deckungsgrad der Krautschicht (in \%) & $0-1$ \\
& EVENNESS & Evenness / Gleichverteilung der Vegetation & $0-3$ \\
& SHANNON & Shannon-Diversitäts-Index & $1-12$ \\
& F & Feuchtezahl (Zeigerwert) & $1-9$
\end{tabular}




$$
F W_{m}=\frac{\sum_{d=1}^{n} d_{i} F W_{i}}{n_{i}}
$$

Abb. 15: Berechnung des Futterwertes im Projektgebiet

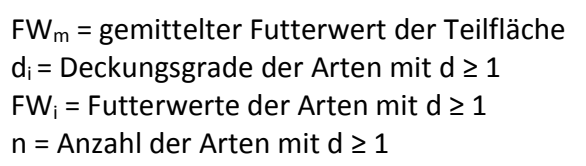

Zur Auswertung des Einflusses der Umweltfaktoren auf die Raumnutzung wurde das Gebiet in gleich große Teilflächen unterteilt. Im GIS wurde hierfür ein Netz mit Teilquadraten von 40 x 40 Metern über das Projektgebiet gespannt. Mit der Wahl der Kantenlänge wurde eine möglichst homogene Abbildung der Umweltfaktoren innerhalb der Teilquadrate angestrebt. Lediglich Ökotone wie Ufer- und Waldsäume konnten aufgrund ihrer Kleinflächigkeit nicht ausreichend dargestellt werden.

In jedem Quadranten, der im GIS die Fläche des Projektgebietes schnitt, wurden die Standortpunkte $(n=4.892)$ gezählt. So wurde für das Modell die abhängige Variable, also das Vorkommen oder NichtVorkommen der Weidetiere, generiert. Das Sommer- und Winterhalbjahr wurde getrennt voneinander ausgewertet. Die Datentabelle ist in Anlage 5.3 wiedergegeben. Über eine Punkt-in-Polygon-Analyse wurden die Umweltparameter für jeden Quadranten $(n=766)$ bestimmt, wobei der Quadratmittelpunkt als Referenzpunkt galt.

Es wurde eine multiple Poisson-Regression durchgeführt. Sie ist ein Spezialfall des verallgemeinerten linearen Modells (GLM) und eignet sich besonders bei Zähldaten (hier: Nutzungshäufigkeiten), da die zu erklärende Variable y per Definition dieses Modells nur ganzzahlige, positive Werte annehmen kann (McCullagh \& Nelder 1989). Der Mittelwert von $y$ wird bei der Poisson-Regression als exp $\left(B_{0}+B_{1} x_{1}+\right.$ $\ldots+B_{k} x_{k}$ ) modelliert. Die Residual deviance gibt - wie das $\mathrm{R}^{2}$ der Standardregression - eine Summe von Residuen und damit die Güte des Modells an.

Bei der schrittweisen multiplen Regressionsanalyse wurden zunächst alle erklärenden Variablen eingebunden (full model) und Schritt für Schritt einzeln herausgenommen. Bei dieser Vorgehensweise liegt als Ergebnis das minimale angemessene Modell (minimum adequate model) vor. Über die Berechnung der deviance wird überprüft, ob die jeweilige Variable signifikant zur Modellverbesserung beigetragen hat (vgl. Leyer \& Wesche 2007). Es kristallisierten sich auf diese Weise jene Faktoren heraus, die das Raumnutzungsverhalten der Pferde steuerten. Das Signifikanzniveau von Variablen wurde dabei auf $p=0,05(*)$ gesetzt.

Bei der Durchführung der Regressionsanalyse zeigten sich vergleichbare Ergebnisse bei skalierten oder gemittelten Umweltfaktoren (s. Anlage 5.2). Im Ergebnis wurden die skalierten Umweltfaktoren dargestellt, da sich die Parameter ( 6 ) direkt miteinander vergleichen lassen.

Die Regressionsanalyse wurde mit der Statistik-Software $R$ (Version 3.0.1) durchgeführt. 


\subsubsection{Beobachtung des Verhaltens}

\subsubsection{Datenerhebung}

Das Verhalten der Weidetiere wurde nach der Methodik des Animal focus sampling (Altmann 1974) dokumentiert. Hierbei werden alle Verhaltensweisen von Fokustieren in Minutenprotokollen festgehalten. Direktbeobachtungen der Tiere ermöglichen eine Auswertung der täglichen Fress- und Ruhezeiten sowie der Veränderung der Anteile von Nahrungsaufnahme, Lokomotion, Ruhe- und Sozialverhalten im Wechsel der Jahreszeiten und mit zunehmender Herdengröße (Martin \& Bateson 1993). Drei adulte Fokustiere, die im Abschnitt Fokustiere näher beschrieben sind, wurden in den Jahren 20082010 dreimal jährlich zu unterschiedlichen Jahreszeiten jeweils von Sonnenaufgang bis Sonnenuntergang beobachtet (Tab. 8). Pferde weisen einen regelmäßigen Tagesrhythmus auf (Schäfer 1993). Die Anfertigung eines Tagesprotokolls muss daher nicht an einem einzigen Tag erfolgen, sondern kann auf mehrere Beobachtungseinheiten aufgeteilt werden.

Nach der Methodik des Animal Focus Sampling wurde zu Beginn der Aufnahmezeit das Verhalten aller Fokustiere notiert. Im Anschluss wurden nur Verhaltensänderungen erfasst. Notiert wurden Verhaltensweisen der Nahrungsaufnahme, des Ruheverhaltens, der Lokomotion, des Komfortverhaltens sowie des Stoffwechsels. Traten mehrere Verhaltensweisen pro Minute auf, wurde nur die Verhaltensart mit dem größten Zeitanteil pro Minute dokumentiert. Abweichend davon wurden soziale Verhaltensweisen als Häufigkeiten erfasst, da sie meist nur wenige Sekunden dauerten und somit keine Berücksichtigung gefunden hätten. Zu jeder vollen Stunde wurde darüber hinaus das Herdengefüge, also die Entfernungen der Tiere untereinander, abgeschätzt. Auch Wetterdaten wurden bei jeder Datenaufnahme dokumentiert (s. Tab. 6). Der Aufnahmebogen ist dem Anhang beigefügt (Anlage 5.1).

Um das natürliche Verhalten so wenig wie möglich zu beeinflussen, wurde ein Mindestabstand von $50 \mathrm{~m}$ zu den Tieren eingehalten, der jedoch teilweise von der Pferden selbst unterschritten wurde. Für eine bessere Übersicht wurde häufig von einer erhöhten Position aus beobachtet. Für die Beobachtungen stand ein Fernglas der Marke Zeiss $(10 \times 50)$ zur Verfügung. Die Uhrzeit wurde mit einer handelsüblichen Armbanduhr abgelesen. Fotos wurden mit einer digitalen Kamera (Marke EOS 500) sowie einem 300er Teleobjektiv aufgenommen.

\subsubsection{Verhaltensweisen}

Das Verhalten von Pferden ist umfassend bei Schäfer (1993) und Waring (2003) beschrieben. Die bei der Beobachtung verwendeten Verhaltenskategorien entstammen einer früheren Arbeit der Autorin (Schaffeld 2000, Mannstedt 2007). Sie sind in Tab. 9 zusammengestellt.

Tab. 8: Beobachtungszeiten in Minuten der Langeländer Exmoor-Pony-Herde über einen dreijährigen Untersuchungszeitraum (April 2008-März 2011)

\begin{tabular}{l|lll|lll|lll|l} 
& Apr 08 & Sept 08 & Dez 08 & Apr 09 & Sept 09 & Jan 10 & Apr 10 & Sept 10 & Jan 11 & Gesamt \\
\hline Tier 1 & 900 & 780 & 540 & 900 & 780 & 540 & 900 & 780 & 540 & 6.660 \\
Tier 2 & 900 & 780 & 540 & 900 & 780 & 540 & 900 & 780 & 540 & 6.660 \\
Tier 3 & 900 & 780 & 540 & 900 & 780 & 540 & 900 & 780 & 540 & 6.660 \\
Gesamt & $\mathbf{2 . 7 0 0}$ & $\mathbf{2 . 3 4 0}$ & $\mathbf{1 . 6 2 0}$ & $\mathbf{2 . 7 0 0}$ & $\mathbf{2 . 3 4 0}$ & $\mathbf{1 . 6 2 0}$ & $\mathbf{2 . 7 0 0}$ & $\mathbf{2 . 3 4 0}$ & $\mathbf{1 . 6 2 0}$ & \\
\hline
\end{tabular}


Tab. 9: Ethogramm mit Abkürzungen und Definitionen der verwendeten Verhaltensweisen

\section{Kürzel Verhaltensweise}

Lokomotion

gal Galopp

tra Trab

sch Schritt

ste Stehen (z.B. beim Kraulen, Säugen, etc.)

doe Dösen, stehend mit entspanntem Gesichtsausdruck, waagerecht gehaltenem Hals und angewinkelter Hinterhand

kau Kauern, liegend mit unter dem Rumpf angewinkelten Beinen

lie Liegen auf der Seite mit entspanntem oder zeitweilig erhobenem Kopf, Extremitäten ausgestreckt oder leicht angewinkelt

Nahrungsaufnahme

$\begin{array}{ll}\text { stf } & \text { Stehen und fressen } \\ \text { std } & \text { Stehen und fressen Erde } \\ \text { gef } & \text { Gehen und fressen (mehr als } 10 \text { m pro Minute) } \\ \text { kna } & \text { Knabbern von Holz (Zweige, Baumrinde oder ähnliches) } \\ \text { scr } & \text { Scharren auf dem Boden } \\ \text { tri } & \text { Trinken }\end{array}$

Stoffwechsel

kot Koten

har Harnen

Komfortverhalten

rei Reiben, Scheuern an Gegenständen zur Hautpflege

wae Wälzen auf dem Boden, ein- oder beidseitig

krz Kratzen mit dem Hinterhuf am Kopf, an den Ohren und am Hals

Territorialverhalten

imt Territoriales Imponieren, Imponierhaltung des Hengstes mit gespitzten Ohren und meist im Trab

mar Markieren, Koten oder Harnen auf Kothaufen an Reviergrenzen

Sexualverhalten

ims Sexuelles Imponieren, Imponierhaltung mit aufgewölbten Hals und im Trab

aus Ausschachten, Erektion der Rute

ona Onanieren, klatschendes Schlagen der erigierten Rute an den Bauch

sae Sägebockstellung, sägebockartig gespreizte Beine, schwach gesenkte Hinterhand und leicht erhobener Schweif, bei rossigen Stuten, submissives Verhalten

bli Blitzen, Abspritzen von Urin und Brunstschleim während der Rosse

fle Flehmen, geruchliche Orientierung mit den Jacobsonschen Organ zur Untersuchung von Kot- und Harnstellen und von rossigen Stuten, ferner zur Identifizierung fremdartiger Gerüche (sexueller Hintergrund)

vor Vorspiel, Zwicken des Hengstes in die Schulter und Flanke der Stute, naso-genitaler Kontakt und Flehmen, Zeichen einer bevorstehenden Paarung, freundliches Verhalten

bes Besteigen, Aufreiten der Hengste

int Koitus, Penetration

rih Riechen von Harn oder Kot, Beriechen von Exkrementen einer (rossigen) Stute

\section{Spielverhalten}

spk Spielkampf, spielerischer Kampf mit Zwicken und gegenseitigem Jagen, meist im Schritt mit kurzen Laufphasen

lau Laufspiel, Bewegungsspiel im Galopp / Trab mit Sprüngen, meist ohne bestimmtes Ziel, einzeln oder gemeinsam

sex Sexualspiel, spielerisches Besteigen der Fohlen untereinander, ohne Erektion 
(Fortsetzung)

Ereignis

sic Sichern, Aufwerfen des Kopfes, Habachtstellung, aufgestellte Ohren

\section{Sozialverhalten}

\begin{tabular}{|c|c|}
\hline zwi & Zwicken, leichtes Beißen mit den Schneidezähnen, dominantes Verhaltes \\
\hline ver & Verfolgen, aufdringliches Hinterherlaufen, dominantes Verhalten \\
\hline vtr & Vertreiben, Verfolgen eines Individuums, um es zu verjagen, aggressives Verhalten \\
\hline dro & Drohen, schwache Form des Beißdrohens, angelegte Ohren oder Drohbewegungen mit dem Kopf \\
\hline bed & Beißdrohen, Freilegen des Schneidezahngebisses und angelegte Ohren \\
\hline sld & Schlagdrohen, Anheben des Hinterteiles und/ oder des Hinterbeines, Drohhaltung \\
\hline bei & Beißen \\
\hline sla & Schlagen, Ausschlagen mit einem oder meist beiden Hinterbeinen \\
\hline ang & Angehen, Angriff auf ein Individuum, aggressives Verhalten \\
\hline tre & $\begin{array}{l}\text { Treiben, Hengst mit waagerecht gestrecktem Hals, angelegten Ohren, gehobenem Schweif, teils Kopfschlenkern, } \\
\text { zum Zusammenhalten der Herde und Rückführung von Stuten, aggressives Verhalten }\end{array}$ \\
\hline anf & Anflehmen, wie flehmen, aber submissives Verhalten \\
\hline auf & Aufsuchen, aktives Gehen zu einem Individuum, freundliches Verhalten \\
\hline fol & Folgen, aktives Hinterhergehen, freundliches Verhalten \\
\hline ScW & Schritt weg, Fortschreiten nach einem erfolgten freundlichen Verhalten \\
\hline nan & Naso-nasaler Kontakt, freundliches Verhalten \\
\hline nak & Nasen-Kruppen-Kontakt, freundliches Verhalten \\
\hline naf & Nasen-Flanken-Kontakt, freundliches Verhalten \\
\hline nah & Nasen-Hals-Kontakt, freundliches Verhalten \\
\hline nag & Naso-genitaler Kontakt, freundliches Verhalten \\
\hline rea & Reiben an, Scheuern an einem anderen Tier zur Fellpflege \\
\hline kra & Kraulen, freundliches Verhalten, soziale Hautpflege von Flanken, Rücken, Hals und Mähne durch Beknabbern \\
\hline lec & Lecken von Herdenmitgliedern \\
\hline unk & $\begin{array}{l}\text { Unterlegenheitskauen, aufeinander Klappern der Zähne und geduckte Körperhaltung, seitlich abfallende Ohren, } \\
\text { eingeklemmter Schweif, bei Fohlen und Jährlingen }\end{array}$ \\
\hline unh & $\begin{array}{l}\text { Unterlegenheit, unterwürfige Körperhaltung mit gesenktem Kopf, seitlich gekippten Ohren und eingezogenem } \\
\text { Schweif, bei Adulten }\end{array}$ \\
\hline mei & $\begin{array}{l}\text { Meiden, aktives, submissives Fortbewegen von einem Individuum oder Aus-dem-Weg-gehen, um einen stören- } \\
\text { den Kontakt zu verhindern (z.B. Meiden fremder Fohlen) }\end{array}$ \\
\hline
\end{tabular}

\subsubsection{Datenauswertung}

Die Analyse der Verhaltensdaten erfolgte mit einem Tabellenprogramm (Microsoft EXCEL). Die Auswertung von saisonalen Unterschieden erfolgte teils mittels Signifikanztests. Der angewandte H-Test von Kruskal und Wallis wird in Kapitel 6.1.1.5 näher beschrieben. 


\subsubsection{Fokustiere}

Die Darstellung der Nahrungspräferenzen erfolgte stellvertretend für die gesamte Herde anhand der Auswertung der Raumnutzung von drei adulten Fokustieren. Als männliches Tier wurde der Leithengst ausgewählt, da er zu Beginn der Datenaufnahme im April 2008 der einzige ausgewachsene Hengst war. Bei den Stuten fiel die Wahl auf eine tragende Stute sowie eine Stute mit Fohlen. Die drei Tiere hatten unterschiedliche Rangpositionen in der Herde. Diese Einschätzung beruhte auf Voruntersuchungen im Jahr 2007.

\subsubsection{Tier 1}

Der Leithengst (Jahrgang 2003) lebte seit Oktober 2006 in der Langeländer Herde. Er war als einziges Tier der Herde im Stutbuch der Exmoor Pony Society unter dem Namen Felix eingetragen. Sein Brandzeichen auf der linken Schulter, eine Raute, stand für "pure bred Exmoor Pony“. Seine Zuchtbuchnummer lautete 243. Auf der linken Hinterhand war die Individualnummer 24 eingebrannt. Felix stammte aus einer deutschen Zuchtherde von R. Willmann, Oldenhütten.

Aufgrund seiner kräftigen Statur und dunklen Färbung ließ sich Felix selbst bei schlechten Sichtverhältnissen deutlich von anderen Tieren unterscheiden (Abb. 16). Prägnant waren sein muskulöser Hals und das glänzende dunkelbraune Fell mit deutlich aufgehelltem Bauch und rotbraunen Bereichen an Vorder- und Hinterhand. Mähne und Schweif waren fast schwarz, dicht und lang. Die Mähne lag größtenteils auf der rechten Halsseite.

Der Hengst hatte einen ruhigen und freundlichen Charakter. Gegenüber Jungtieren zeigte er sich tolerant. Aggressive Verhaltensweisen nahmen erst im Beobachtungsverlauf zu, als die Junghengste ihre Geschlechtsreife erreichten. Felix war eines der ranghöchsten Tiere in der Herde. Die Dänische Naturschutzbehörde hat inn zur Vorbeugung von Inzucht im November 2012 aus der Langeländer Herde entnommen. Er lebt seither in einem nahe gelegenen Schutzgebiet in einer Hengstgruppe.

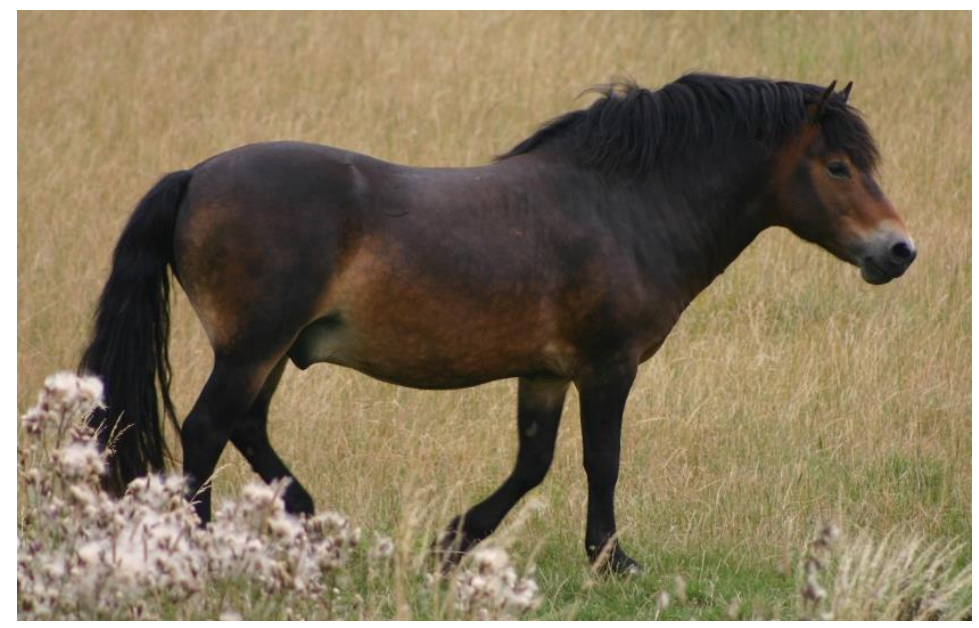

Abb. 16: Leithengst Felix (Tier 1)

\subsubsection{Tier 2}

Das zweite Fokustier war eine zierliche Stute mit einer fast geraden Rückenlinie (Abb. 17), anhand derer sie im Gelände leicht zu erkennen war. Ihre Fellfärbung war auffällig rot-braun mit einem Netzmuster. Sie erhielt den Namen Zora. Die lange, dunkle Mähne lag rechts, der Schweif war dunkel gefärbt. Auch ihr Kopf war zierlich. 
Zora zeigte häufig submissive Verhaltensweisen. Ihr Rang unter den Stuten wurde als niedrig eingestuft. Im Verlauf der Untersuchung zeigte sich, dass sie sich bevorzugt in der Nähe der anderen beiden Fokustiere aufhielt. Aus nicht geklärten Gründen verstarben Zoras Fohlen in den Jahren 2008 und 2009 jeweils im Alter von vier Monaten. Vermutet wurden eine Vergiftung oder ein genetischer Defekt, was zu der Überlegung führte, sie einzuschläfern. Aufgrund ihres Status als Fokustier wurde diese Maßnahme aufgeschoben. Das im Jahr 2010 geborene Fohlen überlebte.

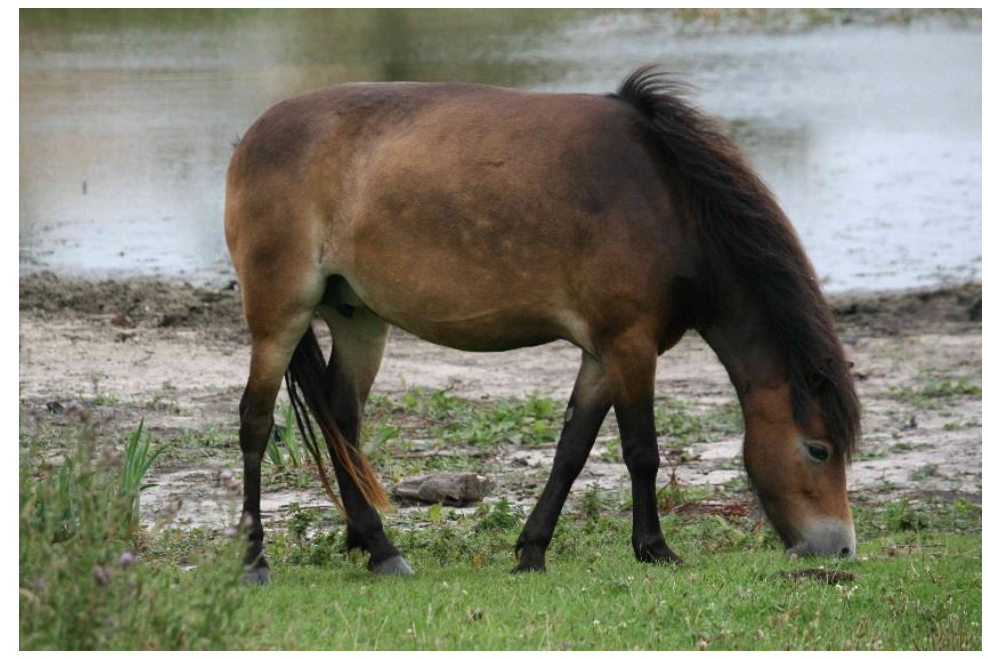

Abb. 17: Zora (Tier 2)

\subsubsection{Tier 3}

Das dritte Fokustier war eine ältere Stute mit einer mittelbraunen Färbung (Abb. 18), die von der Bauchunterseite bis zum Rücken einen deutlichen Farbverlauf zeigte. Das Winterfell war einheitlich dunkelbraun. Aufgrund einer eiförmigen, etwa 20 Zentimeter langen dunklen Verwachsung auf der linken Bauchseite trug sie den Spitznamen Narbe. Sie war mittelgroß und hatte eine kräftige, gedrungene Gestalt. Ihre Mähne lag überwiegend auf der rechten Seite.

In 2009 und 2010 wurden ihre Fohlen erst im September geboren. Möglicherweise kam es im Herbst 2008 zu einer Fehlgeburt. Ihre Jährlinge wurden häufig in ihrer Nähe beobachtet. Sie interagierte nur mit bestimmten Stuten, darunter Tier 2, selten hingegen mit dem Leithengst. Sie hatte eine mittlere Rangposition unter den Stuten.

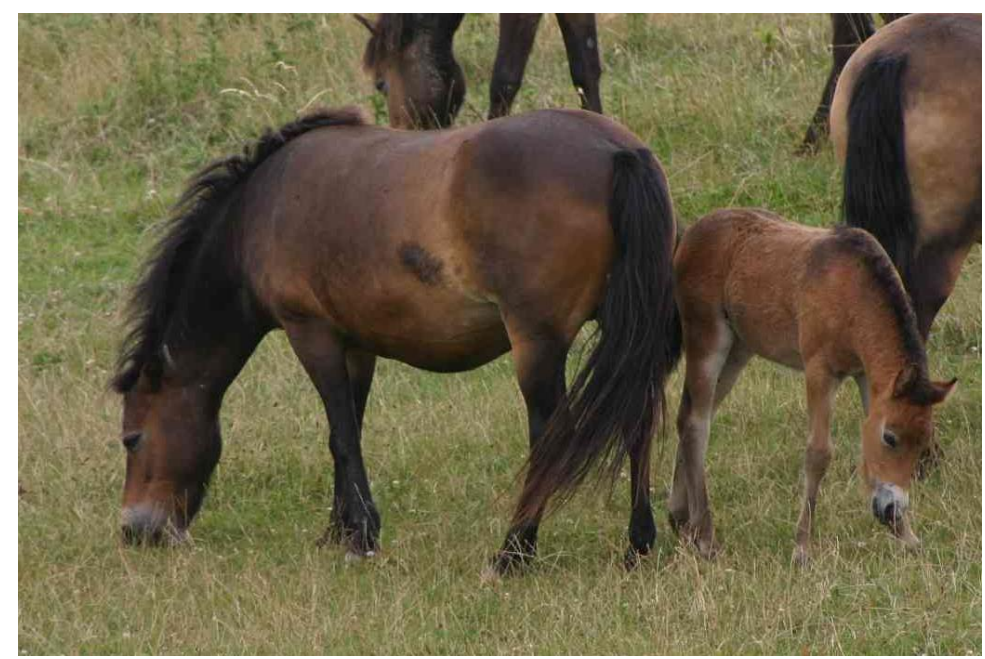

Abb. 18: Narbe (Tier 3) 


\subsection{Habitatnutzung der Weidetiere}

\subsubsection{Home Range}

Zur Bewertung des Aktionsraumes der Herde und dessen Veränderung über die Zeit gingen 4.896 Standortbestimmungen zwischen April 2008 und März 2011 in die Auswertung ein. Die Aufnahmepunkte pro Tier, Untersuchungsjahr und Jahreszeit variierten dabei leicht (Tab. 10).

Aufgrund der besonderen Form des Schutzgebietes war der mit der Polygon-Konvex-Methode (MCP) berechnete Aktionsraum der Fokustiere mit rund 150 ha größer als das den Tieren zur Verfügung stehende Gebiet. Auf eine grafische Darstellung wird daher verzichtet. Der Home Range blieb über die Jahre und Jahreszeiten weitgehend unverändert. Auch die Polygone der drei Fokustiere lagen im GIS nahezu übereinander. Es kann davon ausgegangen werden, dass das Schutzgebiet von den Tieren in seiner gesamten Ausdehnung genutzt wird.

Genauere Hinweise zur Raumnutzung liefert die Kerndichteschätzung. Die Kerngebiete der Weidetiere lagen im Gebietszentrum sowie an der Nord- und Südspitze (Abb. 19). Im Wesentlichen können die Kerngebiete dem Habitattyp nährstoffreicher Weiden zugeordnet werden. Auffällig ist die Nähe der bevorzugten Aufenthaltsbereiche zu Gewässerstrukturen im Gebiet.

Die Aufenthaltswahrscheinlichkeiten im Gebiet veränderten sich mit zunehmender Beweidungsdauer (Abb. 20). Wurden die Tiere anfangs im Grünland eher auf der Fläche verteilt angetroffen, so bevorzugten sie zunehmend bestimmte Areale. Ein solches Weideverhalten verstärkt die Entstehung heterogener Vegetationsstrukturen (siehe 6.3 Entwicklung des Gebietes unter Beweidung). Im ersten Jahr hielt sich die Herde in den heißen Frühlings- und Sommerwochen meist beim Unterstand zwischen den Teilgebieten 10, 12 und 13 auf. Da dieser im Folgejahr gesperrt wurde, wichen die Tiere im Sommer 2009 auf Standorte in Gewässernähe aus. Im dritten Jahr, das vergleichsweise nass und kühl war, suchten sie vermehrt Feldgehölze, Hecken und windgeschützte Areale des Offenlandes auf.

Tab. 10: Aufnahmepunkte pro Jahreszeit, Tier und Untersuchungsjahr

\begin{tabular}{ll}
\hline & Standorterfassungen \\
\hline Frühling (20.03.-21.06.) & 1.668 \\
Sommer (22.06.-21.09.) & 1.170 \\
Herbst (22.09.-21.12.) & 693 \\
Winter (22.12.-19.03.) & 1.365 \\
\hline Tier 1 & 1.707 \\
Tier 2 & 1.697 \\
Tier 3 & 1.492 \\
\hline Apr 2008 - Mrz 2009 & 2.093 \\
Apr 2009 - Mrz 2010 & 1.609 \\
Apr 2010 - Mrz 2011 & 1.194 \\
\hline
\end{tabular}


Bedingt durch das wechselnde Nahrungsangebot ist ein deutlicher jahreszeitlicher Effekt erkennbar. Im Frühjahr (ohne Abb.) verteilten sich die Tiere stärker auf der Fläche, es wurden überwiegend Wiesen und Weiden aufgesucht, wo frisches, saftiges Grün wuchs. Im Sommer konzentrierten sich die Aufenthaltsorte hingegen auf wenige ausgewählte Bereiche: der Unterstand, die Gewässer und Ufer (Abb. 21). Im Herbst (Abb. 21) und Winter (ohne Abb.) zogen sich die Pferde in windgeschützte Areale zurück.

Einfluss auf die Raumnutzung hatte ferner die Tageszeit. Die Tiere nutzten die frühen Morgenstunden für eine Beweidung der seltener frequentierten Randbereiche des Gebietes, also die artenarmen Weiden im Westen sowie die durch den Laubwald isolierte Nordspitze. Abends wurden sie häufig an der Südspitze angetroffen (ohne Abb.).

Die Kernel-Dichten der drei Fokustiere unterschieden sich nur geringfügig voneinander (ohne Abb.). Die Tiere wiesen aufgrund der Herdendynamik - mit Ausnahme von gewissen individuellen Präferenzen innerhalb der Teilgebiete - eine ähnliche Nutzung der Teilgebiete auf. Auch Unterschiede zwischen Hengst und Stuten waren nicht erkennbar.

Die restlichen Abbildungen sind im Anhang (Anlage 5.5) dargestellt.

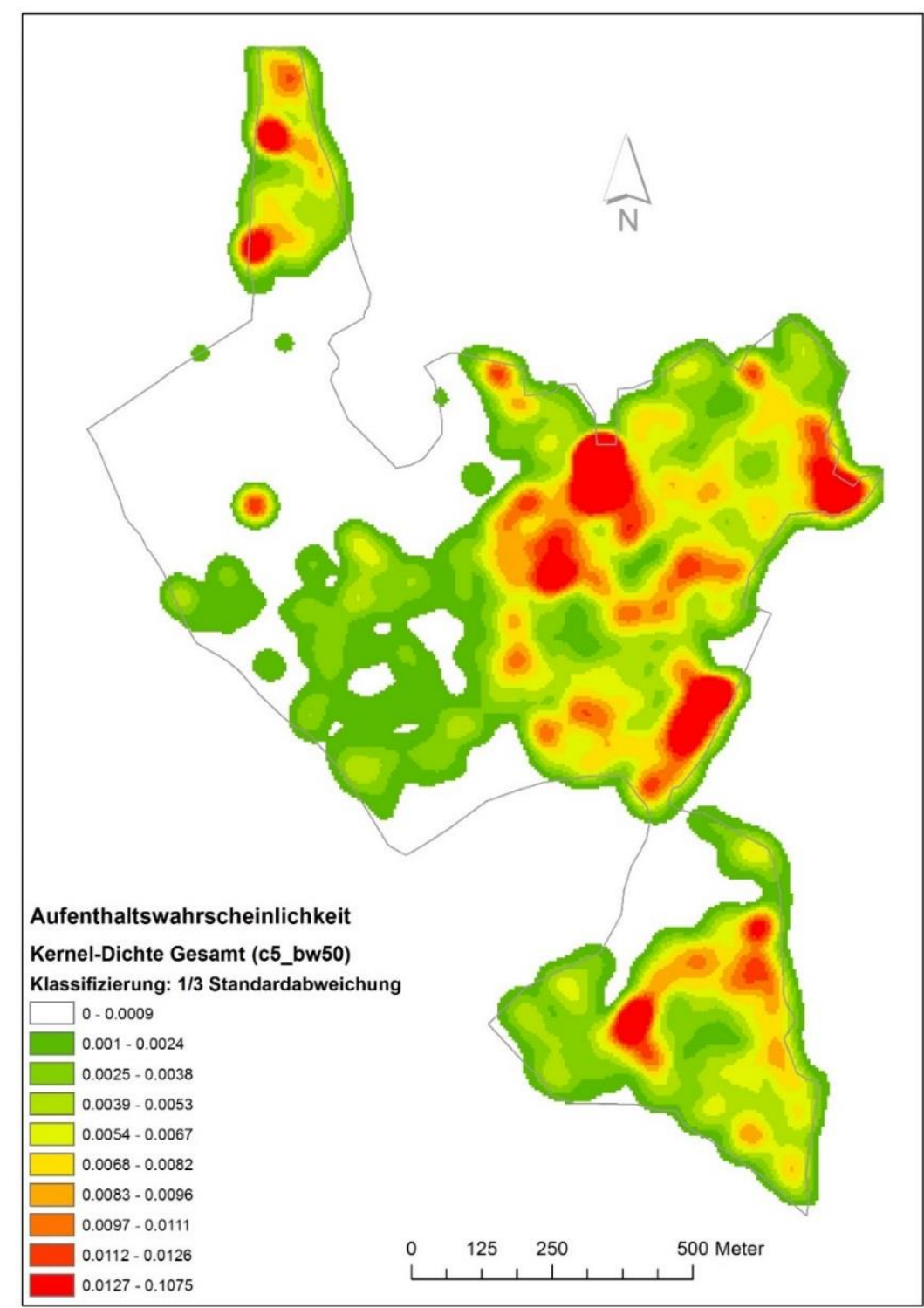

Abb. 19: Aufenthaltswahrscheinlichkeiten der Fokustiere im Projektgebiet (Gauß-Kernel, April 08 - März 11) 

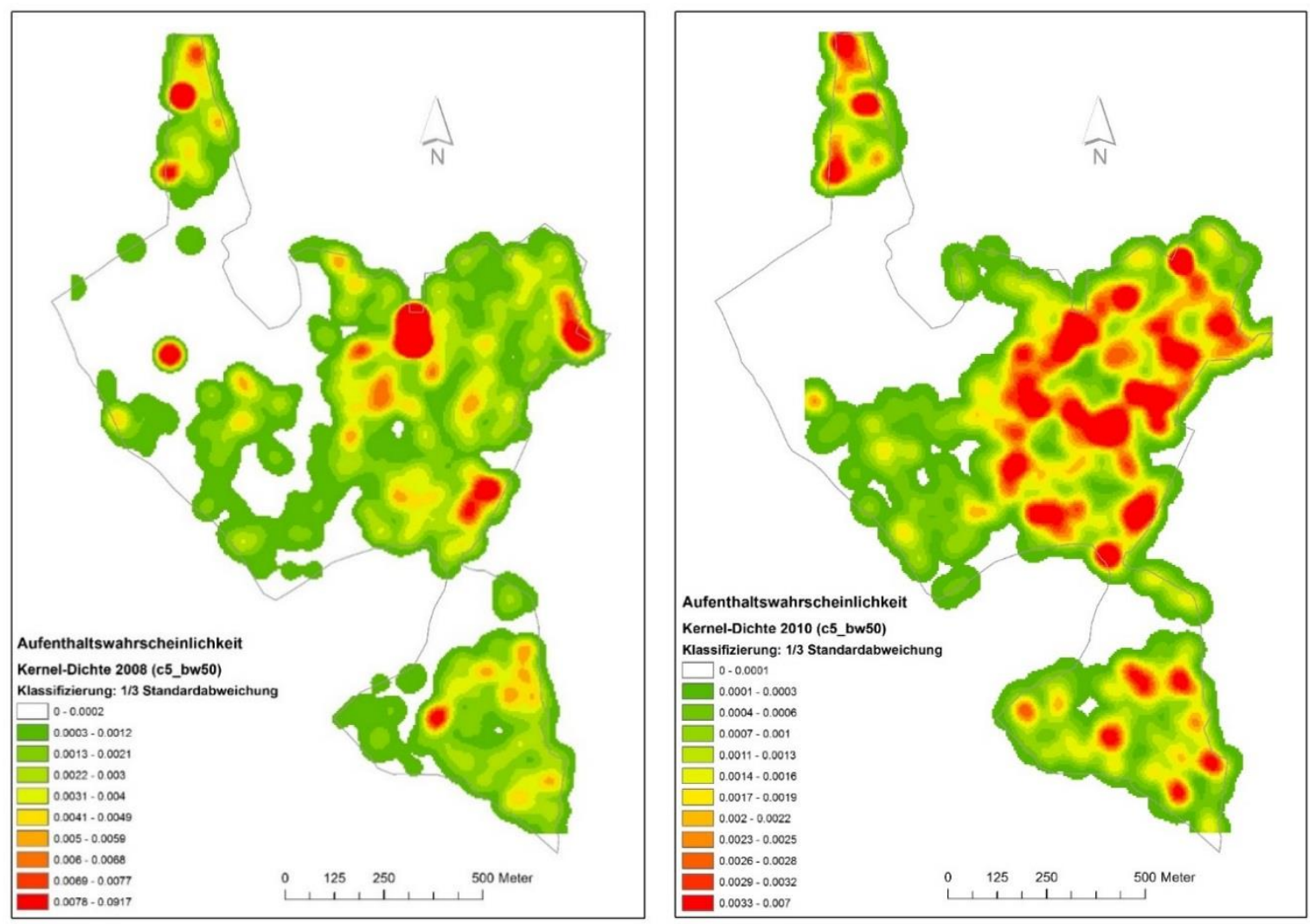

Abb. 20: Aufenthaltswahrscheinlichkeiten (Gauß-Kernel) der Fokustiere mit zunehmender Beweidungsdauer

Links: April 2008 - März 2009 ; rechts: April 2010 - März 2011
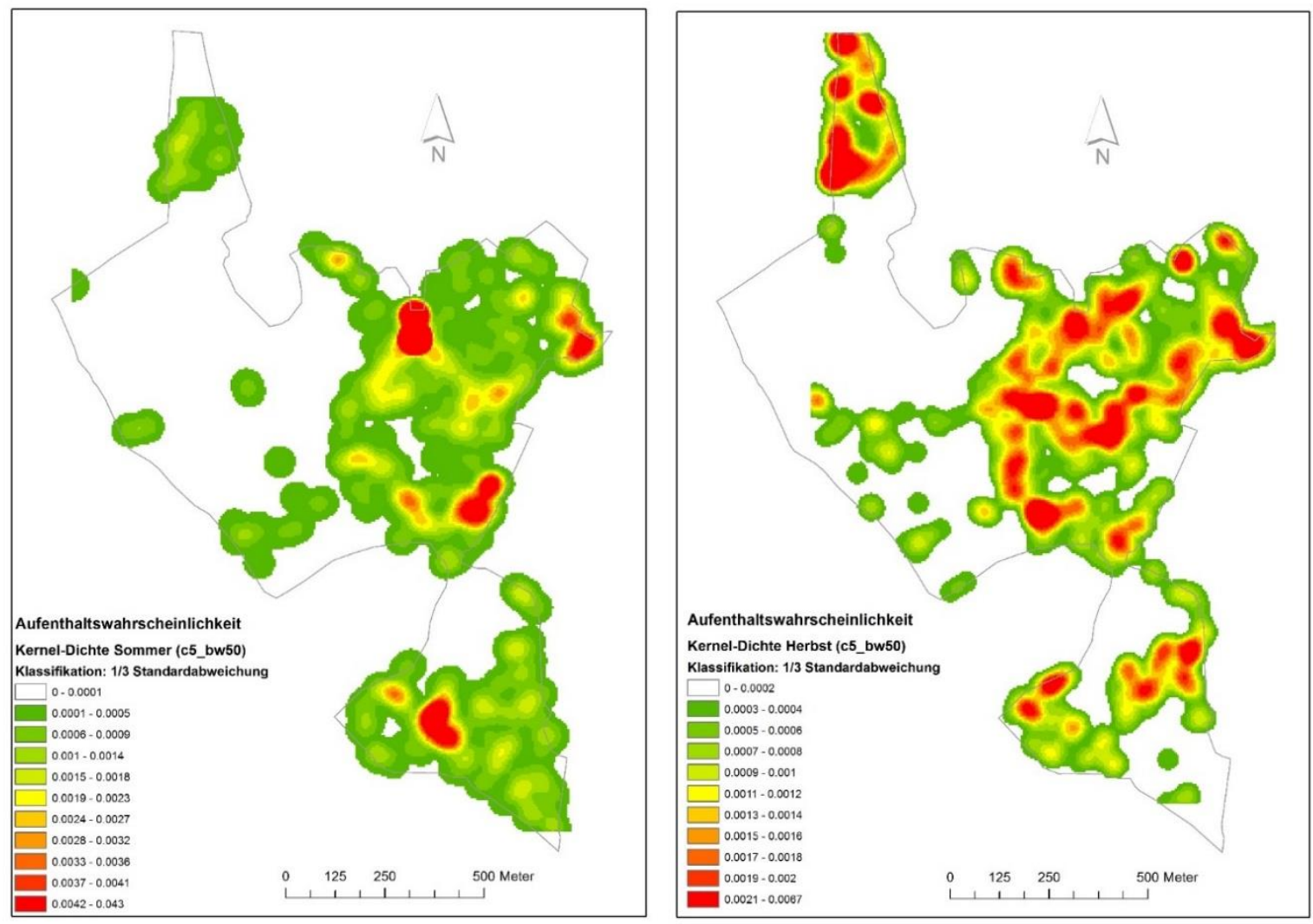

Abb. 21: Aufenthaltswahrscheinlichkeiten (Gauß-Kernel) der Fokustiere zu unterschiedlichen Jahreszeiten

Links: Sommer 2008-10; rechts: Herbst 2008-10 


\subsubsection{Räumliche und zeitliche Habitatnutzung}

Die Tiere der Langeländer Herde wiesen im Untersuchungszeitraum eine räumlich sowie zeitlich heterogene Habitatnutzung des Gebietes auf.

\subsubsection{Habitatnutzung nach Vegetationstypen}

Die Pferde wurden am häufigsten im Frischgrünland beobachtet (Abb. 22). Rund $9 \%$ aller Standorte wurden in Wäldern und Gebüschen registriert. Andere Habitate wie Röhrichte, Sümpfe oder Uferbereiche suchten sie nur sporadisch auf. Dabei entsprach die Raumnutzung der Weidetiere keineswegs der Habitatverfügbarkeit im Projektgebiet ( $\chi^{2}$-Anpassungstest, $\chi^{2}=1426$, $d f=7, P<0,0001$ ). Neben den Grünländern wurden die niederwüchsigen Uferbereiche - in Abb. 22 vertreten durch die Kategorien „Krautige Vegetation oft gestörter Plätze“ und „Süßwasservegetation“ - bevorzugt aufgesucht. Eine geringe Nutzung erfuhren hingegen die hochwüchsigen Röhricht- und Uferstaudengesellschaften an den Weihern und im Moor.

Nicht nur die Habitattypen, auch die Vegetationseinheiten hatten nicht dieselbe Häufigkeitsverteilung $\left(\chi^{2}=4704, d f=30, P<0,0001\right)$. Die Weidetiere zeigten Präferenzen für Assoziationen von Wiesen und Weiden frischer Standorte (Arrhenatheratalia) sowie für gewässernahe, niederwüchsige Gesellschaften wie Chenopodietum glauco-rubri, Ranunculetum peltati und Phragmition-Initialgesellschaften. Unter den Grünlandassoziationen wurden magere und ruderale Glatthaferwiesen eher gemieden, vermutlich weil sie nährstoffärmer beziehungsweise hochwüchsiger waren.

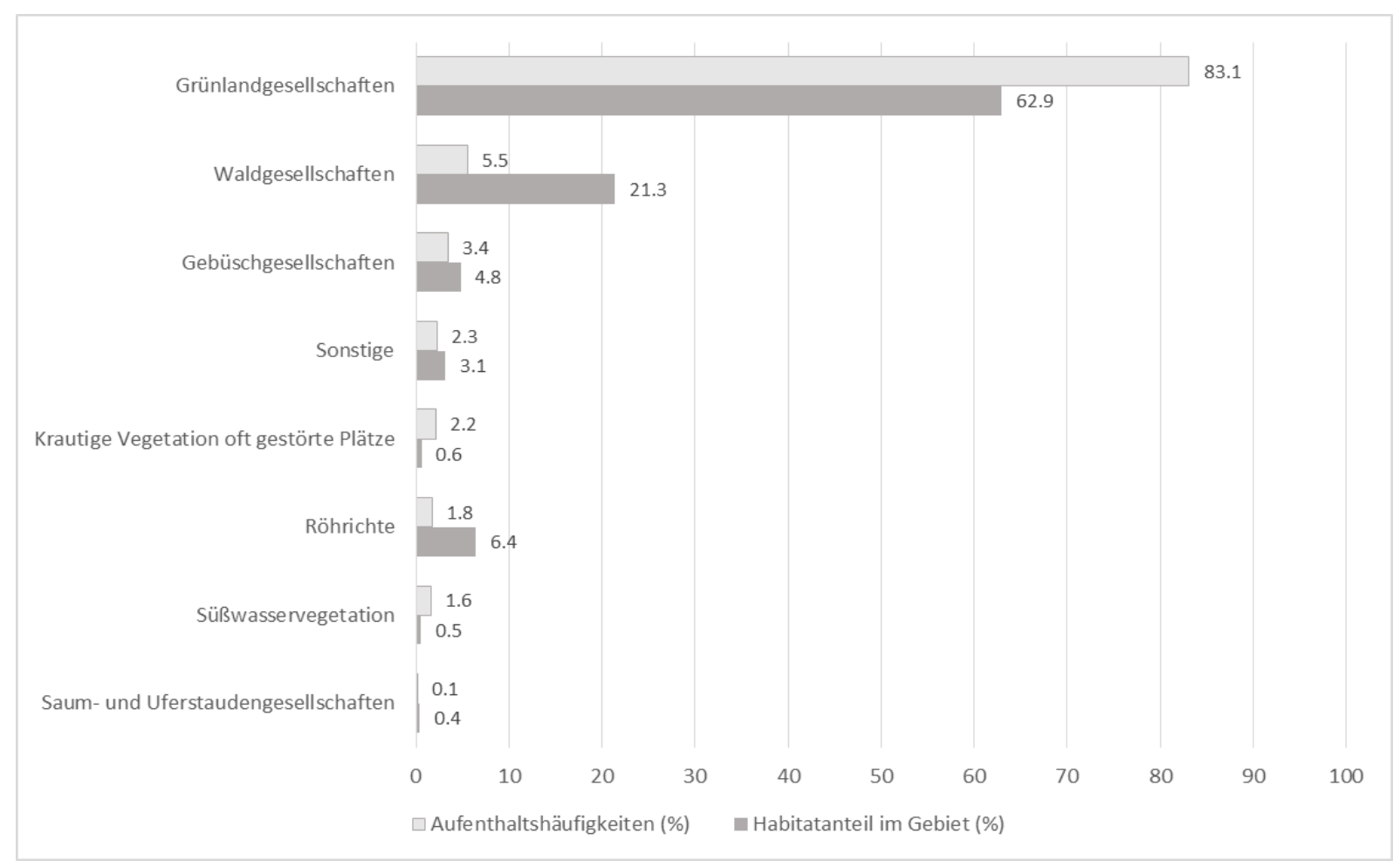

Abb. 22: Habitatnutzung der Weidetiere im Untersuchungszeitraum im Vergleich zur Gebietsausstattung Angaben in \%, Sonstige: Offene Wasserflächen, Flächen ohne Vegetation, Ausschlussfläche 


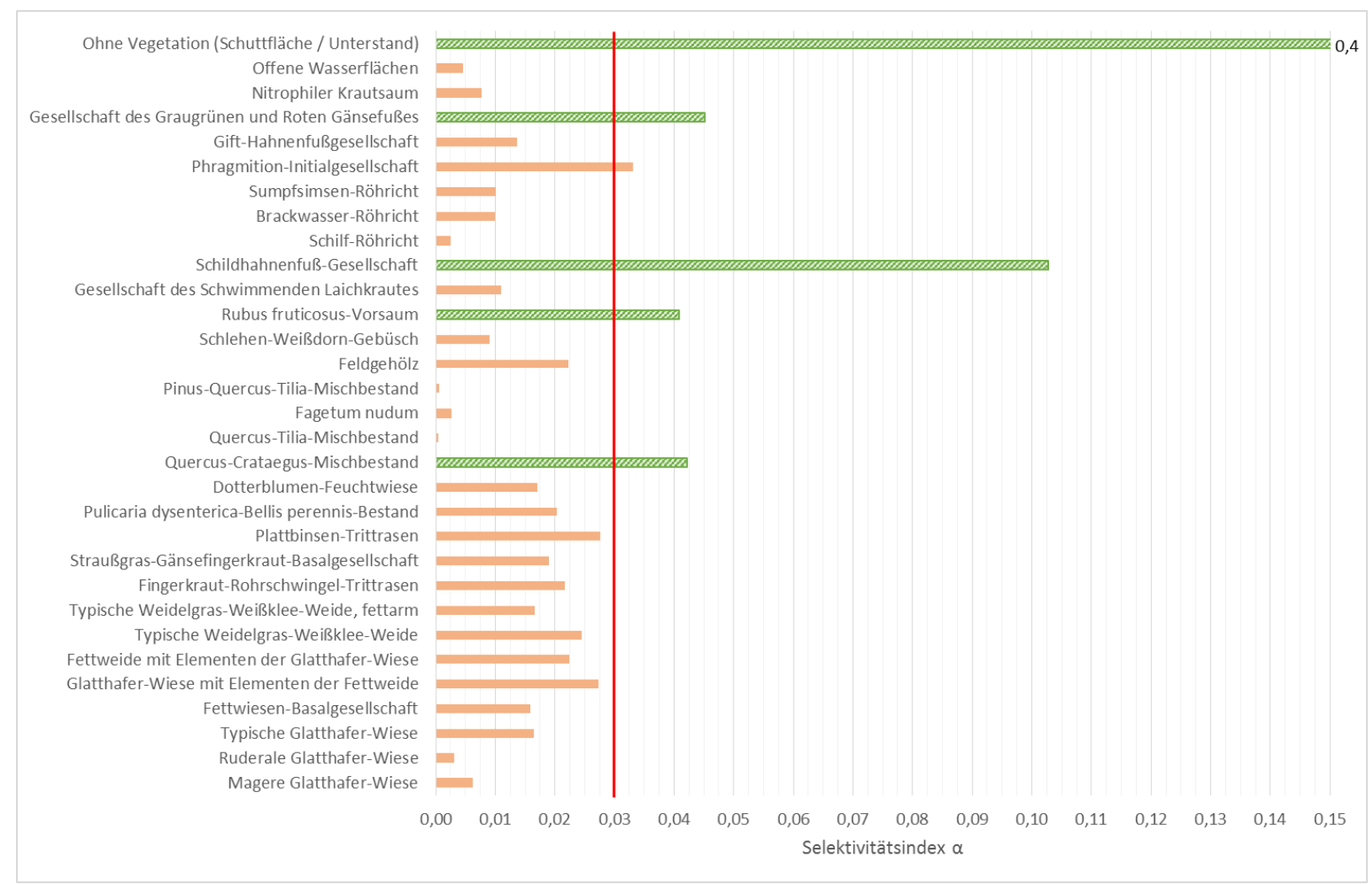

Abb. 23: Bevorzugung oder Meidung von Pflanzengesellschaften im Projektgebiet durch die Weidetiere unter Verwendung des Selektivitätsindexes $\alpha$

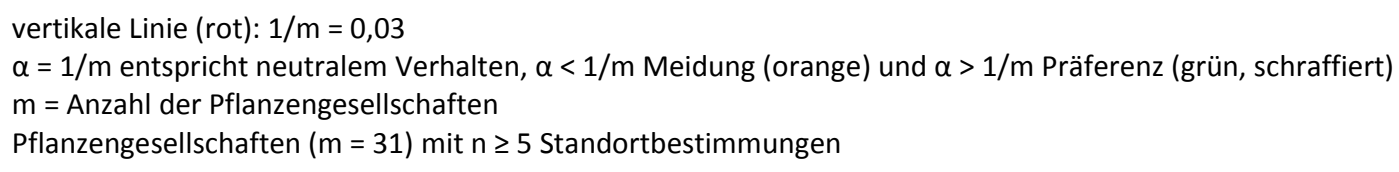

Schilf- und Brackwasser-Röhrichte suchten die Pferde seltener auf. Nahezu vegetationslose Flächen wie ein künstlicher Unterstand und ein nahe gelegener Quercus-Crataegus-Mischbestand wurden hingegen stark frequentiert. Die Präferenz für den Rubus fruticosus-Vorsaum weist die winterharte Brombeere als wichtige Nahrungspflanze der kälteren Jahreszeit aus, zudem diente die Hecke den Tieren als Schutzwall vor den starken Herbstwinden.

Die Meidung oder Bevorzugung von Vegetationseinheiten unter Verwendung des Selektivitätsindex $\alpha$ von Manly \& Chesson ist in Abb. 23 wiedergegeben.

\subsubsection{Saisonale und diurnale Habitatnutzung}

Die Jahreszeiten hatten einen statistisch signifikanten Einfluss auf die Aufenthaltshäufigkeiten in den einzelnen Habitattypen ( $\chi^{2}$-Anpassungstest, $\chi^{2}=388,7, d f=18, P<0,0001$ ). Im Frischgrünland hielten sich die Pferde vor allem zu Beginn der Vegetationsperiode auf (Abb. 24). Im Sommer bevorzugten sie Ufersäume und Flachwasserbereiche sowie vegetationslose Standorte wie den Unterstand oder eine Schuttfläche. Damit minderten sie vermutlich die Belästigung durch Stechinsekten beim Ruhen. Im Herbst grasten sie wieder deutlich häufiger im Grünland, wo sie sich Fettreserven für den Winter anlegten. Dass die Weidetiere sich nun vermehrt von Röhrichten ernährten und diese teilweise stark abweideten - wie im Gebiet von Uthoff (2011) beobachtet wurde -, konnte statistisch nicht belegt werden. 
Im Winter verbrachten die Tiere deutlich mehr Zeit im Wald und Gebüsch als zu anderen Jahreszeiten. Zwar suchten die Ponys den Wald auch im Sommer auf, der Einzelvergleich beider Habitate zeigt jedoch, dass diesem Habitat in der kalten Jahreszeit eine größere Bedeutung zukam $\left(\chi^{2}=4, d f=1\right.$, $P<0,043)$. Hier fanden die Tiere Schutz vor schlechter Witterung und ernährten sich von Blättern, Zweigen und Knospen.

Ferner unterschied sich die Habitatnutzung signifikant zwischen den drei Untersuchungsjahren $\left(X^{2}=187, d f=14, P<0,0001\right)$. In trockenen, heißen Jahren bevorzugten die Pferde ufernahe oder schattige Habitate. Bei gemäßigter Witterung stieg hingegen der Anteil an registrierten Standorten im Grünland um 10 Prozent an (ohne Abb.). Dies kann auch durch die wachsende Herdengröße und das damit verbundene schlechtere Nahrungsangebot begründet sein, da die Tiere zur Deckung ihres Nahrungsbedarfs mehr Zeit auf den nährstoffreicheren Weiden verbringen mussten als zu Beginn der Untersuchung. Dazu passt, dass die Ponys im gleichen Jahr (2010) deutlich mehr grasten als in den Vorjahren (siehe 5.3.1 Aktivitätsbudget).

Auch die Tageszeiten hatten nicht dieselbe Häufigkeitsverteilung $\left(\chi^{2}=69\right.$, df $\left.=21, P<0,0001\right)$, die diurnalen Unterschiede waren jedoch weniger ausgeprägt als die saisonalen. Tagsüber sank der Anteil im Grünland gegenüber frühmorgens und abends von 85,5\% auf $82 \%$ ab (Abb. 25). Zwischen 10 und 17 Uhr wurden vermehrt ufernahe und vegetationsfreie Bereiche aufgesucht, vermutlich auf der Flucht vor Stechinsekten. Die Nutzung von Gebüschgesellschaften nahm zum Abend hin ab, nicht aber jene von Waldbereichen.

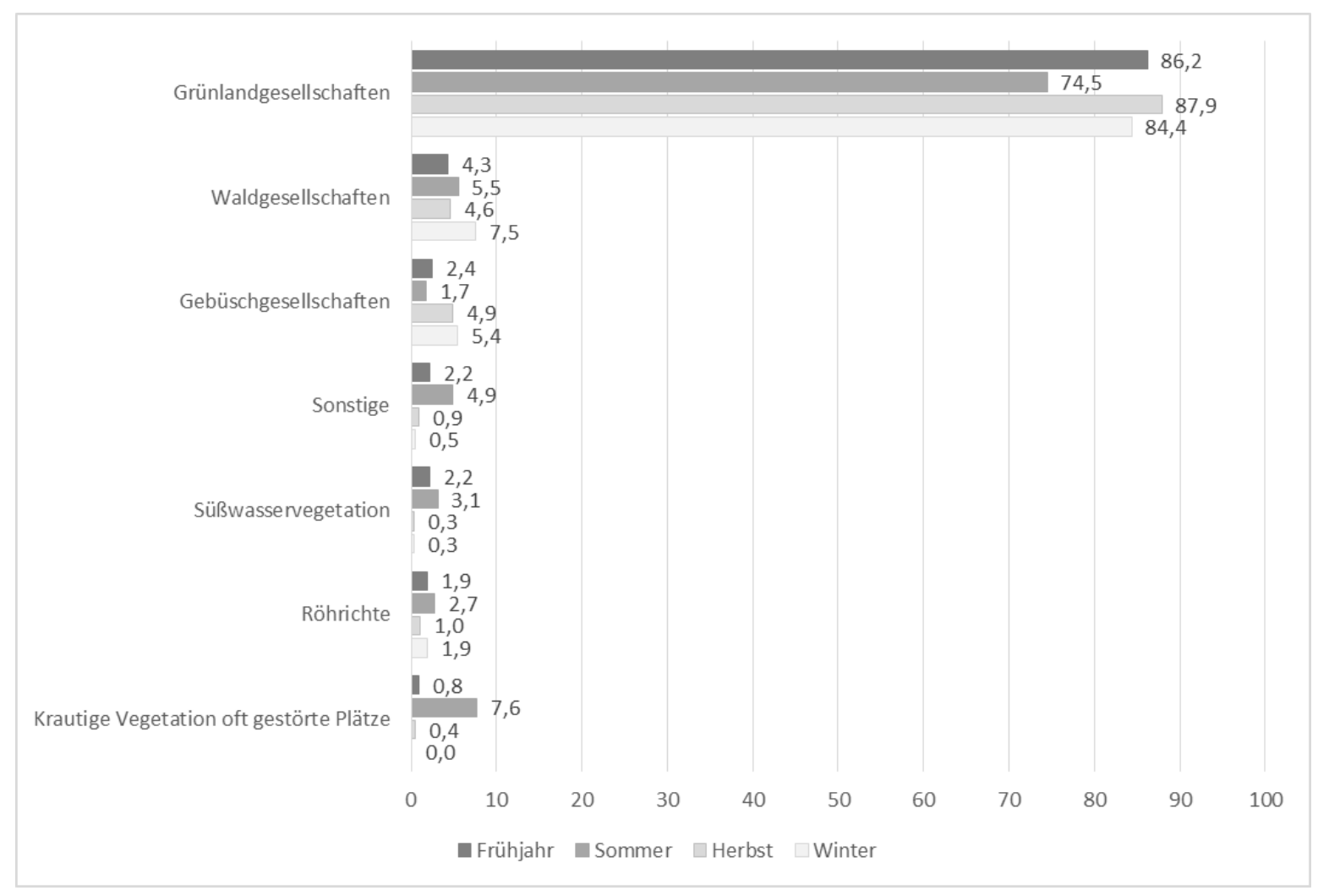

Abb. 24: Jahreszeitliche Unterschiede in der Habitatnutzung der Weidetiere (2008-2011)

Angaben in \%, Sonstige: Offene Wasserflächen, Flächen ohne Vegetation, Ausschlussfläche 


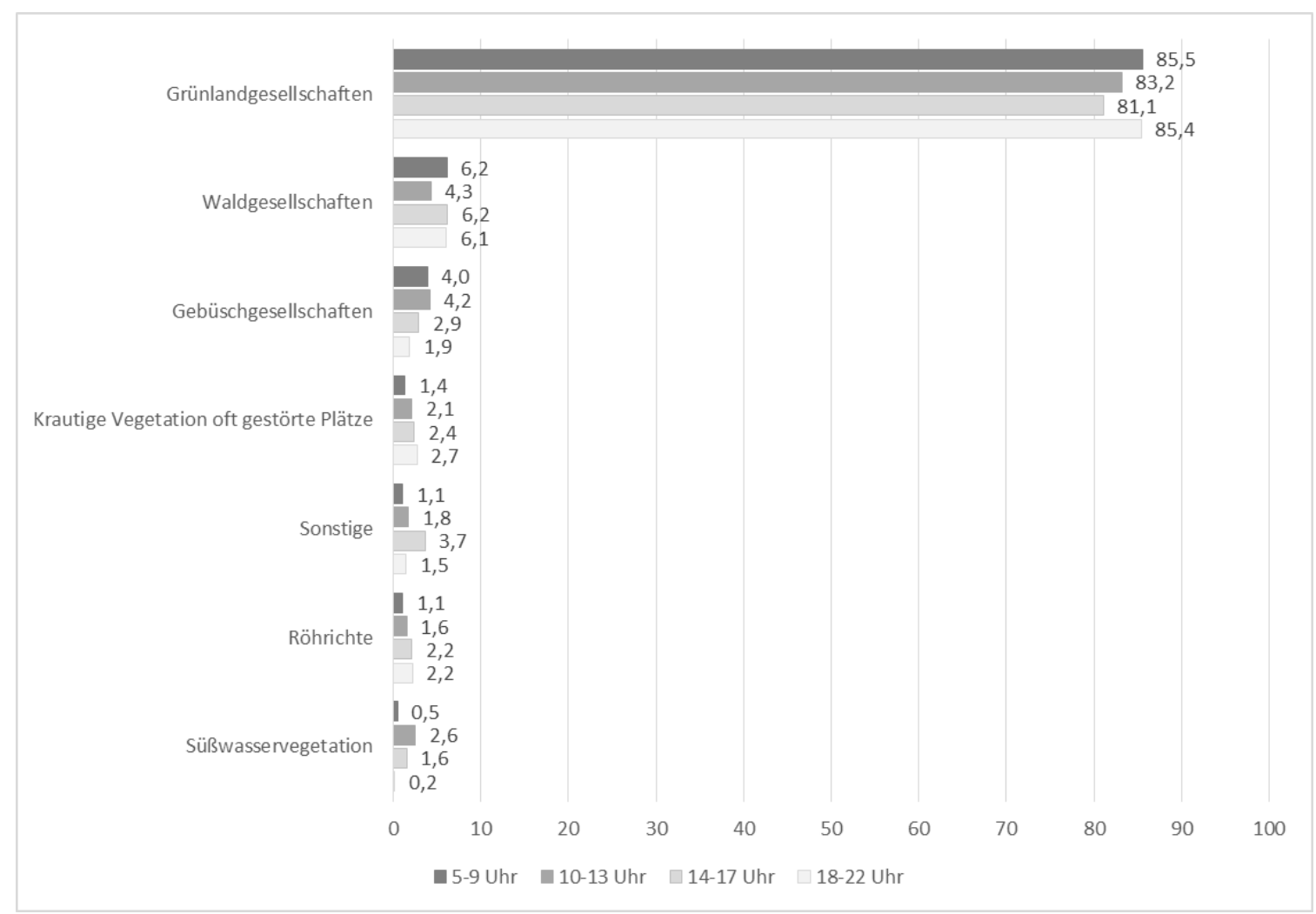

Abb. 25: Tageszeitliche Unterschiede in der Habitatnutzung der Weidetiere (2008-2011)

Angaben in \%, Sonstige: Offene Wasserflächen, Flächen ohne Vegetation, Ausschlussfläche

\subsubsection{Analyse der Raumnutzungspräferenzen}

Die oben skizzierten Ergebnisse zeigen, dass Tiere ihr Weideverhalten im Jahres- und Tagesverlauf verändern. Ihr Raumnutzungsverhalten ist von verschiedenen Faktoren abhängig. Bei Großherbivoren sind im Allgemeinen Vegetationsstrukturen, Futterwerte und bevorzugte Nahrungspflanzen von Bedeutung. Je nach Jahreszeit beeinflussen Habitatstrukturen wie Entfernungen zum Wasser oder Unterstand die Raumnutzung. Bei Pferden wirkt sich auch das Herden- und Sozialverhalten auf die Standortwahl aus.

Zunächst wurden Zusammenhänge zwischen Raumnutzung und Umweltfaktoren überprüft. Mit Hilfe einer multivariaten Regressionsanalyse wurde herausgearbeitet, welchen Faktoren in der Untersuchung die größte Bedeutung zukam.

\subsubsection{Einfluss von Strukturparametern auf die Raumnutzung}

Die oben dargestellte Habitatwahl der Weidetiere lässt einen Zusammenhang zwischen den Aufenthaltswahrscheinlichkeiten und Strukturparametern vermuten. In der Tat korrelierten die Deckungsgrade von Kräutern (Pearson-Korrelation, $r=0,91)$ und Gräsern $(r=0,63)$ als Variablen auf Habitatebene positiv mit der relativen Nutzungshäufigkeit, während sich die Deckungsgrade von Erde $(r=-0,84)$ und Streuauflagen $(r=-0,48)$ entgegengesetzt dazu verhielten. 
Weniger von Bedeutung war die Vegetationshöhe der Krautschicht $\left(V_{\text {max }}\right.$ Kraut $r=0,48 ; V_{\text {med }}$ Kraut $r=0,38)$. Auch die Höhe der Streuschicht hatte nur einen mäßigen Einfluss auf die Standortwahl $\left(V_{\max }\right.$ Streu $r=0,51 ; V_{\text {med }}$ Streu $\left.r=0,5\right)$. Zum einen unterschieden sich die Vegetationshöhen aufgrund der zunehmenden Mosaikstruktur auch innerhalb eines Habitats stark voneinander: Hochwüchsige und abgegraste Flächen lagen teils direkt nebeneinander. Zum anderen wirkte sich der Faktor Vegetationshöhe je nach Jahreszeit unterschiedlich aus: Im Sommer wurden hochwüchsige Flächen aufgrund der Stechinsekten gemieden, im Winter bei geschlossener Schneedecke hingegen bevorzugt aufgesucht, waren die überständigen Gräser dann leichter zu erreichen (siehe 5.2.3.5 Bedeutung von Umweltfaktoren bei der Raumnutzung).

\subsubsection{Einfluss des Verhaltens auf die Raumnutzung}

Bei der Hälfte der Standortbestimmungen $(n=2.586)$ wurde das Verhalten der Weidetiere erfasst. Die Pferde waren zu 65,2 \% mit Nahrungsaufnahme und zu 26,4 \% mit Ruhen beschäftigt. Seltener traten Lokomotion (7,0 \%), Komfort- (0,8 \%) oder Sozialverhalten $(0,6 \%)$ auf. Die Zahlen decken sich weitgehend mit der Auswertung der Tagesprotokolle (siehe 5.3.1 Aktivitätsbudget).

Die Wahl des Habitattyps war abhängig vom Verhalten der Tiere ( $\chi^{2}$-Anpassungstest, $\chi^{2}=372,4, d f=18$, $\mathrm{P}<0,0001)$. Die Grünland-Assoziationen dienten primär der Nahrungsaufnahme, während die Uferbereiche, der Unterstand und der Mischwald bevorzugt zum Ruhen aufgesucht wurden (Abb. 26). Röhrichte wurden hingegen eher durchwandert, da sie im Übergangsbereich vom Gebietszentrum zur Nord- und Südspitze lagen.

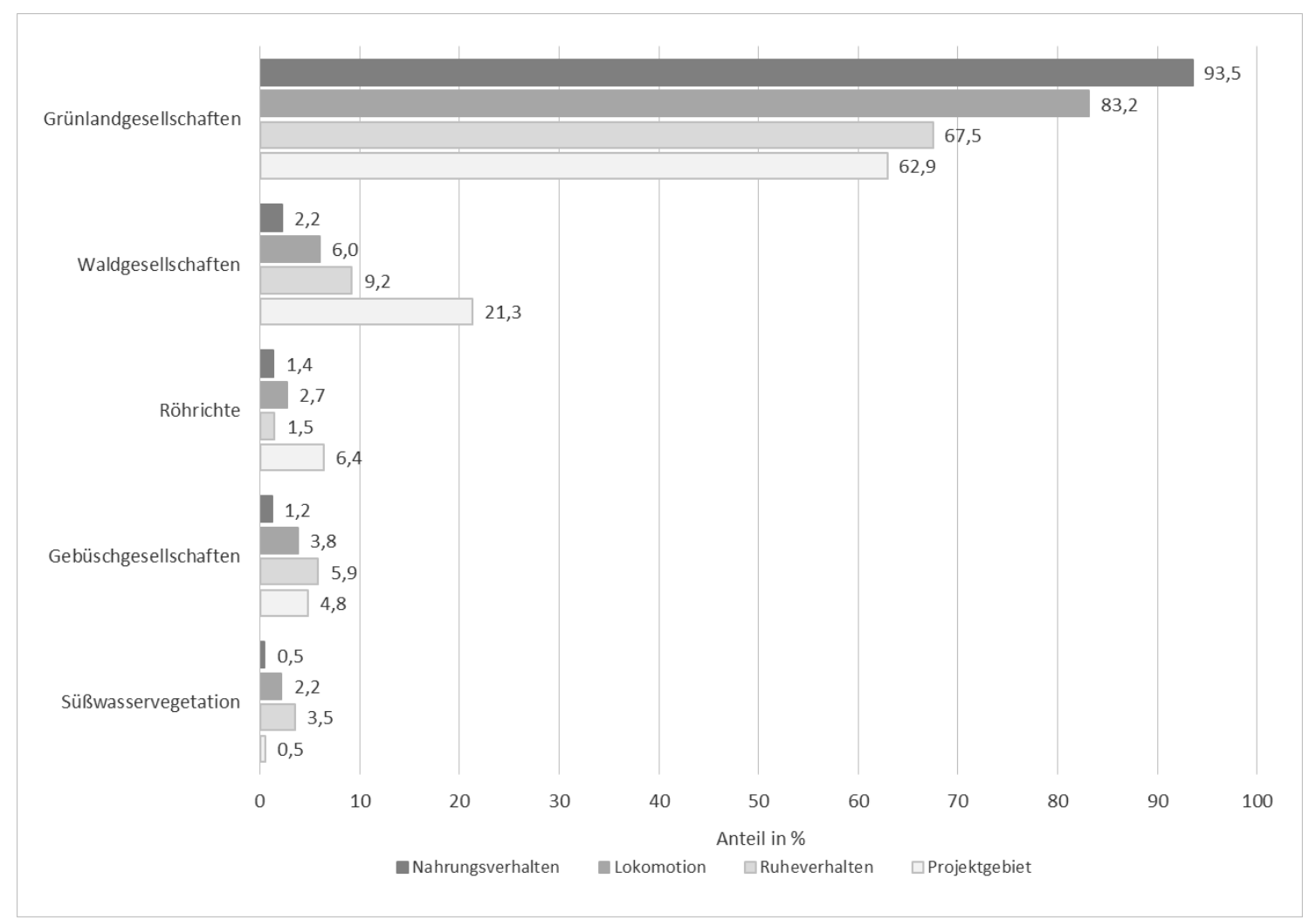

Abb. 26: Einfluss des Verhaltens auf die Habitatwahl in ausgewählten Habitattypen

Anteile von Nahrungsverhalten, Lokomotion und Ruheverhalten im jeweiligen Habitattyp im Vergleich zu seinem Anteil im Projektgebiet (in \%) 


\subsubsection{Einfluss des Wetters auf die Raumnutzung}

Die Standortwahl der Langeländer Ponys wurde von Wind, Niederschlag und Temperaturen beeinflusst (u. a. Delling 2009, Rödde 2009, Stahlhut 2009, Uthoff 2010, Lohrengel 2011, Pötzinger 2011). Deutlich wurde der Wettereinfluss vor allem bei Wetterextremen im Sommer und Winter.

Am stärksten veränderte sich die Raumnutzung bei Niederschlag. Regen allein hatte dabei kaum Einfluss: Er führte weder zu einer Erhöhung des täglichen Waldaufenthaltes noch zu einer Verlagerung der Tagesaktivitäten in geschützte Gebiete. Mit zunehmendem Schneeaufkommen nutzten die Pferde jedoch fast ausschließlich die zentralen Gebiete, während küstennahe Areale gemieden wurden. Im Gebietszentrum war es windgeschützter, die Nahrungsverfügbarkeit bei Schnee höher. Das Futter musste unter der Schneedecke zunächst mühsam hervorgescharrt werden, es erscheint daher sinnvoll, dass die Pferde bei geschlossener Schneedecke vor allem die nährstoffreichen Flächen im Zentrum aufsuchten. Der Wald, die Süd- und Nordspitze wurden kaum aufgesucht. Letztere waren durch ihre Lage bei Schnee schwer erreichbar, ein Aufsuchen der dortigen Weiden zu energieaufwändig. Die Wegstrecken, die ein Tier durchschnittlich zwischen 8-17 Uhr zurücklegte, waren in den Wintermonaten nur halb so lang wie im Sommer (Tab. 11).

Bei zunehmender Windstärke und niedrigen Temperaturen suchten die Pferde bevorzugt windgeschützte Areale auf. Dies waren vor allem die Feldgehölze, Laubwälder und Waldränder sowie die Weiden an der Nordspitze. Bei hohen Temperaturen wurden hingegen gezielt die küstennahen, windexponierten Weiden aufgesucht, die Abkühlung und Schutz von Stechinsekten boten. Bei Windstille im Sommer wichen die Tiere auf Feldgehölze und Baumschatten aus, im Jahr 2008 war vor allem der Unterstand ein beliebter Ort zum Dösen, da dieser aufgrund seiner Bauweise die Eigenschaften eines Windkanals hatte. An heißen Sommertagen wurden zudem vermehrt die Uferbereiche der großen Gewässer aufgesucht.

Die Umwelttemperaturen wirkten sich im Winter direkt auf die Futterwahl aus (Pötzinger 2011). Bei Temperaturen unter dem Gefrierpunkt wählten die Tiere neben Gras häufiger Brombeerranken und junge Triebe, während Hochstauden und Kräuter erst bei etwas höheren Temperaturen gefressen wurden (Tab. 12). Beim Gras als Hauptnahrung änderte sich mit zunehmender Schneedecke die Vegetationshöhe der Nahrungspflanzen (Tab. 13): Ohne Schnee wurde zu $95 \%$, bei geschlossener Schneedecke nur zu 79 \% kurzes, frisches Gras gefressen, dagegen stieg der Anteil an hohem Gras von $2 \%$ auf respektive 21 \% bei Schnee an. Überständige Gräser stellten somit eine wichtige Nahrungsquelle bei hohem Schneeaufkommen dar.

Tab. 11: Bewegungsmuster der Weidetiere im Projektgebiet zu unterschiedlichen Jahreszeiten

Gemittelte Werte von drei Tieren in Metern zwischen 8-17 Uhr

\begin{tabular}{lll}
\hline & pro Tag & pro Std. \\
\hline Jan 11 & 1.629 & 181 \\
Feb 09 & 1.359 & 151 \\
Mrz 09 & 2.322 & 258 \\
Jul 08 & 2.726 & 303 \\
\hline
\end{tabular}


Tab. 12: Futterwahl der Weidetiere im Januar 2011 in Abhängigkeit von der Umgebungstemperatur nach Pötzinger (2011) Gemittelte Werte von drei Tieren, Angabe von Beobachtungsminuten in \%

\begin{tabular}{lllll}
\hline & \multicolumn{2}{l}{ Minuten in } & & \\
Nahrungspflanzen & gesamt & $\mathbf{- 3 , 5}$ bis $\mathbf{- 0 , 1} \mathbf{~}^{\circ} \mathbf{C}$ & $\mathbf{0}$ bis $\mathbf{~}{ }^{\circ} \mathbf{C}$ & $\mathbf{3 , 1}$ bis $\mathbf{6 , 4}{ }^{\circ} \mathbf{C}$ \\
\hline Gras & 93,3 & 91,5 & 92,6 & 94,6 \\
Hohes Gras & 3,8 & 4,4 & 6,1 & 1,8 \\
Hochstauden & 1,0 & 0,8 & - & 1,9 \\
Brombeere & 0,7 & 1,5 & 0,1 & 0,8 \\
Gehölz & 0,3 & 0,6 & 0,1 & 0,3 \\
Krautige Vegetation & 0,3 & - & 0,7 & 0,1 \\
Gebüsch & 0,2 & - & 0,3 & 0,2 \\
Brennnessel & 0,1 & 0,1 & - & 0,2 \\
Junge Triebe & 0,1 & 0,6 & - & - \\
Sonstiges & 0,3 & 0,6 & 0,2 & 0,3 \\
\hline
\end{tabular}

Tab. 13: Futterwahl der Weidetiere im Januar 2011 in Abhängigkeit vom Schneeaufkommen nach Pötzinger (2011)

Gemittelte Werte von drei Tieren, Angabe von Beobachtungsminuten in \%

\begin{tabular}{lllll}
\hline & \multicolumn{2}{l}{ Minuten in \% } & & \\
Nahrungspflanzen & gesamt & ohne Schnee & $\begin{array}{l}\text { offene } \\
\text { Schneedecke }\end{array}$ & $\begin{array}{l}\text { geschlossene } \\
\text { Schneedecke }\end{array}$ \\
\hline Gras & 93,3 & 95,3 & 93,3 & 78,5 \\
Hohes Gras & 3,8 & 2,0 & 2,8 & 20,6 \\
Hochstauden & 1,0 & 1,3 & 0,6 & - \\
Brombeere & 0,7 & 0,6 & 1,2 & - \\
Gehölz & 0,3 & 0,2 & 0,5 & 0,1 \\
Krautige Vegetation & 0,3 & 0,2 & 0,4 & - \\
Gebüsch & 0,2 & 0,1 & 0,1 & 0,8 \\
Brennnessel & 0,1 & 0,2 & 0,1 & - \\
Junge Triebe & 0,1 & - & 0,5 & - \\
Sonstiges & 0,3 & 0,1 & 0,7 & - \\
\hline
\end{tabular}

\subsubsection{Individuelle Unterschiede in der Raumnutzung}

In der Langeländer Herde traten kaum individuelle Unterschiede in der Raumnutzung auf (Tab. 14). Die beiden Stuten, die Tiere 2 und 3, hielten sich etwas häufiger im Grünland auf als der Hengst, der wiederum mehr Zeit im Wald und am Ufer verbrachte. Ob dies geschlechtsspezifische oder individuelle Unterschiede waren, konnte aufgrund der geringen Stichprobengröße nicht geklärt werden. Ein möglicher Grund für die Bevorzugung von Weideflächen könnte der höhere Energiebedarf der tragenden und laktierenden Stuten sein. Sie zeigten in gleicher Weise einen höheren Fressanteil im Tagesaktivitätsbudget und seltenes Ruhen (siehe 5.3 Verhalten der Weidetiere). 
Tab. 14: Individuelle Unterschiede in der Raumnutzung zwischen den Fokustieren

Gemittelte Werte von 2008-2011; Sonstige: Offene Wasserflächen, Flächen ohne Vegetation, Ausschlussfläche

\begin{tabular}{llll}
\hline & \multicolumn{2}{l}{ Häufigkeiten in \% } & \\
Habitate nach Formationen & Tier 1 & Tier 2 & Tier 3 \\
\hline Grünlandgesellschaften & 79,5 & 84,7 & 85,4 \\
Waldgesellschaften & 6,5 & 5,2 & 4,6 \\
Gebüschgesellschaften & 3,9 & 3,0 & 3,4 \\
Krautige Vegetation oft gestörte Plätze & 2,8 & 2,5 & 1,1 \\
Sonstige & 2,8 & 2,0 & 2,3 \\
Röhrichte & 2,3 & 1,2 & 1,9 \\
Süßwasservegetation & 2,1 & 1,4 & 1,3 \\
\hline
\end{tabular}

\subsubsection{Bedeutung von Umweltfaktoren bei der Raumnutzung}

Die Aufenthaltsorte der Pferde im Langeländer Projektgebiet wurden maßgeblich vom Zugang zu Wasserquellen und von der Feuchtezahl der Vegetation beeinflusst (Tab. 15). Insbesondere während der Sommermonate hielten sich die Tiere bevorzugt in der Nähe von Teichen und Weihern auf. Höher gelegene, trockene Flächen wurden jetzt gemieden.

Wichtig war den Tieren ein ausgewogenes Nahrungspflanzenangebot. Häufigkeiten und Evenness waren positiv miteinander korreliert. Vor allem in den Sommermonaten hatten artenreiche Gesellschaften eine hohe Attraktivität und boten den Pferden ein abwechslungsreiches Nahrungsangebot.

Einfluss auf den Aufenthaltsort hatte ferner die Vegetationshöhe der Krautschicht. Ein regelmäßiger Fraß fördert den Neuaufwuchs, so dass Pferde bevorzugt solche Stellen aufsuchten, die sie bereits zuvor abgegrast hatten, während überständige Gräser eher verschmäht wurden. Hinzu kommt die Wechselwirkung von Vegetationshöhe und Belastung durch Stechinsekten: Da hochwüchsige Flächen lästige Stechsauger stärker anlockten, wirkte sich die Höhe der Krautschicht im Sommerhalbjahr stärker auf die Habitatnutzung aus. Aus demselben Grund suchten die Pferde im Sommer Areale mit einer lückigen Vegetationsdecke auf, wie sie vielerorts im Uferbereich auftrat. Im Winterhalbjahr präferierten sie hingegen Flächen mit einer geschlossenen Krautschicht, boten ihnen diese mehr Nahrung. Der Elektrozaun wurde zu jeder Jahreszeit gemieden.

Wälder und Gehölzgruppen waren nur im Winter von Bedeutung. Die Tiere suchten hier Schutz vor kalter Witterung. Ihre Blätter, Knospen und Rinde stellten besonders bei Schneebedeckung - neben den überständigen Gräsern - eine wertvolle Nahrungsquelle für die Ponys dar. Durch den Vergleich von Sommer- und Winterhalbjahr konnte auch nachgewiesen werden, dass die Tiere in der Hauptvegetationsperiode die nährstoffreichen Gebiete präferierten, während sie sich im Winterhalbjahr auf weniger stickstoffreiche Flächen zurückzogen.

Die Ergebnisse zeigen, dass sich die Bedürfnisse der Weidetiere im Jahresverlauf veränderten. Ein reich strukturierter Lebensraum mit freiem Zugang zu Gewässern und Gehölzen ist somit bei einer Ganzjahresbeweidung von großer Bedeutung. Auch nährstoffärmere Flächen, magere Standorte und Gehölze werden in den kargen Wintermonaten beweidet. 
Tab. 15: Ergebnis der schrittweisen multiplen Regressionsanalyse (Poisson-Regression) zu den Faktoren, die das Raumnutzungsverhalten der Pferde im Untersuchungszeitraum steuerten

Signifikanz: $* 0,05 ; * * 0,01 ; * * * 0,001$

\begin{tabular}{|c|c|c|c|c|}
\hline Modell & Variablen & Parameter & $\begin{array}{l}\text { Standard- } \\
\text { fehler }\end{array}$ & Signifikanz \\
\hline \multirow[t]{10}{*}{ Habitatnutzung 2008-2011 } & Entfernung von Gewässern & $-0,371$ & 0,011 & $* * *$ \\
\hline & Evenness-Index & 0,251 & 0,013 & $* * *$ \\
\hline & Feuchtezahl & 0,204 & 0,017 & $* * *$ \\
\hline & Vegetationshöhe der Krautschicht & $-0,158$ & 0,022 & $* * *$ \\
\hline & Höhe & $-0,143$ & 0,015 & $* * *$ \\
\hline & Entfernung vom Zaun & 0,123 & 0,011 & $* * *$ \\
\hline & Reaktionszahl & 0,084 & 0,017 & $* * *$ \\
\hline & Shannon-Index & 0,050 & 0,014 & $* * *$ \\
\hline & Entfernung von Gehölzen & $-0,038$ & 0,012 & $* *$ \\
\hline & Deckungsgrad der Krautschicht & 0,015 & 0,007 & * \\
\hline \multirow[t]{10}{*}{ Habitatnutzung im Sommerhalbjahr } & Entfernung von Gewässern & $-0,438$ & 0,015 & $* * *$ \\
\hline & Evenness-Index & 0,291 & 0,019 & $* * *$ \\
\hline & Höhe & $-0,229$ & 0,021 & $* * *$ \\
\hline & Feuchtezahl & 0,222 & 0,021 & $* * *$ \\
\hline & Vegetationshöhe der Krautschicht & $-0,210$ & 0,029 & $* * *$ \\
\hline & Entfernung vom Zaun & 0,138 & 0,015 & $* * *$ \\
\hline & Nährstoffzahl & 0,111 & 0,034 & $* *$ \\
\hline & Reaktionszahl & 0,105 & 0,041 & $*$ \\
\hline & Shannon-Index & 0,094 & 0,018 & $* * *$ \\
\hline & Deckungsgrad der Krautschicht & $-0,043$ & 0,009 & $* * *$ \\
\hline \multirow[t]{8}{*}{ Habitatnutzung im Winterhalbjahr } & Entfernung von Gewässern & $-0,267$ & 0,018 & $* * *$ \\
\hline & Feuchtezahl & 0,183 & 0,023 & $* * *$ \\
\hline & Evenness-Index & 0,159 & 0,018 & $* * *$ \\
\hline & Entfernung von Gehölzen & $-0,139$ & 0,018 & $* * *$ \\
\hline & Deckungsgrad der Krautschicht & 0,135 & 0,013 & $* * *$ \\
\hline & Vegetationshöhe der Krautschicht & $-0,120$ & 0,032 & $* * *$ \\
\hline & Nährstoffzahl & $-0,097$ & 0,028 & $* * *$ \\
\hline & Entfernung vom Zaun & 0,077 & 0,016 & $* * *$ \\
\hline
\end{tabular}




\subsection{Verhalten der Weidetiere}

\subsubsection{Aktivitätsbudget}

Die Weidetiere verbrachten durchschnittlich $67 \%$ des Tages mit der Nahrungsaufnahme (Abb. 27). Nachtzeiten blieben hier unberücksichtigt. Die Tiere bevorzugten das Weiden im Stand, die häufigste Verhaltensweise war das Stehen und Fressen, bei dem weniger als 10 Meter pro Minute zurückgelegt werden. Andere Aktivitäten der Nahrungsaufnahme wie Fressen von Erde, Knabbern an Ästen oder Scharren am Boden wurden nur selten beobachtet, ebenso das Trinken $(0,1 \%)$.

Die zweitwichtigste Tagesaktivität war das Ruhen (23,7\%). Größtenteils dösten die Tiere dabei im Stehen, ein Kauern oder Liegen am Boden trat selten auf. Auch beim Lokomotionsverhalten, das einen Anteil von 8,5\% am Tagesbudget hatte, dominierten Bewegungsformen wie Schritt oder Stehen. Nur in Gefahrensituationen oder bei größeren Ortswechseln traten Galoppieren oder Traben auf. Die Kategorien Schritt und Stehen schließen zu einem gewissen Anteil soziale Verhaltensweisen mit ein, wie Folgen, Aufsuchen oder Meiden bei der Gangart Schritt und Kraulen beim Stehen.

Das Komfortverhalten $(0,7 \%)$ und der Stoffwechsel $(0,3 \%)$ spielten eine untergeordnete Rolle im Aktivitätsbudget. Ihr Komfortbedürfnis stillten die Ponys größtenteils durch ein Reiben an Bäumen, Zaunpfählen oder anderen Herdenmitgliedern. Wälzen am Boden oder Kratzen waren selten. Beim Stoffwechsel traten Koten und Harnen ungefähr gleich häufig auf.

\subsubsection{Jahresrhythmik}

Bei der Nahrungsaufnahme und beim Ruheverhalten zeigten sich deutliche Unterschiede zwischen den Jahren (Abb. 28), was die Bedeutung von mehrjährigen Studien unterstreicht. Schwankungen können einerseits wetterbedingt sein: In wärmeren und niederschlagsärmeren Jahren nahm das Ruheverhalten zu, die Nahrungsaufnahme hingegen ab. Der höhere Fressanteil im Jahr 2010 kann auch auf das schlechtere Nahrungsangebot aufgrund zunehmender Herdengröße und längerer Beweidungsdauer im Projektgebiet zurückgeführt werden. In warmen Jahren wurde zudem deutlich mehr Komfortverhalten beobachtet.

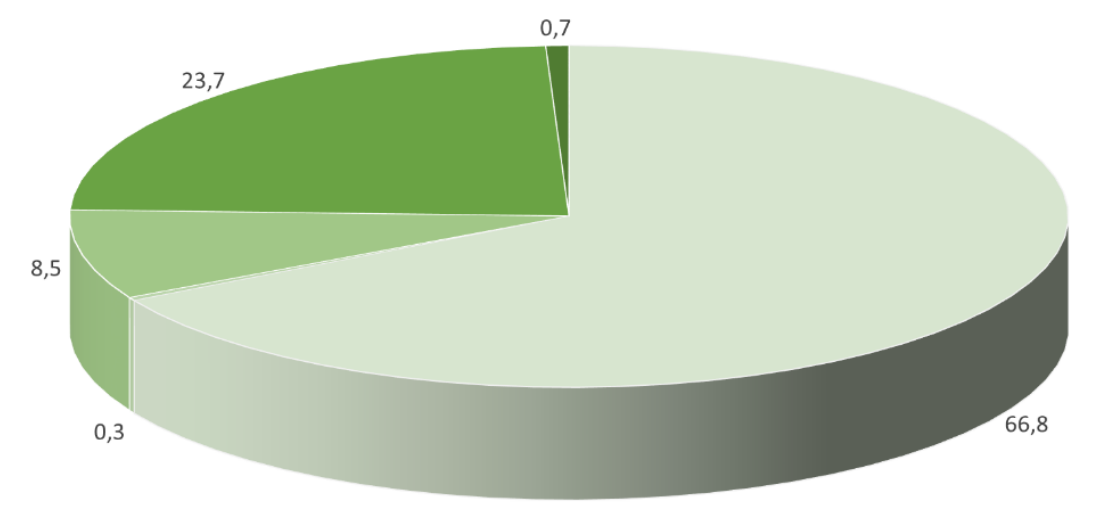

Nahrungsaufnahme $=$ Stoffwechsel $=$ Lokomotion - Ruheverhalten - Komfortverhalten

Abb. 27: Prozentuale Anteile der Verhaltenskategorien an der Gesamtaktivität in den Jahren 2008-2010

Angabe in \%, Mittelwerte der 3 Fokustiere, ohne Sozialverhalten 


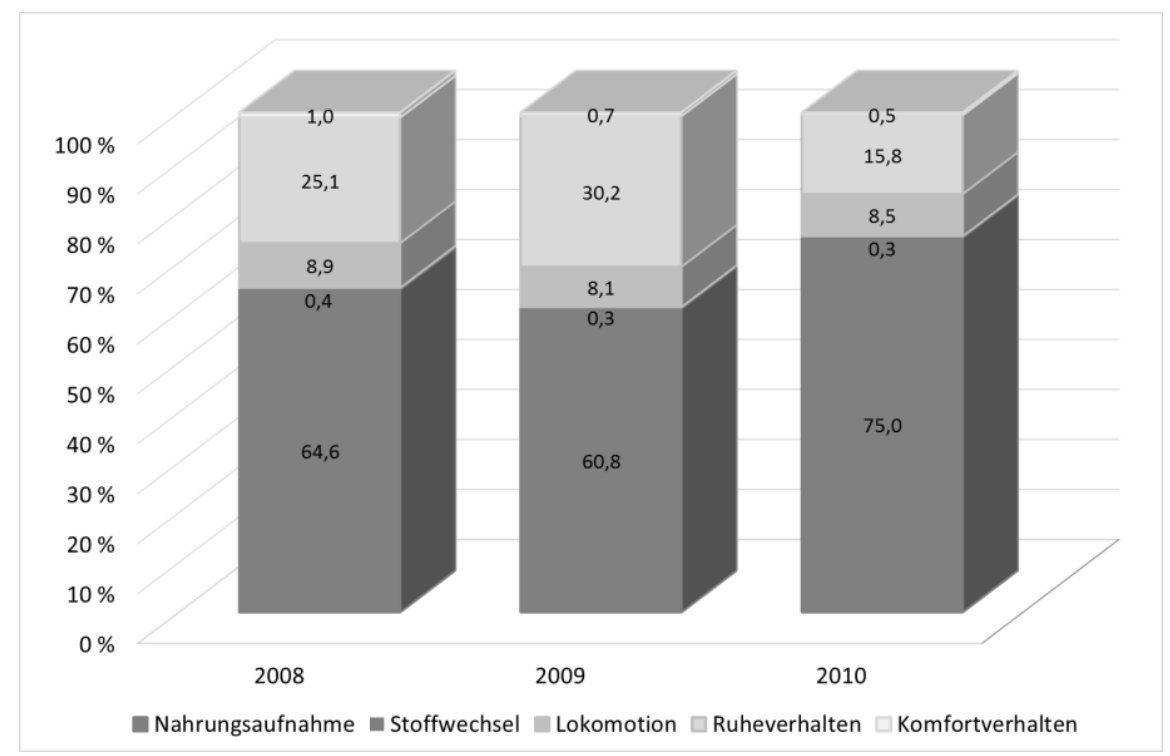

Abb. 28: Anteile der Verhaltensweisen im Jahresvergleich 2008-2010

Angaben in \%; Mittelwerte der 3 Fokustiere

Im Spätsommer fraßen die Tiere etwas häufiger als im Frühling oder Winter, vermutlich als Vorbereitung auf die kräftezehrende Winterzeit. In letzterer bewegten sich die Pferde deutlich weniger und ruhten vermehrt zur Minimierung des Energieaufwandes, während im Frühling ein stärkerer Bewegungsdrang bei den Tieren zu beobachten war (ohne Abb.). Dies deckt sich mit den Ergebnissen der Raumnutzung, die zeigten, dass der Aktionsradius in den Frühlings- und Sommermonaten größer war als im Winter (s. Tab. 11). Die Herde legte größere Entfernungen zu den bevorzugten Nahrungsflächen zurück. Die Anteile von Komfortverhalten und Stoffwechsel variierten hingegen kaum zwischen den Jahreszeiten.

\subsubsection{Tagesrhythmik}

Die Langeländer Herde zeigte die für Pferde typische Tagesrhythmik und Synchronisierung von Verhaltensweisen unter Herdenmitgliedern. Die Tiere weideten verstärkt in den Morgen- und Abendstunden (Abb. 29). Die Nahrungsaufnahme wurde am späteren Vormittag von einer längeren Ruhepause unterbrochen, in der die Herde meist gemeinschaftlich döste. Diese morgendliche Ruhephase konnte das ganze Jahr über beobachtet werden, im Frühling war sie ausgedehnter (von 9 und $13 \mathrm{Uhr}$ ), aber weniger synchron als zu anderen Jahreszeiten.

Die anschließende Fressphase ging häufig einher mit einem Ortswechsel, so dass die Lokomotion nach der Ruhepause zunahm. Am späten Nachmittag trat eine zweite Ruhephase auf, so dass es im Tagesverlauf drei Fressphasen gab. Im Winter fiel die dritte Phase bereits in die Abenddämmerung, wo keine Datenaufnahme mehr möglich war.

Der Tagesrhythmus der Herde war besonders synchron in der kalten Jahreszeit. Vermutlich boten gemeinsame Ruhepausen mehr Schutz vor Kälte. Auch fanden in dieser Jahreszeit weder Fohlenaufzucht noch Paarungen statt, die zu unterschiedlichen Verhaltensanteilen sowie zu einem intensiveren Sozialverhalten geführt hätten (s. 5.3.2 Sozialverhalten). 


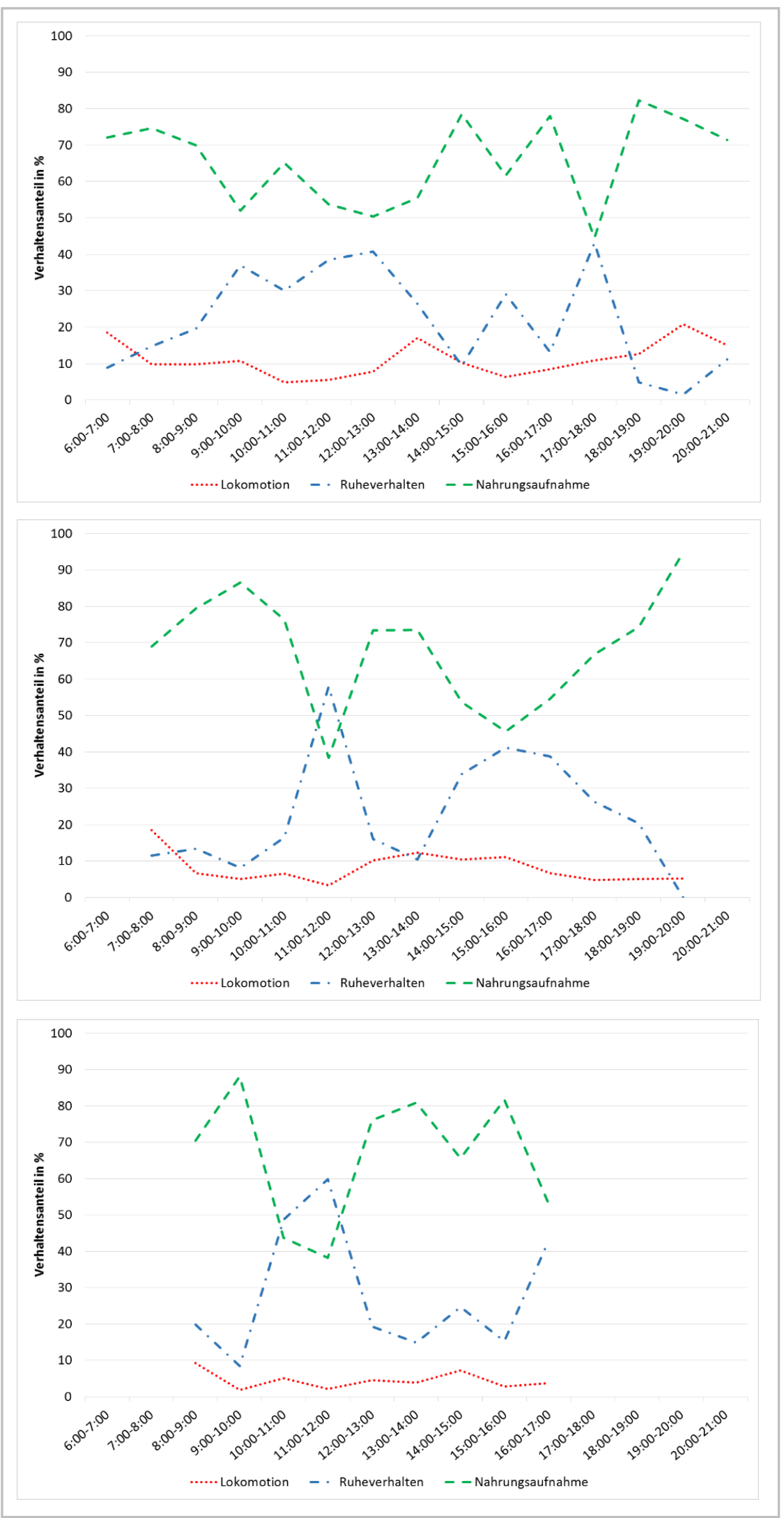

Abb. 29: Tagesrhythmus der Weidetiere im Frühjahr (oben), Spätsommer (Mitte) und Winter (unten) im Beobachtungszeitraum von 2008-2010

Angaben in \% im jeweiligen Stundenabschnitt; Mittelwerte der 3 Fokustiere 


\subsubsection{Individuelle Unterschiede im Verhalten der Fokustiere}

Neben jahres- und tageszeitlichen Schwankungen waren auch individuelle Unterschiede zwischen den Fokustieren zu erkennen. Der Hengst, der nicht mit Fohlenaufzucht beschäftigt war, weidete im Durchschnitt eine Stunde weniger pro Tag als die Stuten (m: 61,1\%, w: 69,6\%). Stattdessen bewegte er sich (m: 11,4\%, w: 7,0 \%) und ruhte häufiger (m: 25,9\%, w: 22,6\%). Auch wälzte er sich doppelt so häufig oder rieb sich an Gegenständen. Das häufigere Harnen ( $m: 0,5 \%$, w: 0,2 \%) ist auf seine Rolle als Leithengst zurückzuführen, da Urinieren oft im Zusammenhang mit Territorial- und Sexualverhalten stattfand.

Auch die beiden Stuten unterschieden sich voneinander hinsichtlich ihres Komfortverhaltens und ihrer Weidedauer: Tier 3 weidete im Durchschnitt täglich eine viertel Stunde mehr als Tier 2 (gemittelt auf 9 Beobachtungstage zwischen 2008-2010). Die geschlechtsspezifischen Differenzen waren jedoch markanter als individuelle Unterschiede unter den Fokustieren.

\subsubsection{Einfluss des Wetters auf das Verhalten}

Die Außentemperaturen beeinflussten signifikant die Nahrungsaufnahme und das Ruheverhalten der Tiere. Sowohl bei starkem Niederschlag als auch bei Schnee nahm das Ruheverhalten im Untersuchungszeitraum um rund 5-15 \% zu (s. Delling 2009, Lohrengel 2011, Pötzinger 2011). Besonders hoch war der Anteil an Dösen bei Temperaturen unter dem Gefrierpunkt (zu $22 \%$ ) und bei geschlossener Schneedecke (34\%).

Auch im Sommer wirkte sich das Wetter auf das Verhalten der Exmoor-Ponys aus. An heißen Tagen standen die Tiere häufig dicht und antiparallel zusammen, um durch ein fortlaufendes Wedeln mit dem Schweif blutsaugende Insekten zu verscheuchen (vgl. Keiper \& Berger 1982). Im Winter hingegen wirkte der enge Körperkontakt dem Verlust von Körperwärme entgegen. Die Individualdichten waren zu diesen Jahreszeiten deutlich geringer als im Frühjahr oder Herbst.

Im Winter wurde zudem das von Mc Donnell (2003) beschriebene Sonnenbaden beobachtet. Die Pferde suchten sonnige, geschützte Flecken im Gelände auf und wärmten ihren Körper auf. 


\subsubsection{Sozialverhalten}

Im Beobachtungszeitraum wurden 34 soziale Verhaltensweisen dokumentiert. Unter Sozialverhalten sind alle freundlichen oder aggressiven Verhaltensweisen zwischen zwei oder mehreren Herdenmitgliedern zu verstehen. Im weiteren Sinne zählen hierzu auch das Territorial- und Sexualverhalten sowie das Sichern bei Gefahren.

Die Interaktionen der Fokustiere waren überwiegend freundschaftlich (Abb. 30): Freundliche Verhaltensweisen traten dreimal häufiger auf als aggressive (409 zu 128). Auch in Konfliktsituationen dominierten schwach aggressive Gesten wie Drohen oder Zwicken. Die häufigste soziale Verhaltensweise war das Kraulen (21 \%): Es verbindet Körper- mit Kontaktpflege und dauerte wenige Sekunden bis mehrere Minuten. Einer gegenseitigen Fellpflege war häufig ein Aufsuchen des Kraulpartners vorgeschaltet, so dass diese Verhaltensweise am zweithäufigsten (14 \%) beobachtet wurde.

Territorialverhalten trat selten und ausschließlich beim Hengst auf: Nur 4mal zeigte er territoriales Imponieren, 6mal ein Markieren seines Revieres. Grund hierfür ist vermutlich die fehlende männliche Konkurrenz. Sexualverhalten wurde in den 111 Beobachtungsstunden $124 \mathrm{mal}$ dokumentiert. Es trat überwiegend beim Hengst (Tier 1: $94 \%$, Tier 2: $2 \%$, Tier 3: $4 \%$ ) und zur Paarungszeit im Frühjahr (Frühjahr: 69 \%, Spätsommer: 25 \%, Winter: 6 \%) auf. Häufige Verhaltensweisen waren dabei Ausschachten, Flehmen, Riechen am weiblichen Harn sowie das Vorspiel.

Das Sichern, also das Aufwerfen des Kopfes in Habachtstellung, war eine häufige Verhaltensweise des Hengstes. Es wurde insgesamt 23mal (Tier 1: $75 \%$, Tier 2: $9 \%$, Tier 3: $13 \%$ ) dokumentiert. Der Hengst kam damit seiner Rolle als Beschützer der Herde nach. Gesichert wurde bei ungewohnten Geräuschen und Bewegungen im Umfeld der Herde.

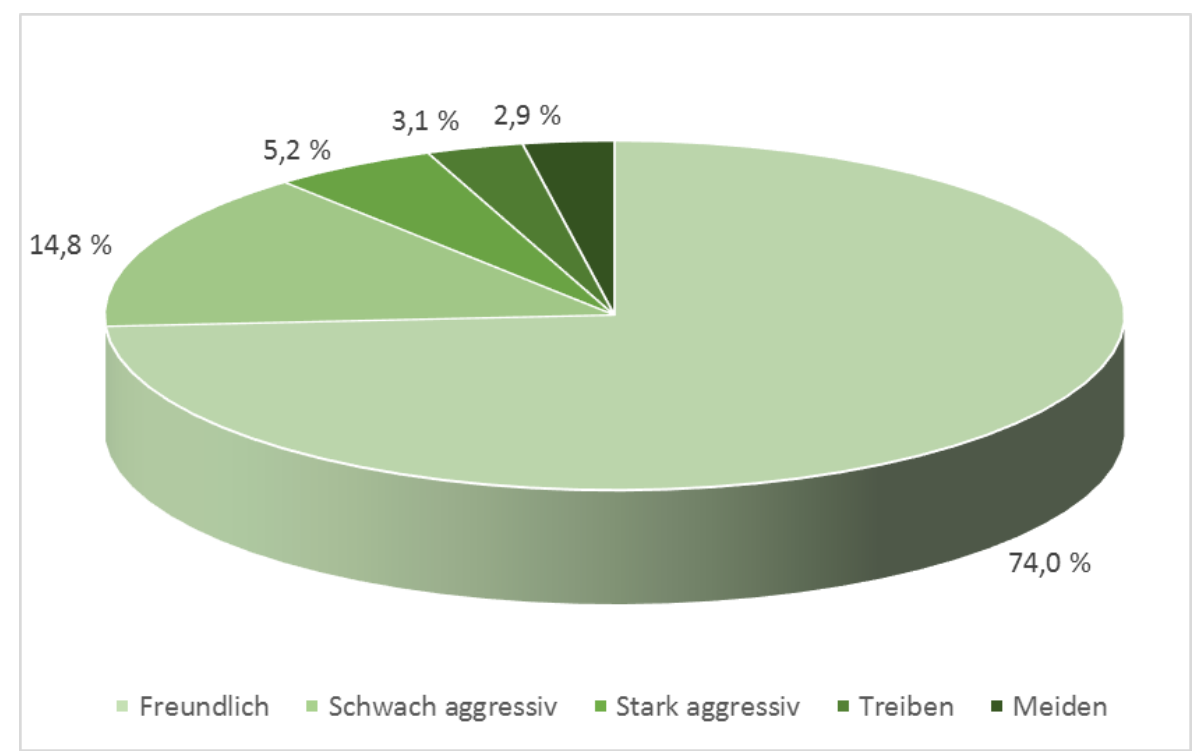

Abb. 30: Häufigkeiten sozialer Verhaltensweisen zwischen den Jahren 2008-2010

Mittelwerte der Fokustiere

schwach aggressiv = Zwicken, Drohen, Beißdrohen, Schlagdrohen; stark aggressiv = Beißen, Schlagen, Vertreiben, Verfolgen, Angehen; freundlich = Summe aller freundlichen Verhaltensweisen, s. Tab. 9 


\subsubsection{Jahresrhythmik}

Soziale Verhaltensweisen nahmen im Beobachtungszeitraum zu (Abb. 31). Das Heranwachsen der Junghengste verstärkte die Konkurrenz zum Leithengst (Tier 1). Die Zunahme an fortpflanzungsfähigen Stuten erklärt die vermehrten territorialen und sexuellen Verhaltensweisen, die steigende Herdengröße die Zunahme an freundlichen und aggressiven Verhaltensweisen zwischen Hengst und Herdenmitgliedern. Das Verhältnis von freundlichen zu aggressiven Verhaltensweisen blieb jedoch unverändert (2008: 73 zu $27 \%$; 2010: 77 zu $23 \%$ ).

Die intensivste Zeit im Jahr war das Frühjahr (Abb. 31), in dem die Geburt der Fohlen und die anschließende Paarung die Anzahl der Interaktionen deutlich erhöhte, auch wenn der Zusammenhang zwischen Jahreszeit und Sozialverhalten statistisch nicht signifikant war ( $\mathrm{H}$-Test nach Kruskal-Wallis, $n=3$, $\mathrm{p}>0,05)$. Im Winter wurden selten soziale Verhaltensweisen beobachtet, gleichwohl sich die Tiere beim Ruhen sehr nah kamen.

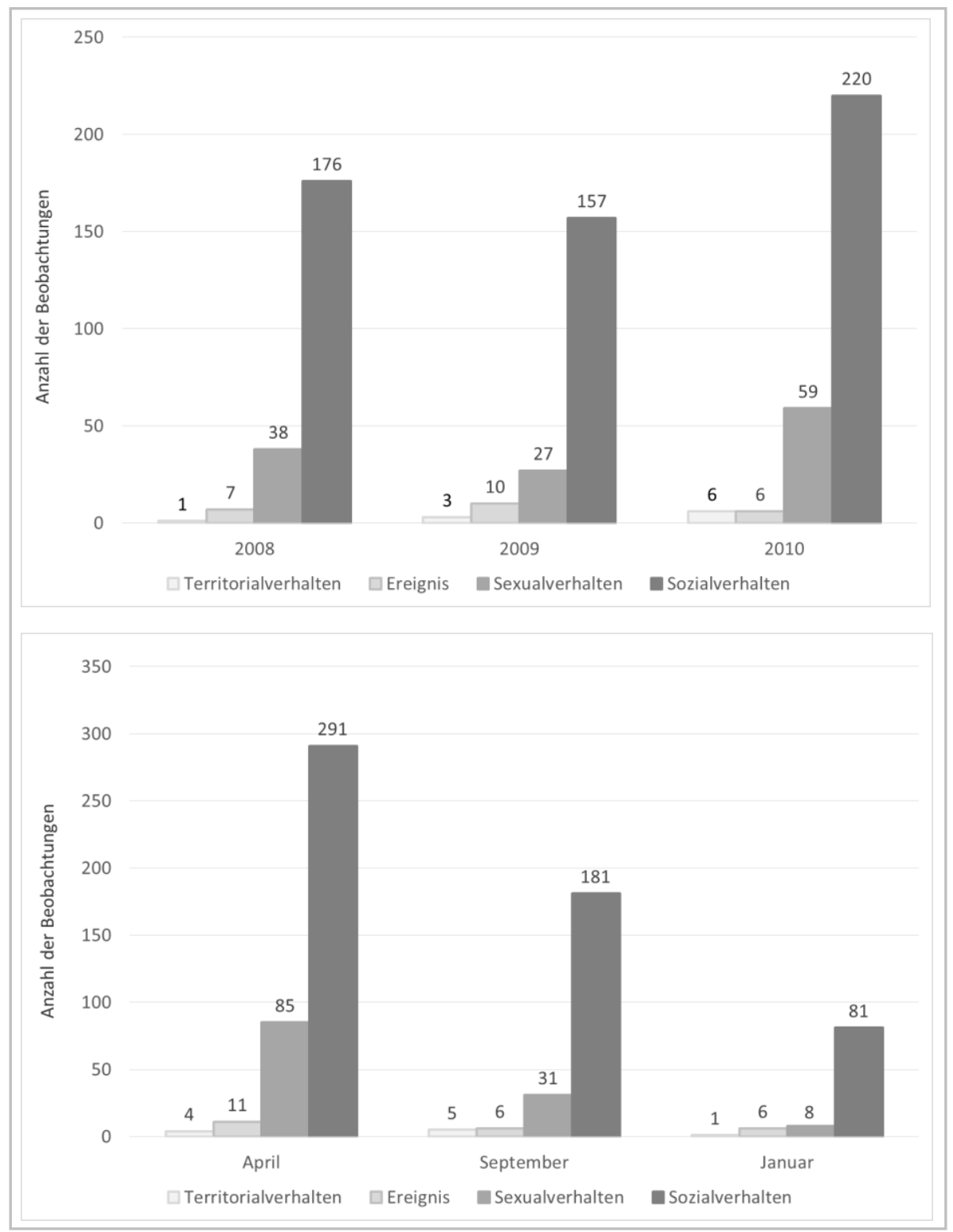

Abb. 31: Häufigkeiten von Sozial-, Territorial- sowie Sexualverhaltens im Jahres- (oben) und jahreszeitlichen (unten) Vergleich Mittelwerte der Fokustiere zwischen den Jahren 2008-2010 


\subsubsection{Tagesrhythmik}

In den frühen Morgen- und Abendstunden wurden die häufigsten sozialen Kontakte dokumentiert (Abb. 35, ohne Territorial- und Sexualverhalten). Das Sozialverhalten fiel überwiegend in die Phasen der Nahrungsaufnahme. In der ersten Tagesruhephase am späten Vormittag sank ihr Anteil besonders stark ab. Der Anteil an freundlichen wie aggressiven sozialen Verhaltensweisen war im Tagesverlauf gleichmäßig verteilt (ohne Abb.).

\subsubsection{Individuelle Unterschiede im Verhalten der Fokustiere}

Das Sozialverhalten war bei den Fokustieren unterschiedlich stark ausgeprägt: Der Hengst zeigte 3mal häufiger soziale Verhaltensweisen als die Stuten (m: 342, w: 110 bzw. 101). Die beiden Stuten unterschieden sich ihrerseits im Aggressionsverhalten: Tier 2 drohte häufiger als Tier 3 (24 zu 14 Beobachtungen in 111 Beobachtungsstunden).

Beim Hengst wurden vermehrt Aufsuchen von Herdenmitgliedern sowie naso-nasale Kontakte dokumentiert. Bei den Stuten dominierten hingegen die Verhaltensweisen Kraulen und Folgen. Neben dem Drohen, das bei allen Fokustieren auftrat, verteidigte sich Tier 2 bevorzugt durch Schlagdrohen, Tier 1 hingegen durch Zwicken, Treiben oder Vertreiben. Tier 3 war eher aggressionsarm.

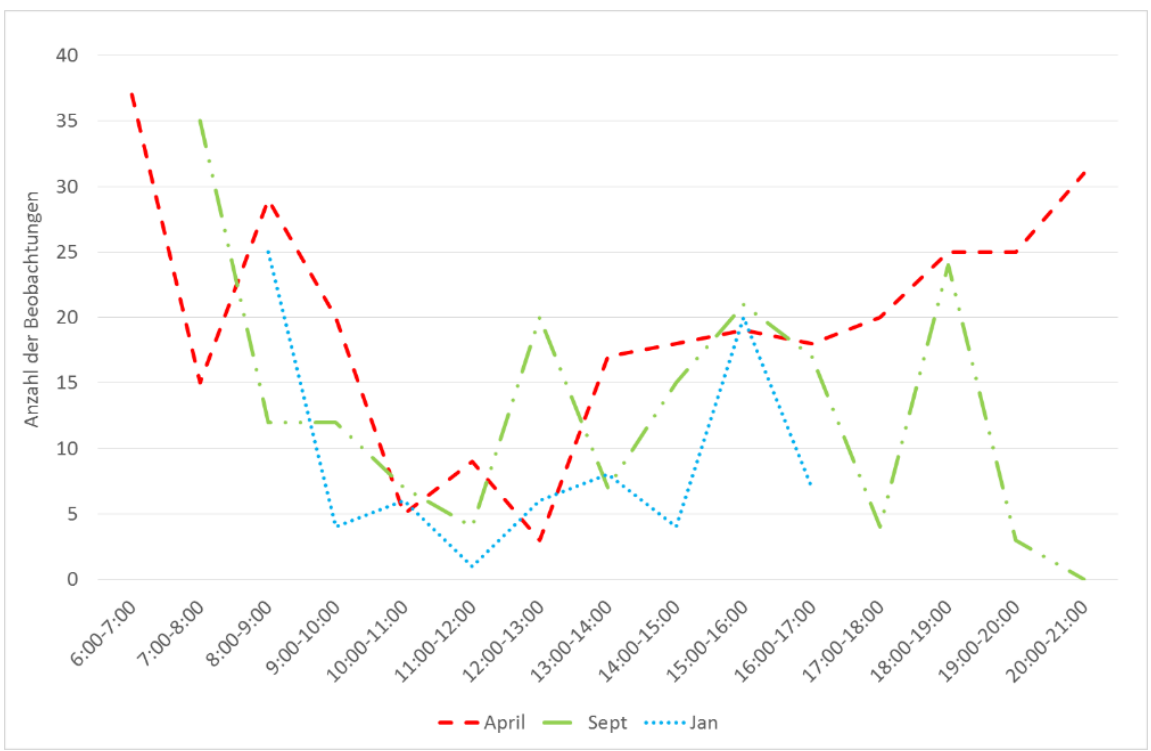

Abb. 32 Häufigkeiten sozialer Verhaltensweisen im Tagesverlauf zu unterschiedlichen Jahreszeiten 



\section{AUSWIRKUNG DER BEWEIDUNG}

Entwicklung des Projektgebietes unter Beweidung

Das Küstengrünland ist ein Beispiel für halbnatürliche Offenlandgesellschaften mit einer artenreichen Flora und Fauna. Es ist in Europa durch Nutzungsintensivierung oder Nutzungsaufgabe gefährdet (Bakker \& Berendse 1999, Smith et al. 2000). Extensive Nutzung dient dem Erhalt und Schutz dieses Lebensraumes und dessen Diversität. Doch nicht nur die Intensitätsstufe der Graslandnutzung hat einen entscheidenden Einfluss auf die Struktur und Artenzusammensetzung des Graslandtyps. Auch die Weidetierart ist von Bedeutung (Nitsche \& Nitsche 1994, Spatz 1994, Luick 1996, Dierschke \& Briemle 2002). Die Beweidung mit Pferden wird in der Landschaftspflege als kritisch bis negativ bewertet und wurde lange Zeit kaum als Möglichkeit für den Biotoperhalt in Betracht gezogen (Nitsche \& Nitsche 1994, Rahmann 1999, Dierschke \& Briemle 2002, Pain 2005, LÜBW 2006). Denn ihre Trittwirkung wird als schädigend, ihr Futteraufnahmespektrum als eng und daher ihr Einfluss auf Flora und Fauna als mindernd eingestuft (Korn 1987). Die zunehmende Anzahl an Beweidungsprojekten mit Pferden deuten allerdings auf einen beginnenden Sinneswandel hin (Becker \& Schmidt 1999, Sieling 2002, Elsäßer 2003, Sonnenburg \& Gerken 2004, Dahinten 2005, Demartin 2005).

Im Schutzgebiet Süd-Langeland wird der Erhalt einer halbnatürlichen Offenlandgesellschaft im Küstengrünland angestrebt. Das Naturschutzziel für die Region sieht vor, durch ganzjährige Pferdebeweidung ein offenes, artenreiches Mosaik an verschiedenen Habitaten als Lebensraum für zahlreiche Arten der mitteleuropäischen Kulturlandschaft zu schaffen. Dabei treffen unterschiedliche Interessen aufeinander. Um bestimmte Dominanzbestände und eine Verbuschung zu vermeiden, ist eine relativ intensive Beweidung erforderlich (Dänisches Ministerium für Umweltschutz 2005, 2006). Auch zahlreiche Vogelarten bevorzugen eine niedrige Vegetation (Dänisches Ministerium für Umweltschutz 2003). Aus botanischer und entomologischer Sicht ist hingegen eine höhere Vegetation geeigneter, während im Sinne der Freizeitnutzung und des Landschaftsbildes eine offene Landschaft erwünscht ist (Dänisches Ministerium für Umweltschutz 2006, Heimes et al. 2010).

Bei einer großräumigen, extensiven Weidehaltung ist die Entwicklung der Pflanzenbestände schwieriger vorauszusehen als bei einer intensiveren Nutzung, die homogene Grünlandbestände aus weidetoleranten Futterpflanzen fördert (von Oheimb et al. 2006). Ziel der vorliegenden Untersuchung ist es daher, die Dynamik im extensiv beweideten Gebiet Süd-Langelands nachzuvollziehen. Die Bewertung von Veränderungen erfolgte dabei im Hinblick auf die Artenzusammensetzung und die Struktur der Vegetation. Das Hauptaugenmerk lag im Grünland, da hier am ehesten Verschiebungen durch die geänderte Bewirtschaftungsform zu erwarten sind (vgl. von Oheimb et al. 2006). 


\subsection{Methodik}

Die in Süd-Langeland durchgeführte vegetationsökologische Studie entsprach einer kontrollierten prospektiven Untersuchung. Über einen bestimmten Zeitraum wurde die Entwicklung verschiedener Pflanzenbestände beschrieben. Gleichzeitig wurden mögliche Wirkungsfaktoren gemessen (Tremp 2005).

\subsubsection{Erfassung der Vegetationsentwicklung}

Zur Untersuchung der Vegetationsentwicklung im Gebiet wurde ein hierarchisches Monitoring eingesetzt (Korner et al. 2000), bei dem Monitoringflächen auf unterschiedlicher Maßstabsebene angelegt wurden. Für Veränderungen auf Landschaftsebene wurden pflanzensoziologische Vegetationskartierungen sowie floristische Bestandsaufnahmen durchgeführt. Für die Untersuchung der Pflanzenbestände wurden kleinflächige vegetationskundliche Dauerflächen angelegt.

\subsubsection{Biotopkartierung}

Um Habitattypen und Vegetationsstrukturen im Projektgebiet darzustellen und die Auswahl der Daueruntersuchungsflächen zu erleichtern, wurde im Jahr 2007 eine flächendeckende Biotopkartierung des Gebietes durchgeführt. Auf der Grundlage eines Luftbildes aus dem Jahr 2006 wurde das Gebiet zunächst in Polygone eingeteilt, die unterschiedliche Bestände von Vegetationseinheiten darstellen. Die Zuordnung der Polygone zu Biotoptypen erfolgte anschließend im Gelände unter Verwendung der Kartieranleitung zur Offenland-Biotopkartierung im Freistaat Thüringen (Thüringer Landesanstalt für Umwelt und Geologie 2001) und der Standard-Biotoptypenliste für Deutschland (Riecken et al. 2003). Das verwendete Formblatt zur Datenerhebung im Gelände der Offenland-Biotopkartierung Thüringen ist dem Anhang beigefügt (Anlage 6.1). Neben den klassischen Kopfdaten wurden alle Biotoptypen und Ausprägungen mit Angabe der Gehölzbedeckung, Flächenanteile sowie eventueller Sonderstandorte erfasst. Alle Arten wurden unter Angabe der Dominanz-Klasse ( $>20 \%$ Deckung, $d=3-20 \%$ Deckung) aufgelistet. Zur Charakterisierung des Gebietes wurden Ausstattungsmerkmale, Nutzungen und Beeinträchtigungen ergänzt und mit Hilfe von Fotos dokumentiert.

Das Gebiet hat eine inhomogene Nutzungsgeschichte: Kleine Parzellen wurden durch verschiedene landwirtschaftliche Betriebe sowie von der Forstbehörde bewirtschaftet. Die Betrachtung der Biotopausstattung erfolgte daher zunächst auf der Grundlage von 20 Teilgebieten mit gleichartiger ehemaliger Nutzung (Gebiet 1-21, ohne 16). Diese Informationen wurden anschließend unter Anwendung von Geoinformationssystemen, der Software ArcGIS (Firma ESRI), zu einer digitalen Gesamtkarte zusammengefügt. Tab. 1 zeigt die frühere Nutzung der Teilgebiete im Vergleich.

Unterstützend zur Biotopkartierung wurden im Juli 2007 Vegetationsaufnahmen nach der Methode von Braun-Blanquet (Braun-Blanquet 1964, Dierschke 1994) unter Verwendung der siebenstufigen Braun-Blanquet-Skala angefertigt: 89 Aufnahmen innerhalb des Projektgebietes sowie 10 Aufnahmen als Kontrollflächen außerhalb des Gebietes im Bereich der gemähten Randstreifen. Die Aufnahmeflächen hatten eine Größe von $1 \mathrm{~m}^{2}$. Ihre Lage ist in Anlage 6.2 dargestellt. Notiert wurden:

- Angaben zur Lokalität (Position anhand von GPS-Daten), Exposition, Höhe über NN, Hangneigung und Relief,

- Bedeckung der Vegetation (in \% differenziert nach Schichten), Deckung von Erde, Totholz, Kot (in \%), 
- Höhe und prozentuale Deckung der Pflanzenarten getrennt nach Schichten (unter Verwendung der Braun-Blanquet-Skala).

Durch die Biotopkartierung wurden grundlegende Aspekte wie die Landschaftsgliederung, menschliche Einflüsse, das Vegetationsmosaik und das Entwicklungsoptimum der Vegetationstypen im Jahresverlauf geklärt. Auf dieser Grundlage wurde festgelegt, welche Vegetationstypen untersucht werden sollten, zu welcher Zeit die Vegetationsaufnahmen erfolgen mussten und wie viele Aufnahmen notwendig waren.

\subsubsection{Pflanzensoziologische Kartierung}

Das Projektgebiet wurde zweimal pflanzensoziologisch kartiert. Als Methodik wurde die Vegetationsaufnahme, d. h. die wiederholte Aufnahme festgelegter Flächen zu verschiedenen Zeiten, gewählt. Ein Vergleich von Aufnahmepaaren oder -gruppen aus verschiedenen Jahren liefert gute Ergebnisse über Entwicklungstrends (Dierschke 1994).

Als Methode der pflanzensoziologischen Datensammlung wurde die Bestimmung des Deckungsgrades (Dominanz) eingesetzt. Unter Dominanz versteht man den Deckungsgrad einer Pflanze bzw. aller Individuen einer Sippe in einer Schicht und bezeichnet das Vorherrschen von Pflanzen auf einer Fläche. Der Deckungsgrad ist der prozentuale Anteil der Teilflächen, die bei senkrechter Projektion aller oberirdischen, lebenden Pflanzenteile einer Sippe auf dem Boden gebildet werden (Dierschke 1994).

Die Erstkartierung erfolgte zu Beginn der Datenaufnahme im Sommer 2008. Es wurden 200 Vegetationsaufnahmen mit einer Größe von $4 \mathrm{~m}^{2}$ bzw. $16 \mathrm{~m}^{2}$ nach der Methode von Braun-Blanquet (Dierschke 1994) unter Verwendung der erweiterten neunstufigen Braun-Blanquet-Skala (Tab. 16) angefertigt. Die Arten wurden getrennt nach Schichten erfasst. Unbekannte Arten wurden zunächst in nummerierten Plastik- oder Papiertüten aufbewahrt, die Nummern auf dem Erhebungsbogen notiert und die Pflanzen später mit Hilfe von Bestimmungsliteratur identifiziert.

Zu allen Probeflächen wurden folgende Kopfdaten festgehalten: Höhe über NN, Exposition, Hangneigung, Relief, Höhe der Vegetation (differenziert nach Schichten), Bedeckung der Vegetation (differenziert nach Schichten in \%), Position anhand von GPS-Daten, Auffälligkeiten im Bestand. Zusätzlich wurde für jede Aufnahmefläche die Tritt- und Verbissbelastung durch die Weidetiere notiert. Dazu wurde eine 4-teilige Skala verwendet (Tab. 17). Das Aufnahmeformular ist dem Anhang beigefügt (Anlage 6.1).

Tab. 16: Erweiterte Braun-Blanquet-Skala (nach Dierschke 1994)

\begin{tabular}{ll}
\hline Skalenwert & Deckung \\
\hline$r$ & $1-2$ Exemplare \\
+ & $1-5(-10)$ Exemplare (spärlich) \\
1 & $>(5-) 10-50(-100)$ Exemplare (zahlreich), Deckung $<5 \%$ \\
$2 m$ & $>(50-) 100$ Exemplare (massenhaft), Deckung $<5 \%$ \\
$2 a$ & Deckung $5-15 \%$ \\
$2 b$ & Deckung $15-25 \%$ \\
3 & Deckung $25-50 \%$ \\
4 & Deckung $50-75 \%$ \\
5 & Deckung $75-100 \%$ \\
\hline
\end{tabular}


Tab. 17: Skala zur Bewertung der Tritt- und Verbissbelastung

\begin{tabular}{ll}
\hline Skalenwert & Belastung \\
\hline 0 & kein \\
1 & gering \\
2 & mittel \\
3 & stark \\
\hline
\end{tabular}

In 2011 wurde eine Wiederholungskartierung im Projektgebiet durchgeführt, um die Verteilung der Pflanzengesellschaften nach drei Beweidungsjahren zu überprüfen. Die Koordinaten der Flächen entsprachen den Standorten der Erstkartierung, um eine Vergleichbarkeit zu gewährleisten. Methodische Ungenauigkeiten wie ein Wechsel des Bearbeiters oder das punktgenaue Auffinden der Aufnahmeflächen lassen sich laut Dierschke (1994) durch eine große Aufnahmezahl ausgleichen. Es wurden 75 der 200 Vegetationsaufnahmen erneut aufgenommen. Da im Grünland die größten Veränderungen zu erwarten sind, wurde dieser Habitattyp vorrangig ausgewählt. Die Größe der Aufnahmeflächen betrug $2 \times 2 \mathrm{~m}$. Zur Bestimmung des Deckungsgrades wurde die erweiterte Braun-Blanquet-Skala verwendet.

Die Lage der Aufnahmeflächen in den Jahren 2008 und 2011 ist in Anlage 6.2 dargestellt.

\subsubsection{Vegetationskundliche Dauerflächen}

Vegetationsveränderungen bestimmter Lebensräume unter Beweidung wurden auf Dauerbeobachtungsflächen untersucht. Sie bilden die exakteste Grundlage syndynamischer Untersuchungen (Dierschke 1994). Die Aufnahmeflächen umfassten dabei die wichtigsten Vegetationstypen der beweideten Landschaft. Für das Samplingdesign wurde die stratifizierte Zufallsauswahl (stratified random sampling) als Kompromiss zwischen subjektiver und zufälliger Probennahme gewählt. Die Unterteilung in Straten vermeidet, dass bestimmte Vegetationstypen nicht berücksichtigt werden, weil sie nicht durch einen zufälligen Stichprobenpunkt getroffen werden (Traxler 1997). Die Auswahl der Aufnahmeflächen orientierte sich an dem prozentualen Anteil der Habitattypen im Untersuchungsgebiet und enthielt sowohl repräsentative als auch seltenere Vegetationsbestände. Einbezogen wurden auch Flächen, die aus vegetationskundlicher Sicht eine geringe Wertigkeit aufwiesen, aber ein gewisses Entwicklungspotential erwarten ließen (vgl. von Oheimb et al. 2006).

Die Datenaufnahme erfolgte jährlich in den Jahren 2008 bis 2011. Im Gebiet wurden 26 vegetationskundliche Dauerflächen (VDF) als Quadrate oder Transekte angelegt (Tab. 18). Ihre Lage und Charakterisierungen sind im Anhang beschrieben (Anlage 6.3). Bei der Wahl der Aufnahmeflächen wurde auf physiognomische, floristische und ökologische Homogenität innerhalb der Flächen geachtet. Jede Aufnahmefläche war Teil eines mindestens um das 2 bis 3-fache größeren, relativ homogenen Vegetationsbestandes (vgl. Schmidt et al. 2006).

Im Grünland wurden 12 Daueruntersuchungsflächen angelegt, wobei eine Fläche (VDF 6) in 2010 aufgrund der Zerstörung des Markierungspfahls trotz unterirdischer Vermarkung verloren ging. Die Dauerflächen repräsentierten artenreiches (VDF 6, 7, 12) und artenarmes (VDF 1, 3, 8, T1) Grünland sowie eine Ackerbrache (VDF 4, 5) und Saatgrasland (VDF 2, 10). Eine Dauerfläche (VDF 9) wurde am Oberhang eines Hügels angelegt und sollte die Entwicklung der Vegetation auf einem mageren Grünlandstandort dokumentieren.

Uferfluren an stehenden Gewässern wurden durch eine Dauerfläche (T2) repräsentiert. Sie wurde in Transektform entlang der Uferlinie angelegt. Diese Fläche stellte zusammen mit den 12 Grünlandflächen die Vegetation des offenen Weidelandes dar. Zusätzlich wurde ein Höhentransekt (T3) von 61 
Metern Länge über unterschiedliche Vegetationstypen angelegt. Er verlief mit kontinuierlichem Gefälle von einer Kuppe den Hang hinab bis zum Ufer eines Weihers.

Im Buchen-Laubwald wurde eine größere Daueruntersuchungsfläche von $25 \mathrm{~m}^{2}$ angelegt (VDF 11), um die Vegetationsentwicklung der Gehölze zu beurteilen.

Um die Auswirkung der Beweidung bewerten zu können und eine natürliche Sukzession auszuschließen (Hakes 1996), wurden 11 Kontrollflächen eingerichtet, die zwar nicht beweidet wurden, sich aber dennoch in ihrer Nutzung unterschieden (Tab. 18). Bei den Kontrollflächen K1-K4 handelte es sich um Flächen außerhalb des Schutzgebietes, die 2-3mal im Jahr gemäht wurden. Sieben weitere Ausschlussflächen innerhalb des Projektgebietes (K5-K10, KT) wurden weder beweidet noch gemäht. Sie wurden allerdings erst 9 Monate nach Beginn der Datenaufnahme, im Januar 2009, eingerichtet.

Die Dauerflächen im Grünland hatten eine Größe von $2 \times 2 \mathrm{~m}$, die Transekte T1 und T2 von $4 \times 1 \mathrm{~m}^{2}$ auf einer Gesamtlänge von 10 Metern (Abb. 33). Beim Höhentransekt T3 lagen 7 Teilflächen, die so genannten Subplots $(1 \times 1 \mathrm{~m})$, im Abstand von jeweils 9 Metern. Auf den Subplots wurden neben den üblichen Kopfdaten wie Lage, Zustand der Vegetation, Nutzungsart und Topographie folgende weitere Parameter erhoben:

- Strukturdaten der Vegetation (Wuchshöhe in cm; Deckungsgrade von Gräsern, Kräutern, Moosen, Streu, offenem Boden, vitaler Vegetation in \%; Anteile von kurz-, mittel- und langrasiger Vegetation in \%),

- Strukturelemente (Weidetierpfade, Kothaufen, Suhlstellen u.a.),

- Deckungsgradschätzung.

Die Deckungsgradaufnahmen erfolgten mithilfe der halbquantitativen Londo-Skala (Dierschke 1994), die eigens für Dauerflächenuntersuchungen entwickelt wurde. Sie ist im unteren Deckungsbereich bis $5 \%$ sehr fein und steigt dann mit 10-\%-Schritten an (Tab. 19). Zwischen $95 \%$ und $100 \%$ ist ein weiterer 5-\%-Schritt eingebaut. Die Londo-Skala wird bei $4 \mathrm{~m}^{2}$ großen Untersuchungsflächen und Aufnahmen durch nur einen Kartierer empfohlen (Traxler 1997). Die Vegetationsaufnahmen erfolgten zum Zeitpunkt der optimalen Entwicklung der Arten im Juni, in denen der überwiegende Teil der im Untersuchungsgebiet vorhandenen Pflanzen in Blüte stand oder bereits fruchtete. Dies erleichterte die Kartierung. Zu jeder Aufnahme wurde eine Fotodokumentation (mit festen Aufnahmestandorten) angefertigt.

a

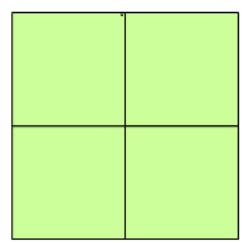

b

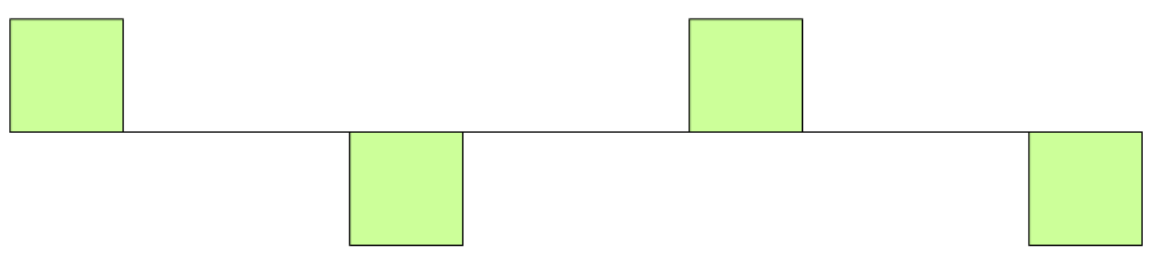

Abb. 33: Form der Dauerflächen als Rechteck mit 4 Quadranten (a) oder als Transekt (b) 
Tab. 18: Beschreibung der vegetationskundlichen Dauerflächen und ihrer Kontrollflächen im Gebiet Süd-Langeland

\begin{tabular}{|c|c|c|c|c|c|c|c|c|c|c|c|}
\hline $\mathrm{Nr}$. & Lebensraumtyp & $\begin{array}{l}\text { Bezeich- } \\
\text { nung }\end{array}$ & Gebiet & $\begin{array}{l}\text { Aufnahme- } \\
\text { paar }\end{array}$ & $\begin{array}{l}\text { Größe } \\
\left(\mathrm{m}^{2}\right)\end{array}$ & $\begin{array}{l}\text { Höhe } \\
\text { (m) }\end{array}$ & Exposition & $\begin{array}{l}\text { Hang- } \\
\text { neigung }\end{array}$ & Relief & $\begin{array}{l}\text { Licht } \\
(\%)\end{array}$ & $\begin{array}{l}\text { Wind- } \\
\text { exposition (\%) }\end{array}$ \\
\hline & Beweidete Vegetationsdauerflächen & & & & & & & & & & \\
\hline 1 & Artenarmes Grünland & V1 & 9 & K6 & 4 & 7 & - & $0^{\circ}$ & Ebene & 100 & 100 \\
\hline 2 & Saatgrasland & V2 & 10 & - & 4 & 6 & S & $2^{\circ}$ & Mittelhang & 100 & 100 \\
\hline 3 & Artenarmes Grünland & V3 & 12 & - & 4 & 4 & - & $0^{\circ}$ & Ebene & 100 & 100 \\
\hline 4 & Ackerbrache & V4 & 13 & K7 & 4 & 6 & W & $2^{\circ}$ & Mittelhang & 100 & 100 \\
\hline 5 & Ackerbrache & V5 & 13 & K3 & 4 & 9 & W & $5^{\circ}$ & Mittelhang & 100 & 100 \\
\hline 6 & Artenreiches Grünland & V6 & 20 & - & 4 & 8 & 0 & $5^{\circ}$ & Mittelhang & 100 & 100 \\
\hline 7 & Artenreiches Grünland & V7 & 5 & K5 & 4 & 5 & NNO & $2^{\circ}$ & Mittelhang & 100 & 50 \\
\hline 8 & Artenarmes Grünland & V8 & 4 & K2 & 4 & 2 & S & $2^{\circ}$ & Hangfuß & 100 & 75 \\
\hline 9 & Magerrasen & V9 & 20 & K9 & 4 & 25 & W & $15^{\circ}$ & Oberhang & 90 & 75 \\
\hline 10 & Saatgrasland & V10 & 19 & K8 & 4 & 9 & NO & $2^{\circ}$ & Mittelhang & 100 & 85 \\
\hline 11 & Gehölze & V11 & 6 & K10 & 25 & 10 & S & $2^{\circ}$ & Mittelhang & 10 & 0 \\
\hline 12 & Artenreiches Grünland & V12 & 1 & K1 & 4 & 5 & sW & $2^{\circ}$ & Rücken & 100 & 100 \\
\hline 13 & Artenarmes Grünland, Uferflur & $\mathrm{T} 1$ & 9 & KT & 4 & $5-7$ & $\mathrm{~N}$ & $12^{\circ}$ & Mittelhang & 100 & 50 \\
\hline 14 & Uferflur & $\mathrm{T} 2$ & 18 & - & 4 & 0 & - & $0^{\circ}$ & Hangfuß & 100 & 75 \\
\hline \multirow[t]{3}{*}{15} & Magerrasen, artenreiches Grünland, Uferflur & T3 & 20 & - & 4 & $5-20$ & 0 & $20^{\circ}$ & Mittelhang & 90 & 75 \\
\hline & Unbeweidete Kontrollflächen & & & & & & & & & & \\
\hline & Dauerflächen außerhalb des Gebietes & & & & & & & & & & \\
\hline 16 & Artenreiches Grünland & K1 & bei 1 & V12 & 4 & 5 & sW & $2^{\circ}$ & Rücken & 100 & 100 \\
\hline 17 & Artenarmes Grünland & K2 & bei 4 & V8 & 4 & 2 & S & $2^{\circ}$ & Hangfuß & 100 & 75 \\
\hline 18 & Ackerbrache & K3 & bei 13 & V5 & 4 & 10 & sW & $0^{\circ}$ & Rücken & 100 & 75 \\
\hline \multirow[t]{2}{*}{19} & Saatgrasland & K4 & bei 19 & V10 & 4 & 10 & NO & $2^{\circ}$ & Rücken & 75 & 50 \\
\hline & Ausschlussflächen innerhalb des Gebietes & & & & & & & & & & \\
\hline 20 & Artenreiches Grünland & K5 & 5 & V7 & 4 & 4 & NO & $2^{\circ}$ & Hangfuß & 100 & 100 \\
\hline 21 & Artenarmes Grünland & K6 & 9 & V1 & 4 & 7 & $\mathrm{O}$ & $2^{\circ}$ & Mittelhang & 100 & 95 \\
\hline 22 & Ackerbrache & K7 & 13 & V4 & 4 & 6 & sW & $2^{\circ}$ & Mittelhang & 100 & 100 \\
\hline 23 & Saatgrasland & K8 & 19 & V10 & 4 & 9 & $\mathrm{~N}$ & $2^{\circ}$ & Oberhang & 100 & 100 \\
\hline 24 & Magerrasen & K9 & 20 & v9 & 4 & 25 & $\mathrm{O}$ & $2^{\circ}$ & Rücken & 75 & 75 \\
\hline 25 & Gehölze & K10 & 6 & V11 & 4 & 10 & S & $2^{\circ}$ & Hangfuß & 25 & 10 \\
\hline 26 & Gewässer, Uferflur & KT & 9 & $\mathrm{~T} 1$ & 4 & $5-7$ & $\mathrm{~s}$ & $10^{\circ}$ & Mittelhang & 100 & 100 \\
\hline
\end{tabular}


Tab. 19: Skalenwerte und entsprechende Deckungsgrade der Londo-Skala (nach Dierschke 1994)

\begin{tabular}{ll}
\hline Skalenwert & Deckung \\
\hline 0,1 & $>1 \%$ \\
0,2 & $1-3 \%$ \\
0,4 & $3-5 \%$ \\
1 & $5-15 \%$ \\
2 & $15-25 \%$ \\
3 & $25-35 \%$ \\
4 & $35-45 \%$ \\
5 & $45-55 \%$ \\
6 & $55-65 \%$ \\
7 & $65-75 \%$ \\
8 & $75-85 \%$ \\
9 & $85-95 \%$ \\
10 & $95-100 \%$ \\
\hline
\end{tabular}

Die Dauerflächen wurden im Gelände dauerhaft vermarkt. An zwei Eckpunkten wurden $10 \mathrm{~cm}$ lange Eisenstücke vergraben. Ein punktgenaues Wiederauffinden der Flächen erfolgte mit Hilfe eines Metalldetektors der Firma Garrett. Zusätzlich wurden Handskizzen angefertigt. Die Standorte wurden mit einem GPS-Gerät der Marke eTrex, Firma Garmin geographisch vermessen und mit Holzpflöcken oberirdisch sichtbar markiert.

\subsubsection{Floristische Bestandserfassung}

Im Zuge der Kartierungen, Geländebegehungen und vegetationskundlichen Untersuchungen wurden alle Gefäßpflanzen und Moose auf Artniveau erfasst (Aichele \& Schwegler 1998, Rothmaler et al. 1999, Oberdorfer 2001, Schubert 2001, Klapp \& Opitz von Boberfeld 2004, 2006, Seybold 2006, Düll 2008) und Belegexemplare gesammelt. Ein Großteil der Arten wurde herbarisiert. Die Nomenklatur der Pflanzen richtete sich nach Schmeil-Fitschen, Flora von Deutschland und angrenzender Länder (Seybold 2006).

\subsubsection{Datenauswertung}

\section{Klassifikation der Vegetation}

Zur Charakterisierung der Pflanzengesellschaften im Untersuchungsgebiet wurden die pflanzensoziologischen Aufnahmen mit Hilfe eines Klassifikationsverfahrens gruppiert. Diese Gruppen wurden anschließend Vegetationseinheiten der Fachliteratur zugeordnet und ihre Lage im Gelände unter Verwendung eines Geografischen Informationssystems (GIS) visualisiert.

Divisives Klassifikationsverfahren

Zur Einordnung der Vegetationsaufnahmen zu Pflanzengesellschaften wurden divisive Klassifikationsmethoden angewandt. Ziel ist hierbei, die Aufnahmedaten in einer zweidimensionalen Tabelle so anzuordnen, dass ähnliche Aufnahmen und sich ähnlich verhaltende Arten nebeneinander stehen. In anderen Worten geht es um das Auffinden von abgrenzbaren Gruppen und das Herausarbeiten von Un- 
terschieden zwischen denselben. Divisive Klassifikationsverfahren versuchen bei der Analyse, den gesamten Datensatz zu betrachten und diesen sukzessiv in kleiner werdende Gruppen aufzuteilen. Dadurch unterscheiden sie sich beispielsweise von agglomerativen Verfahren (Leyer \& Wesche 2008).

Die Erhebungen im Gelände wurden von unterschiedlichen Kartierern durchgeführt. Vor der Klassifikation mussten daher Artenlisten und Schicht-Kategorien vereinheitlicht werden. Zwei Aufnahmen wurden aus dem Datensatz ausgeschlossen: Bei Aufnahme 78-SO war eine räumliche Zuordnung nicht möglich, Aufnahme 7-1-M hob sich stark von anderen Aufnahmen desselben Standortes ab. Im Ergebnis wurden 200 Relevés aus der Kartierung im Jahr 2008 und 74 aus dem Jahr 2011 in der Analyse verwendet (Tab. 20). Die Aufnahmedaten wurden in die digitale Datenbank TURBOVEG eingegeben und anschließend in das Programm JUICE 7.0.42 (Tichý 2002) zur Editierung und Klassifikation pflanzensoziologischer Datensätze eingelesen. Anstatt einer manuellen pflanzensoziologischen Tabellenarbeit wurde zur Klassifizierung des Datensatzes eine TWINSPAN-Analyse (Two-Way Indicator Species Analysis) durchgeführt.

TWINSPAN ist ein divisives, hierarchisches Klassifikationsverfahren, das im Gegensatz zu anderen Verfahren nicht nur Aufnahmen, sondern auch Arten klassifiziert. Bei der Analyse werden verschiedene mathematisch-statistische Algorithmen kombiniert: Correspondence Analysis (Korrespondenzanalyse), Refined Ordination (Verbesserte Ordination) und Indicator Ordination (Indikator-Ordination). Das Verfahren wird bei Leyer \& Wesche (2008) umfassend erläutert. Angewandt wurde der modifizierte TWINSPAN-Algorithmus (Rolecek et al. 2009), bei dem die Cluster nach jedem Teilungsschritt auf ihre Heterogenität hin untersucht werden. Aufgespalten wird jeweils nur das Cluster mit der höchsten Heterogenität, während beim klassischen TWINSPAN-Algorithmus alle Cluster eines Datensatzes bei jedem Teilungsschritt weiter aufgespalten werden (Dichotomie).

Der Datensatz wird so weit aufgeteilt, bis die gewünschte Feinheit der Aufteilung erreicht ist. Dies kann ein bestimmter Grad der Unähnlichkeit (dissimilarity) oder eine festgelegte Anzahl von Clustern sein. Die Anzahl der entstehenden Cluster wurde im Datensatz von 2007 auf 10, von 2008 auf 30 und von 2011 auf 20 festgelegt, um eine Aufgliederung der Gruppen bis auf Subassoziationsniveau zu erreichen. Die Mindestgruppengröße betrug 4 Aufnahmen, der verwendete Index war Whittaker's beta-diversity.

Durch die Wahl geeigneter Schwellenwerte der so genannten pseudo species (künstliche Arten) lässt sich Einfluss darauf nehmen, ob Artabundanzen bei der Analyse ins Gewicht fallen oder unberücksichtigt bleiben. Die Abundanzen einer Art werden dabei mittels nominalskalierter Dummy-Variablen übersetzt, die sich an der verwendeten Schätzskala orientieren. Bei der Analyse in TWINSPAN wurden 6 Schwellenwerte, so genannte pseudo species cut levels, gewählt: bei 0, 2, 5, 25, 50 sowie 75 \% (Tab. 21). Die cut levels entsprachen der in Prozentwerte umgewandelten Skalenwerte der erweiterten Braun-Branquet-Skala, wobei bestimmte Skalenwerte zu einer pseudo species zusammengefasst wurden.

Tab. 20 Übersicht über die mit TWINSPAN ausgewerteten Daten

\begin{tabular}{llll}
\hline Jahr & Bezeichnung & $\begin{array}{l}\text { Anzahl der } \\
\text { Aufnahmen }\end{array}$ & Biotope \\
\hline 2007 & Voruntersuchung, Biotopkartierung & 99 & Offenes Weideland \\
2008 & Vegetationskartierung (Erstkartierung) & 200 & Grünland, Gehölze, Wälder, Ökotone \\
2011 & Vegetationskartierung (Wiederholungskartierung) & 74 & Grünland, Ökotone \\
\hline
\end{tabular}


Tab. 21: Prozent-Übersetzung der Werte der Braun-Blanquet-Skala und Beziehung zwischen den Skalenwerten und den „pseudo species" bzw. „cut levels" (nach Dierschke 1994)

\begin{tabular}{llll}
\hline Skalenwert & \%- Übersetzung & pseudo species & cut level \\
\hline$\cdot$ & 0 & & 1 (bei 0\%) \\
\hline$r$ & 1 & 1 & 2 (bei $2 \%)$ \\
\hline+ & 2 & 1 & \\
\hline 1 & 3 & 2 & 3 (bei $5 \%)$ \\
\hline $2 m$ & 4 & 2 & \\
\hline $2 a$ & 8 & 3 & 4 (bei $25 \%)$ \\
\hline $2 b$ & 18 & 3 & 5 (bei $50 \%)$ \\
\hline 3 & 38 & 4 & 6 (bei $75 \%)$ \\
\hline 4 & 68 & 5 & \\
\hline 5 & 88 & 6 &
\end{tabular}

Die aus der Analyse resultierenden Gruppen wurden auf der Grundlage wichtiger Indikator- und Kennarten sinnvoll zusammengefasst beziehungsweise in Gruppen oder Untergruppen getrennt. Der TWINSPAN-Algorithmus zur Berechnung der Indikatorarten benutzt nur die deutlichsten Arten. Zur Unterstützung der Ergebnisse wurden daher in synoptischen Tabellen die Differentialarten der einzelnen Einheiten nach dem Kriterium der doppelten prozentualen Stetigkeit ermittelt (Bergmeier et al. 1990). Arten mit einer Stetigkeit von $>40 \%$ wurden zur typischen Artenverbindung der Vegetationseinheiten zusammengestellt.

Folgende manuelle Umstellungen wurden durchgeführt:

1) Datensatz von 2007

- Umstellung von Gruppen:

Gruppe 10 (Glatthaferwiese mit Merkmalen der Fettweide) wird hinter Gruppe 5 (Magere Glatthaferwiese) verschoben.

- Neubildung und Auflösung von Gruppen:

Gruppe 2, 3 und 8 werden in jeweils 2 Untergruppen geteilt. Gruppe 7 wird aufgelöst.

- Umstellungen von Aufnahmen:

Aufnahme 21, 22 und 27 werden von Gruppe 5 zu 4 gestellt,

Aufnahme 25 von Gruppe 7 zu 4, Aufnahme 61 zu 10 verschoben.

- Entfernen von Aufnahmen:

Alle Aufnahmen auf unbeweideten Kontrollflächen werden aus der Auswertung entfernt.

2) Datensatz von 2008

- Aufnahme 111 wird von Gruppe 13 zu Gruppe 3 verschoben (Begründung: Fehlen von Chenopodium glaucum bei Auftreten von Ranunculus scleratus und Bidens tripartita)

- Aufnahme 104 von Gruppe 3 zu Gruppe 13 (Vorkommen von Chenopodium glaucum)

- Aufnahme 180 von Crataego-Prunetum zu Quercus-Tilia-Bestand, artenreich (Lage und Prunus avium-Vorkommen)

- Aufnahme 163 als eigene Gruppe (Abies-Crataegus-Bestand mit hohem Grasanteil)

- Gruppe 8 als Untergruppe von Gruppe 10 eingeordnet (Quercus-Tilia-Mischbestand, artenreich und artenarm, mit Begleitarten)

- Aufnahmen 129 und 134 von Gruppe 11 nach Gruppe 12 verschoben, beides Crataego-Prunetum mit unterschiedlichem Standort feucht / trocken (auf Gebiet 6 zu 4 bzw. 6 zu 8)

- Aufnahme 173 zu 171 in Gruppe 8 (beide Hippophae-Quercus-Gebüsch)

- Aufnahme 108 von Gruppe 5 (Initialgesellschaft) nach Gruppe 2 (Schilf-Röhricht) 
- $\quad$ Aufnahme 92 von Gruppe 5 nach Gruppe 2d

- Aufnahme 98 von Gruppe 5 zu Gruppe 3b (Ranunculetum scelerati)

- Aufnahme 87 von Gruppe 3 sowie Aufnahme 213 von Gruppe 16 zu Gruppe 14 (Potentillo-Polygonetalia)

- Aufnahme 37 von Gruppe 20 zu Gruppe 22 (Glatthaferwiese)

- Aufnahme 158 von Gruppe 22, Aufnahme 159 von Gruppe 14 sowie Aufnahme 155 von Gruppe 24 nach Gruppe 25 (Cynosurion)

- $\quad$ Aufnahme 80 von Gruppe 23 zu Gruppe 17b (Pulicaria-Bellis perennis-Bestand)

- Aufnahmen 196, 201 und 206 von Gruppe 25 sowie Aufnahmen 195 und 198 von Gruppe 23 zu Gruppe 24a (gemeinsamer Standort)

- Aufnahmen 118 und 123 von Gruppe 27 sowie Aufnahme 124 von Gruppe 25 zu Gruppe 28 (gemeinsamer Standort)

- $\quad$ Aufnahme 4 von Gruppe 25 zu Gruppe 9 (gemeinsamer Standort Waldsaum)

- Aufnahme 135 von Gruppe 20 zu Gruppe 12 (Arten der Rhamno-Prunetea)

- Aufnahme 149 wird gelöscht, da der Aufnahmeort unbekannt war (fehlerhafte Datengrundlage)

- Aufnahme 49 von Gruppe 20 zu Gruppe 18 verschoben (Auftreten von Bromus hordeaceus und Lolium perenne ohne Festuca rubra)

- Aufnahme 210 gelöscht aufgrund unsicherer Datenqualität

- Cluster 19 und 20 werden zu einem zusammengefügt (Gruppe 18)

3) Datensatz von 2011

- Aufnahme 14 von Gruppe 1 wird zu Gruppe 7 verschoben (Begründung: Einordnung als Potentillo-Polygonetalia anstatt als Phragmition-Initialgesellschaft)

- Aufnahme 39 von Gruppe 2 zu Gruppe 1 verschoben (Einordnung zu Phragmition-Initialgesellschaft)

- Aufnahme 46 aus Gruppe 5 bildet nun eine eigene Gruppe (Quercus-Crataegus-Mischbestand, sehr lückig mit Elementen der angrenzenden Weide)

- Aufnahme 34 von Gruppe 12 zu Gruppe 9 verschoben (nitrophiler Krautsaum)

- Aufnahme 49 von Gruppe 10 zu Gruppe 12 verschoben (ruderale Glatthaferwiese)

- Aufgrund des hoch steten Vorkommens von Festuca rubra und Plantago lanceolata werden folgende Aufnahmen zu Gruppe 13 (Arrhenatheretalia-Basalgesellschaft) verschoben:

- Aufnahme 19 von Gruppe 6, Gruppe 6 wird damit aufgelöst

- Aufnahmen 8 und 9 von Gruppe 9

- Aufnahme 44 von Gruppe 10 , Gruppe 10 wird damit aufgelöst

- Aufnahme 57 von Gruppe 11

- Aufnahmen 18 und 21 von Gruppe 12

- Zwei Gruppen werden aufgelöst, eine neu gebildet, so dass im Ergebnis 19 Gruppen übrig blieben.

Die Datensätze aus den Jahren 2007, 2008 und 2011 wurden separat ausgewertet, die Klassifikationsergebnisse anschließend miteinander verglichen, um kleinräumige Veränderungen der Artenzusammensetzungen zu lokalisieren.

Typisierung und Interpretation der Pflanzengesellschaften

Nach der manuellen Korrektur der Ergebnisse der TWINSPAN-Analyse wurden die entstandenen Gruppen von Vegetationsaufnahmen in der Fachliteratur beschriebenen Pflanzengesellschaften zugeordnet. Vorarbeiten im Projektgebiet wurden von Peter (2008), Söhn (2009) und Stammer (2009) getätigt. Als Referenz für die Benennung der Pflanzengesellschaften dienten Runge (1990), Pott (1995), Dierschke (1997), Passarge (1999), Schubert et al. (2001), Berg et al. (2004), Wilmanns (2007) sowie von Drachenfels (2011). Auch die Bestände der nicht zugänglichen Flächen wurden syntaxonomisch eingeordnet. Vegetationseinheiten, die keiner beschriebenen Assoziation zugewiesen werden konnten, wurden anhand von dominanten Arten benannt.

Als Interpretationshilfe der ermittelten Einheiten wurde der Median der ökologischen Zeigerwerte nach Ellenberg et al. (1992) berechnet. Er gab Aufschluss über mögliche Veränderungen der Standort- 
faktoren durch die Beweidung. Der Zuordnung von Zeigerwerten oder Faktorenzahlen liegt die Annahme zugrunde, dass sich Arten gemäß eines bestimmten ökologischen Gradienten verhalten. Daraus abgeleitet formulierte Ellenberg 9 bis 12-stufige Skalen beispielsweise für die Schattenverträglichkeit (L), die Bodenfeuchtigkeit (F), die Bodenreaktion (R) und der Nährstoffgehalt im Boden (N). Die Bildung eines Medians ist streng genommen für ordinal skalierte Werte nicht zulässig, aufgrund der einfachen Handhabe und der hohen Aussagekraft aber weit verbreitet (Dierschke 1994).

Die Ellenberg-Zeigerwerte wurden als Text-Datei in JUICE importiert. Nicht erfasste Arten wurden mit Hilfe der Angaben des Online-Informationsangebotes des Bundesamtes für Naturschutz (www.floraweb.de) manuell nachgetragen. Für Arten, die nicht bis auf Artniveau bestimmt werden konnten, wurden keine Zeigerwerte angegeben. Gleiches galt für Arten, für die bisher noch keine Zeigerwerte bestimmt wurden.

Zudem wurden Wertzahlen für die Trittverträglichkeit und den Futterwert der Arten errechnet, um die Toleranz der Bestände gegenüber Tritt und Fraß und die Beliebtheit der Bestände bei den Weidetieren zu ermitteln. Diese Werte entstammten der Biologischen Tafel aus Dierschke \& Briemle (2002).

Alle vorgefundenen Arten wurden in einer Gesamtartenliste mit Angabe ihrer jeweiligen EllenbergZeigerwerte, den Futterwert und der Nutzungswertzahlen für die Weide- und Trittverträglichkeit zusammengefasst (Anlage 6.4). Mit Hilfe dieser Daten erfolgten die ökologische Charakterisierung der Vegetationsgruppen und die Beurteilung der Beeinflussung durch die Pferde.

\section{Vegetationskarte}

Die Daten der Vegetationskartierung wurden mit ArcView 9.3 bzw. 10 (Firma ESRI) digitalisiert und als Vegetationskarte dargestellt. Als Grundlage dienten aktuelle Satellitenaufnahmen sowie die Biotoptypenkarte. Die Vegetationskarte enthielt alle im Gebiet angetroffenen Vegetationseinheiten sowie ihre Subassoziationen mit räumlicher Ausdehnung. Pflanzengesellschaften einer Formation wurden mit gleichen Symbolen oder ähnlichen Farbnuancen gekennzeichnet. Offene Wasserflächen oder nutzungsfreie Räume erscheinen als weiße Flächen. Die Flächenanteile der unterschiedlichen Vegetationseinheiten wurden im GIS berechnet.

\section{Bewertung der Vegetationsveränderungen}

Eine Überlagerung der Aufnahmeplots der Jahre 2008 und $2011 \mathrm{im}$ GIS ließ eine unterschiedlich große Abweichung der Aufnahmepunkte erkennen, die auf die Messungenauigkeit des GPS-Gerätes, aber auch auf den Wasserstand zurückgeführt werden kann. Im Jahr 2011 erfolgte die Datenaufnahme 8 Wochen früher als im Jahr 2008, so dass die großen und eher flachen Gewässer wesentlich ausgedehnter waren und die Plots teils unter Wasser lagen. Bei der Bewertung von Vegetationsveränderungen wurde daher die im Jahr 2008 aufgenommene Pflanzengesellschaft am Aufnahmeort von 2011 zu Grunde gelegt.

Ein Beispiel soll dies verdeutlichen: Aufnahme 11-SO lag im Jahr 2008 in einem Rohrkolben-Röhricht. In 2011 musste die Aufnahme aufgrund des höheren Wasserstandes ca. $8 \mathrm{~m}$ weiter nördlich in einem Sumpfbinsen-Kleinröhricht angefertigt werden. Diese Pflanzengesellschaft wurde hier bereits im Jahr 2008 kartiert. Im Ergebnis ist es somit zu keiner Vegetationsveränderung gekommen, obwohl die Aufnahme 11-SO einmal dem Schoenoplecto-Phragmitetum (Rohrkolben-Röhricht), einmal der Eleocharis palustris-Gesellschaft zugeordnet wurde. In der Ergebnistabelle in Anlage 6.6 wird diese abgewandelte Bewertung durch eine Aufnahmenummer in Klammern (Nr. in Publ.) angedeutet.

Die Abweichungen der Aufnahmeplots zwischen den Jahren 2008 und 2011 lagen zwischen 0 und 28 Metern. Ein direkter Vergleich der Aufnahmen war auf dieser Grundlage nicht möglich, daher wurde 
auf eine Auswertung der Daten mittels Ordination oder eine Anwendung von Diversitätsindices verzichtet. Diese Verfahren fanden bei dem Vergleich der Daueruntersuchungsflächen Anwendung, da hier identische Flächen analysiert wurden.

Vegetationsveränderungen auf einer übergeordneten Maßstabsebene lassen sich mit Hilfe von Vegetationskarten im GIS untersuchen. Hierfür wurden ausgewählte Detailgrafiken von Bereichen mit hoher Dynamik im GIS erstellt und die Daten der Jahre 2008 und 2011 miteinander verglichen.

\section{Ordination vegetationsökologischer Daten}

Zur Untersuchung der Entwicklung der Pflanzenbestände wurden nach Abschluss der Datenaufnahme multivariate Analysen durchgeführt. Zur Auswertung der räumlichen und zeitlichen Varianz wurden Ordinationsverfahren angewandt. Deren Ziel ist es, die wesentlichen Gradienten zu finden und in interpretierbaren Diagrammen zu visualisieren, um die Zusammensetzung der Arten in einem bestimmten Lebensraum zu erklären (Leyer \& Wesche 2007). Ordinationen werden auch Gradientenanalysen genannt, da ein direkter Zusammenhang zwischen Standort und Artenzusammensetzung angenommen wird (Tremp 2005). Verschiedene Verfahren fanden bei der Auswertung Anwendung und werden eingangs kurz erläutert.

\section{Auswahl des Ordinationsverfahrens}

Bei einer indirekten Gradientenanalyse werden die ökologischen Zusammenhänge nur im Hinblick auf die in den Aufnahmen auftretenden Arten interpretiert. Gemessene Umweltvariablen werden erst in einem zweiten Schritt zur Erklärung der Ordination herangezogen. Anders geht die direkte Gradientenanalyse vor, die Aufnahmen und Umweltvariablen gleichermaßen berücksichtigt (Leyer \& Wesche 2007). Sie deckt jene Variation der Artenzusammensetzung auf, die in Beziehung zu den gemessenen Umweltvariablen steht.

Möchte man eine indirekte Gradientenanalyse durchführen, entscheidet die Länge des Gradienten über die anzuwendende Methode. Die Gradientenlänge sagt aus, ob Arten gegenüber den untersuchten Parametern eher ein unimodales oder ein lineares Verhalten zeigen. Bei sehr kurzen floristischen Gradienten empfiehlt sich die Durchführung einer Hauptkomponentenanalyse (PCA, principal component analysis). Gradienten gelten dann als kurz, wenn die Aufnahmen mehr als die Hälfte der gleichen Arten aufweisen. Bei langen Gradienten finden hingegen die Korrespondenz-Analyse (CA, Correspondence Analysis) oder deren Weiterentwicklung, die Detrended Correspondence Analysis (DCA), Verwendung. Die DCA ist die derzeit meist verwendete Ordinationsmethode der indirekten Gradientenanalyse (Hammer et al. 2001, Leyer \& Wesche 2007). Sowohl die PCA als auch die CA / DCA sind Eigenanalyse basierte Ordinationen. Dies führt dazu, dass die erste Achse stets den größten Eigen- und Erklärungswert hat.

Analog zur indirekten Gradientenanalyse unterscheidet man auch bei den direkten Verfahren zwischen linearen und unimodalen Typen. Die Kanonische Korrespondenzanalyse (CCA, canonical correspondance analysis) basiert auf der klassischen Korrespondenzanalyse, wertet jedoch die Daten so aus, dass Art- und Umweltdaten gleichermaßen optimal berücksichtigt werden.

\section{Auswertung der vegetationskundlichen Dauerflächen}

Die Entwicklung der Vegetation einzelner Lebensräume wurde mittels einer Ordination der Aufnahmen der vegetationskundlichen Dauerflächen (VDF) untersucht. Vor der Datenauswertung wurden die Rohdaten der jährlichen Geländeaufnahmen für die Analyse vorbereitet. Durch Code-Replacement wurden nominale Daten wie der frühere Nutzungstyp oder die Geländeform in binärskalierte Dummy- 
Variablen mit 0/1-Werten umgewandelt. Auch die erweiterte Braun-Blanquet-Skala wurde von einer Abundanz- in eine Ordinalskala transformiert. Jede Aufnahme erhielt einen zeitlich wie räumlich einheitlichen Code. Um die Ergebnisse der pflanzensoziologischen Kartierung in die Analyse einfließen zu lassen, wurde jeder Untersuchungsfläche eine durch die TWINSPAN-Analyse ermittelte Vegetationseinheit zugeordnet: CYN_TYP_1 bedeutete beispielsweise, dass VDF 1 in der Vegetationseinheit LolioCynosuretum typicum lag. Wissenschaftliche Artnamen wurden auf 7 Buchstaben gekürzt. Anschließend wurden die Daten in die Analysesoftware PAST (PAleontological STatistics, Version 2.11, s. Hammer et al. 2001) importiert.

Zunächst wurde die Gradientenlänge des Datensatzes bestimmt. Da es sich um einen relativ langen Gradienten (SD > 4) handelte, wurde zur Ordination der Daten eine DCA angewandt. Bei der Analyse wurden die Voreinstellungen von PAST verwendet (Algorithmus s. Hill \& Gauch 1980, Oxanen \& Minchin 1997). Die Datensätze der einzelnen Untersuchungsjahre wurden sowohl getrennt als auch gemeinsam hinsichtlich ihrer Variabilität und der Abhängigkeit von den Umweltdaten analysiert. Dabei wurden mögliche Einflussfaktoren überprüft. Zur Analyse wurden allgemeine Standortfaktoren wie Höhe, Exposition, Neigung, Vegetationshöhe, Feuchte- oder Deckungsgrad sowie Beweidungsintensitäten und frühere Flächennutzung (Use = Nutzung von 2000-06, Ush = Nutzung vor dem Jahr 2000) herangezogen. Da die erhobenen Umweltvariablen unterschiedliche Einheiten besitzen, wurden sie zuvor über die Formel $x_{i}$ (normalisiert) $=x_{i} / v \sum x_{i}^{2}$ normalisiert.

Zur weiteren Charakterisierung der Standorte wurden für jede Aufnahmefläche ungewichtete mittlere Ellenberg-Zeigerwerte für Nährstoffe, Feuchte, Reaktion und Temperatur (Ellenberg et al. 2001) sowie Nutzungswertzahlen nach Briemle et al. (2002) berechnet. Nutzungswertzahlen geben Hinweise auf die Toleranz gegenüber mechanischer Beeinflussung wie Schnitt, Tritt oder Fraß und auf die Akzeptanz und Beliebtheit bei landwirtschaftlichen Nutztieren oder beim Wild.

Zusammenhänge zwischen den floristischen Gradienten und Umweltvariablen wurden mit paarweisen Korrelationen analysiert. Bei den Korrelationen wurden die Signifikanzen nach Bonferroni um die Anzahl der Tests korrigiert (Tremp 2005). Die in die DCA einfließenden Umweltvariablen wurden zuvor unter Verwendung von Monte-Carlo-Permutationstests in einer direkten Gradientenanalyse (CCA) auf ihre Signifikanz $(P<0,05)$ hin überprüft. Dabei lautete die Nullhypothese: Die Artenzusammensetzung variierte unabhängig von den untersuchten Standortvariablen. Um festzustellen, ob alle wichtigen Umweltfaktoren berücksichtigt wurden, wurden die Ergebnisse der DCA und der CCA miteinander verglichen. Ist die Differenz der Eigenwerte klein, eignen sich die erhobenen Umweltdaten zur Interpretation des Ordinationsdiagramms. Ist die Differenz zwischen DCA und CCA hingegen groß, kann die Verteilung der Art- und Aufnahmedaten nicht durch die betrachteten Umweltfaktoren erklärt werden. Dabei gilt, je höher ein Eigenwert ist, desto wichtiger ist die Achse bzw. der zugrunde liegende Gradient für die Variation in der Artenzusammensetzung (Leyer \& Wesche 2008).

Um die zeitliche Vegetationsveränderung zu untersuchen, wurden von den Vegetationsaufnahmen nach einer DCA sogenannte Serien erstellt, bei denen jeder Plot im Diagramm als Zeitreihe dargestellt wird. Die jährlichen Aufnahmen eines Plots wurden hierbei durch Linien verbunden. Für 18 Aufnahmen entstanden Serien von 2008-11, für 26 Aufnahmen von 2009-11, da 8 Kontrollflächen erst im Januar 2009 eingerichtet wurden.

\section{Vergleich vegetationsökologischer Daten durch Signifikanztests}

Bestimmte Fragestellungen zur Vegetationsveränderung im Projektgebiet wurden mittels Hypothesenbildung und Signifikanztests überprüft, auch wenn es zu bedenken gilt, dass vegetationsökologische Daten häufig nicht die Grundvoraussetzungen erfüllen, die die klassische Teststatistik erfordert, da die Anzahl der Wiederholungen zu gering, der Umweltzustand nicht in exakter Weise reproduzierbar ist (Tremp 2005). Die Tests dienten zur Absicherung der gemessenen Daten. Statistisch signifikant 
bedeutet dabei, dass die Vertrauenswahrscheinlichkeit der Ergebnisse bei $95 \%(P<0,05), 99 \%$ $(P<0,01)$ oder sogar 99,9\% $(P<0,001)$ Sicherheit liegt (Traxler 1997).

\section{Entwicklung der Vegetationsparameter}

Mit dem Wilcoxon-Test für Paardifferenzen wurde die Veränderung bestimmter Vegetationsparameter überprüft. Dieser nicht-parametrische Test eignet sich - ähnlich wie der parametrische t-Test für verbundene Stichproben - für Probenahmen von derselben Stelle, die aufgrund derselben Ausgangslage nicht unabhängig voneinander sein können (Tremp 2005). Es wurde untersucht, ob sich zwischen 2008-2011 die mittlere Vegetationshöhe, die Deckungsgrade von Krautschicht, Moosen, Streuschicht und offenem Boden auf den Untersuchungsflächen veränderten. Auch wurde getestet, ob sich die beweideten Flächen im Jahr 2011 signifikant von den nicht beweideten Kontrollflächen unterschieden. Die Nullhypothese $\mathrm{H}_{0}$ erwartete, dass die Vegetationsparameter auf den beweideten Untersuchungsflächen im zeitlichen Verlauf beziehungsweise gegenüber den Kontrollflächen unverändert blieben. Die Fragestellung war zweiseitig mit einer Irrtumswahrscheinlichkeit von $5 \%$.

\section{Entwicklung der Artenzahlen}

Mit Hilfe des Wilcoxon-Tests für Paardifferenzen wurde überprüft, ob auf den Daueruntersuchungsflächen zwischen den Jahren 2008 und 2011 nennenswerte Artenverschiebungen stattfanden. Verglichen wurden die Artenzahlen der Subplots von 13 Dauerflächen (ohne Wald) aus den Jahren 2008 und 2011 ( $n=48$ ). Die Nullhypothese $H_{0}$ lautete, dass sich die Artenzahlen nach dreijähriger Pferdebeweidung nicht unterscheiden. Die Fragestellung war zweiseitig, die Irrtumswahrscheinlichkeit betrug $5 \%$ $(P<0,05)$. Analog dazu wurden die Veränderungen auf den 9 Kontrollflächen im Grünland bei Mahd und Brache auf Signifikanz getestet.

\section{Entwicklung der Artenzusammensetzung}

Ferner wurde der Einfluss des Beweidungsdrucks auf das Artenvorkommen unterschiedlicher Grünländer auf Signifikanz getestet. Bei der Auswertung wurde besonders auf die Veränderung der Deckungsgrade einzelner Arten im zeitlichen Verlauf geachtet. Diese quantitativen Vergleiche sind besser geeignet als rein qualitative - wie beispielsweise das Vorkommen oder Fehlen von Arten, da es bei kurzzeitigen Sukzessionsuntersuchungen eher um Dominanzverschiebungen als um Artenwechsel geht (Dierschke 1994).

Für die Analyse wurden die einzelnen Aufnahmen nach Aufnahmezeitpunkt und Grünlandtyp aufgeteilt. Die unterschiedlichen Grünlandtypen entsprachen hierbei den durch die Klassifikation zugeordneten Vegetationseinheiten. So ergaben sich für alle 4 Untersuchungsjahre für die Kategorie 1 Glatthaferwiesen (ARR) 3 Aufnahmen pro Jahr, für Kategorie 2 Typische Fettweiden (CYN) 4 Aufnahmen und für Kategorie 3 Artenarme typische Fettweiden (CYN_ARM) 3 Aufnahmen.

Mittels Rangvarianzanalyse wurden Mittelwertunterschiede zwischen den Kategorien überprüft. Der hier verwendete $\mathrm{H}$-Test von Kruskal und Wallis ist nicht-parametrisch (Abb. 34). Er setzt anders als die Varianzanalyse keine Normalverteilung und Unabhängigkeit der Untersuchungsobjekte voraus, ist allerdings als Verfahren weniger effizient als vergleichbare parametrische (Tremp 2005). Der H-Test vergleicht die Mediane mehrerer univariater Gruppen (Hammer et al. 2001). Die Nullhypothese $\mathrm{H}_{0}$ lautete dabei: Die Aufnahmen stammten von Gruppen mit gleichen Medianen.

Für die Statistik wurden die Daten der Daueruntersuchungsflächen (VDF) im Grünland ohne Transekte (T1-T3), Uferbereiche und Waldflächen sowie ohne Referenzaufnahmen verwendet. Insgesamt waren dies vom Jahr 2008 bis zum Jahr 201140 Aufnahmen. Für die statistischen Tests galt $P<0,05$ als signifikant. Die statistische Auswertung wurde mit PAST 2.11 durchgeführt. 


$$
H=\frac{12}{n(n+1)}\left(\sum_{g} \frac{T_{g}^{2}}{n_{g}}\right)-3(n+1)
$$

Abb. 34 Berechnung der Teststatistik H von Kruskal und Wallis

$\mathrm{n}=$ Anzahl der Beobachtungen

$\mathrm{T}_{\mathrm{g}}=$ Rangsumme der jeweiligen Gruppe

Bestimmte Arten des Datensatzes wurden aufgrund ihrer Eigenschaften als Weideunkräuter oder weideresistente Arten klassifiziert und die Veränderung ihrer Deckungsgrade unter Beweidung untersucht. Weideresistent waren dabei alle Arten mit Zeigerwerten für Weideverträglichkeit von 8-9 in der Biologischen Tafel von Dierschke \& Briemle (2002). Mit Hilfe des Wilcoxon-Tests für Paardifferenzen wurde überprüft, ob sich die Deckungsgrade dieser Arten auf den Daueruntersuchungsflächen zwischen den Jahren 2008 und 2011 signifikant veränderten.

\section{Diversität}

Der Begriff Biodiversität bezieht sich auf die Vielfalt der pflanzlichen Sippen sowie der Lebensräume. Die Bewertung der Biodiversität pro Untersuchungsfläche stellte einen Schwerpunkt der vegetationsökologischen Untersuchungen dar. Da es kaum möglich ist, den Artenreichtum eines Gebietes vollständig zu erheben, beruhten die Angaben der Artenvielfalt auf Schätzungen auf der Basis einiger, genauer untersuchter Probeflächen (Tremp 2005).

\section{Artendiversität}

Das älteste und einfachste Konzept der Artendiversität ( $\alpha$-Diversität) ist der Artenreichtum, also die Anzahl an Arten pro Aufnahmefläche (Dierschke 1994, Tremp 2005). Eine hohe Artenzahl bedeutet jedoch nicht zwangsläufig eine höhere Stabilität oder gar Qualität von Lebensgemeinschaften oder Ökosystemen (Tremp 2005). Für die Diversität gilt, dass Artengemeinschaften, in der alle Arten dieselbe Populationsdichte aufweisen, eine höhere Diversität besitzen als Gemeinschaften, in der einige Arten häufig und andere selten vorkommen. Diese Gleichmäßigkeit der Deckungsanteile beziehungsweise die Dominanzstruktur eines Bestandes oder einer Gesellschaft wird mit der Evenness numerisch ausgedrückt. Die Evenness ist ein Maß für die Gleichverteilung von Elementen und gibt an, ob eine maximale Gleichverteilung der Arten erreicht ist (von Oheimb et al. 2006). Die maximale Diversität liegt dann vor, wenn in einer Gemeinschaft alle Arten in einem gleich quantitativen Verhältnis stehen (Tremp 2005). Je stärker eine oder wenige Arten vorherrschen, desto mehr nähert sich der Wert für die Evenness 0 an, bei totaler Gleichverteilung der Arten liegt er bei 1 (Dierschke 1994).

Der Shannon-Diversitäts-Index $\left(\mathrm{H}^{\prime}\right)$ vereint die $\alpha$-Diversität und die Dominanzstrukturen (Evenness) der Arten miteinander und berechnet die Ungewissheit, eine bestimmte Art bei zufälliger Probenahme aufzufinden (Mühlenberg 1993). Der Shannon-Index steigt mit den Artenzahlen und der Evenness an (Abb. 35). Die maximale Diversität $\mathrm{H}^{\prime}$ liegt dann vor, wenn in einer artenreichen Gemeinschaft alle Arten im gleichen quantitativen Verhältnis stehen. Der Wert 0 bedeutet, dass alle Individuen zu einer Art gehören (Dierschke 1994, Tremp 2005).

Im Fokus der Untersuchung stand die Frage, ob sich die Biodiversität im Gebiet durch eine ganzjährige Pferdebeweidung erhöht oder verringert. Zur Analyse der Vegetationsentwicklung auf den Dauerflächen wurden daher die Evenness und der Shannon-Index berechnet. Dies erfolgte anhand transformierter Deckungswerte der Arten mit Hilfe des Programms JUICE 7.0.42 (Tichý 2002). Veränderungen im Untersuchungszeitraum wurden mit dem Wilcoxon-Test für Paardifferenzen auf Signifikanz überprüft. Die Dauerflächen wurden hierbei 6 Pflanzengesellschaften und ihren Variationen zugeordnet: 
der Typischen Fettweide, ihrer artenarmen Ausprägung, der Fettweide mit Anteilen der Glatthaferwiese, der Basalgesellschaft der Glatthaferwiese sowie ihrer ruderalen oder mageren Ausprägung.

\section{Gradientendiversität}

Zur Untersuchung der Veränderung der Pflanzengemeinschaften entlang eines Gradienten wurde die Turnover-Rate berechnet (Abb. 36). Sie beschreibt den Austausch von Arten über einen bestimmten räumlichen oder auch zeitlichen Gradienten und ist kennzeichnend für die ß-Diversität (Tremp 2005). Berücksichtigt wird hierbei nur die An- oder Abwesenheit von Arten (Mühlenberg 1993). Angewandt wurde der Wilson-Shmida-Koeffizient (Hammer et al. 2001, Koleff et al. 2003).

Zur Berechnung der Gradientendiversität wurden die Vegetationsdaten von Transekt T3 der Jahre 2008 bis 2011 verwendet. Es handelt sich hierbei um einen räumlichen Gradienten über differenzierbare Lebensräume. Darüber hinaus wurden die 13 Daueruntersuchungsflächen (VDF) im offenen Weideland in den Jahren 2008 und 2011 betrachtet. Hier berechnete die Turnover-Rate das Verschwinden oder Auftreten von Arten innerhalb der untersuchten Grünländer.

$$
\begin{aligned}
& \mathrm{H}_{\max }=\text { In s } \quad \mathrm{H}^{\prime} \quad=\text { Diversitätsindex } \\
& \begin{array}{ll}
\mathrm{E}=\frac{\mathrm{H}^{\prime}}{\mathrm{H}_{\max }} & \mathrm{E} \quad=\text { Evenness } \\
& \mathrm{s}=\text { Gesamtzahl der Arten }
\end{array} \\
& H^{\prime}=\sum_{i=1}^{s} p_{i} \ln p_{i} \quad N \quad \begin{array}{c}
\text { Summe der Bedeutungswerte } \\
\text { aller Arten }
\end{array} \\
& \begin{array}{ll}
\mathrm{p}_{\mathrm{i}}=\frac{\mathrm{n}_{\mathrm{i}}}{\mathrm{N}} & \mathrm{n}_{\mathrm{i}}=\text { Bedeutungswert der Art } \\
\mathrm{p}_{\mathrm{i}} \quad=\begin{array}{c}
\text { Relativer Anteil der Art } \mathrm{i} \\
\text { zwischen } 0 \text { und } 1
\end{array}
\end{array}
\end{aligned}
$$

$$
\mathrm{b}_{\mathrm{t}}=\frac{\mathrm{g}(\mathrm{H})+\mathrm{I}(\mathrm{H})}{2 \bar{\alpha}} \quad \begin{array}{ll}
\mathrm{g}(\mathrm{H}) & \begin{array}{l}
\text { = Zahl der Arten, die beim Übergang von Fläche 1 } \\
\text { nach Fläche 2 neu auftraten }
\end{array} \\
\mathrm{I}(\mathrm{H}) & =\text { Zahl der Arten, die nach dem Übergang fehlen } \\
\overline{\mathrm{a}} & =\text { durchșchnittliche Artenzahl }
\end{array}
$$




\subsubsection{Erfassung der Strukturentwicklung}

Die Strukturentwicklung des Gebietes wurde auf verschiedenen räumlichen Ebenen untersucht. Die Entstehung von Habitatmosaiken wurde auf kleinflächigen Strukturdauerflächen, die Verbissbelastung im Gehölz auf Transekten erhoben. Für Veränderungen auf Landschaftsebene wurden regelmäßig Strukturelemente im gesamten Projektgebiet erfasst.

\subsubsection{Erhebungen zur Verbissbelastung im Gehölz}

Die Verbissbelastung der Weidetiere im Gehölz wurde mit Hilfe von Luftbildauswertungen und abgleichenden Geländebegehungen ausgewertet. Im GIS wurden zwei Karten erstellt: Sie bilden den Gehölzaufwuchs im Jahr 2006 vor Beginn der Beweidung sowie im Jahr 2011 am Ende der Datenaufnahme ab. Der Aufwuchs wurde in Form von Deckungsgradklassen der Gehölze erfasst. Mit Hilfe des Wilcoxon-Tests für Paardifferenzen wurde überprüft, ob sich die Flächenanteile der Deckungsgradklassen zwischen 2006 und 2011 signifikant unterschieden.

Auf 6 Transekten wurden jährlich im Winter zusätzlich zum Gehölzaufwuchs die Verbissschäden durch Weidetiere erfasst. Die Transekte lagen an Waldrändern, Lichtungen oder halboffenen Gebüschflächen mit einem hohen Anteil an Jungpflanzen. Auf insgesamt $600 \mathrm{~m}^{2}$ Fläche wurden alle Gehölze hinsichtlich Verbissspuren untersucht. Protokolliert wurden die in Tab. 22 aufgelisteten Parameter. Im dritten Winter (2010/2011) erfolgte die Verbissbeurteilung nur noch auf 5 Transekten, da eine Aufnahmefläche aufgrund einer Entbuschungsmaßnahme zerstört wurde.

\subsubsection{Erfassung von Strukturveränderungen auf mittlerer Maßstabsebene}

Aufgrund der Vielfalt und der kleinräumigen Verzahnung von Lebensraumtypen konnten nicht alle Bestände im Gebiet auf Strukturdauerflächen erfasst werden. Um Strukturveränderungen im gesamten Projektgebiet festzuhalten, wurde das Gebiet in 105 einheitliche Teilflächen unterteilt, die unterschiedlichen Biotopen (beispielsweise Hecke, Grünland oder Ufer) entsprachen. Diese Methodik ermöglicht es, auch kurzfristige, weidebedingte Veränderungen mit einem geringen Arbeitsaufwand abzubilden. Die Teilgebiete wurden der Biotopkategorie mit dem größten Flächenanteil zugeordnet. Diese Einteilung ist zwar subjektiver als eine mit festgelegten räumlichen Grenzen, sie spiegelt aber Entwicklungsaspekte und die Ressourcenverfügbarkeit besser wieder, die wiederum das Verhalten der Weidetiere beeinflussen (Bontjer 2010a, 2010b).

Auf den Teilflächen wurden verschiedene Strukturelemente erfasst (Tab. 23). Dabei sind die relativen Anteile an kurz-, mittel- und langrasiger Vegetation ein Maß für die Intensität der Beweidung (Tab. 24). Die Schätzung erfolgte in Prozent der Deckung im jeweiligen Lebensraumtyp relativ zu der Erwartung einer Vegetationsentwicklung ohne Beweidung (vgl. von Oheimb et al. 2006). Aus dem Anteil langrasiger Vegetation wurden die Weiderückstände im Winter abgeleitet, da sie Unterbeweidung anzeigen. Ergänzend dazu wurde der Beweidungsfaktor für die Teilfläche (Tab. 25) sowie der Anteil an offenem Boden in Prozent angegeben. Der Grad der Verbuschung resultierte aus der Anzahl an Keimlingen und Jungpflanzen in der Krautschicht, der Zustand der Uferbereiche wurde durch den Grad der Verschilfung abgebildet (Tab. 26). Ergänzend hierzu wurden die Bodenfeuchte und der Wasserstand aufgenommen (Tab. 27).

Die Datenaufnahmen erfolgten in den Jahren 2008-2010 viermal im Kalenderjahr in den Monaten Januar, April, Juli und September, wobei die Erhebung im September 2009 entfiel. Auf den Begehungen wurden dominante Pflanzenarten notiert und eine Fotodokumentation angefertigt. 


\section{AUSWIRKUNG DER BEWEIDUNG}

Tab. 22: Parameter zur Bewertung der Verbissbelastung

\begin{tabular}{|c|c|}
\hline Kategorie & Schicht \\
\hline $\mathrm{K}$ & Kraut \\
\hline S & Strauch \\
\hline \multirow[t]{6}{*}{ B } & Baum \\
\hline & Angaben zur Baumart \\
\hline & Anzahl der Pflanzen / abgestorbenen Pflanzen / Jungwüchse pro Art \\
\hline & Höhe (max. in cm) \\
\hline & Anteil der Art auf Fläche (Schätzung in \%) \\
\hline & Anteil der Pflanzen / Jungwüchse ohne Verbiss pro Art (in \%) \\
\hline Kategorie & Schadensart \\
\hline 1 & Verbiss am Leittrieb \\
\hline 2 & Verbiss am Seitentrieb \\
\hline 3 & Schälen \\
\hline 4 & Scheuern \\
\hline 5 & Tritt / Tierpfad \\
\hline Kategorie & Anteil beschädigter Bäume pro Art \\
\hline 1 & unter $25 \%$ \\
\hline 2 & unter $50 \%$ \\
\hline 3 & unter $75 \%$ \\
\hline 4 & über $75 \%$ \\
\hline Kategorie & Anteil beschädigter Triebe \\
\hline 1 & unter $25 \%$ \\
\hline 2 & unter $50 \%$ \\
\hline 3 & unter $75 \%$ \\
\hline 4 & über $75 \%$ \\
\hline Kategorie & Höhe des Verbisses \\
\hline 1 & $10-30 \mathrm{~cm}$ \\
\hline 2 & $30-50 \mathrm{~cm}$ \\
\hline 3 & $50-100 \mathrm{~cm}$ \\
\hline 4 & $100-150 \mathrm{~cm}$ \\
\hline 5 & über $150 \mathrm{~cm}$ \\
\hline
\end{tabular}




\section{AUSWIRKUNG DER BEWEIDUNG}

Tab. 23: Erfassung von Strukturelementen

\begin{tabular}{|c|c|}
\hline Kategorie & Weidetierpfad \\
\hline 1 & keine Trittspuren oder Pfade erkennbar \\
\hline 2 & vereinzelte Trittspuren, Pfad mit wenigen Metern Länge \\
\hline 3 & mehrere deutliche Trittspuren oder Pfade mit Länge über $10 \mathrm{~m}$ \\
\hline 4 & flächig Trittspuren, deutlich erkennbarer Pfad mit über $10 \mathrm{~m}$ Länge oder mehrere m Breite \\
\hline Kategorie & Kothaufen \\
\hline 1 & keine Kothaufen erkennbar \\
\hline 2 & vereinzelte Kothaufen (unter 10) \\
\hline 3 & zahlreiche Kothaufen, vereinzelt deutliche Geilstellen \\
\hline 4 & flächig Kothaufen, große Geilstellen \\
\hline Kategorie & Ameisennester \\
\hline 1 & keine \\
\hline 2 & wenige (1-3) \\
\hline 3 & unter 10 \\
\hline 4 & mehr als 10 \\
\hline Kategorie & Maulwurfshügel \\
\hline 1 & keine \\
\hline 2 & wenige (1-5) \\
\hline 3 & unter 20 \\
\hline 4 & mehr als 20 \\
\hline
\end{tabular}

Tab. 24: Relative Anteile an kurz-, mittel- und langrasiger Vegetation

\begin{tabular}{ll}
\hline Kategorie & Beschreibung \\
\hline kurzrasig & kurz verbissen \\
mittelrasig & etwas abgeweidet oder kleinräumig heterogen verbissen \\
langrasig & weitgehend unverbissen \\
\hline
\end{tabular}

Tab. 25: Beweidungsfaktoren der Kraut- und Baumschicht

\begin{tabular}{ll}
\hline Kategorie & Krautschicht \\
\hline 1 & keine Fraßspuren, einzelne Triebe verbissen \\
2 & mehrere Triebe verbissen, einzelne Büschel verbissen \\
3 & sichtbar (fleckenhaft) durchweidet \\
4 & deutlich beweidet, es stehen nur noch einzelne Büsche / Triebe \\
5 & kurz abgeweidet \\
\hline Kategorie & Baumschicht \\
\hline 1 & kein Verbiss oder Baumschaden \\
2 & wenige Triebe verbissen oder beschädigt \\
3 & zahlreiche Triebe verbissen oder beschädigt \\
4 & deutlicher Verbiss oder Schaden \\
5 & sehr deutlicher Verbiss oder Schaden, abgestorben \\
\hline
\end{tabular}




\section{AUSWIRKUNG DER BEWEIDUNG}

Tab. 26: Grad der Verbuschung und Verschilfung

\begin{tabular}{ll}
\hline Kategorie & Verbuschung \\
\hline 1 & keine Verbuschung erkennbar, keine oder sehr wenige Keimlinge \\
2 & vereinzelt Keimlinge oder Jungpflanzen \\
3 & teilweise Keimlinge oder Jungpflanzen \\
4 & starke Verbuschung, überwiegend Keimlinge oder Jungpflanzen \\
\hline Kategorie & Verschilfung \\
\hline 1 & weitgehend vegetationsfrei \\
2 & rändlich vereinzelt Schilf \\
3 & teilweise Schilf, rändlich durchgehend Schilf \\
4 & flächig Schilf \\
\hline
\end{tabular}

Tab. 27: Bodenfeuchte und Wasserstand

\begin{tabular}{ll}
\hline Kategorie & Bodenfeuchte \\
\hline 1 & trockener Boden \\
2 & mäßig feuchter Boden \\
3 & feuchter Boden \\
4 & stehendes Wasser \\
\hline Kategorie & Wasserstand (bei Gewässern) \\
\hline 1 & ausgetrocknet \\
2 & bis max. 50 cm tief, Boden erkennbar, Uferbereich liegt teilweise frei \\
3 & mittlerer bis normaler Wasserstand, Uferbereich liegt nicht frei \\
4 & hoher Wasserstand, teilweise Überschwemmung \\
\hline
\end{tabular}




\subsubsection{Kartierung von Strukturelementen auf Dauerflächen}

Strukturelemente wurden auf Strukturdauerflächen (SDF) erhoben. Sie hatten eine Größe von jeweils $100 \mathrm{~m}^{2}$. Die Flächen lagen in relevanten Vegetationsbeständen und enthielten einen bis mehrere Lebensraumtypen. Stellte eine Dauerfläche Elemente verschiedener Lebensraumtypen dar, erfolgte die Auswertung anteilig für den jeweiligen Typ. Ihre Lage und Eigenschaften sind in Anlage 6.7 beschrieben. Die Anteile der Lebensraumtypen auf den Dauerflächen entsprachen - mit Ausnahme des Magerrasens - in etwa den Anteilen im Projektgebiet (Tab. 28).

Die Flächen wurden im Gebiet dauerhaft vermarkt und oberirdisch mit einem Holzpfahl markiert. Jede Dauerfläche wurde dreimal jährlich untersucht: im Frühjahr zu Beginn des Hauptwachstums, im Sommer am Ende des größten Vegetationszuwachses und im Frühherbst am Ende der Vegetationsperiode. Im Januar 2009 wurden in geringer Entfernung zu den Strukturdauerflächen 7 weitere Dauerflächen als Ausschlussflächen (A) mit demselben Biotyp angelegt, die zeitgleich untersucht wurden (Tab. 29). Eine Nutzung der Ausschlussflächen durch die Weidetiere war aufgrund einer 1,50 m hohen Umzäunung nicht möglich. Die Ausschlussflächen dienten einem Vergleich von beweideter und unbeweideter Fläche. Die Entwicklung wurde mit standardisierten Fotoaufnahmen dokumentiert.

Auf den 14 Dauerflächen wurden folgende Strukturelemente aufgenommen:

- Vegetationshöhe der Schichten (maximale / mittlere Höhe, Messung in Stichproben)

- Deckungsgrad von Gräsern, Kräutern, Moosen, Streu, offenem Boden, Kot und vitaler Vegetation (Schätzungen in \%)

- Beweidungsfaktoren für die Krautschicht sowie für Gehölze (fünfstufige Skala, s.Tab. 25)

- relative Anteile an kurz-, mittel- und langrasiger Vegetation (in \% bezugnehmend auf die erwartete Vegetationsentwicklung im Lebensraumtyp ohne Beweidung, s. Tab. 24)

- Weidetierpfade (Fläche in $\mathrm{m}^{2}$ ), Maulwurfshaufen, Ameisennester sowie Pferdekothaufen (Zählungen)

- Gehölzentwicklung: Gehölzarten, Wuchshöhe, Wuchsform und Vitalität der Gehölze sowie Grad der Verbuschung (fünfstufige Skala)

- Gegebenenfalls Wasserstand (Höhe in $\mathrm{cm}$ )

Tab. 28: Anteile der Lebensraumtypen im Projektgebiet, auf den Strukturdauer- sowie den Ausschlussflächen (Kontrollflächen)

\begin{tabular}{lllllll}
\hline & \multicolumn{2}{c}{ Projektgebiet } & \multicolumn{2}{c}{ Strukturdauerflächen } & \multicolumn{2}{c}{ Kontrollflächen } \\
Lebensraumtyp & in $\mathrm{m}^{2}$ & in \% & in $\mathrm{m}^{2}$ & in \% & in $\mathrm{m}^{2}$ & in \% \\
\hline Frisch- und Feuchtgrünland & 500.000 & 46,5 & 285 & 40,7 & 139 & 40,9 \\
Magere Grasfluren & 35.000 & 3,3 & 80 & 11,4 & 80 & 23,5 \\
Kleingewässer, Uferfluren, Röhrichte & 95.000 & 8,8 & 45 & 6,4 & 15 & 4,4 \\
Wälder, Gehölze und Waldsaum & 285.000 & 26,5 & 190 & 27,1 & 70 & 20,6 \\
Ackerbrache & 110.000 & 10,2 & 100 & 14,3 & 36 & 10,6 \\
Moor & 43.000 & 4,0 & - & - & - & - \\
Sonstiges & 7.000 & 0,7 & - & - & - & - \\
Summe & $\mathbf{1 . 0 7 5 . 0 0 0}$ & $\mathbf{1 0 0}$ & $\mathbf{7 0 0}$ & $\mathbf{1 0 0}$ & $\mathbf{3 4 0}$ & $\mathbf{1 0 0}$ \\
\hline
\end{tabular}


Tab. 29: Beschreibung der Strukturdauerflächen und ihrer Kontrollflächen im Gebiet Süd-Langeland

\begin{tabular}{|c|c|c|c|c|c|c|c|c|c|}
\hline Nr. & Lebensraumtyp & $\begin{array}{l}\text { Be- } \\
\text { zeich- } \\
\text { nung }\end{array}$ & Gebiet & $\begin{array}{l}\text { Auf- } \\
\text { nahme- } \\
\text { paar }\end{array}$ & $\begin{array}{l}\text { Größe } \\
\left(m^{2}\right)\end{array}$ & $\begin{array}{l}\text { Höhe } \\
\text { (m) }\end{array}$ & $\begin{array}{l}\text { Expo- } \\
\text { sition }\end{array}$ & Relief & $\begin{array}{l}\text { Anteil } \\
\text { Lebensraum- } \\
\text { typ in \% }\end{array}$ \\
\hline & Strukturdauerflächen & & & & & & & & \\
\hline 1 & Artenarmes Grünland, Ufer & S1 & 9 & A1 & 100 & $5-7$ & $\mathrm{~N}$ & Ebene & $75 / 25$ \\
\hline 2 & Artenarmes Grünland & S2 & 10 & $\mathrm{~A} 2$ & 100 & 7 & $S$ & $\begin{array}{l}\text { Mittel- } \\
\text { hang }\end{array}$ & 100 \\
\hline 3 & Ackerbrache & S3 & 13 & A3 & 100 & 10 & SW & $\begin{array}{l}\text { Mittel- } \\
\text { hang }\end{array}$ & 100 \\
\hline 4 & Wald, Gebüsch, artenarmes Grünland & S4 & 4,6 & A4 & 100 & 3 & $S$ & $\begin{array}{l}\text { Unter- } \\
\text { hang }\end{array}$ & $50 / 20 / 30$ \\
\hline 5 & Wald, Weg & S5 & 6 & A5 & 100 & 10 & $\mathrm{~S}$ & $\begin{array}{l}\text { Mittel- } \\
\text { hang }\end{array}$ & $80 / 20$ \\
\hline 6 & Artenreiches Grünland, Röhricht & S6 & 20 & A6 & 100 & 5 & $\mathrm{~S}$ & $\begin{array}{l}\text { Unter- } \\
\text { hang }\end{array}$ & $80 / 20$ \\
\hline 7 & Magerrasen, Gebüsch & S7 & 20 & A7 & 100 & $20-25$ & W & $\begin{array}{l}\text { Ober- } \\
\text { hang }\end{array}$ & $80 / 20$ \\
\hline & Ausschlussflächen & & & & & & & & \\
\hline 8 & Artenarmes Grünland, Ufer & A1 & 9 & S1 & 60 & $5-7$ & $\mathrm{~S}$ & Ebene & $75 / 25$ \\
\hline 9 & Artenarmes Grünland & $\mathrm{A} 2$ & 19 & S2 & 36 & 7 & NO & $\begin{array}{l}\text { Mittel- } \\
\text { hang }\end{array}$ & 100 \\
\hline 10 & Ackerbrache & A3 & 13 & S3 & 36 & 10 & $S$ & $\begin{array}{l}\text { Mittel- } \\
\text { hang }\end{array}$ & 100 \\
\hline 11 & Wald, Gebüsch, artenarmes Grünland & A4 & 4,6 & S4 & 36 & 3 & $\mathrm{~S}$ & $\begin{array}{l}\text { Unter- } \\
\text { hang }\end{array}$ & $10 / 30 / 60$ \\
\hline 12 & Wald, Weg & A5 & 6 & S5 & 36 & 10 & $S$ & $\begin{array}{l}\text { Mittel- } \\
\text { hang }\end{array}$ & $80 / 20$ \\
\hline 13 & Artenreiches Grünland & A6 & 5 & S6 & 36 & 5 & SO & $\begin{array}{l}\text { Mittel- } \\
\text { hang }\end{array}$ & 100 \\
\hline 14 & Magerrasen, Gebüsch & A7 & 20 & S7 & 100 & 15 & $S$ & Kuppe & $80 / 20$ \\
\hline
\end{tabular}




\subsubsection{Datenauswertung}

\section{Bewertung der Verbissbelastung}

Die Daten der Verbisserhebungen aus den drei Untersuchungsjahren wurden miteinander verglichen. Da die Anzahl der Einzelpflanzen im dritten Jahr aufgrund eines fehlenden Transektes geringer war, werden die Flächenanteile und Verbissschäden nur anteilig und nicht absolut dargestellt. Zur Überprüfung, ob eine Art von den Tieren präferiert wurde, wurde der Electivity Index E nach Ivlev berechnet. Dabei wird nach der Formel $E=(r-p) /(r+p)$ der Anteil beschädigter Pflanzen pro Art $(r)$ mit dem Flächenanteil dieser Art auf den Transekten ( $p$ ) in Beziehung gesetzt.

\section{Strukturveränderungen auf mittlerer Maßstabsebene}

Die Auswertung der Strukturentwicklung im Gebiet erfolgte mit Hilfe eines GIS (ArcView 10.0, ESRI). Auf der Grundlage eines Luftbildes wurde eine Karte mit 105 Teilhabitaten angefertigt. Strukturparameter konnten so grafisch abgestuft in Klassen dargestellt werden. Für einen Vergleich zwischen den Jahren wurden die Flächenanteile der Klassen addiert und tabellarisch in einer Tabelle (EXCEL, Microsoft Office) wiedergegeben. Die Auswertung erfolgte für ausgewählte Parameter für die Jahre 2008 und 2010.

\section{Entwicklung der Strukturparameter auf Probeflächen}

Die Ermittlung des Lebensraumtyps der Strukturdauer- und Ausschlussflächen erfolgte im Rahmen der Biotopkartierung im Jahr 2007. Bei die Analyse der Strukturelemente wurden vier Lebensraumtypen berücksichtigt: Das artenreiche und -arme Grünland sowie die Ackerbrache - als sehr artenarmes Grünland - wurden zur Kategorie Frischgrünland zusammengefasst. Der Magerrasen wurde separat ausgewertet, da er sich bezüglich Standort und Vegetationshöhe von den Grünländern unterschied. Laubwälder und Gebüsche wurden zusammengefasst. Den vierten Typ stellte der Uferbereich von Tümpeln mit Röhrichtbeständen dar.

Die Veränderung der Strukturelemente im Untersuchungszeitraum wurde grafisch in Diagrammen abgebildet. Mit dem Wilcoxon-Test für Paardifferenzen wurde sie für bestimmte Strukturparameter auf Signifikanz überprüft (s. 6.1.1.5 Datenauswertung). Dabei wurde sowohl die zeitliche Veränderung auf den beweideten Probeflächen zwischen 2008 und 2010 als auch die Differenz zwischen beweideten und nicht-beweideten Flächen im Jahr 2010 untersucht. Die Nullhypothese $H_{0}$ erwartete keine Veränderung der Strukturparameter im zeitlichen Verlauf beziehungsweise gegenüber den Kontrollflächen. Die Fragestellung war zweiseitig mit einer Irrtumswahrscheinlichkeit von $5 \%$.

\section{Ordination der Strukturerhebungen}

Die Ordination der Strukturdauerflächen erfolgte mittels einer Hauptkomponentenanalyse (Principal Components Analysis, PCA). Mit diesem Ordinationsverfahren wird die Varianz eines multivariaten Datensatzes auf wenige, voneinander unabhängige Komponenten reduziert (Tremp 2005): Aus einer Vielzahl von Variablen, die miteinander korrelieren, werden durch Dimensionsreduktion einige wenige Achsen herausgearbeitet, die den Datensatz gut abbilden. Das mathematische Prinzip ist bei Leyer \& Wesche (2007) erläutert.

Verrechnet wurden die Standortdaten der einzelnen Aufnahmeflächen, also die Umweltvariablen. Diese entsprachen meist linearen Gradienten, eine Grundvoraussetzung der Hauptkomponentenanalyse. Bei der PCA wurden 7 der 27 erhobenen Strukturparameter der Krautschicht betrachtet: mittlere Vegetationshöhe, Deckung der Gräser, Kräuter, Moose, Streu, der Anteil an offenem Boden sowie die Kotmenge als Indiz für den Stickstoffeintrag. Eine Auswahl war erforderlich, da die Stichprobengröße sonst zu klein gewesen wäre: Als Richtwert gilt, dass mindestens dreimal so viele Beobachtungen wie 
Variablen vorhanden sein sollten. Das absolute Minimum ist die gleiche Anzahl von Beobachtungen und Variablen. Zudem korrelierten einige Variablen stark miteinander.

Nicht nur die Anzahl der Variablen, auch die Anzahl der Hauptkomponenten ist bei der PCA begrenzt. Sie entspricht maximal der Anzahl der Variablen. Der Screeplot und die Werte der Ladungen geben Aufschluss über die Güte der Ordination. Der Screeplot ist eine grafische Darstellung des Eigenwerteverlaufs in der Form eines einfachen Liniendiagramms, das einen Überblick darüber gibt, wie viele Hauptkomponenten extrahiert werden können (Tremp 2005). Hierbei wurde die Broken-Stick-Methode zu Hilfe genommen (Abb. 37): Eigenwerte unterhalb der Broken-Stick-Kurve gelten als nicht mehr signifikant (Hammer et al. 2000).

Vor der PCA wurden die Variablen log-transformiert, zentriert und standardisiert (z-Transformation), da die Umweltdaten über unterschiedliche Einheiten verfügten und so nicht miteinander verglichen werden konnten (Leyer \& Wesche 2007). Für jede Aufnahme wurde eine Identifikationsnummer generiert, bestehend aus Nummer der Aufnahmefläche, Jahr und Jahreszeit der Datenaufnahme sowie Lebensraumtyp. Anschließend wurde eine Korrelationsmatrix-PCA durchgeführt. Dank der z-Transformation war die Korrelation von Variablen mit den Hauptkomponentenachsen proportional zum Gewicht der einzelnen Variablen auf der jeweiligen Achse. Diese wird als Ladung bezeichnet. Ihr Wert liegt zwischen 1 und -1. Die Signifikanz der Variablen wurde über die Höhe der Ladungen abgeschätzt. Es gilt dabei die Faustregel: $\pm 0,3$ bedeutet signifikant, $\pm 0,4$ wichtig und $\geq 0,5$ sehr wichtig.

Ausreißer können die Ergebnisse stark beeinflussen, weil sie zu einer höheren Varianz führen. Vor der PCA wurde ein Ausreißer-Screening durchgeführt: Aufnahmen, die mehr als 2,5 Einheiten vom Mittelwert entfernt lagen, wurden entfernt. Bei der Aufnahme im Uferbereich (SDF 6) beispielsweise handelte es sich um eine im Frühjahr überflutete Fläche, auf der keine Deckungsgrade erhoben werden konnten.

In den Ordinationsdiagrammen wurden die 6 Lebensraumtypen des offenen Weidelandes (GL, A, HTR) und der Wälder (GB, LW, WS) mit unterschiedlichen Symbolen dargestellt. Aus Gründen einer besseren Übersichtlichkeit wurden die Ergebnisse der PCA getrennt nach Jahreszeiten dargestellt. Die Skala in den Diagrammen entspricht den Eigenwerten. Es wurden zudem die Eigenwerte der Achsen und der Anteil an erklärter Varianz angegeben, da sie ein Maß für die Güte der Ordination sind.

Für die Auswertung wurden die Programme Excel 2013 (Microsoft Office), ArcView 10.0 (ESRI) sowie PAST 2.11 eingesetzt.

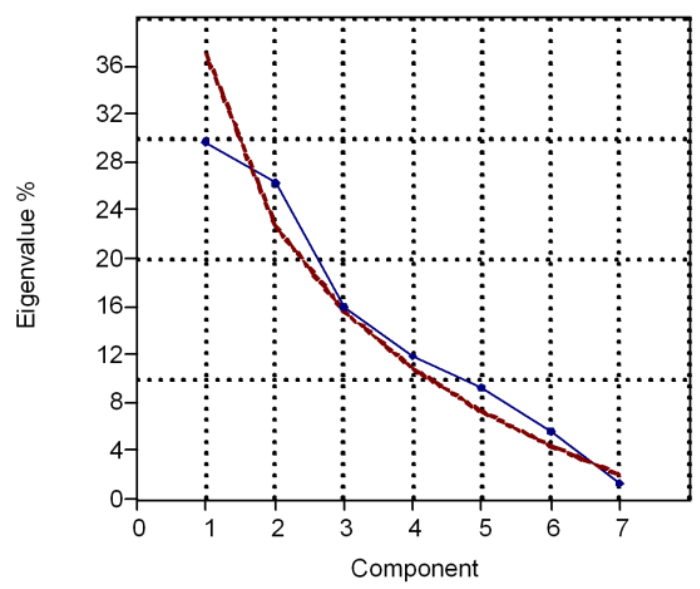

Abb. 37: Screeplot der Hauptkomponentenanalyse (PCA) von sieben Strukturparametern im offenen Weideland blaue $/$ dünne Linie = Eigenwerte der Hauptkomponenten, rote $/$ fette Linie = Broken-Stick-Kurve 


\subsection{Vegetationsausstattung zu Beginn der Beweidung}

Das Projektgebiet Süd-Langeland wies zu Beginn der Pferdebeweidung ein strukturreiches Landschaftsbild mit einer Vielzahl unterscheidbarer Lebensräume auf. Diese Mosaikstruktur ist typisch für kleinräumig gegliederte Landschaften, die in der Vergangenheit eine unterschiedliche Einwirkung des Menschen erfahren haben (Lüdi 1930, Dierschke 1994).

\subsubsection{Lebensraum- und Biotoptypen}

Auf der Grundlage der Standard-Biotoptypenliste für Deutschland (Riecken et al. 2003) wurden 28 unterschiedliche Biotoptypen (vierstelliger Code, z.B. 32.12) mit Ausprägungen (sechsstelliger Code, z.B. 24.03.03 bzw. 24.3.3) identifiziert. Der Nummerierung der Biotoptypenlisten, der Einteilung von Riecken folgend, gliederten sie sich in:

\section{Gewässer}

24.3 Stehende Gewässer

$$
\text { 24.3.3 mesotrophe Weiher }
$$

24.3.5 mesotrophe Tümpel

24.7 Stehende Gewässer anthropogenen Ursprungs

24.8 Zeitweilig trockenfallende Lebensräume unterhalb des Mittelwasserbereiches an stehenden Gewäs sern

32. Felsen, Mauern, Steinbrüche und Rohbodenstandorte

32.6 Steinriegel

32.6.1 Steinriegel

32.12 Schutthalde

\section{3. Äcker und Ackerbrachen}

33.4 Löß-, Lehm-, Tonboden

33.4.4 Brache

34. Trockenrasen, Grünland trockener bis frischer Standorte

$\begin{array}{ll}35.1 & \text { Magerrasen } \\ 34.2 & \text { Artenreiches Grünland frischer Standorte } \\ 34.3 & \text { Artenarmes Intensivgrünland frischer Standorte }\end{array}$

35. Waldfreie Niedermoore und Sümpfe, Grünland nasser bis feuchter Standorte

35.1 Waldfreie oligo- bis mesotrophe Niedermoore und Sümpfe

35.2 Grünland nasser bis feuchter Standorte

38. Röhrichte

38.1 Teichsimsenröhricht

38.2 Schilfröhricht

38.3 Rohrkolbenröhricht

38.4 Schneidenröhricht

39. Wald- und Ufersäume, Staudenfluren

39.1 Wald- und Gehölzsäume 
39.2 Kahlschläge und Lichtungen

39.3 Krautige und grasige Säume und Flure der offenen Landschaft

39.4 Krautige Ufersäume und -fluren an Gewässern

39.6 Ruderalstandorte

41. Feldgehölze, Gebüsche, Hecken, Gehölzkulturen
41.1 Gebüsche autochthon
41.2 Feldgehölz autochthon
41.3 Hecken autochthon
41.5 Einzelbaum, Baumgruppe
$41.7 \quad$ Intensivgehölz

43. Laubwälder und -forste

43.9 Laubwaldforst einheimischer Laubarten

43.9.2 Frisch

44. Nadelwälder und -forste

44.4 Nadelforste heimischer Baumarten

44.4.2 Tannen-Fichten-Forste

44.4.4 Kiefernforste

52. Verkehrsanlagen und Plätze

52.1 Straßen

52.1.2 Wege (.6 Unbefestigt)

Abb. 38 zeigt die räumliche Verteilung der Biotope. Sie wurden 6 verschiedenen Lebensraumtypen zugeordnet (Abb. 39):

- Frisch- und Feuchtgrünland

- Magerrasen und magere Grasfluren

- Gewässer, Uferfluren und Röhrichte

- Wälder, Gebüsche, Gehölze und Waldsaum

- Moor

- Sonstige Habitate (Wege, Steinmauer, etc.).

Die Flächenanteile der Lebensraumtypen fielen unterschiedlich aus (siehe Tab. 28). Mit rund 57 Prozent nahm das Feucht- und Frischgrünland den größten Flächenanteil im Gebiet ein. Es handelte sich dabei überwiegend um echte Fettweiden frischer bis feuchter Standorte. Sie zeichneten sich durch eine niedrige Artenzahl sowie eine unregelmäßige Vertikalentwicklung aus, bei der sich höher gewachsene Bereiche um Tierexkremente mit kurz- bis mittelrasigen Flächen abwechselten. Zudem wurden vielerorts Saatmischungen untergemischt, so dass sich die Artenzusammensetzung auf bestimmten Teilflächen ähnelte.

Es dominierten tritt- und weideresistente Arten sowie Weideunkräuter wie Cirsium arvense und $C$. vulgare. Verbreitet war auch das von Tieren oft verschmähte Tanacetum vulgare. Häufige Arten waren Cerastium holosteoides, Festuca rubra, Holcus lanatus, Plantago lanceolata, Poa pratensis, Ranunculus repens sowie vor allem Lolium perenne und Phleum pratense. Arrhenaterum elatius trat nur in höher gewachsenen Beständen in großer Dichte auf, da es Tritt- und Fressbelastung nicht gut verträgt. 


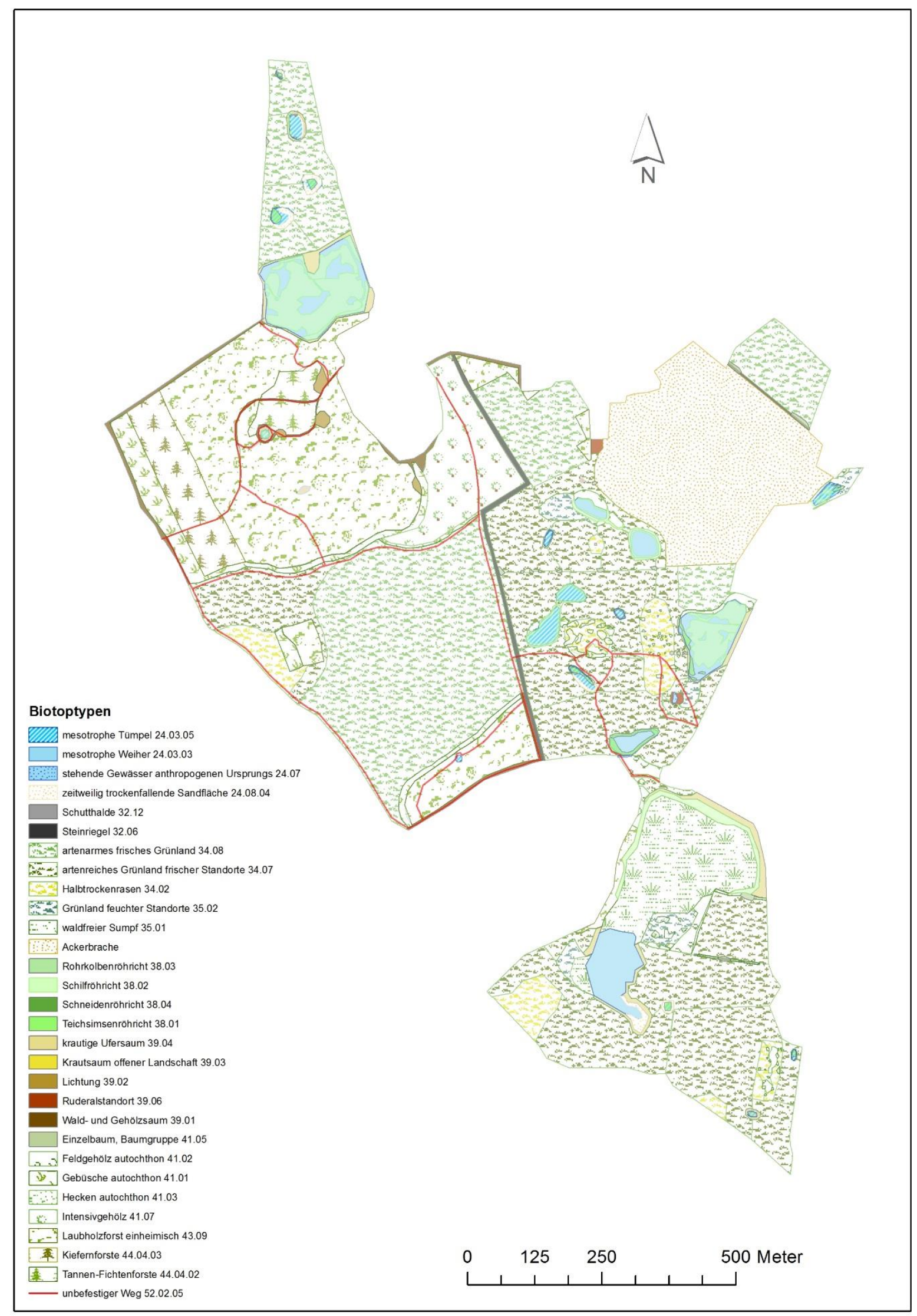

Abb. 38: Biotoptypen im Projektgebiet zu Beginn der Untersuchung 


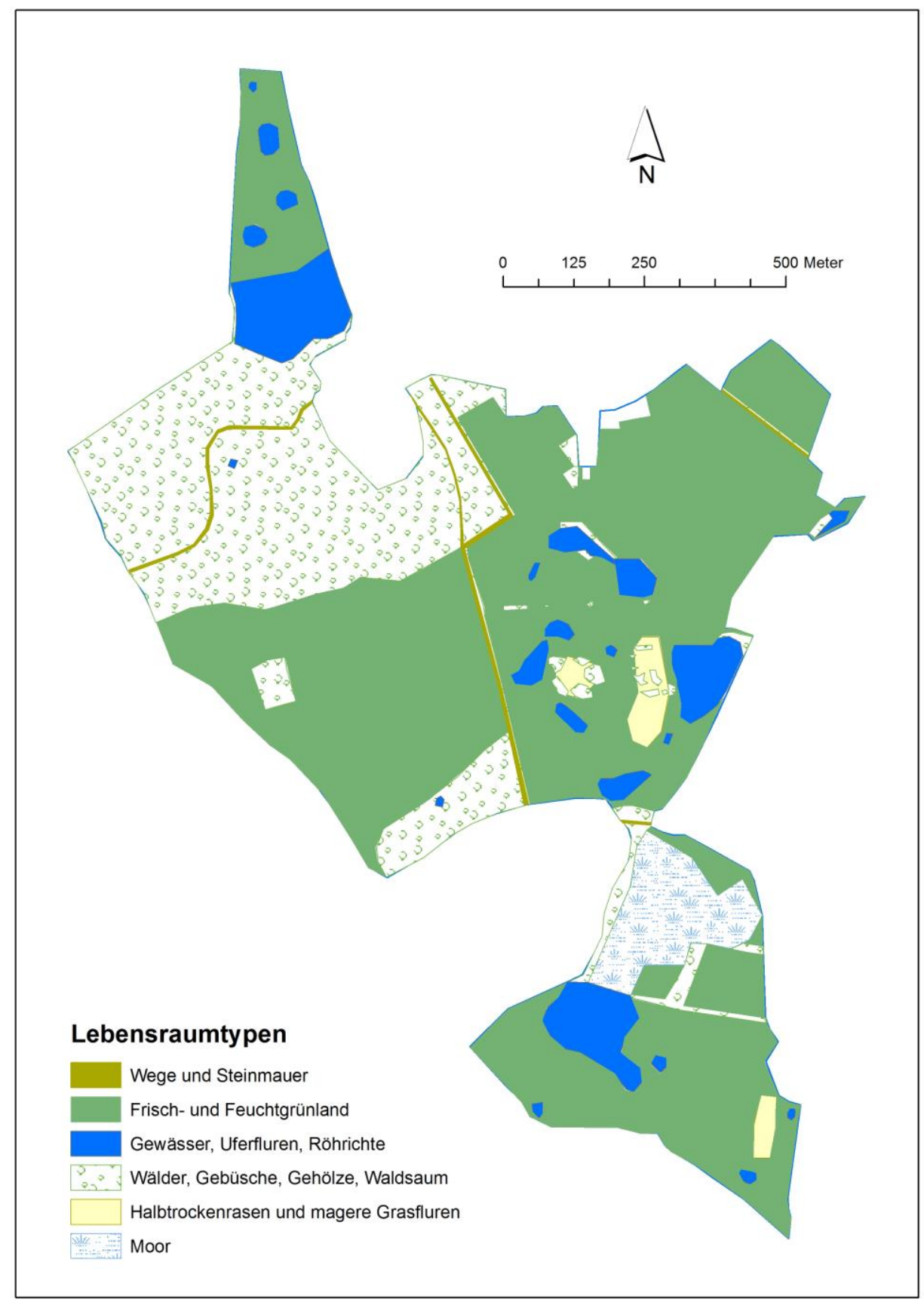

Abb. 39: Lebensraumtypen im Projektgebiet zu Beginn der Untersuchung

Aufgrund der unterschiedlichen Nutzungsgeschichte beziehungsweise der Dauer der Nutzungsaufgabe ließen sich auf den Teilflächen Bestände mit artenärmeren und artenreicheren Ausprägungen unterscheiden (siehe 6.2.2 Pflanzengesellschaften im Grünland). Im zentralen, ehemals als Wiese genutzten Bereich des Gebietes sowie auf Flächen mit Brachlandsukzession traten schwache Ausprägungen einer Glatthaferwiese auf. Sie trugen Merkmale einer Fettweide und zeigten eine ruderale Ausprägung oder eine deutliche Vergrasung bis hin zur Verbuschung (Gebiete 5, 7, 20). Die Bezeichnung der Teilgebiete ist Abb. 5 in Kapitel 3 zu entnehmen.

Vielerorts konnte die Artenzusammensetzung direkt auf den Feuchtgradienten zurückgeführt werden. Das hügelige Gebiet wies im Ufer- und Randbereich der zahlreichen kleinen und größeren Stehgewässer Arten mit einem Feuchtoptimum im frischen Bereich auf, während auf den Kuppen Magerrasen 
wuchsen. Auch optisch war die Wasserverfügbarkeit im Gebiet an den satten grünen Uferbereichen und den früh verblühten, trockenen Kuppen und Hängen erkennbar.

Halbtrockenrasen und magere Grasfluren wiesen einen Flächenanteil von ungefähr 3 Prozent auf, wobei die Zuordnung aufgrund der Kleinflächigkeit schwierig war. Sie lagen auf den Kuppen und Plateaus der Huthügel, häufig zwischen lückigen Gebüschbeständen (Gebiete 1, 5, 20). Die vorkommenden Arten zeigten einen eher trockenen, basenreichen und mageren Wiesenstandort an: Centaurea jacea, Crepis biennis, Potentilla argentea, Knautia arvensis, Echium vulgare, Hypericum perforatum und mit hoher Deckung Ononis repens.

In Ufernähe, vor allem im Bereich der Pferdepfade und Trinkstellen, waren Kriechgras-Gesellschaften anzutreffen, die Wasserüberstauungen und Beweidung gut ertragen. Der Boden war hier meist verdichtet, nährstoffreich und stickstoffhaltig. Vertreten waren Agrostis stolonifera, Carex hirta, Juncus articulatus, Juncus bufonius, Juncus compressus, Potentilla anserina, Potentilla reptans, Ranunculus repens, Rumex crispus und Trifolium repens.

Die Gewässer, Uferfluren und Röhrichte stellten mit knapp 9 Prozent einen wichtigen Bestandteil der Vegetation im Gebiet dar. Die Kleingewässer wurden größtenteils in den vergangenen 20 Jahren künstlich angelegt und zogen sich wie ein Streifen von Norden nach Süden durch das Gebiet. Einige von ihnen fielen im Hochsommer trocken. Die Vegetation war vielfältig ausgeprägt und reichte von vegetationsarmen, nitrophilen Pionierstadien (Zweizahn-Schlammufergesellschaft) über Klein- und Großröhrichte bis hin zu Schwimmblattgesellschaften, Armleuchteralgen und Weidegebüschen.

An der Mehrzahl der stehenden Gewässer waren Röhrichte der Klasse Phragmitetea australis (Röhrichte und Großseggenriede) vertreten. Das sind hochwüchsige, artenarme Verlandungsgesellschaften aus Süß- und Sauergräsern. Häufig wurden Phragmites australis, Lycopus europeus, Alisma plantagoaquatica, Equisetum fluviatile, Typha latifolia, Schoenoplectus lacustris und Eleocharis palustris angetroffen, begleitet von Mentha aquatica, Myosotis palustris, Eupatorium cannabinum und Lythrum salicaria. Der Breitblättrige Rohrkolben und das Gewöhnliche Schilf bildeten vielerorts Einartröhrichte, in geringerem Maße auch die Gewöhnliche Strandsimse und die Salz-Teichbinse.

Die Süßwasser-Vegetation wurde von Wasserpflanzengesellschaften (Potamogetonetea) und Armleuchteralgen (Charetea fragilis) gebildet. Das im südlichen Teil des Projektgebietes liegende Moor ist seit 1960 unter der Obhut einer Vogelschutzorganisation und durfte nicht betreten werden. Aufgrund einer Artenliste des Gebietes ließen sich hier Gesellschaften der Phragmitetea (Röhrichte und Seggenrieder), der Utricularietea (Wasserschlauch-Schwimm-Gesellschaft) und der Lemnetea (WasserlinsenDecken) vermuten.

Die Wälder, Gebüsche, Gehölze und Waldsäume deckten einen Flächenanteil von 26 Prozent ab. Dabei handelte es sich vorwiegend um Mischformen sommergrüner Laubwälder (Klasse Querco-Fagetea) der Ordnung Fagetalia sylvaticae. Sie lagen im zentralen Bereich des Schutzgebietes (Gebiete 3, 6 und 10) und wurden um 1990 auf Agrarland angepflanzt. Flächenmäßig überwog ein Buchenreinbestand mit schwach ausgeprägter Kraut- und Strauchschicht. Ein Quercus-Tilia-Mischbestand wies als Begleitarten Acer pseudoplatanus, A. platanoides, Ulmus glabra und Corylus avellana sowie Epipactis helleborine und Dryopteris filix-mas als krautige Ordnungskennarten auf.

Angrenzend an den ursprünglichen Niederwald, der von der Beweidung ausgeschlossen war, befand sich im Südwesten ein um 1990 angepflanzter Laubwaldforst mit Dominanz von Corylus avellana in der unteren und Quercus robur in der oberen Baumschicht (Gebiet 3). In geringerer Anzahl waren Carpinus betulus, Malus sylvestris und Acer campestre vertreten. Die Gehölze waren stark von ihrer Basis an verzweigt. In der Krautschicht waren kaum Pflanzen vorhanden. Dazu zählten Keimlinge von Quercus robur und Symphoricarpus albus sowie Epipactis helleborine, Dactylis glomerata, Sambucus nigra oder 
Urtica dioica. Vereinzelt kam Brachythecium rutabulum vor. Der Corylus-Quercus-Mischbestand, der sich hier zu einem Niederwald entwickeln sollte, ähnelte einem Eichen-Hainbuchen-Wald, eine häufige Gesellschaft früherer Hude-, Mittel- oder Niederwälder.

Da es sich bei den Wäldern im Projektgebiet um reine Anpflanzungen handelte, konnten nicht alle Bestände einer Klasse zugeordnet werden: Ein Abies procera-Bestand und ein Abies-Quercus-Mischbestand im mittleren Teil des Laubwaldforstes (Gebiete 6 und 7) hatten ihren Ursprung in einer rein forstlichen Nutzung, die Edeltanne Abies procera ist ein aus den USA stammendes Ziergehölz. Dies traf auch für einen Kiefern-Mischbestand im westlichen Bereich des zentral gelegenen Forstes zu (Gebiet 6). Dominante Arten waren hier Pinus sylvestris, Quercus robur und Tilia cordata. Eine Krautschicht war nur schwach ausgebildet, im Randbereich traten jedoch Dactylis glomerata, Festuca rubra und Rubus fruticosus auf. Die Bestände wurden von den Weidetieren aufgrund der hohen Dichte kaum betreten.

Auf Gebiet 5 wurde in den frühen Achtziger Jahren ein Feldgehölz als Remise für Wild angelegt. Der Bestand lag auf einem Hügel im westlichen Bereich des Projektgebietes in Meeresnähe. Er war sehr heterogen mit unterschiedlichen Baumarten verschiedener Höhe und einer mittleren bis starken Deckung der Kronen. Unter der Baumschicht fand sich eine in ihrer Höhe und Artenzusammensetzung variable und verästelte Strauchschicht, was die Begehbarkeit des Areals einschränkte. Der Bestand wurde westlich von einem Gürtel aus Sträuchern (Prunus spinosa, Crataegus monogyna, Hippophae rhamnoides) und Urtica dioica umschlossen. Auch die Krautschicht war kleinflächig unterschiedlich aufgebaut. An lichteren Stellen kamen Geum urbanum und Dactylis glomerata, seltener Arrhenatherum elatius, Galium mollugo, Daucus carota, Fragaria vesca, Medicago lupulina, Tanacetum vulgare und Artemisia vulgaris vor. Das Gebiet wurde von den Pferden und den Rehen genutzt. Die Verbiss- und Trittbelastung waren gering. Ein Teil des Bestandes wurde im Jahr 2010 gerodet.

Auf Gebiet 10 umgab ein lichter Laubwaldforst die Grünlandfläche im Norden, Osten und Westen. Auf der Grünfläche befand sich ehemals ein Abies-Bestand, der zunächst forstlich genutzt, später aber abgeholzt wurde. Der umgebende Laubwald diente als Schutzwald. In der Baumschicht fanden sich neben Quercus robur zu ähnlichen Anteilen Malus sylvestris, Acer pseudoplatanus, Tilia cordata und Acer campestre sowie vereinzelt Prunus avium. Die Krautschicht war nur spärlich ausgebildet und bestand aus Geum urbanum und Poa trivialis sowie aus lichtbedürftigen Arten der angrenzenden Fettweide wie Lolium perenne, Dactylis glomerata und Achillea millefolium. Im östlichen Bereich war die Krautschicht durch Tritt weitgehend zerstört. Der Boden war hier stark verdichtet, da die Fläche von den Weidetieren als natürlicher Unterstand genutzt wurde. Aufgrund von Körperpflege und Verbiss waren die Bäume bis zu einer Höhe von 1,50 m stark beschädigt.

Auf mittleren bis trockenen Standorten im Gebiet gediehen vielerorts Weißdorn-Schlehen-BrombeerGebüsche (Klasse Rhamno-Prunetea) mit Prunus spinosa, Crataegus monogyna, Rosa canina, Cornus sanguinea und Rubus. Bei dieser Assoziation des Crataego-Prunetums handelte es sich um angelegte Gebüschstreifen (Gebiete 3, 6) oder bewachsene Lesesteinsiegel mit starker Verbuschung (Gebiet 15). Die denkmalgeschützte Steinmauer trug vereinzelt einen Vormantel aus Rubus fruticosus agg. Weitere Gebüschbestände lagen im Inneren des zentralen Forstkomplexes auf Gebiet 6: ein Hippophae-Quercus-Gebüsch, ein Abies-Crataegus-Gebüsch mit hohem Grasanteil sowie ein Rubus-Crataegus-Gebüsch mit hohem Grasanteil deuteten in ihrer Artenzusammensetzung und Wuchshöhe auf frühe Sukzessionsstadien und Übergänge zu einer Gehölzgesellschaft hin. Sie stellten meist lichte Bestände dar und wurden überwiegend vom Rehwild aufgesucht.

Als Gehölze wurden alte Baumreihen, Baumgruppen und Solitärbäume zusammengefasst, die in Form von Knicks ehemalige Grenzen aus der Zeit der landwirtschaftlichen Nutzung erkennen ließen (Gebiete $12,13,20)$. Auch im Uferbereich stehender natürlicher Gewässer standen Baumgruppen (Gebiete 2, $8,12,14,18)$. Da die Gehölze seit der Schutzgebietsausweisung nicht mehr gepflegt wurden, waren sie 
meist durchwachsen. Die Gehölze wurden von Weiden- und Pappel-Arten (Salix caprea, Salix pentandra, Populus nigra, Populus alba) dominiert. Seltener waren Stiel-Eiche, Birke und Obstbaumarten wie Prunus syriaca oder Malus sylvestris vertreten, durchmischt mit Prunus spinosa, Crataegus monogyna, Rosa canina, Rubus, Sorbus intermedia und Sambucus nigra. Die Krautschicht setzte sich aus den bestandsbildenden Gräsern der umgebenden Grasfluren, im Uferbereich vor allem aus Rot-Straußgras und Weichem Honiggras zusammen. Häufig wurden Cirsium vulgare, C. arvense, Rumex crispus sowie Urtica dioica angetroffen.

Im Übergangsbereich vom Offenland zu den Gehölzflächen wuchs ein artenreicher Krautsaum, der sich aus Arten der angrenzenden Bestände zusammensetzte, aber auch einige charakteristische Arten aufwies. Aufgrund der halbschattigen Lage traten häufig Anthriscus sylvestris, Arctium lappa, Galium aparine, Geum urbanum und Urtica dioica auf. Sie werden den Stickstoff-Krautfluren oder den ruderalen Glatthaferwiesen als typische Erscheinung an Wegrändern zugeordnet.

Auf stark genutzten Wegen mit frischen bis mäßig trockenen Böden entwickelten sich lückige Trittrasen, auf denen trittresistente Arten wie Lolium perenne und Poa annua dominierten, begleitet von Plantago lanceolata, Poa trivialis, Taracaxum officinalis, Dactylis glomerata und Trifolium repens. Die Wege wurden gelegentlich von den Weidetieren genutzt, überwiegend aber von Besuchern. Im Zuge der Besucherlenkung wurden sie mehrmals im Jahr gemäht.

\subsubsection{Pflanzengesellschaften im Grünland}

Die pflanzensoziologische Voruntersuchung diente der Identifizierung den vorherrschenden Vegetationstypen im offenen Weideland zu Beginn der Pferdebeweidung. Die Grundlage bildeten 99 Vegetationsaufnahmen aus dem Jahr 2007. Im Ergebnis lagen 12 Aufnahmegruppen vor, die durch Zuordnung zu einer Assoziation, Subassoziation oder Variation charakterisiert wurden (Tab. 30). Die zugehörige JUICE-Tabelle sowie die synoptische Tabelle sind im Anhang (Anlage 6.8) zu finden.

Die 12 Gruppen ließen sich eindeutig bestimmten Teilgebieten zuordnen. Wie auch von Peter (2008) im Rahmen von Diversitätsuntersuchungen im Projektgebiet beschrieben, konnten die unterschiedlichen Artenzusammensetzungen im Gebiet zu Beginn der Untersuchung größtenteils durch die frühere Nutzung der Flächen erklärt werden. Sie ging von intensiver bis extensiver Grünlandnutzung über Beweidung mit unterschiedlichen Weidetierarten bis hin zu Ackerland (s. 3.3 Nutzung). Die Zeitpunkte der Extensivierungsmaßnahmen und Nutzungsänderungen unterschieden sich von Fläche zu Fläche. Daraus resultierten unterschiedliche Sukzessionsstadien der Teilgebiete.

Im Zuge der Sukzession verändert sich die Artenzusammensetzung, z. B. durch Einwanderung von Arten aus angrenzenden Pflanzenformationen wie Waldrändern und Säumen. Die Bestandsstruktur entwickelt sich dabei durch Prozesse wie Entmischung, Herden-, Muster- und Dominanzbildung (Dierschke \& Briemle 2002). Auf den Flächen im Projektgebiet war diese Entwicklung unterschiedlich stark vorangeschritten - abhängig von Dauer und Art der Extensivierungsmaßnahmen. Dies wirkte sich auf die $\alpha$-Diversität aus. Die mittleren Artenzahlen der 12 Vegetationseinheiten (s. Anlage 6.9) stiegen mit der Sukzession an. Die Altgrünlandflächen, den Glatthaferwiesen zugeordnet, wiesen die höchsten Artenzahlen auf. Einige der Arten waren aus benachbarten Formationen eingewandert. In gleicher Weise profitierten die angrenzenden, artenärmeren Grünländer von den Extensivierungsmaßnahmen auf den Altgrünländern. Zum Artinventar der Weiden und Saatgrünländer gehörten neben den dominierenden Saatgräsern wie Lolium perenne, Phleum pratense und Poa pratensis sowie Triflolium repens auch typische Grünlandpflanzen, die sich unter intensiver Nutzung nicht ausbreiten konnten, nach der Nutzungsänderung aber Fuß fassten. 
Am artenärmsten waren jene Flächen, die noch relativ lange intensiv, z.B. für Ackerbau genutzt wurden. Durch den Umbruch der Flächen und die Neusaat wurden neue Artenzusammensetzungen geschaffen, die voraussichtlich erst nach und nach durch einwandernde Pflanzen benachbarter Formationen ergänzt werden. Im Allgemeinen wiesen die ehemaligen Wiesenflächen deutlich höhere Artenzahlen auf als die Weideflächen.

Zusammenfassend lässt sich festhalten, dass der Artenreichtum im offenen Weideland unterschiedlich verteilt war, beeinflusst von der früheren Nutzung der Flächen, aber auch von der Geländebeschaffenheit. Zahlreiche Hügel und Senken führten zu variierenden Wind- und Lichtexpositionen sowie einer unterschiedlichen Grundwasserversorgung der Flächen. Ein Auftreten kleinräumiger, feiner Standortunterschiede ist dabei durchaus typisch. Der Artenreichtum und -wandel zwischen angrenzenden Flächen vollzog sich nicht graduell, sondern sprunghaft. Daher ließen die Flächen keinen ökologischen Gradienten (z.B. Nährstoff-, Feuchte- oder Bodensäuregradienten) erkennen (siehe Anlage 6.9). Vermutlich wurde seine Wirkung durch die frühere Nutzungsart überlagert.

Tab. 30: Pflanzensoziologische Einordnung der Gruppen 1-12 der Voruntersuchung im offenen Weideland (2007) mit Angabe des Teilgebietes, aus dem die Vegetationsaufnahmen stammten

\begin{tabular}{|c|c|c|c|c|}
\hline Gruppe & Verband & $\begin{array}{l}\text { Assoziation / } \\
\text { Gruppenbezeichnung }\end{array}$ & Subassoziation / Variation & $\begin{array}{l}\text { Teil- } \\
\text { gebiet }\end{array}$ \\
\hline 1 & Potentillion anserinae & Elymus repens-Gesellschaft & - & 14 \\
\hline 2 & Potentillion anserinae & $\begin{array}{l}\text { Potentillo-Festucetum } \\
\text { arundinaceae }\end{array}$ & - & 8 \\
\hline 3 & $\begin{array}{l}\text { Galio-Urticetea } \\
\text { (Klasse) }\end{array}$ & $\begin{array}{l}\text { Nitrophiler Tripleurospermum } \\
\text { perforatum-Krautsaum }\end{array}$ & - & 6 \\
\hline 4 & Arrhenatherion & $\begin{array}{l}\text { Glatthafer-Wiese } \\
\text { (Arrhenatheretum elatioris) }\end{array}$ & $\begin{array}{l}\text { Ausbildung ruderaler Standorte } \\
\text { (Tanaceto-Arrhenatheretum) }\end{array}$ & 5 \\
\hline 5 & Arrhenatherion & $\begin{array}{l}\text { Glatthafer-Wiese } \\
\text { (Arrhenatheretum elatioris) }\end{array}$ & $\begin{array}{l}\text { Magere Ausprägung, Abies-Crataegus- } \\
\text { Gebüsch mit hohem Grasanteil }\end{array}$ & 7 \\
\hline 6 & Arrhenatherion & $\begin{array}{l}\text { Glatthafer-Wiese } \\
\text { (Arrhenatheretum elatioris) }\end{array}$ & $\begin{array}{l}\text { Schwache Ausprägung mit Merkmalen der Wei- } \\
\text { delgras-Weißklee-Weide }\end{array}$ & 20 u.a. \\
\hline 7 & Cynosurion cristati & $\begin{array}{l}\text { Weidelgras-Weißklee- } \\
\text { Fettweide (Lolio perennis- } \\
\text { Cynosuretum cristati) }\end{array}$ & $\begin{array}{l}\text { Typische Weidelgras-Weißklee-Fettweide, } \\
\text { Bestand mit Merkmalen der Glatthafer- } \\
\text { Wiese }\end{array}$ & 17 u.a. \\
\hline 8 & Cynosurion cristati & $\begin{array}{l}\text { Weidelgras-Weißklee- } \\
\text { Fettweide (Lolio perennis- } \\
\text { Cynosuretum cristati) }\end{array}$ & $\begin{array}{l}\text { Typische Weidelgras-Weißklee-Fettweide, } \\
\text { Weidelgras-Lieschgras-Basalgesellschaft, } \\
\text { artenarm }\end{array}$ & 4 \\
\hline 9 & Cynosurion cristati & $\begin{array}{l}\text { Weidelgras-Weißklee- } \\
\text { Fettweide (Lolio perennis- } \\
\text { Cynosuretum cristati) }\end{array}$ & $\begin{array}{l}\text { Typische Weidelgras-Weißklee-Fettweide, } \\
\text { Weidelgras-Lieschgras-Basalgesellschaft, } \\
\text { artenarme Raps-Ackerbrache }\end{array}$ & 13 \\
\hline 10 & Cynosurion cristati & $\begin{array}{l}\text { Weidelgras-Weißklee- } \\
\text { Fettweide (Lolio perennis- } \\
\text { Cynosuretum cristati) }\end{array}$ & $\begin{array}{l}\text { Typische Weidelgras-Weißklee-Fettweide, } \\
\text { Weidelgras-Lieschgras-Basalgesellschaft } \\
\text { bei fehlendem Weißklee: Bestand mit } \\
\text { Auftreten hochwüchsiger Stauden }\end{array}$ & 19 \\
\hline 11 & Cynosurion cristati & $\begin{array}{l}\text { Weidelgras-Weißklee- } \\
\text { Fettweide (Lolio perennis- } \\
\text { Cynosuretum cristati) }\end{array}$ & $\begin{array}{l}\text { Typische Weidelgras-Weißklee-Fettweide, } \\
\text { Weidelgras-Lieschgras-Basalgesellschaft } \\
\text { bei fehlendem Weißklee: Bestand mit } \\
\text { hohem Grasanteil und Acker-Schachtelhalm }\end{array}$ & 10 \\
\hline 12 & Cynosurion cristati & $\begin{array}{l}\text { Weidelgras-Weißklee- } \\
\text { Fettweide (Lolio perennis- } \\
\text { Cynosuretum cristati) }\end{array}$ & $\begin{array}{l}\text { Typische Weidelgras-Weißklee-Fettweide, } \\
\text { sehr artenarme Ausprägung bei fehlendem } \\
\text { Weißklee und Lieschgras }\end{array}$ & 9 \\
\hline
\end{tabular}




\subsection{Entwicklung des Gebietes unter Beweidung}

Wie sich Vegetation und Gehölze bei einer großräumigen, extensiven Weidenutzung verändern, ist im Allgemeinen schwieriger vorherzusagen als bei einer intensiven Beweidung (von Oheimb et al. 2006). Müssen die Tiere bei einer Standweide mit dem zur Verfügung stehenden Nahrungsangebot vorlieb nehmen, so haben sie auf einer Extensivweide größere Selektionsmöglichkeiten. Anstatt von homogenen Grünlandbeständen mit weidetoleranten Pflanzenarten können sich kleinflächig über- und unterbeweidete Bereiche entwickeln, die eine höhere Lebensraumvielfalt bieten.

Die Datenerhebungen im Projektgebiet sollten klären, ob durch die Pferdebeweidung ein Mosaik an verschiedenen Habitaten als Lebensraum für zahlreiche Arten der typischen mitteleuropäischen Kulturlandschaft geschaffen wird, wie es das Naturschutzziel für die Region vorsieht. Besonders interessant sind dabei offene, artenreiche Grünlandflächen, Trockenrasen, Feuchtwiesen oder Pionierstandorte für die beheimateten Vogelarten, Amphibien und Libellen. Ferner sollten die Weidetiere die Auswirkungen der anfänglichen Brache aufhalten, die Verbuschung im offenen Weideland zurückdrängen und die Gehölzbestände auflichten.

\subsubsection{Entwicklung der Vegetation}

Grundlage für eine Bewertung der Vegetationsentwicklung im gesamten Gebiet waren die pflanzensoziologischen Kartierungen aus den Jahren 2008 und 2011. Die Pferdebeweidung wirkte hier als ein exogener Veränderungsfaktor.

\subsubsection{Pflanzensoziologische Kartierung der Grünland-, Gehölz- und Uferbestände}

Die Basis der soziologischen Klassifikation, mit deren Hilfe Vegetationsveränderungen nachgewiesen wurden, ist der Tabellenvergleich von Aufnahmen. Das Ergebnis der pflanzensoziologischen Tabellenarbeit mit Hilfe des Klassifizierungsprogramms JUICE ist eine geordnete Tabelle, in der die Vegetationsaufnahmen zu Einheiten annähernd gleicher floristischer Zusammensetzung gruppiert werden. Die Abgrenzung der Vegetationseinheiten basiert auf dem Vorhandensein differenzierender Artengruppen sowie deren Deckungsgraden, also sowohl qualitativ als auch quantitativ.

200 Relevés wurden durch die TWINSPAN-Analyse in 30 Gruppen eingeteilt. Aus floristisch-physiognomischen Gründen wurden zahlreiche Umstellungen vorgenommen. Um unterschiedliche Variationen oder Assoziationen innerhalb einer Gruppe abzugrenzen, wurden die Gruppen in Untergruppen gegliedert. Die Änderungen sind im Absatz 6.1.1.5 Datenauswertung zusammengestellt.

Im Ergebnis lagen 30 Aufnahmegruppen in der ersten sowie 44 Gruppen in der zweiten Hierarchieebene vor. Die zugehörige JUICE-Tabelle sowie die synoptische Tabelle sind im Anhang (Anlage 6.10) zu finden. Die Cluster konnten 30 in der Literatur beschriebenen Vegetationseinheiten zugeordnet werden. Sie waren durch ihre Artenzusammensetzung deutlich voneinander abgrenzbar. Bei bestimmten Einheiten war eine Zuordnung jedoch nur bis auf das Ordnungs- oder Verbandsniveau möglich, da es sich um künstliche (da angepflanzte) und nicht um natürlich entwickelte Bestände handelte. Vier weitere, nicht begehbare Bestände wurden auf der Basis von Artenlisten identifiziert. Die syntaxonomische Gliederung der 34 Einheiten als Ergebnis der pflanzensoziologischen Tabellenarbeit ist in Anlage 6.11 dargestellt. Eine Beschreibung der Vegetationseinheiten sowie die Begründung für deren Einordnung finden sich in Anlage 6.12. 
Um die Entwicklung differenziert zu betrachten, wurden im Grünland Ausprägungen der Assoziationen angegeben, die sich durch Dominanzen einzelner Arten ergaben. Wenn möglich, erfolgte die Benennung von Subassoziationen. Bei der Subassoziation der Typischen Weidelgras-Weißklee-Fettweide (Lolio-Cynosuretum typicum) wurden beispielsweise artenarme oder -reiche Ausprägungen sowie Artdominanzen zur Charakterisierung der Bestände zu Hilfe gezogen.

Das Ergebnis der TWINSPAN-Analyse zeigt das Dendrogramm in Abb. 40. Zu erkennen sind farbig markierte Obergruppen, die weitestgehend bestimmten Biotoptypen wie Wälder, Röhrichte, Gebüsche, Ufer- und Waldsaum sowie Grünland entsprechen. Die beiden untersten Gruppen stellen Glatthaferwiesen und Weidelgras-Weißklee-Weiden dar, bei denen die Gruppen 23 und 26 die Übergänge der beiden Verbände repräsentieren.

\subsubsection{Vegetationskarte}

Die Aufnahmegruppen wurden Teilflächen im Untersuchungsgebiet zugeordnet, so dass eine Vegetationskarte entstand. Abb. 41 zeigt die Lage der klassifizierten Bestände als Ergebnis der pflanzensoziologischen Einordnung. Die Flächenanteile der einzelnen Vegetationseinheiten wurden im GIS berechnet (Tab. 31). Vorherrschend und aspektprägend war die Weidelgras-Weißklee-Fettweide (CynosuroLolietum) als Vertreterin des Wirtschaftsgrünlandes. Ihr Anteil im Projektgebiet betrug rund 38 Prozent $\left(407.000 \mathrm{~m}^{2}\right)$. Die Glatthaferwiese (Arrhenatheretum elatioris) nahm weniger als 9 Prozent der Fläche ein $\left(92.000 \mathrm{~m}^{2}\right)$. Bezüglich ihrer Artenzahl und -zusammensetzung stellte die Fettwiesen-Basalgesellschaft (11,3\%) an der Südspitze den Intermediärstatus zwischen beiden Grünlandtypen dar. Trittrasen $(1,9 \%)$ und andere Übergangsbestände $(1,9 \%)$ waren flächenmäßig eher von geringerer Bedeutung, ebenso die Dotterblumen-Feuchtwiese mit 0,9 \% Flächenanteil.

Aufgrund von Artdominanzen wurden im Wirtschaftsgrünland verschiedene Subassoziationen und Varianten identifiziert. Die hohe Anzahl unterschiedlicher Vegetationseinheiten und Ausprägungen auf einer relativ kleinen Fläche spricht für einen Strukturreichtum, der auf unterschiedliche frühere Nutzungsformen zurückgeführt wird. Überlagert man die Ergebnisse der Vegetationskartierung mit einer Karte der ehemaligen Bewirtschaftungsformen (Beweidung, Mahd, Acker etc.), so zeigen sich deutliche Parallelen: Die Glatthafer-Wiese und ihre Subassoziationen (Magere oder Ruderale Wiese) finden sich auf den zur Mahd genutzten Flächen oder auf solchen, die bereits früher extensiv beweidet wurden (s. 6.2.2 Pflanzengesellschaften im Grünland). Beispiele hierfür sind die Teilgebiete 1 und 20.

Die Flächen mit den geringsten Artenzahlen wurden dort angetroffen, wo zuvor Ackerflächen waren oder das Grünland umgepflügt und mit einer Saatmischung versorgt wurde, die zwar reich an hochwertigen Futterpflanzen, aber artenarm war: Die Gebiete 4, 10, 13 und 19 wiesen eine einheitliche, stark reduzierte Artenzusammensetzung auf. Diese Grünlandflächen wurden den artenarmen Ausprägungen des Cynosuro-Lolietum typicum zugeordnet. 


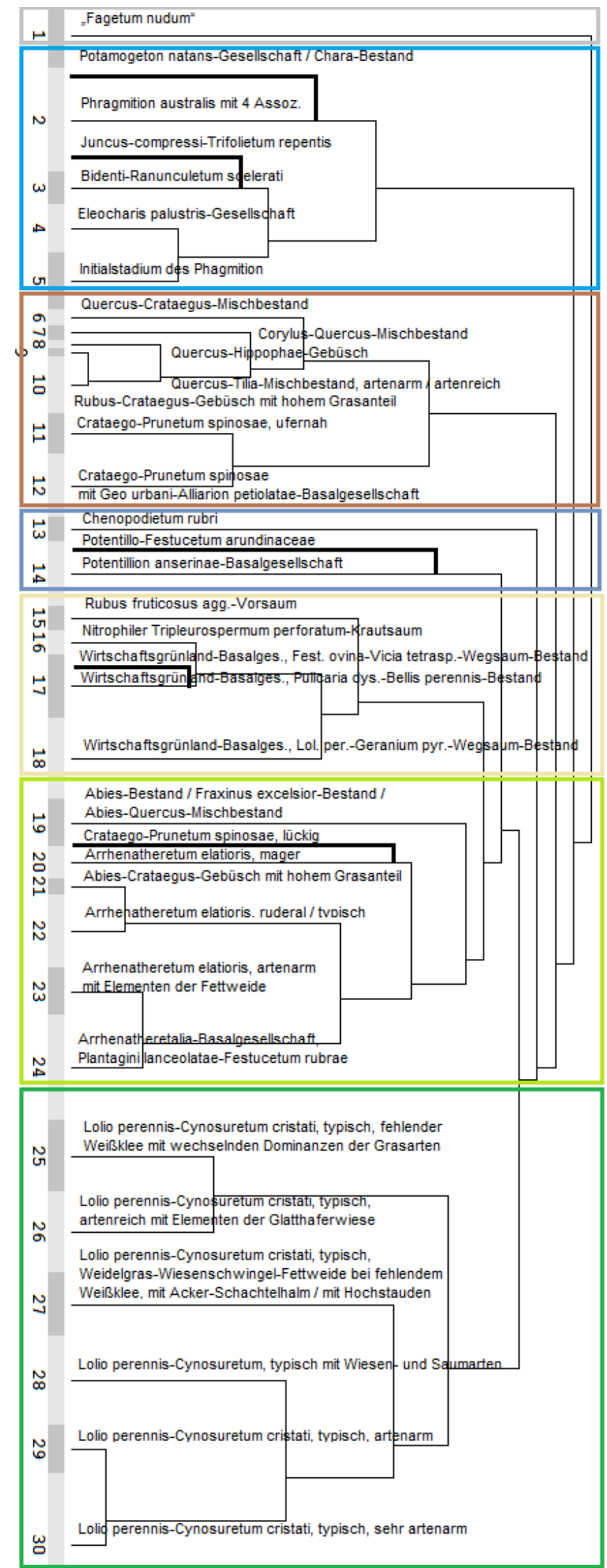

Abb. 40: Dendrogramm der TWINSPAN-Analyse mit der Zuordnung der Gruppen zu Vegetationseinheiten

Die Obergruppen (s. 6.2.1 Lebensraum- und Biotoptypen) sind farbig markiert. 5 ergänzte Einheiten (dickere Striche). 


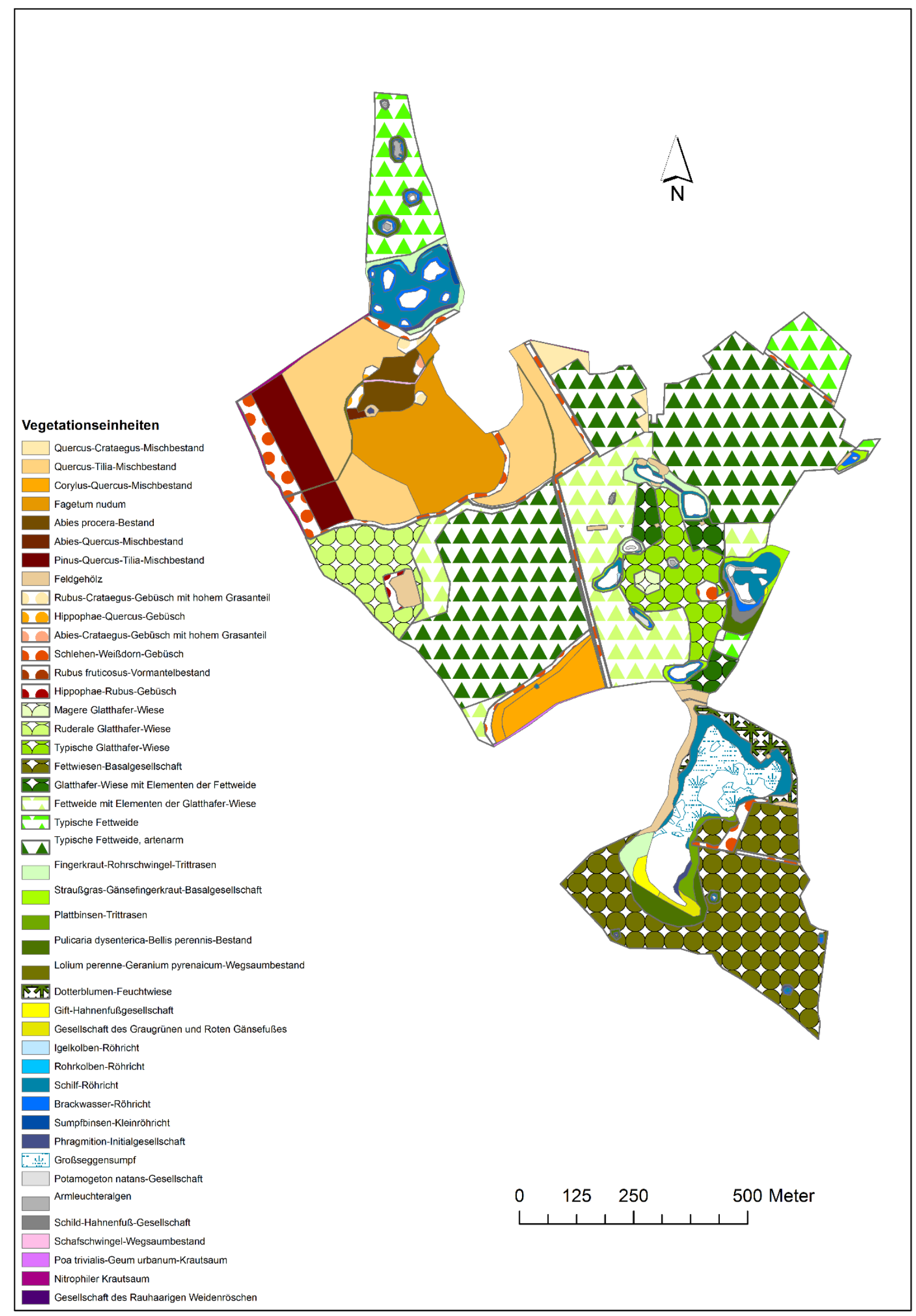

Abb. 41: Vegetationskarte des Schutzgebietes Süd-Langeland mit Vegetationseinheiten (2008) 


\section{AUSWIRKUNG DER BEWEIDUNG}

Tab. 31: Größe und Flächenanteile der Vegetationseinheiten oder Bestände, gegliedert nach Formationen (2008)

\begin{tabular}{|c|c|c|}
\hline Vegetationseinheit / Bestand & Größe $\left(m^{2}\right)$ & Flächenanteil (\%) \\
\hline Gesamt Trittrasen, Wirtschaftsgrünland, Magerrasen & 669.181 & 62,5 \\
\hline Magere Glatthafer-Wiese & 2.391 & 0,2 \\
\hline Ruderale Glatthafer-Wiese & 34.387 & 3,2 \\
\hline Typische Glatthafer-Wiese & 37.494 & 3,5 \\
\hline Fettwiesen-Basalgesellschaft & 120.685 & 11,3 \\
\hline Glatthafer-Wiese mit Elementen der Fettweide & 17.490 & 1,6 \\
\hline Fettweide mit Elementen der Glatthafer-Wiese & 90.768 & 8,5 \\
\hline Typische Weidelgras-Weißklee-Fettweide & 59.811 & 5,6 \\
\hline Typische Weidelgras-Weißklee-Fettweide, artenarm & 256.575 & 24,0 \\
\hline Fingerkraut-Rohrschwingel-Trittrasen & 12.970 & 1,2 \\
\hline Straußgras-Gänsefingerkraut-Basalgesellschaft & 6.298 & 0,6 \\
\hline Plattbinsen-Trittrasen & 596 & 0,1 \\
\hline Pulicaria dysenterica-Bellis perennis-Bestand & 18.221 & 1.7 \\
\hline Lolium perenne-Geranium pyrenaicum-Wegsaum & 2.008 & 0,2 \\
\hline Dotterblumen-Feuchtwiese & 9.487 & 0,9 \\
\hline Gesamt Waldgesellschaften & 229.567 & 21,5 \\
\hline Quercus-Crataegus-Mischbestand & 6.595 & 0,6 \\
\hline Quercus-Tilia-Mischbestand & 88.711 & 8,3 \\
\hline Corylus-Quercus-Mischbestand & 20.970 & 2,0 \\
\hline Fagetum nudum & 60.324 & 5,6 \\
\hline Abies procera-Bestand & 11.499 & 1,1 \\
\hline Abies-Quercus-Mischbestand & 760 & 0,1 \\
\hline Pinus-Quercus-Tilia-Mischbestand & 26.429 & 2,5 \\
\hline Feldgehölz & 14.279 & 1,3 \\
\hline Gesamt Gebüsche und Vorwälder & 47.026 & 4,4 \\
\hline Rubus-Crataegus-Gebüsch mit hohem Grasanteil & 2.219 & 0,2 \\
\hline Hippophae-Quercus-Gebüsch & 1.852 & 0,2 \\
\hline Abies-Crataegus-Gebüsch mit hohem Grasanteil & 727 & 0,1 \\
\hline Schlehen-Weißdorn-Gebüsch & 37.793 & 3,5 \\
\hline Rubus fruticosus-Vorsaum & 2.724 & 0,3 \\
\hline Sanddorn-Gebüsch & 1.711 & 0,2 \\
\hline Gesamt Wasserpflanzen & 5.552 & 0,5 \\
\hline Gesellschaft des Schwimmenden Laichkrautes & 2.144 & 0,2 \\
\hline Armleuchteralgen-Bestand & 1.498 & 0,1 \\
\hline Schildhahnenfuß-Gesellschaft & 1.910 & 0,2 \\
\hline
\end{tabular}




\begin{tabular}{|c|c|c|}
\hline Vegetationseinheit / Bestand & Größe $\left(m^{2}\right)$ & Flächenanteil (\%) \\
\hline Gesamt Röhrichte und Großseggenriede & 69.640 & 6,5 \\
\hline Igelkolben-Röhricht & 185 & 0,0 \\
\hline Schilf-Röhricht & 35.600 & 3,3 \\
\hline Brackwasser-Röhricht & 8.498 & 0,8 \\
\hline Sumpfbinsen-Kleinröhricht & 2.600 & 0,2 \\
\hline Phragmition-Initialgesellschaft & 3.443 & 0,3 \\
\hline Großseggensumpf & 19.314 & 1,8 \\
\hline Gesamt Therophytenreiche Pioniervegetation & 4.310 & 0,4 \\
\hline Gift-Hahnenfußgesellschaft & 2.366 & 0,2 \\
\hline Gesellschaft des Graugrünen und Roten Gänsefußes & 1.944 & 0,2 \\
\hline Gesamt Ruderal-, Ufer- und Saumgesellschaften & 5.921 & 0,6 \\
\hline Festuca ovina-Equisetum arvense-Wegsaum & 662 & 0,1 \\
\hline Poa trivialis-Geum urbanum-Krautsaum & 2.010 & 0,2 \\
\hline Nitrophiler Krautsaum & 3.083 & 0,3 \\
\hline Gesellschaft des Rauhaarigen Weidenröschens & 166 & 0,0 \\
\hline Gesamt Sonstiges & 38.803 & 3,6 \\
\hline Offene Wasserflächen & 35.000 & 3,3 \\
\hline Ausschlussfläche (Gebiet 16) & 2.628 & 0,2 \\
\hline Ohne Vegetation / Unterstand & 735 & 0,1 \\
\hline Wege oder ähnliches & 440 & 0,02 \\
\hline Gesamtfläche & 1.070 .000 & 100 \\
\hline
\end{tabular}

\subsubsection{Vegetationserfassung nach drei Beweidungsjahren}

Nach drei Beweidungsjahren erfolgte eine Wiederholungskartierung. 74 Relevés aus dem Jahr 2011 wurden - wie bei der Erstkartierung - durch den TWINSPAN-Algorithmus in eine festgelegte Anzahl von Gruppen eingeteilt. Die Vorgabe von 20 Gruppen führte zum besten Ergebnis. Drei Gruppen wurden manuell aufgelöst, eine neu gebildet, so dass im Ergebnis 18 Aufnahmegruppen in der ersten Hierarchieebene vorlagen. Das Ergebnis zeigt das Dendrogramm in Abb. 42.

Anders als im Jahr 2008 entsprachen die Gruppen nicht unterschiedlichen Assoziationen, sondern beinhalteten bereits Subassoziationen und Varianten. Auf der zweiten Hierarchieebene lagen 21 Gruppen vor. Die JUICE- und die synoptische Tabelle sind Anlage 6.13 beigefügt. Eine Beschreibung der Vegetationseinheiten sowie die Begründung für deren Einordnung finden sich in Anlage 6.14. 


\section{AUSWIRKUNG DER BEWEIDUNG}

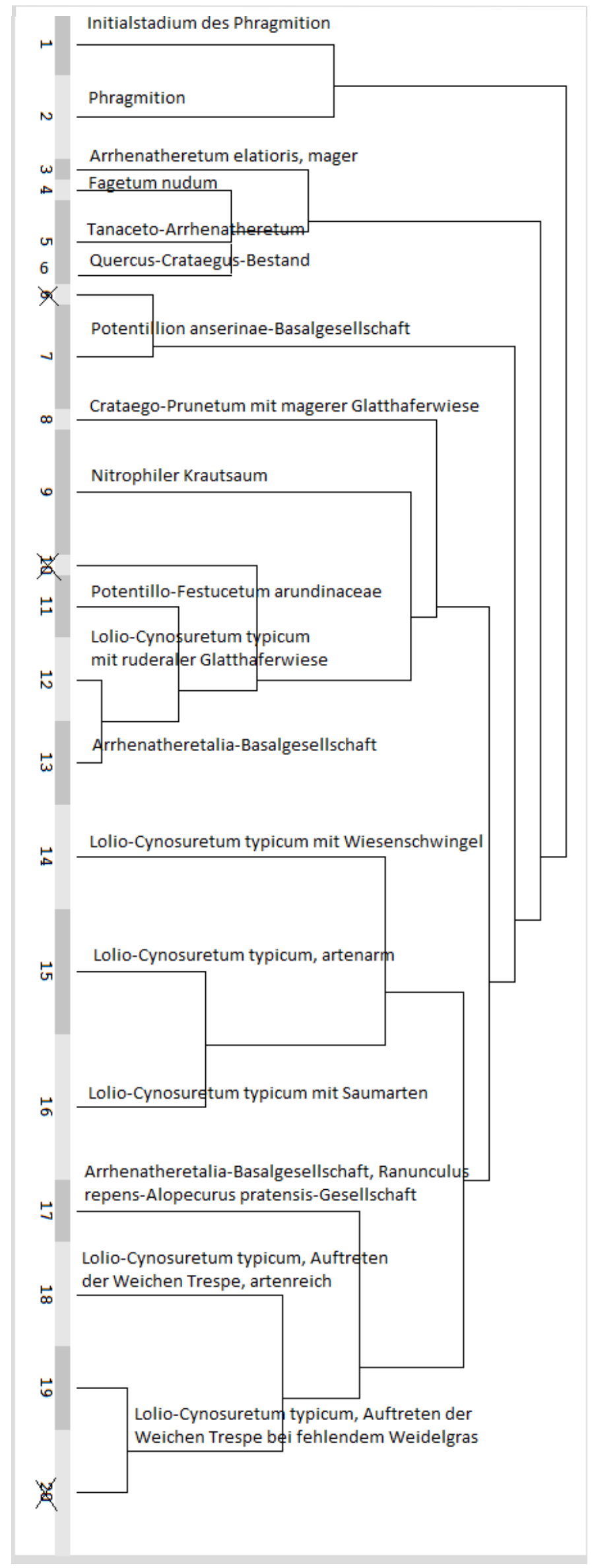

Abb. 42: Dendrogramm der TWINSPAN-Analyse mit Zuordnung der Cluster zu Vegetationseinheiten (2011)

3 Gruppen wurden aufgelöst, eine (Nr. 6) neu gebildet 


\subsubsection{Artenspektrum}

Die im Untersuchungszeitraum kartierten Arten wurden in einer Gesamtartenliste zusammengestellt (Anlage 6.4). Zu jeder Art wurden die Systematik (Ordnungs-, Familien-, Gattungs-, Artname), der Fundort mit Erfassungsjahr und Standort, der Schutzstatus sowie ökologische Wertzahlen (Ellenberg-Zeigerwerte sowie Nutzungswertzahlen) angegeben.

Im Gebiet wurden 363 Arten dokumentiert. Der Großteil wurde im Rahmen der Voruntersuchung (2007) und der Erstkartierung (2008) erfasst. In den Folgejahren kamen nur wenige Sippen hinzu (2009: 13 Arten, 2010: 7, 2011: 6). Die Arten entstammen 205 Gattungen. Diese gehören 33 Ordnungen an. Tab. 32 gibt deren systematische Einordnung im Pflanzenreich wider. Am häufigsten waren Vertreter der Ordnung Poales: Süßgrasartige sind die bestandsbildenden Pflanzen der Weiden und Wiesen. Unter den Kräutern fanden sich viele Arten der Asterales und Lamiales (beide Asternähnliche) sowie der Rosales und Fabales aus der Familie der Rosenähnlichen. Von den Magnolienähnlichen waren die Caryophyllales am häufigsten.

Im Projektgebiet wuchsen seltene Arten: 16 Arten sind durch die FFH-Richtlinie geschützt, darunter Knöllchen-Steinbrech (Saxifraga granulata), Wiesen-Schlüsselblume (Primula veris) und Ausdauernder Lein (Linum perenne) als typische Anzeiger magerer Grünlandstandorte. Am Ufer der Weiher und Tümpel sowie auf den Sumpfwiesen sind Wasser-Schwertlilie (Iris pseudacorus), Echtes Löffelkraut (Cochlearia officinalis), Sumpf-Läusekraut (Pedicularis palustris), Kleines Tausendgüldenkraut (Centaurium pulchellum), Breitblättriges Knabenkraut (Dactylorhiza majalis) und Roter Gänsefuß (Chenopodium rubrum) beheimatet. Im Laubwald wuchs die Breitblättrige Stendelwurz (Epipactis helleborine), während die Gelbe Narzisse (Narcissus pseudonarcissus) vermutlich aus früheren Gärten ausgewildert ist. 42 der kartierten Arten stehen auf der Roten Liste für Pflanzen in Deutschland (Ludwig \& Schnittler 1996, Riecken et al. 2006), davon haben 18 den Status "gefährdet" bis "vom Aussterben bedroht", weitere 22 stehen auf der Vorwarnliste. Bei zwei Arten ist der genaue Status ungeklärt (Anlage 6.4b).

Tab. 32: Systematik der im Projektgebiet aufgetretenen Gefäßpflanzen, Moose und Algen

mit Angabe der Artenzahlen

\begin{tabular}{|c|c|c|c|c|c|c|c|c|c|}
\hline $\begin{array}{l}\text { Reich } \\
\text { Charales } \\
\text { Plantae }\end{array}$ & & & \multicolumn{2}{|l|}{ Abteilung } & \multicolumn{2}{|l|}{ Klasse } & \multicolumn{3}{|l|}{ Ordnung } \\
\hline $\begin{array}{l}\text { Charales } \\
\text { Plantae }\end{array}$ & $\begin{array}{l}\text { Bryophyta } \\
\text { Cormobionta }\end{array}$ & $\begin{array}{l}\text { Laubmoose } \\
\text { Gefäßpflanzen }\end{array}$ & $\begin{array}{l}\text { Pteridophyta } \\
\text { Spermatophyta }\end{array}$ & $\begin{array}{l}\text { Gefäßsporenpflanzen } \\
\text { Samenpflanzen }\end{array}$ & $\begin{array}{l}\text { Bryopsida } \\
\text { Equisetopsida } \\
\text { Polypodiopsida } \\
\text { Coniferopsida } \\
\text { Monocotyledoneae } \\
\text { Dicotyledoneae }\end{array}$ & $\begin{array}{l}\text { Laubmoose i. e. S. } \\
\text { Schachtelhalme } \\
\text { Farne } \\
\text { Kiefernähnliche } \\
\text { Einkeimblättrige Pflanzen } \\
\\
\text { Zw eikeimblätrige Pflanzen }\end{array}$ & $\begin{array}{l}\text { Charales } \\
\text { Bryales } \\
\text { Hypnales } \\
\text { Equisetales } \\
\text { Blechnales } \\
\text { Coniferales } \\
\text { Alismatales } \\
\text { Asparagales } \\
\text { Poales } \\
\text { Nymphaeales } \\
\text { Piperales } \\
\text { Ranunculales } \\
\text { Caryophyllales } \\
\text { Santalales } \\
\text { Saxifragales } \\
\text { Geraniales } \\
\text { Myrtales } \\
\text { Celastrales } \\
\text { Malpighiales } \\
\text { Rosales } \\
\text { Fabales } \\
\text { Fagales } \\
\text { Brassicales } \\
\text { Sapindales } \\
\text { Malvales } \\
\text { Cornales } \\
\text { Ericales } \\
\text { Gentianales } \\
\text { Solanales } \\
\text { Lamiales } \\
\text { Dipsacales } \\
\text { Apiales } \\
\text { Asterales }\end{array}$ & $\begin{array}{c}1 \\
1 \\
2 \\
3 \\
1 \\
2 \\
8 \\
5 \\
68 \\
1 \\
1 \\
15 \\
23 \\
1 \\
3 \\
6 \\
8 \\
1 \\
13 \\
32 \\
24 \\
10 \\
12 \\
3 \\
3 \\
1 \\
6 \\
12 \\
10 \\
34 \\
8 \\
9 \\
37 \\
\end{array}$ & 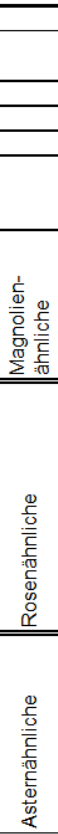 \\
\hline
\end{tabular}




\subsubsection{Bewertung}

Drei Jahre sind pflanzensoziologisch gesehen ein sehr kurzer Zeitraum für signifikante Veränderungen in der Vegetationszusammensetzung. Die Mehrzahl der Aufnahmen aus dem Jahr 2011 wurde dem gleichen Vegetationstyp zugeordnet wie bei der Erstkartierung. Änderungen traten im Uferbereich beim Potentillion anserinae (Gruppe 7) und im Grünland beim Lolio-Cynosuretum typicum (Gruppen $15,17,18)$ auf. Eine Übersicht der zugeordneten Vegetationsaufnahmen liegt Anlage 6.6 bei.

\section{Im Uferbereich}

Im Uferbereich wandelten sich ehemalige Röhrichtgesellschaften beziehungsweise Zweizahn-Knöterich-Teichuferfluren zu Flutrasen (Abb. 43): Aufnahmen des Chenopodietum rubri, Bidenti-Ranunculetum scelerati, des Phagmition-Initialstadiums sowie des Schilfröhrichts (Schoenoplecto-Phragmitetum) wurden im Jahr 2011 der Potentillion anserinae-Basalgesellschaft zugeordnet. Auch innerhalb des Verbandes kam es zu einer Verschiebung eines Juncus compressi-Trifolietum repentis zu einer Potentillion anserinae-Basalgesellschaft (Gruppe 7), ein ufernaher Bellis-perennis-Pulicaria dysenteriaBestand (Wirtschaftsgrünland-Basalgesellschaft) wurde einem Potentillo-Festucetum arundinaceae zugeordnet (Gruppe 10).

Die Übergänge waren fließend. So stellt gerade die Potentillion anserinae-Basalgesellschaft eine Art Sammelbecken für verschiedene Arten des Flutrasens, aber auch angrenzender Lebensräume wie Grünland und Röhrichte dar. Sie beinhaltet per Definition unterschiedlich ausgeprägte Vegetationseinheiten, welche sich zwar nicht durch Assoziationskennarten wie Festuca arundinacea oder Juncus compressus auszeichnen, aber die typische Artenkombination des Verbandes (Potentilla anserina, Carex hirta, Pulicaria dysenterica, Rumex crispus, Agrostis stolonifera, Potentilla reptans) präsentieren. Diese Arten treten auch begleitend im Initialstadium des Phragmitions auf. Es ist daher davon auszugehen, dass sich die betrachteten Flächen im Übergang zwischen Verlandungs- und Grünlandgesellschaften befanden, die je nach Witterungsbedingungen und Wasserstand unterschiedlich stark vernässten.

Hierzu kam die Trittwirkung der Pferde. Die Flächen lagen in der Nähe beliebter Trink- und Badestellen, von Tierpfaden oder Ruheplätzen der Gebiete 1 und 18. Dass hier Fingerkraut-Quecken-Flutrasen vorkamen, verwundert nicht, handelt es sich dabei doch um Pioniergesellschaften, die ursprünglich den Hochwasserbereich von Gewässern besiedelten und heute auch auf anthropogenen Standorten im Grünlandbereich zu finden sind. Sie bilden dabei oft relativ instabile, gestörte Ökotone - hier verursacht durch den häufigen Tritt - zwischen stabilen Bereichen (Pott 1995). Aufgrund der linienförmigen Saumbiotope kam es möglicherweise zu Ungenauigkeiten bei der Digitalisierung im GIS. Eine weitere potenzielle Fehlerquelle könnte die Tatsache darstellen, dass die Vegetationsaufnahmen im Jahr 2011 aufgrund des höheren Wasserstandes an abweichenden Standorten angefertigt wurden (Abb. 44).

\section{Im Grünland}

Vergleicht man die Bestandsaufnahmen der Grünlandflächen der Jahre 2008 und 2011, so zeigten sich auch hier erste Veränderungen, wenn auch nur auf Subassoziations- und Variationsniveau. Durch die Beweidung haben die Glatthaferwiesen im Gebietszentrum an Ausdehnung verloren (Abb. 45). Andererseits sind die sehr artenarmen Fettweiden-Bestände zurückgegangen (Tab. 33).

Da die Teilflächen vorher eine unterschiedliche Nutzung erfuhren, unterschieden sich frühere Wiesen zu Projektbeginn in ihrer Artenzusammensetzung von ehemaligen Weiden. Im Jahr 2011 hatte sich dieser Effekt aufgrund der flächendeckenden Pferdebeweidung bereits deutlich verloren. Im Gebietszentrum wurden die Vegetationseinheiten kleinflächiger, die Verteilung orientierte sich weniger an früheren Gebietsgrenzen als an geografischen Gegebenheiten oder Nutzungspräferenzen der Weidetiere. 

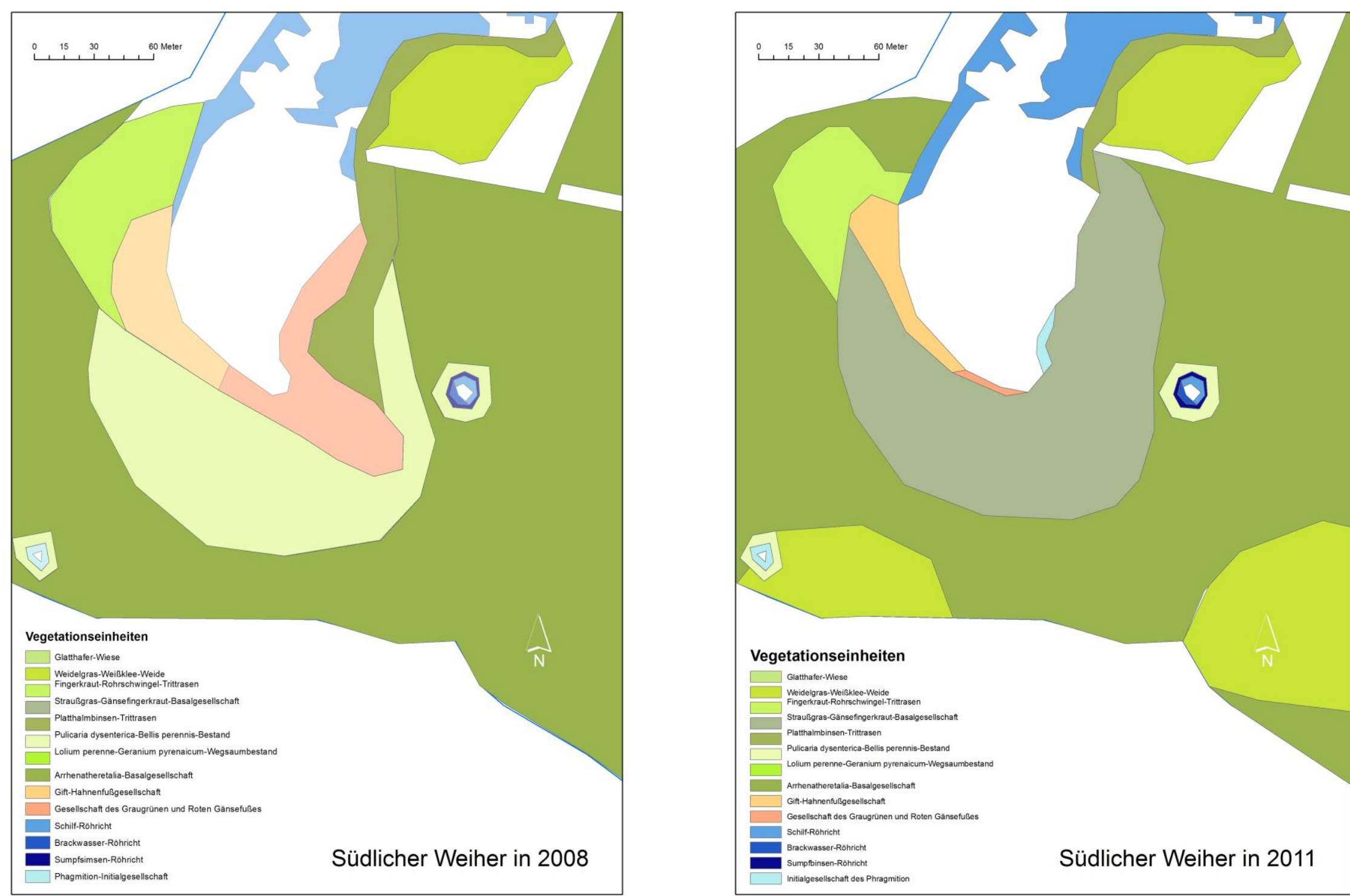

Abb. 43: Kartierte Pflanzengesellschaften im Uferbereich des Weihers von Gebiet 1 in den Jahren 2008 (links) und 2011 (rechts) 

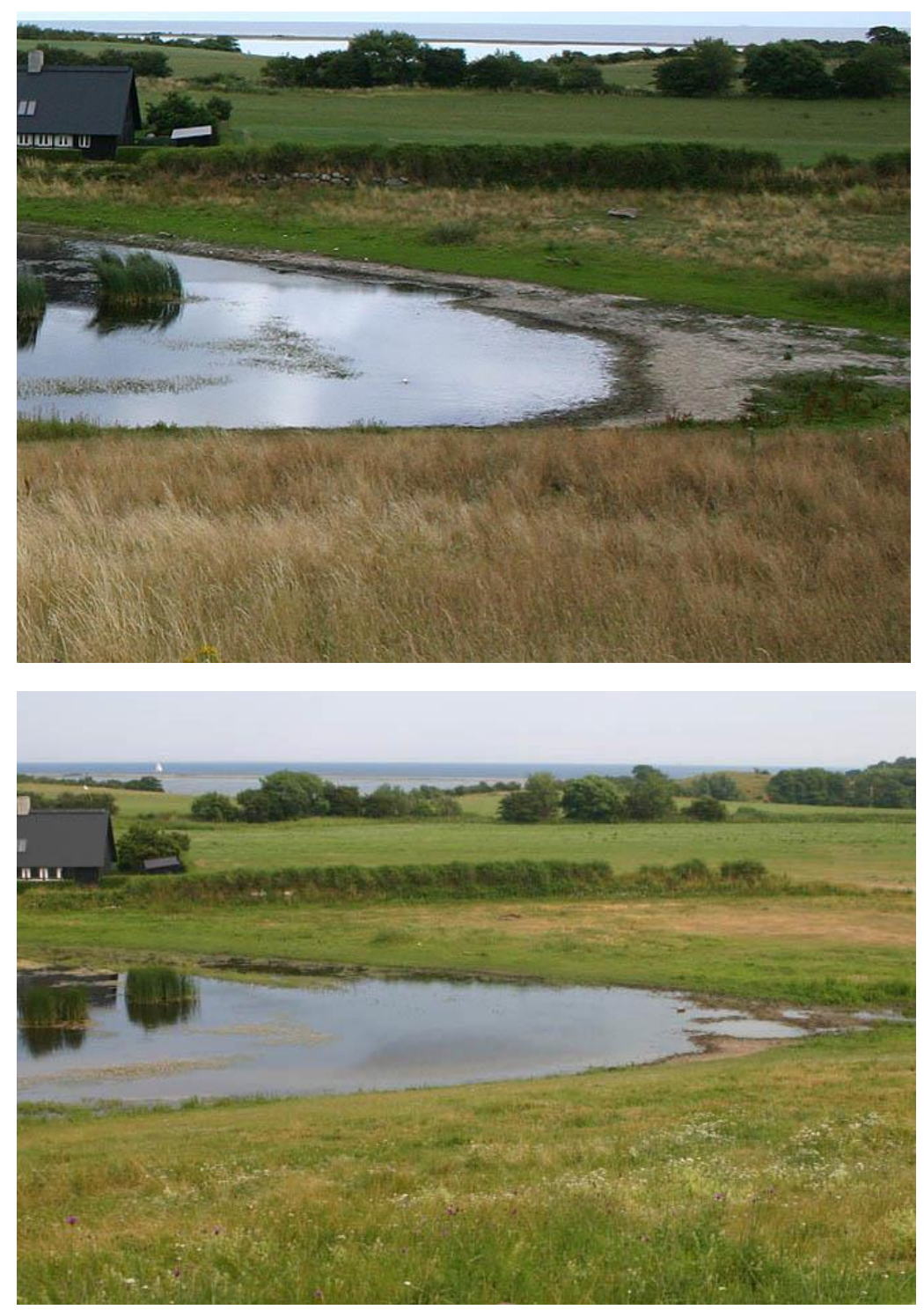

Abb. 44: Südlicher Uferbereich am Weiher im Gebietszentrum im Juli 2008 (oben) und 2010 (unten)

Bedingt durch den niedrigen Wasserstand war der Anteil an offener Erde im Uferbereich im Jahr 2008 deutlich höher. Aufgrund der starken Störungen hat sich hier eine Schild-Hahnenfuß-Gesellschaft etabliert.

Tab. 33: Artenzahlen der den Glatthaferwiesen und Fettweiden zugeordneten Gruppen der Vegetationskartierungen 2008: 94 Aufnahmen, 2011: 54 Aufnahmen; MW = Mittelwert der Artenzahlen

\begin{tabular}{|c|c|c|c|c|c|c|c|c|c|c|c|c|}
\hline \multirow{2}{*}{$\begin{array}{l}2008 \\
\text { Gruppe Nr. }\end{array}$} & \multicolumn{4}{|c|}{ Glatthaferwiese } & \multirow[t]{2}{*}{ MW } & \multicolumn{6}{|c|}{ Fettweide } & \multirow[t]{2}{*}{ MW } \\
\hline & 20 & 22 & 23 & 24 & & 25 & 26 & 27 & 28 & 29 & 30 & \\
\hline Anzahl der Aufnahmen & 2 & 10 & 3 & 16 & & 8 & 10 & 6 & 14 & 7 & 18 & \\
\hline Anzahl der Arten & 26 & 41 & 22 & 46 & 33,75 & 24 & 39 & 20 & 41 & 17 & 17 & 23,75 \\
\hline 2011 & \multicolumn{4}{|c|}{ Glatthaferwiese } & MW & \multicolumn{6}{|c|}{ Fettweide } & MW \\
\hline Gruppe Nr. & 3 & 5 & 12 & 16 & & 11 & 13 & 14 & 15 & 17 & 18 & \\
\hline Anzahl der Aufnahmen & 1 & 4 & 12 & 3 & & 3 & 5 & 6 & 7 & 5 & 8 & \\
\hline Anzahl der Arten & 13 & 31 & 49 & 25 & 29,5 & 32 & 25 & 19 & 26 & 34 & 29 & 27 \\
\hline
\end{tabular}



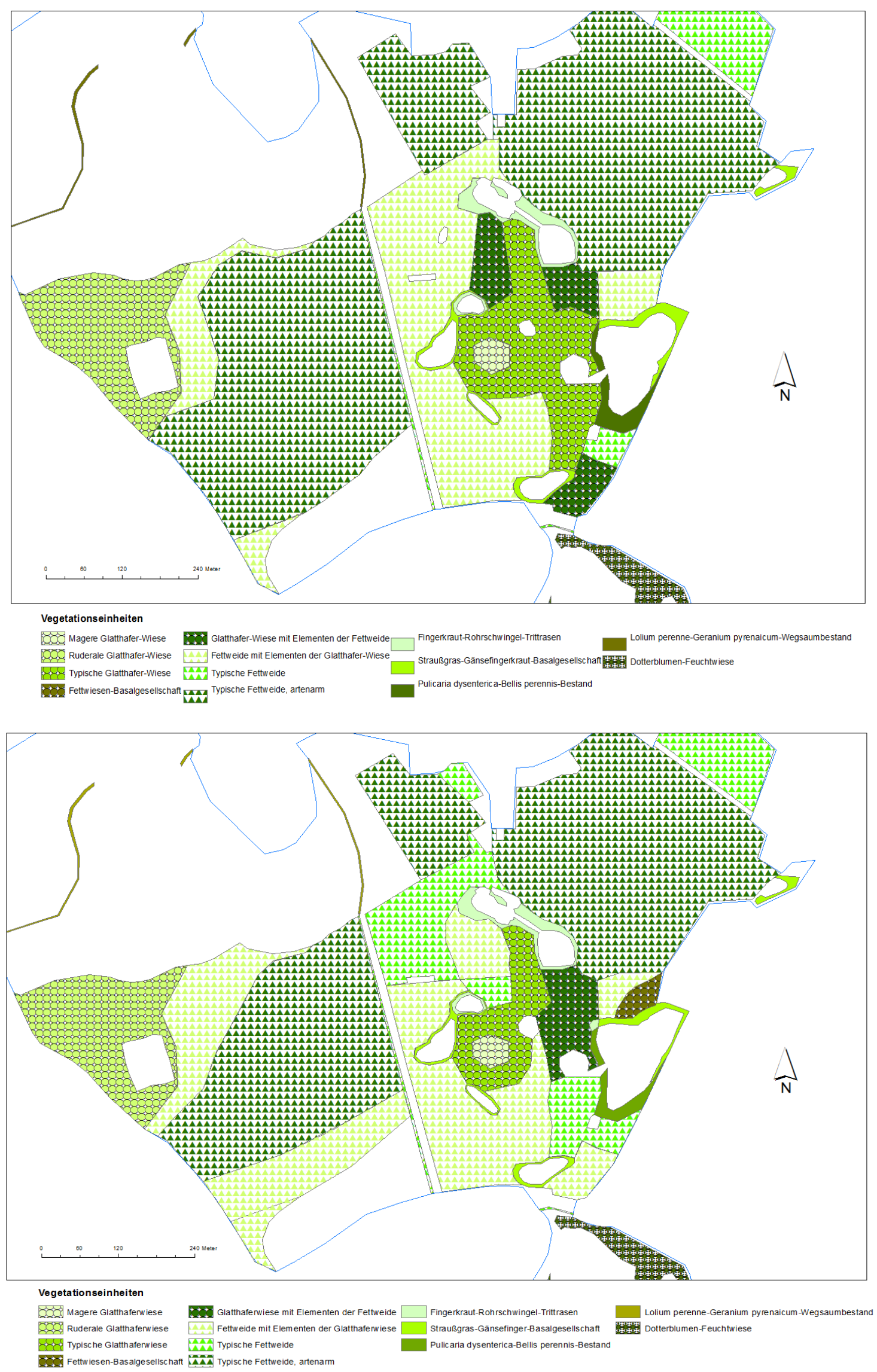

Abb. 45: Grünland-Pflanzengesellschaften im Gebietszentrum in den Jahren 2008 (oben) und 2011 (unten) 
Ferner haben Lolium perenne, Phleum pratense und Arrhenatherum elatius gegenüber dem Jahr 2008 abgenommen, während sich andere Graslandarten wie Festuca rubra, Poa pratensis oder Bromus hordeaceus ausbreiteten. Warum sich gerade die Tritt und Fraß empfindliche Weiche Trespe flächig ansiedelte, ist nicht klar. Möglicherweise erleichterte die stellenweise niedrig gefressene Vegetation mit offenen Bodenstellen dem einjährigen, winterannuellen Therophyten das Auskeimen seiner Samen.

Auch Kräuter wie Trifolium repens wurden durch die Beweidung gefördert. Diese Entwicklung verwundert nicht: Bei einer extensiven Bewirtschaftung von Weidelgras-Weißklee-Fettweiden werden die Stickstoffdüngung unterlassen und die Beweidungsdichte reduziert. Ein Weißklee betonter Pflanzenbestand stellt sich laut Dierschke \& Briemle (2002) vor allem dann ein, wenn wie hier im Untersuchungsgebiet die Flächen bereits früh im Jahr beweidet werden.

Die dem Lolio-Cynosuretum zugeordneten Gruppen wiesen sich im Jahr 2011 als mäßig bis gut stickstoffversorgte Standorte aus (Ellenberg-Zeigerwerte $N=5,5-6,5)$. Im Jahr 2008 lagen die Stickstoffzahlen noch etwas höher ( $N=5,9-6,75)$. Ob sich die Flächen bei einer fortgeführten extensiven Pferdebeweidung zu Magerweiden entwickeln, bleibt abzuwarten. Einerseits zeigte das Gebiet bereits nach wenigen Beweidungsjahren das typische Erscheinungsbild einer großräumigen, extensiven Standweide, von Sträuchern und Feldgehölzen durchsetzt mit einem ausgeprägten Mosaik unterschiedlich stark abgefressener Bereiche mit entsprechend variablen Lebensmöglichkeiten für viele Pflanzen und Tiere (Dierschke \& Briemle 2002). Auch das anspruchsvolle Weidelgras ist zurückgetreten. Es wuchsen jedoch noch zu viele Stickstoffanzeiger wie beispielsweise Poa annua, Anthriscus sylvestris und Taraxacum officinale auf der Fläche, um von einer beginnenden Ausmagerung zu sprechen. Um dies zu beschleunigen, wäre eine Beseitigung der Kothaufen von den Weideflächen erforderlich, was im Projektgebiet weder umsetzbar noch gewollt ist - bietet doch auch der Dung einen Lebensraum für Käfer und Pilze.

\subsubsection{Entwicklung der Strukturen}

Viele der seltenen und bedrohten Arten der europäischen Natur- und Kulturlandschaft benötigen Lebensräume mit einer hohen Dynamik, Pionierstadien und Strukturreichtum. Dynamische Prozesse erhöhen die Artenvielfalt, auch konkurrenzschwache Arten überleben.

Für viele Lebensgemeinschaften sind neben dem Abbau der vorjährigen Streuauflagen vor allem Veränderungen der Vegetations- und Gehölzstruktur durch Verbiss und Komfortverhalten von Bedeutung (von Oheimb et al. 2006). Ferner beeinflussen Weidetiere die Eigenschaften des Bodens, gerade im Uferbereich, wo die Weidetiere sich häufig zum Trinken und Baden aufhalten. Im Rahmen der Strukturuntersuchungen wurde erforscht, welche Auswirkungen die Beweidung auf die Entwicklung der Gehölze und die Strukturen der offenen Weidelandschaft hatte.

\subsubsection{Strukturentwicklung der Gehölze}

Bei der Beurteilung der Gehölzentwicklung wurde zwischen Altbeständen und Jungwuchs, der erst während der Beweidung gekeimt ist, unterschieden. Da Pferde klassische Grasfresser sind, ist ihr Einfluss auf etablierte Gehölzbestände in der Regel eher gering. Ein Schaden am Baum führt selten gleich zu dessen Absterben. Für Jungpflanzen stellen Tritt und Fraß jedoch eine erhebliche Gefahr dar. Eine Bewertung der Schäden an aufgewachsenen Gehölzen wurde durch eine Transektuntersuchung abgebildet, der Einfluss der Weidetiere auf die Verbuschung im offenen Weideland durch einen Vergleich des Gehölzaufwuchses vor sowie nach 5 Jahren Beweidung mittels Luftbildaufnahmen. 
Vor Beginn der Pferdebeweidung im Jahr 2006 waren rund 63 \% der Flächen gehölzfrei (Tab. 34, Abb. 18). Dies waren vor allem die ehemaligen Wiesen, Weiden und Äcker. Weitere $9 \%$ des Gebietes wiesen Gehölzdeckungsgrade zwischen 5-50 \% auf und wurden als gehölzarm bezeichnet. Dabei zeigten die ruderalen und mageren Glatthaferwiesen einen etwas höheren Verbuschungsgrad als die ehemaligen Fettweiden und Äcker. Auch seltener genutzte Randbereiche des Gebietes und Uferabschnitte mit beginnender Verbuschung zwischen Altholzinseln fielen in diese Deckungsgradklasse. Insgesamt waren knapp drei Viertel der Fläche im Jahr 2006 frei von Gehölzen oder nur geringfügig verbuscht. Dem gegenüber stand ein Flächenanteil von $28 \%$, der mäßig bis stark zugewachsen war (Deckungsgrade über 50 \% sowie Altgehölze). Dies betraf die Laub- und Nadelwaldforste, die Gebüschstreifen und Feldgehölze. Sie lagen schwerpunktmäßig im Bereich der Gewässerränder oder im Randbereich des von der Beweidung ausgeschlossenen Niederwaldes, teils an früheren Gebietsgrenzen in Form von linearen Baumbeständen.

\section{Entwicklung im offenen Weideland}

Nach 5 Jahren extensiver Pferdebeweidung nahmen gehölzfreie oder leicht verbuschte Flächen (mit Gehölzdeckungsgraden unter 50 \%) um rund drei Prozent auf 75,4 \% zu (Tab. 34). Die Entbuschungsmaßnahmen im Gebiet sowie die Auflichtung des Forstes (siehe Absatz Entwicklung der bereits aufgewachsenen Gehölze) erklären den leichten Anstieg in der Deckungsgradklasse von 25-50 \%. Bemerkenswert ist die Zunahme gehölzfreier Flächen (0-5 \% Deckung) um 8,3 \%. Wie Abb. 46 zeigt, wurden vor allem die Gehölzdeckungen auf den zentralen Grünlandflächen sowie auf der ruderalen Glatthaferwiese im westlichen Teil reduziert. Dies wird auf die Fraß- und Trittwirkung der Pferde zurückgeführt, die diese Bereiche intensiv nutzten.

Die Beweidung bewirkte somit, dass sich Flächen mit einem geringen Gehölzanteil in gehölzfreie Bereiche entwickelten. Obwohl Pferde nicht dem Ernährungstyp der „Browser“ zugeordnet werden, waren sie auf Süd-Langeland dennoch in der Lage, die beginnende Verbuschung des offenen Weidelandes im Projektgebiet erkennbar zu verringern.

Tab. 34: Relative Flächenanteile der Gehölzdeckungsgradklassen im Projektgebiet vor und nach 5 Jahren Pferdebeweidung

\begin{tabular}{llllll}
\hline Deckungsgrad Gehölz & $\mathbf{2 0 0 6}$ & Anteil in \% & $\mathbf{2 0 1 1}$ & Anteil in \% & Differenz \\
\hline 0 - 5 \% Deckung & 682.000 & 63,3 & 771.000 & 71,6 & $\mathbf{+ 8 , 3} \%$ \\
5 - 25 \% Deckung & 90.000 & 8,4 & 29.000 & 2,7 & $-5,7 \%$ \\
25 - 50 \% Deckung & 4.000 & 0,4 & 12.000 & 1,1 & $+0,7 \%$ \\
50 - 75 \% Deckung & 21.000 & 1,9 & 15.000 & 1,4 & $-0,5 \%$ \\
$75-100 \%$ Deckung & 256.000 & 23,7 & 232.000 & 21,5 & $-2,2 \%$ \\
Altgehölze & 25.000 & 2,3 & 18.000 & 1,7 & $-0,6 \%$ \\
\hline
\end{tabular}



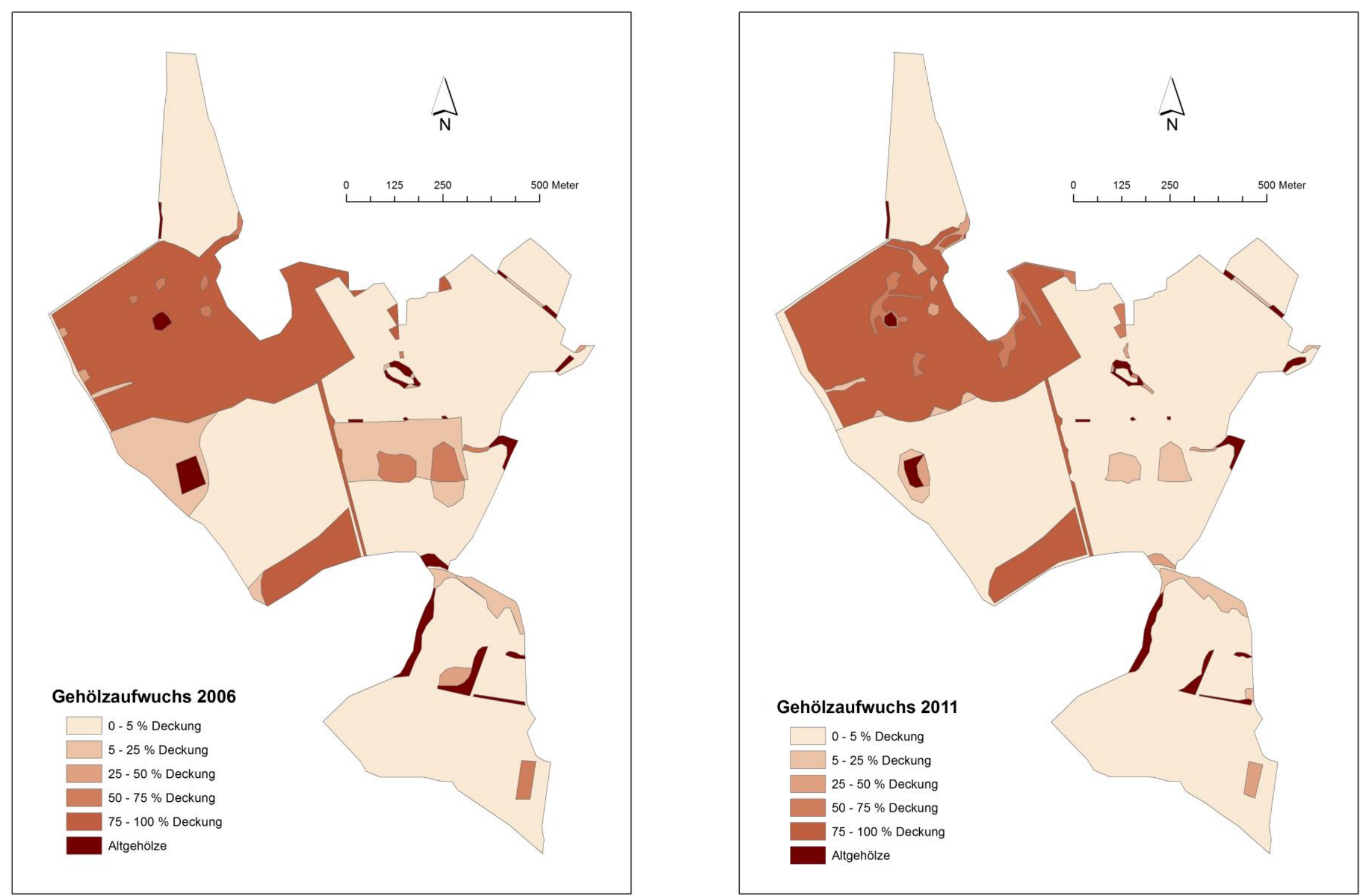

Abb. 46: Verteilung der Gehölze vor Beginn der Pferdebeweidung (links) nach 5 Beweidungsjahren (rechts) mit Angabe der Gehölzdeckungsgrade 


\section{Entwicklung der bereits aufgewachsenen Gehölze}

Gehölzbereiche mit älterem Baumbestand und Deckungsgraden von über 50 \%, die im Forst oder auf den trockenen Kuppen vorkamen, wurden in ihrer Struktur durch die Weidetiere kaum verändert. Trotz zunehmender Beweidungsintensität blieben die Deckungsgrade hier nahezu unverändert, wenn man die Abholzungsmaßnahmen der Forstbehörde aus dem Ergebnis herausrechnet. Die Einrichtung von Waldkorridoren im Jahr 2009 erfolgte im Zuge der FSC-Zertifizierung. Die leichtere Zugänglichkeit der zuvor geschlossenen Waldbereiche führte indirekt dazu, dass kleine Areale mit einer geringeren Gehölzdeckung entstanden. Sie entwickelten sich sowohl entlang der neu geschaffenen Korridore als auch auf Lichtungen (Abb. 46).

Deutlich zeigte sich auch der Einfluss der Pferde am Waldrand: An stark frequentierten Stellen, wo Tierpfade von den Grünländern in den Wald führten, entstanden Einkerbungen entlang der Waldränder. Eine „Browsingline“, also eine Verformung der Waldränder durch Verbiss bis zu einer bestimmten Baumhöhe, trat jedoch im Gebiet nicht auf. Aufgrund ihrer Nähe zu Grünländern und Wegen mit höherer Nutzungsintensität dehnten sich die Altholzbestände kaum aus. Zwischen den Einzelbäumen war lediglich eine zunehmende Versaumung und Verbuschung erkennbar. Insgesamt betrachtet waren die Veränderungen der Anteile in den 6 Deckungsgradklassen statistisch nicht relevant (Wilcoxon-Test, $p>0,05)$.

Zusätzlich zur Auswertung der Luftaufnahmen wurden im Projektgebiet über 500 Einzelpflanzen entlang von Transekten auf Verbissschäden untersucht. Innerhalb von drei Jahren hat der Pflanzenbestand leicht abgenommen. Dies beruhte weniger auf weidebedingten Verlusten im Baumbestand als auf Schwankungen im Deckungsgrad der Strauchschicht (vor allem bei Rubus idaeus). Die Gehölze zeigten trotz Beweidung eine hohe Vitalität, weniger als 0,05\% der untersuchten Pflanzen wurden bei der Datenaufnahme der Kategorie „abgestorben“ zugeordnet. Gleichwohl nahm der Anteil an Jungpflanzen deutlich ab.

Auf den Transekten wurden 23 Arten kartiert (Abb. 47). Im dritten Erhebungsjahr 2010/11 hatten Prunus spinosa $\left(65 \mathrm{~m}^{2}\right)$, Rubus fruticosus agg. $\left(58 \mathrm{~m}^{2}\right)$ und Quercus robur $\left(46 \mathrm{~m}^{2}\right)$ den größten Flächenanteil. Aufgrund von Baumfällungen waren die Anteile von Hundsrose, Schwarz- und Weißdorn sowie Rotbuche rückläufig. Pappel, Hasel, Birke, Süßkirsche und vor allem Brombeere kamen mit der Pferdebeweidung am besten zurecht: Ihre Flächenanteile vergrößerten sich im Untersuchungszeitraum. Was jedoch nicht bedeutete, dass diese Arten nicht verbissen wurden: Neben Spitz- und Feldahorn und dem Roten Hartriegel zeigten auch Birke, Hasel und Pappel häufige Verbissschäden. Bei anderen Arten veränderte sich der Flächenanteil zwischen 2008 und 2010 nur geringfügig.

Bei den nicht oder gering beschädigten Pflanzen handelte sich meist um bewehrte Arten wie Weißund Schwarzdorn, Rose und Stachelbeere sowie Nadelhölzer wie die Edeltanne (Abb. 48). Über die Hälfte der Pflanzen wiesen keine Schäden auf. Die Verbissintensität wurde von der Witterung beeinflusst: Im kalten und schneereichen Winter 2009/10 wurden mehr Gehölze beschädigt als in den anderen beiden Jahren, die jährlichen Unterschiede der Verbissintensitäten waren insgesamt jedoch gering (Abb. siehe Anlage 6.19). Meist waren nur in etwa $25 \%$ der Triebe einer Pflanze von Verbiss betroffen (das entspricht der Schadensklasse 2), so dass die Verbissbelastung insgesamt gering war.

Verbissschäden unterteilten sich ferner in Fraß am Seiten- oder Haupttrieb, Tritt oder Scheuern. Am häufigsten wurden Seitentriebe verbissen, während Baumschäden durch Scheuern oder Schälen nur vereinzelt auftraten (Abb. 49). 


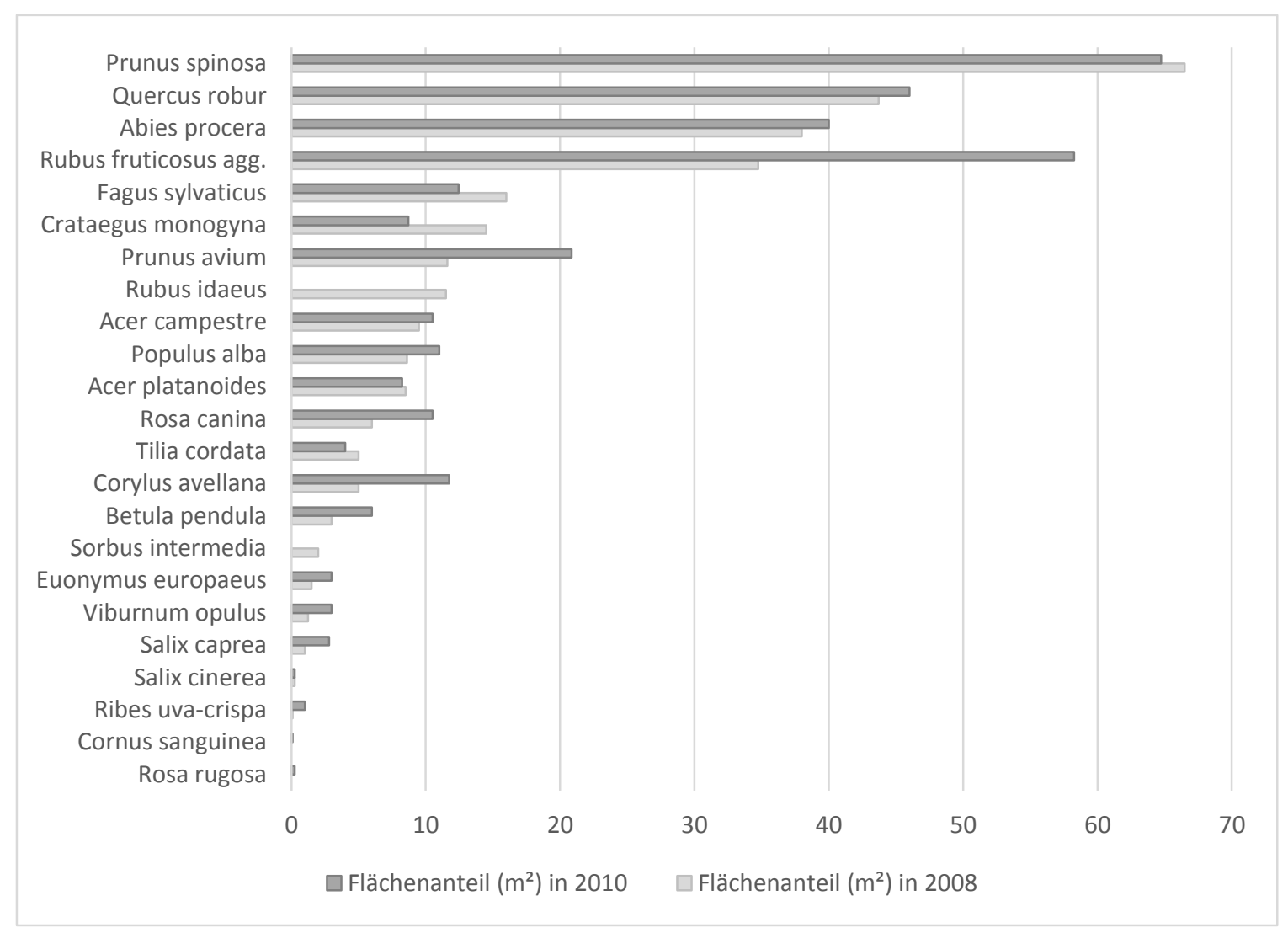

Abb. 47: Flächenanteile der 23 auf den Transekten erfassten Gehölzarten in den Jahren 2008 bzw. 2010

Die Anteile des zerstörten Gebüschtransektes wurden nicht berücksichtigt.

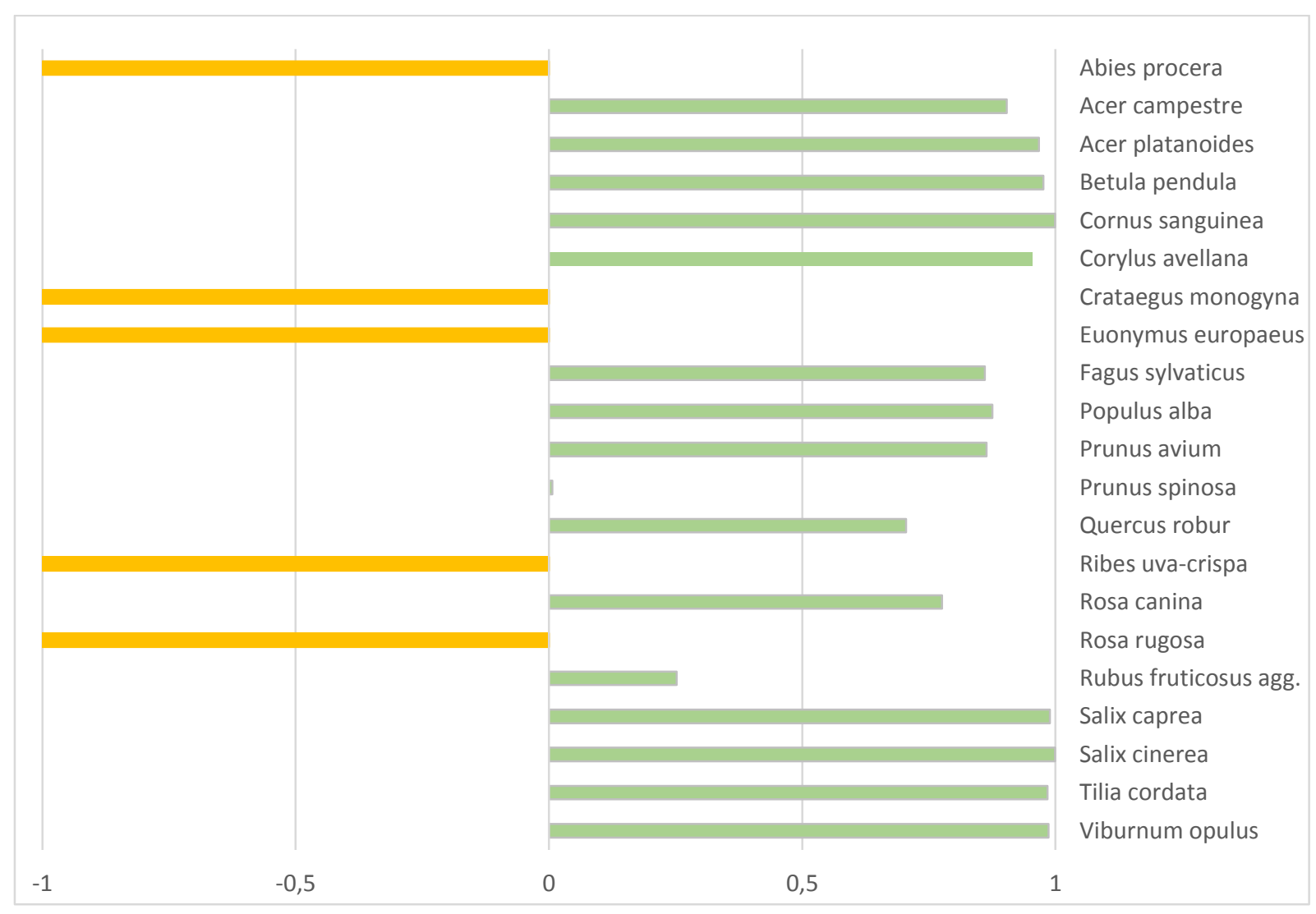

Abb. 48: Attraktivität der untersuchten Pflanzenarten auf den Transekten im Hinblick auf den Verbiss im Winter 2010/11

Electivity Index E, E > +0,25 = bevorzugte Arten; $\mathrm{E}<-0,25=$ gemiedene Arten; $\mathrm{E}+0,25<0>-0,25=$ neutral 
Im Projektgebiet verbissen Pferde und Rehe Gehölze. Eine eindeutige Zuordnung zu einer Tierart war schwierig, da selten frischer Verbiss beobachtet wurde: Zwar zeigt das Reh als Wiederkäuer eine faserige, rechtwinklige Abbissstelle, das Pferd hingegen eine glatte Abbissfläche (Abb. 50). Diese tritt allerdings auch bei Feldhasen und Mäusen auf, die zahlreich im Gebiet vertreten sind, was eine Zuordnung von Verbissschäden in den unteren Höhenstufen erschwerte. Ein bestimmter Anteil des beobachteten Verbisses im Gehölz wurde daher vermutlich nicht von den Pferden verursacht. Nur Schäden durch Scheuern (Abb. 50) oder Tritt konnten ihnen eindeutig zugeordnet werden. Die Zunahme von Verbiss in über 1,50 m Höhe von 3,4 \% auf 11,4 \% deutet jedoch auf einen gewissen Weideeinfluss der Ponys hin (vgl. Abb. 49). Auch wurden Tiere direkt beim Fressen von frischen Blättern im Unterholz beobachtet.
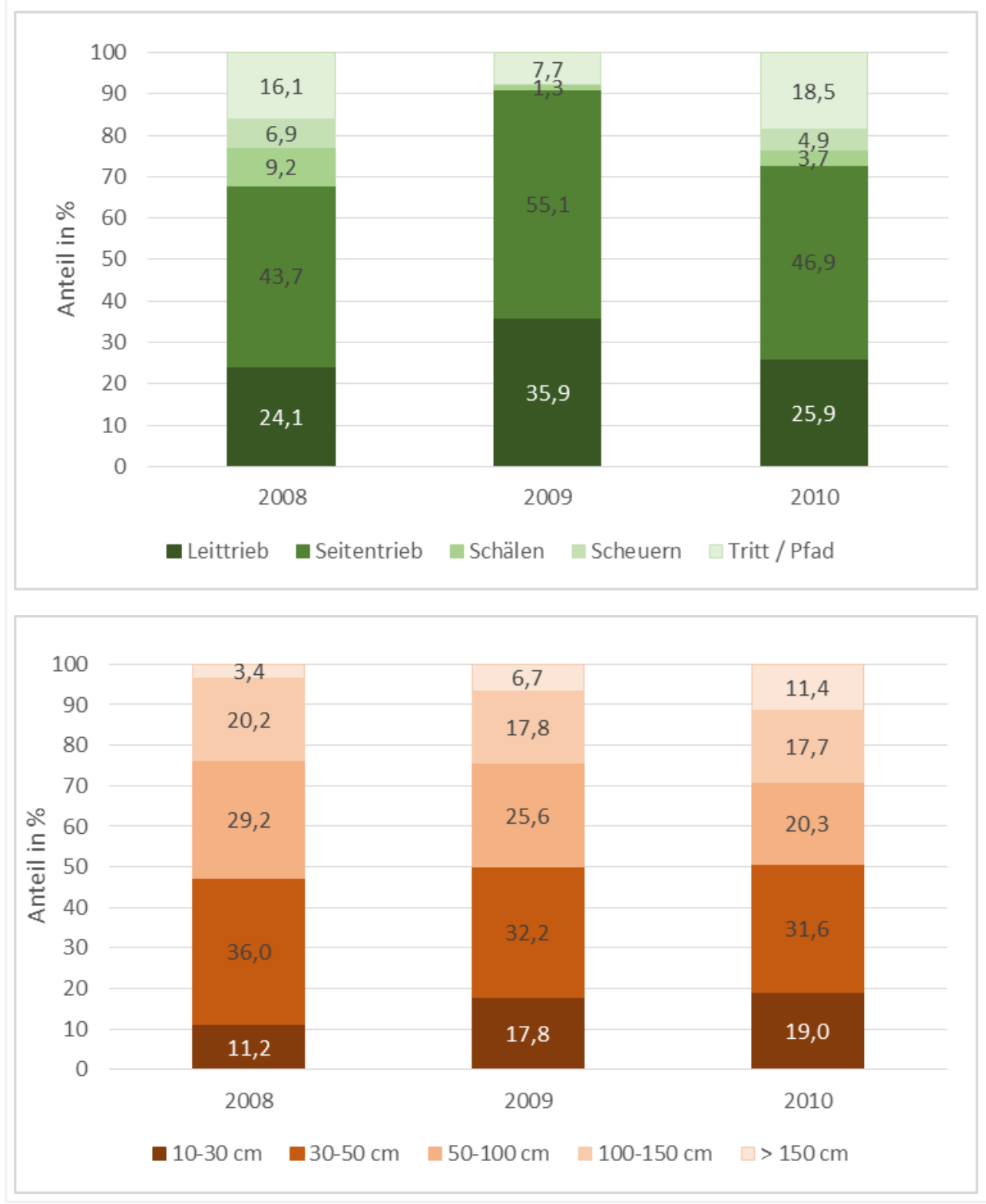

Abb. 49: Verbissschäden nach Schadensarten (oben) und Höhenstufen (unten) auf den Transektflächen 

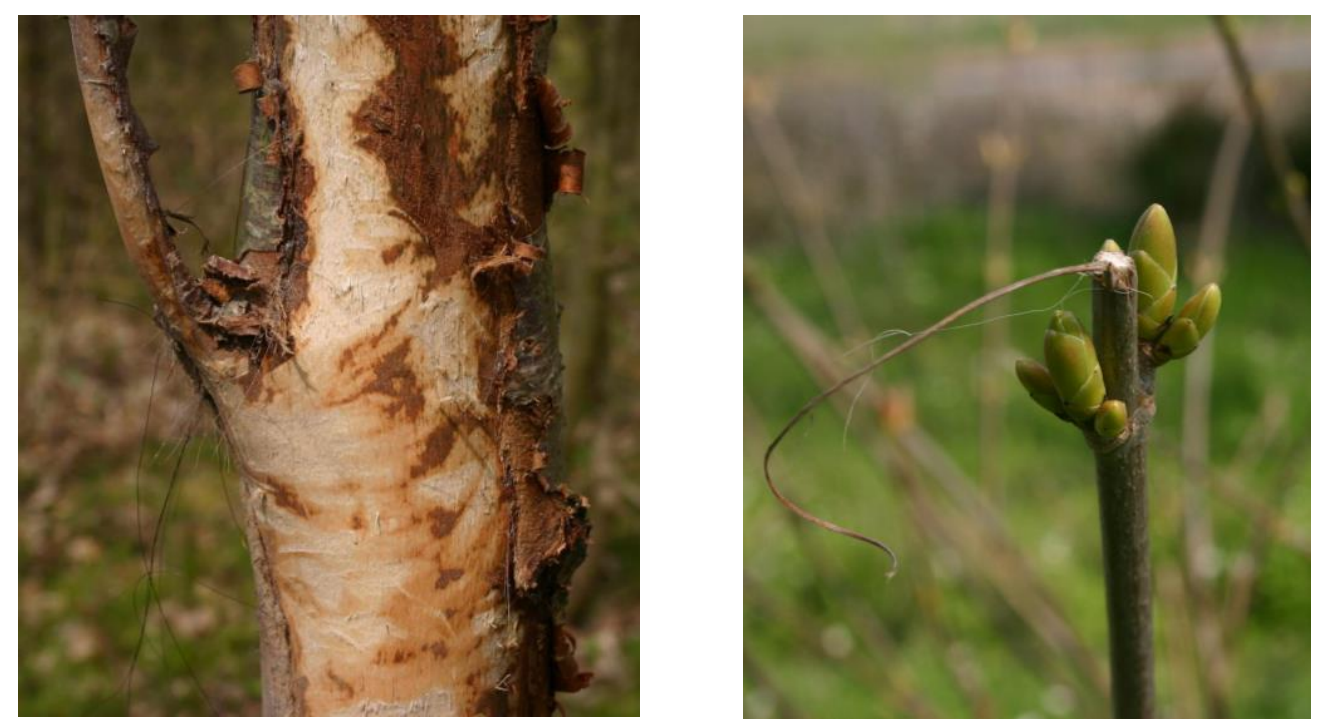

Abb. 50: Gehölzschäden verursacht durch Scheuern und Knabbern in Widerristhöhe (links) oder durch Fraß von Trieben an Stockausschlägen (rechts)

\section{Fazit der Gehölzentwicklung}

Der Einfluss einer ganzjährigen Pferdebeweidung auf die Gehölzentwicklung im Gebiet ist aufgrund der zahlreichen Eingriffe der Naturschutzbehörde in den Baum- und Strauchbestand schwer zu beziffern. Zwar zeigte sich eine beginnende Auflichtung der Forste, ein nennenswerter weidebedingter Rückgang der Gehölzbestände war nicht zu verzeichnen. Dies überrascht nicht, da Pferde keine Tiere des Waldes, sondern des Offenlandes sind.

Gerade in diesem Lebensraumtyp wirkte sich die Beweidung jedoch nachweislich auf die Strukturentwicklung der Gehölze aus. Auch bei geringem Besatz wurden Baumkeimlinge und Jungpflanzen erfolgreich verbissen oder zertrampelt. Dadurch wurde ein Zuwachsen der Flächen verhindert. Die Pferde waren gar in der Lage, beginnende Brachen oder leicht verbuschte Grünlandflächen in gehölzfreie Flächen zurückzuführen. Dies bestätigt den optischen Eindruck, dass die Verbuschung auf den Weideflächen trotz angrenzender Gebüschbestände nicht zugenommen hat. Da eine Verbuschung jedoch nicht von Jungpflanzen, sondern von dem bereits bestehenden, hochgewachsenen Baumbestand ausgeht, werden die Weidetiere einen Gehölzaufwuchs im Grünland nur bei einer fortlaufenden Beweidung in ausreichenden Besatzdichten verhindern können.

Die Verbissbelastung im Gehölz traf nicht alle Arten in gleicher Weise. Gerade bewehrte Arten oder Nadelhölzer wurden gemieden. Andere Arten, darunter auch typische Pioniergehölze wie Birke und Pappel, breiteten sich trotz Verbissschäden aus. Mittelfristig kann dies zu einer Veränderung der Baumartenzusammensetzung im Gebiet führen. Insgesamt ist die Verbissbelastung durch die Pferde als gering einzuschätzen, was höchstwahrscheinlich mit der guten Nahrungssituation im Schutzgebiet zusammenhing. Dies könnte sich bei einem höheren Tierbesatz, einer Ausmagerung der Grünlandflächen oder nach einer Serie von schneereichen Wintern ändern. Entwicklungen im Gehölz wie Stockausschläge, Vielstämmigkeit oder Buschformen, wie sie für Hudelandschaften typisch sind, traten aufgrund des geringen Weidedrucks oder der kurzen Weidedauer im Projektgebiet kaum auf. 


\subsubsection{Entwicklung weiterer Gebietsstrukturen}

\section{Strukturanalyse der Kraut- und Streuschicht auf mittlerer Maßstabsebene}

Die Pferde beweideten die Teilflächen des Projektgebietes mit unterschiedlicher Intensität. Im Juli 2008 war die Beweidungsintensität noch gering (Abb. 51): Zwei Drittel der Flächen wurden nicht oder nur oberflächlich beweidet (Tab. 35), darunter vor allem die Wälder und Gebüsche. Nur 12 \% der Flächen zeigten deutliche Fraßspuren. Die Aktivitäten der Tiere konzentrierten sich in diesem überdurchschnittlich heißen Frühling und Sommer vermehrt auf den Unterstand und die Weideflächen in Gewässernähe im Gebietszentrum. Hier war die Vegetation am stärksten abgegrast. Im Uferbereich trat eine mittlere Beweidungsintensität auf.

Mit zunehmender Herdengröße stieg die Beweidungsintensität. Der Anteil nicht oder kaum beweideter Flächen im Jahr 2010 nahm gegenüber 2008 um rund ein Viertel ab. Über die Hälfte des Gebietes war sichtbar beweidet, ein Fünftel der Fläche sogar kurz oder deutlich abgegrast (Abb. 51). Die Aktivitäten der Ponys erstreckten sich auf nahezu alle Grünländer im Gebiet, wenn auch mit unterschiedlicher Intensität. Die Nordspitze wurde aufgrund ihrer schlechteren Erreichbarkeit seltener aufgesucht, auch die trockenen Kuppen zeigten nur eine geringe bis mittlere Beweidungsintensität. In Abb. 51 ist die zeitlich-dynamische Entwicklung zwischen den Untersuchungsjahren erkennbar, die mit der Besatzdichte und den Wetterbedingungen zusammenhing. Hinzu kommt eine räumliche Komponente mit einer unterschiedlichen Nutzungsintensität der Teilflächen zur gleichen Zeit. Selbst bei einem Besatz von über 70 Tieren im Sommer 2010 wies das Gebiet noch höherwüchsige Areale auf, da die Pferde bestimmte Flächen erst später im Jahr oder gar nicht beweideten, was zu einer Strukturvielfalt und einer heterogenen Ressourcenverfügbarkeit im Gebiet beitrug.

Die Weiderückstände im Gebiet waren hoch: Mindestens 70 \% der Flächen wiesen im Winter Rückstände von mindestens $20 \%$ auf (Tab. 36). Zu den Flächen mit Weiderückständen gehörten in erster Linie das Moor sowie Wälder und Gebüsche, deren Krautschicht kaum beweidet wurde, während die Grünländer geringe bis mittlere Weiderückstände zeigten (Abb. 52). Gewässer wurden bei der Auswertung nicht berücksichtigt, da hier keine Beweidung erfolgte (Tab. 36, Kategorie 0), es sei denn, die Teiche fielen trocken, so dass die Pferde die Vegetation erreichten.

Die Teilflächen im offenen Weideland wurden nicht nur im jahreszeitlichen Verlauf, sondern auch von Jahr zu Jahr unterschiedlich intensiv beweidet (Tab. 36). Im Winter 2009/10 waren die Weiderückstände geringer als in den Jahren 2008/09 und 2010/11. Die unterschiedliche Zugänglichkeit der Teilgebiete, bedingt durch Überschwemmungen und Schneevorkommen, sowie die variierenden Witterungsbedingungen (Niederschlagsmenge, Temperaturen) wirkten sich hierbei auf die Beweidung und die Weiderückstände aus.

Tab. 35: Anteile der Beweidungsintensitäten im Projektgebiet in den Jahren 2008 und 2010

Gesamtfläche: 107,8 ha

\begin{tabular}{|c|c|c|c|c|c|}
\hline \multirow[t]{2}{*}{ Kategorie } & \multicolumn{2}{|l|}{ Juli 2008} & \multicolumn{2}{|l|}{ Juli 2010} & \multirow[t]{2}{*}{ Differenz } \\
\hline & $\mathrm{m}^{2}$ & in $\%$ & $m^{2}$ & in $\%$ & \\
\hline unbeweidet & 315.223 & 29,2 & 242.164 & 22,5 & $-6,7 \%$ \\
\hline oberflächlich & 395.568 & 36,7 & 216.222 & 20,0 & $-16,7 \%$ \\
\hline sichtbar & 313.433 & 29,1 & 395.844 & 36,7 & $+7,6 \%$ \\
\hline deutlich & 54.443 & 5,0 & 224.066 & 20,8 & $+15,8 \%$ \\
\hline kurz abgeweidet & 0 & 0,0 & 371 & 0,0 & $0 \%$ \\
\hline
\end{tabular}



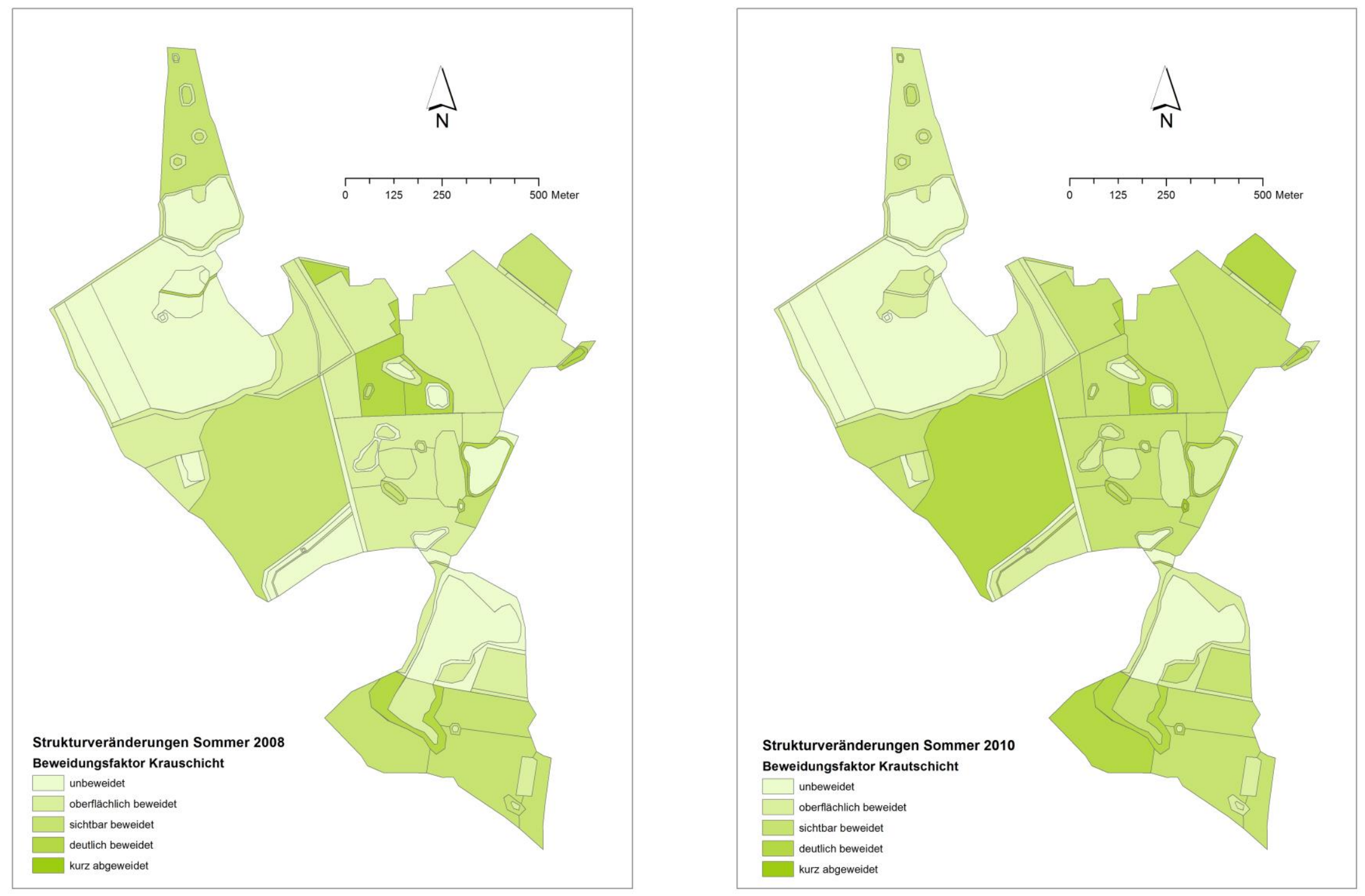

Abb. 51: Beweidungsintensitäten in 5-stufiger Skala im Juli 2008 (links) und 2010 (rechts) im Vergleich 

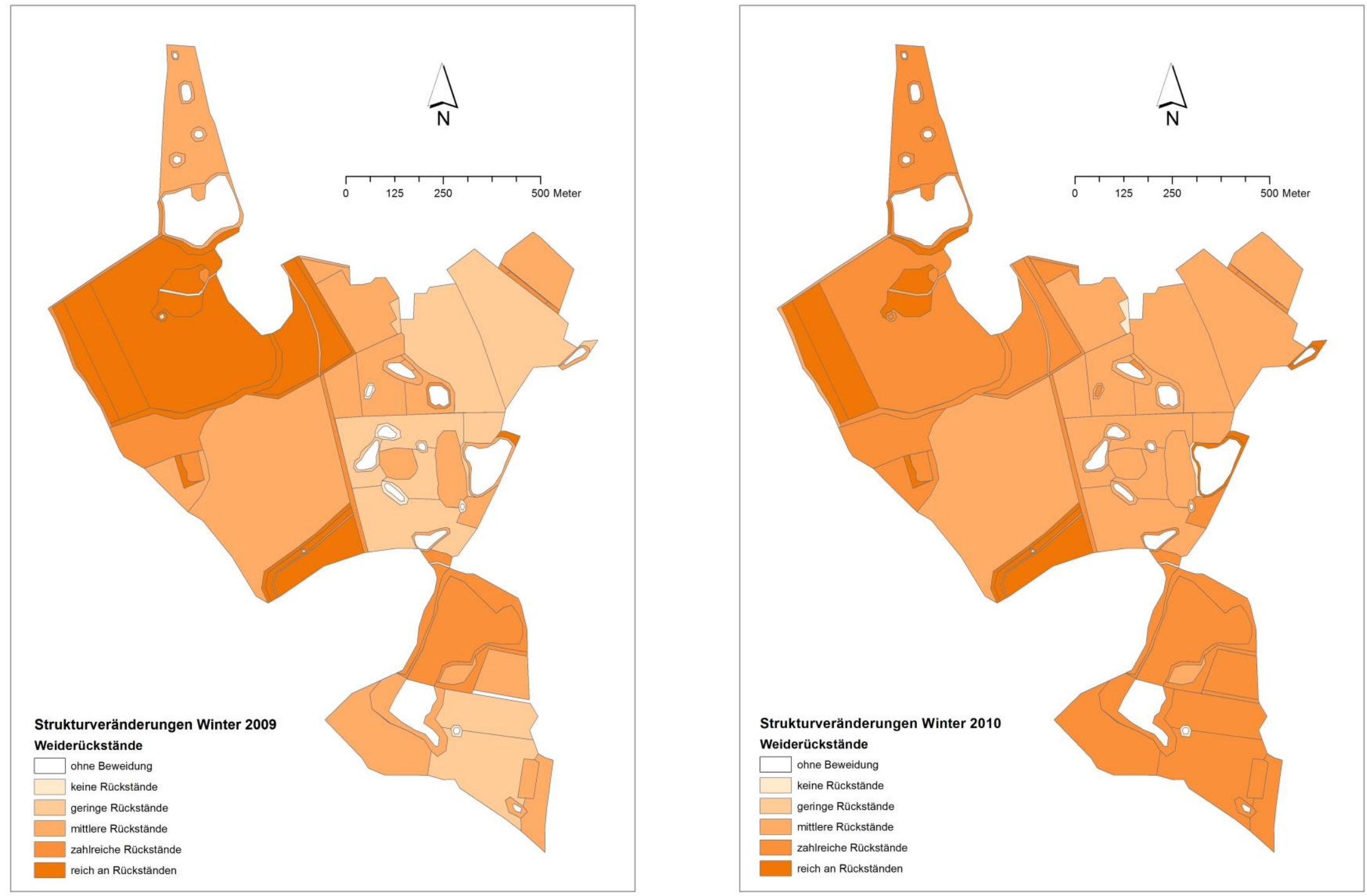

Abb. 52: Anteile der Weiderückstände in 6-stufiger Skala im Winter 2009/10 (links) und 2010/11 (rechts) im Vergleich 
Tab. 36: Weiderückstände in 5-stufiger Skala auf den Teilgebieten im Projektgebiet in den Jahren 2008-2010

Kategorie 0 = Flächen ohne Beweidung, z.B. Gewässer

\begin{tabular}{lllllll}
\hline Kategorie & $\begin{array}{l}\text { Januar } 2009 \\
\mathrm{~m}^{2}\end{array}$ & in $\%$ & Januar 2010 & \multicolumn{2}{c}{ Januar 2011} \\
$\mathrm{~m}^{2}$ & in $\%$ & $\mathrm{~m}^{2}$ & in \% \\
\hline keine & 50.215 & 4,7 & 4.997 & 0,5 & 3.363 & 0,3 \\
gering & 25.527 & 2,4 & 254.074 & 23,6 & 0 & 0,0 \\
mittel & 455.752 & 42,3 & 399.584 & 37,0 & 453.562 & 42,0 \\
zahlreich & 437.021 & 40,5 & 108.060 & 10,0 & 473.057 & 43,9 \\
reich an & 49.949 & 4,6 & 250.451 & 23,2 & 88.945 & 8,2 \\
0 & 60.203 & 5,6 & 57.295 & 5,3 & 59.740 & 5,5 \\
\hline
\end{tabular}

\section{Strukturentwicklung des Bodens}

Durch die Beweidung mit Pferden veränderten sich das Bodenrelief und der Anteil offenen Bodens. Die Trittwirkung der Tiere auf die Grasnarbe wirkte sich dabei direkt auf die Vegetationsbedeckung aus. Eine Zunahme von Maulwurfshügeln oder Ameisennestern, die auf einen indirekten Weideeinfluss hindeuten, war im Untersuchungszeitraum kaum erkennbar.

Der Anteil offenen Bodens lag meist unter 5 Prozent (Tab. 15). Er schwankte stark nach Jahreszeit und Vegetationstyp: Im Laubwald und am Ufer war er zu Beginn der Untersuchung am höchsten (Abb. 53). Nach zwei Beweidungsjahren nahm der Anteil offenen Bodens ab. Dies verwundert zunächst, erwartet man doch eine Zunahme offener Bodenstellen durch die Trittwirkung der Weidetiere. Der geringere Erdanteil auf den Waldflächen im Sommer 2010 kann auf die Auflichtung der Gehölze durch Abholzung zurückgeführt werden. Durch die neu entstandenen Waldkorridore drang mehr Licht zum Waldboden, so dass sich die Kraut- und Moosschicht im Laub- und Nadelwald entfaltete. Dies erklärt die Abnahme von Flächen mit 35-64 \% offenem Boden (Kategorie 4) von 12,5 auf unter 1 \% (s. Tab. 37).

Anders war die Entwicklung im Grünland und im Uferbereich. Mit Ausnahme von zwei Altgewässern mit dichtem Schilfgürtel entstanden an allen Gewässern offene Bodenstellen, teilweise durch Tritt stark verdichtet. Je nach Nutzungsintensität lag der Erdanteil am Ufer zwischen 15-85 \%. Auch die an Gewässer angrenzenden Grünlandflächen zeigten im Sommer 2010 einen höheren Rohbodenanteil als in 2008. Im Allgemeinen zeigten Magerrasen sowie ehemalige Ackerflächen einen höheren Erdanteil als frühere Weiden und Wiesen. Insgesamt stieg der Anteil offenen Bodens im Grünland innerhalb von zwei Jahren leicht an, sowohl an feuchten, lehmigen als auch auf den sandigen, trockenen Standorten wie den Hängen. Flächen mit geschlossener Vegetationsdecke nahmen um rund $7 \%$ ab.

Tab. 37: Anteile offenen Bodens in 6-stufiger Skala auf den Teilgebieten im Projektgebiet in den Jahren 2008-2010

Gesamtfläche 107,8 ha

\begin{tabular}{|c|c|c|c|c|c|}
\hline \multirow[t]{2}{*}{ Kategorie } & \multicolumn{2}{|l|}{ Juli 2008} & \multicolumn{2}{|l|}{ Juli 2010} & \multirow[t]{2}{*}{ Differenz } \\
\hline & $\mathrm{m}^{2}$ & in $\%$ & $\mathrm{~m}^{2}$ & in $\%$ & \\
\hline unter $5 \%$ & 682.844 & 63,3 & 606.878 & 56,3 & $-7 \%$ \\
\hline 5 bis $14 \%$ & 206.455 & 19,1 & 430.431 & 39,9 & $+20,8 \%$ \\
\hline 15 bis $34 \%$ & 54.253 & 5,0 & 33.909 & 3,1 & $-1,9 \%$ \\
\hline 35 bis $64 \%$ & 134.744 & 12,5 & 7.078 & 0,7 & $-11,8 \%$ \\
\hline 65 bis $84 \%$ & 371 & 0,0 & 371 & 0,0 & $0 \%$ \\
\hline über 85 \% & 0 & 0,0 & 0 & 0,0 & $0 \%$ \\
\hline
\end{tabular}



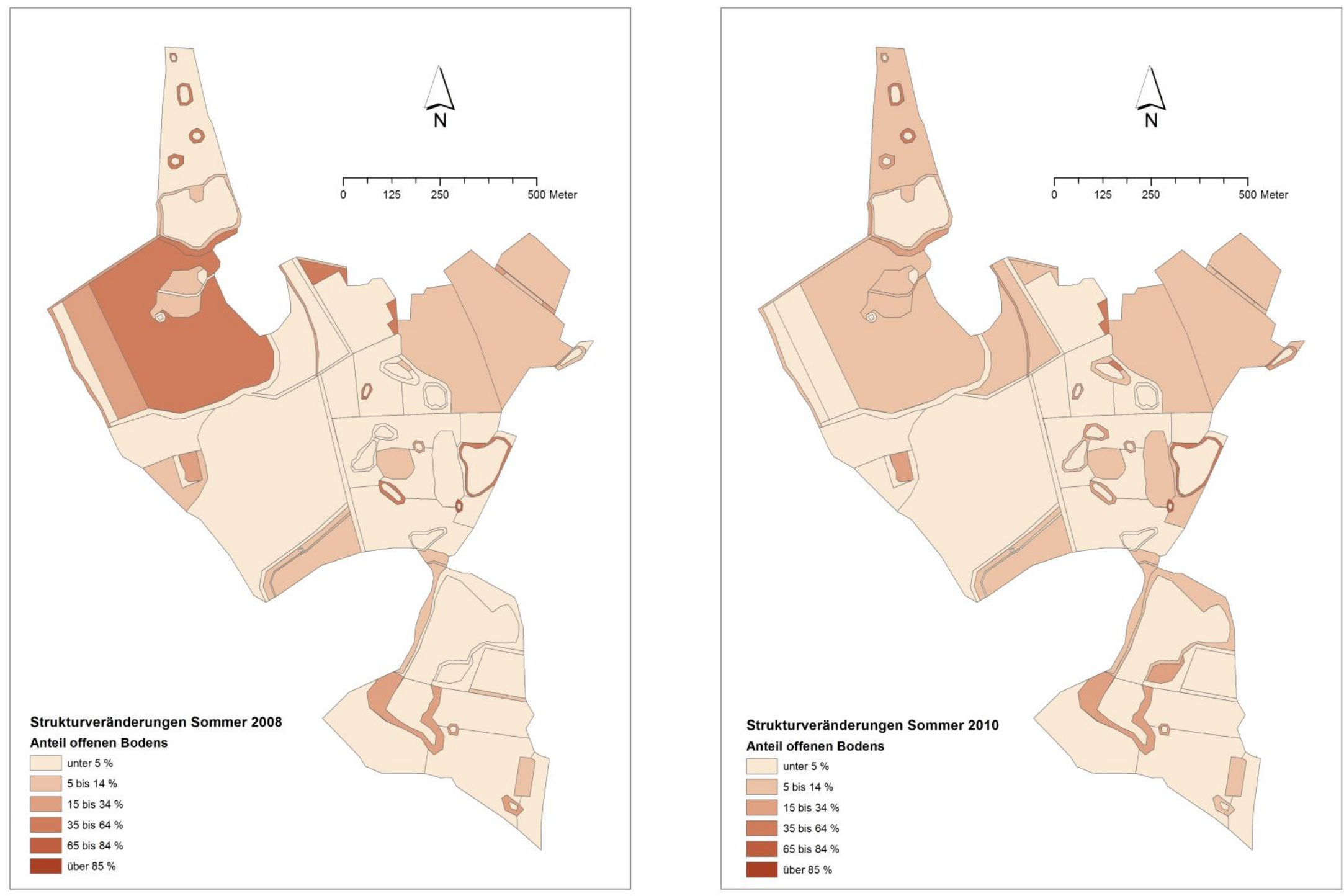

Abb. 53: Anteile offenen Bodens in 6-stufiger Skala im Sommer 2008 (links) und 2010 (rechts) im Vergleich 

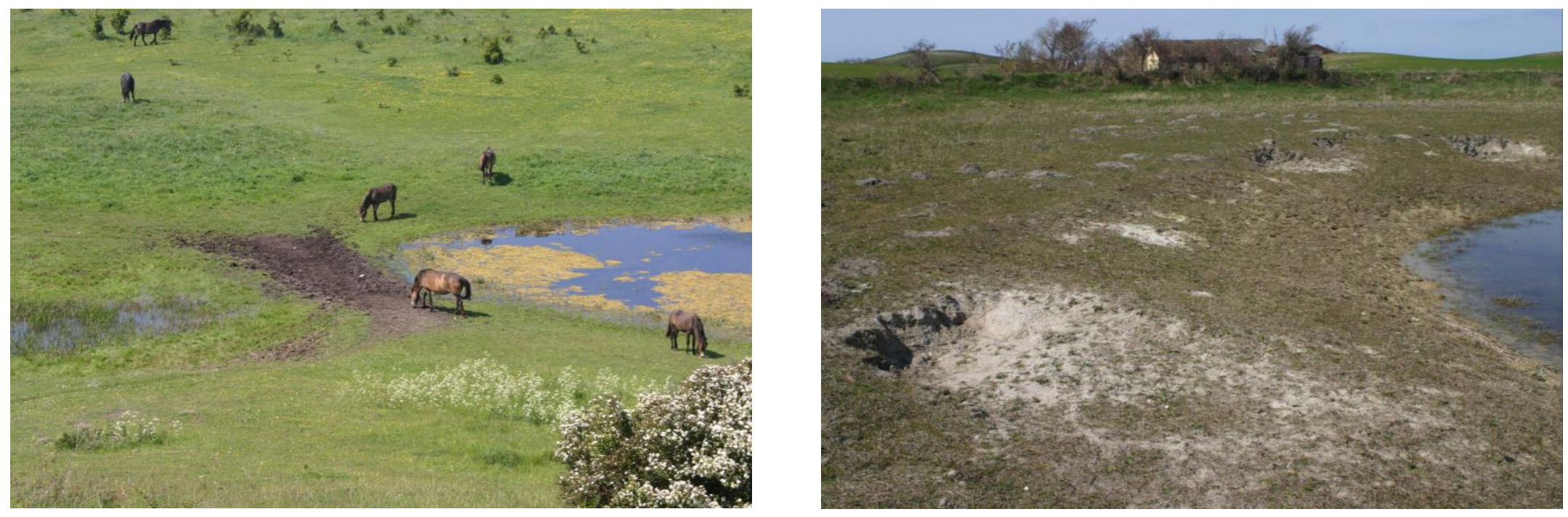

Abb. 54: Offene Bodenstellen an feuchten Standorten hervorgerufen durch Tritt (links) oder durch Scharren (rechts)
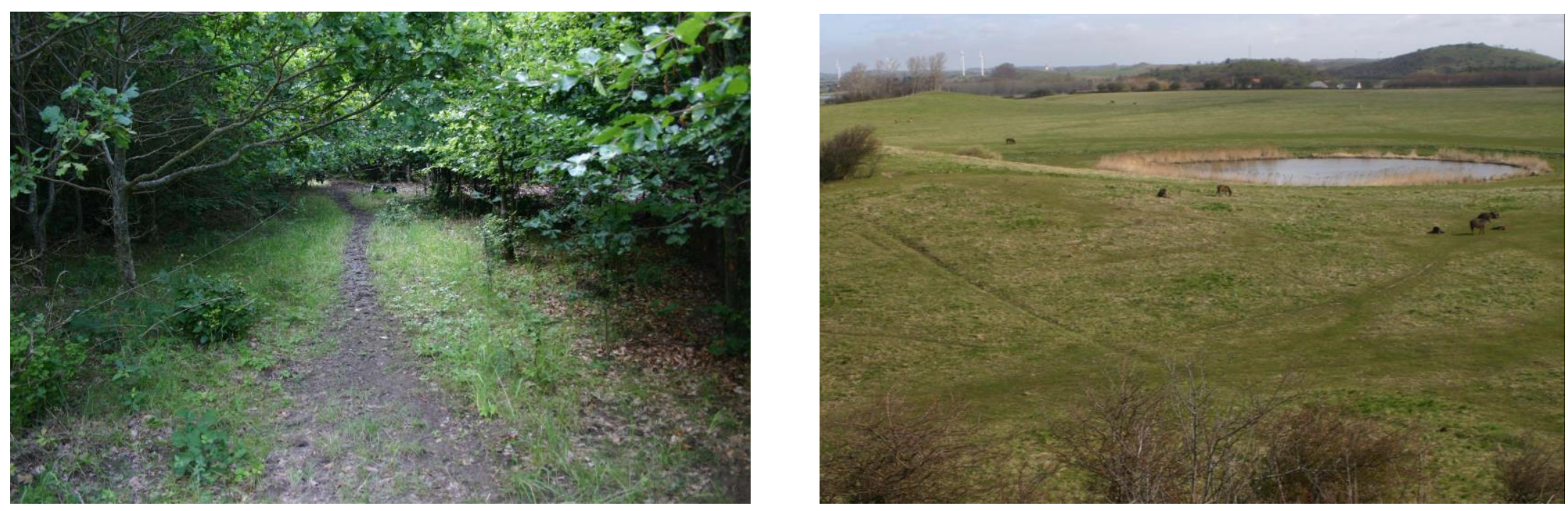

Abb. 55: Weidetierpfade im Projektgebiet - Hauptpfad im Laubwald (links) und grüne Pfade mit vereinzelten offenen Bodenstellen im Grünland (rechts) 
Offene Bodenstellen entstanden durch regelmäßiges Scharren, Wälzen und vor allem durch Tritt auf Weidetierpfaden. Die Hauptpfade, die regelmäßig von den Pferden genutzt wurden, waren weitgehend vegetationsfrei. Sie waren in etwa 25 Zentimeter breit und hatten sich mehrere Zentimeter tief in den Boden eingesenkt. Auch auf grünen Pfaden, die seltener oder nur von einzelnen Tieren genutzt wurden, traten offene Bodenstellen auf. Ihre Lage wechselte von Zeit zu Zeit, so dass die Stellen wieder zuwuchsen und eine gewisse Dynamik im Bodenrelief förderten.

\section{Dung}

Als Großherbivore produzieren Pferde regelmäßig große Mengen an Kot. Bei einer ganzjährigen Weidetätigkeit verbleiben die Nährstoffe aus dem Kot im Gebiet. Eine Ausmagerung der Flächen geht nur langsam vonstatten. Kot stellt im Freiland einen wichtigen Lebensraum für koprophage Tierarten dar. Pferdeäpfel trocknen aufgrund der raufutter- und grasreichen Nahrung schnell aus. In den Sommermonaten wurden sie daher im Projektgebiet rasch abgebaut und traten optisch kaum in Erscheinung. Nur im Winter kam es zu einer Akkumulation von Kothaufen, vor allem an wettergeschützten Orten mit verdichteten Böden.

Die Dunghaufen lagen überwiegend auf Weiden und Tierpfaden, seltener im Wald oder Uferbereich. Sie traten an den bevorzugten Aufenthaltsorten auf, da Pferde Kot über den Tag verteilt während der Nahrungsaufnahme absetzen. Sowohl im Jahr 2008 als auch im Jahr 2010 konzentrierten sich die Kothaufen im Gebietszentrum, im Sommer 2008 auch an der Südspitze (Abb. 57).

Kothaufen wurden teilweise an bestimmten Stellen, den so genannten Geilstellen, abgesetzt (Abb. 56). Daher entsprachen Grünflächen mit hoher Beweidungsintensität im Sommer 2010 (s. Abb. 27) nicht zwangsläufig Flächen mit einem gehäuften Dungvorkommen. Mittelfristig kommt es aufgrund dieses spezifischen Verhaltens der Pferde vermutlich zu einer Nährstoffumverteilung.

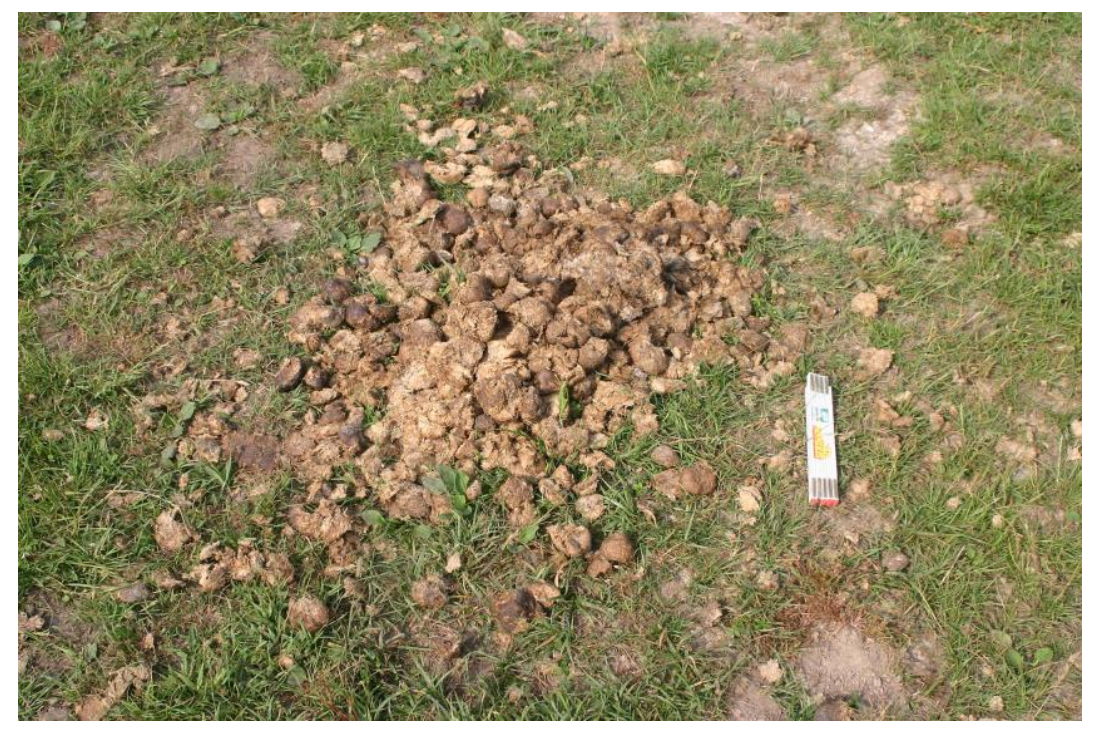

Abb. 56: Geilstelle mit einer Anhäufung von Pferdedung im Juli 2010 

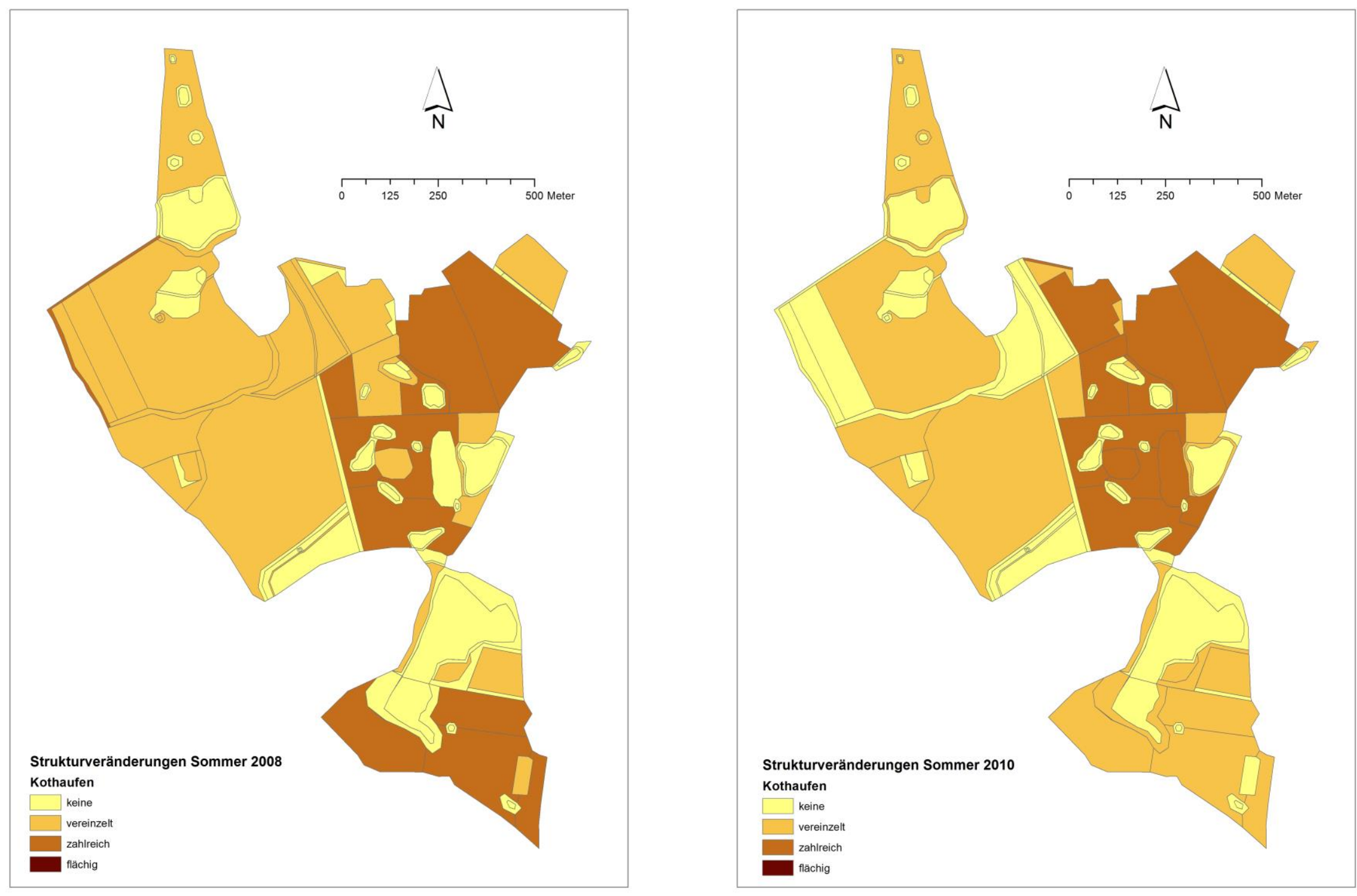

Abb. 57: Nährstoffeintrag durch Pferdedung in 4-stufiger Skala im Sommer 2008 (links) und 2010 (rechts) im Vergleich 


\subsection{Entwicklung einzelner Lebensräume unter Beweidung}

\subsubsection{Entwicklung der Pflanzengesellschaften einzelner Lebensräume}

Im Gebiet wurden Dauerflächen in unterschiedlichen Biotopen eingerichtet, um eine Veränderung der Pflanzengesellschaften sowie Diversitätsunterschiede zwischen Weide- und Brachland zu untersuchen. Zwischen den Jahren 2008 und 2011 wurden 98 Vegetationsaufnahmen angefertigt. Davon lagen 66 Aufnahmen auf Typischen Fettweiden (Lolio perennis-Cynosuretum cristati), 14 auf Glatthaferwiesen (Arrhenatheretum elatioris), 11 im Uferbereich (Eleocharis palustris-Gesellschaft, Bidenti-Ranunculetum scelerati) und $7 \mathrm{im}$ Buchenwald (Fagetum nudum). Die Aufnahmen wurden auf beweideten $(n=57)$ und unbeweideten $(n=41)$ Flächen getätigt. Der Höhentransekt wurde gesondert ausgewertet $(n=4)$.

\subsubsection{Vegetationsparameter}

Der Gesamtdeckungsgrad auf den Flächen betrug durchschnittlich $98 \%$. Er schwankte zwischen Uferbereichen $\left(D_{\text {gesamt }}=58,1 \%\right)$ und Fettweiden $\left(D_{\text {gesamt }}=97,0 \%\right)$ bzw. Glatthaferwiesen $\left(D_{\text {gesamt }}=98,4 \%\right)$. Die Krautschicht war im Grünland am dichtesten (Fettweide $D_{\kappa s}=91,6 \%$, Glatthaferwiese $D_{\kappa s}=90,0 \%$ ), unter dem geschlossenen Kronendach im Buchenwald am spärlichsten $\left(D_{K S}=4,1 \%\right)$. Die Daten der vier Untersuchungsjahre variierten nur geringfügig. Außer im Uferbereich (Abb. 58) beeinflusste die extensive Beweidung den Deckungsgrad nicht signifikant (Tab. 16). Auf den Kontrollflächen verursachte die Mahd Schwankungen im Deckungsgrad der Krautschicht, die dreijährige Brache hatte hingegen keinen erkennbaren Effekt (Abb. 59, Tab. 39).

Das ganzjährige Abgrasen der Flächen verringerte signifikant den Anteil von abgestorbenem Pflanzenmaterial, während Nicht-Beweidung ihn erhöhte (s. Tab. 38 und Tab. 39). Auf das Vorkommen von Moosen hatte die Nutzungsart kaum Auswirkung (s. Tab. 38). Tendenziell war ihr Anteil leicht rückläufig. Auch auf den nicht beweideten Flächen veränderte sich der Moosanteil zwischen 2009 und 2011 nicht signifikant. Zu Beginn nahm er leicht zu, im dritten Brachejahr - mit zunehmender Vegetationshöhe - wieder ab (ohne Abb.).

Der Anteil an offenem Boden nahm während der extensiven Beweidung signifikant zu (s. Tab. 38). Am stärksten waren die Uferbereiche betroffen, auch im Grünland nahmen vegetationsfreie Stellen zu (Abb. 60 und Abb. 61). Nur im Buchenwald war der Trend gegenläufig (von 17 auf $1 \%$ ). Dies lag nicht an einem vermehrten Pflanzenwachstum auf dem kahlen Waldboden, denn der Deckungsgrad der Krautschicht blieb unverändert niedrig (2008: 4,0 \%; 2011: 4,2 \%), sondern an einer Zunahme der Streuauflagen (2008: 78,1\%; 2011: 96,8 \%), also von Laub, das den Waldboden bedeckte.

Durch die Beweidung hat sich die Vegetationshöhe signifikant verringert (s. Tab. 38): Im Jahr 2008 lag sie bei durchschnittlich $33 \mathrm{~cm}$, nach drei Beweidungsjahren war sie nur noch ein Drittel so hoch (Abb. 62). Auf den unbeweideten Kontrollflächen nahm sie erwartungsgemäß zu (s. Tab. 39). Die gemähten Kontrollflächen variieren - abhängig vom Mahdtermin - stark in ihrer Vegetationshöhe (Abb. 63). Auf den Kontrollflächen ohne Nutzung nahm die Vegetationshöhe zu.

Mit zunehmendem Besatz erhöhte sich der Beweidungsfaktor, d.h. der Anteil an gefressener oder zerstörter Vegetation signifikant (s. Tab. 38). Das Maximum wurde im Jahr 2010 erreicht, danach fiel er wieder leicht ab (ohne Abb.). Dies deckte sich mit der Besatzstärke: Im Sommer 2010 verzeichnete die Herde ihren Höchststand mit 78 Tieren, im Folgejahr grasten nur noch 60 Pferde im Gebiet. 


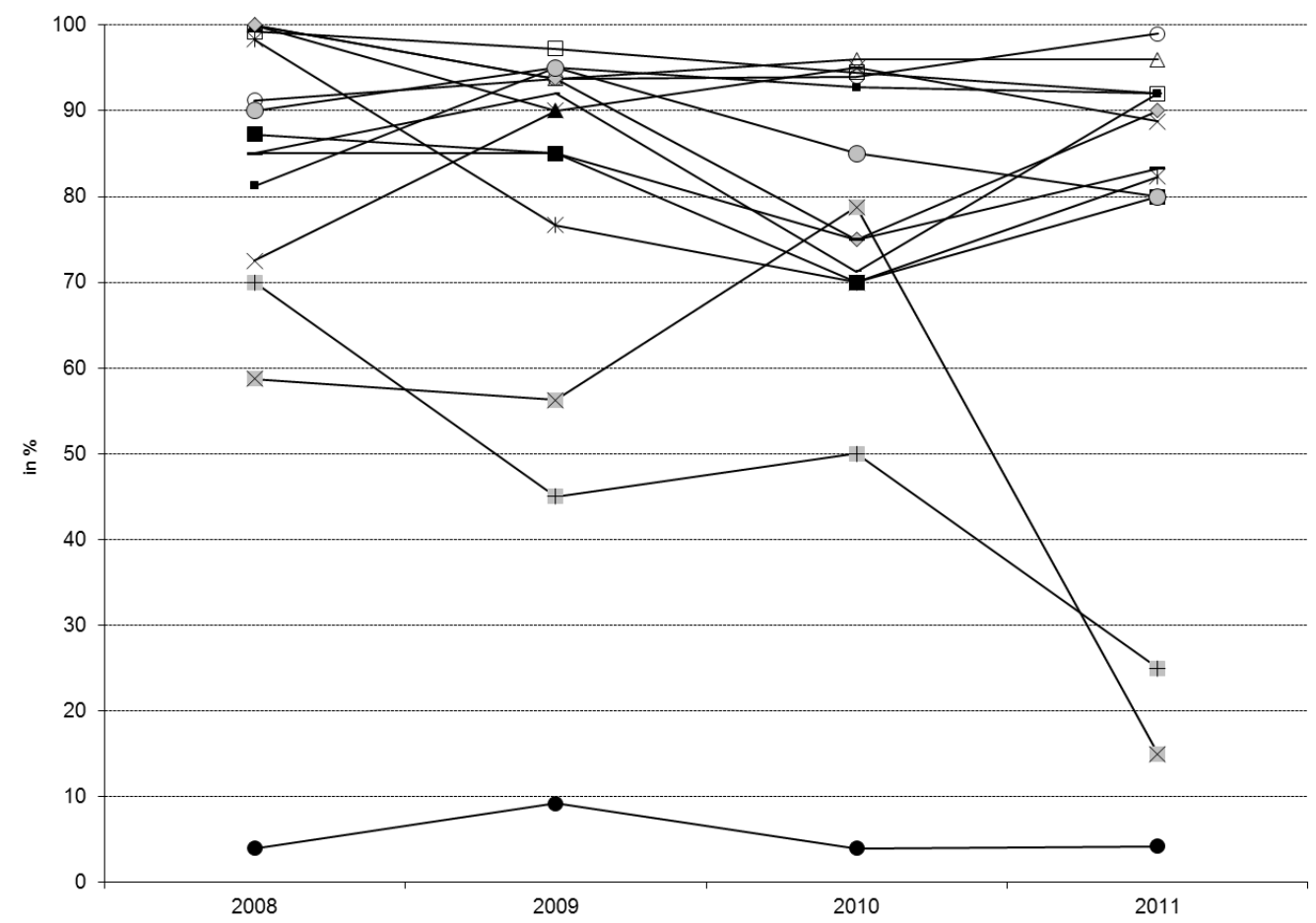

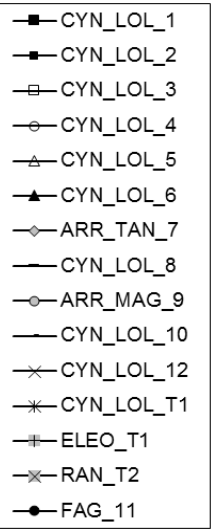

Abb. 58: Deckungsgrad der Krautschicht auf den Untersuchungsflächen zwischen den Jahren 2008-2011

Für VDF 6 liegen nur Daten aus 2008 und 2009 vor.

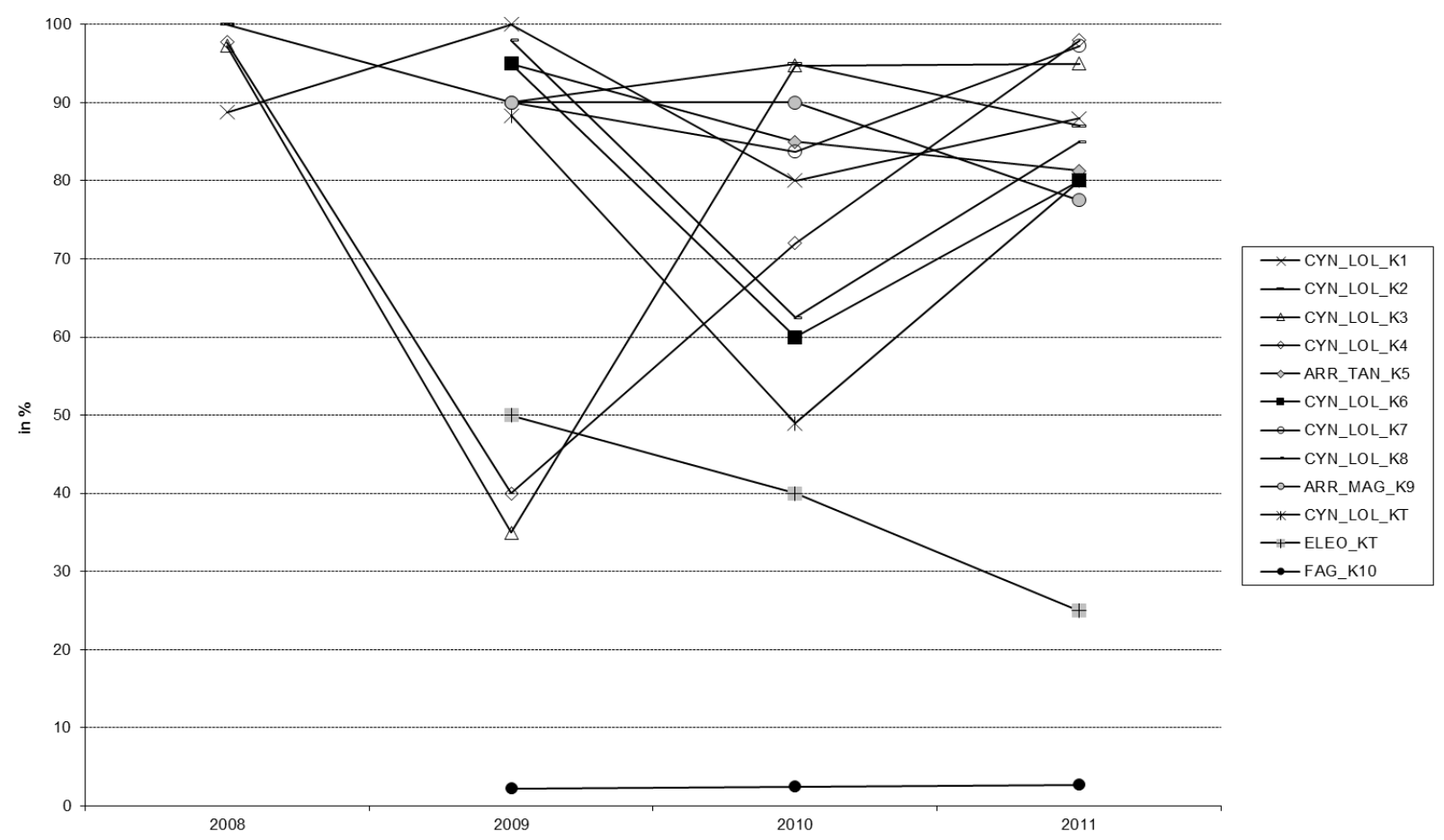

Abb. 59: Deckungsgrad der Krautschicht auf den Kontrollflächen zwischen den Jahren 2008-2011

K1-K4: Kontrollflächen mit gelegentlicher Mahd, Daten aus 2008-2011 K5-K10 und KT: Kontrollflächen ohne Nutzung, Daten aus 2009-2011 


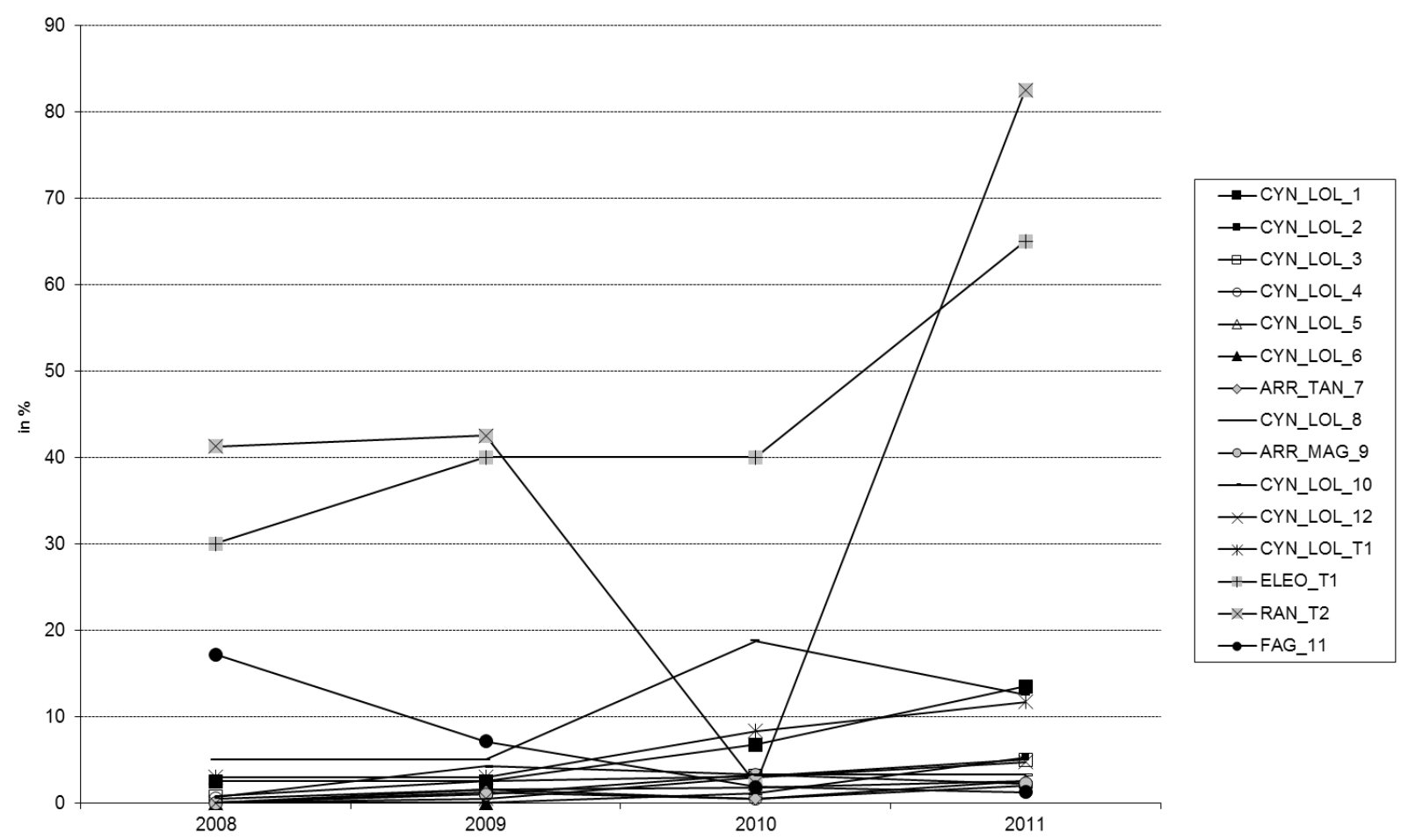

Abb. 60: Anteil an offenem Boden auf den Untersuchungsflächen zwischen den Jahren 2008-2011

Für VDF 6 liegen nur Daten aus 2008 und 2009 vor.

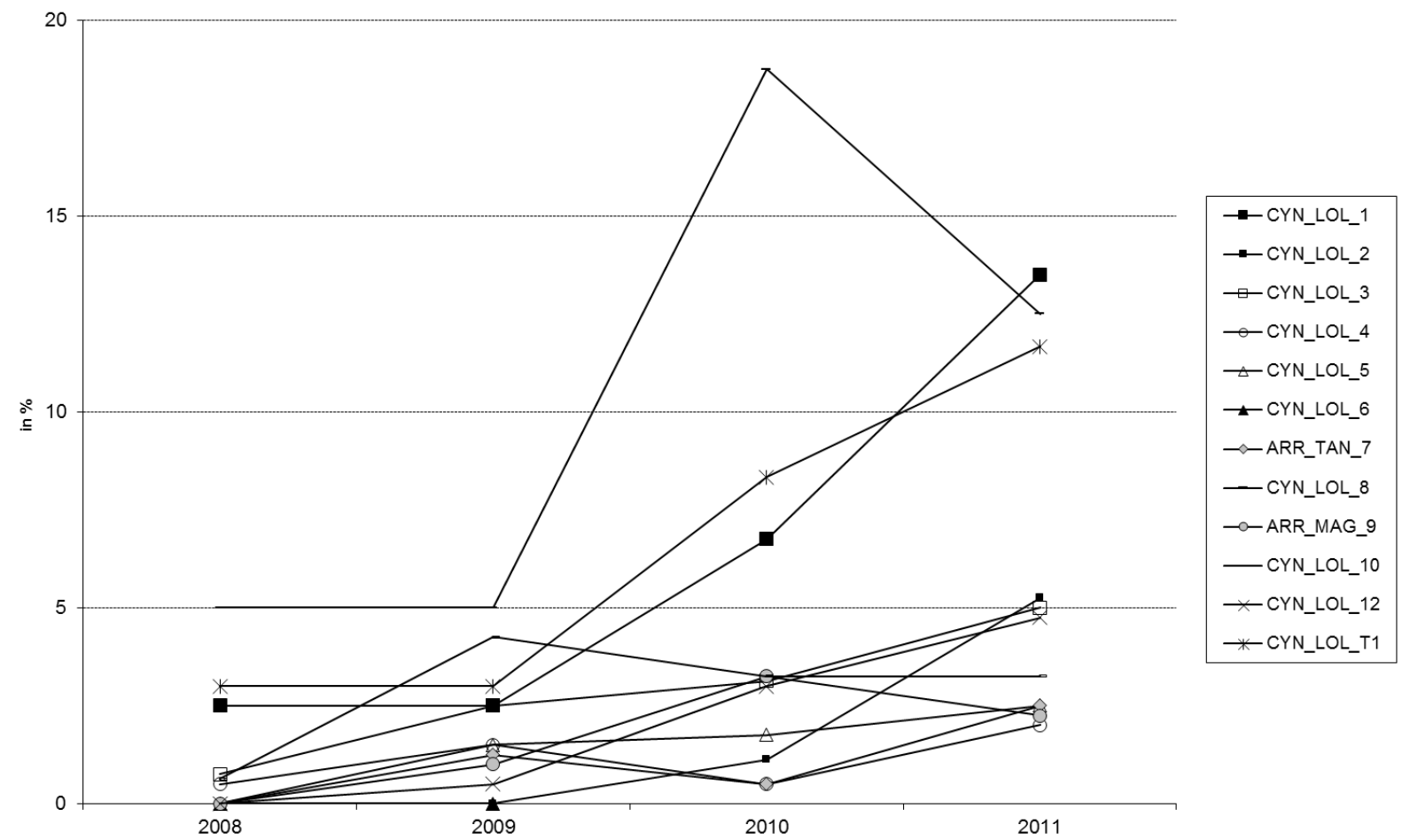

Abb. 61: Anteil an offenem Boden auf den Untersuchungsflächen im Grünland zwischen den Jahren 2008-2011

Für VDF 6 liegen nur Daten aus 2008 und 2009 vor. 


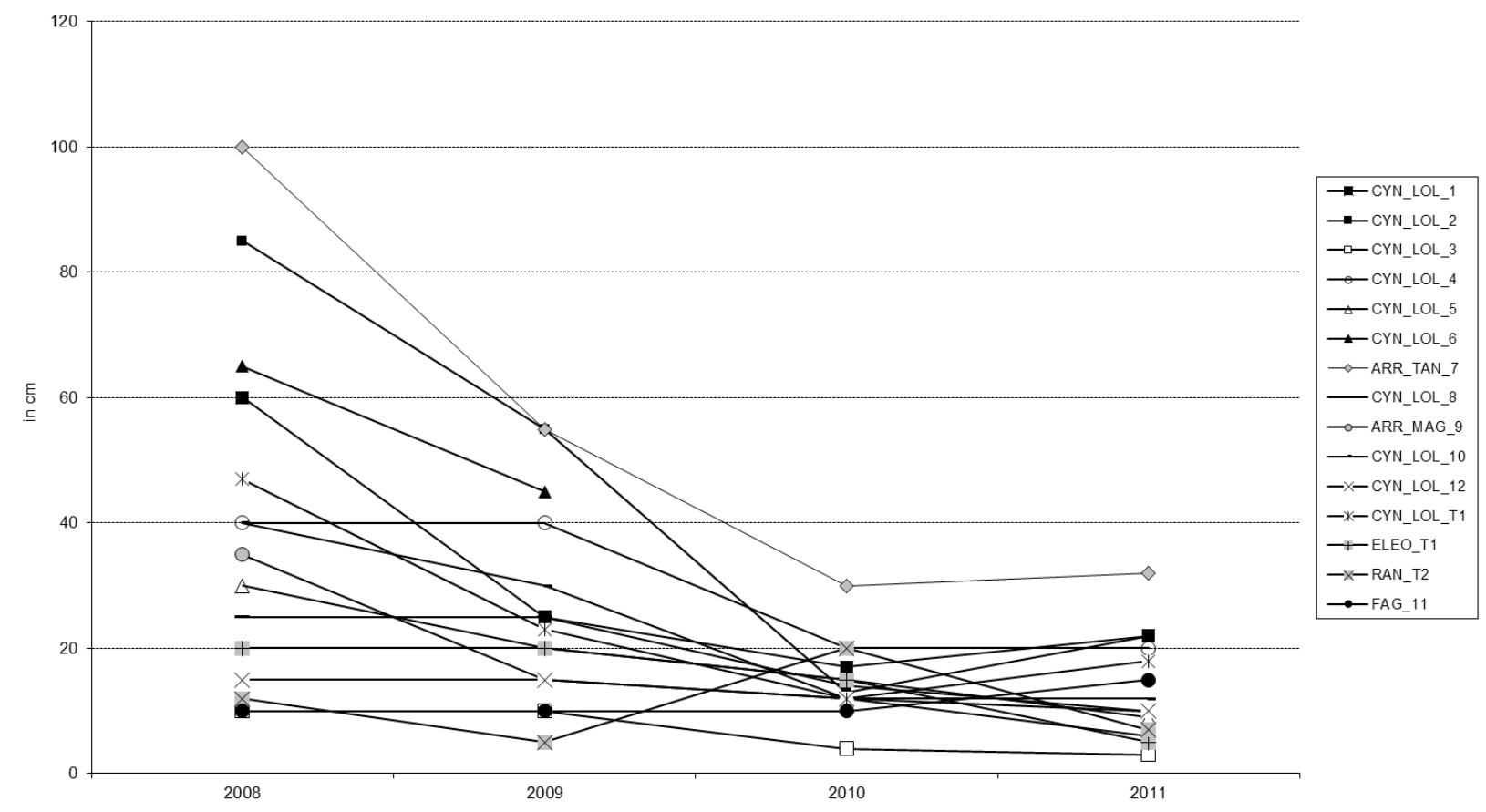

Abb. 62: Mittlere Vegetationshöhe der Krautschicht auf den Untersuchungsflächen zwischen den Jahren 2008-2011

Für VDF 6 liegen nur Daten aus 2008 und 2009 vor.

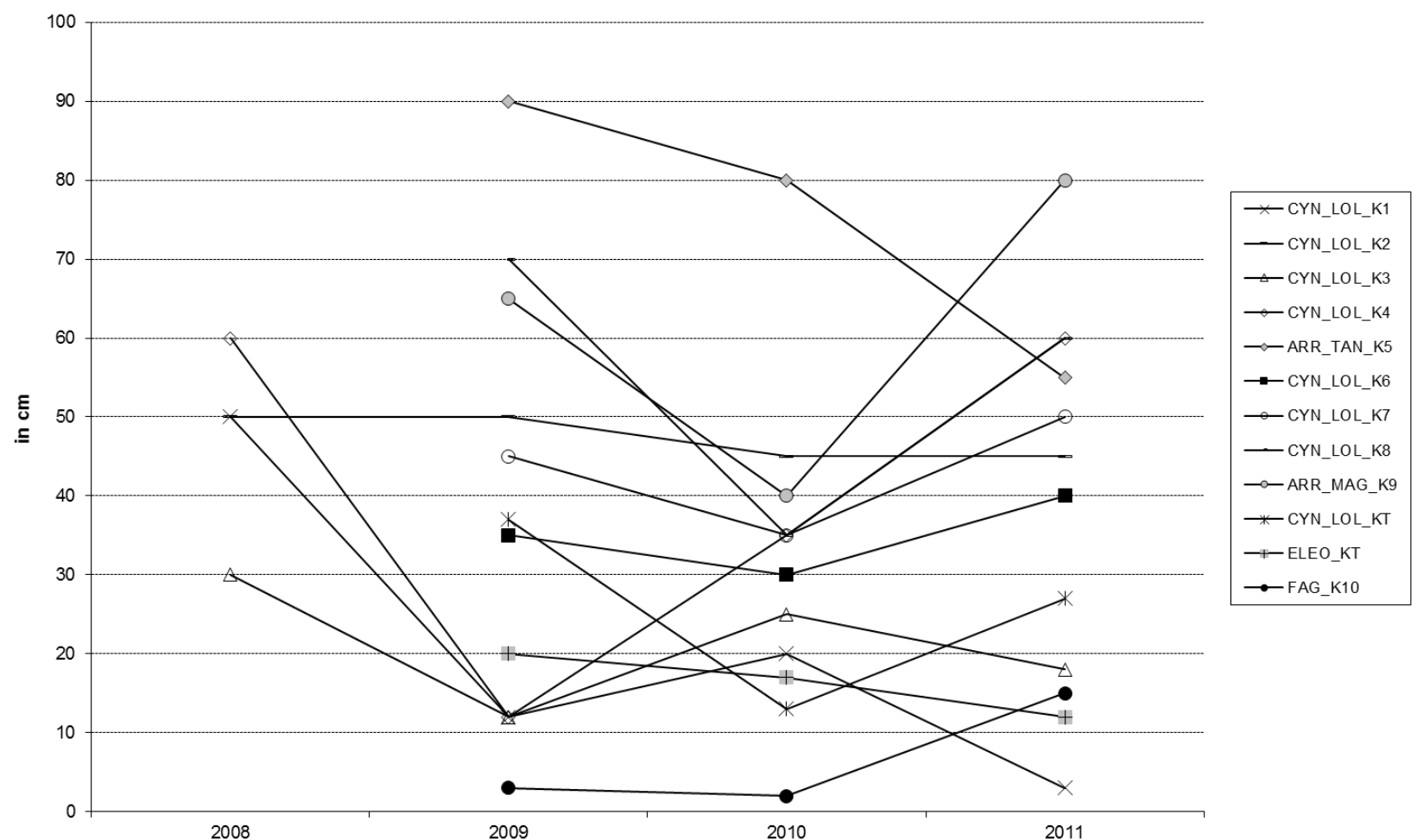

Abb. 63: Mittlere Vegetationshöhe der Krautschicht auf den Kontrollflächen zwischen den Jahren 2008-2011

K1-K4: Kontrollflächen mit gelegentlicher Mahd, Daten aus 2008-2011

K5-K10 und KT: Kontrollflächen ohne Nutzung, Daten aus 2009-2011 
Tab. 38: Entwicklung von Vegetationsparametern auf den Vegetationsdauerflächen zwischen den Jahren 2008-2011

Die Signifikanz der Unterschiede zwischen 2008 und 2011 auf den beweideten Flächen wurde für verschiedene Parameter mit einem zweiseitigen Wilcoxon-Test für Paardifferenzen mit $\mathrm{P}=0,05$ überprüft. Ratio 1 bedeutet unverändert, Ratio $>1$ Abnahme, Ratio $<1$ Zunahme.

\begin{tabular}{lll}
\hline Vegetationsparameter & $\begin{array}{l}\text { Ratio } \\
\mathbf{2 0 0 8 / 2 0 1 1}\end{array}$ & $\begin{array}{l}\mathbf{p} \\
\text { (n= 14) }\end{array}$ \\
\hline Mittlere Höhe der Krautschicht & 2,77 & 0,001 \\
Anteil offener Boden & 0,47 & 0,011 \\
Deckungsgrad Streuschicht & 4,67 & 0,015 \\
Beweidungsfaktor & 0,74 & 0,016 \\
Deckungsgrad Krautschicht & 1,1 & 0,245 \\
Deckungsgrad Moosschicht & 2,11 & 0,968 \\
\hline
\end{tabular}

Tab. 39: Entwicklung von Vegetationsparametern auf beweideten und nicht-beweideten Dauerflächen zwischen den Jahren 2008-2011

Die Signifikanz der Unterschiede zwischen Beweidung (VDF) und Nicht-Beweidung (K) wurde für verschiedene Parameter mit einem zweiseitigen Wilcoxon-Test für Paardifferenzen mit $\mathrm{P}=0,05$ überprüft. Ratio 1 bedeutet unverändert, Ratio $>1$ Abnahme, Ratio $<1$ Zunahme.

\begin{tabular}{lll}
\hline Vegetationsparameter & $\begin{array}{l}\text { Ratio } \\
\text { VDF / K }\end{array}$ & $\begin{array}{l}\mathbf{p} \\
\text { (n= 11) }\end{array}$ \\
\hline Beweidungsfaktor & 2 & 0,006 \\
Anteil offener Boden & 4,33 & 0,009 \\
Deckungsgrad Streuschicht & 0,24 & 0,009 \\
Mittlere Höhe der Krautschicht & 0,47 & 0,016 \\
Deckungsgrad Krautschicht & 1,02 & 0,110 \\
Deckungsgrad Moosschicht & 2,96 & 0,755 \\
\hline
\end{tabular}

\subsubsection{Gradienten im Untersuchungsgebiet}

Das Ordinationsdiagramm der DCA für die Vegetationsaufnahmen aus dem Jahr 2008 ergab eine klare Differenzierung der Vegetationseinheiten. In der Ordination spannten sich die Gesellschaften entlang von zwei Dimensionen auf (Abb. 45). Links standen die ufernahen Aufnahmen, das heißt die Gifthahnenfuß-Gesellschaft und die Kleinröhrichte, in der Mitte die Verbände der Weiden und Wiesen, am rechten Rand der Buchenwaldbestand. Entlang der zweiten Dimension wurden hauptsächlich die mageren und ruderalen Glatthaferwiesen von den anderen Grünlandgesellschaften getrennt. Die erste Dimension der Ordination erklärte 17,2 \%, die zweite Dimension 16,8 \% der floristischen Variation. Es handelte sich somit nur um relativ schwache Gradienten.

Die erste Dimension ist mit den Ellenberg-Zeigerwerten für Feuchte und Licht negativ korreliert (Tab. 40). Die Aufnahmen wurden im Ordinationsdiagramm entlang eines abnehmenden Feuchtegradienten angeordnet. Weiterhin korreliert die erste Dimension positiv mit der Reliefform Unterhang, da die Uferstandorte in den Senken, der Buchenwald und die Glatthaferwiesen auf den Oberhängen oder Kuppen lagen. Etwas schwächer sind die Zusammenhänge mit dem Beweidungsfaktor der Krautschicht und dem Anteil an offenem Boden. Dies lässt vermuten, dass die Vegetation der Uferbereiche stärker von Störungen wie Fraß und Tritt betroffen ist als andere Standorte. 
Die zweite Achse ist schwach negativ mit dem Ellenberg-Zeigerwert für Nährstoffe korreliert (nach Bonferroni-Korrektur ist der $\mathrm{p}$-Wert nicht signifikant). Dies deutet darauf hin, dass die Nährstoffversorgung der Standorte die Verschiedenheit der untersuchten Grasländer beeinflusst. Des Weiteren wirkten sich die Höhe sowie der Neigungsgrad der Flächen auf die zweite Dimension aus, da - wie oben erläutert - die nährstoffärmeren Glatthaferwiesen höher lagen als die Fettweiden.

Die positiv korrelierte Mahdzahl der ersten Achse sagt aus, dass mit zunehmenden Gradienten vermehrt Mahd verträgliche Arten auftraten. Die Glatthaferwiesen und Waldbestände wurden in der Tat von den Pferden seltener frequentiert, so dass sich grünlandähnliche Bedingungen einstellten und sich Arten hier ansiedelten, die selten oder erst später im Jahr gefressen wurden. Auch die frühere Nutzung spielt hier sicher eine Rolle, auch wenn eine direkte Korrelation der Aufnahmescores mit der früheren Nutzungsform keinen Zusammenhang aufzeigt (ohne Abb.).

Stellt man im Ordinationsdiagramm nur die Grünlandaufnahmen dar, so stehen die artenarmen Typischen Fettweiden am linken Rand des Ordinationsdiagramms, es folgen die schwachen Ausprägungen der Weidelgras-Weißklee-Weide mit Merkmalen der Glatthaferwiese und die Arrhenatheretalia-Basalgesellschaft (Abb. 47). In der Mitte liegt die ruderale Glatthaferwiese, am rechten Rand sondert sich die magere Ausprägung der Glatthaferwiese ab. Die erste Dimension erklärte $31 \%$, die zweite $20 \%$ der Variation.

Die erste Achse korreliert negativ sowohl mit den Zeigerwerten für Feuchte und Nährstoffe als auch mit der Weidezahl W (Tab. 41). Die Typischen Fettweiden gediehen somit auf den nährstoffreicheren, frischen Böden, während die ruderalen und mageren Glatthaferwiesen auf trockenen Standorten mit geringerem Nährstoffgehalt vorkamen. Dabei nahmen weideresistente Arten ab. Bei der zweiten Dimension zeigt sich kein Zusammenhang mit den ökologischen Wertzahlen. Die Achse korreliert auch nicht mit den früheren Nutzungsformen Weide, Mahd oder Agrarland, wohl aber schwach mit dem Beweidungsfaktor. Demnach beeinflusste die Nutzungsintensität die floristische Diversität der Grasländer.

Im Biplot, der gemeinsamen Darstellung von Art- und Aufnahmedaten, finden sich im Grünland typische Weide- und Wiesenarten (Abb. 49). Im rechten Bereich des Ordinationsdiagramms siedeln sich Vertreter der Typischen Glatthaferwiesen wie Alopecurus pratensis, Arrhenatherum elatius und Dactylis glomerata sowie der Magerwiesen wie Knautia arvensis, Lotus corniculatus, Luzula campestris und Ranunculus bulbosus an. Im Bereich der Aufnahme der Ruderalen Glatthaferwiese treten Graslandund Ruderalpflanzen wie Artemisia vulgaris, Festuca rubra agg., Plantago lanceolata und Tanacetum vulgare auf. Bromus hordeaceus und Bromus erectus, Trennarten für Tal-Glatthaferwiesen, markieren in der Diagrammmitte den Übergang zu den nährstoffreicheren Grünländern.

Im linken Bereich der Ordination liegen typische Arten der Fettweiden: Bellis perennis, Cirsium vulgare, Leontodon autumnalis, Lolium perenne, Phleum pratensis, Poa pratensis und Ranunculus repens. Die Anordnung der Arten im Ordinationsraum entspricht den Zeigerwerten: Frischezeiger stehen am linken, Trockenheitszeiger am rechten Rand. Gleiches gilt für die Stickstoffzahl.

Die in die DCA eingeflossenen Umweltvariablen wurden unter Verwendung von Monte-Carlo-Permutationstests in einer direkten Gradientenanalyse (CCA) auf ihre Signifikanz überprüft. Diese waren: Deckungsgrad der Streuschicht, Anteil an offenem Boden, mittlere Vegetationshöhe, Beweidungsfaktor, Meereshöhe, die Zeigerwerte für Feuchte, Licht und Nährstoffe sowie frühere Nutzung als Mahd, Weide oder Agrarland. Mit einem Permutationstest wurden bei einem Signifikanzniveau von $95 \%$ die signifikanten Variablen ermittelt: Der Zeigerwert für Licht, der Beweidungsfaktor der Krautschicht sowie die mittlere Vegetationshöhe der Krautschicht erklärten am besten die Variabilität des Datensatzes (Abb. 50). Ferner hatten auch der Zeigerwert für Feuchte, die Meereshöhe sowie die frühere Nutzung als Agrarland Einfluss auf die Signifikanz $(p<0,05)$. 
Das Ordinationsdiagramm in Abbildung 51 zeigt die Anordnung der Arten mit den 3 signifikanten Umweltvariablen. Die erste Achse stellt im Wesentlichen die Weideverträglichkeit der Arten dar, die direkt mit der Beweidungsintensität zusammenhing. Eine signifikante Korrelation der Weidezahl mit der ersten Achse wurde bereits durch die Korrelation mit den Aufnahmescores ermittelt (s. Tab. 41). Im rechten Bereich des Diagramms stehen tritt- und fraßresistente Arten wie Plantago lanceolata, Leontodon autumnalis, Taraxacum officinalis agg. und Trifolium repens. Beweidung förderte den Wuchs dieser Rosettenpflanzen.

Tab. 40: Zusammenhänge zwischen den Aufnahmescores der beiden ersten Achsen der DCA und den Umweltvariablen (Pearson-Korrelationen)

Signifikante Werte nach Bonferroni-Korrektur sind fett dargestellt.

\begin{tabular}{|c|c|c|c|c|}
\hline \multirow[t]{2}{*}{ Umweltvariablen } & \multicolumn{2}{|c|}{ 1. Achse der DCA } & \multicolumn{2}{|c|}{ 2. Achse der DCA } \\
\hline & $r$ & $\mathbf{p}$ & $r$ & $\mathbf{p}$ \\
\hline Zeigerwert für Feuchte & $-0,78$ & 0,001 & 0,18 & 0,526 \\
\hline Zeigerwert für Licht & $-0,67$ & 0,006 & $-0,29$ & 0,292 \\
\hline Zeigerwert für Nährstoffe & $-0,12$ & 0,659 & $-0,62$ & 0,015 \\
\hline Zeigerwert für Reaktion & $-0,01$ & 0,974 & $-0,10$ & 0,734 \\
\hline Anteil an offenem Boden & $-0,50$ & 0,055 & 0,42 & 0,117 \\
\hline Beweidungsfaktor der Krautschicht & $-0,52$ & 0,046 & $-0,03$ & 0,903 \\
\hline Meereshöhe & 0,30 & 0,270 & 0,50 & 0,058 \\
\hline Hangneigung & $-0,04$ & 0,901 & 0,53 & 0,04 \\
\hline Mahdzahl M & 0,65 & 0,009 & $-0,56$ & 0,03 \\
\hline
\end{tabular}

Tab. 41: Zusammenhänge zwischen den Aufnahmescores der beiden ersten Achsen der DCA und den Umweltvariablen im Grünland (Pearson-Korrelationen)

Signifikante Werte nach Bonferroni-Korrektur sind fett dargestellt

\begin{tabular}{lcccc}
\hline Umweltvariablen & \multicolumn{2}{c}{ 1. Achse der DCA } & \multicolumn{2}{c}{ 2. Achse der DCA } \\
& $\mathbf{r}$ & $\mathbf{p}$ & $\mathbf{r}$ & $\mathbf{p}$ \\
\hline Zeigerwert für Feuchte & $-\mathbf{0 , 8 4}$ & $\mathbf{0 , 0 0 1}$ & $-0,32$ & 0,309 \\
Zeigerwert für Nährstoffe & $-\mathbf{0 , 8 6}$ & $<\mathbf{0 , 0 0 1}$ & $-0,32$ & 0,314 \\
Zeigerwert für Reaktion & 0,34 & 0,278 & 0,12 & 0,715 \\
Beweidungsfaktor der Krautschicht & $-0,37$ & 0,233 & 0,61 & 0,034 \\
Meereshöhe & 0,73 & 0,007 & $-0,04$ & 0,895 \\
Nutzung als Wiese & 0,19 & 0,552 & $-0,20$ & 0,524 \\
Nutzung als Weide & 0,02 & 0,940 & $-0,01$ & 0,969 \\
Nutzung als Agrarland & $-0,29$ & 0,365 & 0,29 & 0,360 \\
Weidezahl W & $-\mathbf{0 , 7 9}$ & $\mathbf{0 , 0 0 2}$ & 0,16 & 0,624 \\
\hline
\end{tabular}



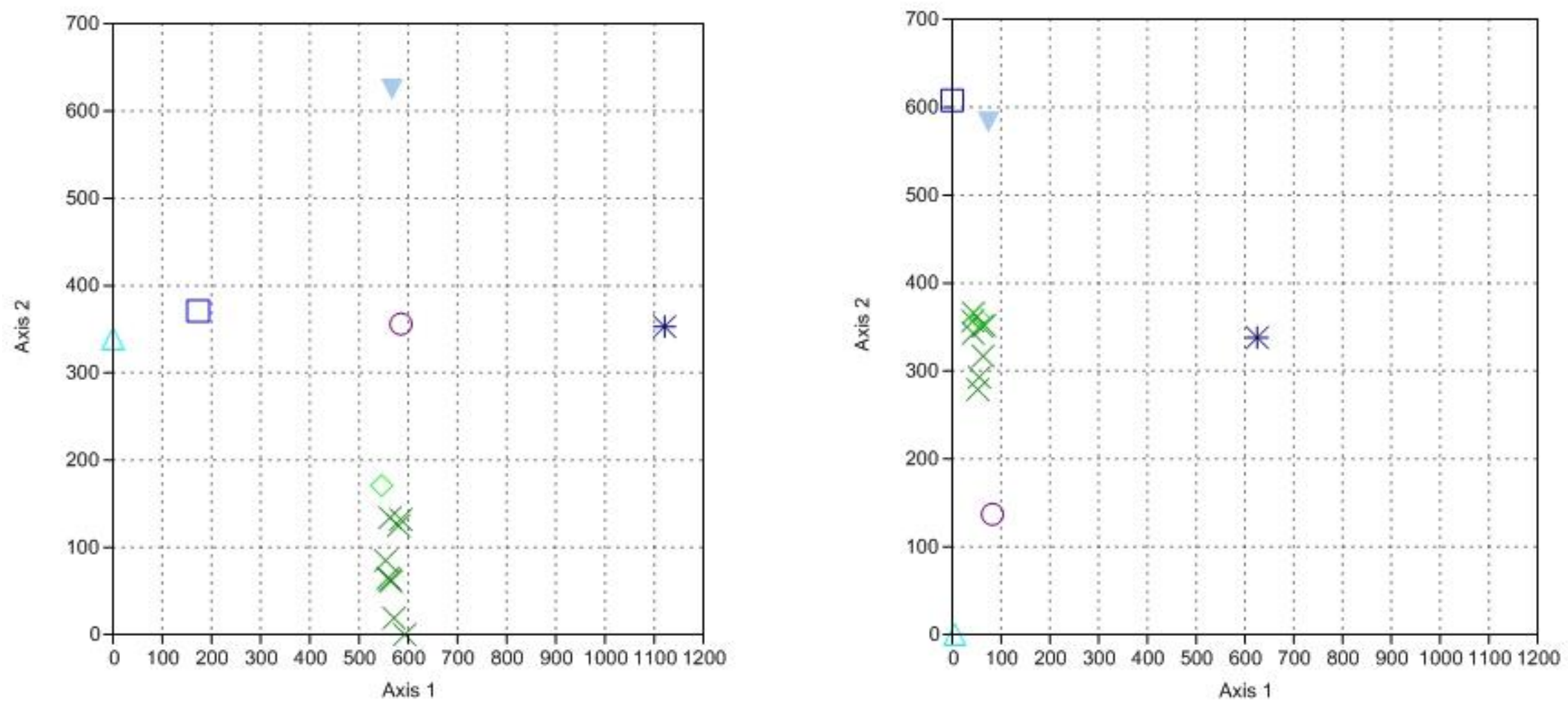

Abb. 45 (links): Indirekte Gradientenanalyse (DCA) der Untersuchungsflächen aus dem Jahr 2008, dargestellt nach Vegetationseinheiten

Eigenwerte: 1 . Achse 0,$96 ; 2$. Achse 0,86 .

$\times=$ Lolio-Cynosuretum typicum; $\bigcirc=$ Arrhenatheretum elatioris, ruderal; $\nabla=$ Arrh. elat., mager; $\diamond=$ Arrhenatheretalia-Basalgesellschaft; $\triangle=$ Eleocharitetum palustris;

$\square=$ Ranunculetum scelerati; $*$ = Fagetum nudum

Abb. 46 (rechts): Indirekte Gradientenanalyse (DCA) der Untersuchungsflächen aus dem Jahr 2011, dargestellt nach Vegetationseinheiten

Eigenwerte: 1 . Achse 0,$98 ; 2$. Achse 0,81

Erläuterung der Symbole siehe Abb. 45 

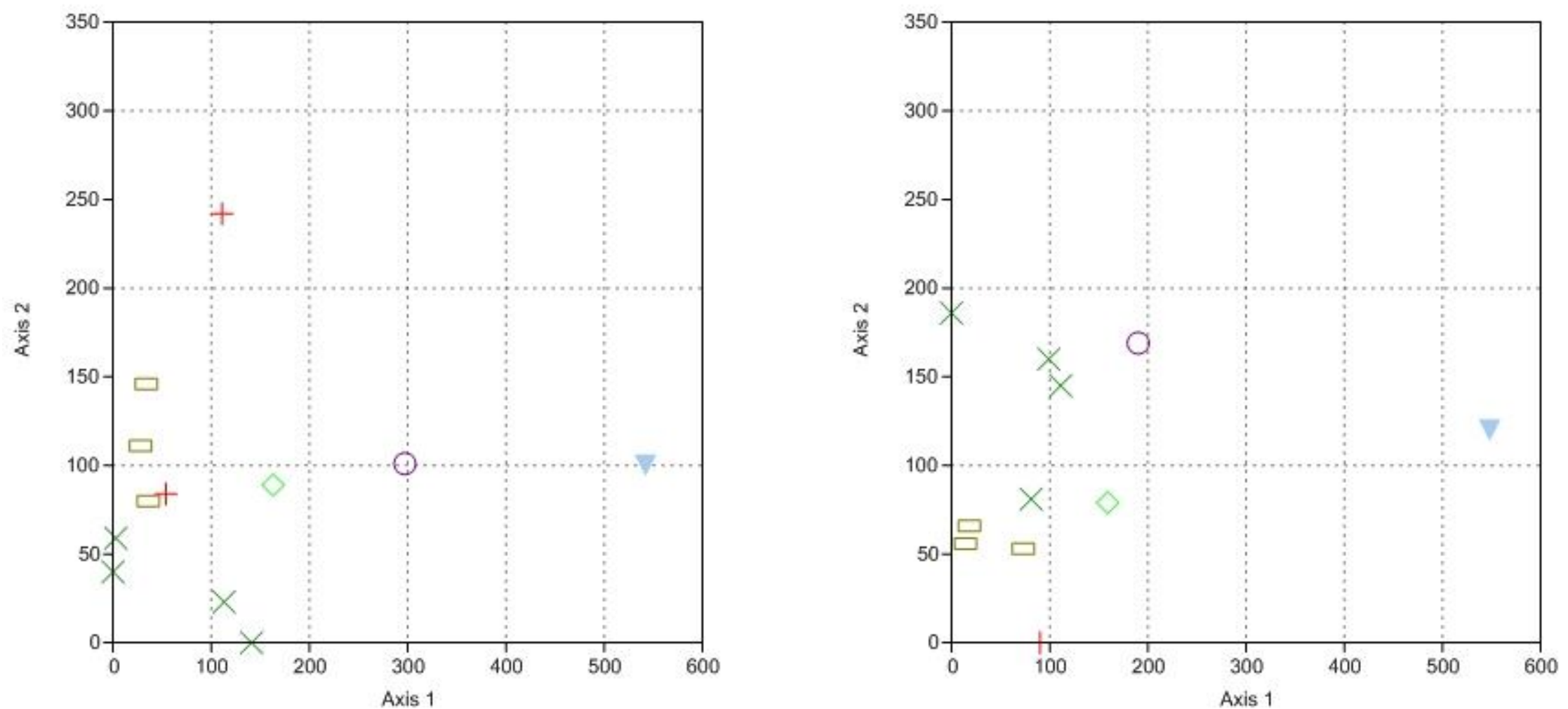

Abb. 47 (links): Indirekte Gradientenanalyse (DCA) der Grünlandflächen aus dem Jahr 2008, dargestellt nach Vegetationseinheiten mit Subassoziationen und Varianten

Eigenwerte: 1 . Achse 0,$87 ; 2$. Achse 0,35 .

$\square$ = Lolio-Cynosuretum typicum, artenarm; $\times$ = Lolio-Cyn. typ.; + = Lolio-Cyn. typ., artenreich; $\diamond=$ Arrhenatheretalia-Basalgesellschaft; $\bigcirc=$ Arrhenatheretum elatioris, ruderal;

$\boldsymbol{\nabla}=$ Arrh. elat., mager

Abb. 48 (rechts): Indirekte Gradientenanalyse (DCA) der Grünlandflächen aus dem Jahr 2011, dargestellt nach Vegetationseinheiten mit Subassoziationen und Varianten.

Eigenwerte: 1 . Achse 0,$84 ; 2$. Achse 0,24

Erläuterung der Symbole siehe Abb. 47 


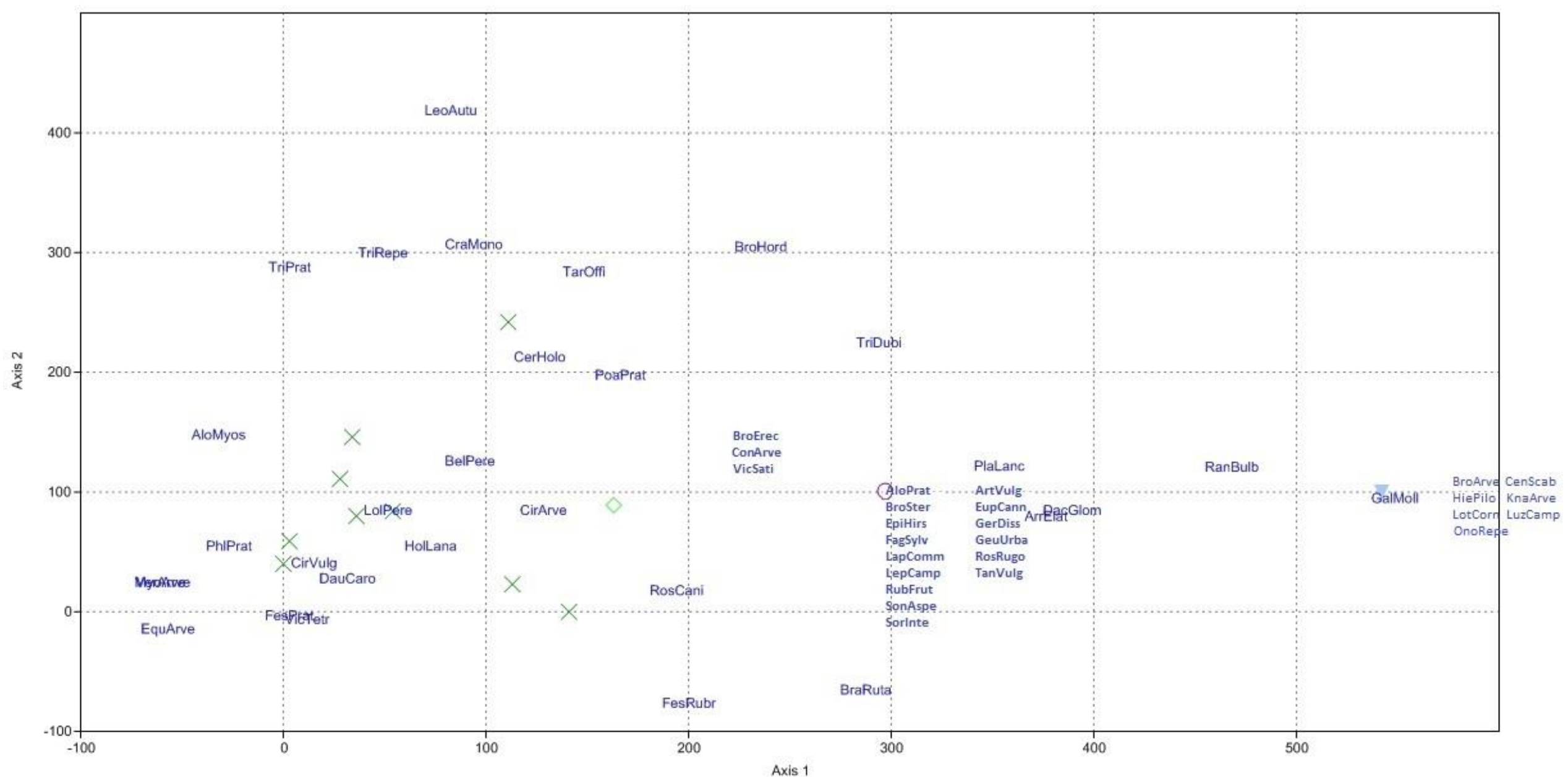

Abb. 49: Indirekte Gradientenanalyse (DCA) der Grünlandflächen aus dem Jahr 2008

Im Biplot werden 11 Aufnahmen und 47 Arten gemeinsam dargestellt. Eigenwerte: 1. Achse 0,87; 2. Achse 0,35.

Abkürzungen der Arten s. Tab. 42; $\times=$ Lolio-Cynosuretum typicum; $\bigcirc=$ Arrhenatheretum elatioris, ruderal; $\nabla=$ Arrh. elat., mager; $\diamond=$ Arrhenatheretalia-Basalgesellschaft; $\triangle=$

Eleocharitetum palustris; $\square=$ Ranunculetum scelerati; $*$ = Fagetum nudum 
Tab. 42: Die auf den Untersuchungsflächen vorkommenden Arten mit Kürzeln

\begin{tabular}{|c|c|c|c|c|c|}
\hline Kürzel & Wissenschaftlicher Name & Kürzel & Wissenschaftlicher Name & Kürzel & Wissenschaftlicher Name \\
\hline AloMyos & Alopecurus myosuroides & EquArve & Equisetum arvense & MyoArve & Myosotis arvensis \\
\hline AloPrat & Alopecurus pratensis & EupCann & Eupatorium cannabinum & OnoRepe & Ononis repens \\
\hline ArrElat & Arrhenatherum elatius & FagSylv & Fagus sylvatica & PhIPrat & Phleum pratense \\
\hline ArtVulg & Artemisia vulgare & FesPrat & Festuca pratense & PlaLanc & Plantago lanceolata \\
\hline BelPere & Bellis perennis & FesRubr & Festuca rubra & PoaNemo & Poa nemoralis \\
\hline BraRuta & Brachythecium rutabulum & GalApar & Galium aparine & PoaPrat & Poa pratensis \\
\hline BroArve & Bromus arvensis & GalMoll & Galium mollugo & PolLapa & Polygonum lapathifolia \\
\hline BroErec & Bromus erectus & GerDiss & Geranium dissectum & QueRobu & Quercus robur \\
\hline BroHord & Bromus hordeaceus & GerPyre & Geranium pyrenaicum & RanBulb & Ranunculus bulbosus \\
\hline BroSter & Bromus sterilis & GeuUrba & Geum urbanum & RanRepe & Ranunculus repens \\
\hline CarHirt & Carex hirta & HiePilo & Hieracium pilosella & RosCani & Rosa canina \\
\hline CenPulc & Centaurium pulchellum & HolLana & Holcus lanatus & RosRugo & Rosa rugosa \\
\hline CenScab & Centaurea scabiosa & JunArti & Juncus articulatus & RubFrut & Rubus fruticosus agg. \\
\hline CerHolo & Cerastium holosteoides & KnaArve & Knautia arvensis & SonAspe & Sonchus asper \\
\hline CirArve & Cirsium arvense & LapComm & Lapsana communis & Sorlnte & Sorbus intermedia \\
\hline CirPalu & Cirsium palustre & LeoAutu & Leontodon autumnalis & TanVulg & Tanacetum vulgare \\
\hline CirVulg & Cirsium vulgare & LepCamp & Lepidium campestre & TarOffi & Taraxacum officinalis agg. \\
\hline ConArve & Convolvulus arvensis & LolPere & Lolium perenne & TriDubi & Trifolium dubium \\
\hline CraMono & Crataegus monogyna & LotCorn & Lotus corniculatus & TriPrat & Trifolium pratense \\
\hline DacGlom & Dactylis glomerata & LuzCamp & Luzula campestris & TriRepe & Trifolium repens \\
\hline DauCaro & Daucus carota & LycEuro & Lycopus europaeus & VerArve & Veronica arvensis \\
\hline ElePalu & Eleocharis palustris & LysVulg & Lysimachia vulgaris & VicSati & Vicia sativa agg. \\
\hline EpiHirs & Epilobium hirsutum & Moss & Bryophyta spec. & VicTetr & Vicia tetrasperma \\
\hline
\end{tabular}

Im linken unteren Bereich des Diagramms (Abb. 51) finden sich Licht liebende Arten der Magerrasen, die nur bei sehr extensiver Nutzung auftreten. Vertreter dieses basiphilen Xerothermgraslandes waren beispielweise Centaurea scabiosa, Knautia arvensis, Lotus corniculatus, Ranunculus bulbosus und weiter im Zentrum des Diagramms gelegen - auch Bromus erectus und Daucus carota. Am äußeren rechten Rand sonderten sich feuchtigkeitsliebende Arten wie Carex hirta, Cirsium palustre, Lycopus europaeus und Lysimachia vulgaris ab, die nicht alle weideunverträglich sind, aber einen hohen Weidedruck durch Tritt erfuhren, da die Pferde die Uferbereiche zum Trinken und Baden aufsuchten. Die erste Achse korrelierte daher nicht nur positiv mit dem Beweidungsfaktor, sondern auch negativ mit den Zeigerwerten für Licht und Feuchtigkeit, wie bereits bei der DCA festgestellt wurde (s. Tab. 41).

Im oberen Teil des Diagramms erscheinen bei zunehmender Vegetationshöhe der Krautschicht hochwüchsige Gräser wie Arrhenatherum elatius, Dactylis glomerata und Festuca pratensis. Sie sind klassische Vertreter der Oberschicht von Wiesenbeständen. Begleitet werden diese Bestände von Ruderalpflanzen wie Artemisia vulgaris und Tanacetum vulgaris oder Geum urbanum mit Hauptvorkommen in nährstoffreichen Stauden- und ausdauernden Unkrautfluren. Hochwüchsige Bestände zeugen von Unterbeweidung, was häufig die Ausbreitung von Weideunkräutern wie Artemisia vulgaris, Equisetum arvensis und Rosa rugosa zur Folge hat. 
In der Diagrammmitte finden sich schließlich typische Vertreter von Fettweiden, die weideverträglich sind und auf Frischwiesen wachsen. Cirsium- und Trifolium-Arten zählen hierzu ebenso wie hochwertige Futtergräser: Festuca rubra, Lolium perenne, Phleum pratensis und Poa pratensis. Horstpflanzen wie Cerastium holostoides, Festuca spec., Holcus lanatus, Lolium perenne oder Trifolium pratense gedeihen in der Mittelschicht erfolgreich, da Fraß und Mahd mehrstängelige Neuaustriebe fördern. Eine Ausnahme bildeten lediglich die Wald- und Gebüscharten Crataegus monogyna, Fagus sylvatica, Poa nemoralis und Quercus robur, die sich gegenüber den drei ausgewählten Umweltvariablen intermediär verhielten, da sie weder auf viel Licht noch auf Feuchtigkeit angewiesen waren, meist eine spärliche Krautschicht aufwiesen und nur geringen Weidedruck erfuhren.

Die Ergebnisse des indirekten und direkten Ordinationsverfahrens stimmen im Wesentlichen überein. Die Eigenwerte der beiden Ordinationsverfahren unterscheiden sich nur geringfügig (Tab. 43), was dafür spricht, dass sich die erhobenen Umweltdaten zur Interpretation des Ordinationsdiagramms eignen. Auch der Permutationstest stuft die erklärte Varianz der Arten-Umwelt-Beziehung als signifikant $(p=0,002)$ ein, so dass die Varianz innerhalb der Arten über die getesteten Umweltvariablen erklärt werden kann.

Tab. 43: Eigenwerte unterschiedlicher Korrespondenzanalysen (CA, DCA, CCA) für die Daueruntersuchungsflächen im Jahr 2008

\begin{tabular}{llll}
\hline $\mathbf{2 0 0 8}$ & 1. Achse & 2. Achse & 3. Achse \\
\hline Eigenwert CA & 0,961 & 0,924 & 0,896 \\
Eigenwert DCA & 0,961 & 0,848 & 0,360 \\
Eigenwert CCA & 0,951 & 0,888 & 0,813 \\
\hline
\end{tabular}

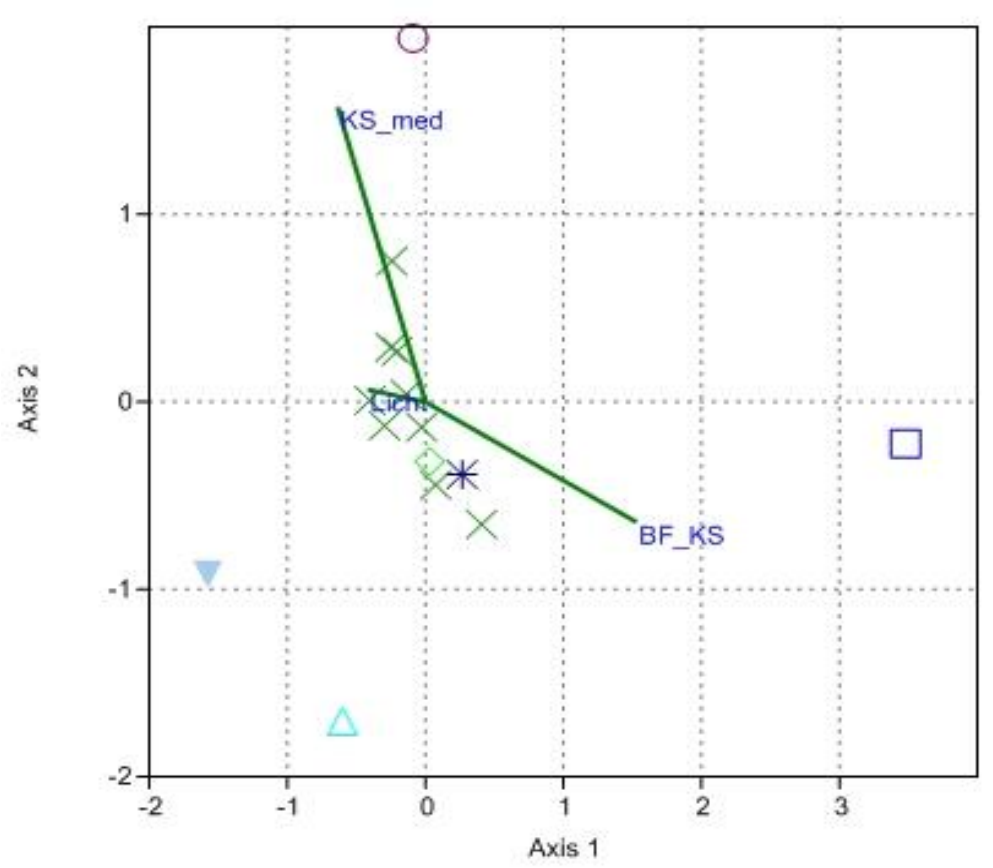

Abb. 50: Direkte Gradientenanalyse (CCA) der Untersuchungsflächen aus dem Jahr 2008 mit 3 hoch signifikanten Umweltvariablen, dargestellt nach Vegetationseinheiten

$\times=$ Lolio-Cynosuretum typicum; $\bigcirc=$ Arrhenatheretum elatioris, ruderal; $\nabla$ = Arrh. elat., mager; $\diamond=$ Arrhenatheretalia-Basalgesellschaft; $\triangle$ = Eleocharitetum palustris; $\square=$ Ranunculetum scelerati; $*$ = Fagetum nudum; Licht $=$ Zeigerwert für Licht; BF_KS = Beweidungsfaktor der Krautschicht; KS_med = mittlere Vegetationshöhe der Krautschicht 


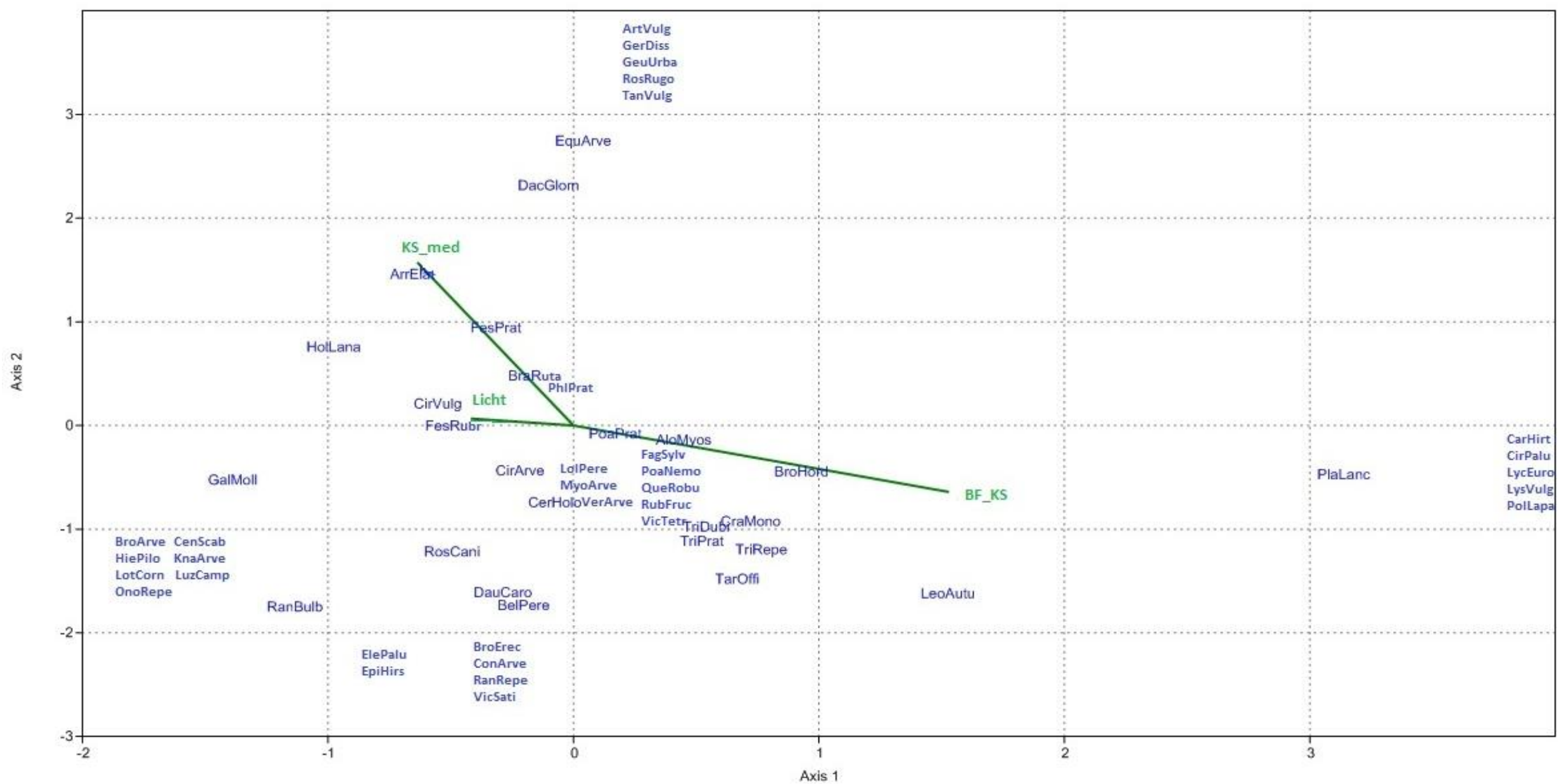

Abb. 51: Direkte Gradientenanalyse (CCA) der Arten mit 3 hoch signifikanten Umweltvariablen

Dargestellt sind 62 der 66 Arten. Eigenwerte: 1 . Achse 0,70; 2. Achse 0,39.

Abkürzungen der Arten s. Tab. 42; Abkürzungen der Umweltvariablen s. Abb. 50 


\subsubsection{Ordination der Aufnahmen aus verschiedenen Jahren}

Um zu erkennen, in welche Richtung sich die Vegetation entwickelte, wurden die Daten der 4 Aufnahmejahre miteinander verglichen. Für 17 Aufnahmeflächen lagen Daten von 2008-2011 vor, ab dem Jahr 2009 kamen 7 weitere Aufnahmen auf Ausschlussflächen hinzu. Im Ordinationsdiagramm (DCA) ist erkennbar, dass die Aufnahmen im Laufe der Jahre näher zusammenrückten (Abb. 45-46). Aufnahmen von 2011 zeigten folglich eine größere floristische Ähnlichkeit als im Jahr 2008. Die Gradientenlänge der 1. Achse hat sich von SD = 4,2 (2008) auf 3,5 (2011) verkürzt, obwohl die Artenanzahl zunahm (s. 6.4.1.4 Artenreichtum und Diversität). Die Eigenwerte der ersten drei Achsen sind in etwa gleich geblieben (Tab. 44).

Auch die Grünlandflächen näherten sich unter einem einheitlichen Nutzungsregime in ihrer floristischen Diversität an: Die Grünlandaufnahmen gruppierten sich im Ordinationsdiagramm von 2011 in der unteren, linken Ecke, während sie drei Jahre zuvor weiter auseinander lagen (Abb. 47-48). Eine Ausnahme stellt nur die magere Glatthaferwiese dar.

Die Aufnahmen wurden als Zeitreihen dargestellt. Aus der Ordination aller Aufnahmen von 2008-2011 geht hervor, dass sich die meisten Flächen in eine einheitliche Richtung entwickelten, und zwar nach rechts unten (Abb. 52). Ausgenommen davon war nur die stark gestörte Fläche im Uferbereich eines Weihers, an der sich eine Gift-Hahnenfuß-Gesellschaft (RAN) angesiedelt hat.

Auch die Grünlandflächen, allein ordiniert, wiesen einen einheitlichen Trend nach rechts auf, wobei sich die Fettweiden hin zu den ruderalen und mageren Glatthaferwiesen entwickelten (Abb. 53). Das Zick-Zack-Muster der einzelnen Jahre zeigt die jährlichen Schwankungen an. Die größten Veränderungen zeigten genau jene Flächen, die im Frühherbst 2009 zur Verhinderung der Ausbreitung von Cirsium-Samen einmalig gemäht wurden.

Vergleichend wurde die Entwicklung auf den nicht-beweideten Kontrollflächen betrachtet. Bereits zu Beginn der Untersuchung wiesen die Vergleichsflächen eine unterschiedliche Artenzusammensetzung auf (ohne Abb.), da sie nicht zu $100 \%$ gleichwertig waren. Dies trat besonders deutlich bei der mageren Glatthaferwiese in Erscheinung. Ihre Kontrollfläche (ARR_MAG_K) entsprach in ihrer Artenzusammensetzung vielmehr einer typischen als einer mageren Glatthaferwiese und ähnelte stärker der ruderalen Glatthaferwiese (ARR_TAN_K). Daher liegen die beiden Glatthaferwiesen-Aufnahmen bei der Ordination der Kontrollflächen näher zusammen als bei der Ordination der Untersuchungsflächen (Abb. 54, vergleiche zu Abb. 52).

Die Kontrollflächen entwickelten sich im Untersuchungszeitraum als Brache oder unter Mahd in unterschiedliche Richtungen (Abb. 55). Verglichen mit den Aufnahmen unter Beweidung (vgl. Abb. 53) zeigten sie insgesamt eine dynamischere Entwicklung, der Trend geht hierbei nach rechts oben. Beginnende Brache oder ein- bis zweischürige Mahd scheinen demnach anfänglich die floristische Diversität stärker zu beeinflussen als die Einführung einer extensiven Beweidung mit Pferden.

Tab. 44: Eigenwerte der Korrespondenzanalyse (CA) der Untersuchungsflächen in den Jahren 2008-2011

\begin{tabular}{llll}
\hline & 1. Achse & 2. Achse & 3. Achse \\
\hline Eigenwert CA 2008 & 0,962 & 0,937 & 0,910 \\
Eigenwert CA 2011 & 0,984 & 0,848 & 0,830 \\
\hline
\end{tabular}




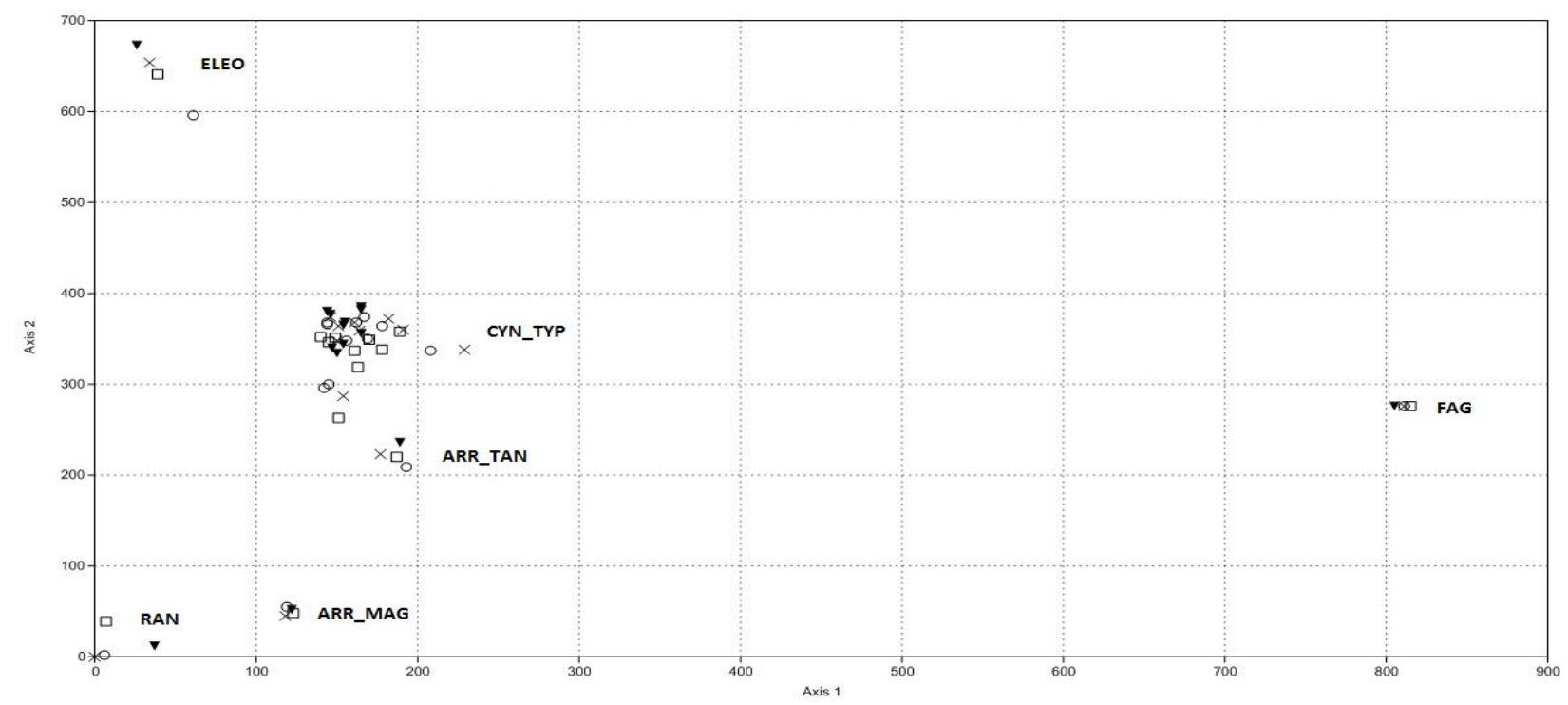

Abb. 52: Indirekte Gradientenanalyse (DCA) von 14 Untersuchungsflächen, dargestellt als Zeitreihe von 2008-2011

Eigenwerte: 1 . Achse 0,$97 ; 2$. Achse $0,81$.

Von einer Aufnahme (VDF6) sind nur die Daten von 2008 und 2009 vorhanden.

$\Delta=2008 ; O=2009 ; \times=2010 ; \square=2011$;

ELEO = Eleocharitetum palustris; CYN_TYP = Lolio-Cynosuretum typicum; ARR_TAN = Arrhenatheretum elatioris, ruderal; $A R R \_M A G=$ Arrh. elat., mager; RAN = Ranunculetum scelerati; $F A G=$ Fagetum nudum

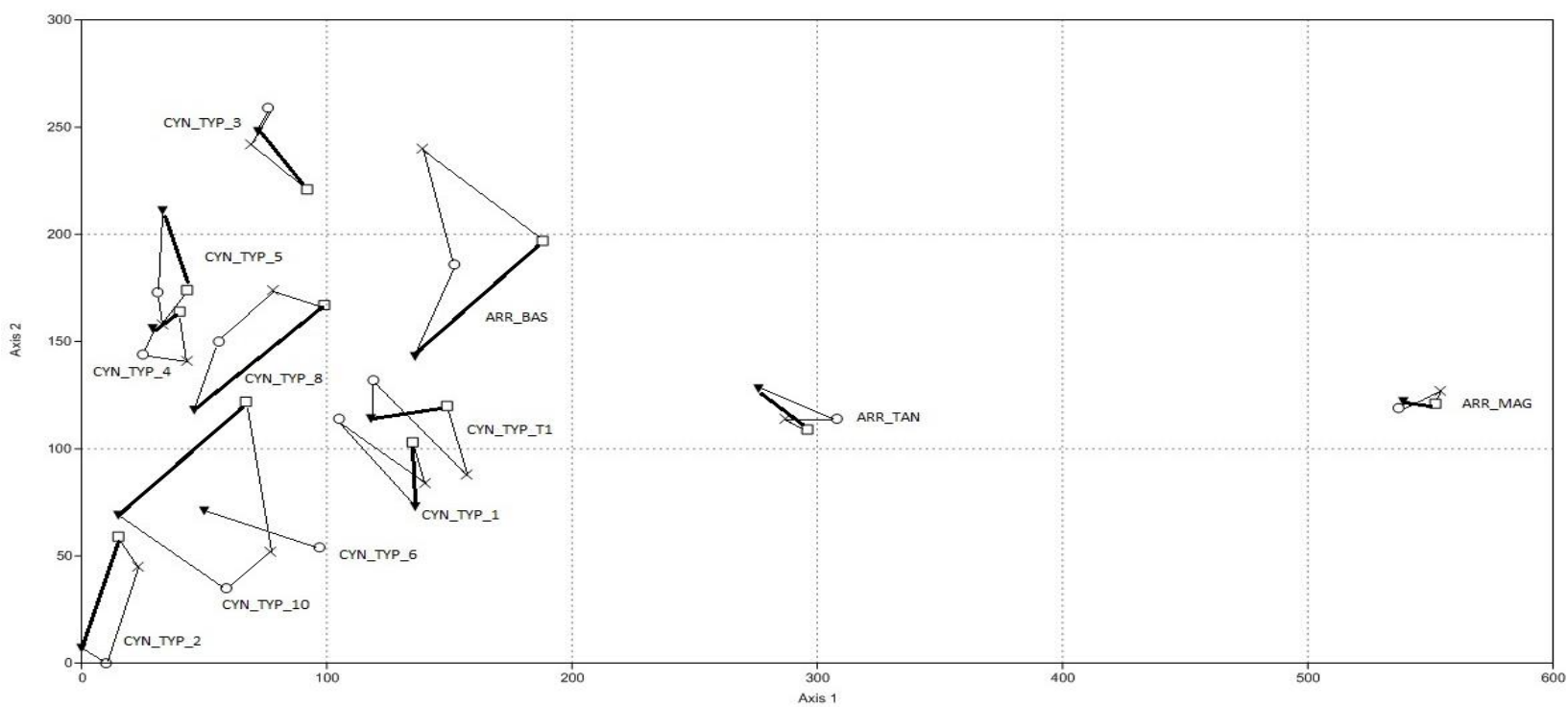

Abb. 53: Indirekte Gradientenanalyse (DCA) von 11 Untersuchungsflächen im Grünland, dargestellt als Zeitreihe von 20082011

Eigenwerte: 1 . Achse 0,$87 ; 2$. Achse 0,3 .

Von einer Aufnahme (VDF6) sind nur die Daten von 2008 und 2009 vorhanden.

$\Delta=2008 ; \bigcirc=2009 ; X=2010 ; \square=2011$; dünne Linien verbinden einzelne Jahre, dicke Linien das Jahr 2008 mit dem Jahr 2011; CYN_TYP = Lolio-Cynosuretum typicum; ARR_BAS = Arrhenatheretalia-Basalgesellschaft; ARR_TAN $=$ Arrhenatheretum elatioris, ruderal; ARR_MAG = Arrh. elat., mager 


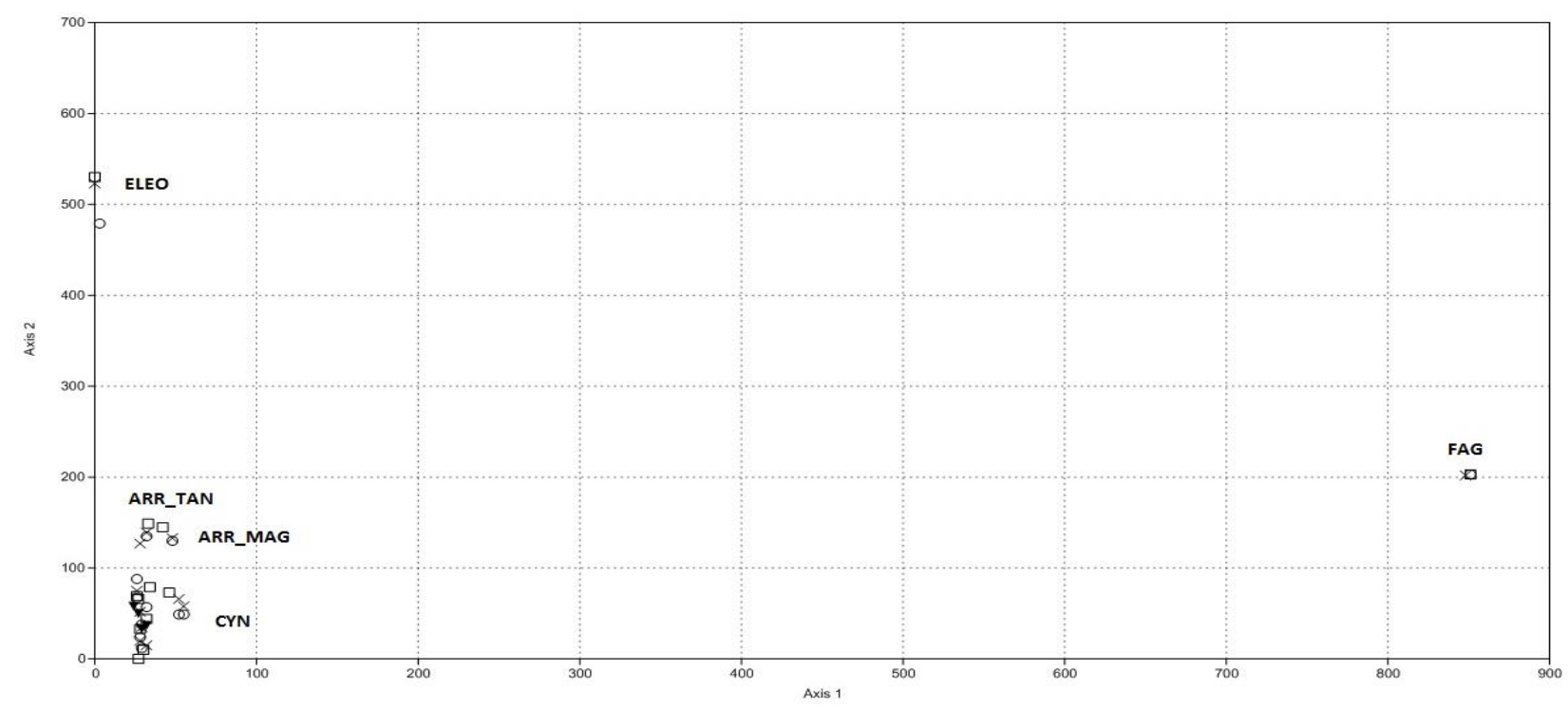

Abb. 54: Indirekte Gradientenanalyse (DCA) der 12 Kontrollflächen, dargestellt als Zeitreihe

Eigenwerte: 1 . Achse 0,$99 ; 2$. Achse 0,85 .

Zeitreihe von 2008-2011 für 4 Aufnahmen, von 2009-2011 für 8 Aufnahmen.

$\Delta=2008 ; \bigcirc=2009 ; \times=2010 ; \square=2011$;

ELEO = Eleocharitetum palustris; CYN_TYP = Lolio-Cynosuretum typicum; ARR_TAN = Arrhenatheretum elatioris, ruderal; ARR_MAG = Arrh. elat., mager; RAN = Ranunculetum scelerati; FAG = Fagetum nudum

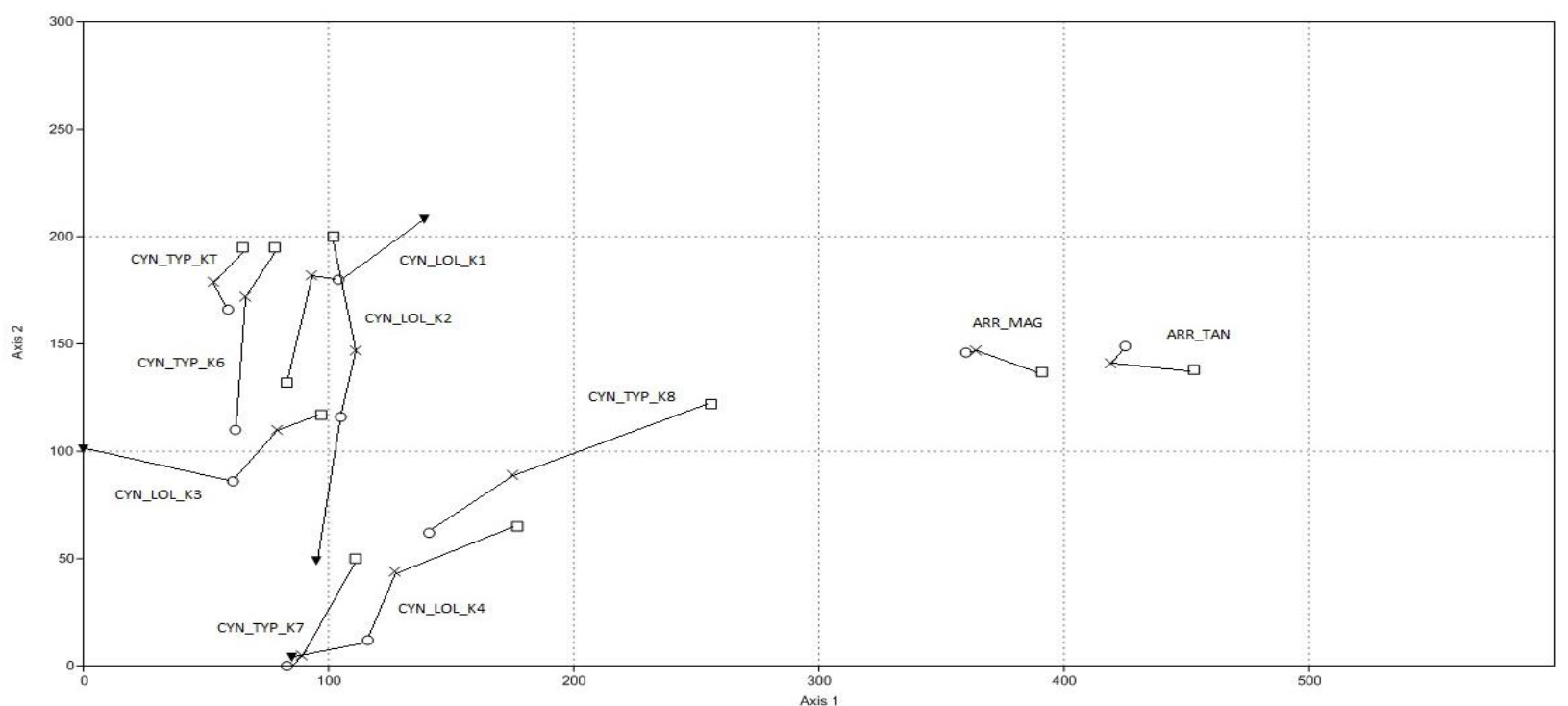

Abb. 55: Indirekte Gradientenanalyse (DCA) der 10 Kontrollflächen im Grünland, dargestellt als Zeitreihe

Eigenwerte: 1 . Achse 0,$8 ; 2$. Achse 0,3 .

Zeitreihe von 2008-2011 für 4 Aufnahmen, von 2009-2011 für 6 Aufnahmen.

$\Delta=2008 ; \bigcirc=2009 ; \times=2010 ; \square=2011$; die Linien verbinden einzelne Jahre;

CYN_LOL = Lolio-Cynosuretum; CYN_TYP = Lolio-Cyn. typicum; ARR_TAN = Arrhenatheretum elatioris, ruderal;

ARR_MAG = Arrh. elat., mager 


\subsubsection{Artenreichtum und Diversität}

Die $\alpha$-Diversität, welche die durchschnittliche Artenzahl je Aufnahmefläche angibt, war im Jahr 2008 auf den Glatthaferwiesen am höchsten, im Uferbereich am geringsten (Abb. 56). Unter Beweidung entwickelten sich die Flächen unterschiedlich: Auf der mageren Glatthaferwiese nahmen die Artenzahlen leicht $a b$, im Uferbereich schwankten sie am stärksten. Insgesamt haben auf den Untersuchungsflächen im Grünland im betrachteten Zeitraum nennenswerte Artenverschiebungen hin zu einem gröBeren Artenreichtum stattgefunden (Abb. 57), die statistisch hoch signifikant waren (Wilcoxon-Test für verbundene Stichproben, $\left.n=48, W_{R}=842, p<0,001\right)$.

Auf den Kontrollflächen nahmen die Artenzahlen bei Mahd zwischen den Jahren 2008 und 2011 leicht, aber nicht signifikant zu (Wilcoxon, $n=16, W_{R}=77, p=0,287$ ), bei Brache wurden die Fettweiden artenreicher, die Glatthaferwiesen artenärmer (Wilcoxon, $n=20, W_{R}=99, p<0,001$ ).

Der Wert der mengenanteiligen Gleichmäßigkeit der Arten, die Evenness, stieg mit der Beweidungsdauer an (Wilcoxon, $n=6, p=0,046$ ): Im Jahr 2011 war die Evenness im Grünland signifikant höher als zu Beginn der Untersuchung. Das bedeutet, dass die Gesamtdeckung der Vegetation nach drei Beweidungsjahren gleichmäßiger auf unterschiedliche Arten verteilt war. Am niedrigsten waren die Werte auf den artenarmen Fettweiden, die erst im Jahr 2006 durch Einsaat in Weideland überführt worden waren (Tab. 45, Abb. 58). Mit der Artenzunahme erhöhte sich im betrachteten Zeitraum auch ihr Grad an Gleichverteilung. Verglichen wurden hierbei sechs Ausprägungen von Grünlandgesellschaften zwischen den Jahren 2008 und 2011.

Der Shannon-Index bewertet die Diversität einer Pflanzengemeinschaft, indem er die durchschnittliche Artenzahl pro Aufnahmefläche und den Durchschnittswert der Evenness kombiniert. Zusammen mit den Artenzahlen und der Evenness nahm auch die Artendiversität im Untersuchungszeitraum signifikant zu (Wilcoxon-Test, $n=6, p=0,028$ ). Am höchsten war sie in der Arrhenatheretalia-Basalgesellschaft an der Südspitze des Gebietes, am geringsten im artenarmen Grünland, den ehemaligen Ackerflächen (Abb. 59).

Tab. 45: Artendiversität $H^{\prime}$ und Evenness E der untersuchten Grünländer zwischen den Jahren 2008-2011

\begin{tabular}{lcccccccc}
\hline Grünlandkategorie & \multicolumn{3}{c}{ Shannon-Index H' } & \multicolumn{4}{c}{ Evenness E } \\
& $\mathbf{2 0 0 8}$ & $\mathbf{2 0 0 9}$ & $\mathbf{2 0 1 0}$ & $\mathbf{2 0 1 1}$ & $\mathbf{2 0 0 8}$ & $\mathbf{2 0 0 9}$ & $\mathbf{2 0 1 0}$ & $\mathbf{2 0 1 1}$ \\
\hline Lol-Cyn. typ., artenarm & 1,247 & 1,419 & 1,402 & 1,616 & 0,686 & 0,73 & 0,803 & 0,682 \\
Lol-Cyn. typ. & 1,34 & 1,585 & 1,681 & 1,986 & 0,647 & 0,753 & 0,752 & 0,692 \\
Lol-Cyn. typ. mit Arrh. & 2,002 & 1,985 & 2,06 & 2,152 & 0,807 & 0,776 & 0,763 & 0,733 \\
Arrh., basal & 2,224 & 2,374 & 2,582 & 2,409 & 0,769 & 0,804 & 0,806 & 0,812 \\
Arrh. typ., ruderal & 1,974 & 2,172 & 2,174 & 2,128 & 0,712 & 0,751 & 0,767 & 0,738 \\
Arrh. typ., mager & 1,842 & 1,79 & 1,636 & 1,891 & 0,698 & 0,737 & 0,72 & 0,658 \\
\hline
\end{tabular}




\section{AUSWIRKUNG DER BEWEIDUNG}

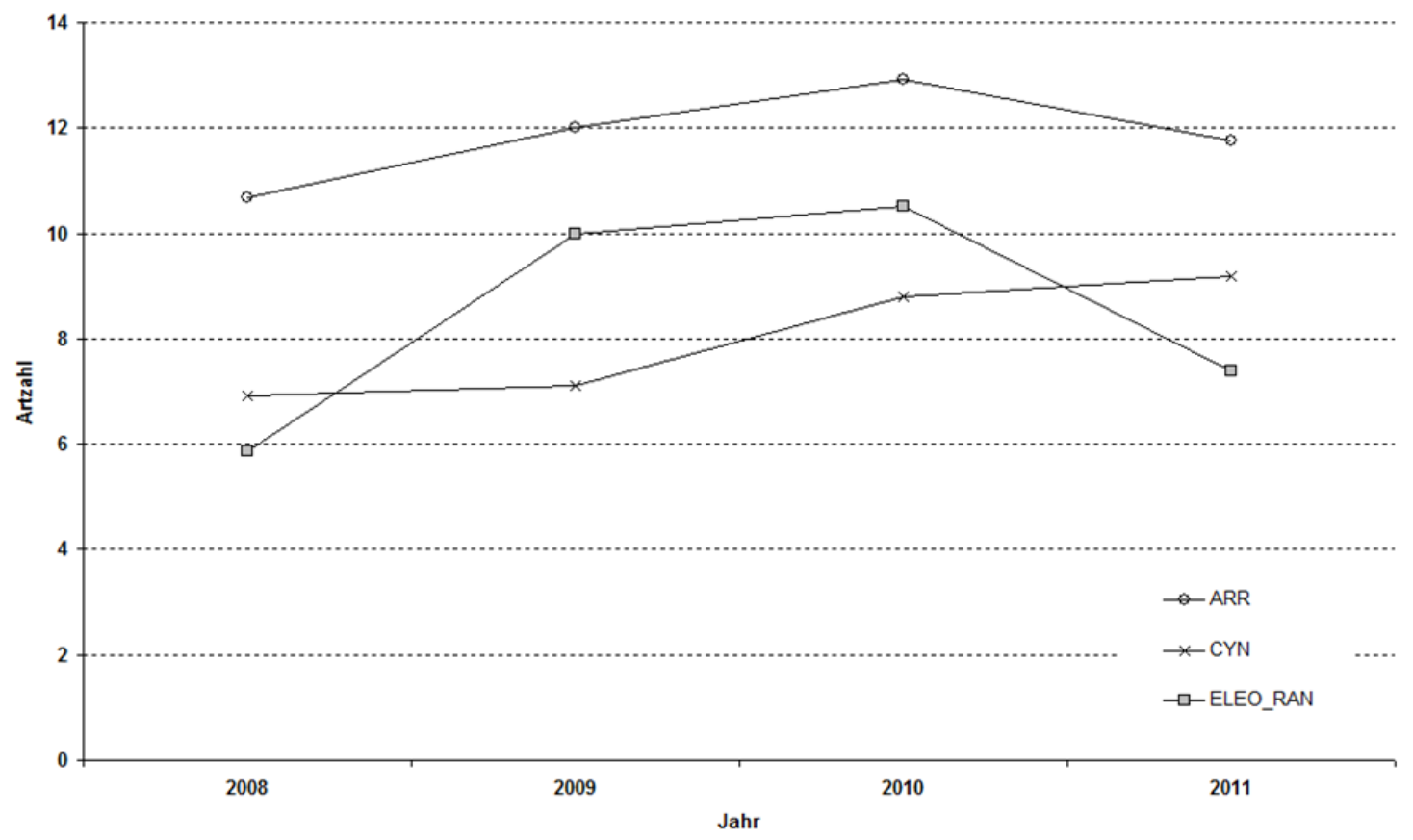

Abb. 56: Entwicklung der mittleren Artenzahlen auf den Untersuchungsflächen im Grünland und im Uferbereich zwischen den Jahren 2008-2011 $(n=48)$

ARR = Glatthaferwiesen; CYN = Typische Fettweiden; ELEO_RAN = Sumpfbinsen- und Gift-Hahnenfuß-Gesellschaft

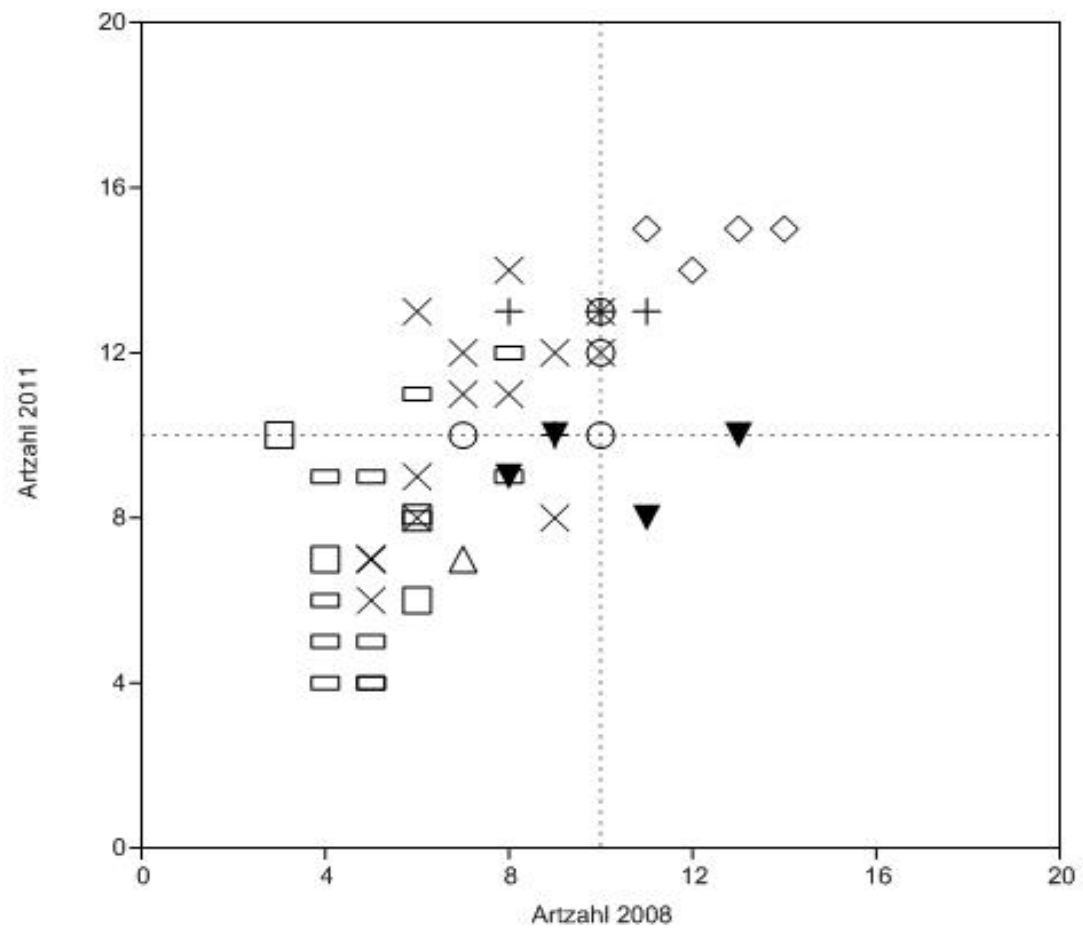

Abb. 57: Entwicklung der Artenzahlen auf den Subplots der VDF im offenen Weideland zwischen 2008-2011 $(n=48)$

Aufnahmen im linken oberen Dreieck zeigen eine Artenzunahme, Aufnahmen im rechten unteren Dreieck eine Abnahme an.

$\times$ = Lolio-Cynosuretum typicum; $\square$ = Lolio-Cyn. typ., artenarm; + = Lolio-Cyn. typ., mit Elementen der Arrh.;

$\bigcirc=$ Arrhenatheretum elatioris, ruderal; $\boldsymbol{\nabla}=$ Arrh. elat., mager; $\diamond=$ Arrhenatheretalia-Basalgesellschaft;

$\triangle$ = Eleocharitetum palustris; $\square=$ Ranunculetum scelerati 


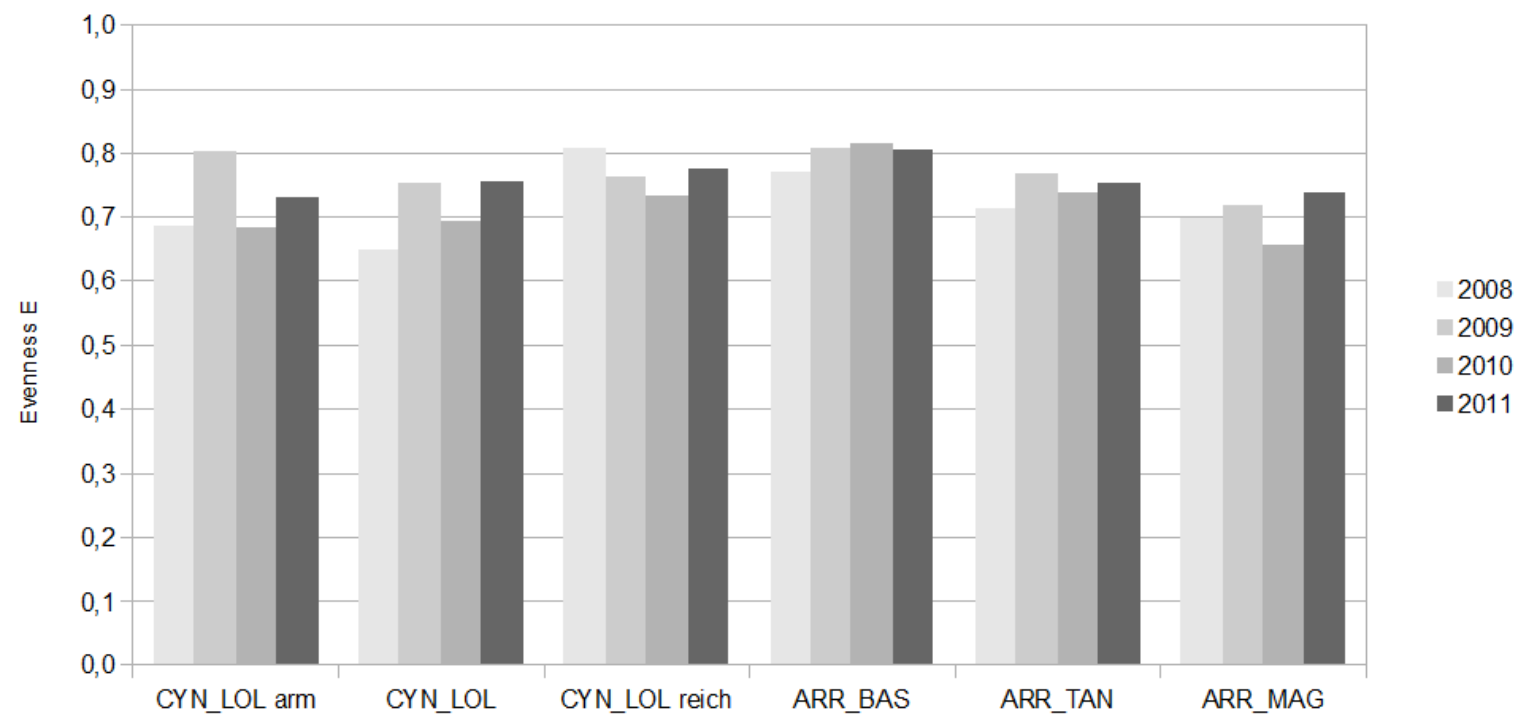

Abb. 58: Evenness E im Grünland, dargestellt nach Vegetationseinheiten mit Variationen

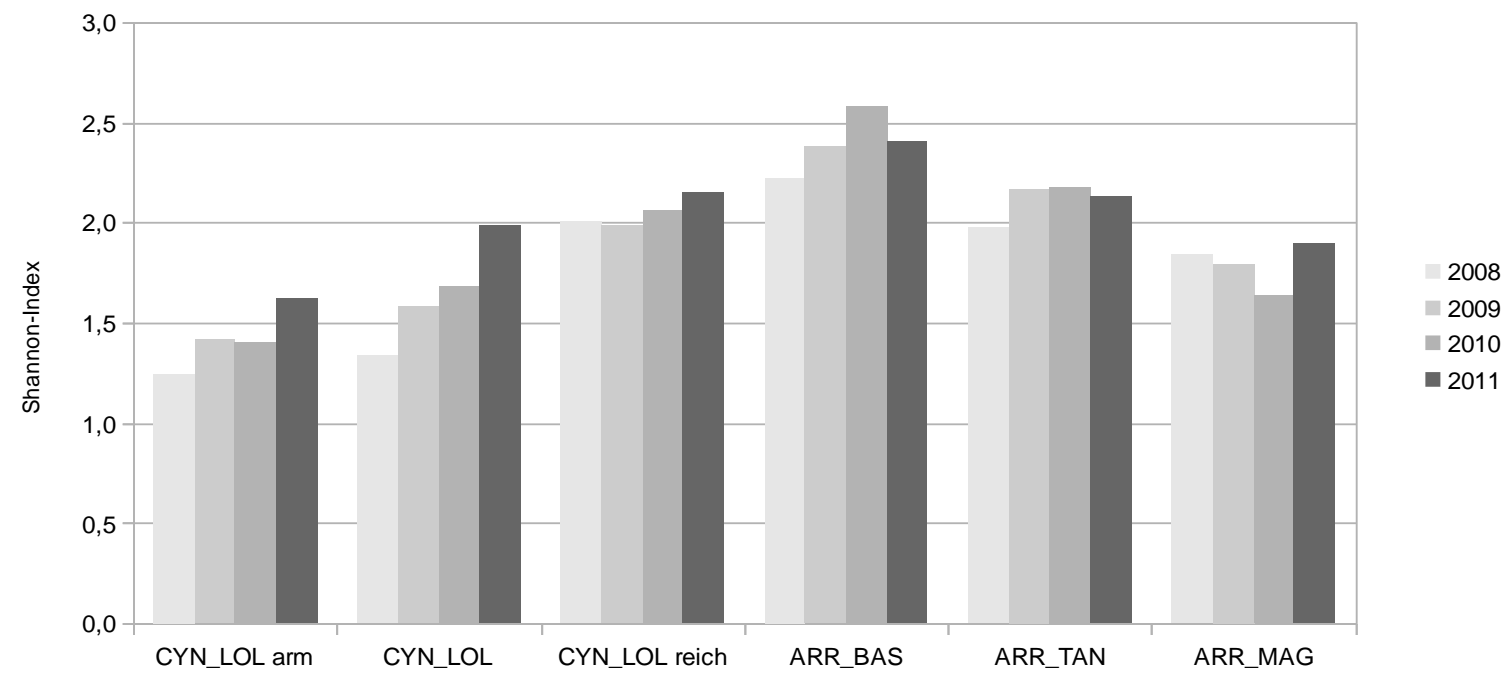

Abb. 59: Diversität nach Shannon $H^{\prime}$ im Grünland, dargestellt nach Vegetationseinheiten mit Variationen $\left(H_{\max }=4,78\right)$

\subsubsection{Gradientendiversität}

Ein Vergleich der Artzahlen zeigt an, ob neue Arten im Untersuchungszeitraum hinzugekommen sind, sagt aber noch nichts darüber aus, ob die Arten, die zu Beginn der Untersuchung auf den Flächen wuchsen, auch nach drei Jahren noch vorhanden waren. Es beantwortet also nicht die Frage nach der Veränderung der Pflanzengemeinschaft durch die Pferdebeweidung. Erst eine Berechnung des Austausches der Arten im Beobachtungszeitraum trägt diesem Sachverhalt Rechnung. Diese TurnoverRate ist kennzeichnend für die $\beta$-Diversität (Tremp 2005).

Angesichts der kurzen Untersuchungsdauer von 3 Jahren wurde insgesamt nur eine geringe TurnoverRate erwartet. Die Artendynamik war im stark gestörten Uferbereich am größten, auf der selten beweideten mageren Glatthaferwiese am geringsten (Tab. 46). Alle weiteren Grünlandaufnahmen lagen 
mit Werten von $b_{t}=0,1-0,33$ im unteren Bereich. Somit war die Artenzusammensetzung innerhalb der Weiden recht stabil. Die höchste Dynamik zeigten genau jene Flächen, die zuvor als Grünland (CYN_TYP_10, 8, 2) oder als Ackerland (CYN_TYP_4) genutzt wurden. Die frühere Nutzungsform wirkte sich demnach auf die Artendynamik aus, auch wenn dieser Zusammenhang statistisch nicht signifikant war (H-Test nach Kruskal-Wallis, $n=10, p>0,05$ ).

Anders fielen die Turnover-Raten des Höhentransektes aus. Dieser reichte von der mageren Glatthaferwiese auf der Hügelkuppe bis zum nitrophilen Ufersaum. Die Turnover-Raten sind in Abb. 64 dargestellt. Sie steigen immer dann an, wenn die Pflanzengesellschaft wechselte. Im Jahr 2011 waren die Turnover-Raten höher als in 2008, die Beweidung verstärkte die Unterschiedlichkeit der Flächen, was die in der Literatur vertretende Meinung, extensive Beweidung fördere die Entstehung kleiner Mosaike (von Oheimb et al. 2006), stützt. Ein Vergleich derselben Flächen in den Jahren 2008 und 2011 zeigt mit Werten von $b_{t}=0,38-0,5$ höhere Turnover-Raten an als auf den anderen Dauerflächen im Grünland $\left(b_{t}=0,09-0,33\right)$.

Die Turnover-Raten $b_{t}$ der Daueruntersuchungsflächen zwischen den Jahren 2008 und 2011 standen weder im Zusammenhang mit der Nutzungsintensität im Jahr 2011 (Pearson-Korrelationskoeffizient $r=0,26, \mathrm{n}=20)$ noch mit einem Feuchtegradienten $(r=-0,085, \mathrm{n}=20$ ) (ohne Abb.).

Auch die Pflanzengesellschaft erklärte nicht eindeutig, warum sich die Artenzusammensetzung bestimmter Flächen unter Beweidung stärker veränderte als andere. Aus der Anordnung der Vegetationseinheiten nach steigenden Turnover-Raten im linearen Modell (Abb. 65) lässt sich ableiten, dass sich die Typischen Fettweiden unter extensiver Pferdebeweidung weniger veränderten als die ehemaligen Glatthaferwiesen und die Gesellschaften der Ufersäume. Dies ist verständlich, da viele der Typischen Fettweiden im Gebiet bereits früher von Rindern oder Schafen beweidet wurden, was ein Vorherrschen tritt- und weideresistenter Pflanzen erwarten lässt. Diese Arten siedelten sich nun auch auf den Glatthaferwiesen an, was zu einer größeren Dynamik in deren Artbestand führte.

Tab. 46: Turnover-Raten $b_{t}$ auf den VDF im offenen Weideland zwischen den Jahren 2008-2011

\begin{tabular}{ll}
\hline Pflanzengesellschaft_VDF & bt \\
\hline ARR_MAG_9 & 0,09 \\
CYN_TYP_T1 & 0,11 \\
CYN_TYP_5 & 0,11 \\
ARR_BAS_12 & 0,19 \\
CYN_TYP_3 & 0,23 \\
CYN_TYP_1 & 0,23 \\
CYN_TYP_2 & 0,23 \\
CYN_TYP_4 & 0,23 \\
CYN_TYP_8 & 0,26 \\
ARR_TAN_7 & 0,31 \\
CYN_TYP_10 & 0,33 \\
RAN_PEL_T2 & 0,33 \\
ELEO_P_T1 & 0,56 \\
\hline
\end{tabular}




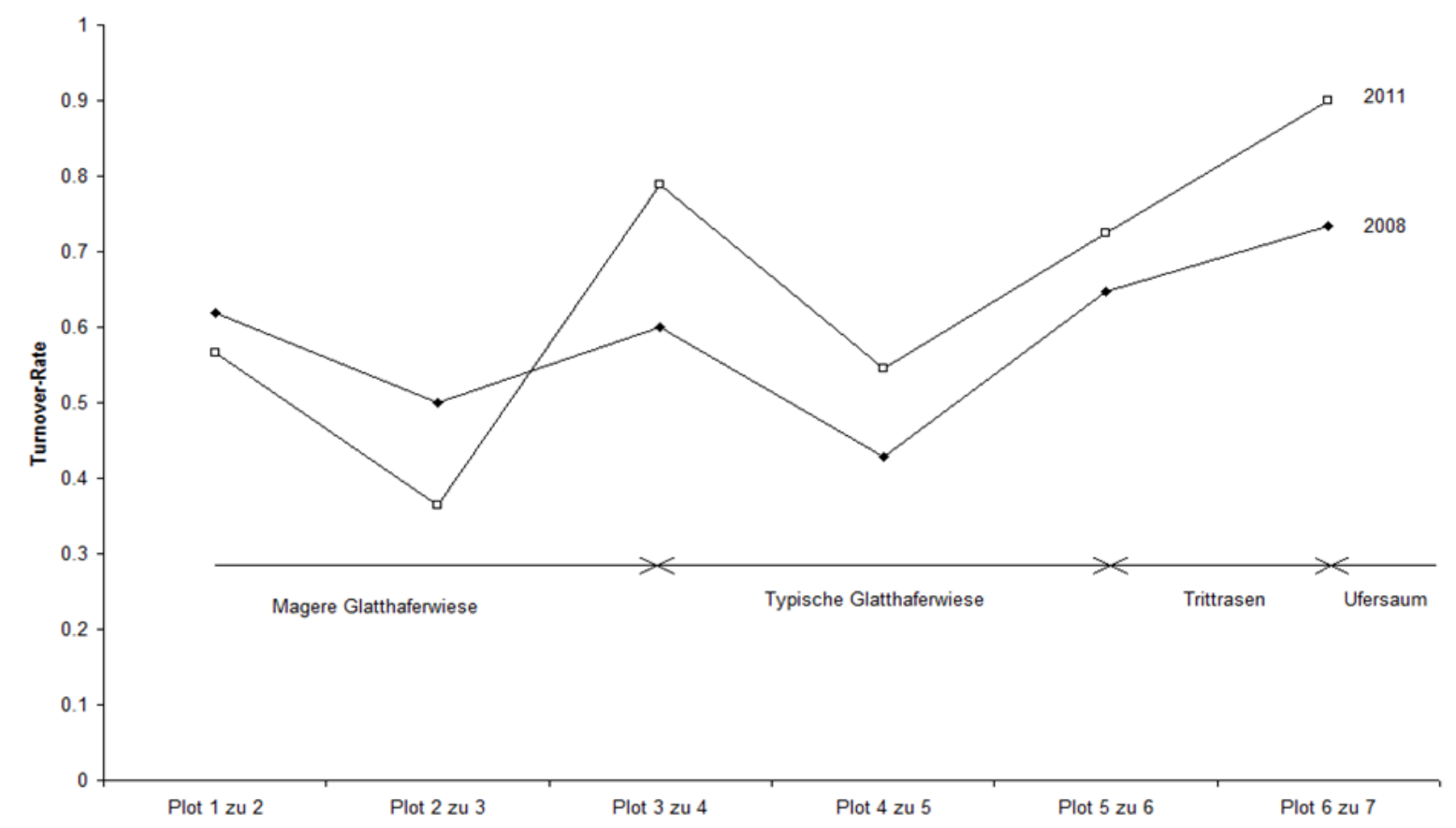

Abb. 64: Turnover-Raten $b_{t}$ zwischen den Vegetationsaufnahmen des Höhentransektes im Gradienten der differenzierbaren Vegetationstypen in den Jahren 2008-2011

Die Vergleiche beziehen sich auf benachbarte Paare (plots).

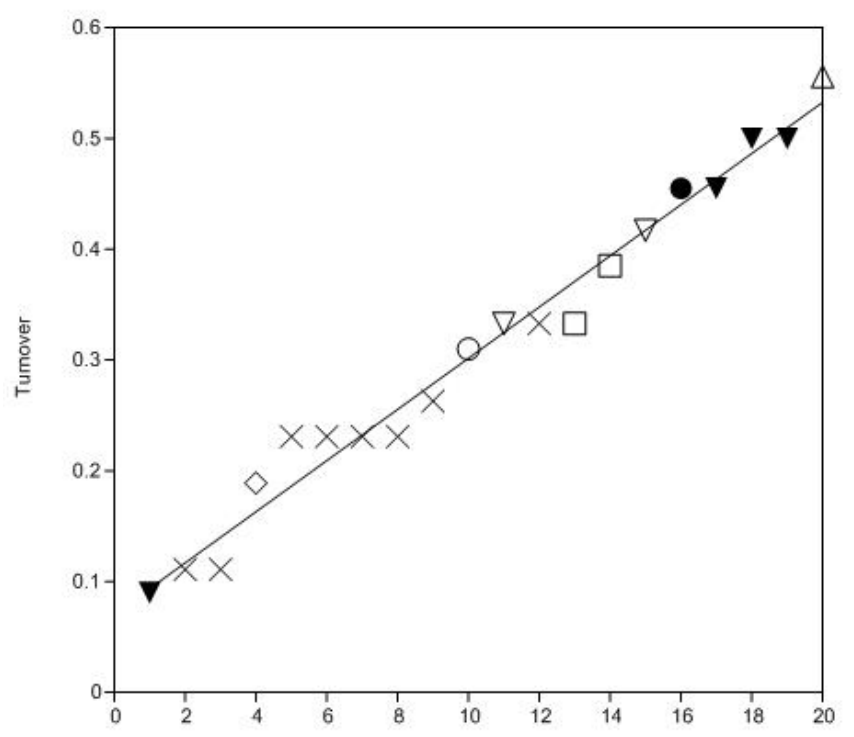

Abb. 65: Turnover-Raten $b_{t}$ der 13 Dauerflächen und 7 Plots des Höhentransektes, angeordnet nach steigender Artendynamik der Pflanzengesellschaften zwischen 2008-2011

$\times=$ Lolio-Cynosuretum typicum; $\bigcirc=$ Arrhenatheretum elatioris, ruderal; $\nabla$ = Arrh. elat., mager; $\diamond=$ Arrhenatheretalia-Basalgesellschaft; $\triangle$ = Eleocharitetum palustris; $\square=$ Ranunculetum scelerati; $\bullet$ = Fagetum nudum 


\subsubsection{Artenzusammensetzung}

In den voran gegangenen Kapiteln wurde der Frage nachgegangen, ob sich die Artendiversität unter dem Einfluss der extensiven Beweidung veränderte. Abschließend gilt es zu prüfen, in welche Richtung sich die floristische Zusammensetzung, die Gemeinschaft der Arten, entwickelte.

Die Dauerflächen zeigten zwischen den Jahren 2008 und 2011 keine signifikante Veränderung in ihrer Artenzusammensetzung ( $\mathrm{H}$-Test von Kruskal und Wallis, $\mathrm{P}<0,05)$. Möglicherweise war der Untersuchungszeitraum zu gering, um beweidungsrelevante Vegetationsveränderungen auf Artniveau nachzuweisen. Auch Weideunkräuter (Wilcoxon-Test, $n=17, p=0,169$ ) oder weideresistente Arten (Wilcoxon-Test, $n=9, p=0,066$ ) nahmen auf den Grünlandflächen nicht signifikant zu.

Gleichwohl verhielten sich die einzelnen Arten sehr unterschiedlich. Arten mit einem steten Vorkommen auf den Untersuchungsflächen wurden anhand von Diagrammen auf Tendenzen untersucht. Das weideunempfindliche Deutsche Weidelgras (Lolium perenne) nahm auf den artenarmen Typischen Fettweiden, auf denen es vermutlich im Jahr 2006 ausgesät wurde, deutlich ab und pendelte sich - wie auf älteren Typischen Fettweiden im Gebiet - bei einem Deckungsgrad von 15-20 \% ein (Abb. 66, Abb. 67). Das Wiesen-Rispengras (Poa pratensis), das dank seiner unterirdischen Rhizome Beweidung gut verträgt und die durch Tritt entstehenden Lücken durch Rasenbildung füllt, trat im Jahr 2011 auf den Typischen Fettweiden häufiger auf als zu Beginn der Untersuchung. Leicht rückläufig waren hingegen die Deckungsgrade von Phleum pratense, Festuca pratensis und Festuca rubra, die etwas weideempfindlicher sind (s. Biologische Tafel in Dierschke \& Briemle 2002).

Die drei Glatthaferwiesen wurden aufgrund ihrer Unterschiedlichkeit getrennt betrachtet. In der Rotschwingel-Magerwiesen-Gesellschaft (ARR_BAS) nahmen trittresistente Rosettenpflanzen wie Plantago lanceolata oder andere, von den Pferden verschmähte Weideunkräuter wie Ranunculus bulbosus zu. Die Acker-Kratzdistel, deren Blüten von den Exmoor-Ponys gern gefressen werden, vermehrte sich nicht. Die Weiche Trespe breitete sich im lückigen, ungepflegten Grünland aus, während die Deckung vom Rot-Schwingel rückläufig war.

Auch das Wiesen-Knäuelgras vertrug die Nutzungsänderung nicht. Auf der ehemals brachliegenden, ruderalen Glatthaferwiese (ARR_TAN) nahm die Deckung dieses hochwertigen Futtergrases unter Beweidung auf ein Drittel ab, während sich bei Weidetieren unbeliebte Pflanzen wie Tanacetum vulgare, Artemesia vulgare und Rosa rugosa ausbreiteten. Die magere Glatthaferwiese (ARR_MAG) war weniger durch Tritt und Fraß als durch die trockenen, nährstoffarmen Bedingungen geprägt. Glatthafer und Wiesen-Knäuelgras verschwanden allmählich, während anspruchslosere Gräser wie Bromus arvensis oder Luzula campestris besser mit den Bedingungen der exponierten Hanglage zurechtkamen.

Überprüft wurde ferner der Zusammenhang zwischen dem Vorkommen bestimmter Arten und den im Gebiet erfassten Vegetationsparametern. Die Deckungsgrade weideresistenter Arten waren auf den Flächen mit dem höchsten Weidedruck im Jahr 2011 signifikant höher als auf den geringer beweideten ( $\mathrm{H}$-Test von Kruskal und Wallis, $\mathrm{P}<0,05)$. Die untersuchten Dauerflächen wurden dabei gemäß ihres Beweidungsfaktors in vier Kategorien eingeteilt. Aus dem Vorkommen von Weideunkräuter resultierte jedoch nicht unmittelbar eine höhere Krautschicht im Jahr 2011 (H-Test von Kruskal und Wallis, $P>0,05)$. 


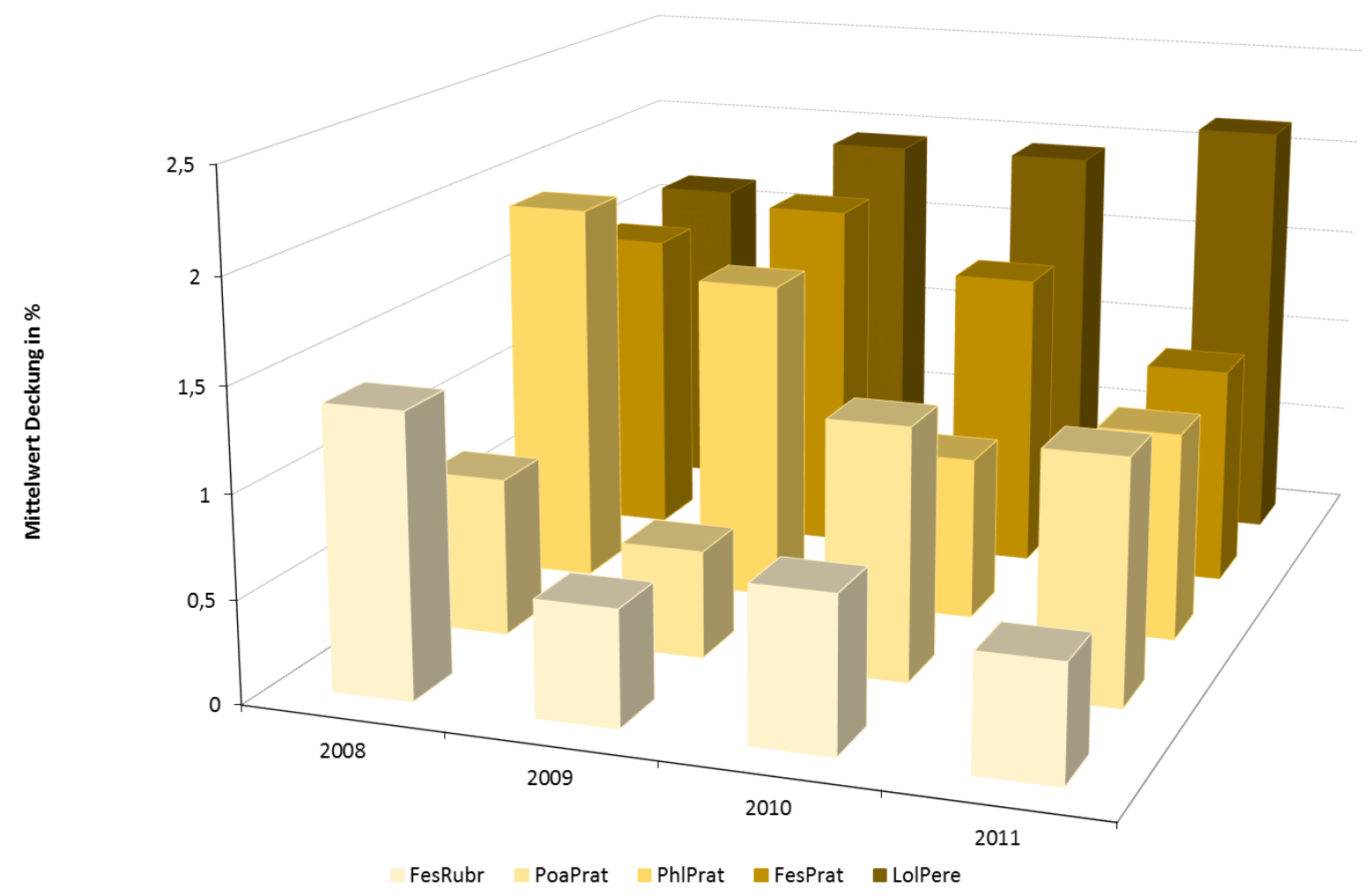

Abb. 66: Deckungsgrade wichtiger Gräser der Typischen Fettweiden (CYN_LOL, $n=4)$ zwischen den Jahren 2008-2011

Die Deckungsangaben entsprechen der Londo-Skala.

Bezeichnungen der Artnamen s. Tab. 42

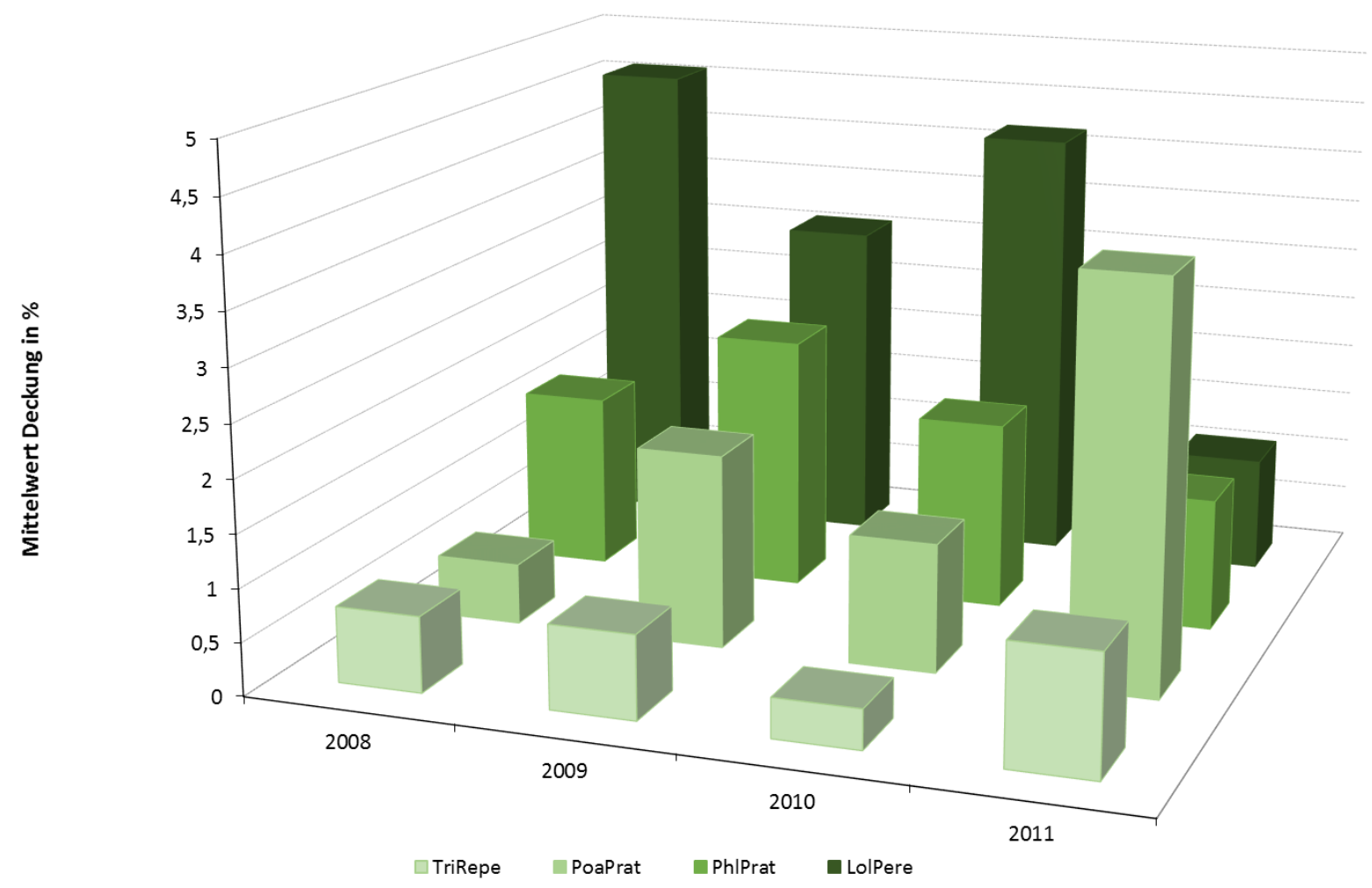

Abb. 67: Deckungsgrade wichtiger Arten der artenarmen Typischen Fettweiden (CYN_LOL arm, $n=3$ ) zwischen den Jahren 2008-2011

Die Deckungsangaben entsprechen der Londo-Skala.

Bezeichnungen der Artnamen s. Tab. 42 


\subsubsection{Entwicklung der Strukturen einzelner Lebensräume}

Die Strukturveränderungen durch Beweidung wurden auf Dauerflächen zu verschiedenen Jahreszeiten untersucht. Von den insgesamt 105 Datenaufnahmen lagen 63 auf beweideten Strukturdauer- und 42 auf unbeweideten Ausschlussflächen. Die Dauerflächen enthielten ein bis mehrere Lebensraumtypen. Die jeweiligen Flächenanteile sind in Tabelle 8 aufgelistet. Die Auswertung erfolgte getrennt nach Lebensraumtypen.

\subsubsection{Strukturparameter}

Auf den Strukturdauer- und Ausschlussflächen wurden über drei Jahre verschiedene Parameter erhoben. Die Datenreihen werden chronologisch nach Jahreszeiten oder Jahren dargestellt, um die zeitliche Entwicklung nachzuvollziehen. Für jeden Lebensraumtyp wird lediglich eine Auswahl der auf den Strukturdauerflächen gewonnenen Ergebnisse grafisch dargestellt. Alle weiteren Abbildungen sowie Datentabellen befinden sich im Anhang (Anlage 6.15 und 6.16).

\section{Frischgrünland}

Das Frisch- und Feuchtgrünland hatte mit rund 61 ha Fläche den größten Anteil im Untersuchungsgebiet (s. Tab. 28). Aufgrund der unterschiedlichen Nutzungsgeschichte ließen sich auf den Teilflächen Bestände mit artenärmeren und artenreicheren Ausprägungen unterscheiden. Auch auf den Strukturdauerflächen waren beide Ausprägungen vertreten. Aufgrund der geringen Probegröße $(n=5)$ wurden beide Biotoptypen, also das artenreiche Grünland sowie das artenarme Intensivgrünland frischer Standorte, gemeinsam ausgewertet.

Im ersten Jahr der Beweidung war ein Großteil der Grasfluren hochwüchsig mit einer ausgeprägten Streuauflage bis in die Sommermonate hinein. Ein Weideeinfluss der nur 24 Adulttiere war kaum zu erkennen. In den Folgejahren nahm der Anteil an langrasiger Vegetation sichtbar ab. Dies ging einher mit einer Zunahme mittelrasiger Vegetation, während der kurzrasige Anteil in etwa gleich blieb (Abb. 68). Die Anteile schwankten im Jahresverlauf je nach Wetter und Beweidungsintensität. In nassen Jahren waren im Sommer nur knapp $10 \%$ der Bestände kurzrasig, in trockenen Jahren hingegen über $40 \%$. Aufgrund der ganzjährigen Beweidung war der kurzrasige Anteil bei den Frühjahrserhebungen mit rund $38 \%$ am höchsten, im Sommer am geringsten.

Mit zunehmender Besatzstärke nahm auch die Vegetationshöhe der Kraut- und Streuschicht stark ab. Diese Veränderung war optisch erkennbar (Abb. 69). Im dritten Jahr bestand die Streuschicht nur noch aus niedergetrampelten Stängeln von wenigen Zentimetern Höhe. Entgegengesetzt entwickelten sich die Ausschlussflächen: Im Sommer 2010 war die Vegetation auf den Brachen durchschnittlich fast viermal so hoch wie auf den Weiden. Im Frühjahr, wenn der Beweidungsdruck nach den Wintermonaten am größten war, beweideten die Pferde auch die Randbereiche der Ausschlussflächen über den Zaun hinweg. So kam es zu einem geringen Anteil an kurzrasigen Flächen innerhalb der Ausschlussflächen. Im Allgemeinen lag dieser Anteil unter $10 \%$.

Die Streudeckung war im Frühjahr am höchsten. Über die Jahre hinweg blieb ihr Gesamtanteil mit 13$14 \%$ nahezu unverändert (Abb. 70). Eine längere Schneebedeckung oder eine ausgeprägte Trockenheit erhöhten sie vorübergehend. Ähnlich verhielten sich die Deckungsgrade von Gräsern, Kräutern und Moosen. Im Allgemeinen nahmen die Kräuter im Jahresverlauf zu und erreichten im Spätsommer ihre maximale Ausdehnung. Mit zunehmender Beweidungsintensität vergrößerte sich ihr Anteil in dieser Jahreszeit sogar leicht (2008: $13 \%$; 2009; 18,6\%; 2010: $18 \%$ ). 


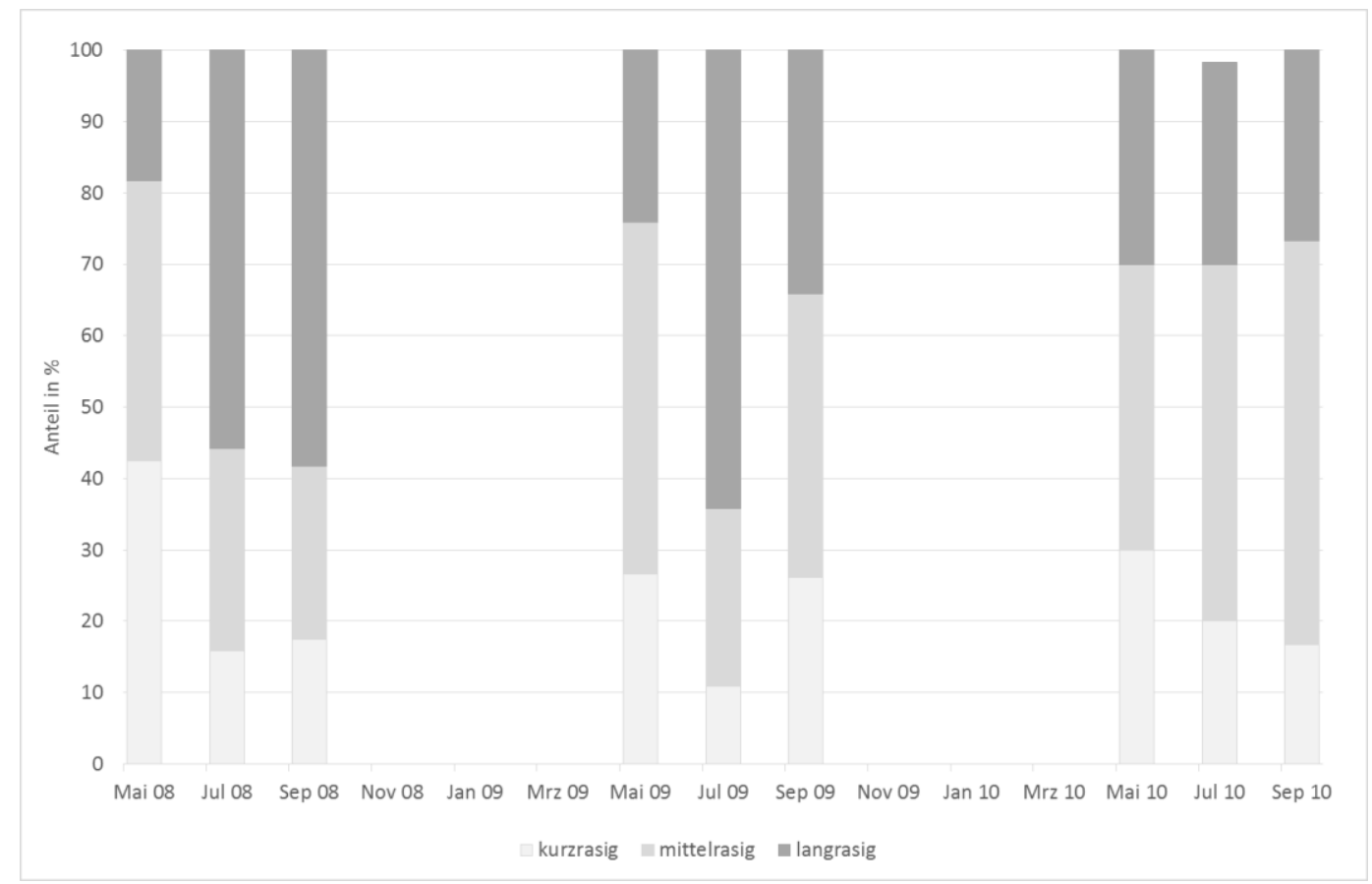

Abb. 68: Relative Anteile an kurz-, mittel- und langrasiger Vegetation im Grünland $(n=5)$

Auf den Kontrollflächen schwankten die Deckungsgrade von Streu, Erde, Gräsern und Kräutern stärker als auf den beweideten Grünlandflächen. Der Streuanteil lag durchschnittlich bei $30 \%$. Kräuter breiteten sich aus - zu Ungunsten der Gräser, deren Anteil im zweiten Brachejahr nur noch bei 37 \% lag, während sie auf den Weideflächen zwei Drittel der Fläche abdeckten.

Der Anteil offenen Bodens nahm im Untersuchungszeitraum deutlich zu. Er war abhängig von der Witterung und bei den Frühjahrserhebungen am größten: Im April 2010 erreichte er einen Anteil von $15 \%$ nach monatelanger Schneebedeckung. Die Bodenstellen wuchsen im Verlauf des Jahres mehr oder minder zu, verschwanden jedoch nie vollständig. Auf den Kontrollflächen nahm der Anteil offenen Bodens hingegen von $7 \%$ im ersten Brachejahr auf 0,7 \% im zweiten ab.

Offene Bodenstellen im Grünland lagen meist auf Weidetierpfaden. Sie entstanden auch durch Pflegemaßnahmen im Gebiet oder waren ein Überbleibsel ehemaliger Ackerbrachen. Durch den Tritt bildeten sich im Gebiet Hauptpfade, die nicht mehr zuwuchsen, da die Pferde die einmal angelegten Wege über Jahre hinweg regelmäßig nutzten. Die Tierpfade dehnten sich im Untersuchungszeitraum auch bei zunehmender Besatzdichte nicht aus, Einfluss hatte hier jedoch die Witterung: Im regenarmen Frühjahr 2008 nahmen Tierpfade nur $30 \mathrm{~m}^{2}$ Fläche ein, im nassen Frühjahr 2009 waren es $120 \mathrm{~m}^{2}$. Da vermehrte Niederschläge den Vegetationsaufwuchs in der Regel fördern, ist dies nur mit der stärkeren Schädigung der Grasnarbe bei feuchten Böden zu erklären.

Durchschnittlich machten Tierpfade 14 \% der Strukturdauerflächen im Grünland aus - ein hoher Wert. Dieser lag möglicherweise daran, dass die Ponys die Markierungspfähle gern als Kratzhilfe aufsuchten. Zudem wurden nicht nur Hauptpfade, sondern auch „grüne Pfade“ erfasst, deren Lage in Abhängigkeit von der Beweidungsintensität und der Habitatnutzung einer gewissen Dynamik unterlag und somit den überraschend hohen Flächenanteil verursacht haben kann.

Ameisenhügel und Maulwurfshügel wurden auf den Grasfluren nur sporadisch beobachtet. Eine Bewertung ihrer Zu- oder Abnahme ist daher nicht möglich. Auch auf den Ausschlussflächen war ihr Vorkommen zu gering, um eine Entwicklungstendenz erkennen zu lassen. 

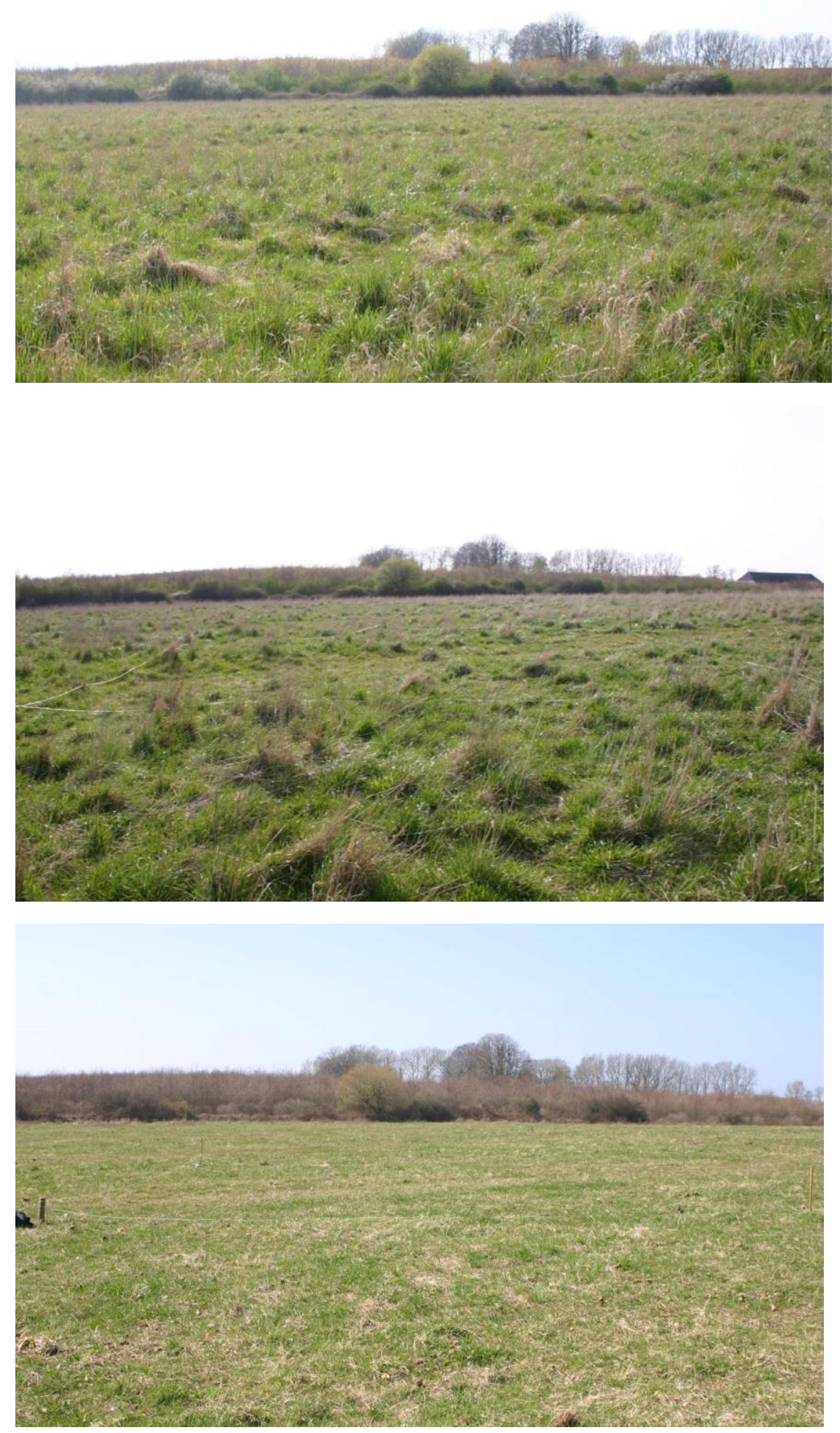

Abb. 69: Entwicklung auf der Strukturdauerfläche SDF 2 im Frischgrünland bei den Frühjahrserhebungen Ende April in den Jahren 2008 (oben), 2009 (Mitte) und 2010 (unten) 


\section{AUSWIRKUNG DER BEWEIDUNG}

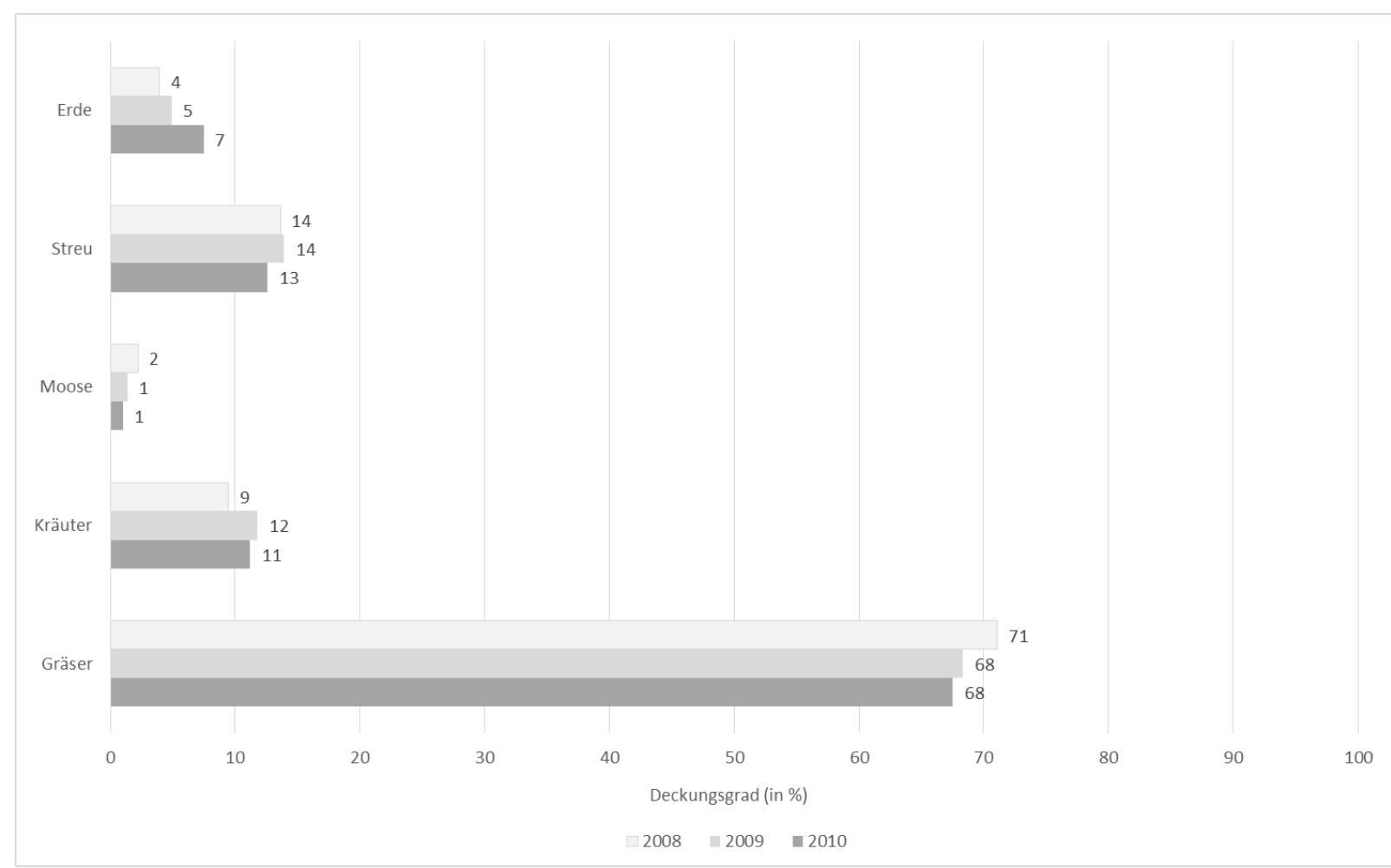

Abb. 70: Anteile von Gräsern, Kräutern, Moosen, Streu und offenen Boden an der Deckung der Krautschicht im Grünland in den Jahren 2008-2010 ( $n=5)$

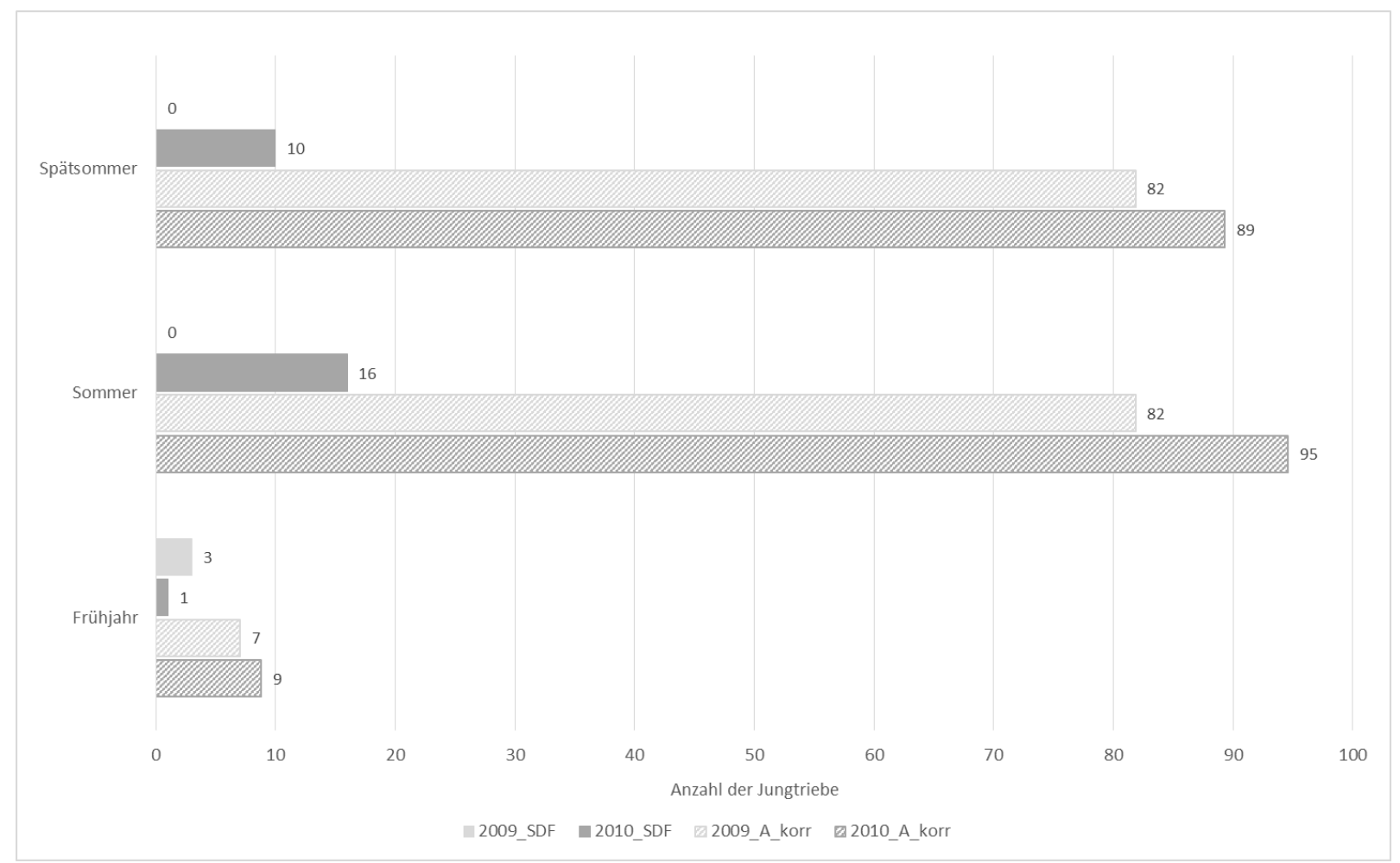

Abb. 71: Entwicklung der Verbuschung im Grünland auf Strukturdauer- (SDF) und Ausschlussflächen (A, schraffiert) im Vergleich $(n=10)$

$A_{\text {korr }}$ bedeutet, die Werte von A wurden hochgerechnet, so dass sich SDF und A flächenmäßig entsprechen 
Signifikant vermehrten sich Keimlinge und Jungpflanzen auf den unbeweideten Flächen. Zwar nahm die Verbuschung auch auf den Weideflächen im dritten Untersuchungsjahr zu. Rechnet man jedoch die Untersuchungs- und die Vergleichsfläche anteilig hoch, so war die Verbuschung auf den Brachflächen je nach Jahreszeit 6-9mal höher als auf den beweideten (Abb. 71). Daraus wird geschlussfolgert, dass die Weidetiere das Aufkeimen von Gehölzen im offenen Weideland verhindern und eine Verbuschung zurückdrängen. Je nach Standort siedelten sich Weiß- und Schwarzdorn, Schwedische Vogelbeere, Süß-Kirsche, Hunds-Rose, Hartriegel, Gemeiner Schneeball und Brombeere an.

Die Anzahl der Kothaufen war im Frühjahr am größten: Im Mai wurden auf den Dauerflächen bis zu 70 Kothaufen gezählt, im Sommer nur ein Drittel davon. Durchschnittlich waren es 32 Haufen auf $385 \mathrm{~m}^{2}$ Fläche. Hochgerechnet auf das Gesamtgebiet ergeben sich rund 50.000 Kothaufen auf $610.000 \mathrm{~m}^{2}$ Grünlandfläche (entsprechend 0,08 Kothaufen $/ \mathrm{m}^{2}$ ).

\section{Magerrasen}

Magere Grasfluren wiesen im Untersuchungsgebiet einen Flächenanteil von 3,3\% auf. Sie fanden sich auf den Hängen und Kuppen der Geländeerhebungen, häufig zwischen lückigen Gebüschbeständen gelegen. Vor der Pferdebeweidung wurden die Flächen bewirtschaftet, aufgrund der schlechten Erreichbarkeit zeigten sich aber deutliche Anzeichen von Brache und Verbuschung, die auf eine geringe Nutzung hinwiesen. Die Vegetation war relativ blütenreich. Aufgrund der Kleinflächigkeit wurde nur eine Untersuchungsfläche auf Magerrasen eingerichtet.

Manche Entwicklungen verliefen auf den mageren Grasfluren ähnlich wie im Frischgrünland, es traten jedoch auch Unterschiede auf. Der Beweidungsdruck war anfangs sehr gering und nahm nur leicht zu. Erst im dritten Jahr war die Vegetation an manchen Stellen erstmalig kurzrasig. Auch die Vegetationshöhe verringerte sich erst im zweiten Beweidungsjahr (Abb. 72), wobei sich der Magerrasen durch eine niedrigere Krautschichthöhe vom Frischgrünland unterschied. Auf den Ausschlussflächen entwickelten sich die Vegetationshöhen entgegengesetzt.

Aufgrund des trockenen Standortes war der Streuanteil auf den mageren Grasfluren höher als im Frischgrünland (Abb. 73). Die Gräser waren bereits im Spätsommer vollständig verblüht und wurden bei den Aufnahmen als Streu kartiert. Sie überragten dabei die noch blühenden Kräuter. Auf der Ausschlussfläche waren die Streuauflagen viel umfangreicher.

Die Deckung der Gräser betrug in etwa 50 \% (Abb. 74). Auch unter Weideausschluss blieb sie bei zirka $46 \%$. Kräuter deckten nur ein Viertel der Fläche ab und nahmen unter Beweidung leicht zu. Der niedrige Kräuteranteil im Sommer 2008 wurde durch das trocken-heiße Frühjahr verursacht, durch das viele Kräuter im Sommer bereits vertrocknet waren und bei der Aufnahme als Streu kartiert wurden. Der Streuanteil war daher in dieser Aufnahme höher als in den Folgejahren. Anders als im Grünland nahmen die Kräuter unter Weideausschluss nicht zu, sondern ab.

Die Deckung der Moose verringerte sich unter Beweidung von $8 \%$ auf nahezu $0 \%$. Dies ging einher mit einer Zunahme offenen Bodens bis auf 5 \% der Fläche, ein Wert, der für Magerrasen in Hanglage charakteristisch ist. Die Grünfläche entwickelte sich scheinbar langsam von einem dichten zu einem offenen Magerrasen. Auf der Brache nahm der offene Boden hingegen ab. Der hohe Wert im ersten Jahr wurde durch die Einrichtung des Weideschutzzaunes verursacht, im Folgejahr waren die umgegrabenen Flächen wieder zugewachsen.

Der Nährstoffeintrag durch Kot auf Magerrasen ist aufgrund der geringen Nutzungsintensität geringer als im Grünland. Hochgerechnet auf die Gesamtfläche waren es zirka 1.750 Kothaufen auf $35.000 \mathrm{~m}^{2}$ (entsprechend 0,05 Kothaufen $/ \mathrm{m}^{2}$ ). Ameisenhügel waren auf der Brache häufiger als auf beweideten Magerrasen. Aufgrund der geringen Probegröße kann dies aber rein standortbedingt sein und muss 
nicht mit dem Nutzungsregime zusammenhängen. Gleiches gilt für die Verbuschung, die auf der Weidefläche höher war als auf der Brache. Durch das angrenzende Gebüsch wuchsen mehr Keimlinge und Jungpflanzen auf dem Magerrasen als im Grünland. Ihr Anteil blieb - über die drei Jahre betrachtet aber in etwa gleich. Es traten Weißdorn und Hunds-Rose als Jungpflanzen auf. Im Herbst des dritten Untersuchungsjahres wurde der Gehölzbestand gerodet, um ein Zuwachsen dieses Lebensraumes zu verhindern.

\section{Ufer}

Gewässer- und Uferfluren nahmen im Projektgebiet etwa 9,5 ha ein. Das waren rund $9 \%$ der Gesamtfläche. Vor Beginn des Pferdeprojektes wurden die Uferbereiche mit Rindern beweidet oder lagen brach. Die Röhrichtbestände waren hochwüchsig, wenig strukturiert und reich an Streuauflagen, die Uferfluren der künstlich angelegten, jüngeren Tümpel hingegen meist niederwüchsig. Sie bestanden aus Kleinröhrichten, Feuchtwiesen oder Trittrasen. Uferstrukturdauerflächen wurden sowohl im Schilfröhricht als auch im Kleinröhricht angelegt. Ein Teil der Flachgewässer war stark zugewachsen oder von einem dichten Gürtel aus Schilf (Phragmites australis) umrandet, andere waren nahezu vegetationsfrei.

Die Beweidungsintensität im Uferbereich variierte je nach Jahreszeit: Die Pferde suchten die Gewässer vor allem in den warmen Monaten zum Ruhen, Trinken und Baden auf. Die erhöhte Trittbelastung führte zu einem höheren Anteil kurzrasiger Vegetation und offenen Bodenstellen. Letztere stiegen im dritten Jahr um $10 \%$ an (Abb. 75). Durchschnittlich war fast ein Drittel der Uferfläche vegetationslos. Besonders ausgeprägt war die Situation im Frühjahr 2010: Der Erdanteil betrug 50 \%. Die Herde war zu diesem Zeitpunkt größer als je zuvor. Hinzu kamen ein spät einsetzender Frühling und häufige Niederschläge, die zu einer Überflutung des Ufers führten (Abb. 77). Die Pferde förderten somit vegetationsfreie Standorte auf feuchten Böden. Unter Weideausschluss verringerten sich die vegetationsfreien Flächen deutlich (Abb. 76). Da nur im Kleinröhricht eine Vergleichsfläche eingerichtet wurde, wurden nur diese beiden Flächen miteinander und nicht mit dem Schilfröhricht verglichen.

Durch das regelmäßige Aufsuchen der Gewässer an heißen Tagen dehnten sich die Tierpfade im Sommer am stärksten aus, obwohl die Vegetation jetzt ihren maximalen Zuwachs erfuhr (ohne Abb.). Dieser Effekt trat umso stärker auf, desto wärmer es war, da die Tiere länger am Ufer verweilten. Über die drei Jahre betrachtet nahm der Anteil der Tierpfade aber nur geringfügig zu, da sich die Flächen bei geringerer Nutzungsintensität regenerierten.

Am auffälligsten waren der Rückgang der mittleren Vegetationshöhe und der Streuschicht der Röhrichte und Kleinröhrichte (Abb. 78). Auf der Uferbrache wuchs die Vegetation höher als an den beweideten Ufern, der Streuanteil nahm zu. Die Tiere fraßen die Ufervegetation meist erst später im Jahr im Herbst oder Winter, wenn die Weiden abgegrast waren. Daher war die Vegetation auf der beweideten Uferfläche im Frühjahr und Spätsommer niedriger als auf der Ausschlussfläche, während sich beide Flächen bei der Sommererhebung kaum unterschieden.

Das Vorkommen von Gräsern und Kräutern variierte im Jahresverlauf. Insgesamt war es aufgrund zunehmender vegetationsfreier Stellen leicht rückläufig (Abb. 79). Moose traten nur selten auf, ihre Deckung war weitgehend konstant. 


\section{AUSWIRKUNG DER BEWEIDUNG}
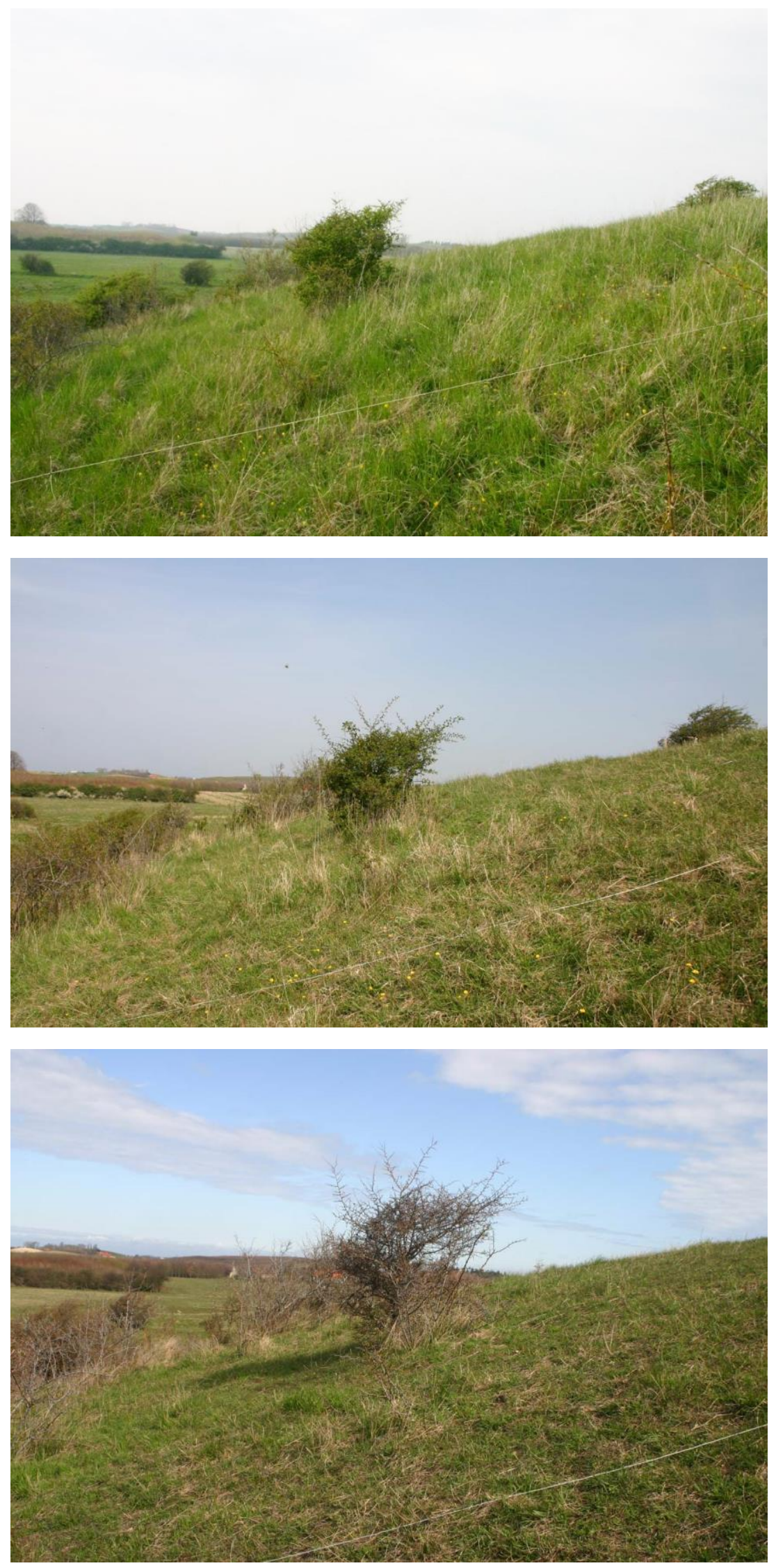

Abb. 72: Entwicklung auf der Strukturdauerfläche SDF 7 auf Magerrasen bei den Frühjahrserhebungen Ende April in den Jahren 2008 (oben), 2009 (Mitte) und 2010 (unten) 


\section{AUSWIRKUNG DER BEWEIDUNG}

60

70

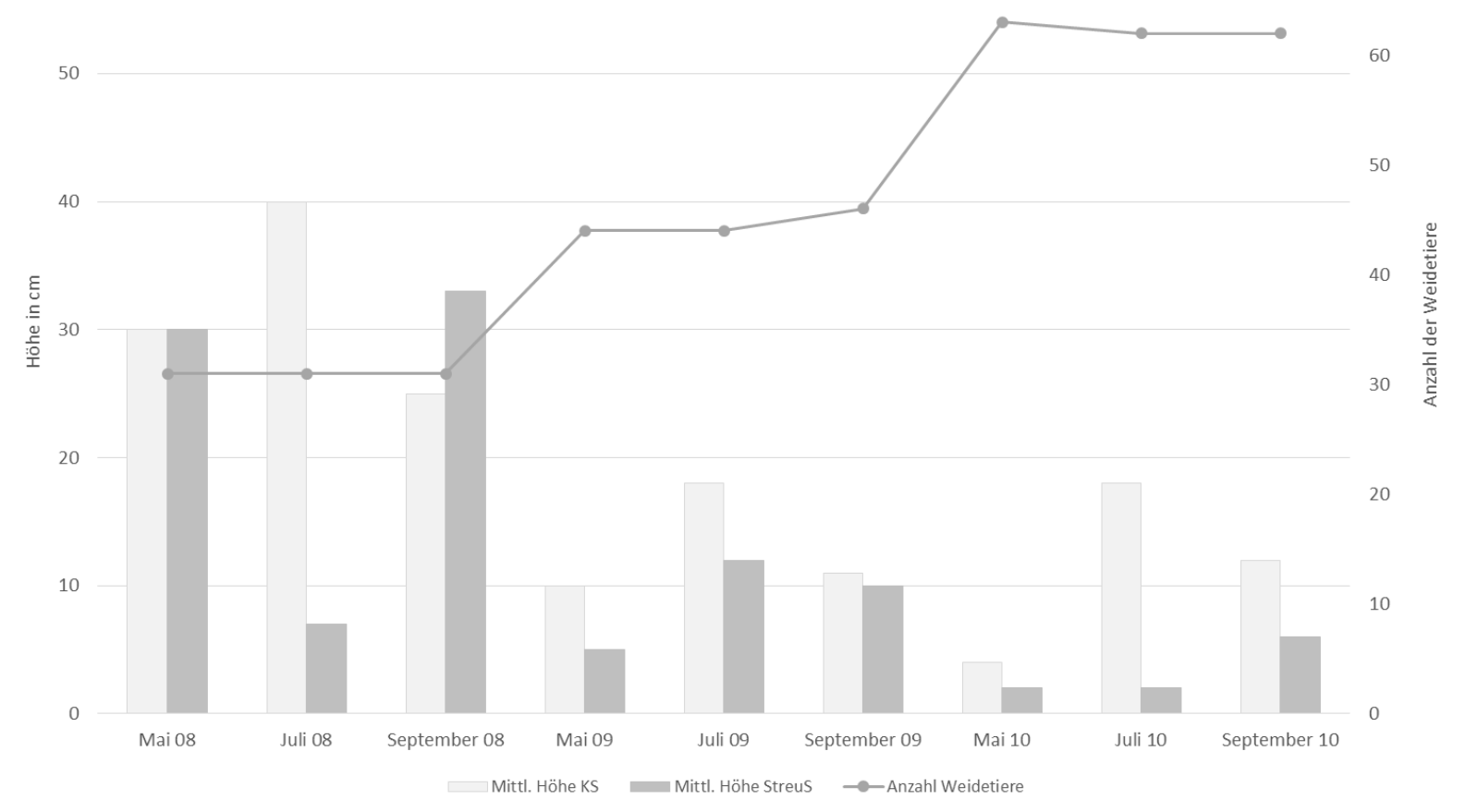

Abb. 73: Entwicklung der mittleren Höhe der Kraut- und Streuschicht bei zunehmender Besatzstärke auf Magerrasen $(n=1)$

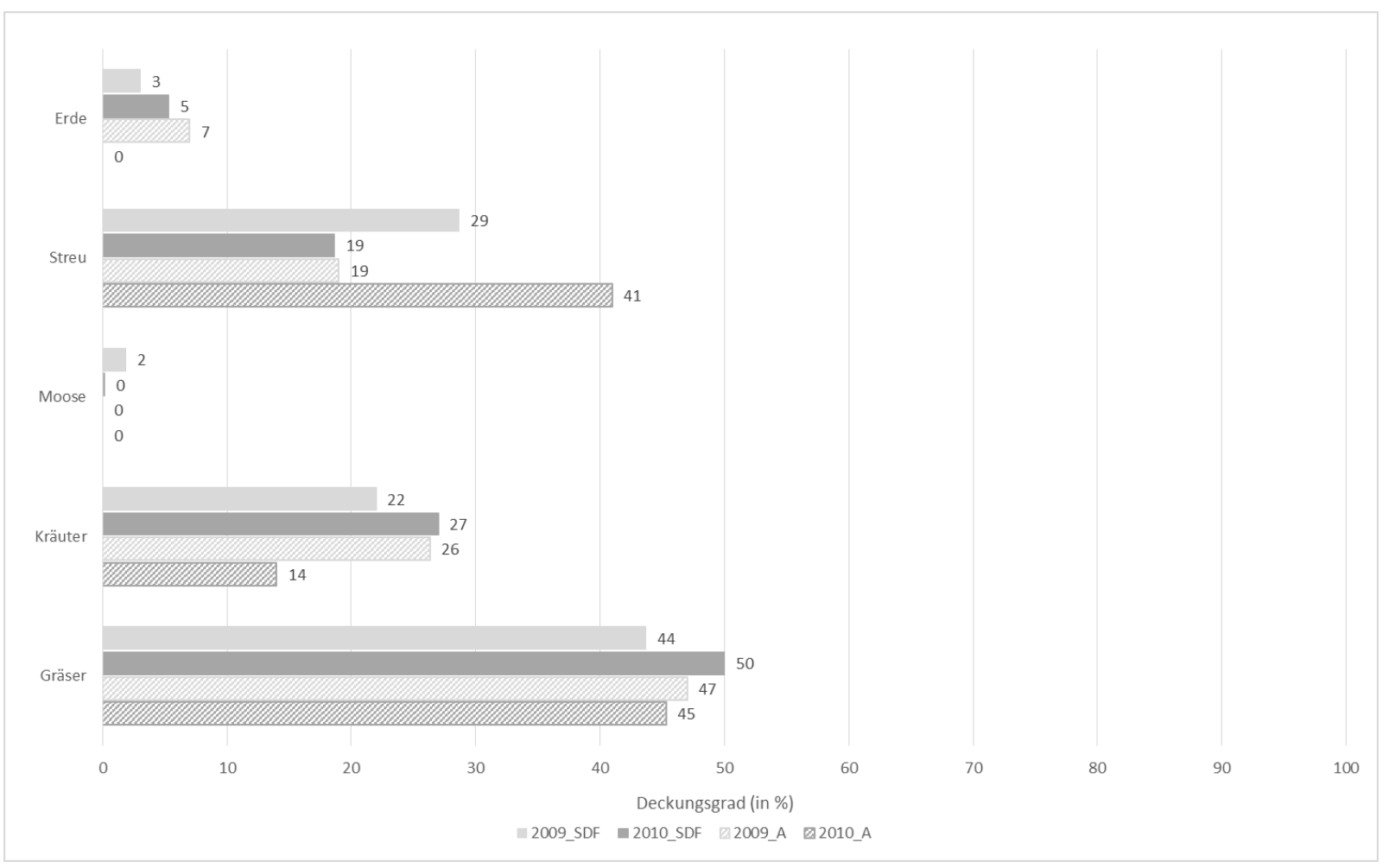

Abb. 74: Anteile von Gräsern, Kräutern, Moosen, Streu und offenen Boden an der Deckung der Krautschicht auf Magerrasen auf Strukturdauer- (SDF) und Ausschlussflächen ( $A$, schraffiert) $(n=2)$ 


\section{AUSWIRKUNG DER BEWEIDUNG}

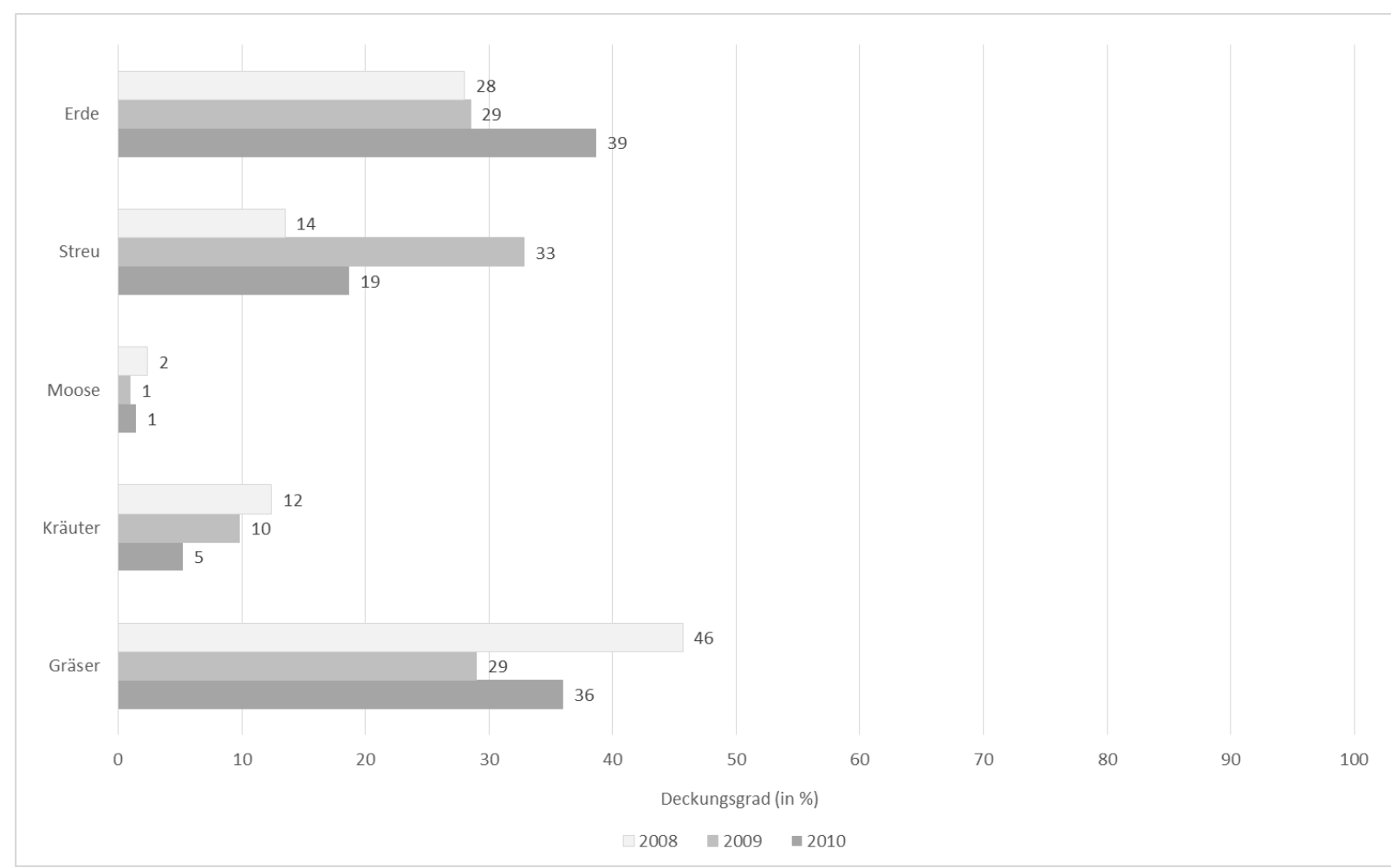

Abb. 75: Anteile von Gräsern, Kräutern, Moosen, Streu und offenen Boden an der Deckung der Krautschicht im Uferbereich $(n=2)$

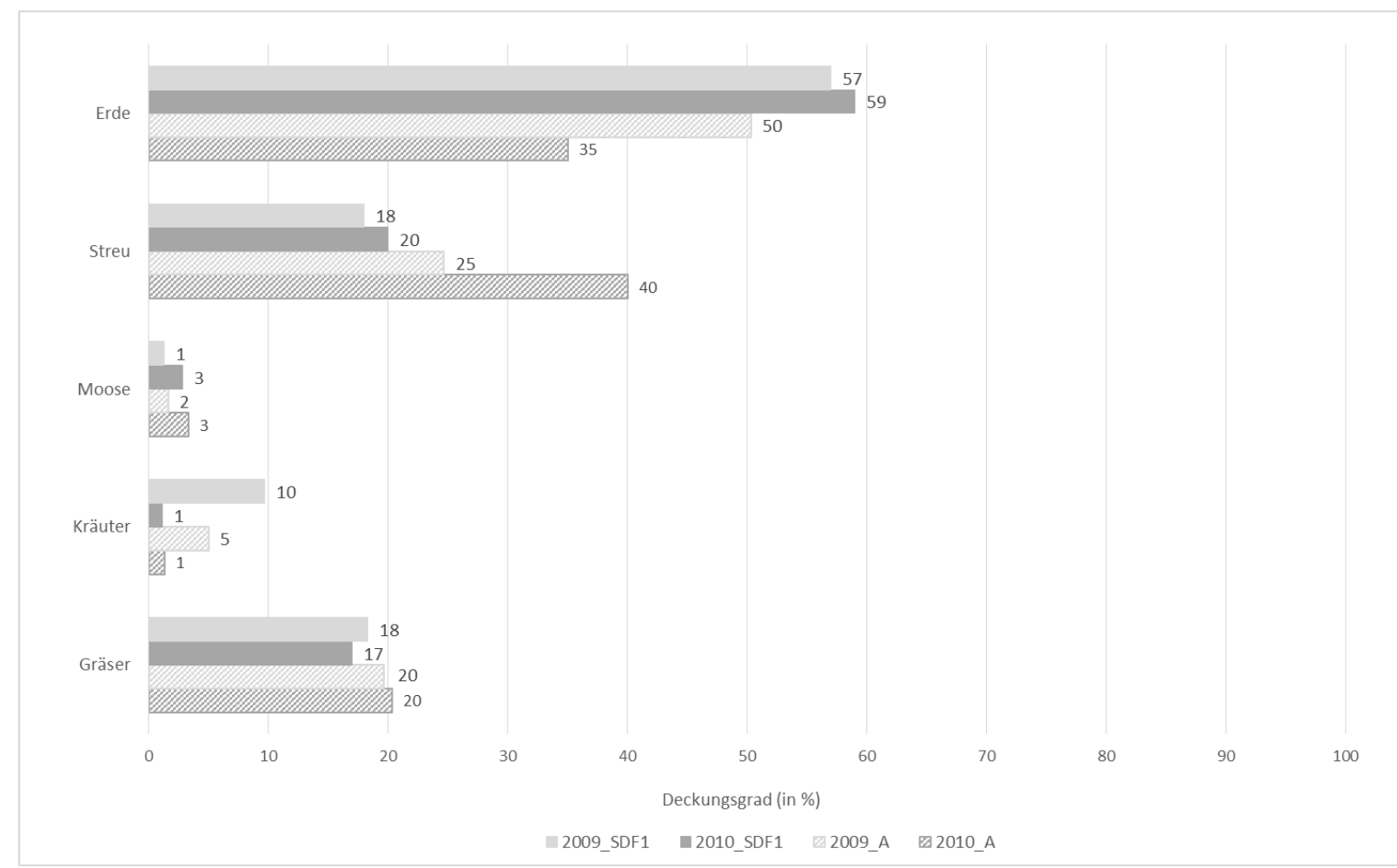

Abb. 76: Anteile von Gräsern, Kräutern, Moosen, Streu und offenen Boden an der Deckung der Krautschicht im Uferbereich auf der Strukturdauerfläche (SDF) und ihrer Vergleichsfläche (A, schraffiert) $(n=2)$ 

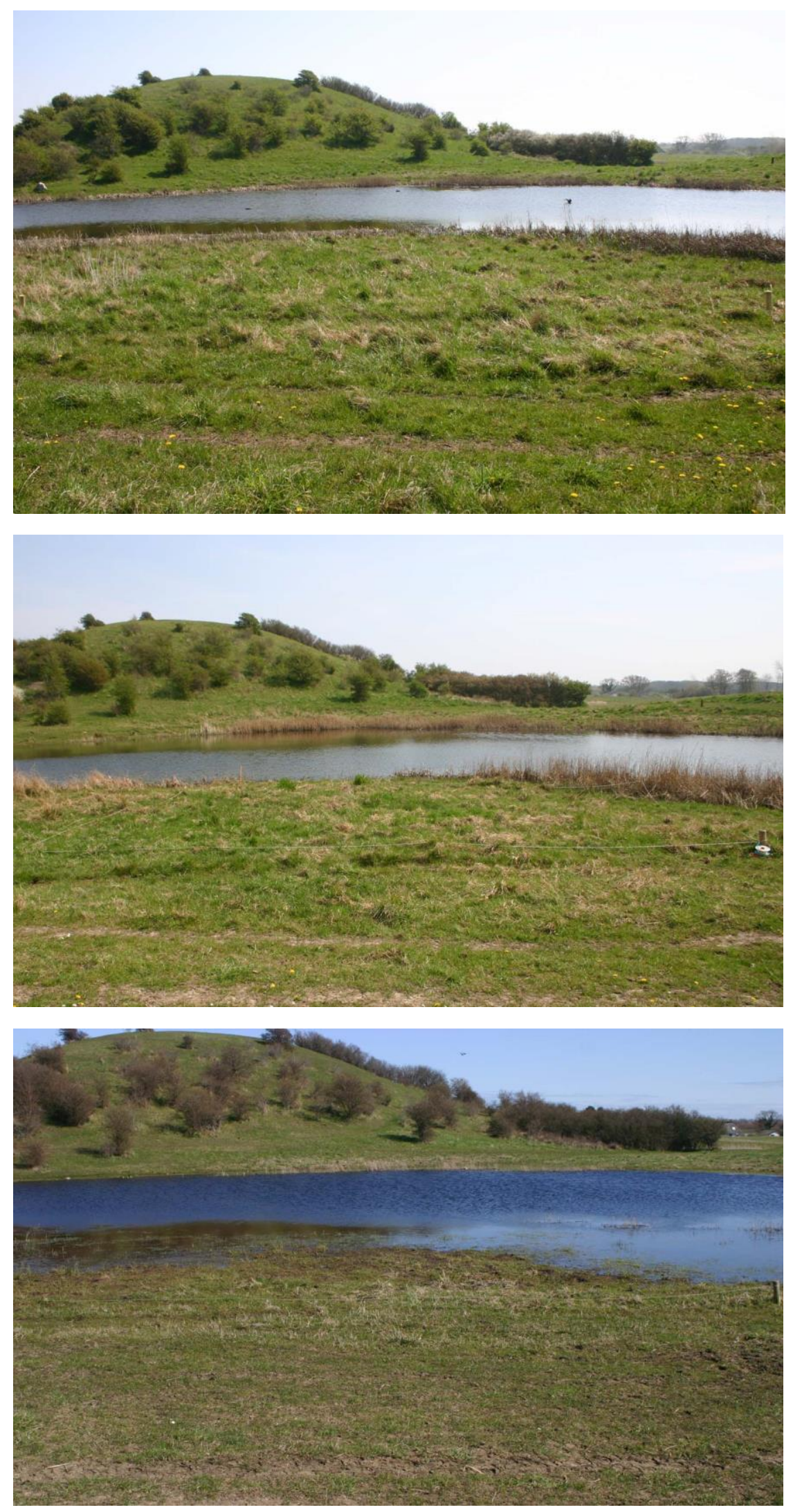

Abb. 77: Entwicklung auf der Strukturdauerfläche SDF 6 im Uferbereich bei den Frühjahrserhebungen Ende April in den Jahren 2008 (oben), 2009 (Mitte) und 2010 (unten)

Der Uferbereich stand im Jahr 2010 vollständig unter Wasser. 


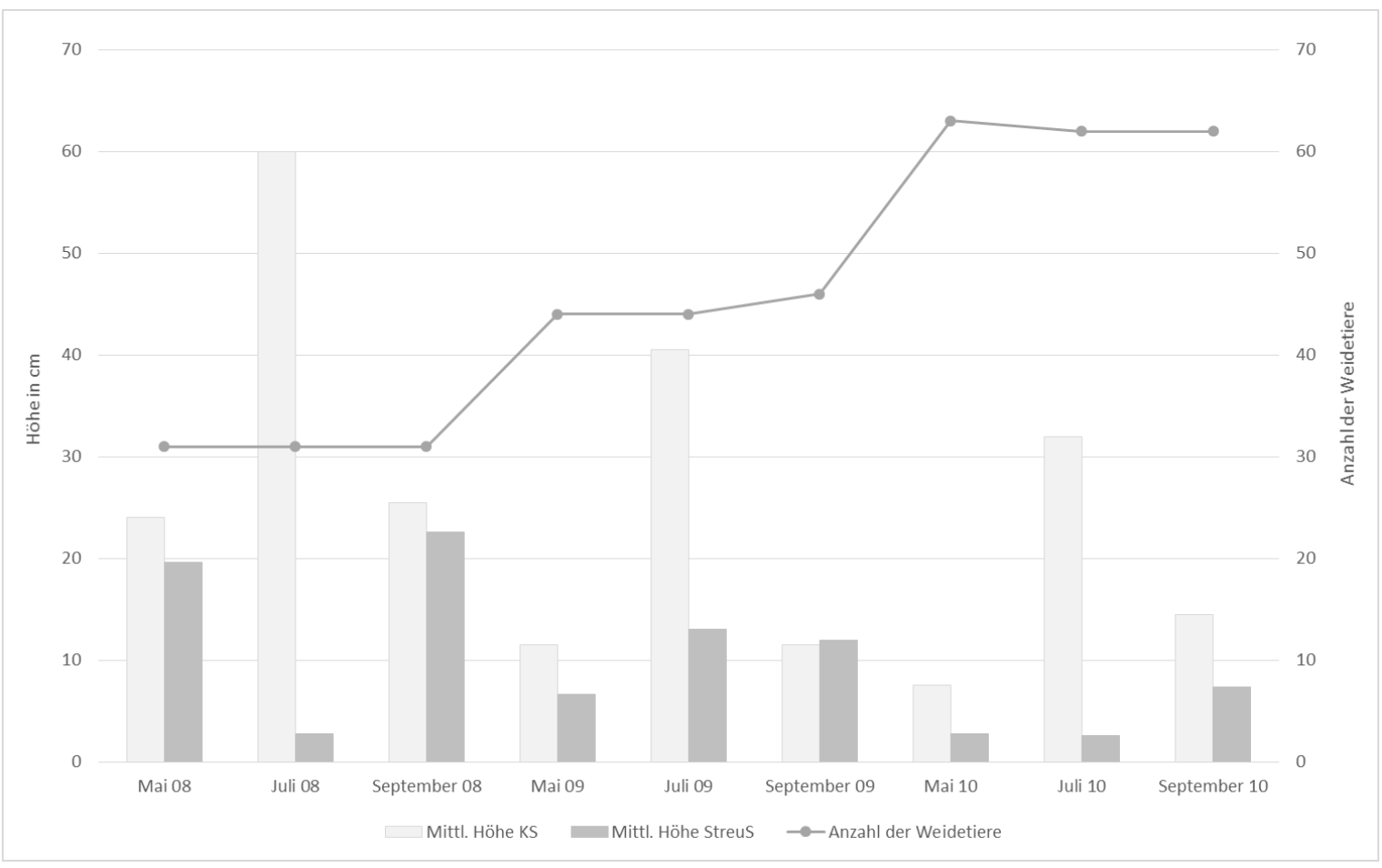

Abb. 78: Entwicklung der mittleren Kraut- und Streuschichthöhe bei zunehmender Besatzstärke im Uferbereich $(n=2)$

Der Nährstoffeintrag durch Pferde war im Uferbereich sehr gering, da hier in der Regel kein Kot abgesetzt wurde. Anders verhielt es sich mit Graugänsen, die bestimmte Uferabschnitte stark verkoteten. Maulwurfs- und Ameisenhügel sowie Gehölzjungwuchs traten in diesem Lebensraum nicht oder kaum auf. Auch am Ufer war die Verbuschung auf der Brache stärker ausgeprägt als auf beweideten Flächen. Der fehlende Tritt bot Gehölzkeimlingen eine bessere Ansiedlungsmöglichkeit. Es wurden Keimlinge von Prunus avium und $P$. spinosa kartiert, die aus dem benachbarten Knicks einwanderten.

\section{Wälder und Gebüsche}

Gehölze und Waldsaum waren auf Süd-Langeland mit 28,5 Hektar vertreten. Dazu zählten sowohl geschlossene Laub- und Nadelwaldforste als auch Gebüsche, Hecken und kleinere Feldgehölze. Aufgrund des dichten Baumbestandes war die Strauch- und Krautschicht in den Wäldern nur spärlich ausgebildet, was sich zum Teil ab Herbst 2008 aufgrund der Waldkorridore änderte.

Die Weidetiere hatten kaum Einfluss auf das Gehölz. Weder im Gebüsch noch im Laubwaldforst traten erkennbare Veränderungen auf. Die beiden Biotope unterschieden sich zwar hinsichtlich ihrer Deckungsgrade und Vegetationshöhen voneinander, nicht aber bezüglich ihrer geringen Attraktivität für Pferde. Durchschnittlich $75 \%$ der Krautschicht zeigten keine Spuren von Tritt oder Fraß. Beim verbleibenden Anteil mittel- bis kurzrasiger Vegetation war eine genaue Zuordnung zu Pferden oder Rehen nicht immer möglich. Für eine geringe Nutzung der beiden Habitattypen spricht auch, dass der Streuanteil im Untersuchungszeitraum zunahm (Abb. 79). Die Schwankungen von offener Erde und Gräsern sind maßgeblich durch die Zunahme von Streuauflagen begründet, nicht durch eine Weidewirkung.

Aufgrund des geringen Weidedrucks waren die Unterschiede zwischen der Weide- und Ausschlussfläche gering (Abb. 80). Die Vegetationshöhen waren auf der Brache etwas höher. Der anfangs erhöhte Anteil offenen Bodens auf der Waldbrache war auf die Errichtung des Schutzzaunes zurückzuführen. Ameisen- und Maulwurfshügel traten nur sporadisch auf und ließen keinen Entwicklungstrend erkennen. Auch der Nährstoffeintrag durch Kot war gering und unabhängig von Besatzstärke oder Beweidungsdauer. 


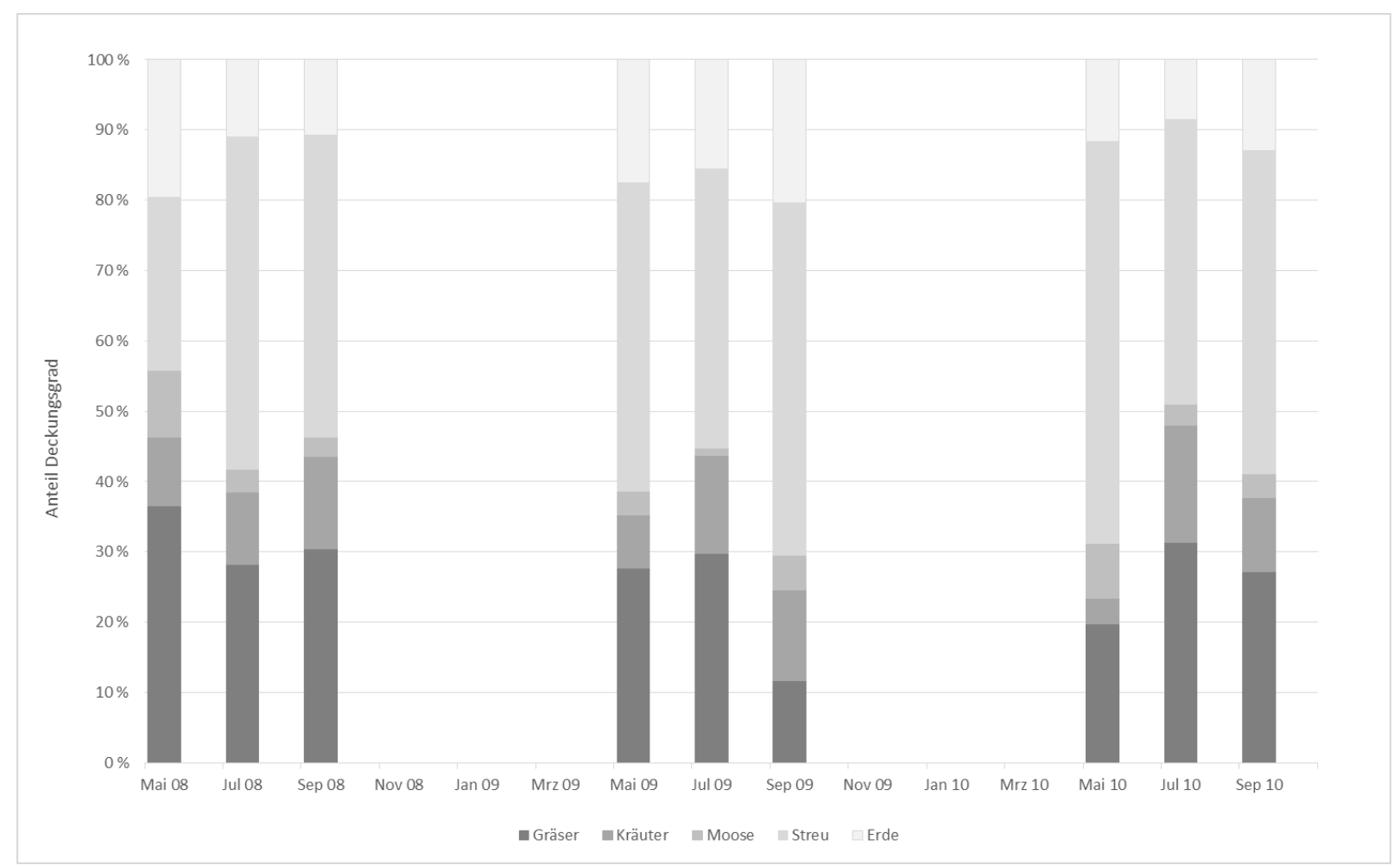

Abb. 79: Relative Anteile von Gräsern, Kräutern, Moosen, Streu und offenen Boden an der Deckung der Krautschicht im Wald, dargestellt im zeitlichen Verlauf $(n=2)$

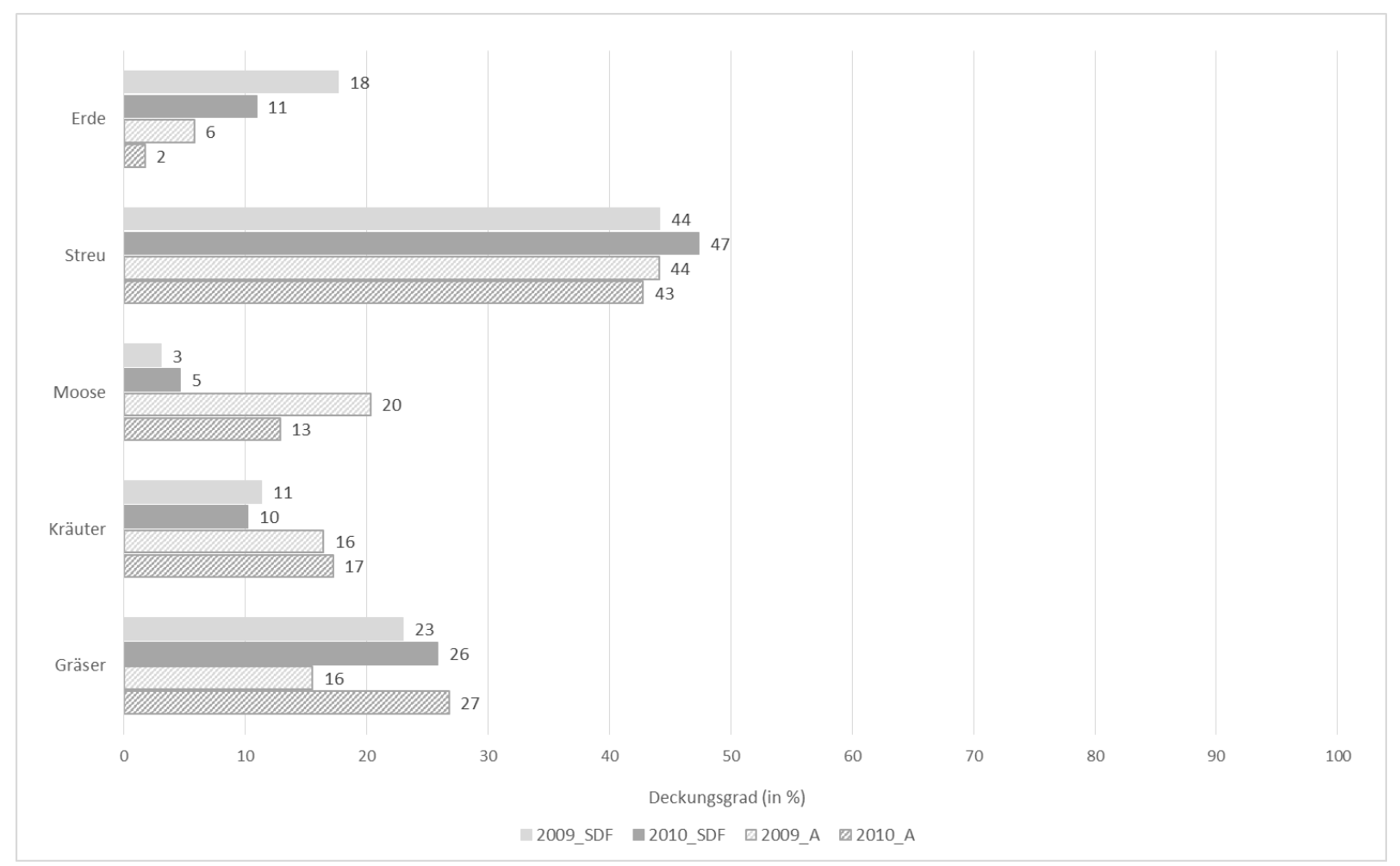

Abb. 80: Anteile von Gräsern, Kräutern, Moosen, Streu und offenen Boden an der Deckung der Krautschicht im Wald auf Strukturdauer-(SDF) und Ausschlussflächen ( $A$, schraffiert) $(n=3)$ 


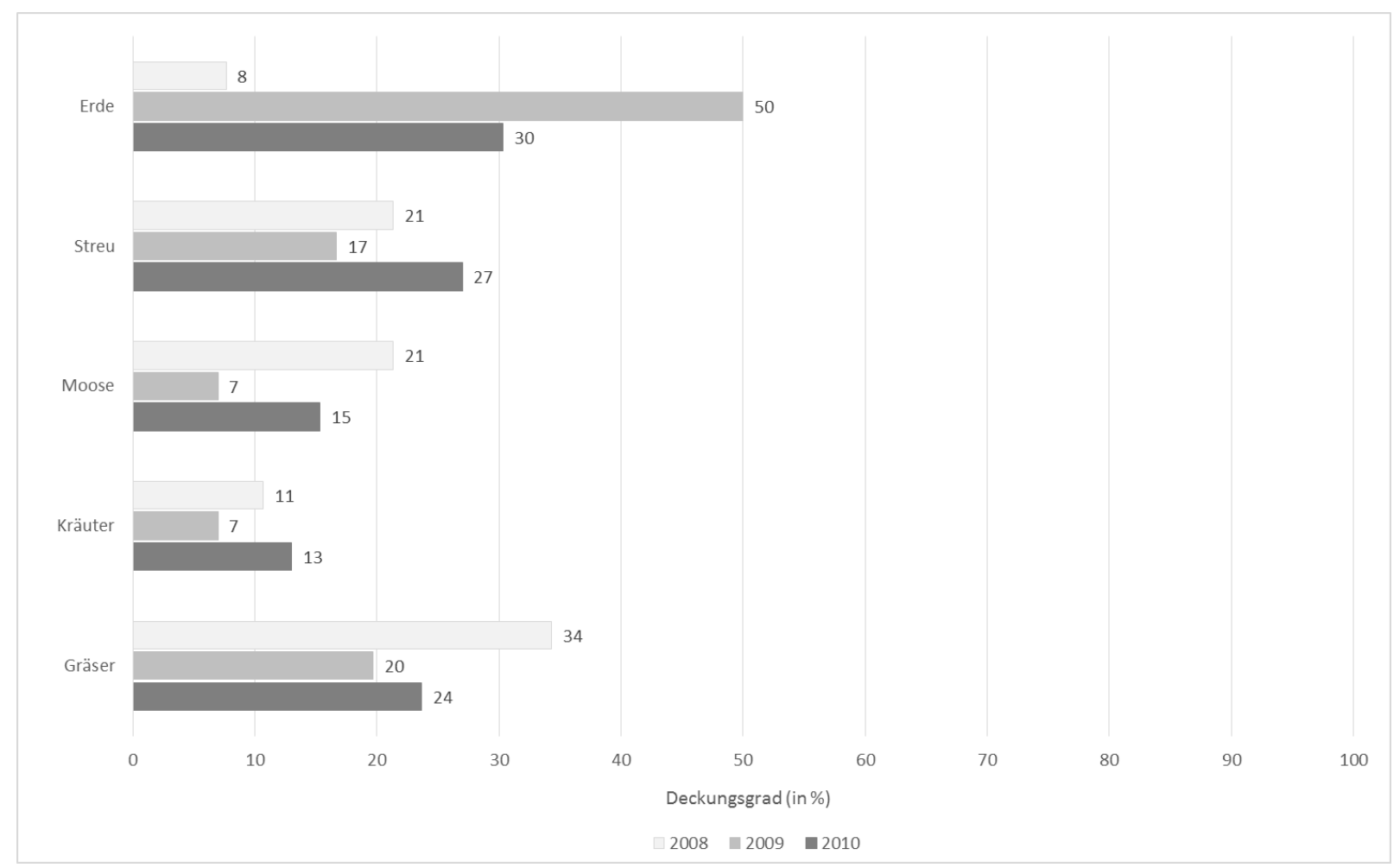

Abb. 81: Anteile von Gräsern, Kräutern, Moosen, Streu und offenen Boden an der Deckung der Krautschicht auf dem Waldweg $(n=1)$

Die Ausdehnung der Tierpfade auf den Walddauerflächen blieb weitestgehend unverändert gering. Eine genauere Betrachtung des durch die Laubwald-Dauerfläche verlaufenden, zirka 1,50 m breiten Waldweges zeigt, dass die Beweidungs- und Trittintensität in etwa gleich blieb, da die Tiere nicht den gesamten Waldweg, sondern nur den mittig verlaufenen Pfad nutzten. Dessen Fläche dehnte sich nur geringfügig aus. Der Pfad selbst wurde durch die Trittbelastung jedoch weitestgehend vegetationsfrei. Dies verdeutlicht der sprunghafte Anstieg des Erdanteils auf 50 \% im zweiten Jahr. Der Anteil offenen Bodens nahm also auch in diesem Biotoptyp mit zunehmender Beweidungsdauer und Besatzstärke zu (Abb. 81). Dies ging einher mit einem leicht rückläufigen Anteil von Gräsern und Moosen auf der Gesamtfläche. Die Anzahl der Ameisenhügel und Kothaufen auf dem Waldweg blieb unter Beweidung unverändert.

\subsubsection{Ordination der Strukturerhebungen}

Die Ergebnisse der Hauptkomponentenanalyse (PCA) verdeutlichen die Entwicklung der Lebensräume unter Beweidung. In der PCA wurden die sieben Strukturparameter Vegetationshöhe, Anteil offener Boden, Deckung von Gras, Kräuter, Moos und Streu sowie Nährstoffeintrag durch Pferdedung der Strukturerhebungen von 2008-2010 berücksichtigt. Die Auswertung erfolgte getrennt nach Jahreszeiten und Lebensräumen für eine bessere Übersichtlichkeit und Homogenität der Datensätze.

Die Lebensräume unterschieden sich hinsichtlich ihrer Struktureigenschaften deutlich voneinander. Gut erkennbar ist die Trennung zwischen Wald und Offenlandhabitaten (Abb. 82, Abb. 83, Abb. 84). Die Buchen und Eichenforsten sowie der Waldweg finden sich im linken Teil des Ordinationsdiagrammes, während die Lebensräume des offenen Weidelandes weiter rechts angesiedelt sind. Ihnen ge- 
meinsam waren relativ hohe Deckungsgrade von Kräutern und Gräsern bei gleichzeitig geringer Streuauflage und einem geringen Anteil an offenem Boden. Auch die Gebüsche sind hier zu finden. Durch ihre Lage am Waldrand oder als kleine Einheiten im Grünland wiesen sie in ihrer Struktur mehr Ähnlichkeit zum Grünland und Magerrasen auf als zum geschlossenen Wald. Am äußeren rechten Rand liegt die Ackerbrache als sehr artenarmes Frischgrünland.

Die Aufspannung der Lebensraumtypen im Diagramm ist im ersten Untersuchungsjahr kleiner als in den Folgejahren. Die Beweidung führte also bereits im zweiten Untersuchungsjahr zu deutlichen Unterschieden hinsichtlich der Strukturentwicklung in den einzelnen Lebensraumtypen. Dabei entwickelten sich die Flächen in unterschiedliche Richtungen beziehungsweise mit unterschiedlichen Geschwindigkeiten. Die Frühjahrserhebungen ließen eine größere Strukturdynamik erkennen als andere Jahreszeiten, auch wenn die Entwicklungsrichtung in fast allen Lebensraumtypen recht einheitlich war und eine Abnahme der Vegetationshöhe bei gleichzeitiger Zunahme an offenen Bodenstellen anzeigte. Bedingt dadurch waren die Deckungen von Gräsern und Kräutern etwas rückläufig. Die größten Schwankungen zeigten dabei die Uferfluren. Die Zunahme der Besatzstärke wirkte sich als entscheidender Umweltfaktor bei der Strukturentwicklung aus.

Während im Frühjahr gerichtete Entwicklungen vorherrschten, waren im Sommer und Spätsommer vor allem zyklische oder regressive Entwicklungen erkennbar. Das dritte Untersuchungsjahr hatte eine größere Ähnlichkeit mit dem ersten. Ein Einfluss von Niederschlagsmengen oder Umwelttemperaturen auf die Entwicklung der Strukturen konnte dabei nicht festgestellt werden.

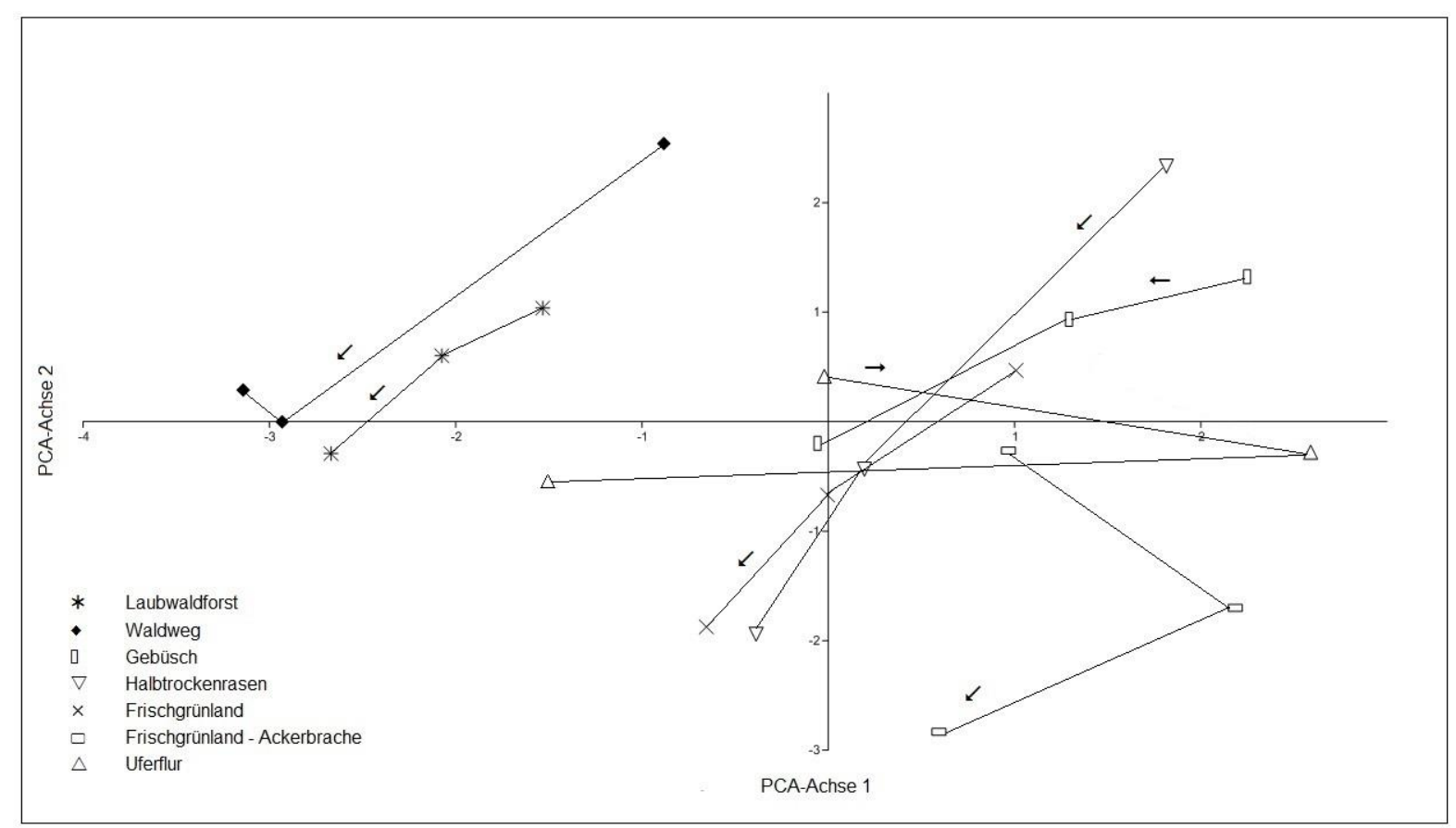

Abb. 82: Hauptkomponentenanalyse des Frühjahraspektes von 7 Strukturparametern in 7 Lebensraumtypen

Daten von 7 Strukturdauerflächen gemittelt für jedes Erhebungsjahr (2008-2010), die Pfeile zeigen die Entwicklungsrichtung an. Strukturparameter: Vegetationshöhe, Anteil offener Boden, Deckung von Gräsern, Kräutern, Moos und Streu sowie Nährstoffeintrag durch Pferdedung.

Erklärte Varianz der 1. Achse 42,4 \%, Eigenwert 2,97; Varianz der 2. Achse 26,3 \%, Eigenwert 1,84. 


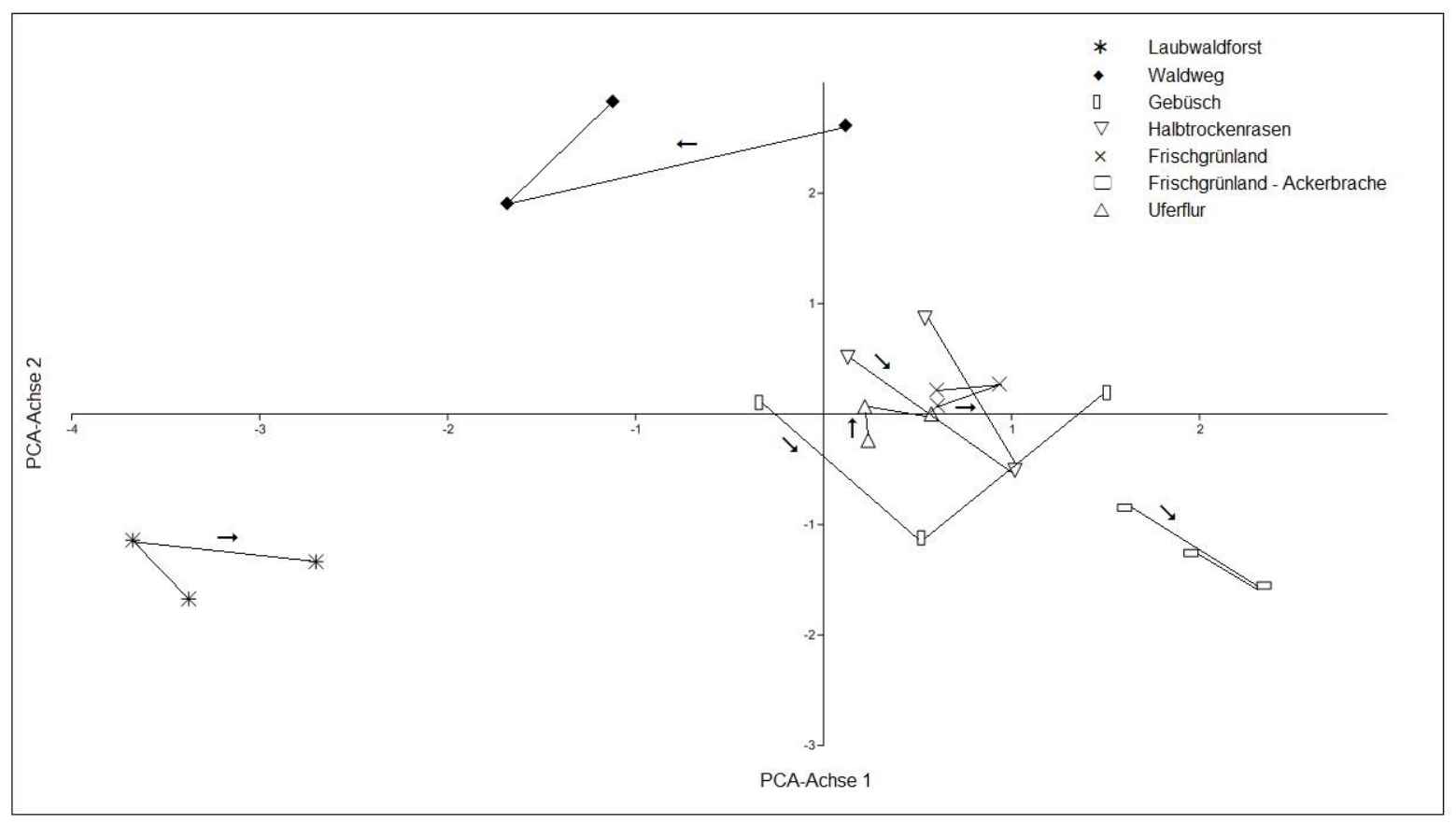

Abb. 83: Hauptkomponentenanalyse des Sommeraspektes von 7 Strukturparametern in 7 Lebensraumtypen

Daten von 7 Strukturdauerflächen gemittelt für jedes Erhebungsjahr (2008-2010), die Pfeile zeigen die Entwicklungsrichtung an. Strukturparameter: Vegetationshöhe, Anteil offener Boden, Deckung von Gräsern, Kräutern, Moos und Streu sowie Nährstoffeintrag durch Pferdedung.

Erklärte Varianz der 1. Achse 38,7 \%, Eigenwert 2,71; Varianz der 2. Achse 22,8 \%, Eigenwert 1,59.

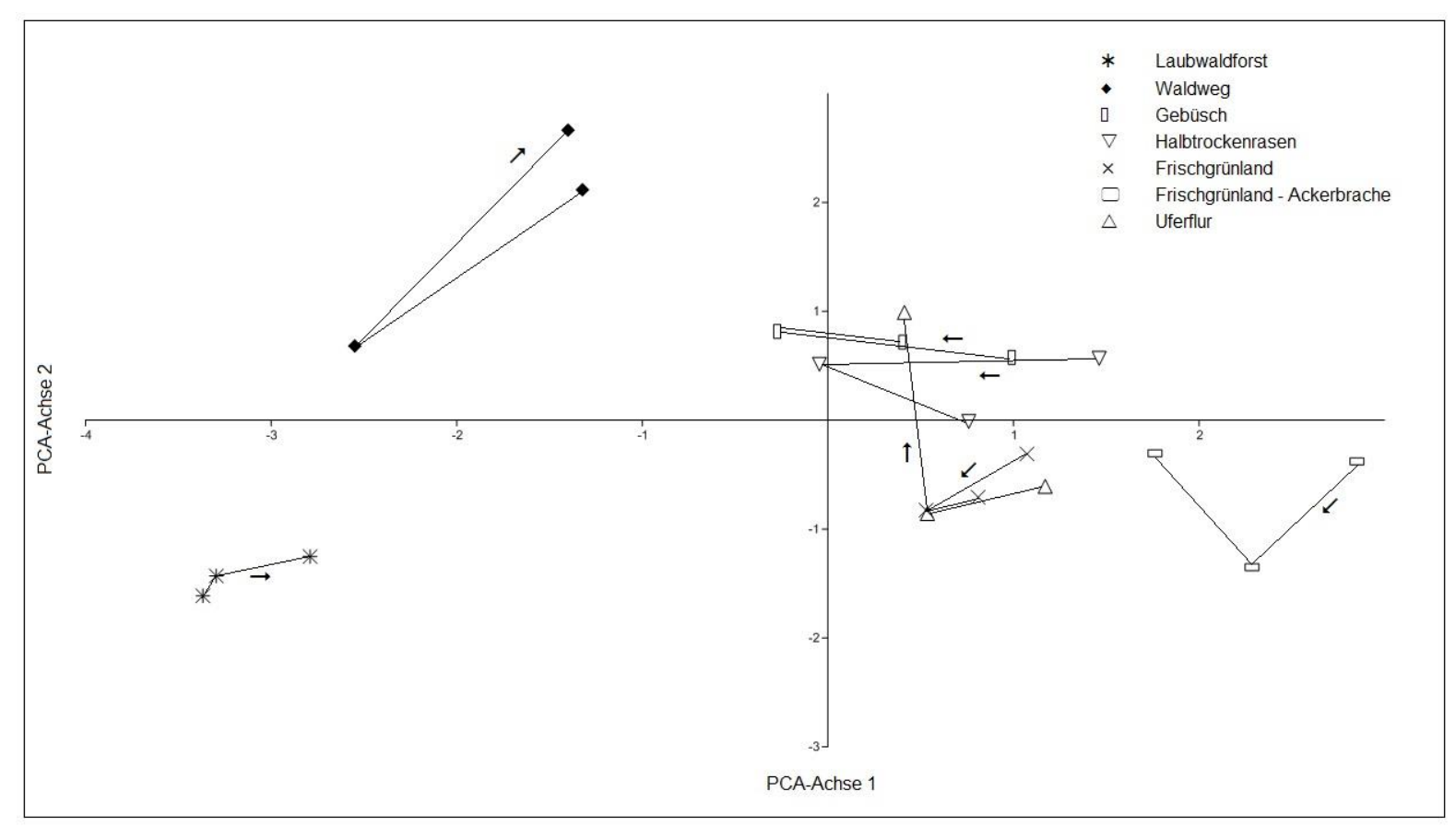

Abb. 84: Hauptkomponentenanalyse des Spätsommeraspektes von 7 Strukturparametern in 7 Lebensraumtypen

Daten von 7 Strukturdauerflächen gemittelt für jedes Erhebungsjahr (2008-2010), die Pfeile zeigen die Entwicklungsrichtung an. Strukturparameter: Vegetationshöhe, Anteil offener Boden, Deckung von Gräsern, Kräutern, Moos und Streu sowie Nährstoffeintrag durch Pferdedung.

Erklärte Varianz der 1. Achse 46,1 \%, Eigenwert 3,23; Varianz der 2. Achse 18,4 \%, Eigenwert 1,29. 



\section{DISKUSSION}

Zusammenfassende Bewertung und Empfehlungen für vergleichbare Beweidungsprojekte

An der Südspitze Langelands wurden Exmoor-Ponys angesiedelt, um die offene Kulturlandschaft zu erhalten und wertvollen Lebensraum für gefährdete Arten der heimischen Flora und Fauna zu schaffen. Die Erwartungen an die Weidetiere waren hoch: Sie sollten die drohende Verbuschung durch Weißdorn, Schlehe und Brombeere zurückdrängen, den Forst auflichten, die Artenvielfalt auf den ehemals intensiv genutzten Grünländern erhöhen, eine strukturreiche Landschaft mit Nischen für seltene, konkurrenzschwache Arten schaffen und auch noch als Publikumsmagnet des regionalen Tourismus dienen.

Die Entwicklungen im Projektgebiet waren schwierig vorherzusehen. Zu wenig ist bisher über die Habitatnutzung von frei lebenden Pferden in Ganzjahresbeweidung bekannt. Ein Verständnis des Nutzungsverhaltens dieser Großherbivore zu unterschiedlichen Jahreszeiten kann helfen, die Auswirkungen von Beweidung auf offene Weidelandschaften Mitteleuropas abzuschätzen. Zudem geben die pflanzensoziologischen Untersuchungen im Gebiet Aufschluss über die Entwicklungstendenz der häufigsten Habitattypen unter Beweidung.

In diesem abschließenden Kapitel möchte ich die zentralen Ergebnisse meiner Studie zusammenführen und im Hinblick auf ihre Aussagekraft und Übertragbarkeit bewerten. Dies schließt Fragen nach der Eignung des Projektgebietes für die seltenen Exmoor-Ponys sowie deren Auswirkungen auf die Pflanzen- und Tierwelt ein. Auch die gewählte Methodik wird kritisch beleuchtet. Abschließend werden Empfehlungen ausgesprochen, die aus den Erfahrungen während der fünfjährigen Pferdebeweidung abgeleitet wurden. 


\subsection{Eignung des Gebietes zur Pferdebeweidung}

Die Raumnutzung von Pferden wird von einer Vielzahl von Faktoren beeinflusst. Zum einen sind hier weidetier- und vegetationsbedingte Eigenschaften zu nennen, die für die Nahrungswahl wichtig sind. Auch Saisonalität, Witterungseinflüsse und Habitatstrukturen spielen bei Ganzjahresbeweidungen eine große Rolle (vgl. Ganskopp et al. 1986, Duncan 1992, Crane et al. 1997, Scheibe et al. 1998, Cameron et al. 2001, Lamoot 2004, Wollenweber 2007). Beim Pferd als soziales Tier sind ferner Tagesrhythmik, soziale Hierarchien und die Gruppendynamik der Herde von Bedeutung (vgl. Crane et al. 1997, Roth 2002). Welche dieser Faktoren für die Raumnutzung einer Herde ausschlaggebend sind, ist somit nicht leicht zu beantworten, kann doch davon ausgegangen werden, dass sich die Faktoren beeinflussen. In Abb. 85 und Abb. 86 wird das Spektrum wichtiger Einflussfaktoren grafisch dargestellt.

Zur Bewertung von Habitatansprüchen einer Art reicht die Erfassung von Habitatstrukturen in einem bestimmten Gebiet und ihrer jeweiligen Nutzung durch die Weidetiere nicht aus. Es gilt, aus den beobachteten Habitatpräferenzen jene Faktoren herauszuarbeiten, die für die Art von Bedeutung sein könnten (Abb. 86). Denn die Eignung eines Gebietes leitet sich aus dem Vorhandensein dieser relevanten Habitatstrukturen ab (Mühlenberg \& Slowik 1997). Die zusammenfassende Betrachtung der Raumnutzungsdaten im Beweidungsprojekt Süd-Langeland soll dem Verständnis des komplexen Wirkungsgefüges von biotischen und abiotischen Faktoren einer Ganzjahresbeweidung unter naturnahen Bedingungen dienen und die Frage nach einer Eignung des Gebietes aus Tier- und Naturschutzsicht beantworten. Aufgrund der Unterschiede zu anderen Weidetierarten werden vorwiegend Ergebnisse anderer Untersuchungen von Equus betrachtet.

\subsubsection{Raumnutzung und Anforderungen der Weidetiere an ihren Lebensraum}

\subsubsection{Vegetation und Habitatstrukturen}

Eine erste Annäherung an die Raumnutzung der Exmoor-Ponys im Untersuchungszeitraum lieferte die Auswertung des Home Range und der Kernel-Dichten. Es zeigte sich, dass die Raumnutzung der Ponys von Jahr zu Jahr leicht variierte. Ursachen hierfür waren vor allem die Witterung und der unterschiedliche Wachstumsbeginn der Vegetation. Mit fortschreitender Beweidungsdauer und zunehmender Herdengröße veränderte sich aber auch die Nahrungsverfügbarkeit im Gebiet.

Das Gebiet wurde von den Tieren in seiner gesamten Ausdehnung genutzt. Dass der Home Range berechnet durch die Polygon-Methode - eine größere Ausdehnung ergab als die den Tieren zur Verfügung stehende Fläche, rührt daher, dass die Herde vermutlich ohne die Begrenzung durch den Elektrozaun ein wesentlich größeres Gebiet bewohnen würde: Studien an frei lebenden Pferden sprechen von einem Home Range von über $10 \mathrm{~km}^{2}$ (Ganskopp \& Vavra 1986), also einem Zehnfachen der Fläche Süd-Langelands. Die Polygon- und Kernel-Methoden lieferten - wie auch Roth (2002) feststellte - nur vage Angaben zur Verteilung der Tiere im Gesamtgebiet. Sie beantworteten weder die Frage, in welcher Pflanzengesellschaft sich die Tiere bevorzugt aufhielten, noch bildeten sie eine zeitliche Nutzungsveränderung hinreichend ab. Empfehlenswerter, wenn auch zeitaufwändiger sind daher Punkt-in-Polygon-Analysen in einem Geografischen Informationssystem (GIS). 


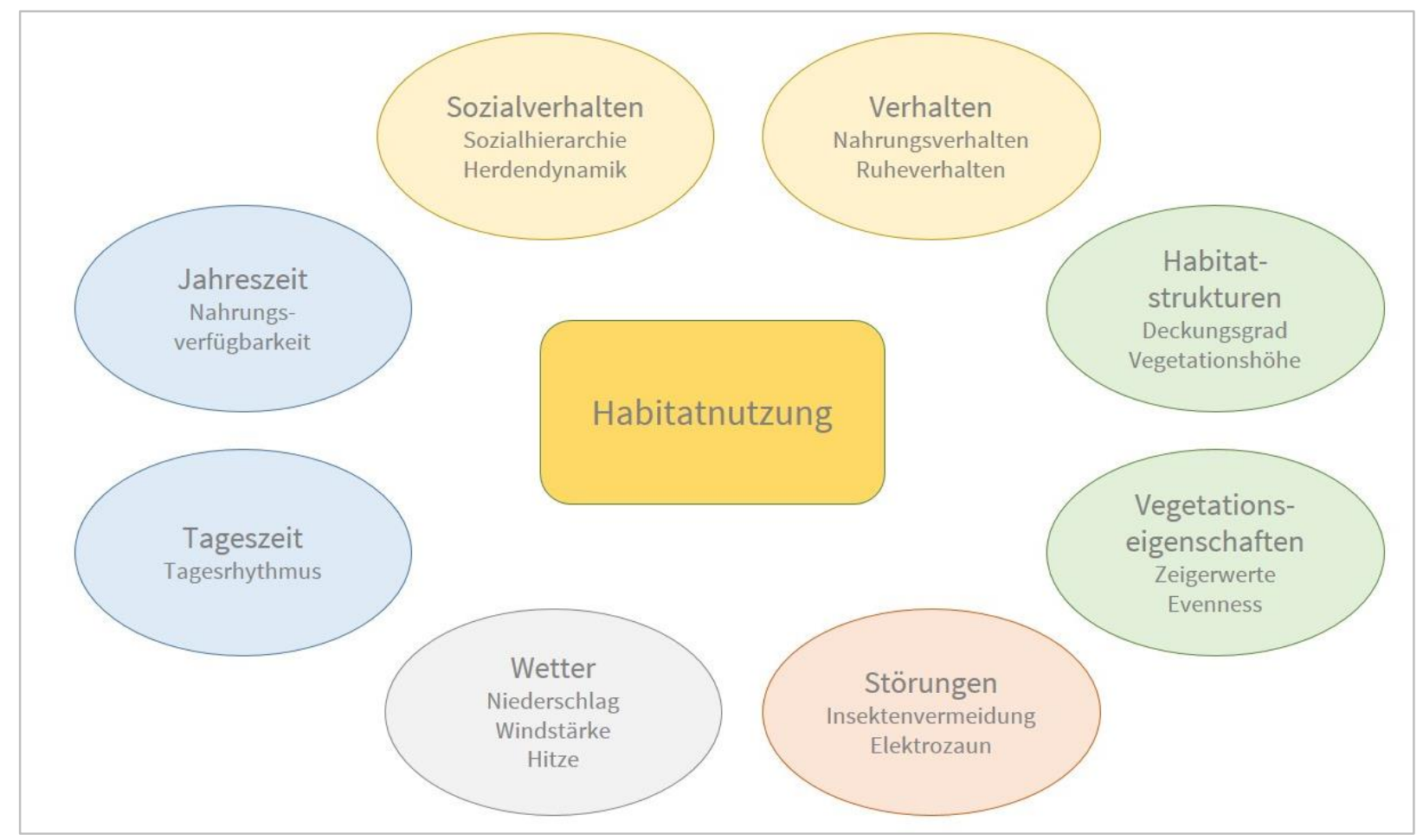

Abb. 85 Einflussfaktoren der Habitatnutzung bei Pferden unter Ganzjahresbeweidung auf Süd-Langeland

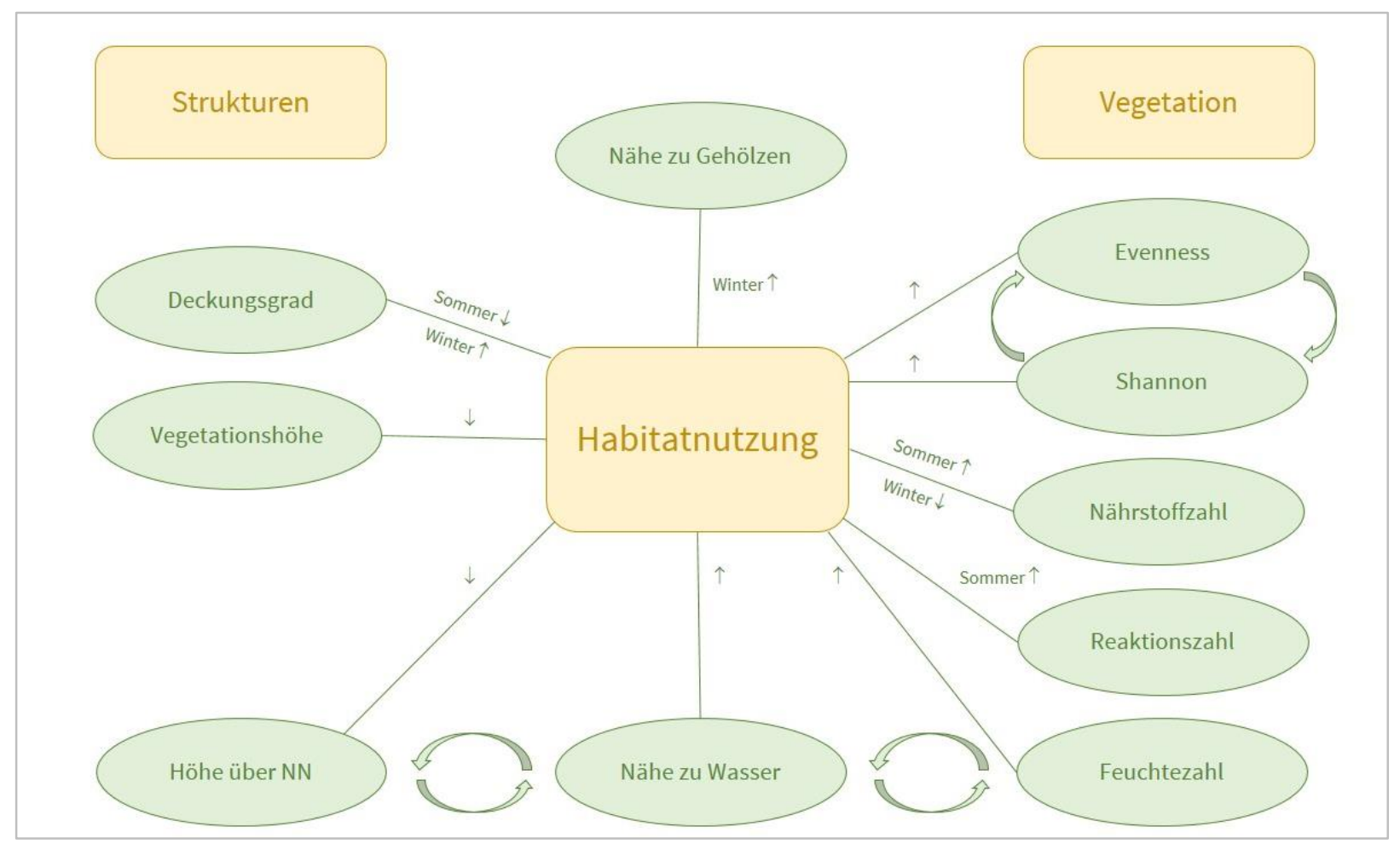

Abb. 86: Wirkungsgefüge einiger für das Exmoor-Pony wesentlicher ökologischer Faktoren bei der Habitatnutzung im offenen Weideland am Beispiel Süd-Langeland

$\uparrow$ fördernd, $\downarrow$ hemmend, $\leftrightarrow$ Pararmeter stehen in Wechselwirkung zueinander 
Die Kerngebiete der Exmoor-Ponys lagen eindeutig im Bereich der Wiesen und Weiden. Die Tiere zeigten Präferenzen für die nährstoffreicheren Assoziationen der Wiesen und Weiden frischer Standorte sowie für gewässernahe, niederwüchsige Gesellschaften. Eine geringere Nutzung erfuhren ruderale und magere Glattwiesen sowie hochwüchsige Röhricht- und Uferstaudengesellschaften. Dass nicht alle Habitate in einem Lebensraum von Pferden gleichermaßen oder entsprechend ihres Flächenanteils genutzt werden, ist vielfach beschrieben worden (Salter \& Hudson 1980, Berger 1986, Ganskopp \& Vavra 1986, Crane 1997, Lamoot 2004, Delling 2013). Eine Vorliebe für Grünländer ist typisch für Großherbivoren und ist bei Pferden für unterschiedliche europäische Weidelandschaften belegt (Duncan 1983, Pratt et al. 1986, Putman et al. 1987, Gordon 1989, Menard et al. 2002). Dabei bevorzugen wilde oder halbwilde Pferde die frischen und gemäßigten vor den mageren Standorten.

Im Projektgebiet erklärte sich dies, wie die Regressionsanalyse ergab, sowohl durch den höheren Feuchtegrad als auch den größeren Nährstoffgehalt frischer Weiden und Wiesen. Damit gehen in der Regel eine größere Abundanz und Biomasse sowie ein höherer Wassergehalt der Pflanzen einher, Faktoren, die die Habitatnutzung von großen Herbivoren positiv beeinflussen (vgl. Senft et al. 1985, Pinchak et al. 1991, Duncan 1992, Smith et al. 1992, Kobbelt 2000, Roth 2002). Auch Scheibe et al. (1998) berichten, dass die Wahl der Futterstellen mit der Frische der Vegetation zusammenhänge. Der Nährstoffgehalt und der Futterwert der Vegetation waren in Süd-Langeland weniger von Bedeutung als strukturelle Eigenschaften wie die Vegetationsdeckung und -höhe. Pferde fressen bei entsprechendem Nahrungsangebot auch Pflanzen mit sehr geringem Futterwert, wie Untersuchungen im Hühnerfeld für Pfeifengras und Wollgras zeigten (Preuschhof 2005). Dies trifft besonders für Pferderassen vom Nordtyp zu, die in hohem Maß Binsengewächse, Sauergräser und hartblättrige Süßgräser wie Rasenschmiele oder Pfeifengras fressen (LÜBW 2005). Zudem zeigt der Nährstoffgehalt der Grünländer jahreszeitliche Schwankungen. Bei der Analyse war der Faktor insgesamt betrachtet bei der Habitatnutzung der Langeländer Exmoor-Ponys nicht signifikant, denn er war im Sommerhalbjahr positiv, im Winterhalbjahr negativ korreliert. Andere Beweidungsstudien, die den Nährstoffgehalt oder den Futterwert als wichtigstes Selektionskriterium angaben, haben keine Daten in den Wintermonaten erhoben (Kobbelt 2000, Roth 2002, Holsten 2003), so dass sie deshalb möglicherweise zu abweichenden Ergebnissen kommen.

Als Grasfresser bevorzugten die Ponys Flächen mit einem hohen Grasanteil sowie geringen Streuauflagen. Wichtig für die Habitatwahl war die Vegetationshöhe der Krautschicht. Auch andere Autoren berichten von einer Bevorzugung von Kurzgras- gegenüber Langgrassteppen bei Pferden (Kolter et al. 1999, Vulink 2001, Roth 2002, Lamoot 2004). Dabei werden laut Lamoot et al. (2005) ganzjährig Vegetationshöhen von unter $20 \mathrm{~cm}$ bevorzugt. Kurzgefressenes Gras wächst schneller nach und ist schmackund nahrhafter für die Tiere (Salter \& Hudson 1979, Van Soest 1982, Duncan 1992, WallisDeVries \& Daleboudt 1994, LÜBW 2005). Kobbelt (2000) fand zudem heraus, dass Przewalski-Pferde in der ungarischen Puszta die ehemals überschwemmten Flächen gerne aufsuchten, da hier das junge nachwachsende Gras sehr proteinreich war.

Auf Langeland war zudem ein zyklisches Nutzungsmuster erkennbar, bei dem Teilgebiete über einen Zeitraum von einigen Tagen bis Wochen nicht aufgesucht wurden, um dann wiederum stärker beweidet zu werden. Möglicherweise bieten die Pferde der Vegetation mit Nutzungsintervallen die Gelegenheit zur Regeneration und zum Nachwachsen junger Sprosse. Eine zyklische Weidenutzung tritt auch bei anderen Herbivoren auf (Drent \& van der Wal 1999). Scheibe et al. (1998) stellten bei PrzewalskiPferden fest, dass sich soziale Tiere, die im Herdenverband grasen, sehr schnell präferierte Flächen schaffen, auf denen stets frischer Aufwuchs vorhanden ist, da vom Nahrungsangebot im Sommer nur ein Teil genutzt werden kann. So entwickelt sich ein positiver Rückkoppelungsprozess, der zunächst wohl zufällig entstandene Präferenzflächen langfristig stabilisiert. Dieses Nahrungsverhalten trug auch im Projektgebiet zur beobachteten Differenzierung der Vegetation bei. Es kristallisierten sich dabei 
bestimmte Areale heraus, die bevorzugt und intensiv beweidet wurden, während andere mittel- bis hochrasig waren. Letztere wiesen vermehrt überständige Nahrungspflanzen auf und wurden nur noch zum Abkoten aufgesucht. Die Auswirkungen dieser differenzierten Nutzung der Weideflächen werden in 7.2 Auswirkungen der Beweidung auf die Vegetation diskutiert.

Eine niedrigere Vegetation ist für Pferde nicht nur aus Gründen der Futterqualität attraktiver. Das Verweilen in niedrigerer Vegetation gewinnt vor allem in warmen Monaten an Bedeutung, wenn Stechinsekten gehäuft auftreten. Denn Pferde haben eine dünne und hochsensible Haut und leiden erheblich unter Fliegen und Mücken (Pollmann 2005). Da die Insekten auf kurzrasigen oder vegetationslosen Flächen weniger Halt und Schutz finden, sinkt hier die Belästigung durch sie. Stechinsekten stören vor allem das Ruheverhalten der Tiere (Duncan 1992). Dies erklärt, warum die Langeländer Ponys im Sommer eine hohe Präferenz für ufernahe Standorte zeigten, an denen sie die Vegetation durch Tritt weitgehend zerstört hatten. Diese Orte dienten im zweiten und dritten Untersuchungsjahr als Ersatz für den gesperrten Unterstand, der von den Tieren zuvor aufgrund seiner Windkanal ähnlichen Eigenschaften intensiv genutzt wurde. Denn Pferde suchen zur Vermeidung der Stechinsekten oft windexponierte oder geografisch höher gelegene Stellen auf (vgl. Keiper \& Berger 1982, van Dierendonck et al. 1996, Roth 2002). Auch die von Keiper \& Berger (1982) beschriebene antiparallele Kopf-SchweifAusrichtung mit Schweifschlagen dient diesem Zweck und wurde in Süd-Langeland häufig beobachtet.

Dass die Uferbereiche im Projektgebiet eine größere Nutzung zeigten, als ihr Flächenanteil vermuten ließe, lag also an ihrer Attraktivität als Ruheplatz. Niederwüchsige Ufergesellschaften wurden den hochwüchsigen Röhrichten deutlich vorgezogen. Da Fress- und Nahrungsplätze bei den Beobachtungen nicht weit auseinander lagen, grasten die Tiere in Süd-Langeland vorwiegend auf den gewässernahen Grünflächen. Zudem haben Pferde keine besondere Fähigkeit zur Wasserspeicherung, sie müssen regelmäßig Wasser trinken oder Pflanzen mit einem hohen Wassergehalt aufnehmen (Duncan 1992). Dies erklärt, warum die Wassernähe in der vorliegenden Studie der wichtigste Einflussfaktor bei der Raumnutzung war.

Eine Vorliebe für Uferbereiche ist bei Groß-Herbivoren bereits dokumentiert worden (Roath \& Krueger 1982, Pinchak et al. 1991, Smith et al. 1992, Bunzel-Drüke et al. 2001, von Oheimb et al. 2006). Sie wird häufig auf Nahrungspräferenzen zurückgeführt (Peinetti et al. 2001, Ripple \& Beschta 2004). In trockenen Gebieten hing die Gewässernähe von Elchen und Maultierhirschen aber auch vom Wasserbedarf der Tiere ab (Skovlin et al. 2002, Newmark et al. 2012). Auch bei wild lebenden Pferden trat in Raumnutzungsstudien die Bedeutung von Gewässern zutage (Ganskopp \& Vavra 1986, Duncan 1992, Crane 1997). In Wyoming war beispielweise die Größe des Home Range negativ korreliert zur Dichte von Wasserquellen innerhalb desselben. Je wärmer es war, desto geringer waren die Entfernungen der Tiere zum Wasser (Ganskopp \& Vavra 1986). Die Ergebnisse lassen sich gerade aufgrund der ähnlichen, sehr guten Wasserversorgung gut mit den Bedingungen in Süd-Langeland vergleichen, wo Gewässer einen Flächenanteil von $9 \%$ einnahmen.

Wichtig war den Langeländer Tieren zudem ein ausgewogenes Nahrungspflanzenangebot. Vor allem in den Sommermonaten hatten artenreiche Gesellschaften eine hohe Attraktivität und boten den Pferden eine abwechslungsreiche Kost. Dieses Ergebnis deckt sich mit jenen einer Langzeitstudie von Duncan (1992), der in der Camargue eine größere Selektivität der wild lebenden Pferde während der wärmeren Jahreszeit feststellte, wenn reichlich Futter vorhanden war. Diese Präferenz erklärt sich durch ihre Nahrungsweise: Pferde gehen bei der Futtersuche selektiv vor, in dem sie sich die bestschmeckenden Pflanzen einzeln heraussuchen (Schäfer 1993). Je artenreicher die Bestände sind, desto differenzierter können die Tiere ihre Futterwahl treffen. Einartbestände, wie sie teils im Schilf oder Forst auftraten, und artenarme Flächen boten den Tieren nicht die bevorzugten Nahrungspflanzen oder Selektionsmöglichkeiten und wurden daher meist gemieden. 
Den Wäldern und Gebüschen im Gebiet kam aufgrund der spärlichen oder schwer zugänglichen Krautschicht nur eine untergeordnete Rolle zu: Die Pferde verbrachten hier weniger als $10 \%$ ihrer Zeit. Die Gehölze boten den Tieren jedoch - vor allem im Winterhalbjahr - wichtige Strukturen für Nahrung, Schutz und Körperpflege im Hinblick auf eine artgerechte Tierhaltung bei Ganzjahresbeweidung. Ihr Anteil am Gebiet wirkt sich damit entscheidend auf dessen Eignung als Lebensraum aus. Jene Flächen, die aus Naturschutzsicht stärker hätten beweidet werden sollen wie die dichten Laubwald- und Gebüschareale sowie die unzugänglichen Schilfbereiche der Stillgewässer, stellten für die Ponys weniger attraktive Habitate dar. Aufgrund der ganzjährigen Beweidung zeigten sich dennoch erste positive Effekte der Auflichtung und Offenhaltung dieser Lebensräume (s. 7.2.2 Förderung einer halboffenen Weidelandschaft). Auch Lamoot (2004) hob die Bedeutung von Gehölzen in der Pferdebeweidung auf Küstendünen hervor: Die Krautschicht der Gebüsche wurde im Herbst und vor allem im Winter beweidet, die der Wälder im Winter und zeitigen Frühjahr. Auch im Hutewaldprojekt Solling suchten ExmoorPonys regelmäßig den Wald auf und nutzten inn zum Schutz sowie als Nahrungslieferant in Form von Eicheln, Zweigen und Knospen (Krannich 2005). Wälder und Gebüsche stellen daher auch für klassische Grasfresser wertvolle Habitate dar, auch wenn die Gehölze selbst kaum verbissen werden.

\subsubsection{Saisonalität, Tagesrhythmik und Sozialverhalten}

Bei einer Ganzjahresbeweidung wirken sich die Jahreszeiten selbstverständlich auf das Raumnutzungsverhalten aus. Die Exmoor-Ponys in Süd-Langeland nutzten die verschiedenen Habitattypen im Jahresverlauf mit unterschiedlicher Intensität. Sie richteten sich dabei nach den Hauptwachstumsphasen der einzelnen Vegetationstypen (vgl. Dierschke 1994, Dierschke \& Briemle 2002): Während die gut gedüngten Weiden und Wiesen mit ihrem Löwenzahn-Aspekt den Pferden bereits im Frühling nahrhaftes Futter boten, entwickelte sich die Ufervegetation erst später. Röhrichte und andere Ufergesellschaften wurden daher erst im Hoch- und Spätsommer beweidet, als die Frisch- und Magerwiesen und Weiden teils verblüht waren. Im Herbst und Winter suchten die Pferde deutlich häufiger Wälder und Gehölze auf. Die energiereichen Knospen und jungen Zweige stellten dann eine wichtige Nahrungsergänzung in der kalten Jahreszeit zusätzlich zur Krautschicht dar.

Im Winterhalbjahr wichen die Ponys auf die weniger nahrhaften Flächen im Gebiet aus, wie die Regressionsanalyse ergab. Ist nur nährwertarmes oder überständiges Futter vorhanden bzw. sind die beliebten Pflanzen bereits abgegrast, werden also auch solche gefressen, die bei entsprechender Auswahlmöglichkeit verschmäht oder nur in geringem Umfang genutzt würden. Hoher, zum Teil abgestorbener Aufwuchs wurde im Sommer eher gemieden und diente im Winter als Futterreserve. Diese Beobachtungen decken sich mit anderen Untersuchungen (Wenk 2004, LÜBW 2005). Durch ihr Nutzungsverhalten erhöhten die Langeländer Ponys die Nahrungsverfügbarkeit im Jahresverlauf. Die daraus hervorgehenden temporären Brachen bieten wiederum eine bessere Ernährungssituation für die blütenbesuchende Fauna und die darauf aufbauende Nahrungskette (von Oheimb et al. 2006).

Eine saisonale Abhängigkeit des Raumnutzungsverhaltens bei Pferden ist bekannt (Berger 1977, Salter \& Hudson 1979, Keiper \& Berger 1982, Duncan 1992, Van Dierendonck et al. 1996, Kobbelt 2000, Roth 2002, Lamoot 2004, Delling 2013), gleichwohl es auch gegensätzliche Forschungsergebnisse dazu gibt (Denniston et al. 1982, Ganskopp \& Vavra 1986, Crane et al. 1997). Neben der unterschiedlichen Verfügbarkeit im Jahresverlauf entscheiden auch die Schmackhaftigkeit und Frische von Nahrungspflanzen über ihre Attraktivität als Futterpflanze (Salter \& Hudson 1979, Duncan 1992, Scheibe et al. 1998).

Die Habitatwahl änderte sich im Tagesverlauf: Morgens und abends wurden überwiegend Grünländer, tagsüber auch Uferbereiche aufgesucht. Zur Nacht hin gewannen die Gehölze an Bedeutung. Vermutlich spielten hier Witterungseinflüsse, das Verhalten und die Herdendynamik eine größere Rolle als der Vegetationstyp, denn die Standortwahl war abhängig vom Verhalten der Tiere und dem Wechsel von 
Fraß- zu Ruhezeiten. Auch laut Crane et al. (1997) ist die Tagesrhythmik frei lebender Pferde unabhängig vom Habitattyp. Laut Roth (2002) ist die soziale Organisation der Pferde sogar ausschlaggebend für die gesamte Raumnutzung, da die Haremstruktur der Przewalski-Pferde zu einer Aufteilung des Gebietes unter einzelnen Gruppen führte. Diese Situation lag in Süd-Langeland nicht vor. Das Herden- und Sozialverhalten war ein wichtiger, nicht aber der Hauptfaktor der räumlichen Nutzung.

\subsubsection{Einfluss des Wetters}

Exmoor-Ponys sind als Robustpferde im Allgemeinen unempfindlich gegenüber Witterungseinflüssen (Riediger 1995, Willmann 2005, Baker 2008). Dennoch wirkten sich Temperaturverhältnisse und Wetterextreme auf die Habitatnutzung aus (vgl. Delling 2009, Lohrengel 2011). Die von Pollmann (2005) beschriebenen Anpassungsmechanismen von Weidetieren bei Hitze oder Kälte wurden auch bei den Exmoor-Ponys auf Süd-Langeland dokumentiert: Aufsuchen kühlerer Orte mit Schatten oder Luftbewegung, Anfeuchten des Fells in Stillgewässern zur Erzeugung von Verdünstungskälte sowie eine Reduzierung von Futteraufnahme und Aktivität im Sommer. Die beim Pferd auftretende Thermoregulation durch Schwitzen erfordert zudem eine ausreichende Wasserversorgung bei Hitze und erklärt die große Bedeutung der Wassernähe bei der Habitatwahl.

Zur Erhaltung der Körperkerntemperatur bei Kälte orientierten die Langeländer Ponys ihre Schmalkörperseite zum Wind (vgl. Pollmann 2005). Regen allein hatte kaum Einfluss auf ihre Habitatnutzung, wie auch Tyler (1972), Wollenweber (2007) und Baker (2008) bei frei lebenden Pferden feststellten. Ein gezieltes Aufsuchen geschützter Orte bei Regen - wie bei Araberpferden von Kuhne (2003) beobachtet - trat im Gebiet sowie im Allgemeinen bei Robustpferden (Schäfer 1993, LÜBW 2005) nicht auf.

Einfluss hatte jedoch das Auftreten von Schnee. Die Langeländer Ponys bevorzugten bei der Nahrungsaufnahme schneefreie vor -bedeckten Flächen (vgl. Delling 2009). Aufgrund der Schneelage wurden bestimmte Bereiche im Gebiet zeitweise nicht genutzt: Im Winter 2009/10 konnten die Pferde weder die Nord- noch die Südspitze erreichen, auch im Folgejahr blieb ihnen der Zugang zu den nördlichen Weiden über Wochen verwehrt. Dies hatte sowohl Auswirkungen auf die Ressourcenverfügbarkeit als auch auf die Vegetationsentwicklung im Gebiet: Zum einen stand den Tieren in den nährstoffärmeren Monaten weniger Weidefläche zur Verfügung. Dies muss zukünftig bei der Festlegung des maximalen Tierbesatzes Berücksichtigung finden, da gerade die Wintermonate den Versorgungsengpass für die Tiere darstellen. Zudem wurden die Flächen über einen mehrwöchigen Zeitraum nicht beweidet, was langfristig die Entwicklung der Vegetationsstruktur beeinflusst. Auch Schäfer (1993) und Tyler (1972) beschreiben, dass Pferde bei ungünstigem Wetter dazu neigen, in der Nähe ihrer Ruheplätze zu verbleiben. Dies begründet die geringe Nutzung der Laubwälder bei Schnee, sie waren von den zentralen Flächen durch die Steinmauer abgetrennt.

Neben dem Ausbilden eines dichten Haarkleides und Ansetzen von Unterhautfettgewebe reduzierten die Ponys - anders als bei Weidetieren üblich (Pollmann 2005) - im Winter ihre Futteraufnahme und erhöhten ihr Ruheverhalten (vgl. Delling 2009, Uthoff 2010). Dies trat auch bei Exmoor-Ponys im Tierpark Sababurg, Nordhessen auf (Delling 2013). Andere Autoren fanden keinen Zusammenhang zwischen Fressverhalten und Witterung oder stellten gar eine Erhöhung der Futteraufnahme im Winter fest (Duncan 1985, Houpt et al. 1986, van Dierendonck et al. 1996, Cosyns et al. 2001, Menard et al. 2002). Die Unterschiede können durch unterschiedliche Rassen begründet sein, da in den Vergleichsstudien keine Exmoor-Ponys untersucht wurden. Die Anteile des Nahrungsverhaltens im Jahresmittel der Langeländer Ponys stimmten jedoch mit anderen Freilandbeobachtungen weitgehend überein (Duncan 1980, 1985, Crowell-Davis 1986, Jarrige \& Marin-Rosset 1987, Schäfer 1993, Riediger 1995, van Dierendonck et al. 1996, Crane 1997, Lamoot 2004, Wollenweber 2007, Delling 2013): Die Futteraufnahme bei frei lebenden Pferden nimmt in etwa 50-70\% des Tagesbudgets in Anspruch. 
Bei stürmischem Wetter dienten Laubwälder als Rückzugsort (vgl. Delling 2009, Uthoff 2010), ebenso hielten sich die Pferde im Windschatten der Hügel oder der Steinmauer auf. Welcher der Faktoren Wind, Regen, Schneefall oder Kälte - die Habitatnutzung am stärksten beeinflusste, konnte nicht geklärt werden, da starker Wind im Gebiet meist mit niedrigen Temperaturen, Regen oder Schneefall zusammenfiel. Ein angepasstes Verhalten bei Sturm ist jedoch typisch bei Pferden in Freilandhaltung (vgl. Tyler 1972, Pratt et al. 1986, Klimov 1988, Schäfer 1993, Scheibe 1998, Wollenweber 2007).

\subsubsection{Eignung des Gebietes im Hinblick auf Habitatansprüche und eine artgerechte Tierhaltung}

Die Ergebnisse zeigen, dass sich die Bedürfnisse der Weidetiere im Jahresverlauf veränderten. Wichtig waren den Weidetieren neben frischen und artenreichen Grünländern zur Deckung des täglichen Nahrungsbedarfs Gewässer und vegetationsarme Uferbereiche, die sie vor allem zum Ruhen aufsuchten. Sogar nährstoffärmere Flächen und magere Standorte wurden in den Wintermonaten beweidet und sollten daher von der Beweidung nicht ausgeschlossen werden. Lichtere Gehölze dienten im Winter dem Schutz und der Nahrungsaufnahme zum Zeitpunkt des geringsten Vegetationswachstums. Daher sollten Wälder und größere Baumgruppen Bestandteil einer halboffenen Weidelandschaft sein, um den Weidetieren eine möglichst umfassende Befriedigung ihrer Bedürfnisse zu ermöglichen. Von Oheimb et al. (2006) empfehlen, auch Gewässer in Beweidungsflächen einzubeziehen, auch wenn dies Probleme hinsichtlich der Tiergesundheit z.B. durch Befall mit Leberegeln aufwerfen kann.

Ein reich strukturierter Lebensraum mit freiem Zugang zu Gewässern und Gehölzen ist bei einer Ganzjahresbeweidung von großer Bedeutung. Das Schutzgebiet Süd-Langeland bot den Tieren diese Strukturvielfalt. Auch fanden sie ausreichende Nahrungsmöglichkeiten vor. Obwohl keine Zufütterung erfolgte, magerten die Tiere im Winter nicht über das normale Maß hinaus ab: Ihre Kondition verschlechterte sich zwar sichtlich, eine Mangelsituation trat jedoch nicht auf. Die Ponys waren in der Lage, sich durch ihr Verhalten und eine saisonal abgestimmte Raumnutzung an die naturnahen Lebensbedingungen im Schutzgebiet anzupassen. Sie nutzten die wärmeren Monate für eine erhöhte Energiezufuhr und glichen das im Winter entstandene Defizit im Frühjahr innerhalb weniger Wochen wieder aus. Ähnliches berichten auch Scheibe et al. (1998) über Przewalski-Pferde in einem Semireservat. Der Flächenbesatz musste in Süd-Langeland jedoch durch gezielte Entnahmen auf einem maximalen Wert von 0,5 Großvieheinheiten pro Hektar gehalten werden. Obwohl Entnahmen für die gesamte Herde großen Stress bedeuten (Schröder 2010), sind regelmäßige Bestandsregulierungen auch weiterhin erforderlich, da die Langeländer Herde aufgrund des Stutenüberschusses starken Zuwachs erfährt und keine natürliche Abwanderung möglich ist.

Eine artgerechte Tierhaltung von Pferden erfolgt im Herdenverband mit ungehinderten Bewegungsmöglichkeiten und Sozialkontakten (Schröder 2010). Diese Bedingungen waren im Projektgebiet erfüllt. Die Haltung von Großherbivoren im natürlichen Herdenverbund in ganzjähriger Weidehaltung entspricht einer tierschutzkonformen Haltung. Bei sozialen lebenden Tieren wird dabei im Tierschutz ein besonderes Augenmerk auf die natürliche Entwicklung der Herdenstruktur hinsichtlich Altersstruktur, Rangordnung und Geschlechterverhältnis gelegt, die ein Lernen aus und Weitergeben von Erfahrungen durch ältere Individuen an die nachfolgenden Generationen ermöglicht (Schröder 2010). Voraussetzung hierfür sei eine freie Wahl von Habitat und Nahrungsplätzen, wie sie im Projektgebiet zugelassen wurde. Die Haltung von Exmoor-Ponys trägt zudem zum Erhalt dieser bedrohten Haustierrasse bei (Willmann 2005). 


\subsubsection{Bewertung von Nahrungspräferenzen durch Kotuntersuchungen}

Informationen zur Nahrungsökologie einer Art tragen entscheidend zum Verständnis ihres Verhaltens und Einflusses auf den Lebensraum bei (Mühlenberg 1993). Nicht alle Methoden zur Untersuchung von Nahrungspräferenzen bei Herbivoren sind im Freiland anwendbar (Gates 1980, Cuartas \& GarciaGonzalez 1996). Eine Dokumentation der Futterpflanzen durch direkte Beobachtung, wie sie im Projektgebiet im Winter 2010/11 durchgeführt wurde (Pötzinger 2011), lieferte Hinweise darauf, dass die Morphologie und Vegetationshöhe der Nahrungspflanzen von Witterungsbedingungen beeinflusst werden (s. 5.2.3.3 Einfluss des Wetters auf die Raumnutzung). Diese Methodik eignet sich jedoch nicht, um Nahrungspräferenzen auf Artniveau zu erfassen. Doch gerade der Nachweis artspezifischer Vorlieben ist für die Bewertung ihres Einflusses hilfreich, da sich die Selektivität von Pferden bei fortlaufender Beweidung direkt auf die Artenzusammensetzung der Pflanzengesellschaften auswirkt (LÜBW 2006). Im Projektgebiet wurde daher eine umfassende Kotanalyse durchgeführt. Kotuntersuchungen werden meist bei Wildtieren eingesetzt, wo Beobachtungen oder Futterversuche nicht anwendbar sind. Die Vorteile dieser nicht-invasiven Methodik wurden von zahlreichen Autoren beschrieben (u.a. Peden et al. 1973, Chapius \& Lefeuvre 1980, Gates 1980, Holechek et al. 1982, Hanley et al. 1985, McInnis \& Vavra 1986, Cuartas \& Garcia-Gonzalez 1996, Treydte 2004, Kupfernagel 2004). Vorreiter waren Barthlott \& Martens (1979), die die Cuticular-Taxomonie von Gräsern der westafrikanischen Savanne zur Anwendung von Kotanalysen beschrieben. Eine vergleichbare Arbeit für mitteleuropäische Gramineen fehlt bislang.

Ziel der Kotanalyse war es, die Nahrungspflanzen bis auf das Art- oder Gattungsniveau zu bestimmen und saisonale Schwankungen sowie Mengenverhältnisse zu identifizieren. Die Arten der gefressenen monokotyledonen Pflanzen lassen sich im Pferdedung aufgrund von Cuticularresten bestimmen (Mühlenberg 1993). Über drei Jahre hinweg wurden in regelmäßigen Abständen Kotproben der Ponys genommen. Jede Kotprobe $(n=15)$ bestand aus 5-7 frischen Pferdeäpfeln, die zu einer Mischprobe verarbeitet wurden. Für die mikroskopische Analyse der Blattepidermen in den Pferdefaeces wurde die Methode nach Stewart (1967) und Owen (1975) verwendet. Die Proben wurden im Labor nach Radl (1987) aufbereitet, angefärbt und fixiert. Zur Auswertung der Mengenverhältnisse zwischen den Pflanzenarten wurden die ersten 100 Fragmente pro 0,1 ml Lösungsprobe ausgezählt (Mühlenberg 1993). Es wurden nur Fragmente ausgewertet, die aus mindestens 10 Zellen bestanden und ein Stoma aufwiesen. Da sich die Arten bei der Verdauung unterschiedlich stark zersetzen, wurde nicht die Anzahl, sondern die Gesamtgröße aller Fragmente einer Art geschätzt (Stewart 1967, 1970, Gates 1980). Dennoch gilt es bei der Auswertung zu beachten, dass Gräser und holzige Arten meist über-, krautige Arten unterschätzt werden (Holechek \& Valdes 1985, Cuartas \& Garcia-Gonzalez 1996).

Zur Identifizierung der Arten in den Kotproben wurde ein Referenzatlas aus den häufigsten Gräsern im Projektgebiet erstellt - in Anlehnung an Studien von Barthlott \& Martens (1979) und Hoppe-Dominik (1989). Die Cuticulae wurden im Labor mit der Chrom-Salpeter-Isolation bearbeitet, obgleich sie nur zu mittelmäßigen Ergebnissen führte, da Chrom als Rückstand auf den Cuticulae zurückblieb oder die Chrom-Salpetersäure die Pflanzengewebe nicht immer vollständig auflöste. Die Cuticulae der Blattober- und Unterseite von 20 Gräsern wurden im Lichtmikroskop (20x, 40x, 100x) auf differenzierende Merkmale untersucht: Vorhandensein und Form von Kieselkörpern, Stomata, Mikro-, Stachel- und Borstenhaare, Papillen und Langzellen sowie das Zellmuster. Auch 5 krautige Pflanzen wurden bewertet. Das Zellmuster stellt ein wichtiges Merkmal zur Unterscheidung von Mono- und Dikotyledonen dar (Barthlott \& Martens 1979). Von den Zellstrukturen der Arten wurden Zeichnungen angefertigt, aus der Merkmalsübersicht ein Bestimmungsschlüssel erstellt, um die Referenzpflanzen bis auf das Artoder Gattungsniveau unterscheiden zu können.

Die angewandte Methodik der Kotanalyse führte zu keinem verwertbaren Ergebnis: Es war nicht möglich, die Fragmente aus den Kotproben den Arten der Vergleichsproben zuzuordnen, da die Fragmente 
aus den Kotproben meist nur aus wenigen Zellen bestanden, die weder eine zusammenhängende Zellstruktur noch die erforderlichen Bestimmungsmerkmale wie Kieselkörper, Langzellen und Stoma für eine sichere Identifikation aufwiesen. Auch eine Zuordnung der Fragmente zu unterschiedlichen Gattungen war nicht möglich. Ob die Kotproben falsch aufbereitet wurden oder sich die Methodik für eine Kotanalyse beim Exmoor-Pony nicht eignet, konnte nicht geklärt werden. Da nur ein geringer Prozentsatz der Fragmente (unter $10 \%$ ) sicher bestimmt werden konnte, sind Aussagen zu bevorzugten Nahrungspflanzen oder Mengenanteilen nicht möglich.

Auf Süd-Langeland eignete sich die Kotuntersuchung folglich nicht zur Analyse von Nahrungspräferenzen, sie erfolgte über die Habitatnutzungsanalyse. Dem Vorteil der nicht-invasiven Probennahme stand eine schwierige Identifikation der verdauten Bestandteile mit geringer Aussagekraft gegenüber. Hinsichtlich der Qualität der Ergebnisse finden sich in der Literatur unterschiedliche Angaben (Hubbard \& Hansen 1979, Walter \& Hudson 1979, McInnis \& Vavra 1987, Gates 1980, Treydte 2004). Zusammenfassend ist eine Identifikation der Fragmente von Mono- und Dikotyledonen im Kot nur von erfahrenen Botanikern umzusetzen. Die Auswertung bleibt subjektiv, da der Prozess meist manuell erfolgt (Alipayo et al. 1992, Cuartas \& Garcia-Gonzalez 1996). 


\subsection{Auswirkungen der Beweidung auf die Vegetation}

Positive Effekte einer extensiven Beweidung mit Groß-Herbivoren werden durch zahlreiche rezente Studien bestätigt. Sie wurden sowohl auf trockeneren Standorten (u.a. Lamoot 2004, Bromisch 2005, Rüther \& Venne 2005, von Oheimb et al. 2006) als auch im Feuchtgrünland (u.a. Redecker et al. 2000, Holsten 2003, Demartin 2005, Preuschhof 2005, Bunzel-Drüke et al. 2008, Mann \& Tischew 2010) dokumentiert. Die vorliegende Untersuchung schließt eine wichtige Lücke in der Bewertung der Auswirkungen einer Beweidung aus naturschutzfachlicher Sicht. Denn bisher werden Pferde selten ganzjährig in Alleinhaltung zur Biotoppflege eingesetzt. Der mehrjährige Betrachtungszeitraum zeigt erste Tendenzen auf, wie sich halboffene Kulturlandschaften langfristig unter dem Einfluss von frei lebenden Pferden entwickeln. Das Pilotprojekt Süd-Langeland bietet damit Naturschutzprojekten neue Erkenntnisse zur Biotoppflege von Wiesen, Weiden und Mooren an.

Zentrale Ziele des Beweidungsprojektes waren der Erhalt offener Bereiche, die Förderung von Übergangsstadien sowie die Schaffung von Pionierstandorten. Insgesamt wurden eine höhere Arten- und Strukturvielfalt und eine dynamische Flächenentwicklung angestrebt (Dänisches Ministerium für Umweltschutz 2006). Ob diese Ziele erreicht wurden und welche Auswirkungen die Pferdebeweidung auf die Vegetation im Gebiet hatte, soll im Folgenden bewertet und diskutiert werden.

\subsubsection{Einfluss der Weidetiere auf unterschiedliche Vegetationstypen}

Die Biotoptypen im Gebiet veränderten sich unterschiedlich unter Pferdebeweidung. Ihnen gemeinsam waren die Abnahme der Krautschicht und der Streuauflagen sowie die Zunahme an offenen Bodenstellen durch den Fraß, die Trittwirkung und das Komfortverhalten der Weidetiere. Die Auswirkungen waren im Uferbereich und dem angrenzenden Feuchtgrünland am höchsten (vgl. auch Söhn 2009), es reichte bis zur Entstehung neuer Vegetationseinheiten an stark frequentierten Uferabschnitten. Es handelte sich dabei um Flächen im Übergang zwischen Verlandungs- und Grünlandgesellschaften, die je nach Witterungsbedingungen und Wasserstand unterschiedlich stark vernässten. Es entwickelten sich Gesellschaften, die mechanische Störungen gut ertragen. Die Trittwirkung der Weidetiere begünstigte beispielsweise die Ansiedlung von typischen Arten der kurzlebigen Schlammboden-Pionierfluren wie Gift-Hahnenfuß (Ranunculus scleratus) und Kleines Tausendgüldenkraut (Centaurium pulchellum).

Die gestörten Flächen unterlagen einer hohen jahreszeitlichen Dynamik, die durch die jährlich schwankenden Wasserstände noch verstärkt wurde. Die Störungen waren im Winter und im Sommer am höchsten, wenn der Boden durch die nasse Witterung aufgeweicht oder im Sommer aufgrund der intensiven Nutzung stark zertrampelt und verdichtet war. Im Frühjahr regenerierten die Flächen teilweise, so dass der Pioniercharakter immer neu geschaffen wurde. Bei den Vegetationserhebungen wurden von Jahr zu Jahr sehr unterschiedliche Artenzusammensetzungen vorgefunden. Die Bedeutung dieser feuchten Rohbodenbereiche für die Flora und Fauna wird später diskutiert.

Positive Effekte hatte die Beweidung auch auf den Biotopkomplex der Gewässer. Den überwiegend künstlich angelegten Stillgewässern drohten vor Beginn der Beweidung Verschilfung und Verlandung. Wie auch von Uthoff (2009) beschrieben, fraßen die Weidetiere im Herbst vermehrt auf den Feuchtwiesen und in den Schilfbeständen (Phragmites australis) und drängten damit die Röhrichte zurück, die zuvor große Bereiche der Stillgewässer eingenommen hatten. Dies wird sowohl durch vergleichende Luftaufnahmen aus den Jahren 2006 und 2011 als auch durch die Erhebungen auf den Strukturdauerflächen bestätigt. Obwohl die Auswertung des Raumnutzungsverhaltens eine Meidung der Röhrichte ergab - vermutlich, weil deren Nutzung nur auf einen kurzen Zeitraum beschränkt war, begrenzten die Weidetiere deren Ausbreitung durch Fraß und Tritt. Die Trittwirkung war vor allem im 
Bereich der Sumpfbinsen- und Brackwasserröhrichte mit Vorkommen von Gewöhnlicher Strandsimse (Bolboschoenus maritimus), Salz-Teichbinse (Schoeno-plectus tabernaemontani) und Gewöhnlicher Sumpfbinse (Eleocharis palustris) von Bedeutung. Von der Vegetationsöffnung profitierten stellenweise niedrigwüchsige und ausdauernde krautige Feuchtwiesenarten wie Sumpfdotterblume (Caltha palustris) und Sumpf-Läusekraut (Pedicularis palustris), ferner auch seltene Seggen-Arten.

Auf das Frischgrünland als zentraler Biotoptyp im Projektgebiet hatte die Beweidung einen mittleren Einfluss. Es traten kleinflächige Verschiebungen in der Verbreitung der Pflanzengesellschaften unter Abnahme der weideempfindlichen Glatthaferwiesen auf, wobei sich die Grünflächen unter dem einheitlichen Beweidungsregime in ihrer floristischen Diversität annäherten. Ein Vergleich von Flächen mit und ohne Beweidung deutet daraufhin, dass sich eine Nutzungsaufgabe auf das Artengefüge stärker auswirkt als eine Änderung der Bewirtschaftungsform. Unter Beweidung führten die geänderten Licht- und Nährstoffverhältnisse in der Krautschicht zu einem Einwandern neuer Arten in die Grünlandgesellschaften sowie einer Verringerung von Bracheanzeigern.

Die Effekte der ungelenkten Ganzjahresbeweidung mit Pferden sind zusammenfassend als positiv zu bewerten, führten sie zu einer größeren Struktur- und Artenvielfalt. Gerade die artenarmen Fettwiesen, die erst kurz vor Beginn der Beweidung aus Ackerbrachen durch Einsaat hervorgegangen waren, profitierten davon. Vermutlich begünstigten die Pferde das Einwandern neuer Arten aus angrenzenden, artenreicheren Beständen durch Endo- und Epichorie, offene Bodenstellen an Tierpfaden und Scharrstellen sowie Dunghaufen boten Lebensraum für verschiedene Arten.

Die für das Frischgrünland beschriebenen positiven Entwicklungen trafen im Wesentlichen auch für die mageren Standorte zu, wobei der Einfluss auf den Magerrasen aufgrund der selteneren Nutzung geringer war als im Grünland. Die niedrige Turnover-Rate ist dabei durchaus positiv zu bewerten, ist eine Veränderung des Artenspektrums in diesem gefährdeten Biotoptyp nicht gewollt. Gleichwohl verhinderte die Beweidung die drohende Verbrachung. Aufgrund der etablierten Gebüschbestände von Weißdorn, Hundsrose und Schlehe im direkten Umfeld konnten die Weidetiere ein Zuwachsen der Magerrasen nicht verhindern, so dass im Jahr 2010 eine Teilrodung erfolgte.

Die Gehölze im Projektgebiet waren aufgrund ihrer Ausdehnung durchaus landschaftsprägend. Im Sinne einer halboffenen Weidelandschaft bestand dennoch der Wunsch, die Bestände aufzulichten und einzudämmen, um neue Übergangsbereiche zwischen Grünland und Wald zu schaffen (Dänisches Ministerium für Umweltschutz 2006). Die Vielfalt der Gehölze reichte von älteren Baumgruppen über kleinere artenreiche Feldgehölze und Gebüschstreifen bis hin zu angepflanzten Nadel- und Laubwäldern - so unterschiedlich war auch der Einfluss der Weidetiere auf den Baumbestand. Die Offenhaltung der Grünlandflächen und Auflichtung der Waldbestände durch Beweidung wird im folgenden Absatz thematisiert.

\subsubsection{Förderung einer halboffenen Weidelandschaft}

Der Erhalt halboffener Kulturlandschaften in Mitteleuropa erfordert eine an den Lebensraum angepasste Biotoppflege. Gerade auf produktiven Standorten schreiten Prozesse von Sekundärsukzessionen im Grünland schnell voran, so dass durch die ausgesetzte Nutzung im Zuge der Schutzgebietsausweisung bereits erste Anzeichen von einer Sukzession zu erkennen waren. Ein prioritäres Ziel des Beweidungsprojektes war daher, die anfängliche Graslandbrache aufzuhalten, die Verbuschung im offenen Weideland zurückzudrängen und die Gehölzbestände aufzulichten. Mit einer sichtbaren Reduktion der Krautschicht und der Streuauflagen im Beweidungsverlauf wurde eine Verbuschung durch Initialgehölze im Grünland verhindert: Durch Tritt und Verbiss der Baumkeimlinge und Jungpflanzen von 
überwiegend Rosa-, Prunus-, Crataegus- und anderen Laubholzarten wurden beginnende Brachen und leicht verbuschte Grünlandflächen in gehölzfreie Flächen zurückgeführt. Ähnliches stellten auch andere Autoren in Beweidungsprojekten mit Groß-Herbivoren fest (Demartin 2005, Rahmann \& Tawfik 2000, Lamoot et al. 2005, von Oheimb et al. 2006, Gerken 2008).

Obwohl in Süd-Langeland bei Futterknappheit durchaus Gehölze von den Pferden verbissen wurden, vermochten sie Gehölzbereiche mit älterem Baumbestand und Deckungsgraden von über $50 \%$ nicht aufzulichten. Die Besatzstärke reichte angesichts des großen Waldareals nicht aus. Da die Verbuschung überwiegend über die Ausbreitung von Diasporen des bereits bestehenden, hochgewachsenen Baumbestandes verursacht wird, können Weidetiere einen Gehölzaufwuchs im Weideland nur bei einer fortlaufenden Beweidung in ausreichenden Besatzdichten verhindern (von Oheimb et al. 2006). Dass wie in Süd-Langeland der Einfluss der Großherbivore auf den Gehölzaufwuchs hinter den Erwartungen des Naturschutzmanagements zurückblieb, berichten auch andere Beweidungsprojekte (Cosyns al. 2001, Holsten 2003, Demartin 2005, Lamoot al. 2005, Strohwasser 2005, von Oheimb et al. 2006). Die Weidetierart spielt hierbei eine untergeordnete Rolle: Auch bei Rindern und Schafen waren in großflächigen Beweidungsprojekten weiterhin Entkusselungen erforderlich, um die Verbreitung von Pionierarten einzudämmen. Es gibt jedoch auch positive Erfahrungen bei Pferden: Preuschhof (2005) gibt beispielsweise an, dass Islandpferde Rotbuchen, Zitterpappeln und Ebereschen im Hühnerfeld bei Göttingen schälten, was teils zum Absterben der Bäume führte. Auch im Hutewaldprojekt Solling wurden Rotbuchen von Exmoor-Ponys teils stark verbissen (Krannich 2005). In weiten Teilen des Untersuchungsgebietes verlangsamten die Ponys damit erheblich den Ausdunklungsprozess der Lichtwälder und förderten die Waldverjüngung (Zweckverband Naturpark Solling-Vogler 2006, Gerken 2008).

Im Projektgebiet nahm der Anteil an Jungpflanzen im Wald deutlich ab. Zudem zeigte sich, dass die Pferde die von der Naturschutzbehörde angelegten Waldkorridore nutzten und erweiterten. Mittelfristig kann es somit aufgrund der besseren Zugänglichkeit der Waldareale zu der gewünschten Auflichtung im Forst kommen. Mittels der Anfertigung von entsprechenden Gehölzkarten sollte diese Entwicklung weiter verfolgt werden. Eine Alternative zu den in Süd-Langeland angelegten Schneisen stellt eine Mischbeweidung von Pferden und Rindern dar: Die Rinder öffneten in Küstendünen die dichte Gebüschvegetation auf, so dass die Pferde - ihnen folgend - die nun zugänglichen Krautschichten beweideten (Lamoot 2004).

\subsubsection{Förderung von Vielfalt und Dynamik}

\subsubsection{Strukturvielfalt}

Im Projektgebiet trat eine räumlich und zeitlich heterogene Flächennutzung zutage. Wurden die Grünflächen zu Beginn der Pferdebeweidung noch gleichmäßig genutzt, stachen zunehmend, gesprenkelt über die Fläche, stärker frequentierte Bereiche hervor. Die Ergebnisse der Raumnutzung spiegeln dabei jene der Vegetationsuntersuchungen wider. Im Verlauf der Beweidung entwickelten sich große Flächen mit einer einheitlichen Vegetationsstruktur verstärkt zu einem Mosaik verschiedener Offenlandlebensräume. Vor allem im Gebietszentrum wurden die Vegetationseinheiten kleinflächiger, ihre Verteilung orientierte sich weniger an den früheren Gebietsgrenzen als an geografischen Gegebenheiten oder Nutzungspräferenzen der Weidetiere. Es kristallisierten sich zunehmend Kleinstlebensräume wie blütenreiche Hochstaudenfluren oder niedrige Pioniervegetation heraus, die eng nebeneinander lagen. Unterstützt wurde diese Entwicklung durch Maulwurfshügel, Weidetierpfade, Scharrstellen und Trittsiegeln mit stärkerer Nutzung sowie hochwüchsigen Geilstellen, wo die Sukzession fortschritt. Das ungleichmäßige Absetzen von Dung wird dabei zu einer Nährstoffumverteilung im Gebiet führen (vgl. 
LÜBW 2006, von Oheimb et al. 2006). Zudem entstanden in Süd-Langeland offene Bodenstellen an feuchten, lehmigen sowie an sandigen, trockenen Standorten.

Die Entwicklung führte insgesamt zu einer größeren Strukturvielfalt und heterogenen Ressourcenverfügbarkeit im Gebiet. Diese Heterogenität der Nutzung entspricht im Wesentlichen dem bei Pferden häufig beschriebenen Phänomen der Etablierung von Fraß- und Nichtfraßbereichen, die zur Entstehung einer vielschichtigen Vegetationsstruktur mit hochwüchsigen Geilstellen sowie intensiv beweideten Bereichen führt (Duncan 1992, Vulink 2001, Lamoot 2004, LÜBW 2006). Die natürlichen Gegebenheiten, unterschiedlicher Fraßdruck und Selektivität sowie regelmäßige Störungen und Zerstörungen der Grasnarbe rufen eine mosaikartige Diversität an Kleinstandorten hervor, in der viele Tier- und Pflanzenarten ihre Nische finden (Dierschke \& Briemle 2002, Bolz 2005, von Oheimb et al. 2006).

Eine differenzierte Nutzung der Weidefläche wird aus Naturschutzsicht nicht immer begrüßt, weil die Beseitigung der Nichtfraßbereiche eine Nachpflege erfordert (LÜBW 2006). Da diese Strukturvielfalt jedoch ein erklärtes Ziel des Schutzprojektes war, erfolgte eine Pflegemahd in Süd-Langeland nur punktuell zur Reduzierung der Distelbestände, nicht aber flächendeckend, zumal weitere negative Begleiterscheinungen extensiver Beweidungen im Grünland wie Verbrachung und Verbuschung kaum auftraten. Anders verhielt es sich im Moor, Wald und Gebüsch, deren Krautschicht kaum beweidet wurde. Diese Flächen zeigten am Ende der Vegetationsperiode zahlreiche Weiderückstände, was sich mittelfristig auf die Artenzusammensetzung auswirken wird, da die Brachsituation auf den Weideausschlussflächen bereits nach wenigen Jahren zu einer veränderten Arten- und Strukturvielfalt führte.

\subsubsection{Floristische Diversität}

Das neue Beweidungsregime wirkte sich bis auf das Artniveau aus: Bereits nach drei Untersuchungsjahren zeigte sich eine leichte, statistisch signifikante $(p<0,001)$ Artenzunahme im Grünland um 2-3 Arten, ohne dass es zu einem vermehrten Wachstum von Weideunkräutern oder trittunempfindlichen Arten kam (s. 6.4.1.4 Artenreichtum und Diversität). Die Vegetation war gleichmäßiger auf verschiedene Arten verteilt, die Evenness-Werte auf den untersuchten Grünländern stiegen signifikant an $(p<0,05)$. Die Pferdebeweidung wirkte damit der Dominanz und Herdenbildung als typische Anzeichen von Brachlandsukzessionen entgegen.

Das Ziel des Projektes war es, die standorttypische Artenvielfalt der dänischen Kulturlandschaft zu fördern. Die Pferdebeweidung führte zu Veränderungen im Artengefüge. Aufgrund der heterogenen Ausgangssituation der Teilflächen entwickelten sich die Flächen unterschiedlich, so dass es schwierig ist, die Entwicklung als negativ oder positiv einzustufen. Im Untersuchungszeitraum nahm die Biodiversität auf den Grünlandflächen zu. Dies ist im Wesentlichen auf das Einwandern von Arten aus benachbarten Flächen zurückzuführen. Dieser Prozess schreitet, wie mehrfach belegt wurde (u.a. Fischer 1987, Jensen 1998, Thorn 2000), gerade bei Graslandarten nur sehr langsam voran. Hier haben die Ponys vermutlich die wichtige Rolle des Diasporentransportes übernommen, so dass sich Wiesen- und Weidenarten im Projektgebiet zunehmend vermischten.

Ein Neuauftreten von Pflanzenarten wurde im Untersuchungszeitraum kaum beobachtet. Dies lässt Rückschlüsse auf das vorhandene Samenpotenzial im Gebiet zu. Zwar wird die Samenkeimung zurückgegangener oder verschwundener Arten durch eine Reduktion der Brachauflagen angekurbelt, so dass manche Arten wieder auftauchen (Dierschke \& Briemle 2002). Da ein Großteil der Graslandarten jedoch keine dauerhaft keimfähigen Samen im Boden akkumuliert (Thompson et al. 1997, Bekker et al. 1998), wird die fortschreitende Graslandregeneration im Projektgebiet aufgrund der langjährigen intensiven landwirtschaftlichen Ackernutzung vor dem Extensivierungsbeginn im Jahr 2006 vermutlich kaum durch Samenreserven erfolgen. 
Auf der Artenliste stechen vereinzelt besonders geschützte Arten hervor wie Breitblättriges Knabenkraut (Dactylorhiza majalis), Knöllchen-Steinbrech (Saxifraga granulata) oder Wiesen-Schlüsselblume (Primula veris), deren Vorkommen auf Sonderstandorte zurückzuführen sind. Diese naturschutzfachlich hochwertigen Lebensräume wie Sumpfdotterblumenwiesen und Magerrasen nahmen bislang durch die extensive Pferdebeweidung aufgrund geringer Weideintensitäten keinen Schaden. Eine Unempfindlichkeit seltener und gefährdeter Arten wie Orchideen gegenüber Beweidung bis hin zu ihrer Förderung zeigen auch andere Studien zu Extensivbeweidungen (Schmidt \& Becker 2000, Köhler et al. 2013). Hierzu sind langjährige Untersuchungen im Projektgebiet erforderlich.

Die dominierenden Lebensraumtypen des Projektgebietes, die frischen, artenreichen Grünländer entwickelten sich unter Pferdebeweidung grundsätzlich positiv: Unterschiedlich in ihrem Feuchtegrad und Nährstoffgehalt, näherten sich die Weiden und Wiesen einander in ihrer floristischen Diversität an. Die Ausdehnung der artenreichen Glatthaferwiesen im Gebiet hat sich zwar leicht verringert. Doch gerade der Trend der zuvor sehr artenarmen Weiden oder der in ihrer Artenzusammensetzung nicht natürlichen und monotonen Saatwiesen hin zu Grünländern mit höherer Diversität zeigt positive Effekte einer extensiven Pferdebeweidung auf. Das Gebiet eignet sich aufgrund der dominierenden, von Natur aus eher produktiveren Grünlandstandorte zwar nicht für die Förderung bedrohter Vegetationstypen, da viele der bedrohten Arten auf magere Standorte angewiesen sind (Blab 1993), die bislang im Gebiet nur kleinflächig vertreten sind. Die Extensivierung der ehemals intensiv bewirtschafteten Flächen hilft dennoch dem Arten- und Biotopschutz, da ein großer Prozentsatz der bestandsbedrohten Tier- und Pflanzenarten auf extensiv genutzte Flächen angewiesen ist (Dierschke \& Briemle 2002) und hier möglicherweise Ersatzlebensräume vorfindet.

Im Hinblick auf die angewandte Methodik lässt sich zusammenfassen, dass die Datenerfassung auf unterschiedlichen Skalenniveaus zu guten Ergebnissen führte. Die Daten zur Erfassung der Vegetationsveränderungen auf einem mittleren Skalenniveau ergänzten bei geringem Personal- und Materialaufwand sowohl die detaillierten pflanzensoziologischen Aufnahmen auf den Vegetations- und Strukturdauerflächen als auch die Auswertung der Satellitenaufnahmen.

\subsubsection{Vergleich zu anderen Beweidungsprojekten}

Die beobachteten Auswirkungen der Pferdebeweidung auf die Vielfalt und Dynamik der Landschaft im Projektgebiet stehen im Einklang mit den Ergebnissen anderer Beweidungsprojekte, in denen Großherbivore in großflächiger Ganzjahreshaltung eingesetzt wurden (u.a. Solling-Vogler: Richter-Scheidweiler 2004, Gundelfinder Moos: Demartin 2005, Hühnerfeld: Preuschhof 2005, Moosheide / Senne: Rüther \& Venne 2005, Höltigbaum: von Oheimb et al. 2006, Tote Täler: Köhler et al. 2013).

Im Hutewaldgebiet Solling-Vogler, in dem Exmoor-Ponys und Rinder gemeinsam leben, waren die mittleren Artenzahlen auf den beweideten Flächen höher als auf den unbeweideten. Der Anteil an offenen Boden war größer im beweideten Grünland, was konkurrenzschwachen Arten und Rohbodenkeimern bessere Ansiedlungsmöglichkeiten bot (Richter-Scheidweiler 2004). Auch laut Mann \& Tischew (2010) ist eine extensive Ganzjahresbeweidung mit Megaherbivoren eine geeignete Methode für die Renaturierung artenreicher Grünlandbestände auf ehemals intensiv ackerbaulich genutzten Flächen. Neben der extensiven Beweidung sei zudem die Anhebung der Grundwasserstände wichtig für die positive Entwicklung der Grünlandbestände im Wulfener Bruch gewesen, da seltene Arten die nassen Böden schneller besiedelten. Vermutlich hatte die Einstellung der Entwässerungsmaßnahmen in Süd-Langeland zu Beginn der Pferdebeweidung einen ähnlich positiven Einfluss auf die Entwicklung der Grünländer, der - da er zeitgleich begann - vom Effekt der extensiven Pferdebeweidung nicht zu trennen ist.

Es gibt in jüngerer Zeit durchaus auch negative Erfahrungsberichte aus extensiven Beweidungsprojekten. Eine langjährige Beweidung von Grünlandbiotopen mit Galloways in Niederbayern wirkte sich zum 
Teil negativ auf seltene und gefährdete Pflanzenarten von Wiesenbiotopen aus (Regierung von Niederbayern 2008). Feuchte bis wechselfeuchte Ausbildungen von mageren Flachland- und Berg-Mähwiesen sowie Pfeifengraswiesen vertrugen die extensive Umtriebswiese dabei schlechter als frische bis trockene Ausbildungen. Das Weidemanagement muss daher an die standörtlichen Gegebenheiten angepasst werden, was einen erhöhten Arbeits- und Kostenaufwand mit sich zieht.

Die Ergebnisse der vorliegenden Studie legen nahe, die Vegetationseinheiten einer gewissen Dynamik unterlagen, von der maßgeblich das Potentillion anserinae und das Lolio-Cynosuretum typicum betroffen waren. Auf dem Großteil der Flächen blieb die Pflanzengesellschaft nach drei Beweidungsjahren jedoch unverändert. Auch in der Camargue veränderten sich die Pflanzenbestände im Grünland unter langjähriger Pferdebeweidung nur langsam (Duncan 1992), während im Höltigbaum 50 \% der Flächen nach vier Jahren einen anderen Vegetationstyp aufwiesen (von Oheimb et al. 2006). Diese Unterschiede begründen sich möglicherweise dadurch, dass die Weideflächen im Höltigbaum nährstoffärmer waren und der ehemalige Truppenübungsplatz zuvor nicht beweidet wurde, während in Süd-Langeland bereits früher Rinder und Schafe auf Teilflächen grasten.

\subsubsection{Ausmagerung von Grünlandflächen}

Die Grünflächen im Untersuchungsgebiet wurden seit dem Jahr 2006, teilweise bereits seit den 1990er Jahren nicht mehr gedüngt. Die Pferde ernährten sich ausschließlich vom Aufwuchs im Gebiet, auch im Winter wurde nicht zugefüttert. Mahdschnitte erfolgten nur partiell im Abstand von zwei Jahren, um den Tieren kein Futter für die Wintermonate zu entziehen. Obwohl der Dung im Gebiet verblieb, zeigten die Vegetationserhebungen keine Zunahme von Stickstoffanzeigern auf den Weideflächen an. Da durch Pferdebeweidung - anders als bei Wiederkäuern, die einen geringen Teil des aufgenommenen Stickstoffs über Fleisch, Milch oder Wolle von der Fläche exportieren (Bauschmann 2005) - nahezu keine Nährstoffe entzogen werden, ist die Ausmagerung der Grünlandflächen in Süd-Langeland vermutlich gering. Die Standweide ist zudem eine Nutzungsform mit geringen Nährstoffentzügen, so dass eine Aushagerung ein langfristiger Prozess ist (Ellenberg 1986, Tesch 1999). Ein Nährstoffentzug auf den Grasfluren wird sich daher erst nach einer längeren Beweidungsdauer bemerkbar machen.

Auch anderenorts war eine Aushagerung von nährstoffreichen Flächen durch extensive Beweidung gering (vgl. Holsten 2003). Dennoch sollte es ein Ziel des Naturschutzmanagements im Projektgebiet sein, das ehemals intensiv genutzte Grünland in Extensivgrasland und Magerrasen zu überführen, da gerade diese Flächen für bedrohte und seltene Graslandarten von Bedeutung sind. Die damit verbundene Degradation des Grünlandes (Dierschke \& Briemle 2002) stellt bei genügsamen Weidetierarten wie dem Exmoor-Pony kein Problem dar (vgl. LÜBW 2005). 


\subsection{Auswirkungen der Beweidung auf die Fauna}

Gleichwohl im Projektgebiet nur wenige gefährdete Tierarten nach der Flora-Fauna-Habitat-Richtlinie (1992) vorhanden sind, bietet das Gebiet biozönotisch bedeutende Ökotonstrukturen wie Feldgehölze, Gebüsche, Säume und Offenland an, die für eine Reihe von Arten von Bedeutung sind. Durch die Grundwasseranhebung und Extensivierung zu Beginn der Schutzgebietsausweisung im Jahr 2006 wurde das Gebiet weiter renaturiert, so dass es heute einen wertvollen Lebensraum inmitten der intensiv genutzten Agrarlandschaft Dänemarks darstellt.

Da tierökologische Analysen im Untersuchungszeitraum nicht erfolgten, werden die festgestellten Veränderungen durch die extensive Pferdebeweidung im Hinblick auf die zu erwartende Fauna mitteleuropäischer Kulturlandschaften diskutiert. Es werden kurz die Anforderungen der charakteristischen Artengruppen der Vögel, Amphibien und Insekten an ihren Lebensraum skizziert und anschließend bewertet, wie sich die Beweidung mit Exmoor-Ponys auf deren Vorkommen auswirken würde.

\subsubsection{Anforderungen von Tierarten an ihren Lebensraum}

Nicht nur zwischen, auch innerhalb der Tiergruppen divergieren die Lebensraumansprüche der Arten stark. Beispielsweise benötigen einige Arten innerhalb der Artengruppe der Wiesenvögel sehr offene und weite Strukturen, wie sie beispielsweise in Küstennähe vorzufinden sind, während andere offene, aber dennoch strukturierte Landschaften bevorzugen, wie sie im Projektgebiet Süd-Langeland vorherrschen. Auch unterscheiden sich die Ansprüche von Rast- und Durchzugsvögeln teils deutlich von denen, die in einem Gebiet im Offenland brüten. Es werden daher schwerpunktmäßig Arten betrachtet, die für die angestrebten Naturschutzziele im Projektgebiet von Bedeutung sind: Diese sind vor allem der Schutz von Brut- und Zugvögeln sowie der Erhalt seltener Amphibienarten. Auch die Bedeutung der Entomofauna wird hervorgehoben.

Weiden und Wiesen bilden wichtige Ressourcen für die Arten des Kulturgraslandes, denn eine strukturreiche Offenlandschaft deckt die Bedürfnisse vieler Arten ab. Zwar werden in Graslandökosystemen vor allem Tierarten gefördert, die Vermehrungsstrategen wie beispielsweise die Feldmaus sind. Es gibt aber auch eine Reihe stenöker Arten, die vor allem im nährstoffärmeren Feuchtgrasland beheimatet sind (Kratochwil \& Schwabe 2002). Zu erwähnen sei auch die Gruppe der Habitatwechsler, die auf eine strukturelle Habitatvielfalt angewiesen ist. Hierzu gehören unter anderem Moorfrosch und Kammmolch sowie Nachtfalter, deren Entwicklungsstadien - Larve und Imagines - unterschiedliche Habitate bewohnen (von Oheimb et al. 2006).

Die meisten Arten des Offenlandes haben gemeinsam, dass sie durch die natürliche Sukzession sowie der Verlandung von Gewässern in ihrem Bestand gefährdet sind, da sie bei einer weitgehenden Selbstentwicklung der Natur keine geeigneten Flächen für die Nahrungssuche und Brut vorfinden. Für Vögel ist dabei die Vegetationsstruktur der wichtigste Faktor für die Habitatwahl. Von einer niedrigeren Vegetationsstruktur und Offenbodenstellen profitieren alle Arten, die am Boden ihre Nahrung suchen. Dies trifft sowohl für die bereits erwähnten Limikolen zu, für die vor allem kurzrasige Flächen im späten Frühjahr wichtig sind (Demartin 2005), als auch für Feldlerchen, die großflächige Offenlandschaften mit lückiger Vegetation benötigen (Holsten 2003). Gerade in nährstoffreichen Habitaten besteht die Gefahr, dass die Krautschicht rasch aufwächst oder von der Flatterbinse (Juncus effusus) dominiert wird (Pegel 2002). Zudem sind für Limikolen der Prädatorendruck oder mögliche Veränderungen im Nahrungsangebot durch Versauerung wichtig (Vulink 2001). 
Bei Insekten ist aufgrund des kleineren Aktionsradius neben der Vegetationsstruktur auch die Artenzusammensetzung und der Feuchtegrad des Grünlandes von großer Bedeutung: Die meisten Zikadenarten ernähren sich beispielsweise von Süßgräsern, Seggen und Binsen, doch kommen bestimmte Arten nur in Arrhenatheretalia-, andere nur in Molinietalia-Gesellschaften vor (Kratochwil \& Schwabe 2002). Wildbienen sind zumeist wärmeliebend und profitieren ebenso wie Tagfalter von artenreichen und nicht gedüngten Grünländern (Holsten 2003). Auch viele Hummelarten ziehen blütenreiche Glatthaferwiesen anderen Biotopen vor (Kratochwil \& Schwabe 2001). Aufgrund der häufig sehr spezifischen Lebensraumanforderungen von Insektenarten können sich Veränderungen in der Flächennutzung gravierend auf kleinere Populationen auswirken (Holsten 2003).

\subsubsection{Vorkommen besonderer Tierarten im Projektgebiet}

In Süd-Langeland leben zahlreiche typische Säugetierarten der mitteleuropäischen Kulturlandschaft: Alles- und Pflanzenfresser wie Gelbhalsmaus (Apodemus flavicollis), Feldmaus (Microtus arvalis), Feldhase (Lepus europaeus) und Reh (Capreolus capreolus) sowie Raubsäuger wie Rotfuchs (Vulpes vulpes) oder verschiedene Marder (Dachs, Steinmarder, Wiesel, Iltis).

Von Bedeutung ist das Südfünische Inselmeer, in dem das Projektgebiet liegt, vor allem als Brutgebiet und Ruheplatz für tausende von Stand- und Zugvögeln. Das Moor Gulstav Mose mit einer Fläche von rund 7 Hektar wurde daher im Jahr 1971 als Vogelschutzgebiet ausgewiesen (Dänisches Ministerium für Umweltschutz 2003). 232 Vogelarten wurden hier gesichtet. Den Status als internationales Naturschutzgebiet verdankt Langelands Südspitze den Brutkolonien von Möwen (Sturmmöwen, Lachmöwen, Silbermöwen, Mantelmöwen) und Seeschwalben (Küstenseeschwalben, Zwergseeschwalben, Brandseeschwalben, Flussseeschwalben). Auch teils stark gefährdete Limikolenarten kommen hier vor, unter ihnen Bekassine, Doppelschnepfe, Austernfischer, Kiebitz, Sandregenpfeifer, Rotschenkel und seltener Säbelschnäbler, Pfuhlschnepfe und Alpenstrandläufer (Dansk Ornitologisk Forenings, www.dofbasen.dk, Stand Juli 2014). In der halboffenen Kulturlandschaft Süd-Langelands finden Rebhühner, Fasane und Feldlerchen gute Lebensbedingungen (Dänisches Ministerium für Umweltschutz 2006). Zahlreiche Graugänse nutzen das Gebiet als Rast- und Nahrungshabitat.

Besonders hervorzuheben sind seltene Vorkommen von Amphibien und Reptilien im Gebiet: Die Rotbauchunke (Bombina bombina) wurde in den Neunziger Jahren gezielt wieder angesiedelt (Dänisches Ministerium für Umweltschutz 2006). In den Gewässern sind auch der Nördliche Kammmolch (Triturus cristatus), der Moorfrosch (Rana arvalis) und der Springfrosch (Rana dalmatina) vertreten. Die Zauneidechse (Lacerta agilis) bevorzugt hingegen die trockenen Standorte der Lesesteinriegel. Im Projektgebiet treten zahlreiche Tag- und Nachtfalterarten auf, die jedoch mit Ausnahme des Zitronenfalters (Gonepteryx rhamni) und des Kleinen Eisvogels (Limenitis camilla) allesamt häufig sind (Dansk Ornitologisk Forenings, www.dofbasen.dk, Stand Juli 2014).

\subsubsection{Auswirkungen der Pferdebeweidung aus tierökologischer Sicht}

Populationen unterschiedlicher Tiergruppen werden direkt oder indirekt durch das Weidemanagement beeinflusst (Kratochwil \& Schwabe 2002). Zur Wirkung der extensiven Beweidung auf die Fauna liegen bislang sehr heterogene und auch divergierende Erkenntnisse und Ansichten vor (Regierung von Niederbayern 2008). Da die Pflege von floristisch und faunistisch bedeutsamen Lebensräumen mit Weidetieren im Naturschutz zunehmend an Bedeutung gewinnt, werden die Auswirkungen auf bestimmte Tiergruppen in den vergangenen Jahren intensiver untersucht (u.a. Kratochwil \& Schwabe 
2001, Holsten 2003, Bolz 2005, Demartin 2005, Rüther \& Venne 2005, von Oheimb et al. 2006). Das Hauptaugenmerk liegt dabei auf Vogel- und Insektenarten, weidebedingte Veränderungen bei Säugetieren und Amphibien werden seltener erfasst.

Die Pferdebeweidung im Projektgebiet reduzierte den Aufwuchs der Vegetation so stark, dass offene Weideflächen und kurzrasige Bereiche entstanden. Diese bieten einen Lebensraum für Arten des offenen Weidelandes. Gleichzeitig entwickelte sich aufgrund der selektiven Nahrungsweise der Pferde ein kleinräumiges Mosaik unterschiedlicher Habitatstrukturen im Gebiet mit kurz gefressenen Grünflächen sowie Hochstaudenbereichen und Säumen im Übergang zu Gehölzen. Saisonale Präferenzen veränderten den Weidedruck auf die jeweiligen Habitate. Großflächige ganzjährige Beweidungsprojekte bewirken somit - ähnlich wie andere rotierende Systeme - eine zeitlich-dynamische Flächennutzung, die für jene Arten wichtig ist, die auf eine strukturelle Habitatvielfalt angewiesen sind. Zudem wird das Nahrungsangebot für die Vogelwelt verbessert, da der Bewuchs während des ganzen Jahres sehr heterogen ist und sich damit immer wieder neue Nahrungshabitate ergeben (Demartin 2005). Die auftretenden Weiderückstände sind aus agrarwirtschaftlicher Sicht zwar nicht erwünscht, sie stellen aber für Wildtiere eine wichtige Nahrungsgrundlage dar oder bieten interessante Habitatstrukturen für Kleinsäuger und Insekten (vgl. Holsten 2003, LÜBW 2006). Die durch die Trittwirkung der Pferde entstandenen offenen Bodenstellen sind zudem für xerotherme Arten von Bedeutung (Bolz 2005).

Die Ergebnisse im Projektgebiet deuten darauf hin, dass sich eine großflächig ungesteuerte, extensive Beweidung aufgrund der entstandenen Strukturvielfalt und der Grünlandextensivierung nicht negativ auf die Fauna auswirkt. Auch andere Autoren kommen zu dem Schluss, dass es kurzfristig zu positiven Effekten für bestimmte Tierarten kommt (u.a. Pfadenhauer 1999, Schrautzer 2001, Bolz 2005, Rüther \& Venne 2005, von Oheimb et al. 2006, Köhler et al. 2013). Die Auswirkungen einer Beweidung müssen jedoch differenziert für unterschiedliche Artengruppen, Beweidungszeiträume und Lebensraumtypen betrachtet werden, da sich die Zoozönosen des Kulturgraslandes mit zunehmender Beweidungsdauer verändern. Gerade ein Nutzungswechsel wirkt sich zunächst stark auf die Zusammensetzung der Bodenfauna oder die Insektenbestände aus, diese stabilisieren sich jedoch nach einigen Beweidungsjahren wieder (Kratochwil \& Schwabe 2002).

\subsubsection{Avifauna}

Für die Vogelwelt ergeben sich überwiegend positive Effekte durch eine Beweidung. Fraß in Röhrichten drängt dominante Schilfbestände (Phragmites australis) zurück und stellt dadurch die aus avifaunistischer Sicht erwünschten offenen Wasserflächen und niederwüchsigen Vegetationsbestände wieder her, wie auch niederländische Beweidungsprojekte im Beltringharder Koog und in Oostvaardersplassen zeigten (Vulink 2001, Gruber 2002). Dies wirkte sich positiv auf die Limikolenbestände aus.

Die ehemaligen Ackerflächen im Projektgebiet wiesen bisher eine geringe Brutplatzqualität auf. Die Attraktivität dieser Flächen für die Vogelwelt ist durch die Nutzungsänderung und Extensivierung gestiegen. Anders verhält es sich bei den Brachen ruderaler Glatthaferwiesen im Gebiet. Sie sind oft attraktive Vogellebensräume (Flade 1994, Handke 1997), ihre Beweidung kann daher zu einem Rückgang von Arten wie Feldschwirl, Sumpfrohrsänger oder Schlagschwirl führen. Während sich eine Zunahme von Übergangsbereichen und Gehölzinseln vorteilhaft auf Arten der Säume wie den Neuntöter auswirkt (von Oheimb et al. 2006), beeinflusst Tritt direkt und indirekt den Bruterfolg von boden- oder bodennah brütenden Vogelarten. Je nach Vornutzung der Flächen profitieren somit unterschiedliche Vogelarten von einer extensiven Beweidung (vgl. Holsten 2003). 


\subsubsection{Entomofauna}

Zu Insekten liegen im Gegensatz zur Avifauna keine Artenlisten über rezente Vorkommen im Projektgebiet vor. Aus anderen Untersuchungen wird berichtet, dass Vorkommen gefährdeter Heuschreckenund Schmetterlingsarten beispielsweise von einer Beweidung mit Pferden in Allein- oder Mischhaltung profitieren, und zwar sowohl auf trockenen, steinigen als auch auf offenen, dynamischen Sandstandorten (Bolz 2005, Bromisch 2005). Sogar in Feuchtgebieten brachte der oft als kritisch eingestufte Tritt von Pferden neue, für spezialisierte Arten wichtige Lebensräume hervor: Die weidebedingten Störstellen wurden von konkurrenzschwachen Arten besiedelt (Bolz 2005, Demartin 2005).

Wärmebedürftige Wildbienen- und Tagfalterarten haben Vorteile bei einer niedrigen Vegetationsdecke (Westrich 1989, Settele et al. 1999). Auch Tritt wirkt sich für einige Wildbienenarten positiv aus, wenn Abbruchstellen auf Mineralboden geschaffen werden, die als Nistplätze genutzt werden können. Andererseits leiden Raupen und Puppen von Tagfaltern unter dem Tritt der Großsäuger (Holsten 2003). Von Oheimb et al. (2006) heben zahlreiche positive Effekte einer extensiven Rinderbeweidung in einer halboffenen Weidelandschaft hervor, die auch für Pferde zutreffen müssten: Von der Strukturvielfalt profitieren Habitatwechsler wie Nachtfalter, von einem zunehmenden Blütenangebot (Acker-Kratzdistel, Knautie, Jakobs-Greiskraut) blütenbesuchende Insektenarten. Kleinflächige Habitatmosaike und ein Nebeneinander von kurz- und langrasigen Bereichen sind wichtig für Heuschrecken, Laufkäfer und Spinnen sowie Stechimmen und Nachtfalter. Auf den durch Tritt verursachten Rohböden finden sich mehr Laufkäfer und bodenbewohnende Spinnen. Die offenen, sonnigen Uferbereiche sind Libellen wichtig. Auch Rüther \& Venne (2005) stellten fest, dass Heuschrecken unter extensiver Pferdebeweidung trockener Sandstandorte in Abhängigkeit von der Beweidungsintensität in den Arten- oder Individuenzahlen zunahmen.

Eine Studie aus Bayern auf wechseltrockenen bis wechselfeuchten Standorten weist jedoch darauf hin, dass bei einer langjährigen, extensiven Standweide mit Rindern die Weideflächen zunehmend vergrasen (Regierung von Bayern 2008). Vor allem die Bestände von als gefährdet eingestuften, xerothermophilen Heuschrecken sowie von Saumbewohnern, die trockenwarme Lebensräume bevorzugen, gingen hierbei zurück, während sie auf einer gemähten Vergleichsfläche nahezu unverändert blieben. Es verblieben nur noch Ubiquisten sowie Heuschreckenarten, die für mesophiles Berggrünland typisch sind. Auch für Insekten sind daher langjährige Untersuchungen von großer Bedeutung, um die Folgen einer extensiven Beweidung für bedrohte Arten vorhersagen zu können.

\subsubsection{Amphibien}

Die im Projektgebiet vorkommende Rotbauchunke benötigt Stillgewässer mit schwankenden Wasserständen und flachen, reich strukturierten und sonnenexponierten Uferbereichen (Raabe 1951, Günther \& Schneeweiß 1996, Frenz 2004). Die Pferde suchten regelmäßig die für die seltenen Amphibien angelegten, flachen Teiche an der Nordspitze auf. Durch Fraß und Tritt verhinderten die Weidetiere die Entstehung von hochwüchsigen Einartröhrichten an diesen Kleingewässern und förderten eine für Rotbauchunken wichtige, artenreiche Wasservegetation (Raabe 1951, Andersen 1996). Auch andere Amphibienarten profitieren laut von Oheimb et al. (2006) von einer extensiven Beweidung: Die zunehmende Verzahnung verschiedener Lebensraumtypen und Strukturen wirkt sich positiv auf Habitatwechsler wie den Moorfrosch und den Kammmolch aus, beide Arten kommen im Projektgebiet vor. 


\subsubsection{Kophrophagen}

Pferdebeweidung wirkt sich nicht nur indirekt auf die Fauna durch die landschaftsgestaltende Tätigkeit ihres Fraß-, Tritt- und Kotverhaltens aus, die in dieser Arbeit im Vordergrund stand, sondern auch direkt durch eine Förderung von Tierarten, die an den Tierorganismus gebunden sind wie Ekto- und Endoparasiten (Bolz 2005). Zudem führen Dung- und Urinablagerungen zu lokalen Nährstoffanreicherungen, ein wichtiges Mikrohabitat für koprophage Wirbellose (Holsten 2003). Pferdedung wird als Brutsubstrat von etlichen Insekten begehrt, zum Beispiel von Mistkäfern und zahlreichen Arten von Blatthornkäfern (Bolz 2005).

\subsubsection{Fazit}

Die Auswirkungen der extensiven Pferdebeweidung auf die unterschiedlichen Tiergruppen werden in Abb. 87 und Abb. 88 zusammenfassend dargestellt. Dabei wird deutlich, dass sich ein Merkmal auf eine Tiergruppe fördernd, auf eine andere hingegen bestandsgefährdend auswirken kann. Eine pauschale Bewertung von extensiven Beweidungsformen ist daher selten zielführend. Vielmehr muss festgelegt werden, ob gezielt bestimmte Arten geschützt werden sollen und welche Maßnahmen hierfür erforderlich sind, da eine nicht-gesteuerte Beweidung nicht den Bedürfnissen aller Arten gerecht werden kann (vgl. Holsten 2003). In Süd-Langeland wurde als Pflegeziel eine naturnahe Entwicklung ohne konkrete Zielvorgabe, allenfalls die Wiederherstellung artenreicherer Systeme in der intensiv genutzten Agrarlandschaft angestrebt, was ein Erreichen des Schutzzieles erleichterte.

Die Überlegungen zu Auswirkungen einer Pferdebeweidung aus tierökologischer Sicht werfen - trotz der beobachteten ersten positiven Effekte auf die im Projektgebiet vorkommenden Tierarten - Fragen auf, die nur durch eine systematische Erfassung von relevanten Tierbeständen im Gebiet beantwortet werden können. Ob eine kontrollierte Beweidung einer ungesteuerten vorzuziehen ist, bleibt jedoch fraglich. Denn das Konzept zur Entwicklung halboffener Weidelandschaften setzt eine unbeeinflusste, naturnahe Entwicklung der Flächen voraus, bei der die eingesetzten Großherbivoren die Landschaft durch ihre Lebensweise gestalten, und nicht der Mensch (Kampf 2000, Bunzel-Drüke et al. 2001). Dass es hierbei zu einem Verlust von Arten - teils auch von seltenen Arten - kommen kann, ist unbestritten. Dies trifft vor allem für geschlossene Populationen von lokal in einem Gebiet verbreiteten Insektenarten mit speziellen Ansprüchen an die Vegetationsstruktur und Störungsintensitäten zu (Holsten 2003). Geht es also wie beispielsweise auf ehemaligen Truppenübungsplätzen oder Heideflächen um die Erhaltung von Zielarten in ihrem Ökosystem (Kampf 2000) und weniger um die Sicherstellung einer Offenhaltung der Landschaft durch eine großflächige extensive Beweidung, so ist eine kontrollierte Beweidung zu bevorzugen (Holsten 2003). Steht hingegen - wie im Projektgebiet Süd-Langeland - die Entwicklung einer halboffenen Natur- und Kulturlandschaft im Vordergrund, die eine artenreiche, standorttypische Flora und Fauna aufweist, so bietet eine extensive, ganzjährige Pferdebeweidung ohne Koppelung gute Voraussetzungen zum Erreichen der formulierten Naturschutzziele. Zumal durch die Ansiedlung des Exmoor-Ponys im Projektgebiet ein wichtiger Beitrag zum Erhalt dieser seltenen ursprünglichen Pferderasse getätigt wurde.

Da verbesserte Lebensbedingungen für die heimische Fauna ein Ziel des Langeländer Beweidungsprojektes ist, sind die fehlenden systematischen faunistischen Erhebungen im Gebiet kritisch zu sehen. Die hier untersuchten Veränderungen der Vegetation und Struktur im Projektgebiet lassen nur die Vermutung zu, dass sich die Biodiversität durch die Pferdebeweidung erhöhen wird. Bestandskartierungen relevanter Tierartengruppen werden dringend empfohlen. 


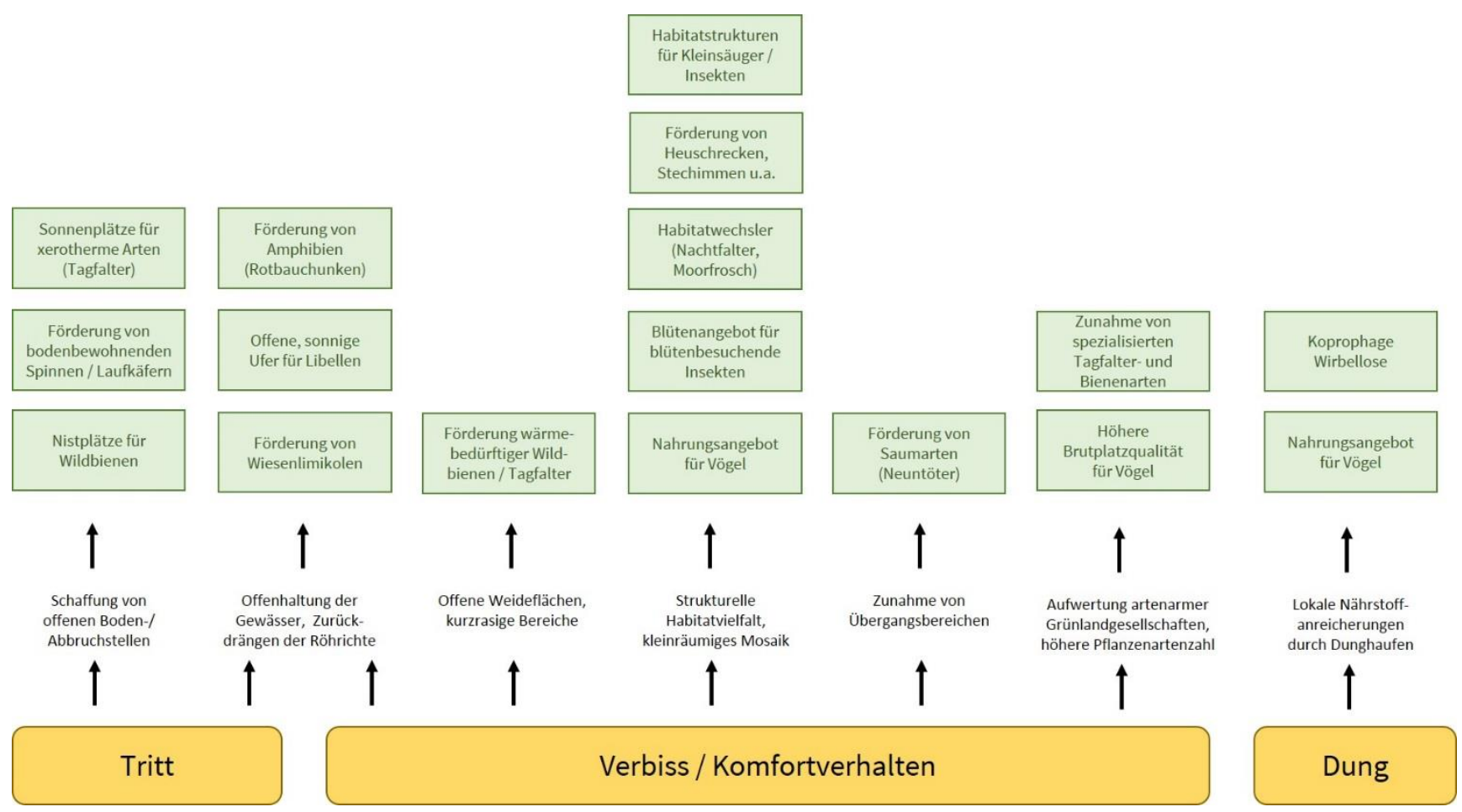

Abb. 87: Mögliche positive Auswirkungen einer extensiven Pferdebeweidung auf die Fauna der mitteleuropäischen Kulturlandschaft

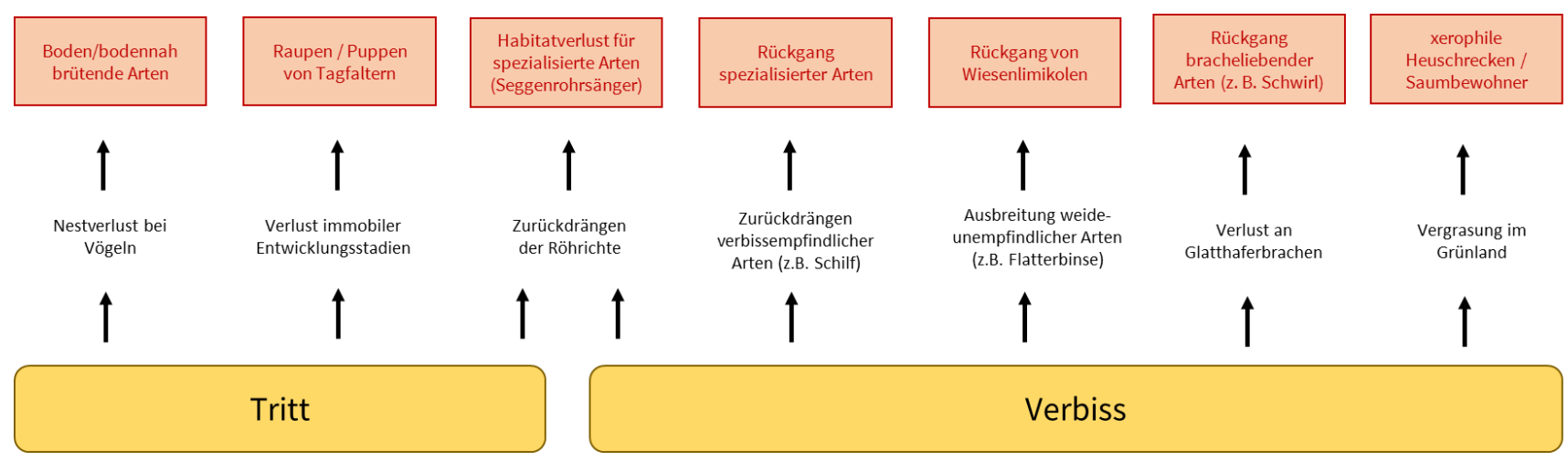

Abb. 88: Mögliche negative Auswirkungen einer extensiven Pferdebeweidung auf die Fauna der mitteleuropäischen Kulturlandschaft 


\section{4 Übertragbarkeit der Ergebnisse}

Die Auswirkungen einer Pferdebeweidung auf die Flora und Fauna hängen stark von der Ausgangssituation der zu beweidenden Fläche ab. Weisen Flächen ähnliche abiotische Bedingungen auf und wird ein vergleichbares Weidemanagement gewählt, sind viele der im Projektgebiet Süd-Langeland gewonnenen Ergebnisse auf andere Beweidungsprojekte übertragbar. Diese Einschränkung ist erforderlich, da sich bestimmte Faktoren wie beispielsweise der Wasser- oder Nährstoffgehalt sowie frühere Nutzungsformen entscheidend auf die Vegetations- und Strukturentwicklung eines Gebietes auswirken können. Auch der Einfluss von Weidetieren auf die örtliche Fauna hängt ganz wesentlich von den Ansprüchen der Tierarten an ihren Lebensraum ab, ebenso vom gewählten Weidemanagement und - bei ungesteuerter Beweidung - der tatsächlichen Attraktivität einzelner Biotope für die Weidetiere.

\subsubsection{Weidemanagement}

Im Projektgebiet Süd-Langeland wurden ausschließlich Exmoor-Ponys, eine sehr ursprüngliche, robuste Pferderasse, eingesetzt. Ganzjährige Beweidungen mit Pferden werden in Naturschutzprojekten bislang selten erprobt. Dieses Weidemanagement stellt daher bereits eine Besonderheit dar. Die Ergebnisse lassen sich nicht oder nur eingeschränkt auf Beweidungen mit anderen Arten übertragen, da Weidetiere sehr unterschiedliche Nahrungspräferenzen, Fraßtechniken und Trittwirkungen haben (s. 2.4.3 Vergleich von Pferden zu anderen Weidetierarten). Die Ponys zeichneten sich durch ihr selektives Nahrungsverhalten, einen heterogenen Nährstoffeintrag durch die Anlage konzentrierter Kotstellen sowie eine starke bodenverdichtende Wirkung durch Tritt aus. Da Pferde klassische Grasfresser sind, war ihr Einfluss auf Gehölzbestände eher gering. Die Wahl der Nutztierart sollte daher auf die gewünschten Naturschutzziele im Gebiet angepasst sein.

Die Besatzstärke im Projektgebiet war im Untersuchungszeitraum nicht konstant, da sich die Herde durch Geburten stark vergrößerte. Die maximale Bestandsgröße wurde nicht natürlich durch dichteabhängige Faktoren wie Ressourcen oder Konkurrenz geregelt, sondern durch eine gezielte Bestandsregulierung. Die maximale Besatzdichte wurde dabei aus der berechneten Tragekapazität der Weideflächen abgeleitet, die die örtlichen Boden- und Klimaverhältnisse berücksichtigte (vgl. Messerer 2006). Eine Anpassung der Besatzstärke an die abiotischen Bedingungen im Gebiet ist zwingend erforderlich, um Unter- oder Überbeweidung zu verhindern. In die Betrachtung potenzieller Nahrungsflächen der Pferde wurden Gehölze und Gewässer nicht einbezogen, gleichwohl sie beweidet wurden. Diesen Habitaten kommt zwar eine große Bedeutung als Strukturelemente und im Hinblick auf ein artgerechtes Tierverhalten zu, ihr Nährwert ist aber gering.

Das Weidemanagement war entscheidend für die Entwicklung der Pflanzenbestände im Untersuchungsgebiet. Die durchgängige Beweidung aller Teilbereiche war dabei ein wichtiger Einflussfaktor, da die Pferde eine saisonal unterschiedliche Raumnutzung aufwiesen. Bestimmte Weideeffekte stellen sich erst ein, wenn die Tiere auch im Winterhalbjahr auf der Fläche gehalten werden (vgl. Bromisch 2005, Krannich 2005, von Oheimb et al. 2006, Gerken 2008). Eine Halbjahresbeweidung oder Sommerweide ist mit der hier vorgestellten Situation nicht vergleichbar. Die oft beschriebenen Verbiss- und Bodenschäden, die im Winterhalbjahr vermehrt auftraten, waren Teil der gewünschten Weideauswirkungen in Süd-Langeland. Der Tritt schädigte teils dauerhaft die hochwüchsigen Röhrichtbestände an und in den Gewässern und führte zu offeneren, strukturreicheren Ufersäumen.

Die Untersuchungen zum Weideverhalten haben gezeigt, dass die Beweidungsintensität auf großflächigen Weiden im Wesentlichen vom Zugang zu Wasserquellen und dem Feuchtegrad der Vegetation abhängt. Auf trockenen Standorten zeigen Exmoor-Ponys vermutlich ein anderes Verhalten als in 
Moorlandschaften, in denen sie ursprünglich beheimatet sind. Die Pferde bevorzugten niederwüchsige Grünland- und Uferbestände mit frisch nachwachsendem Gras und einem abwechslungsreichen Nahrungsangebot. An Säumen und Übergängen zwischen früheren Teilgebieten wurden höherwüchsige Bereiche mit Altgrasbeständen angetroffen. Um eine Vergrasung und Verbrachung dieser Areale zu verhindern, müsste die Beweidungsintensität während der Hauptvegetationszeit angehoben, im Winter wieder reduziert werden, damit die Tiere ohne Zufütterung über den Winter kommen. Eine vorübergehende Erhöhung des Bestandes im Sommer ist aus betriebswirtschaftlichen und personellen Gründen im Untersuchungsgebiet nicht möglich. Einen vergleichbaren Effekt hatte die Bestandsregulierung im Herbst.

Ob sich empfindliche Lebensräume für eine ungesteuerte Ganzjahresbeweidung eignen, hängt vom Gesamtnahrungsangebot ab. Im Projektgebiet standen den Tieren ausreichend nährstoffreiche Weideflächen zur Verfügung, so dass der Weidedruck auf die trockenen, nährstoffärmeren Standorte in den Wintermonaten zwar leicht zunahm, aber nicht zu dauerhaften Bodenschäden führte. Diese Biotope wurden daher nicht von der Beweidung ausgeschlossen. Da Pferde nassen Untergrund bei Möglichkeit meiden, passen sie ihre Nahrungsorte den Boden- und Witterungsverhältnissen an (LÜBW 2006): Das Moor und die Feuchtgrünländer wurden beispielsweise vermehrt im Sommer aufgesucht. Durch dieses Raumnutzungsverhalten werden Trittschäden auf feuchten Böden reduziert. Stellen diese schützenswerten Lebensräume nicht nur Sonderstandorte, sondern einen Großteil der Nahrungsflächen dar, fallen Fraß- und Trittschäden vermutlich größer aus. Das Weidemanagement muss dann entsprechend angepasst werden.

\subsubsection{Gebietseigenschaften}

Das Projektgebiet Süd-Langeland stellt aus vegetationsökologischer Sicht in seiner Ausgangssituation eine typische Kulturlandschaft im Übergang von halb intensiver zu halb extensiver Landnutzung dar. Zahlreiche typische mittel- und nordeuropäische Tier- und Pflanzenarten sind hier vertreten. Das Gebiet weist nur wenige Sonderstandorte auf, die einen besonderen Schutz erfordern. Vielmehr zeichnet es sich durch seine Vielfalt an Biotopen aus, die eng verzahnt nebeneinander liegen.

Aufgrund der unterschiedlichen früheren Nutzungsformen im Grünland wiesen die Teilgebiete verschiedene Pflanzengesellschaften auf. Da Weidesysteme bei ausbleibender Zufütterung bezüglich ihrer Nährstoffbilanz ausgeglichene Systeme sind (von Oheimb et al. 2006), ist davon auszugehen, dass die Trophielevel fortbestehen werden. Eine Ausmagerung der Flächen wird daher nur sehr langsam zu beobachten sein (vgl. Ellenberg 1986, Holsten 2003). Gleichwohl wurde deutlich, dass die Übergänge zwischen den Teilbereichen durch einwandernde Arten und unter gleichförmiger Nutzung zunehmend verwischten und sich die Bestände der Wiesen und Weiden bezüglich Diversität, Artenzusammensetzung und Trophieverhältnisse einander annäherten. Auswirkungen einer Beweidung auf Populationen der im Projektgebiet vorkommenden Pflanzenarten der Wiesen und Weiden dürften auch für andere Weidelandschaften Gültigkeit haben.

Das Gebiet weist eine ungewöhnliche Form auf, die das Raumnutzungsverhalten der Tiere beeinflusste. Die Meidung bestimmter Infrastrukturelemente wie Elektrozäune oder enger Schneisen sowie die Bevorzugung von Markierungspfählen oder künstlicher Unterstände führten zu einer Verzerrung des natürlichen Nutzungsverhaltens. Diese Effekte fallen umso größer aus, je kleiner das Gebiet ist. Dies muss bei der Betrachtung von Weideauswirkungen Berücksichtigung finden. 


\subsubsection{Naturschutzziel}

Ob Pferde oder andere Tiere für die Beweidung ausgewählt werden, wie hoch die Besatzdichte im Jahresverlauf sein sollte und welche Flächen wann beweidet werden, wirkt sich maßgeblich auf die Vegetation aus. Zunächst muss jedoch beantwortet werden, welches Ziel der Flächeneigentümer oder Naturschützer mit der Beweidung erreichen möchte. Dies ist der Dreh- und Angelpunkt in der Entscheidung für oder gegen eine Pferdebeweidung, zumal die Auswertung des Raumnutzungsverhaltens gezeigt hat, dass sich zahlreiche Faktoren auf die Standortwahl der Pferde auswirken, so dass sich die Entwicklung nicht genau vorhersagen lässt.

Die Dänische Naturschutzbehörde war bereit, im Projektgebiet Süd-Langeland mögliche Auswirkungen einer ganzjährigen Beweidung mit Großherbivoren als Modell für eine naturnahe Landnutzung von küstennahem Weideland zu testen. Die Ziele einer Offenhaltung von Grünlandflächen, einer Erhöhung von Biodiversität und Strukturvielfalt sowie des Schutzes seltener Tier- und Pflanzenarten wurden zwar angestrebt, jedoch nicht, wie in Monitoringplänen üblich, mit definierten Zielvorgaben festgeschrieben. Die Unvorhersehbarkeit der Entwicklung war allen Beteiligten bewusst. Die Abkehr von einer intensiven Landwirtschaft wurde bereits in den 1990er Jahren durch partielles Pestizidverbot und Flächenaufkauf begonnen und wird nun durch die extensive Beweidung mit Exmoor-Ponys fortgeführt. Damit steht das Beweidungsprojekt Süd-Langeland im Geiste des Konzeptes halboffener Weidelandschaften, das seit 20 Jahren im Naturschutz an Bedeutung gewinnt. Es strebt sowohl die Erhaltung der typischen Kulturlandschaft aus Weiden, Wiesen, Gehölzen und Gewässern und den hier beheimateten Tier- und Pflanzenarten bei geringen Pflegekosten als auch die Entwicklung attraktiver Naherholungsgebiete an, die dem Menschen ein Erleben von Wildnis ermöglichen (vgl. Kampf 2000, Krannich 2005, Meßner 2005, von Oheimb et al. 2006, Bunzel-Drüke et al. 2008). Wird ein anderes Naturschutzziel verfolgt, müssen die Rahmenbedingungen der Beweidung entsprechend abgewandelt werden. 


\subsection{Empfehlungen für eine extensive Pferdebeweidung}

Neben den zahlreichen Chancen für den Naturschutz ist die Tierhaltung nicht frei von administrativen und fachlichen Herausforderungen. Aus dem Einsatz halbwilder oder wilder Herden resultieren rechtliche Unsicherheiten und Risiken, die häufig unterschätzt werden. Derartige Ereignisse können zum Verlust der Herde führen oder Konflikte mit dem Tierschutz provozieren. Auch beim Einsatz robuster Rassen in artgerechter Tierhaltung ist es daher erforderlich, behördliche und veterinärrechtliche Vorgaben im Vorfeld abzuklären und umzusetzen, um Kostensteigerungen und imageschädigende Darstellungen von Tierschutzvereinen zu verhindern.

Die in einem Schutzgebiet erforderlichen Maßnahmen sind im Wesentlichen vom angestrebten Naturschutzziel abhängig. Zur Förderung einer halboffenen Kulturlandschaft und zur Wiederherstellung artenreicher Systeme in einer zuvor intensiv oder halbintensiv genutzten Agrarlandschaft durch eine Beweidung mit Großherbivoren werden folgende Empfehlungen ausgesprochen.

\subsubsection{Weidetiere}

\subsubsection{Eignung der Weidetiere}

Im Projektgebiet wurde eine robuste ursprüngliche Pferderasse eingesetzt, die bereits seit Jahrzehnten in der Region lebte. Ungeachtet der Diskussion um den Status des Exmoor-Ponys als möglicher Nachfolger des mitteleuropäischen Wildpferdes, lässt sich festhalten, dass diese Rasse ideal an die vorherrschenden, teils rauen klimatischen Bedingungen angepasst war und es im Untersuchungszeitraum im Gebiet daher weder zu nahrungsmangelbedingten Todesfällen noch zu anderen tierschutzrelevanten Einschränkungen kam. Dank der Robustheit der Tiere war der Pflegeaufwand gering. Die Fohlenmortalität in Langeland war zwar sehr hoch - im Mittel 20 \% durch natürliche Todesursachen -, dies ist aber nicht ungewöhnlich für Pferdepopulationen in Freilandhaltung. Andere Studien berichten sogar über höhere Sterberaten in freier Wildbahn: zum Beispiel von $40 \%$ bei Przewalski-Pferden im Hustai Nationalpark, Mongolei (Usukhjargal 2008) bis hin zu 50 \% bei Wildpferden in den Kaimanawa-Bergen in Neuseeland (Cameron et al. 2001).

\subsubsection{Weidemanagement}

Die Weidetiere wurden im Projektgebiet ganzjährig, ohne Koppelung und ohne Zufütterung gehalten. Der Verzicht auf eine Winterfütterung war möglich, weil im Vorfeld die maximale Besatzdichte berechnet wurde. Der Gesundheitszustand der Ponys wurde durch regelmäßige Kontrollen im Projektgebiet überprüft, was entsprechendes Personal erforderte. Um Unterernährung in den Wintermonaten zu verhindern, sollten Gehölze und Gewässer bei der Festlegung des Tierbesatzes nicht als vollwertige Nahrungsflächen zählen und wurden daher in Süd-Langeland nicht berücksichtigt. Grundsätzlich ist die Besatzstärke für extensive Beweidung abhängig von den jeweiligen Standortverhältnissen (vgl. Kampf 2000, von Oheimb et al. 2006, Heimes 2010). Da die Grünflächen in Süd-Langeland im Allgemeinen eine hohe Produktivität aufwiesen, war ein kurzzeitiges Überschreiten der Besatzstärke von 0,5 Großvieheinheiten pro Hektar (GV/ha) für die Versorgungssicherheit der Tiere unproblematisch. Dennoch wurde der Wert als Richtwert genommen, da der Engpass im Nahrungsangebot bei einer Ganzjahresbeweidung in den Wintermonaten und im Übergang zum Frühjahr liegt.

In Fachkreisen wird die Maßnahme der Zufütterung kontrovers diskutiert, seit Bilder von verhungerten Rindern, Pferden und Rothirschen im niederländischen Naturentwicklungsgebiet Oostvaardersplassen 
durch die Medien gingen (Handelingen Tweede Kamer, 28.01.2010). In der in den Niederlanden vertretenen ökoethischen Sichtweise steht nicht die Sorgfaltspflicht für das einzelne Individuum im Vordergrund, sondern die Interessen der Population in seinem Ökosystem (vgl. Schröder 2012). Ein Verlust von kranken oder schwachen Tieren - wie er auch im Projektgebiet bei den Fohlen auftrat - ist dabei unvermeidlich und entspricht der natürlichen Selektion in freier Natur. Diese Auffassung wurde auch in Süd-Langeland vertreten. Aus ethischer Sicht kann eine Zufütterung in Notsituationen zwar befürwortet werden, um ein Sterben oder Leiden von Tieren zu verhindern. Dies war jedoch im Projektgebiet aufgrund der zuvor kalkulierten Besatzdichte und der nachgeschalteten Bestandsregulierung nicht erforderlich. Wird nicht zugefüttert, fressen die Tiere im Winter Pflanzen, die sie sonst verschmähen würden (Vera 2005). Zudem führt eine Winterfütterung bei einer Beweidung zu Naturschutzzwecken zu einem ungewollten Nährstoffeintrag auf die Fläche, der gewünschte Verbiss im Gehölz bleibt aus (Wiegleb \& Brunk 2004). Auch verursacht eine Zufütterung in hierarchisch organisierten Herden wie auch dem Exmoor-Pony eine Überversorgung von ranghohen Tieren, die im Frühjahr zu früh trächtig werden, während rangniedrige Tiere von der Zusatzversorgung nicht profitieren, obwohl sie diese nötig hätten (van Klink 2008). Die Winterfütterung verfehlt damit ihr Ziel und sollte in ganzjährigen Beweidungsprojekten halboffener Weidelandschaften vermieden werden.

Aufgrund der saisonalen Raumnutzung der Pferde wird eine Ganzjahresbeweidung ohne Koppelung empfohlen, wenn als Naturschutzziele die Offenhaltung der Landschaft sowie Weideeffekte auf Gehölze und Röhrichte angestrebt werden. Bei einer reinen Sommerweide oder einer Halbjahresbeweidung lassen sich nicht die gewünschten Auflichtungen in geschlossenen Waldarealen oder ein Verbiss von Gebüschinitialen erwirken, da sich die Weidetiere im Frühjahr und Sommer größtenteils auf den nährstoffreicheren Weiden aufhalten. Auch Dominanzbestände im Ufer- oder Dünenbereich von Arten wie Schilf (Phragmites australis) oder Land-Reitgras (Calamagrostis epigejos) werden durch eine ganzjährige Beweidung stärker zurückgedrängt (vgl. Heimes 2010).

$\mathrm{Da}$ in Beweidungsprojekten keine natürliche Abwanderung möglich ist, muss eine regelmäßige Bestandsregulierung erfolgen. Diese sollte bereits bei der Planung berücksichtigt und die erforderlichen Strukturen aufgebaut werden. Der Verkauf von einzelnen Tieren an andere Beweidungsprojekte, wie er im Projektgebiet im September 2010 erstmals erfolgte, stellt dabei nur eine vorübergehende Lösung dar. Eine Bestandsregulierung ist ab dem Erreichen der Kapazitätsgrenze jährlich oder alle zwei Jahre erforderlich, da die Herde trotz hoher Fohlenmortalität eine hohe Zuwachsrate hat. Empfehlenswert ist hierbei eine Vermarktungsstrategie, bei der Jungtiere an Privatpersonen, Tierparks, Zoos und andere Einrichtungen abgegeben werden. Im Fokus steht hierbei der Erhalt dieser seltenen ursprünglichen Pferderasse, die Tiere können jedoch darüber hinaus mit einer entsprechenden Ausbildung auch als Reit- und Zugpferde eingesetzt werden. Erfahrungen aus England und Deutschland haben gezeigt, dass die Nachfrage des mittelgroßen Exmoor-Ponys als Reitpferd aufgrund seines freundlichen, aufmerksamen Gemüts groß ist (Willmann 2005, Baker 2008). Der Verkauf sollte im Alter von 8-9 Monaten, spätestens im Frühjahr zur Geburt der neuen Fohlengeneration erfolgen. Ältere Tiere können nur vermittelt werden, wenn sie an menschlichen Kontakt gewöhnt werden, was in Beweidungsprojekten in der Regel schwierig ist (vgl. Zweckverband Naturpark Solling-Vogler 2006). Eine Vermarktung von Pferdefleisch sollte eine nachrangige Option sein, zumal dies in Dänemark nicht sehr verbreitet ist.

Pferde würden in freier Wildbahn ein deutlich größeres Areal bewohnen, als es im Projektgebiet möglich war. Um eine saisonal abhängige Habitatwahl und eine ausreichende Ressourcenverfügbarkeit für die Weidetiere zu gewährleisten und ihnen gleichzeitig als sozial lebendes Herdentier genug Raum für ein natürliches Gruppen- und Sozialverhalten zu geben, sollte die Gebietsgröße bei strukturreichen Lebensräumen nicht unter 100 Hektar liegen. Nicht unerheblich sind dabei die Gebietsform und die Erreichbarkeit der Teilflächen. Aufgrund der Engpässe im Übergang zur Nord- und Südspitze fiel das Projektgebiet kleiner aus als die tatsächliche Gesamtfläche. Durch die längliche, eingeschnittene Form 
bietet es der Herde vermutlich auch in Zukunft keine Möglichkeit einer Aufspaltung in zwei oder mehrere Haremsgruppen, was der natürlichen Sozialstruktur von Wildpferden entsprechen würde (vgl. Tyler 1972, Schäfer 2000, Waring 2003).

\subsubsection{Infrastruktur}

Das Raumnutzungsverhalten der Ponys wurde stark vom Zugang zu Wasserquellen beeinflusst. Bei der Einrichtung einer Weidelandschaft sollte daher bereits auf die Verfügbarkeit und Lage dieser Strukturen geachtet werden. Auch der Verlauf des Elektrozaunes, die Nutzbarkeit eines Unterstandes oder die Erreichbarkeit von Teilflächen wirkten sich auf die Nutzungsintensitäten aus und sollten bei der Planung berücksichtigt werden, um - falls erforderlich - eine Überbeweidung besonders empfindlicher Vegetationsbereiche zu verhindern.

Der Betrieb eines fest installierten Elektrozaunes, wie er im Projektgebiet eingesetzt wurde, ist im Vergleich zum Stacheldrahtzaun kosten- und pflegeintensiver, da er regelmäßig freigeschnitten und auf Funktionstüchtigkeit überprüft werden muss. Die Verletzungsgefahr der Pferde wird jedoch durch Elektrozäune deutlich reduziert. Zudem ist die Verwendung von Stacheldraht bei reinen Pferdekoppeln in Deutschland seit einigen Jahren aus tierschutzrechtlichen Gründen verboten (s. OVG Thüringen vom 28.09.2000). Der Zaun wurde von den Pferden nicht überwunden, stellte für die Rehwildbestände im Gebiet aber keine Barriere dar.

\subsubsection{Pflegemaßnahmen}

Nicht alle im Projektgebiet angestrebten Naturschutzziele konnten durch die extensive Pferdebeweidung realisiert werden. Hier wurden seitens der Naturschutzbehörde begleitende Pflegemaßnahmen ergriffen.

\subsubsection{Im Gehölz}

Die Pferde drängten aufkeimende Sträucher und Gehölzareale im offenen Weideland durch Verbiss und Tritt zurück, sie vermochten aber nicht, die etablierten, großflächigen Gebüschbestände zu reduzieren. Ist dies erwünscht, muss früher oder später eine Rodung erfolgen, da diese Habitate auch bei Futterknappheit kaum beweidet werden und sich weiter ausbreiten. Im Projektgebiet wurden punktuell Gebüsche aus Weißdorn, Schlehe und Brombeere im Bereich der Magerrasen und der denkmalgeschützten Steinmauer entfernt, um diese seltenen Lebensräume zu erhalten. Nicht immer sind diese flankierenden Maßnahmen jedoch sinnvoll. Beim maschinellen Entfernen von Gehölzaufwuchs stört der Einsatz von Maschinen den Boden, Zersetzungsprozesse der abgestorbenen unterirdischen Biomasse führen zu lokaler Eutrophierung (Bruun \& Ejrnæs 1998). Zudem ist die Bedeutung von Gehölzen und Gebüschen als Strukturelement zu berücksichtigen (Heimes 2010). Nutzen und Schaden der Maßnahmen müssen daher abgewogen werden.

Die zum Zwecke einer forstlichen Nutzung angepflanzten Laub- und Nadelwälder im westlichen Projektgebiet sollten durch die Weidetiere aufgelichtet werden, um ein Einwandern von Wald- und Saumarten in die artenarmen Bestände zu fördern. Die Auswertung der Raumnutzung zeigte jedoch, dass die Ponys die Waldbereiche kaum und saisonal unterschiedlich nutzten. Förderlich wirkte sich hierbei die Schaffung von Waldkorridoren im Forst im Zuge der FSC-Zertifizierung auf die Nutzungshäufigkeit aus: Sie dienten als Tierpfade. Entlang dieser Korridore entstanden vermehrt Tritt- und Fraßschäden, 
die zu Ausbuchtungen im Gehölzbestand und kleineren Lichtungen führten. Pflegemaßnahmen und Beweidung unterstützten sich somit gegenseitig in ihrer Wirkung.

\subsubsection{Pflegemahd und alternative Weidekonzepte}

Eine vor- oder nachgeschaltete Mähnutzung fördert die Grünlandextensivierung und Ausmagerung ehemals intensiv genutzter Flächen. Vor der Nutzung als Extensivweide dient eine Mahd dem Nährstoffexport, eine Nachmahd als Reinigungsschnitt verhindert bei geringen Besatzstärken und selektiver Unterbeweidung eine Überhandnahme unerwünschter Arten (Dierschke \& Briemle 2002). Im Projektgebiet wurden im September 2008 sowie 2010 Reinigungsschnitte auf Teilflächen 20 Zentimeter über der Grasnarbe durchgeführt, um die Ausbreitung von Cirsium-Samen auf angrenzende Ackerflächen zu verringern. Struktur- und vegetationskundliche Untersuchungen auf den Flächen wiesen in Folge eine gesteigerte Dynamik hinsichtlich der Artenzusammensetzung auf, so dass die Frage im Raum steht, ob sich gekoppelte Weide-Mahd-Nutzungen positiv auf die Biodiversität auswirken. Zur langfristigen Sicherung extensiver Lebensräume empfiehlt Wagner (2005) in NATURA 2000-Gebieten den Einsatz rotierender Mähweidesysteme: Weidereste und Selektionsvorteile für weidefeste Pflanzen werden durch einen eingeschalteten Schnitt eliminiert, Gehölze im Offenland zurückgedrängt. Das System entspricht im Wesentlichen einer extensiven Umtriebsweide, die sich vor allem bei empfindlichen, ursprünglich Mahd angepassten Biotopkomplexen mit hoher Standortdiversität eignet (Regierung von Niederbayern 2008). Es ist nicht für großflächige Ganzjahresbeweidungen ausgelegt.

\subsubsection{Erholungsnutzung und begleitende Öffentlichkeitsarbeit}

Das Schutzgebiet Süd-Langeland diente der Erholungsnutzung. Die Naturschutzbehörde hat sich bewusst für ein uneingeschränktes Zutrittsrecht für Besucher entschieden, um die Bewegungsfreiheit Erholungssucher nicht einzuschränken. Dies ist in zahlreichen Beweidungsprojekten üblich (Vermeulen 2014), da Zutrittsbeschränkungen die Akzeptanz von Naturschutzprojekten stark mindern können (von Oheimb et al. 2006). In Süd-Langeland dienten die markierten Wanderwege vornehmlich der Orientierung im Gelände, weniger der Besucherlenkung. Mit Ausnahme des Vogelschutzgebietes im Niedermoor durften alle Bereiche des Projektgebietes betreten werden.

Die Anwesenheit der als Wildpferde bezeichneten Exmoor-Ponys wirkte als wahrer Publikumsmagnet. Zahlreiche dänische Medien berichteten über die Ansiedlung der Ponys und die im Beweidungsprojekt angestrebten Naturschutzziele. Das Medieninteresse wurde somit genutzt, um der Öffentlichkeit die Thematik der Regeneration naturnaher Landschaften zu vermitteln. Weitere Maßnahmen der Öffentlichkeitsarbeit waren öffentliche Führungen in den Sommermonaten in dänischer und englischer Sprache sowie Faltblätter, die über Besonderheiten des Gebietes und die angestrebte Entwicklung einer halboffenen Kulturlandschaft durch Pferdebeweidung informierten. Besucher wurden dabei auf wichtige Verhaltensregeln im Gelände hingewiesen, wobei sich zeigte, dass viele einen verantwortungsvollen Umgang mit Pferden in freier Wildbahn erst wieder lernen müssen. Das Beweidungsprojekt SüdLangeland bietet somit auch die Chance, früher in Mitteleuropa natürlich vorkommende Großherbivore in einer ursprünglichen Herdenstruktur zu erleben. 



\section{ZUSAMMENFASSUNG}

Über- und Ausblick

Im Forschungsvorhaben „Halboffene Weidelandschaft Süd-Langeland“ wurde die Entwicklung einer küstennahen Kulturlandschaft unter extensiver Beweidung untersucht. Das Projekt versteht sich als Pilotstudie über Auswirkungen einer ganzjährigen Beweidung mit wild lebenden Pferden unter ökologischen Gesichtspunkten. Auf der Grundlage von Erhebungen zur Arten- und Strukturvielfalt sollte dargelegt werden, wie sich die ökologische Qualität der Flächen unter Beweidung verändert und ob die gewünschten Naturschutzziele der Offenhaltung und des Artenschutzes erreicht werden. Schwerpunkte der wissenschaftlichen Begleituntersuchung waren das Weidetierverhalten sowie die Strukturund Vegetationsentwicklung des Gebietes. Die Ergebnisse lieferten zudem Hinweise, welche Rahmenbedingungen bei der Einrichtung halboffener Weidelandschaften zu berücksichtigen sind.

Das 107 Hektar große Projektgebiet liegt an der Südspitze der dänischen Insel Langeland. Die Flächen dienten früher überwiegend als Agrar- oder Grünland, später wurden sie zunehmend mit Rindern oder Schafen beweidet. Die Nutzung war sehr heterogen: Grünland grenzte an Weiden, Brachen an Äcker. Zu Beginn der Pferdebeweidung wies das Gebiet ein strukturreiches Landschaftsbild mit ausgedehnten Grasfluren auf, die durch Knicks, Gemäuer, Feldgehölze und Stillgewässer gegliedert waren. Eine denkmalgeschützte Steinmauer durchzieht das Gebiet von Norden nach Süden. Der Boden besteht vorwiegend aus fruchtbarem lehmigen Moränenboden, der im Bereich des Niedermoors feuchter, auf den rundkuppigen Hügeln trockener und sandiger ist. Hier finden sich Magerrasen. Ältere Gehölze sind nur vereinzelt im Uferbereich der Teiche vorhanden, die aufgeforsteten Waldflächen bestehen aus Jungwald und Gebüsch.

Die Südspitze Langelands hat aufgrund seiner Bedeutung für den Vogelzug den Status Special Protected Area. Zahlreiche geschützte Lebensräume finden sich hier. Die Ansiedlung der Weidetiere ist Teil des South Langeland Nature Conservation Project des Umweltministeriums, deren Ziel der Erhalt der offenen küstennahen Landschaft als Lebensraum bedrohter Vogel-, Insekten- und Amphibienarten ist. Das Schutzgebiet ist auch für den Tourismus interessant. Besucher haben ein uneingeschränktes Zutrittsrecht, mit Ausnahme des Vogelschutzgebietes Gulstav Mose.

Seit Oktober 2006 werden Exmoor-Ponys (Equus ferus f. caballus) im Projektgebiet zur Beweidung ganzjährig ohne Koppelung eingesetzt. Diese ursprüngliche Pferderasse eignet sich dank seiner Robustheit für eine Ganzjahresweide. Die Tiere lebten im Familienverband, was ihrer natürlichen Sozialstruktur entspricht. Die Herde bestand anfangs aus einem Leithengst, Stuten und deren Nachwuchs. Im Verlauf der Untersuchung bildeten sich Junggesellengruppen. Der Tierbestand und die Besatzdichte erhöhten sich von Jahr zu Jahr durch Geburten. Trotz einer hohen Fohlenmortalität von 20-25 \% stieg die Herdengröße innerhalb von vier Jahren von 26 auf 78 Tiere an.

Zur Bewertung der Habitatnutzung wurden von April 2008 bis März 2011 rund 5.000 Datenpunkte von drei Fokustieren erhoben. Die Positionskoordinaten wurden mit georeferenzierten Luftbildern und thematischen Karten in einem GIS überlagert. Der Zusammenhang zwischen Raumnutzungsverhalten und Umweltbedingungen wurde mittels eines verallgemeinerten linearen Modells (Poisson-Regression) analysiert. 
Die Tiere der Langeländer Herde wiesen eine räumlich und zeitlich heterogene Habitatnutzung des Gebietes auf. Sie bevorzugten die nährstoffreicheren Assoziationen der Wiesen und Weiden frischer Standorte sowie gewässernahe, niederwüchsige Gesellschaften. Eine geringere Nutzung erfuhren ruderale und magere Glattwiesen sowie hochwüchsige Röhricht- und Uferstaudengesellschaften. Die Beweidungsintensität auf den großflächigen Weiden hing im Wesentlichen vom Zugang zu Wasserquellen und dem Feuchtgrad und Nährstoffgehalt der Vegetation ab. Wichtig für die Habitatwahl war zudem die Vegetationshöhe der Krautschicht. Die Ponys bevorzugten Flächen mit einem hohen Grasanteil sowie geringen Streuauflagen. Die niederwüchsigen Uferbereiche dienten häufig als Ruheplatz. Wichtig war den Tieren zudem ein ausgewogenes Nahrungspflanzenangebot. Vor allem in den Sommermonaten hatten artenreiche Gesellschaften eine hohe Attraktivität und boten den Pferden eine abwechslungsreiche Kost.

Die Auswertung der Raumnutzung zeigte, dass die Ponys die angepflanzten Laub- und Nadelwälder kaum nutzten. Dennoch boten die Gehölze den Tieren im Winterhalbjahr wichtige Strukturen für Nahrung, Schutz und Körperpflege im Hinblick auf eine artgerechte Tierhaltung. Ihr Anteil am Gebiet wirkt sich damit entscheidend auf dessen Eignung als Lebensraum aus.

Ein reich strukturierter Lebensraum mit freiem Zugang zu Gewässern und Gehölzen ist bei einer Ganzjahresbeweidung von großer Bedeutung. Auch nährstoffärmere Flächen, magere Standorte und Gehölze werden in den Wintermonaten beweidet. Auf Langeland war zudem ein zyklisches Nutzungsmuster erkennbar. Möglicherweise bieten die Pferde der Vegetation mit Nutzungsintervallen die Gelegenheit zur Regeneration und zum Nachwachsen junger Sprosse.

Das Exmoor-Pony als Robustrasse war ideal an die vorherrschenden, teils rauen klimatischen Bedingungen angepasst, so dass es im Untersuchungszeitraum weder zu nahrungsmangelbedingten Todesfällen noch zu tierschutzrelevanten Einschränkungen kam. Der Flächenbesatz wurde durch gezielte Entnahmen unter dem Maximalwert von 0,5 GV/ha für extensive Beweidungsprojekte gehalten. In die Berechnung der Besatzstärke flossen nur offene und halboffene Weideflächen ein. Eine Anpassung des Flächenbesatzes an die abiotischen Bedingungen durch Bestandsregulierungen ist auch in Zukunft erforderlich, um Überbeweidung zu verhindern und einen Verzicht auf Winterfütterung sicherzustellen. Dies sollte bereits bei der Planung von Beweidungsprojekten berücksichtigt werden, indem die erforderlichen Strukturen für eine Weitervermittlung von Einzeltieren aufgebaut werden. Dies schließt eine begleitende Öffentlichkeitsarbeit mit ein.

Zur Beurteilung der Weideauswirkungen wurde im Jahr 2008 eine flächendeckende Vegetationskartierung durchgeführt. Nach drei Jahren erfolgte eine Wiederholungskartierung. Zudem wurde die Struktur- und Vegetationsentwicklung der Grünland-, Gehölz- und Uferflächen auf beweideten und nichtbeweideten Dauerflächen fortlaufend dokumentiert. Es erfolgten zeitgleich Erhebungen auf mittlerem Skalenniveau zur Erfassung von Beweidungsintensitäten. Die Verbissbelastung im Gehölz wurde mittels Luftbildauswertungen und Messungen bewertet. Auf Transekten wurden hierbei Schadensarten, Höhenstufen, Baumartenpräferenzen und Gehölzaufwuchs erfasst.

Die Beweidung zeigte bereits nach wenigen Jahren einen deutlichen Effekt auf das Landschaftsbild und die prägenden biotischen Strukturelemente im Projektgebiet. Im Verlauf der Beweidung entwickelten sich große Flächen mit einer einheitlichen Vegetationsstruktur verstärkt zu einem Mosaik verschiedener Offenlandlebensräume. Vor allem im Gebietszentrum wurden die Vegetationseinheiten kleinflächiger, ihre Verteilung orientierte sich weniger an den früheren Gebietsgrenzen. Es kristallisierten sich zunehmend Kleinstlebensräume wie blütenreiche Hochstaudenfluren oder niedrige Pioniervegetation heraus, die eng nebeneinander lagen. Unterstützt wurde diese Entwicklung durch Weidetierpfade, Scharrstellen und Trittsiegel mit stärkerer Nutzung sowie hochwüchsige Geilstellen, wo die Sukzession fortschritt. Das ungleichmäßige Absetzen von Dung bei Pferden führte zu einer Nährstoffumverteilung 
im Gebiet. Durch Tritt entstanden vermehrt offene Bodenstellen sowohl an feuchten, lehmigen als auch an sandigen, trockenen Standorten. Die Entwicklung führte insgesamt zu einer größeren Strukturvielfalt und heterogenen Ressourcenverfügbarkeit im Gebiet.

Die Weidetiere reduzierten durch Tritt und Verbiss die Höhe der Krautschicht, die Streuauflagen und den Aufwuchs von Baumkeimlingen von Rosa-, Prunus-, Crataegus- und anderen Laubholzarten. Durch die Schädigung des Gehölzjungwuchses verhinderten sie eine zunehmende Verbuschung offenen Weidelandes und wandelten zudem leicht verbuschte Grünlandflächen in gehölzfreie Flächen um. Der Einfluss auf Gehölzbereiche mit älterem Baumbestand und hohen Deckungsgraden war jedoch gering. Die Waldkorridore, die im Zuge der FSC-Zertifizierung angelegt wurden, wirkten sich allerdings positiv auf die Nutzungshäufigkeit aus. Entlang dieser Korridore entstanden vermehrt Tritt- und Fraßschäden, die zu Ausbuchtungen im Gehölzbestand und kleineren Lichtungen führten. Pflegemaßnahmen und Beweidung unterstützten sich somit gegenseitig in ihrer Wirkung.

Die Auswirkungen der Beweidung waren an den feuchten Bereichen der Stillgewässer und im angrenzenden Feuchtgrünland am höchsten. Die gestörten Flächen unterlagen einer hohen jahreszeitlichen Dynamik, die durch schwankende Wasserstände noch verstärkt wurde. Davon betroffen waren maßgeblich das Potentillion anserinae und das Lolio-Cynosuretum typicum. In stark frequentierten Uferbereichen entstanden neue Vegetationseinheiten, auf dem Großteil der Flächen blieben die Pflanzengesellschaften nach drei Beweidungsjahren jedoch unverändert.

Die dominierenden Lebensraumtypen des Projektgebietes, die frischen, artenreichen Grünländer, entwickelten sich unter Pferdebeweidung grundsätzlich positiv: Unterschiedlich in ihrem Feuchtegrad und Nährstoffgehalt, näherten sich die Weiden und Wiesen einander in ihrer floristischen Diversität an. Die Ausdehnung der artenreichen Glatthaferwiesen im Gebiet hat sich zwar leicht verringert. Doch gerade der Wandel artenarmer Weiden oder Saatwiesen hin zu Grünländern mit höherer Diversität zeigt die positiven Effekte einer extensiven Pferdebeweidung auf. Nach drei Untersuchungsjahren nahm die Artenzahl im Grünland signifikant zu, im Wesentlichen durch Einwanderung aus benachbarten Flächen. Neue Pflanzenarten kamen im Untersuchungszeitraum kaum hinzu. Die Vegetation war gleichmäßiger verteilt. Die Pferdebeweidung wirkte somit Dominanz und Herdenbildung als typische Anzeichen von Brachlandsukzessionen entgegen. Ein vermehrtes Wachstum von Weideunkräutern oder trittunempfindlichen Arten wurde dabei nicht beobachtet.

Die Strukturdiversität und die Lage im Südfünischen Inselmeer begründen die Bedeutung des Gebietes für den Vogelschutz. Vögel sind extrem mobil. Die Wiederbesiedlung des Gebietes durch weniger mobile Arten wie Insekten und Amphibien hängt von Restpopulationen auf der dänischen Insel ab. Durch gezielte Wiederansiedlungsprojekte wie bei Bombina bombina können kurzfristig neue, bedrohte Arten auftreten, angesichts der dominierenden Intensivlandwirtschaft bleibt eine natürliche Einwanderung neuer Tier- und Pflanzenarten abzuwarten.

Die Ergebnisse der Studie legen nahe, dass sich eine extensive Pferdebeweidung zur Steigerung von Arten- und Strukturvielfalt in einer ehemals intensiver genutzten Kulturlandschaft eignet. Unterschiedliche Beweidungsintensitäten und wiederkehrende Störungen durch die Weidetiere führten zu einer dynamischen Flächenentwicklung sowie der Entstehung von Pionierstandorten, vor allem im Bereich von Ökotonen. Entscheidend für die Entwicklung der Pflanzenbestände war das Weidemanagement im Untersuchungsgebiet mit einer durchgängigen Beweidung aller Teilbereiche. Diese Beweidungsform wird zur Offenhaltung der Landschaft und für Weideeffekte auf Gehölze und Röhrichte empfohlen. Verbiss- und Bodenschäden, die im Winter vermehrt auftraten, waren Teil der gewünschten Weideauswirkungen: Der Tritt schädigte die hochwüchsigen Röhrichte an und in den Gewässern und führte damit zu offeneren, strukturreicheren Ufersäumen. 



\section{SUMMARY}

Overview and outlook

The aim of the research project "Semi-open Pasture Landscape South Langeland" was to study the vegetation and landscape changes in a grass-dominated nature reserve, under year-round extensive grazing with free-ranging horses. Furthermore, the survey should point out the requirements needed to install semi-open pastures in cultural landscapes.

The project area is located at the southern point of the Danish island Langeland (107 hectares). The former land used was heterogeneous. The area was initially used mainly as agricultural country or grassland, later also for grazing with cattle or sheep. As the project started the area was rich in habitat types including large areas of grasslands with initially different diversity as well as ponds, hedges, woodland and shrubs.

The southern part of Langeland is an important bird refuge. Within the project area many protected habitats can be found. The herd of Exmoor Ponies (Equus ferus f. caballus) was installed in the area as part of the South Langeland Nature Conservation Project in October 2006. The main goal has been to develop and support a rich plant community under the influence of large herbivores and to optimize ecological conditions for insects, amphibians and birds. The project was also meant as an attraction for the public, especially for summer guests. Visitors have free access to the nature reserve, except for Gulstav Mose, as a bird sanctuary.

Due to its robustness, the Exmoor Pony is well suited for a year-round grazing management. The grazing animals were kept in a harem group which consisted of a stallion, several mares and their offspring. This corresponds to the natural social structure of horses. Bachelor groups developed during this survey. Despite a high foal mortality, the herd grew from 26 to more than 78 animals within four years, making it necessary to sell out several ponies. The stocking-rate was limited to a maximum of 0.5 livestock-units (LU) per hectare, in order to avoid additional feeding in wintertime. When calculating the stocking rate, only open and semi-open pastures were considered.

In the framework of the scientific studies accompanying the project, the sites utilization of grazing animals as well as the development of vegetation and landscape structure under the impact of grazing were examined. Position and behavior of focus animals were documented over three years. Habitat preferences were analyzed using geographic information systems (GIS), in order to determine the effect of environmental and land use characteristics on the vegetation. The vegetation and structure development of grasslands, woodlands and banks of waterbodies was documented, on grazed and ungrazed permanent plots. Moreover, grazing intensities in different habitat types and browsing damages were analyzed. In 2008 and 2011, an area-wide vegetation mapping was performed to define vegetation changes due to grazing.

The scientific survey documents that the horses had a great impact on the vegetation structures. The grassland consists now of lower and higher growing areas which can be described as a spatially and temporally dynamic mosaic, from different habitats on a low scale. Sharp boundaries between habitats in the structured landscape have been removed and broad transitional zones between wood-habitats and open habitats developed instead. Through grazing, the ponies kept the grassland and most of the 
riverside vegetation open. They turned the former monotonous farmland into a botanically and ornithological diverse area. Especially in moist habitats with fluctuating water levels, the grazing impact led to the development of new plant communities. More than 30 vegetation units are found in the area. Small patches of bare soil, as important pioneer habitats were formed in dry, as well as in wet grasslands.

By reducing significantly the vegetation highs and quantities of biomass, seedlings of tree and shrub species were damaged by the horses. The grazing animals slowed down the outspread of bushes in the grasslands and at the forest borders. By that, they turned grasslands with initial shrub invasion back to open grasslands. However, the impact on the forested areas was low. Exmoor ponies are not suitable for reopening forests as they are mainly grazers. They use the forests to a minor degree as a natural shelter and for grazing, particularly in winter times when they feed upon buds and leaves. Woodlands are there for important in terms of animal welfare in year-round grazing projects. Besides, installing paths inside the forests in line with the FSC designation has increased the habitat use in the forested areas by the horses. To achieve the protection targets in the area, further accompanying management measures like tree and shrub felling can be recommended from time to time.

Due to a regime of continuous grazing throughout the year, former pastures and meadows assimilated in their floristic diversity. Although the extension of meadows decreased slightly during the sample period, biodiversity had risen in the project area because of the upgrading of former farmland. Intensification of grazing has reduced the cover of tall grasses promoting less competitive species. Numbers and evenness of species have risen significantly since the grazing started, while weeds in pastureland did not increase. However, immigration of new plant species was low cause of the surrounding intensive agriculture.

The scientific studies showed that it was possible to enhance the structural diversity of former intensive cultural landscape through extensive horse grazing. A rich structured biotope with free access to water resources and woods for shelter is of great importance in year-round grazing projects. The ponies displayed a spatially and temporally varying habitat use preferring nutrient-rich grassland vegetation units and low growing bankside plant communities. Drier or ruderal grassland and high growing reed beds were mostly avoided and frequented increasingly in winter time. Grazing intensities depended on distance from water as well as moisture levels and $\mathrm{N}$ supply of the vegetation. Species-rich grasslands were preferred for nutrition. Vegetation heights influenced the habitat use when feeding or resting. A cyclic habitat use throughout the year was observed which enabled the growth of the favored fresh grass.

The high numbers of visitors account for the great interest of the public in free-ranging horses under natural conditions. The project offers the possibility to document the natural development of the herd structure in semi-wild horses. Due to the unfeasible migration of grazing animals, a management plan for surplus horses is required and should be planned from the outset. The successful establishment of extensive grazing projects requires therefor a technical and scientific steering with advisory experts in nature conservation as well as accompanying public relations. 


\section{GLOSSAR}

Assoziation: Als Assoziation wird ein Vegetationstyp von bestimmter floristischer Zusammensetzung mit relativ einheitlicher Struktur bezeichnet, der durch Charakter- und Differenzialarten erkennbar ist und sich unter etwa gleichen Standortbedingungen gebildet hat (Dierschke 1994).

Biotop: Als Biotop wird der Lebensraum einer spezifischen Lebensgemeinschaft verstanden, der im Regelfall durch eine bestimmte Mindestgröße und Abgrenzbarkeit von benachbarten Biotopen gekennzeichnet ist (Wiegleb et al. 2002). Ein Biotop bezieht sich auf die abiotische Umwelt und umreißt meist ein bestimmtes topographisches Gebiet mit mehr oder weniger einheitlichen Umweltbedingungen.

Biotoptyp: Ein Biotoptyp ist ein abstrahierter Typus aus der Gesamtheit gleichartiger oder ähnlicher Biotope und dient der Beschreibung der Landschaft. Im Bereich des Naturschutzes und der Landschaftspflege werden Biotope aus pragmatischen Gesichtspunkten Biotoptypen zugeordnet.

Biozönose: Eine Biozönose ist die Lebensgemeinschaft aller Pflanzen, Tiere und Mikroorganismen in einem bestimmten Landschaftsbereich (Dierschke 1994).

Endogene Faktoren: Faktoren, durch die Entstehung, Erhaltung und Fortentwicklung von Pflanzengesellschaften beeinflussen, können von außen (exogen) oder von innen (endogen) auf den Pflanzenbestand wirken (Abb. 89). Endogene Faktoren sind Wechselwirkungen zwischen den Individuen eines Bestandes (Koexistenz, Konkurrenz etc.).

Exogene Faktoren: Faktoren, durch die Entstehung, Erhaltung und Fortentwicklung von Pflanzengesellschaften beeinflussen, können von außen (exogen) oder von innen (endogen) auf den Pflanzenbestand wirken (Abb. 89). Exogene Faktoren sind beispielsweise Klima, Gestein, Boden und Nährstoffe.

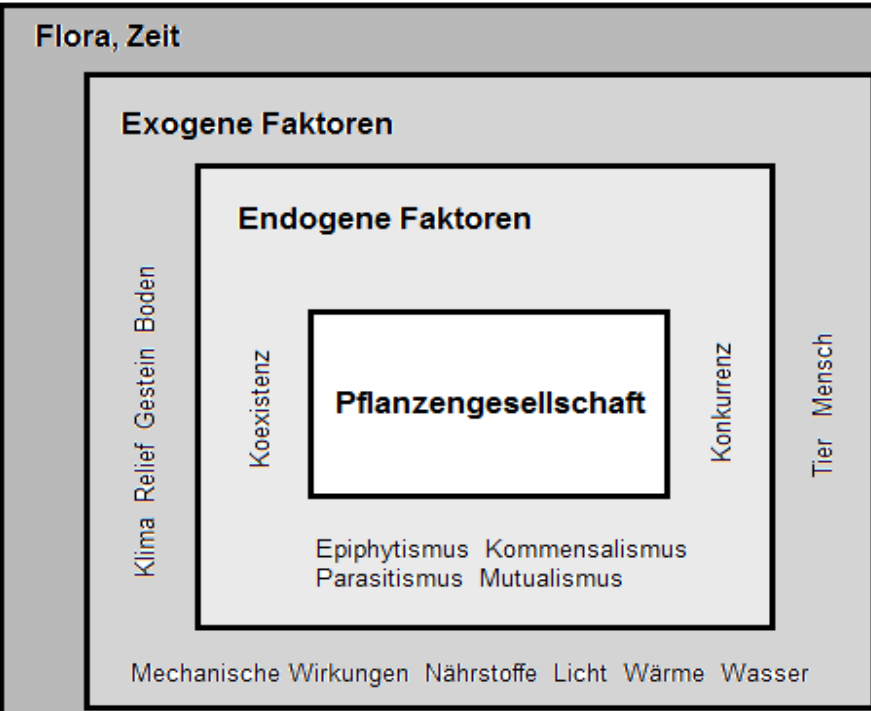

Abb. 89: Faktoren von Pflanzengesellschaften nach Dierschke (1994) 
Extensivierung: Unter Extensivierung von Grünland versteht man eine Aufgabe der Nährstoffzufuhr, extensive Nutzung durch Mahdreduzierung oder Wiederaufnahme extensiver Beweidung (Dierschke 1994). Sie kann von einer sehr intensiven Nutzung ausgehen, bei der ein hoher Nährstoffgehalt im Boden vorhanden ist. Ein wesentliches Ziel besteht darin, diesen Reichtum durch Nutzung des Aufwuchses zu reduzieren, und zwar möglichst auf ein Niveau, das sich auf die natürlichen Standortverhältnisse einstellt. Der Naturschutz unterstützt diese Entwicklung mit Hilfe von Förderprogrammen seit Beginn der neunziger Jahre (Dierschke \& Briemle 2002).

Flora: Gesamtheit der Pflanzensippen eines Gebietes

Fluktuation: Typ der Vegetationsdynamik, oft rhythmische Veränderungen durch Witterung, Überschwemmungen oder menschliche Eingriffe

Habitat: Der individuelle und raumkonkrete Lebensraum der Individuen einer Art, der Raum, in dem sie regelmäßig anzutreffen sind oder vorkommen und sich fortpflanzen. Das Habitat bezeichnet immer einen Lebensraum von Individuen einer einzelnen Art, während der Begriff Biotop als Lebensraum mehrerer Arten definiert ist, die einer Lebensgemeinschaft zugeordnet werden (Bernotat et al. 2002). Der Lebensraum einer Art (Habitat) ist nur in den seltensten Fällen deckungsgleich mit einem Biotop: Ein Habitat kann mehrere Biotope oder Teilbereiche eines Biotops umfassen. Arten mit hoher Mobilität und differenzierten Lebensraumansprüchen beanspruchen Habitate, die aus einer Vielzahl von Biotoptypen zusammengesetzt sein können. Viele Tierarten sind weniger auf Biotoptypen als auf bestimmten Strukturen in ihrem Lebensraum angewiesen wie beispielsweise Hecken, Schilf- und Uferbereiche oder Waldsäume. Ihre Analyse ermöglicht Aussagen über Habitatansprüche und die von einer Art präferierten Habitattypen (Bernotat et al. 2002).

Habitatelemente: Einzelne strukturelle Bestandteile eines Habitats, die eine funktionale Bedeutung für die jeweilige Art haben (Bernotat et al. 2002). Bestimmte Habitatelemente wie Totholz, Zaunpfähle, Offenbodenbereiche oder Lesesteinhaufen sind für Säugetiere von großer Bedeutung.

Habitatnutzung: Im übergeordneten Sinne basiert die Habitatnutzung auf der Definition des Habitats als Lebensraum eines Individuums (oder einer Art). Im engeren Sinne bezieht sich der Begriff auf die Lage der Aufenthaltsorte innerhalb bestimmter Habitattypen.

Habitattyp: Ein Habitattyp ist ein abstrahierter Typus aus der Gesamtheit gleichartiger Habitate einer Art. Habitattypen einer Art sind in diesem Sinn die besiedelten Lebensraumtypen (Bernotat et al. 2002).

Herbivore: Arten, die sich überwiegend von mehr oder weniger harten Pflanzenteilen ernähren

Home Range: Er bezeichnet die Fläche, die ein Individuum oder eine soziale Gruppe in einem bestimmten Zeitraum frequentiert. Die Begriffe Home Range und Aktionsraum werden synonym verwendet.

Kartierung: Kartierungen dienen der Erfassung von Lebensräumen. Biotoptypen-Kartierungen sind beispielsweise flächendeckende Kartierungen eines bestimmten Untersuchungsraumes basierend auf einer vorgegebenen Klassifikation (Wiegleb et al. 2002). Sie finden häufig Verwendung, obwohl sie tierökologische Aspekte in der naturschutzfachlichen Planung nicht mit abdecken können (Brinkmann 1998, Drachenfels 1994).

Kennarten: Die Zuordnung von Pflanzenbeständen zu bestimmten Vegetationstypen erfolgt mit Hilfe von Kenn- und Trennarten. Dies sind pflanzensoziologische Begriffe für Arten mit einem begrenzten Verbreitungsgebiet, die eine Aussage über den Pflanzenbestand ermöglichen. Kenn- oder Charakterarten sind Arten, die einen eindeutigen Verbreitungsschwerpunkt in einem bestimmten Biozönosetyp haben (Kaiser et al. 2002).

Landschaft: Bei einer großräumigen Betrachtung von Biotopen spricht man von einer Landschaft, die die zweidimensionale Erstreckung von Landschaftstypen bezeichnet, die sich über mehrere Kilometer regelmäßig wiederholen (Formon et al. 1986). 
Meidung: eine unterdurchschnittliche Nutzung von Habitaten in Relation zu ihrer Abundanz oder Verfügbarkeit in einem Gebiet

Nutzungsintensität: Die Nutzung eines bestimmten Habitattyps entspricht seinem prozentualen Anteil an allen Standorterfassungen eines Individuums.

Periodizität: Typ der Vegetationsdynamik, Veränderungen von Jahr zu Jahr innerhalb einer Gesellschaft

Pflanzengesellschaft: Eine abstrahierbare, bestimmte Artzusammensetzung (Biozönose) von Pflanzen. Pflanzengesellschaften wachsen an einem ökologischen Standort und bilden den botanischen Teil von Biotopen. Die Lehre der Pflanzengesellschaften bezeichnet man als Pflanzensoziologie.

Präferenz: eine überdurchschnittliche Nutzung von Habitaten in Relation zu ihrer Abundanz oder Verfügbarkeit in einem Gebiet

Sukzession: Typ der Vegetationsdynamik, gerichtete zeitliche Aufeinanderfolge von Gesellschaften, ausgelöst und gesteuert von Standortveränderungen oder von Wirkungen der Vegetation

Teilhabitat: Ein Habitat besteht aus mehreren Teilhabitaten, also aus verschiedenen Bestandteilen des Gesamtlebensraumes, die für die Art unterschiedliche Funktionen beinhalten und in einer artspezifischen Kombination über räumlich-funktionale Beziehungen miteinander verknüpft sind.

Trennarten: Die Zuordnung von Pflanzenbeständen zu bestimmten Vegetationstypen erfolgt mit Hilfe von Kenn- und Trennarten. Trenn- oder Differenzialarten sind sich in ihrem Vorkommen in einem bestimmten Gebiet fast oder ganz ausschließende Arten. Sie dienen zur Unterscheidung und Kennzeichnung nahe verwandter Pflanzengesellschaften und helfen, innerhalb von Assoziationen Untereinheiten unterschiedlicher ökologischer Rahmenbedingungen zu differenzieren (Kaiser et al. 2002).

Vegetation: Gesamtheit der Vergesellschaftungen von Pflanzen in einem bestimmten Gebiet (Abb. 90)

Vegetationsdynamik: Pflanzenbestände unterliegen ständigen Veränderungen. Die Dynamik ist ein wesentliches Kennzeichen der Vegetation. Je nach Art, Dauer und Richtung der Veränderungen lassen sich für Bestände verschiedene Typen der Dynamik unterscheiden (Dierschke 1994).

Vegetationsentwicklung: Unter Vegetationsentwicklung versteht man kurz- bis längerfristige, gerichtete Veränderungen, meist im Bereich mehrerer Gesellschaften, die aufeinander folgen (Dierschke 1994).

Vegetationsgeschichte: langfristige Entwicklung der Vegetation

Vegetationskomplex: Das räumliche Anordnungsmuster verschiedenartiger Vergesellschaftungen von Pflanzen, aber auch daraus abgeleitet das Gesellschaftsinventar eines Landschaftsausschnittes. Zur Charakterisierung der Pflanzengesellschaften wird eine Einteilung in Vegetationstypen vorgenommen.

Vegetationstyp: Ein Vegetationstyp ist die typisierte Vergesellschaftung von Pflanzen.

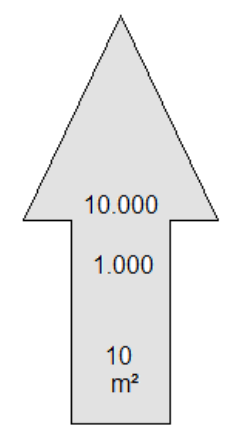

\begin{tabular}{|l|l|}
\hline Vegetationsdecke & Biosphäre \\
Vegetationszonen & Biome \\
\hline Pegetationstypen & Ökosystem \\
\hline Einzelpflanze & Ökosystem \\
\hline
\end{tabular}





\section{LITERATUR}

Aichele, D. \& H.-W. Schwegler (1998): Unsere Gräser: Süßgräser, Sauergräser, Binsen. 11. Aufl. Kosmos Verlag, Stuttgart. Alipayo, D.R. Valdez, L. Holecek \& M. Cardenas (1992): Evaluation of microhistological analysis for determining ruminant diet botanical composition. J. of Range Manag. 45: 148-152.

Altmann, J. (1974): Observational study of behaviour: sampling methods. Behaviour 49: 227-267.

Andersen, A.-M. (1996): Bedeutung der Renaturierung und Neuanlage von Gewässern für den Erhalt der Rotbauchunke auf Fünen. In: Krone, A. \& K.-D. Kühnel (Hrsg.) (1996): Die Rotbauchunke - Sonderheft 1 der RANA, Natur \& Text, Berlin, 21-31.

Andreae, B. (1972): Landwirtschaftliche Betriebsformen in den Tropen. Hamburg/Berlin.

ANL Bayerische Akademie für Naturschutz und Landschaftspflege (Hrsg.) (2005): Bewahren durch Dynamik: Landschaftspflege, Prozeßschutz, Beweidung - Praxisschwerpunkt Pferdebeweidung. Sammelband der Veranstaltungen „Pferdebeweidung in der Landschaftspflege“ und „Bewahren durch Dynamik“. Laufen/Salzach.

ANL Bayerische Akademie für Naturschutz und Landschaftspflege (Hrsg.) (1995): Landschaftspflegekonzept Bayern, Band II.9 Streuwiesen. München

Assmann, T. \& B. Falke (1997): Bedeutung der Hudelandschaften aus tierökologischer und naturschutzfachlicher Sicht. In: Klein, M., U. Riecken \& E. Schröder: Alternative Konzepte des Naturschutzes für extensiv genutzte Kulturlandschaften. Münster, Landwirtschaftsverlag. Schriftenreihe für Landschaftspflege und Naturschutz 54: 129-144.

Baker, S. (1991): The Exmoor gathering. Exmoor Pony Society Newsletters 1991:25-27.

Baker, S. (1993): Survival of the fittest. A natural history of the Exmoor Pony. Exmoor Books, Dulverton.

Baker, S., C. Greig, H. Macgregor \& A. Swan (1998): Exmoor Ponies - Britain's prehistoric wild horses? British Wildlife 9: 304-313.

Baker, S. (2008): Survival of the Fittest - A natural history of the Exmoor Pony. Second Edition. Exmoor Books, Dulverton, Somerset, $244 \mathrm{~S}$.

Bakker, J. P. \& F. Berendse (1999): Constraints in the restoration of ecological diversity in grassland and heathland communities. - Trends Ecol. Evol. 14: 63-68, London.

Barthlott, W. \& B. Martens (1979): Cuticular-Taxomonie der Gräser eines westafrikanischen Savannesgebietes unter dem Aspekt der Futterpräferenz-Analyse wildlebender Großsäuger. Trop. und subtrop. Pflanzenwelt, 30 (1979). Akad. der Wissenschaften und der Literatur, Mainz.

Bauschmann, G. (2005): Naturschutzfachliche Überlegungen zum Einsatz von alten Haustierrassen in der Landschaftspflege. LNU Seminarberichte 6: 29-41, Arnsberg.

Beck, R. (1994): Die Abschaffung der Wildnis. Landschaftsästhetik, bäuerliche Wirtschaft und Ökologie zu Beginn der Moderne. In: Naturlandschaft - Kulturlandschaft. Der Bürger im Staat. Heft 1, 14-21.

Becker, C. \& M. Schmidt (1999): Beweidung von Extensivgrünland mit Island-Pferden. Natur und Kulturlandschaft 3: 354361.

Beije, H., H. Dekker, J. L. J. Hendriks et al. (2002): Grazing and grazing animals. Vakblad Natuuurbeheer 41, 63 S., Wageningen.

Bekker, R.M., J.H.J. Schaminée, J.P. Bakker \& K. Thompson (1998): Seed bank characteristics of Dutch plant communities. Acta. Bot. Neerl. 47 (1): 15-26. Amsterdam.

Bender, I. (1998): Der Urtyp im Pferd: Ansprüche an die Haltung. - Freizeit im Sattel - Die Fachzeitschrift rund ums Reiten, Jg.1998 (6): 558-560, Bonn.

Berg, C., J. Dengler, A. Abdank \& M. Isermann (Hrsg.) (2004): Die Pflanzengesellschaften Mecklenburg-Vorpommerns und ihre Gefährdung. Landesamt für Umwelt, Naturschutz und Geologie Mecklenburg-Vorpommern. Weissdorn-Verlag Jena.

Berger, J. (1986): Wild Horses of the Great Basin. University of Chicago Press, Chicago. 
Berger, J. (1977): Organizational systems and dominance in feral horses in the Grand Canyon. Behav. Ecol. Sociobiol. 2:131-146.

Bergmeier, E., W. Härdtle, U. Mierwald, B. Nowak \& C. Peppler (1990): Vorschläge zur syntaxonomischen Arbeitsweise in der Pflanzensoziologie. - Kieler Notiz. Pflanzenkd. Schleswig-Holstein u. Hamburg 20: 92-103, Kiel.

Beutler, A. (1997): Das Weidelandschaftsmodell: Großtiere und Vegetation Mitteleuropas im Jungpleistozän und Frühholozän, Versuch einer Rekonstruktion der natürlichen Landschaft. In: Gerken, B. \& C. Meyer (Hrsg.): Vom Waldinnensaum zur Hecke - Geschichte, Situation und Perspektiven eines Natur-Lebensraum-Gefüges. Natur u. Kulturlandschaft, Heft 2, Höxter, 194-206.

Beyer H. L. (2012): Geospatial Modelling Environment. Version: 0.7.2 RC2, http://www.spatialecology.com/gme.

BfN (2013): Halboffene Weidelandschaften. Quelle: http://www.bfn.de/0311_weide.html, abgerufen am 20.12.13.

Bibikova, V. I. (1967): Zum Studium der ältesten Hauspferde in Osteuropa. Bulletin Mosk. Naturf. Gesell. Abt. Biol. 72: 106-118.

Bibikova, V. I. (1986): On the History of Horse Domestication in South-East Europe. - In: Telegin, D. Y. (Hrsg.): Settlement and Cemetery of Copper Age Horse Keepers on the Middle Dnieper. Bar Int. Ser. 287, 135 - 180.

Bökönyi, S. (1984): Horse. Evolution of domesticated animals: 162-184. London, New York (Longman).

Bolz, R. (2005): Auswirkungen der Pferdebeweidung auf naturschutzfachlich wertvolle Lebensräume - Faunistische Aspekte. Laufener Seminarbeiträge 1/05, S. 83-91.

Bontjer, A. (2010a): Mesoscale Vegetation Structure Analysis. In: Plachter, H. \& U. Hampicke (Hrsg.): Large-scale livestock grazing. A management tool for nature conservation. Springer, Berlin, 79-84.

Bontjer, A. (2010b): Mesoscale Vegetation Structure on Differently Used Cattle Pastures in the Thuringian Rhoen. In: Plachter, H. \& U. Hampicke (Hrsg.): Large-scale livestock grazing. A management tool for nature conservation. Springer, Berlin, 183-201.

Braun-Blanquet, J. (1964): Pflanzensoziologie. 3. Aufl. (Springer). Wien. New York.

Briemle, G., S. Nitsche \& L. Nitsche (2002): Nutzungswertzahlen für Gefäßpflanzen des Grünlandes. Schriftenreihe für Vegetationskunde Heft 38: 203-225, Bonn.

Briemle, G. (1978): Zur Verarmung der Kulturlandschaft. Leben \& Umwelt 15 (2): 36-37, Biologie-Verlag, Wiesbaden.

Bromisch, W. (2005): Beweidung durch Przewalski-Pferde im Naturschutzgebiet "Tennenloher Forst" - Ein Projekt des Landschaftspflegeverbandes Mittelfranken. Laufener Seminarbeiträge 1/2005: 163-166.

Bruun, H. H. \& R. Ejrnæs (1998): Overdrev - en beskyttet naturtype. Miljø- og Energiministeriet, Skov- og Naturstyrelsen, Gads Forlag, Kopenhagen: $222 \mathrm{~S}$.

Bunzel-Drüke, M., C. Böhm, P. Finck, G. Kämmer, R. Luick, E. Reisinger, U. Riecken, J. Riedl, M. Scharf \& O. Zimball (2008): „Wilde Weiden“, Praxisleitfaden für Ganzjahresbeweidung in Naturschutz und Landschaftsentwicklung. Westkämper Verlag.

Bunzel-Drüke, M., L. Hauswirth \& M. Scharf (2002): Die Klostermersch - Ein Fluss erobert seine Aue zurück. Staatl. Umweltamt Lippstadt, 20 S., Lippstadt.

Bunzel-Drüke, M., J. Drüke \& H. Vierhaus (2001): Der Einfluss von Großherbivoren auf die Naturlandschaft Mitteleuropas. Erschienen in einer niederländischen Naturschutzzeitschrift.

Bunzel-Drüke, M., J. Drüke, L. Hauswirth \& H. Vierhaus (1999): Großtiere und Landschaft - Von der Praxis zur Theorie. In: Gerken, B. \& M. Görner (Hrsg.): Europäische Landschaftsentwicklung mit großen Weidetieren - Geschichte, Modelle und Perspektiven. Natur- und Kulturlandschaft (Höxter/Jena) 3: 210-229.

Bunzel-Drüke, M. (1997): Großherbivore und Naturlandschaft. - Schriftenreihe Landschaftspflege u. Naturschutz 54: 109-128.

Burt, W. H. (1943): Territoriality and home range concepts as applied to mammals. Journal of Mammalogy 24: S. 346352.

Cameron, E.Z. et al. (2001): Population dynamics 1994-98, and management, of Kaimanawa wild horses. Wellington, N.Z., Dept. of Conservation.

Chapius, J.I. \& J.C. Lefeuvre (1980): Evolution saisonniére du regime alimentaire du lapin de garenne Oryctolagus cuniculus (L.) en „lande“: résultats de deux ans d'analyses. Bull. Ecol. 11:587-597.

Clutton-Brock, J. (1999): A Natural History of Domesticated Mammals, 2nd edition. - Cambridge University Press, The Natural History Museum. 238 pp. 
Cosyns, E., T. Degezelle, E. Demeulenaere \& M. Hoffmann (2001): Feeding ecology of Konik horses and donkeys in Belgian coastal dunes and its implications for nature management. Belg. J. Zool., 131: 111-118.

Crowell-Davis, S. L., K. A. Houpt \& C. M. Carini (1986): Mutual grooming and nearest-neighbor relationships among foals of Equus caballus. Applied Animal Behaviour Science 15: 113-123.

Cuartas, P. \& R. Garcia-Gonzalez (1996): Review of available techniques for determing the diet of large herbivores from their faeces. Oecologia Montana 5, 47-50.

Dänisches Meteorologisches Institut, www.dmi, zuletzt abgerufen am 13.01.2013.

Dänisches Ministerium für Umweltschutz (2006): Südlangeland. Wanderungen Nr. 63T. Generaldirektorat für Forst und Natur.

Dänisches Ministerium für Umweltschutz (2003): Protection of Nature Act. No. 9 of 3 January 1992.

Dahinten, B. (2005): Beweidung von kleinflächigen Landschaftspflegeflächen - Mobile Pferdebeweidung. Laufener Seminarbeiträge 1/05, S. $121-124$.

Delling, M. (2013): Behaviour, interactions and habitat use of European bison (Bison bonasus), Exmoor ponies (Equus ferus) and Dybowski deer (Cervus nippon hortulorum) in a mixed-species enclosure at Tierpark Sababurg. Dissertation. Georg-August-Universität Göttingen.

Delling, M. (2009): Winterliche Habitatnutzung von Exmoorponys auf Langeland (Dänemark). Unveröffentl. Diplomarbeit, Univ. Göttingen, $122 \mathrm{~S}$.

Demartin, G. (2005): Beweidung von Naturschutzflächen - Effekte auf Flora und Fauna am Beispiel des NSG „Gundelfinger Moos". Laufener Seminarbeiträge 1/05, S. 93 - 98.

Denniston, R.H., M. Boyce, W.D. McCort, J. Timmerman, B. Holz \& L. Wollrab (1982): “Conclusions" and "Suggestions for Management". University of Wyoming - Feral Horse Study. USDI, BLM, Washington, D.C., S. 43-47.

Dent, A. (1970): The pure bred Exmoor Pony. The Exmoor Press, Dulverton.

Dierendonck, M.C. van, N. Bandi, D. Batdorj, S. Diigerlham \& B. Munkhtsog (1996): Behavioural observations of reintroduced Takhi or Przewalski horse (Equus ferus przewalskii) in Mongolia. Applied Animal Behaviour Science 50: 95-114.

Dierking, U. (1993): Halboffene Weidelandschaften. In: Landesamt für Naturschutz und Landschaftspflege (Hrsg.): Perspektiven des Naturschutzes in Schleswig-Holstein. Kiel: S. 45-47.

Dierking, U. (1992): Halboffene Weidelandschaften - Eine Zielsetzung im Naturschutz in Schleswig-Holstein? Bauernblatt, Landpost 46/1992. In: Landesamt für Naturschutz und Landschaftspflege (Hrsg.): Beiträge zu Naturschutz und Landschaftspflege 1991-1994: 51-54.

Dierschke, H. \& G. Briemle (2002): Kulturgrasland: Wiesen, Weiden und verwandte Staudenfluren. Stuttgart. Ulmer.

Dierschke, H. (1997): (Hrsg.): Synopsis der Pflanzengesellschaften Deutschlands. Heft 3: Molinio-Arrhenatheretea, Teil 1: Arrhenatheretalia. Wiesen und Weiden frischer Standorte. Göttingen, 1997.

Dierschke, H. (1994): Pflanzensoziologie - Grundlagen und Methoden. Ulmer, UTB für Wissenschaft.

Drachenfels, O. v. (2011): Kartierschlüssel für Biotoptypen in Niedersachsen. Naturschutz und Landschaftspflege in Niedersachsen, Heft A/4, Stand März 2011.

Düll, R. (2008): Moose einfach und sicher bestimmen. Ein illustrierter Exkursionsführer zu den Arten Deutschlands und angrenzender Länder. Wiebelsheim, Quelle \& Meyer.

Duncan, P. (1992): Horses and grasses. The nutritional ecology of equids and their impact on the Camargue. SpringerVerlag New York, USA. 287 Seiten.

Duncan, P. (1985): Time budgets of Camargue horses. III. Environmental influences. Behav. 92, 188-208.

Duncan, P. (1980): Time-budgets of Camargue horses. II. Time budgets of adult horses and weaned sub-adults. Behav. 72, 26-49.

Ebhardt, H. (1954): Verhaltensweisen von Islandpferden in einem norddeutschen Freigelände. In: Säugetierkundliche Mitteilungen, Heft 4. Stuttgart.

Edwards, P.-J. \& S. Hollis (1982): The distribution of excreta on New Forest grassland used by cattle, ponies and deer. Journal of Applied Ecology (19): 953-964.

Ellenberg, H. \& C. Leuschner (2010): Vegetation Mitteleuropas mit den Alpen in ökologischer, dynamischer und historischer Sicht, 6. Aufl., Ulmer, Stuttgart.

Ellenberg, H., H. E. Weber, R. Düll, V. Wirth \& W. Werner (2001): Zeigerwerte von Pflanzen in Mitteleuropa. 3. AuflageScripta Geobotanica 18: 258 S. 
Ellenberg, H. (1986): Vegetation Mitteleuropas mit den Alpen in ökologischer Sicht, 4. Aufl.. Ulmer, Stuttgart.

Elsäßer, M. (2003): Pferdeweiden. Anforderungen - Maßnahmen - Pflege. Merkblätter für die Umweltgerechte Landbewirtschaftung, Nr. 17 (2), Landesanstalt für Pflanzenbau Forchheim.

Ewald, K. (1994): Traditionelle Kulturlandschaften. Elemente - Entstehung - Zweck - Bedeutung. Naturlandschaft - Kulturlandschaft. Der Bürger im Staat, Heft 1, 37-42.

FAL (Bundesforschungsanstalt für Landwirtschaft) (Hrsg.) (1994): Konzept zur Erhaltung und Nutzung tiergenetischer Ressourcen in der Landwirtschaft der Bundesrepublik Deutschland. Braunschweig.

Flade, M. (1994): Die Brutvogelgemeinschaften Mittel- und Norddeutschlands. IHW-Verlag. Eching.

Finck, P., W. Härdtle, B. Redecker \& U. Riecken (Bearb.) (2004): Weidelandschaften und Wildnisgebiete - Vom Experiment zur Praxis. Schriftenreihe f. Landschaftspflege u. Naturschutz 78.

Finck, P., U. Riecken \& E. Schröder (2002): Pasture Landscapes and Nature Conservation - New strategies for the preservation of open landscapes in Europe. In: B. Redecker, P. Finck, W. Härdtle, U. Riecken, E. Schröder (Hrsg.): Pasture Landscapes and Nature Conservation. Springer, 2002.

Finck, P., M. Klein, U. Riecken \& E. Schröder (1998): Schutz und Förderung dynamischer Prozesse in der Landschaft. Münster, Landwirtschaftsverlag. Schriftenreihe für Landschaftspflege und Naturschutz 56: 424 S.

Finck, P., U. Hauke, E. Schröder, R. Forst \& G. Woithe (1997): Naturschutzfachliche Landschafts-Leitbilder. Rahmenvorstellungen für das Nordwestdeutsche Tiefland aus bundesweiter Sicht. Münster, Landwirtschaftsverlag. Schriftenreihe für Landschaftspflege und Naturschutz 50: $265 \mathrm{~S}$.

Fischer, A. (1987): Untersuchungen zur Populationsdynamik am Beginn von Sekundärsukzessionen. Die Bedeutung von Samenbank und Samenniederschlag für die Wiederbesiedlung vegetationsfreier Flächen in Wald- und Grünlandgesellschaften. Diss. Bot. 110: 1-234. Berlin, Stuttgart.

Forbes, J. M. (1986): Voluntary food intake and diet selection in farm animals. Butterworths, London.

Frenz, K. (2004): Populationsstruktur und Habitatansprüche der Rotbauchunke (Bombina bombina LINNAEUS, 1761) im niedersächsischen Elbetal. Unveröff. Diploamarbeit, Universität Lüneburg, Institut für Ökologie und Umweltchemie.

Ganskopp D. \& M. Vavra (1986): Habitat Use by Feral Horses in the Northern Sagebrush Steppe. J. of Range Manag. 39(3).

Gates, S. (1980): Studies of the ecology of the free-ranging Exmoor Pony. Ph. D. Thesis, Exeter University.

Geologische Forschungsanstalt für Dänemark und Grönland (GEUS), www.geus.dk, zuletzt abgerufen am 4.11.2011.

Gerken, B. (2008): Hutelandschaftspflege und Artenschutz mit großen Weidetieren im Naturpark Solling-Vogler. Teil 1 Hauptvorhaben. Teil 2 - wissenschaftliche Begleitung. Bundesamt für Naturschutz (Hrsg.), Bonn-Bad Godesberg.

Gerken, B. \& M. Görner (Hrsg.) (1999): Europäische Landschaftsentwicklung mit großen Weidetieren - Geschichte, Modelle und Perspektiven. Natur- und Kulturlandschaft (Höxter/Jena) 3, 210 - 232.

Gerken, B. \& C. Meyer (Hrsg.) (1998): Wo lebten Pflanzen und Tiere in der Naturlandschaft und der frühen Kulturlandschaft Europas? Referate der gleichnamigen Tagung am 22. und 23. März 1995 in Neuhaus/Solling, Höxter.

Gruber, S. (2002): Überlebensrate und Flächennutzung in Kiebitzfamilien (Vanellus vanellus) an der Westküste Schleswig-Holsteins. Wiesenvogelschutz in Norddeutschland und den Niederlanden. Symposium 4./5.9.2002: 57-58.

Grundkort Fyn, www.grundkortfyn.dk, abgerufen am 4.11.2011.

Grunow, J. O. (1980): Feed and habitat preferences among some large herbivores on African veld. Proceedings of the Grassland Society of Southern Africa 15: 141-146.

Günther, R. \& N. Schneeweiß (1996): Rotbauchunke - Bombina bombina (L. 1761). In: Günther, R. (Hrsg.) (1996): Die Amphibien und Reptilien Deutschlands, Fischer-Verlag, Jena, 215-232.

Hafner, R. (2001): Nichtparametrische Verfahren der Statistik. Springer Verlag.

Hakes, W. (1996): Multivariate Ordinationsmethode zur Analyse von Veränderungen in der Vegetationsstruktur - Grundlagen und Beispiele aus Sukzessionsforschung und Monitoring Naturschutz und Landschaftsplanung, 1.

Hammer, Ø., D.A.T. Harper, \& P. D. Ryan (2001): PAST Paleontological Statistics Software Package for Education and Data Analysis. Palaeontologia Electronica 4 (1): 9pp.

Hampicke, U. (1997): Warum ist Landnutzung oft so unwirtschaftlich? Verhandlungen der Gesellschaft für Ökologie, Band 27, 253-262.

Handke, K. (1997): Natur- oder Kulturlandschaft - ein Beitrag zur Leitbilddiskussion in der Bremer Flussmarsch aus tierökologischer Sicht. Schr.-R. f. Landschaftspfl. u. Natursch. 54: 93-108. 
Hanley, T.A., D.E. Spalinger, K.A. Hanley \& J.W. Schoen (1985): Relationsips between fecal and rumen analyses for deer diet assessments in Southeastern Alaska. Northwest Science, 59: 10-16.

Heptner, V. G. \& N. P. Naumov: Die Säugetiere der Sowjetunion, Band 1: Paarhufer und Unpaarhufer. Jena, G. Fischer, 1966

Heimes, C., J. Kollmann \& E. Bergmeier (2010): Vegetation und Management seltener Pflanzenarten im Küstengrünland einer dänischen Ostseeinsel. Tuexenia 30: 243-269, Göttingen.

Herre, W. (1961): Grundsätzliches zur Systematik des Pferdes. Zeitschrift für Tierzüchtung und Züchtungsbiologie 75: 57-78.

Hill, M.O. \& H.G. Gauch (1980): Detrended Correspondence analysis: an improved ordination technique. Vegetation 42:47-58.

Hintz, H. F., H. F. Schryver \& J.E. Lowe (1971): Comparison of a blend of milk products and linseed meal as protein supplements for young growing horses. J. Anim. Sci. 33:1274.

Holechek, J.L. \& R. Valdez (1985): Magnification and shrub stemmy material influcence on fecal analysis accuracy. J. of Range Manag. 38: 350-353.

Holechek, J.L., M. Vavra \& R.D. Pieper (1982): Botanical composition determination of range herbivore diet: a review. J. Range Manage. 35: 309-315.

Holsten, B. (2003): Der Einfluss extensiver Beweidung auf ausgewählte Tiergruppen im Oberen Eidertal. Dissertationsschrift Math.-Naturwiss. Fak. Christian-Albrechts-Universität Kiel.

Hoppe-Dominik, B. (1989): Habitatpräferenz und Nahrungsansprüche des Waldbüffels, Syncerus caffer nanus, im Regenwald der Elfenbeinküste. - Dissertation, Technische Universität Braunschweig. $237 \mathrm{~S}$.

Hubbard, R.E. \& R.M. Hansen (1979): Diet of wild horses, cattle and mule deer in the Piceance Basin, Colorado. J. of Range Manag. 29 (5), Sept 1979.

Hüppe, J. (1997): Vegetationsdynamik in „halboffenen Hudelandschaften“ - Abhängigkeit von Nutzungsintensität und natürlichen Ausgangsbedingungen sowie Anforderungen an künftige Naturschutzziele. - Schriftenreihe für Landschaftspflege und Naturschutz 54: 145-159.

Jansen, T. (2002): Untersuchungen zur Phylogenie und Domestikation des Hauspferdes (Equus ferus f. caballus), Stammesentwicklung und geografische Verteilung. Diss. Math.-Naturwiss. Fak. Universität Bonn.

Jensen, K. (1998): Species composition of soil seed bank and seed rain of abandoned wet meadows and their relation to above-ground vegetation. Flora 193: 345-355.

Jarrige, R. \& W. Martin-Rosset (1987): Le Cheval: reproduction, selection alimentation, exploitation. INRA, Paris.

Kämmer, G. (2010): Halboffene Weidelandschaften - Erfahrungen des Vereins BUNDE WISCHEN mit diesem neuen Instrument des Naturschutzes. www.bundewischen.de.

Kampf, H. (2000): Beweidung in den Niederlanden. Arbeitsgemeinschaft Biologischer Umweltschutz im Kreis Soest e. V., ABU info 24 (2/00)

Kapfer, A. (1995a): Wieder beweiden? Möglichkeiten und Grenzen der Beweidung als Maßnahme des Naturschutzes und der Landschaftspflege. Beiträge der Akademie für Natur und Umweltschutz Baden-Württemberg, Bd. 18, Tübingen, 6-7.

Kapfer, A. (1995b): Der Einfluss der Beweidung auf die Vegetation aus der Sicht des Naturschutzes. Beiträge der Akademie für Natur- und Umweltschutz Baden-Württemberg, Bd. 18, Tübingen, 27-36.

Keiper, R. R. \& J. Berger (1982): Refuge-seeking and pest avoidance by feral horses in desert and island environments. Applied Animal Ethology. 9, 111-120.

Klapp, E \& W. Opitz von Boberfeld (2006): Taschenbuch der Gräser. Eugen Ulmer, Stuttgart.

Klapp, E \& W. Opitz von Boberfeld (2004): Gräserbestimmungsschlüssel für die häufigsten Grünland- und Rasengräser. Eugen Ulmer, Stuttgart.

Klapp, E. (1971): Wiesen und Weiden: Eine Grünlandlehre. 620 S. Berlin/Hamburg. Parey.

Klein, M., U. Riecken \& E. Schröder (Bearb.) (1997): Alternative Konzepte des Naturschutzes für extensiv genutzte Kulturlandschaften. Münster Landwirtschaftsverlag, Schriftreihe für Landschaftspflege und Naturschutz 54: 310 S.

Kleyer, M. et al. (2004): Freie Beweidung mit geringer Besatzdichte und Fräsen als alternative Verfahren zur Pflege von Magerrasen. - In: Fink, P., Härdtle, W., Redecker, B., Riecken, U.: Weidelandschaften und Wildnisgebiete - Vom Experiment zur Praxis. Schriftenreihe für Landschaftspflege und Naturschutz 78, 161-182. 
Van Klink, E.G.M. \& H. Kampf (2004): Veterinärrechtliche Erfahrungen mit großflächigen Beweidungsprojekten in den Niederlanden - Nationale Herangehensweise und Europäische Dimension. In: Finck, P., Härdtle, W., Redecker, B. \& Riecken, U. (Bearb.) Weidelandschaften und Wildnisgebiete - Vom Experiment zur Praxis. - Schr.-R. f. Landschaftspfl. u. Natursch. 78, 429-438.

Kobbelt, A. (2000): Nahrungsökologie der Przewalskipferde im Hortobágy Nationlapark (Ungarn). Diplomarbeit, Universität zu Köln.

Koleff, P., K.J. Gaston \& J.J. Lennon (2003): Measuring beta diversity for presence-absence data. Journal of Animal Ecology 72: 367-382.

Kolter, L., C. Schach \& T. Weber (1999): Habitat Use of Feral and Przewalski's Horses. Natur- und Kulturlandschaft 3: $332-$ 342.

König, H., T. Hübner, C. Michels \& A. Pardey (2003): Neue Säule des Naturschutzes - Naturentwicklungsgebiete und Beweidung. LÖBF-Mitteilungen 4/2003, S. 21-28.

Korn, S. v. (2009): Landschaftspflege mit Weidetieren. Naturschutz und Biologische Vielfalt 71.

Korn, S. v. (1992): Schafe in Koppel- und Hütehaltung. Ulmer Verlag, Stuttgart, 1992.

Korn, S. von (1987): Im Einsatz in der Landschaftspflege. Welche Tierarten eignen sich? DLG-Mitt. 18: 974-977.

Korner, I., A. Traxler \& T. Wrbka (2000): Vegetationsökologisches Beweidungsmonitoring Nationalpark Neusiedler See Seewinkel 1990-1998. Biol. Forschungsinstitut Burgenland, Illmitz.

Krannich, R. (2005): Das Hutewaldprojekt im Solling - Ein Baustein für eine neue Ära für Naturschutz und Landschaftsentwicklung. Laufener Seminarbeiträge 1/05: 59-69.

Kupfernagel, C. (2004): Populationsdynamik und Habitatnutzung des Feldhamsters (Cricetus cricetus) in Südost-Niedersachsen. Ökologie, Umsiedlung und Schutz. Technische Universität Carolo-Wilhelmina zu Braunschweig, Dissertation, 117 Seiten.

Lamoot, I., C. Vandenberghe, D. Bauwens \& M. Hoffmann (2005): Grazing behaviour of free-ranging donkeys and Shetland ponies in different reproductive states. J Ethol (2005) 23:19-27.

Lamoot, I. (2004): Foraging behaviour and habitat use of large herbivores in a coastal dune landscape. Dissertation, Universiteit Gent.

LÜBW Landesanstalt für Umwelt, Messungen und Naturschutz Baden-Württemberg (Hrsg.) (2006): Dokumentation und Handreichung zur Biotoppflege mit Pferden.

Leyer, I. \& K. Wesche (2007): Multivariate Statistik in der Ökologie. Eine Einführung. Springer Verlag.

Lohrengel, J. (2011): Habitatnutzung und Verhalten halbwilder Exmoor-Ponys im Herbst/ Winter. Unveröffentl. Masterarbeit, Georg-August-Univ. Göttingen.

Lüdi, W. (1930): Die Methoden der Sukzessionsforschung in der Pflanzensoziologie. Handb. biol. Arbeitsmeth. 11 (5): 527-728. Berlin, Wien.

Luick, R. (1996): Extensivweiden und ihre Geschichte in Deutschland. Ber. Instit. Landschafts-Pflanzenökologie Univ. Hohenheim 5: 31-50.

Mann, S. \& S. Tischew (2010): Die Entwicklung von ehemaligen Ackerflächen unter extensiver Beweidung (Wulfener Bruch). Hercynia N.F. 43, 119-147.

Mannstedt, T. (2007): Sozialverhalten von Exmoorponyfohlen (Equus ferus f. caballus) (Mammalia: Equidae). Species, Phylogeny and Evolution 1,2: 91-98.

Martin, P. \& P. Bateson (1993): Measuring Behaviour, 2nd ed. New York: Cambridge University Press.

Martin, D. \& H. Manthe (2005): Einsatz wildlebender Großherbivoren zur Offenhaltung der Landschaft im Bereich des Projektes Wildtierland Klepelshagen. Gestaltungsmöglichkeiten für die Landwirtschaft in einem zukünftigen Nationalpark Peenetal. Greifswald.

Manly, B. F. J. (2009): Statistics for environmental science and management. Taylor \& Francis, 2009.

McCullagh P. \& J. A. Nelder (1989): Generalized Linear Models. Second Edition. CRC Monographs on Statistics \& Applied Probability, Buch 37.

McDonnell, S. M. (2003): The Equid Ethogram: A Practical Field Guide to Horse Behavior. The Blood-Horse Inc.

McInnis, M. \& M. Vavra (1987): Dietary Relationships among Feral Horses, Cattle and Pronghorn in Southeastern Oregon. Journal of Range Manag., 40 (1). 
Menard, C., P. Duncan, G. Fleurance, J. Y. Georges \& M. Lila (2002): Comparative foraging and nutrition of horses and cattle in European wetlands. - Journal of Applied Ecology39: 120-133:

Messerer, M. (2006): Praktischer Versuch zur Ermittlung der Nahrungsgrundlage und möglicher Besatzstärke von Przewalski-Pferden auf Sandmagerrasen. Unveröffentlichte Diplomarbeit, Fachbereich Landwirtschaft Fachhochschule Weihenstephan.

Meßner, U. (2005): Beweidung und andere landwirtschaftliche Aktivitäten in Nationalparken. Gestaltungsmöglichkeiten für die Landwirtschaft in einem zukünftigen Nationalpark Peenetal. Greifswald, 04.02.05.http://laoek.botanik.uni-greifswald.de/projekte/Stiftungs-NPZeitplan-Dateien/WS2-Landwirtschaft(Peenetal).pdf

Mohr, E. (1959): Das Urwildpferd. Die Neue Brehm-Bücherei 249.

Morris, D. (1993): Foreword. In: Baker, S. (1993): Survival of the fittest. A natural history of the Exmoor Pony. Exmoor Books, Dulverton.

Mühlenberg, M. \& J. Slowik (1997): Kulturland als Lebensraum. Quelle \& Meyer, Wiesbaden.

Mühlenberg, M. (1993): Freilandökologie. Quelle \& Meyer, Heidelberg.

Newmark, W. D. \& E. A. Rickart (2012): High-use movement pathways and habitat selection by ungulates. Mammalian Biology 77, 293-298.

Nitsche, S. \& L. Nitsche: Extensive Grünlandnutzung. Neumann Verlag, 1994.

Nöllert, A. \& C. Nöllert (1992): Die Amphibien Europas. Franckh-Kosmos-Verlag, Stuttgart.

Oberdorfer, E. (2001): Pflanzensoziologische Exkursionsflora für Deutschland und angrenzende Gebiete. Eugen Ulmer Verlag, Stuttgart.

Oheimb, G. v., I. Eischeid, P. Finck, H. Grell, W. Härdtle, U. Mierwald, U. Riecken \& J. Sandkühler (2006): Halboffene Weidelandschaft Höltigbaum. Perspektiven für den Erhalt und die naturverträgliche Nutzung von Offenlandlebensräumen. Naturschutz und Biologische Vielfalt, Heft 36. Bundesamt für Naturschutz, Bonn.

Olff, H. \& M. E. Ritchie (1998): Effects of herbivores on grassland plant diversity. TREE Vol. 13, Nr. 7, Elsevier Science.

Oliver, S. Z. (2007): Small-scale feeding and habitat preferences of herbivore game species in the grassland of the Central Free State. Unveröffentl. Masterarbeit, Universität Bloemfontein, Südafrika.

Owen, M. (1975): An assessment of fecal analysis technique in waterfowl feeding studies. J. of Wildlife Manage. 39 (2): 271-279.

Owen-Smith, N. (1999): The animal factor in veld management. In: Tainton N.M. (ed.), Veld Management in South Africa, University of Natal Press, Pietermaritzburg, pp. 117-138.

Oxanen, J. \& P. R. Minchin (1997): Instability of ordination results under changes in input data order: explanations and remedies. Journal of Vegetation Science 8: 447-454.

Pain, J. (2005): Pferdebeweidung in der Landschaftspflege - Zusammenfassung der Tagung am 20.-21. September 2004 in Erlangen. Laufener Seminarbeiträge 1/05: 17-18.

Passarge, H. (1999): Pflanzengesellschaften Nordostdeutschlands 2. II. Helocyperosa und Caespitosa. Cramer in der Gebr.-Borntraeger-Verl.-Buchh., Berlin.

Peden, D.G., R.M. Hansen, R.W. Rice \& G.M. Van Dyne (1974): A Double Sampling Technique for Estimating Dietary Composition. J. of Range Manag. 27(4).

Pegel, H. (2002): Naturschutzmaßnahmen und deren Auswirkungen auf den Brutvogelbestand in der Fehntjer Tief Niederung (Niedersachsen). Wiesenvogelschutz in Norddeutschland und den Niederlanden. Hochschule Vechta. Symposium 4./5.9.2002: 89-92.

Peinetti, H.R., R.S.C. Menezes, \& M.B. Coughenour (2001): Changes induces by elk browsing in the aboveground biomass production and distribution of willow Salix monticola Bebb: their relationships with plant water, carbon, and nitrogen dynamics. Oecologia 127, 334-342.

Peter, K. (2008): Diversitätsmuster und Artenzusammensetzung der Grünlandflächen im Zentrum des Pony-Schutzgebietes, Südlangeland. Unveröffentl. Bachelorarbeit, Georg-August-Univer. Göttingen.

Petrides, G.A. (1975): Principal foods versus preferred foods and their relation to stocking rate and range condition. Biological Conservation 7: 161-169.

Pfadenhauer, J. (1999): Leitlinien für die Renaturierung süddeutscher Moore. Natur und Landschaft 74: 18-29.

Pflumm, W. (1996): Biologie der Säugetiere. Parey Buchverlag Berlin. 
Pinchak, W.E., M.A. Smith, R.H. Hart \& J.W. Waggoner Jr. (1991): Beef cattle grazing distribution patterns on foothill range. J. Range Manage. 44: 267-275.

Pirkelmann, H. (1991): Pferdehaltung. - 2. Aufl., Eugen Ulmer, Stuttgart.

Plachter, H. \& U. Hampicke (Hrsg.) (2010): Large-scale livestock grazing. A management tool for nature conservation. Springer Verlag, Berlin.

Pott, R. (1995): Die Pflanzengesellschaften Deutschlands. Ulmer, Stuttgart.

Pott, R. (1993): Farbatlas Waldlandschaften. Ulmer, Stuttgart.

Pott, R. \& J. Hüppe (1991): Die Hudelandschaften Nordwestdeutschlands. Abh. Westf. Museum Naturkunde, 53 (2/3), $313 \mathrm{~S}$.

Pötzinger, R. (2011): Fressverhalten und Bewegungsmuster halbwilder Exmoorponys im Winter. Unveröff. Bachelorarbeit, Univ. Göttingen.

Preuschhof, B. (2005): Adlerfarn oder Arnika? Beweidung mit Islandpferden im „Hühnerfeld“. Laufener Seminarbeiträge 1/05: 153-161.

Raabe, E. W. (1951): Über den Biotop der Unken. Die Heimat: Zeitschrift für Natur und Landeskunde in Schleswig-Holstein und Hamburg, 58, 268-288.

Radl, G. (1987): Jahreszeitliche Änderungen in der Nahrungswahl dreier verschieden großer Antilopenarten im Comoenationalpark (Elfenbeinküste) - Eine Analyse über Kotproben. - Diplomarbeit, Universität Würzburg.

Rahmann, G. \& E. S. Tawfik (Hrsg.) (2000): Landschaftserhaltung mit Nutztieren im sozio-ökonomischen Kontext. Dargestellt am Beispiel der Entbuschung des Biosphärenreservates Rhön. Verlag Dr. Kovac.

Rahmann, G. (2000): Biotoppflege als neue Funktion und Leistung der Tierhaltung. Agraria, Studien zur Agrarökologie, Band 28, Habilitationsschrift, Hamburg.

Rahmann, G. (1999): Biotoppflege mit Pferden: Möglichkeiten und Grenzen der Pflege von Streuwiesen (mit Dominanz Pfeifengras und Adlerfarn) durch Islandpferde. Natur und Kulturlandschaft 3: 362-376.

Regierung von Niederbayern (Hrsg.) (2008): Pilotprojekt zur Beweidung repräsentativer Grünlandbiotope des Bayerischen Waldes. Schriftenreihe Naturschutz in Niederbayern, Heft 5.

Reisinger, E. (2004): Ausgewählte naturschutzfachliche und sozioökonomische Anforderungen für die Etablierung großflächiger Weidesysteme. In: Finck, P., W. Härdtle, B. Redecker \& U. Riecken (Bearb.): Weidelandschaften und Wildnisgebiete - Vom Experiment zur Praxis. Münster Landwirtschaftsverlag. Schriftenreihe für Landschaftspflege und Naturschutz 36: $187 \mathrm{~S}$.

Reisinger, E. \& B. Schmidtmann (2001): Das Nessequellgebiet bei Erfurt - Ein Modellprojekt zur ganzjährigen extensiven Beweidung mit Robustrindern und Pferden. NZH Akademie- Berichte 2: 153-172.

Remmert, H. (1991): Das Mosaik-Zyklus-Konzept und seine Bedeutung für den Naturschutz: Eine Übersicht. In: ANL (Hrsg.): Das Mosaik-Zyklus-Konzept der Ökosysteme und seine Bedeutung für den Naturschutz. Laufener Seminarbeiträge 5/91: 5 - 15.

Riecken, U., P. Finck, U. Raths, E. Schröder \& A. Ssymank (2006): Rote Liste der gefährdeten Biotoptypen Deutschlands. Zweite fortgeschriebene Fassung 2006. Naturschutz und Biologische Vielfalt 34.

Riecken, U., M. Bunzel-Drüke, U. Dierking, P. Finck, W. Härdtle, G. Kämmer, E. Reisinger \& J. Sandkühler (2004): Perspektiven großflächiger Beweidungssysteme für den Naturschutz: "Lüneburger Erklärung zu Weidelandschaften und Wildnisgebieten". - In: Finck, P., W. Härdtle, B. Redecker \& U. Riecken (Bearb.): Weidelandschaften und Wildnisgebiete - Vom Experiment zur Praxis. - Schriftenreihe Landschaftspflege u. Naturschutz 78: 527-539.

Riecken, U., P. Finck, U. Raths, E. Schröder \& A. Ssymank (2003): Standard-Biotoptypenliste für Deutschland. BfN Schriftenreihe für Landschaftspflege und Naturschutz, Heft 75.

Riecken, U., P. Finck \& E. Schröder (2001): Tagungsbericht zum Workshop „Großflächige halboffene Weidesysteme als Alternative zu traditionellen Formen der Landschaftspflege“. Natur und Landschaft 76: 125-130.

Riecken, U., P. Finck, M. Klein \& E. Schröder (1998): Überlegungen zu alternativen Konzepten des Naturschutzes für den Erhalt und die Entwicklung von Offenlandbiotopen. Natur und Landschaft 73: 261-27.

Riecken, U., M. Klein \& E. Schröder (1997): Situation und Perspektiven des extensiven Grünlandes in Deutschland und Überlegungen zu alternativen Konzepten des Naturschutzes am Beispiel der Etablierung „halboffener Weidelandschaften“. Schriftenreihe Landschaftspflege u. Naturschutz, 54: 7-23.

Riediger, B. (1995): Untersuchungen zur Domestikation beim Exmoorpony. Unveröffentl. Diplomarbeit, Univ. Mainz. 
Ripple W.J. \& R.L. Beschta (2004): Wolves and the ecology of fear: can predation risk structure ecosystems? Bioscience 54, 755-766.

Roath, L.R \& W.C. Krueger (1982): Cattle grazing influence in a mountain riparian zone. J. Range Manage. 35:100-104.

Rödde, S. (2009): Habitatnutzung von Exmoorponys auf Langeland (Dänemark). Unveröffentl. Diplomarbeit, Georg-August-Univ. Göttingen.

Rodgers, A. R. \& J. G. Kie (2011): HRT: Home Range Tools for ArcGIS - Draft User's Manual. Centre for Northern Forest Ecosystem Research. Ontario Ministry of Natural Resources.

Rolecek J, L. Tichý, D. Zeleny \& M. Chytry (2009): Modified TWINSPAN classification in which the hierarchy respects cluster heterogeneity. J. Veg. Sci 20: 596-602.

Roth, F. (2002): Entwicklung der räumlichen und sozialen Organisation von Przewalski-Pferden (E. ferus przewalskii) unter naturnahen Bedingungen im Pentezuggebiet (Hortobágy Nationalpark, Ungarn). Dissertation der Mathematisch-Naturwissenschaftlich-Technischen Fakultät der Martin-Luther-Universität Halle-Wittenberg.

Rothmaler, W., M. Bäßler, R. Schubert \& E. J. Jäger (1999): Gefäßpflanzen - Grundband. Spektrum Akad. Verl., Heidelberg.

Rubinstein, D. I. (1981): Behavioral ecology of island feral horses. Equine Vet. J., 13: 27-34.

Runge, F. (1990): Die Pflanzengesellschaften Mitteleuropas: eine kleine Übersicht. 10./11., verb. und vermehrte Aufl. Verlag Aschendorff, Münster 1973.

Rüther, P. \& C. Venne (2005): Beweidung mit Senner Pferden auf trocknen Sand-Standorten: Erste Ergebnisse. Laufener Seminarbeiträge 1/05: 131-152.

Salter R.E. \& R.J. Hudson (1980): Range Relationships of Feral Horses with Wild Ungulates and Cattle in Western Alberta. J. of Range Manag. 33(4).

Salter R.E. \& R.J. Hudson (1979): Feeding Ecology of Feral Horses in Western Alberta. J. of Range Manag. 32(3).

Santos, S. M., M. da Luz Mathias, \& A. P. Mira (2011): The influence of local, landscape and spatial factors on the distribution of the Lusitanian and the Mediterranean pine voles in a Mediterranean landscape. Mammalian Biology 76: 133142.

Schäfer, M. (2000): Handbuch Pferdebeurteilung. Franck-Kosmos, 374 S., Stuttgart.

Schäfer, M. (1993): Die Sprache des Pferdes: Lebensweise, Verhalten, Ausdrucksformen. Erweiterte Neuausgabe, Stuttgart, Franck-Kosmos.

Schaffeld, T. (2000): Das Sozialverhalten von Exmoorponyfohlen (Equus caballus) am Beispiel der Herde des Sababurger Tierparks. 117 S. + Anhang. - Diplomarbeit angefertigt am Institut für Zoologie und Anthropologie der Georg-AugustUniversität zu Göttingen.

Scheibe, K. M., B. Lange, C. Sieling, A. Scheibe, C. Heinz \& F. Gladitz (1998): Entwicklung von Ortpräferenzen bei Przewalskipferden und Heckrindern und ihr Einfluss auf Vegetationsstrukturen. In: Wallschläger, D., M. Freude, D. Köhler (Hrsg.): Verhaltensbiologie und Naturschutz. Brandenburgische Umweltberichte 3, 69-77.

Schmidt, M., C. Becker, P. Fischer \& B. Preuschhof (2006): Vegetationsökologisches Dauerflächen-Monitoring in einer beweideten Hutelandschaft: Das „Hühnerfeld“ im Kaufunger Wald. - BfN-Skripte 178: 177-180. Bonn-Bad Godesberg.

Schmidt, M. \& C. Becker (2000): Erhaltung und Regeneration einer Hutelandschaft im Kaufunger Wald - Sieben Jahre Dauerflächen-Monitoring im NSG „Hühnerfeld“. Jahrb. Natursch. Hessen 5: 108-120.

Schrautzer, J. (2001): Niedermoore Schleswig-Holsteins: Charakterisierung und Beurteilung ihrer Funktion im Landschaftshaushalt. Habilitationsschrift im Fach Ökologie an der Christian-Albrechts-Universität zu Kiel.

Schwabe, A., A. Zehm, C. Eichberg, M. Stroh et al. (2004): Extensive Beweidungssysteme als Mittel zur Erhaltung und Restitution von Sand-Ökosystemen und ihre naturschutzfachliche Bedeutung. In: P. Finck, W. Härdtle, B. Redecker \& U. Riecken (Bearb.). Weidelandschaften und Wildnisgebiete. - Schr.-R. f. Landschaftspfl. u. Natursch. 78: 63-92.

Schubert, R., Hilbig, W. \& S. Klotz (1995): Bestimmungsbuch der Pflanzengesellschaften Mittel- und Nordostdeutschlands. G. Fischer, Jena.

Schubert, R. (2001): Bestimmungsbuch der Pflanzengesellschaften Deutschlands. Spektrum, Akad. Verl., Heidelberg.

Schumacher, W. (1988): Notwendigkeit und Umfang von Pflegemaßnahmen auf Schutzflächen anhand ausgewählter Beispiele. In: Naturlandstiftung Hessen (Hrsg.): Landwirte als Partner des Naturschutzes. Tagungsbericht. Schriftenreihe Angewandter Naturschutz 7, 25-38.

Schuster, H.-J. (1995): Bedeutung der Weidehaltung bei der Entstehung der Kulturlandschaft - ein agrargeschichtlicher Exkurs. Beiträge der Akademie für Natur- und Umweltschutz Baden-Württemberg, Bd. 18, Tübingen, 8-16. 
Senft, R. L., R. L. Rittenbouse \& R. G. Woodmansee (1985): Factors influencing patterns of cattle grazing behavior on shortgrass steppe. J. Range. Manage. 38:82-87.

Settele, J., R. Feldmann \& R. Reinhardt (1999): Die Tagfalter Deutschlands - Ein Handbuch für den Freilandökologen, Umweltplaner und Naturschützer. Verlag Eugen Ulmer, Stuttgart.

Seybold, S. (2006): Schmeil-Fitschen. Flora von Deutschland und angrenzender Länder. 93. Aufl., Quelle \& Meyer Verlag: Wiebelsheim.

Sieling, C. (2002): Auswirkungen der Beweidung mit Przewalski-Herden auf die Vegetation. In: Marx, C., A. Sternschulte (Hrsg.) (2000): „....so frei, so stark...“. Westfalens wilde Pferde. Schriften des Westfälischen Freilichtmuseums Detmold Landesmuseum für Volkskunde Bd. 21. 232 S. Klartext Verlag, Essen.

Silverman, B. W. (1986): Density estimation for statistics and data analysis. Chapman and Hall, Ltd., London, UK.

Skovlin, J.M., P. Zager \& B. Johnson (2002) Elk habitat selection and evaluation. In: Toweill, D.E. \& J.W. Thomas (Eds.): North American Elk. Ecology and Management. Smithsonian Press, Washington D.C., 531-553.

Skov- og Naturstyrelsen (2006): Südlangeland. Wanderungen Nr. 63 T. Kopenhagen, 4 S.

Skov- og Naturstyrelsen (2005): Wild Horses - Exmoor Ponies in Klise Nor on South Langeland. Kopenhagen, 2 S.

Skov- og Naturstyrelsen (2003): Velkommen til Fugleværnsområdet Gulstav Mose, Sydlangeland. Kopenhagen, 2 S.

Slob, A. (1966): Beschouwing over de tarpan (Equus przewalskii gmelini ANTONIUS, 1912). - Lutra 8, 1 - 15.

Smith, R. S., R. S. Shiel, D. Millward \& P. Corkhill (2000): The interactive effects of management on the productivity and plant community structure of an upland meadow: an 8-year field trial. J. Appl. Ecol. 37: 1029-1043, Oxford.

Smith, M.A., J.D. Rodgers, J.L. Dodd \& Q.D. Skinner (1992): Habitat selection by cattle along an ephemeral channel. J. Range Manage. 45: 638-643.

Söhn, L. (2009): Artenzusammensetzung und Verbreitung linearer und kleinflächiger Vegetatiosstukturen im ExmoorPony-Gebiet in Südlangeland (Dänemark). Unveröffentl. Bachelorarbeit, Georg-August-Univ. Göttingen.

Soest, P. J. van (1982): Nutritional Ecology of the Ruminant. O \& B Books, Oregon.

Sonnenburg, H., B. Gerken, H.-G. Wagner \& H. Ebersbach (2003): Das Hutewaldprojekt im Naturpark Solling-Vogler. LÖBF-Mitteilungen 4/03, S.40-47.

Sonnenburg, H. \& B. Gerken (2004): Das Hutewaldprojekt im Solling: Ein Baustein für eine neue Ära des Naturschutzes. 2. Aufl. 41 S. Höxter.

Spatz, G. (1994): Freiflächenpflege. Ulmer, Stuttgart.

Speed, J. G. \& M. Etherington (1952): The Exmoor Pony and a survey of the evolution of the horses in Britain I. British Veterinary Journal 109: 329-338.

Stahlhut, F. (2009): Bewegungsmuster und Habitatnutzung von Exmoorponys auf Langeland (Dänemark). Unveröffentl. Bachelorarbeit, Georg-August-Univ. Göttingen.

Stammer, S. (2009): Vegetationskartierung und Beeinflussung der Vegetation durch Exmoor-Ponys in Südlangeland (Dänemark). Unveröffentl. Bachelorarbeit, Georg-August-Univ. Göttingen.

Stewart, D.R.M. (1967): Analysis of plant epidermis in faeces: a technique for studying the food preferences of grazing herbivores. J. Appl. Ecol. 4, 83-111.

Stewart, D.R.M. \& J. Stewart (1970): Food preference data by faecal analysis for African plains Ungulates. Zoologica Africana 5 (1), 115.

Stuth, J.W. (1991): Foraging Behavior. In: Heitschmidt R.K. \& Stuth J.W. (Hrsg.): Grazing Management: An ecological perspective. Timber Press, Portland, Oregon, 65-83.

Taylor, H. (2001): Ponies, Cattle and Deer in the New Forest, Hampshire, England: Historical Practical Aspects of New Forest Management. - Natur und Kulturlandschaft 4: 160-164.

Tesch, A. (1999): Grünlandextensivierung im Moorgürtel der Hamburger Elbmarsch. Naturschutz und Landschaftsplanung 31: 342-350.

Thompson, K., J. Bakker \& R. Bekker (1997): The soil seed banks of North West Europe. Methodology, density and longevity. 276 S. Cambridge University Press, Cambridge.

Thorn, M. (2000): Auswirkungen von Landschaftspflegemaßnahmen auf die Vegetation von Streuwiesen. Natur Landschaft 75 (2): 64-73.

Thüringer Landesanstalt für Umwelt und Geologie (2001): Kartieranleitung zur Offenland-Biotopkartierung im Freistaat Thüringen. Jena. 
Tichý, L. (2002): JUICE, software for vegetation classification. - J. Veg. Sci. 13: 451-453.

Traxler, A. (1997): Handbuch des vegetationsökologischen Monitorings. Methoden, Praxis, angewandte Projekte, Teil A: Methoden. Umweltbundesamt Wien, Monographien Band 89A.

Tremp, H. (2005): Aufnahme und Analyse vegetationsökologischer Daten. UTB Verlag, Stuttgart.

Treydte, A. C. (2004): Habitat use of wildlife and diet preferences of the warthog (Phacochoerus africanus) on a former cattle ranch in a tanzanian savanna. Swiss Federal Institute of Technology, Zürich. Dissertationsschrift.

Tyler, S. J. (1972): The behaviour and social organization of New Forest Ponies. Anim. Behav. Monogr., 5: 87-196.

Uerpmann, H.-P. (1990): Die Domestikation des Pferdes im Chalkolithikum West- und Mitteleuropas. Madrider Mitteilungen $31,109-153$.

Usukhjargal, D. (2008): Current state of re-introducing Przewalski's Horse (Equus Przewalskii Poljakov, 1881) population in Hustai National Park, Mongolia. Hustai National Park Trust.

Uthoff, A. (2010): Tag - und Nachtverhalten sowie Habitatnutzung einer Herde Exmoorponys in einem Naturschutzgebiet auf Langeland (Dänemark). Unveröffentl. Diplomarbeit, Univ. Göttingen, 90 S.

Van Hoven, W. (2000): Wildvoeding in die natuur. In: Bothma J. du P. (ed.). Wildplaas bestuur (3rd edition). Van Schaik Uitgewers, Pretoria, 168-182.

Vera, F. (2005): Dynamik durch große wildlebende Pflanzenfresser - eine Voraussetzung für biologische Vielfalt. Laufener Seminarbeiträge 1/05: 33-48.

Vermeulen, R. (2014): Natural Grazing - Challenges arising from interactions with animal welfare, veterinary legislation and nature conservation. Tagungsbeitrag der NABU-Tagung "Managementstandards für Beweidungsprojekte im Naturschutz", NNA, Schneverdingen, 11.-12. April 2014.

Voigt, Aksel (2002): Maintaining biodiversity and open landscapes by grazing in the County of South Jutland, Denmark. In: Redecker, B., et al. (Hrsg.): Pasture Landscapes and Nature Conservation. Springer, 2002.

Voss, K. (1999): Die Bedeutung extensiv beweideten Feucht- und Überschwemmungsgrünlandes in Schleswig-Holstein für den Naturschutz. Dissertation, Mathematisch-Naturwissenschaftliche Fakultät der CAU Kiel.

Vulink, J. T. (2001): Hungry Herds. Management of temperate lowland wetlands by grazing. Ministerie van Verkeer an Waterstaat, Directoraat-Generaal Rijkswaterstaat, Directie ljsselmeergebied, Lelystad, 394 S.

Vulink, J.T. \& M.R. van Eerden (1998): Hydrological conditions and herbivory as key operators for ecosystems development in Dutch artificial wetlands. In: Wallis de Vries, M., J.P. Bakker \& S.E. van Wieren (Hrsg.): Grazing and Conservation Management. Kluwer Academic Publishers, Dordrecht, 217-252.

Wagner, F. \& R. Luick (2005): Extensive Weideverfahren und normativer Naturschutz im Grünland - Ist auf FFH-Grünland die Umstellung von Mähnutzung auf extensive Beweidung ohne Artenverlust möglich? Naturschutz und Landschaftsplanung 37(3): 69-79.

WallisDeVries, M. F. (1994): Foraging in a Landscape Mosaic: Diet Selection and Performance of Free-ranging Cattle in Heathland and Riverine Grassland. Den Haag.

Waring, G. H. (2003): Horse Behaviour. Second Edition, William Andrew publishing.

Westrich, P. (1989, 1990): Die Wildbienen Baden-Württembergs. Band 1 und 2, Ulmer, Stuttgart.

Wiegleb, G. \& I. Brunk (2004): Die künftige Bedeutung großflächiger Beweidungssysteme mit Haus- und Wildtieren für das Biotopmanagement auf Truppenübungsplätzen. In: P. Finck, W. Härdtle, B. Redecker \& U. Riecken (Bearb.). In: Weidelandschaften und Wildnisgebiete. - Schr.-R. f. Landschaftspfl. u. Natursch. 78: 129-144.

Wollenweber, K. (2007): Das Verhalten einer Pferdeherde (Liebenthaler Pferde) unter naturbelassenen Lebensbedingungen im Hinblick auf chronobiologische Aspekte, klimatische Einflüsse sowie deren Raumnutzung. Berlin, Freie Univ., Diss., 2007, Mensch \& Buch Verl., $151 \mathrm{~S}$.

Wilmanns, O. (2007): Ökologische Pflanzensoziologie: eine Einführung in die Vegetation Mitteleuropas. 6., neu bearb. Auflage, Quelle \& Meyer, Wiesbaden.

Willmann, R. (1999): Das Exmoor-Pferd: eines der ursprünglichsten halbwilden Pferde der Welt. Natur und Museum 129: 389-407.

Willmann, R. (2005): Das Exmoor-Pony: eine der bemerkenswertesten Pferderassen der Welt. Epona Heft 8: 6-9.

Wohlleben, P. (2009): Naturschutz ohne Natur. Von den Grenzen der Umweltpolitik. wjs Verlag, Berlin.

Woike, M. \& P. Zimmermann (1992): Biotope pflegen mit Schafen. AID 1197, Bonn. 



\section{DANKSAGUNG}

Diese Forschungsarbeit hat mich über viele Jahre begleitet und wäre nicht ohne die Unterstützung von vielen, mir wichtigen Menschen möglich gewesen.

Mein besonderer Dank gilt meinem Betreuer, Herrn Prof. Dr. Rainer Willmann, der diese Arbeit von der ersten Idee an begleitet hat. Danke für die wertvollen Anregungen, die gemeinsame Begeisterung für das Forschungsthema und das Vertrauen darauf, dass dieses Projekt ein gutes Ende findet.

Meinen herzlichen Dank richte ich an Herrn Prof. Dr. Erwin Bergmeier für die Übernahme des Ko-Referats. Die konstruktiven Diskussionen haben mir sehr geholfen und diese Arbeit auf ein sicheres Fundament gestellt.

Ich danke dem dänischen Generaldirektorat für Forst und Natur für die Möglichkeit, das Forschungsvorhaben auf Langeland realisieren zu können. Besonders bedanken möchte ich mich bei John Theilgaard, der mir ein wichtiger Ansprechpartner vor Ort war. Mange tak, John!

Mein großer Dank geht an Dr. Alexander Malinowski, der mich sicher durch die Untiefen der Statistik manövriert hat.

Ich danke allen Studentinnen und Studenten, die im Forschungsvorhaben Süd-Langeland mitgearbeitet haben.

Danke den Mitarbeiterinnen und Mitarbeitern der Abteilung Systematik des Zoologischen Instituts und der Abteilung Pflanzensoziologie des Botanischen Instituts für die gute Zusammenarbeit, insbesondere Dr. Petra Fischer für ihre hilfreichen Hinweise zur Methodik.

Die GIS-Software-Lizenzen zur Auswertung der Raumnutzung wurden mir im Rahmen des Absolventenprogramms von ESRI Deutschland kostenlos zur Verfügung gestellt. Danke dafür.

Für das Korrekturlesen danke ich Ralf Mannstedt, Fritz Delgehausen und Ulrike Jürgens.

Ohne die Unterstützung meiner Familie wäre diese Arbeit nur ein Traum geblieben. Für die unermüdliche Hilfe, Mut zusprechen und Rücken freihalten möchte ich mich von ganzem Herzen bedanken. 



\section{ERKLÄRUNG}

\section{Promovierenden-Erklärung der Georg-August-Universität Göttingen}

Mannstedt, Tonja

Frankenfeldstraße 20

30519 Hannover

Ich beabsichtige, eine Dissertation zum Thema „Biotoppflege mit Pferden - Auswirkungen einer ganzjährigen Beweidung mit Exmoor-Ponys (Equus ferus f. caballus) auf halboffene Weidelandschaften am Beispiel Süd-Langeland“ an der Georg-August-Universität Göttingen anzufertigen. Dabei werde ich von Herrn Prof. Dr. Rainer Willmann betreut.

Ich gebe folgende Erklärung ab:

1. Die Gelegenheit zum vorliegenden Promotionsvorhaben ist mir nicht kommerziell vermittelt worden. Insbesondere habe ich keine Organisation eingeschaltet, die gegen Entgelt Betreuerinnen und Betreuer für die Anfertigung von Dissertationen sucht oder die mir obliegenden Pflichten hinsichtlich der Prüfungsleistungen für mich ganz oder teilweise erledigt.

2. Hilfe Dritter wurde bis jetzt und wird auch künftig nur in wissenschaftlich vertretbarem und prüfungsrechtlich zulässigem Ausmaß in Anspruch genommen. Insbesondere werden alle Teile der Dissertation selbst angefertigt; unzulässige fremde Hilfe habe ich dazu weder unentgeltlich noch entgeltlich entgegengenommen und werde dies auch zukünftig so halten.

3. Die Ordnung zur Sicherung der guten wissenschaftlichen Praxis an der Universität Göttingen wird von mir beachtet.

4. Eine entsprechende Promotion wurde an keiner anderen Hochschule im In- oder Ausland beantragt; die eingereichte Dissertation oder Teile von ihr wurden nicht für ein anderes Promotionsvorhaben verwendet.

Mir ist bekannt, dass unrichtige Angaben die Zulassung zur Promotion ausschließen bzw. später zum Verfahrensabbruch oder zur Rücknahme des erlangten Grades führen.

Hannover, den 1. Dezember 2014 



\section{ANHANG}

Material

3.1 Gebietseigenschaften des Projektgebietes Süd-Langeland

3.2 Topographie im Projektgebiet Süd-Langeland

Raumnutzung und Verhalten der Weidetiere

5.1 Aufnahmebogen Habitatnutzung

5.2 Mapping der Umweltfaktoren

5.3 Zusammenhang zwischen Habitatnutzung und Umweltfaktoren im Projektgebiet Süd-Langeland

5.4 Entwicklung der Herdenstruktur der Langeländer Exmoor-Ponys

5.5 Aufenthaltswahrscheinlichkeiten der Exmoor-Ponys im Projektgebiet Süd-Langeland

5.6 Ruheplätze der Weidetiere im Projektgebiet Süd-Langeland

5.7 Umweltfaktoren im Projektgebiet Süd-Langeland

Auswirkungen der Beweidung

6.1a Formblatt zur Datenerhebung im Gelände

6.1b Formular Vegetationskartierung Projektgebiet Süd-Langeland

6.2a Aufnahmeplots der pflanzensoziologischen Voruntersuchung (2007)

6.2b Aufnahmeplots der pflanzensoziologischen Erst- und Wiederholungskartierung

6.3 Beschreibung und Lage der vegetationskundlichen Dauerflächen (VDF) und Transekte (T)

6.4a Gesamtartenliste des Projektgebietes Süd-Langeland

6.4b Rote-Liste-Arten im Schutzgebiet Süd-Langeland

6.5 Artenlisten der nicht begehbaren Bestände und der Vegetationskomplexe

6.6 Vergleichende Übersicht der Vegetationseinheiten im Projektgebiet Süd-Langeland nach drei Beweidungsjahren

6.7 Beschreibung und Lage der Strukturdauerflächen (SDF)

6.8 Synoptische Tabelle und Juice-Tabelle aller Aufnahmen aus 2007 nach der TWINSPAN-Analyse

6.9 Voruntersuchung im offenen Weideland (2007) 
6.10 Synoptische Tabelle und Juice-Tabelle aller Aufnahmen aus 2008 nach der TWINSPAN-Analyse

6.11 Syntaxonomische Einordnung der Vegetationseinheiten

6.12 Beschreibung der Vegetationseinheiten im Projektgebiet

6.13 Synoptische Tabelle und Juice-Tabelle aller Aufnahmen aus 2011 nach der TWINSPAN-Analyse

6.14 Beschreibung der Vegetationseinheiten im Projektgebiet nach dreijähriger Beweidung

6.15 Strukturentwicklung der Lebensraumtypen (SDF)

6.16 Strukturentwicklung der Lebensraumtypen (A)

6.17 Strukturveränderungen im Projektgebiet Süd-Langeland

6.18 Entwicklung der Gehölzbestände im Projektgebiet Süd-Langeland

6.19 Entwicklung der Gehölzbestände im Projektgebiet Süd-Langeland unter Beweidung 